\title{
Lower Limb Prostheses: Measurement Instruments, Comparison of Component Effects by Subgroups, and Long- Term Outcomes
}


Number 213

\section{Lower Limb Prostheses: Measurement Instruments, Comparison of Component Effects by Subgroups, and Long-Term Outcomes}

\section{Prepared for:}

Agency for Healthcare Research and Quality

U.S. Department of Health and Human Services

5600 Fishers Lane

Rockville, MD 20857

www.ahrq.gov

Contract No. 290-2015-00002-I

Prepared by:

Brown Evidence-based Practice Center

Providence, RI

Investigators:

Ethan M. Balk, M.D., M.P.H.

Abhilash Gazula, M.P.H.

Georgios Markozannes, M.Sc.

Hannah J. Kimmel, M.P.H.

Ian J. Saldanha, M.B.B.S., M.P.H., Ph.D.

Linda J. Resnik, Ph.D.

Thomas A. Trikalinos, M.D., Ph.D. 


\section{Key Messages}

\section{Purpose of Review}

To assess validity of instruments used in adult lower limb amputees, whether patient characteristics can predict relative effectiveness of different lower limb prosthesis (LLP) components, and long-term LLP use.

\section{Key Messages}

- Thirty of 50 evaluated instruments (ambulatory/functional outcomes and other measures) have evidence of validity and reliability. Many studies use nonvalidated instruments.

- Based on a small number of studies, patient characteristics do not predict who would most benefit from a given LLP component. Half of studies used nonvalidated instruments and analyses were inadequate.

- Only a few studies assessed long-term LLP use; 11 to 22 percent of patients abandon their LLP after 1 year; people with above-the-knee amputations are more likely to abandon their prostheses than people with below-the-knee amputations; 24 to 29 percent of people with LLPs use them only indoors 1 year after they first receive the prostheses. The studies, though, had important methodological issues. 
This report is based on research conducted by the Brown Evidence-based Practice Center (EPC) under contract to the Agency for Healthcare Research and Quality (AHRQ), Rockville, MD (Contract No. 290-2015-00002-I). The findings and conclusions in this document are those of the authors, who are responsible for its contents; the findings and conclusions do not necessarily represent the views of AHRQ. Therefore, no statement in this report should be construed as an official position of AHRQ or of the U.S. Department of Health and Human Services.

None of the investigators have any affiliations or financial involvement that conflicts with the material presented in this report.

The information in this report is intended to help health care decisionmakers—patients and clinicians, health system leaders, and policymakers, among others-make well-informed decisions and thereby improve the quality of health care services. This report is not intended to be a substitute for the application of clinical judgment. Anyone who makes decisions concerning the provision of clinical care should consider this report in the same way as any medical reference and in conjunction with all other pertinent information, i.e., in the context of available resources and circumstances presented by individual patients.

This report is made available to the public under the terms of a licensing agreement between the author and the Agency for Healthcare Research and Quality. This report may be used and reprinted without permission except those copyrighted materials that are clearly noted in the report. Further reproduction of those copyrighted materials is prohibited without the express permission of copyright holders.

AHRQ or U.S. Department of Health and Human Services endorsement of any derivative products that may be developed from this report, such as clinical practice guidelines, other quality enhancement tools, or reimbursement or coverage policies, may not be stated or implied.

This report may periodically be assessed for the currency of conclusions. If an assessment is done, the resulting surveillance report describing the methodology and findings will be found on the Effective Health Care Program Web site at www.effectivehealthcare.ahrq.gov. Search on the title of the report.

Persons using assistive technology may not be able to fully access information in this report. For assistance contact EPC@ahrq.hhs.gov.

Suggested citation: Balk EM, Gazula A, Markozannes G, Kimmel HJ, Saldanha IJ, Resnik LJ, Trikalinos TA. Lower Limb Prostheses: Measurement Instruments, Comparison of Component Effects by Subgroups, and Long-Term Outcomes. Comparative Effectiveness Review No. 213. (Prepared by the Brown Evidence-based Practice Center under Contract No. 290-2015-00002-I.) AHRQ Publication No.18-EHC017-EF. Rockville, MD: Agency for Healthcare Research and Quality; September 2018. Posted final reports are located on the Effective Health Care Program search page. DOI: https://doi.org/10.23970/AHRQEPCCER213. 


\section{Preface}

The Agency for Healthcare Research and Quality (AHRQ), through its Evidence-based Practice Centers (EPCs), sponsors the development of systematic reviews to assist public- and private-sector organizations in their efforts to improve the quality of health care in the United States. These reviews provide comprehensive, science-based information on common, costly medical conditions, and new health care technologies and strategies.

Systematic reviews are the building blocks underlying evidence-based practice; they focus attention on the strength and limits of evidence from research studies about the effectiveness and safety of a clinical intervention. In the context of developing recommendations for practice, systematic reviews can help clarify whether assertions about the value of the intervention are based on strong evidence from clinical studies. For more information about AHRQ EPC systematic reviews, see www.effectivehealthcare.ahrq.gov/reference/purpose.cfm.

AHRQ expects that these systematic reviews will be helpful to health plans, providers, purchasers, government programs, and the health care system as a whole. Transparency and stakeholder input are essential to the Effective Health Care Program. Please visit the Web site (www.effectivehealthcare.ahrq.gov) to see draft research questions and reports or to join an email list to learn about new program products and opportunities for input.

If you have comments on this systematic review, they may be sent by mail to the Task Order Officers named below at: Agency for Healthcare Research and Quality, 5600 Fishers Lane, Rockville, MD 20857, or by email to epc@ahrq.hhs.gov.

Gopal Khanna, M.B.A.

Director

Agency for Healthcare Research and Quality

Stephanie Chang, M.D., M.P.H.

Director

Evidence-based Practice Center Program

Center for Evidence and Practice Improvement Agency for Healthcare Research and Quality
Arlene S. Bierman, M.D., M.S.

Director

Center for Evidence and Practice Improvement Agency for Healthcare Research and Quality

Lionel L. Bañez, M.D.

Task Order Officer

Center for Evidence and Practice Improvement Agency for Healthcare Research and Quality

Elise Berliner, Ph.D.

Task Order Officer

Center for Evidence and Practice Improvement Agency for Healthcare Research and Quality 


\section{Acknowledgments}

The authors gratefully acknowledge the following research associates and clinical and methodological experts who participated in this review: Gaelen Adam, M.L.I.S.; Susan E. D’Andrea, Ph.D.; Mengyang Di, M.D., Ph.D.; Molly Magill, Ph.D.; Jennifer Quiroz, B.A.; Stacey L. Springs, Ph.D.; Erin R. Twomey-Wilson, M.S., M.A.S.; along with Michael Handrigan, M.D., and Susan Miller, M.D., from the Centers for Medicare \& Medicaid Services.

\section{Key Informants}

In designing the study questions, the EPC consulted a panel of Key Informants who represent subject experts and end-users of research including clinicians, allied health professionals, and patient representatives. Key Informant input can inform key issues related to the topic. Key Informants are not involved in the analysis of the evidence or the writing of the report.

Therefore, in the end, study questions, design, methodological approaches, and/or conclusions do not necessarily represent the views of individual Key Informants.

Key Informants must disclose any financial conflicts of interest greater than \$5,000 and any other relevant business or professional conflicts of interest. Because of their role as end-users, individuals with potential conflicts may be retained. The TOO and the EPC work to balance, manage, or mitigate any conflicts of interest identified.

The list of Key Informants who provided input to this report follows:

Jeffrey Cain, M.D.

Vice Chair/Chair Elect

Amputee Coalition

Manassas, VA

David Crandell, M.D.*

Assistant Professor, Department of Physical

Medicine and Rehabilitation

Spaulding Rehabilitation Hospital

Boston, MA

Ignacio Gaunaurd, Ph.D., M.S.P.T.*

Miami Veterans Affairs Healthcare System

University of Miami

Miami, FL

*Provided input on Draft Report.
George Gondo, M.A.*

Director of Research \& Grants

Amputee Coalition

Knoxville, TN

Brian Hafner, Ph.D.

Professor, Rehabilitation Medicine

University of Washington

Seattle, WA 


\section{Technical Expert Panel}

In designing the study questions and methodology at the outset of this report, the EPC consulted several technical and content experts. Broad expertise and perspectives were sought. Divergent and conflicted opinions are common and perceived as healthy scientific discourse that results in a thoughtful, relevant systematic review. Therefore, in the end, study questions, design, methodologic approaches, and/or conclusions do not necessarily represent the views of individual technical and content experts.

Technical Experts must disclose any financial conflicts of interest greater than \$5,000 and any other relevant business or professional conflicts of interest. Because of their unique clinical or content expertise, individuals with potential conflicts may be retained. The TOO and the EPC work to balance, manage, or mitigate any conflicts of interest identified.

The list of Technical Experts who provided input to this report follows. Note that in this instance, the Key Informants also served as Technical Experts; thus, the panels were composed of the same members.

Jeffrey Cain, M.D.

Vice Chair/Chair Elect

Amputee Coalition

Manassas, VA

David Crandell, M.D.*

Assistant Professor, Department of Physical

Medicine and Rehabilitation

Spaulding Rehabilitation Hospital

Boston, MA

Ignacio Gaunaurd, Ph.D., M.S.P.T.*

Miami Veterans Affairs Healthcare System

University of Miami

Miami, FL
George Gondo, M.A.*

Director of Research \& Grants

Amputee Coalition

Knoxville, TN

Brian Hafner, Ph.D.

Professor, Rehabilitation Medicine

University of Washington

Seattle, WA

*Provided input on Draft Report.

\section{Peer Reviewers}

Prior to publication of the final evidence report, we sought input from independent Peer Reviewers without financial conflicts of interest. However, the conclusions and synthesis of the scientific literature presented in this report do not necessarily represent the views of individual reviewers.

Peer Reviewers must disclose any financial conflicts of interest greater than $\$ 5,000$ and any other relevant business or professional conflicts of interest. Because of their unique clinical or content expertise, individuals with potential nonfinancial conflicts may be retained. The TOO 
and the EPC work to balance, manage, or mitigate any potential nonfinancial conflicts of interest identified.

The list of Peer Reviewers follows:

Vibhor Agrawal, Ph.D., A.T.P.

Assistant Professor, Department of Physical Therapy

University of Miami

Miami, FL

Joseph Czerniecki, M.D., M.S.

Professor of Rehabilitation

University of Washington

Seattle, WA
Janna Friedly, M.D.

Associate Professor, Rehabilitation

Medicine

University of Washington

Seattle, WA

Danielle Melton, M.D.

Director of Limb Loss Program at The Institute of Rehabilitation and Research University of Texas-Houston

Houston, TX 


\section{Lower Limb Prostheses: Measurement Instruments, Comparison of Component Effects by Subgroups, and Long-Term Outcomes}

\section{Structured Abstract}

Background. Lower limb prosthesis (LLP) candidates are a heterogeneous group. Many LLP options exist. How to best match an amputee with an LLP is unclear. Optimal selection of devices should be guided by evidence on which amputees would do best with which LLP component or configuration, and which evaluation instruments are valid and reliable in this population.

Methods. We addressed questions pertaining to: assessing validity, reliability, and related psychometric properties for assessment techniques, predictor tools, and outcome measures in lower limb amputees; determining which patient and other characteristics may predict which LLP configuration or component would result in better clinical and patient-centered outcomes for different lower limb amputees (i.e., heterogeneity of treatment effect); determining whether patient expectations align with outcomes; evaluating whether patients are satisfied with the process of obtaining their LLPs; and describing long-term use of LLPs. The review does not evaluate overall comparative effectiveness among LLP components, nor does it include assessment of biomechanical outcomes. We searched six databases and other sources through October 2017 for eligible studies.

Results. We found eligible studies that assessed the psychometric properties of 50 instruments (classified as assessment techniques, prediction tools, and outcome measures). Of these, 30 have evidence for both validity and reliability, but only 17 of these have evidence that was deemed generalizable to the Medicare population. Most of the remaining instruments have evidence of either validity or reliability, but not both. Of 13 studies reporting data or analyses to allow assessment of heterogeneity of treatment effect, 7 used both predictor and outcome measures with evidence of validity. These studies mostly included younger men with unilateral transfemoral amputations due to trauma. Overall, studies did not identify participant characteristics that predict which lower limb amputees would benefit most or least from a given component (low strength of evidence); the studies were almost all underpowered to address this Key Question. Two studies provide low strength of evidence that people are satisfied with their encounters with their prosthetists. No eligible study addressed how study participants' preprescription expectations of ambulation align with outcomes. Based on eight eligible studies, there is low strength of evidence that (1) about 11 to 22 percent of lower limb amputees who receive an LLP prescription stop using the prosthesis at about 1 year and (2) people with unilateral transfemoral amputations are about twice as likely to abandon their LLP than those with transtibial amputations. There is low strength of evidence that 24 to 29 percent of LLP recipients use their prostheses only indoors at 1 year.

Conclusions. Numerous instruments assessing ambulation, function, quality of life, and other patient-centered outcomes have evidence of validity and reliability for people with lower limb amputations. The literature does not provide adequate evidence regarding whether specific characteristics or preprescription instruments are predictive of which specific LLP component 
individuals should receive to maximize ambulation, function, and quality of life, or to minimize abandonment or limited use. Further high-quality research in representative samples of people with LLPs is needed to inform optimal matching of prosthetic components to patients and to assess patient expectations and satisfaction with care. 


\section{Contents}

Evidence Summary ........................................................................................................................ ES-1

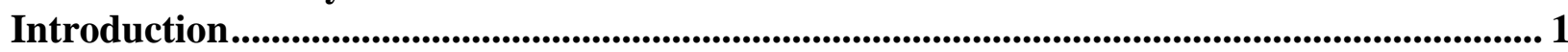

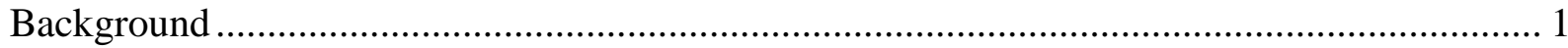

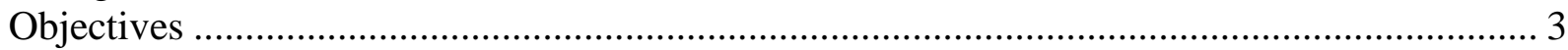

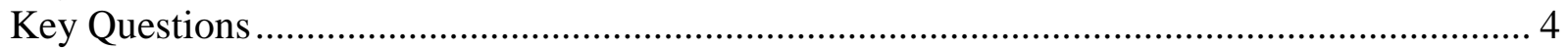

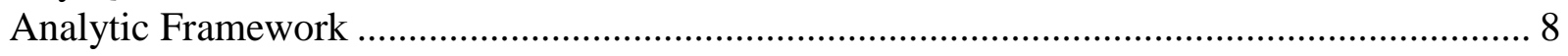

Methods.................................................................................................................................... 10

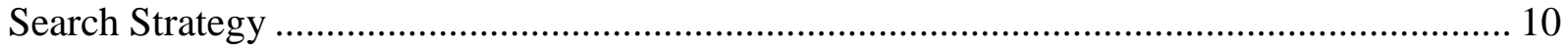

Study Eligibility Criteria ................................................................................................. 10

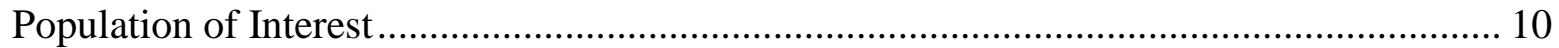

Interventions or Predictors of Interest (and Instruments for KQ 1-3) ............................... 11

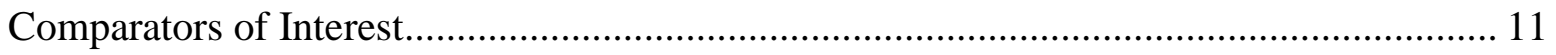

Outcomes of Interest ................................................................................................... 12

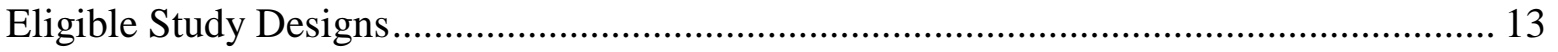

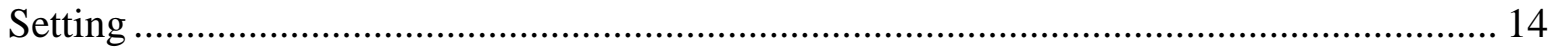

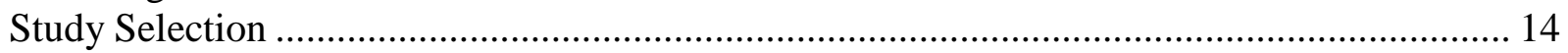

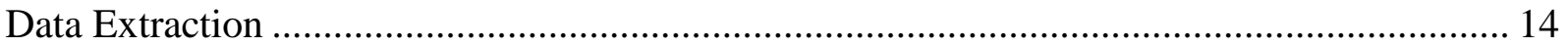

Study Generalizability Categorization ................................................................................ 17

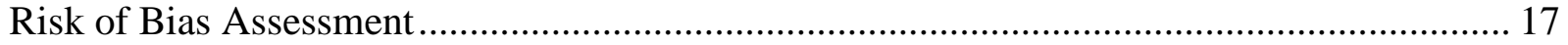

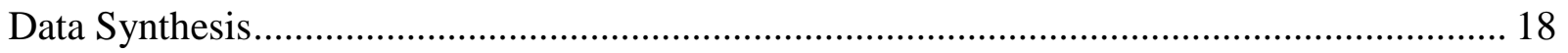

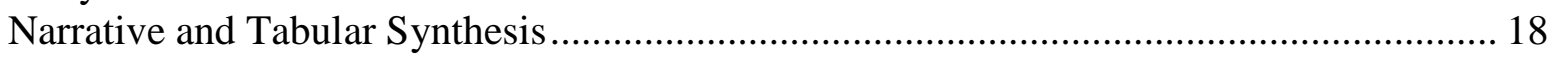

Post Hoc Analyses ....................................................................................................... 18

Summarizing Findings Across Studies ............................................................................. 18

Grading the Strength of Evidence................................................................................... 19

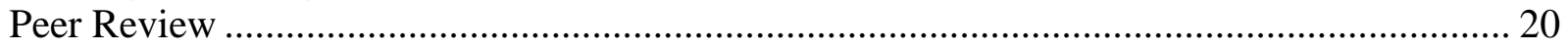

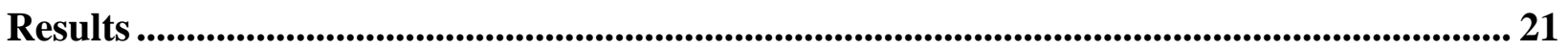

Summary of Studies ............................................................................................................... 21

Key Questions 1 to 3. Assessment Techniques, Prediction Tools, Functional Outcome

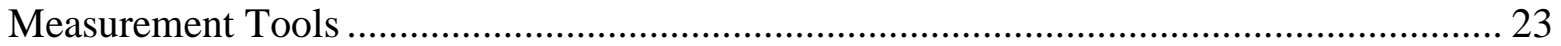

Key Question 1. Assessment Techniques ............................................................................. 108

Key Points........................................................................................................ 108

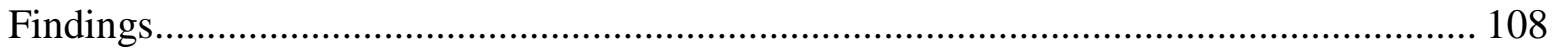

Key Question 2. Prediction Tools ................................................................................... 109

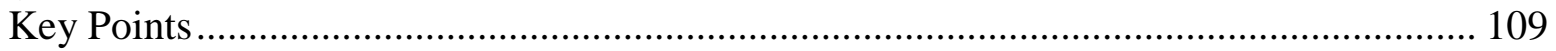

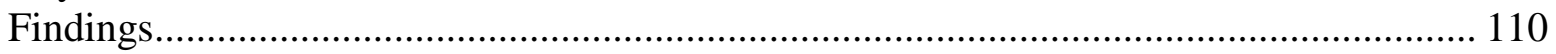

Key Question 3. Functional Outcome Measurement Tools..................................................... 112

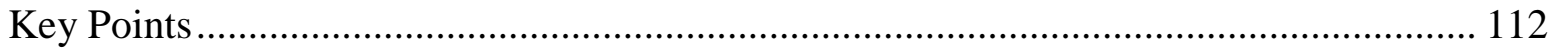

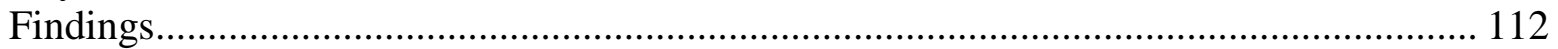

Key Question 4. LLP Comparative Effectiveness by Subgroup............................................... 116

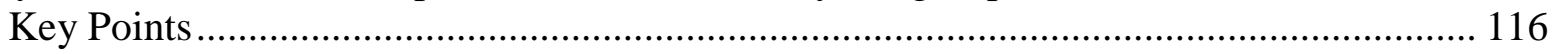

Comments On Key Question and Evidence Base ............................................................ 116

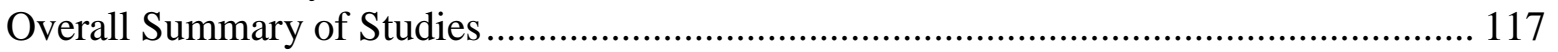

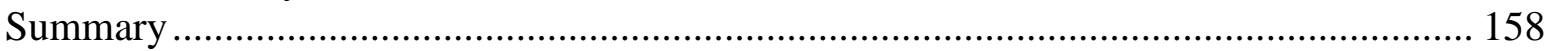

Key Question 5. Expectations of Ambulation ....................................................................... 161 
Key Question 6. Patient Satisfaction With Process .................................................................... 161

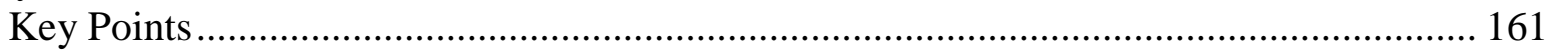

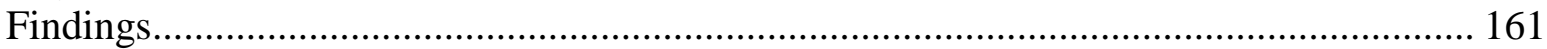

Key Question 7. Long-Term Outcomes................................................................................ 165

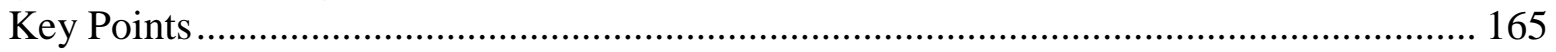

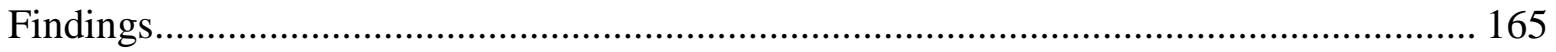

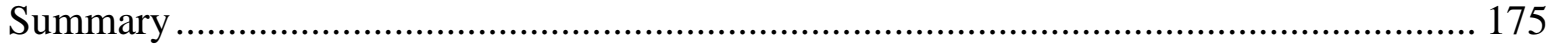

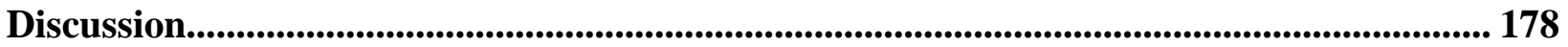

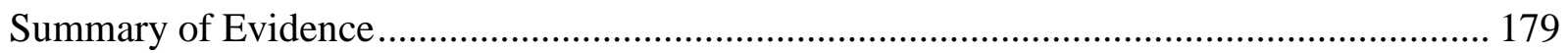

Evidence Limitations .................................................................................................... 182

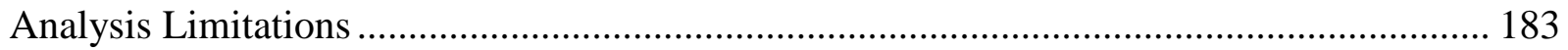

Future Research Recommendations............................................................................ 184

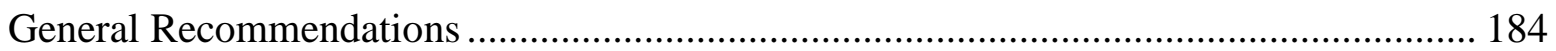

Studies of Heterogeneity of Treatment Effect ........................................................ 185

Studies on Expectations, Satisfaction With Services, and Long-Term Followup .............. 186

Conclusions and Clinical Implications .............................................................................. 186

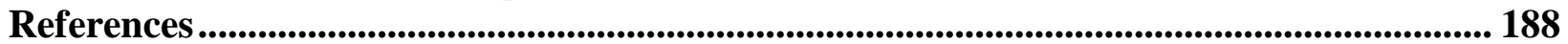

Abbreviations and Acronyms .................................................................................................................. 195

Tables

Table A. Instruments with evidence of both validity and reliability generalizable to the

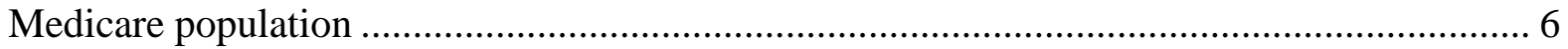

Table B. Instruments with evidence of either validity or reliability generalizable to the

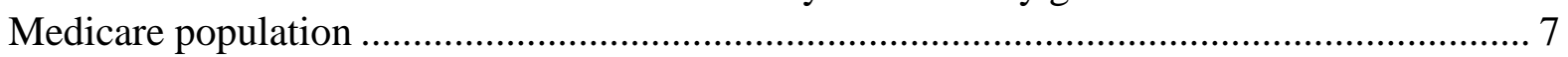

Table C. Instruments with evidence of both validity and reliability not generalizable to the Medicare population .......................................................................................................... 8

Table D. Instruments with evidence of either validity or reliability not generalizable to the

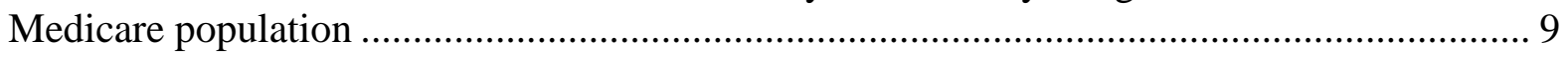

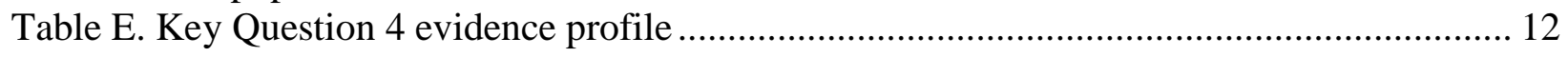

Table F. Key Questions 5 and 6 evidence profile ........................................................................... 13

Table G. Key Question 7 evidence profile.................................................................................. 15

Table 1. Lower limb extremity prosthesis Medicare Functional Classification Levels (K levels). 2

Table 2. Metrics for evaluation of reliability, validity, and related psychometric properties....... 16

Table 3. Study descriptive data: 1 Leg Stand through 6MWT ....................................................... 27

Table 4. Summary of instrument psychometric validity properties: 1 Leg Stand through

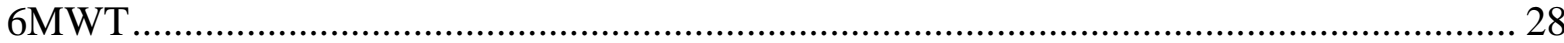

Table 5. Summary of other instrument psychometric properties: 1 Leg Stand through 6MWT .. 30

Table 6. Study descriptive data: AAS through AMPSIMM ........................................................ 33

Table 7. Summary of instrument psychometric validity properties: AAS through AMPSIMM.. 34

Table 8. Summary of other instrument psychometric properties: AAS through AMPSIMM...... 36

Table 9. Study descriptive data: Barthel Index through Employment Questionnaire ................... 39

Table 10. Summary of instrument psychometric validity properties: Barthel Index through Employment Questionnaire ...................................................................................................... 40

Table 11. Summary of other instrument psychometric properties: Barthel Index through

Employment Questionnaire …………………………………............................................. 41

Table 12. Study descriptive data: FAC through Functional Reach Test........................................ 44 
Table 13. Summary of instrument psychometric validity properties: FAC through Functional Reach Test.

Table 14. Summary of instrument psychometric validity properties: FAC through Functional Reach Test.

Table 15. Study descriptive data: Houghton Scale through L Test ......................................... 50

Table 16. Summary of instrument psychometric validity properties: Houghton Scale through

L Test

Table 17. Summary of instrument psychometric validity properties: Houghton Scale through

L Test 53

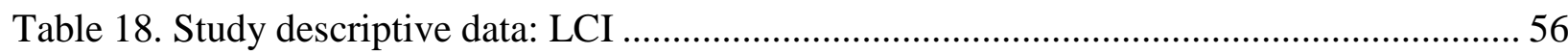

Table 19. Summary of instrument psychometric validity properties: LCI ............................... 57

Table 20. Summary of other instrument psychometric properties: LCI .................................. 59

Table 21. Study descriptive data: LEMOCOT through Patient Activity Monitor....................... 62

Table 22. Summary of instrument psychometric validity properties: LEMOCOT through

Patient Activity Monitor .

Table 23. Summary of other instrument psychometric properties: LEMOCOT through Patient Activity Monitor

Table 24. Study descriptive data: PEQ 67

Table 25. Summary of instrument psychometric validity properties: PEQ ............................. 68

Table 26. Summary of other instrument psychometric properties: PEQ ................................. 70

Table 27. Study descriptive data: PFI through PPA .......................................................... 74

Table 28. Summary of instrument psychometric validity properties: PFI through PPA ............. 75

Table 29. Summary of other instrument psychometric properties: PFI through PPA ................. 77

Table 30. Study descriptive data: PROMIS through PROS .................................................... 79

Table 31. Summary of instrument psychometric validity properties: PROMIS through PROS .. 80

Table 32. Summary of other instrument psychometric properties: PROMIS through PROS ...... 81

Table 33. Study descriptive data: PSFS through SCS .......................................................... 84

Table 34. Summary of instrument psychometric validity properties: PSFS through SCS .......... 85

Table 35. Summary of other instrument psychometric properties: PSFS through SCS .............. 86

Table 36. Study descriptive data: Short Form Health Surveys through Single Beam Test ......... 89

Table 37. Summary of instrument psychometric validity properties: Short Form Health Surveys through Single Beam Test............................................................................ 90

Table 38. Summary of other instrument psychometric properties: Short Form Health Surveys

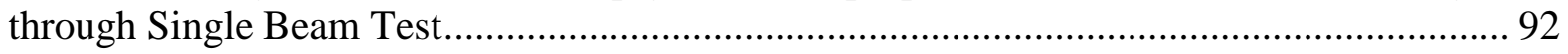

Table 39. Study descriptive data: SIP-PD through Tandem Test ............................................ 94

Table 40. Summary of instrument psychometric validity properties: SIP-PD through Tandem Test.

Table 41. Summary of other instrument psychometric properties: SIP-PD through Tandem

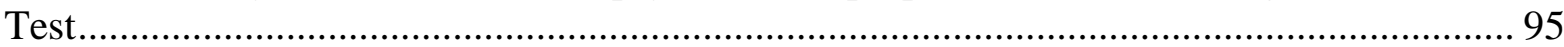

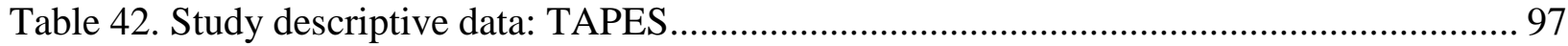

Table 43. Summary of instrument psychometric validity properties: TAPES .......................... 98

Table 44. Summary of other instrument psychometric properties: TAPES ........................... 100

Table 45. Study descriptive data: TFP through TUG …..................................................... 102

Table 46. Summary of instrument psychometric validity properties: TFP through TUG .......... 103

Table 47. Summary of other instrument psychometric properties: TFP through TUG ............. 104

Table 48. Study descriptive data: TWT through WHOQOL-BREF....................................... 106 
Table 49. Summary of instrument psychometric validity properties: TWT through WHOQOL-BREF

Table 50. Summary of other instrument psychometric properties: TWT through WHOQOL-BREF

Table 51. Summary of psychometric properties of instruments evaluated as initial assessment tools

Table 52. Summary of predictive validity of instruments.

111

Table 53. Study design and participant characteristics of studies comparing components ........ 119

Table 54. Components evaluated in eligible comparative studies.......................................... 121

Table 55. Comparative study risk of bias/study quality ................................................... 122

Table 56. Summary of subgroup comparisons

Table 57. Subgroup analyses: Alaranta, 1994, comparing energy-storing versus conventional ankle/foot components

Table 58. Subgroup analyses: De Asha, 2014, comparing hydraulic versus rigid ankle/foot components

Table 59. Subgroup analyses: Gard, 2003, comparing shock-absorbing versus non-shockabsorbing pylons

Table 60. Subgroup analyses: Hafner, 2009, comparing microprocessor versus mechanical knee components

Table 61. Subgroup analyses: Hahn, 2015, comparing C-Leg ${ }^{\mathrm{TM}}$ or C-Leg Compact ${ }^{\mathrm{TM}}$ versus prior mechanical knees

Table 62. Subgroup analyses: Hahn, 2016, comparing Genium ${ }^{\mathrm{TM}}$ microprocessor versus prior knee components (mostly C-Leg ${ }^{\mathrm{TM}}$ microprocessor knee).

Table 63. Subgroup analyses: Hasenoehrl, 2017, comparing microprocessor versus mechanical knees

Table 64. Subgroup analyses: Isakov, 1985, comparing locking versus open knee components136

Table 65. Subgroup analyses: Kahle, 2008, comparing microprocessor (C-Leg ${ }^{\mathrm{TM}}$ ) versus mechanical knee components ...

Table 66. Subgroup analyses: Moore, 2017, comparing hydraulic versus nonhydraulic foot/ankle components

Table 67. Subgroup analyses: Silver-Thorn, 2009, comparing locking (Total Knee 2000 ${ }^{\mathrm{TM}}$ ) versus hydraulic knee components

Table 68. Subgroup analyses: Theeven, 2011, comparing microprocessor (2 settings) versus mechanical knee components

Table 69. Subgroup analyses: Traballesi, 2011, comparing Marlo anatomic versus ischial component socket components

Table 70. Subgroup analyses: Wong, 2015, comparing microprocessor versus mechanical knee components

Table 71. Key Question 4 evidence profile

Table 72. Key Questions 5 and 6 evidence profile

Table 73. Study design and participant characteristics of studies reporting long-term followup after prosthesis prescription.

Table 74. Long-term followup study risk of bias/study quality............................................ 168

Table 75. Long-term followup results

Table 76. Key Question 7 evidence profile 


\section{Figures}

Figure 1. Analytic framework for assessment and assignment of lower limb prostheses ............ 9

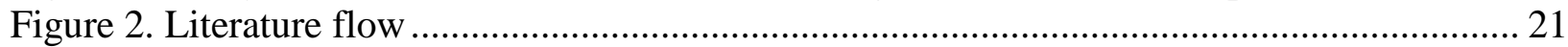

\section{Appendixes}

Appendix A. Search Strategy

Appendix B. Excluded Studies

Appendix C. Study Results Key Questions 1 to 3 (in separate Excel file)

Appendix D. Study Results Key Question 4 (in separate Excel file) 


\section{Evidence Summary}

\section{Introduction}

\section{Background}

An estimated 1.9 million people in the United States are living with limb loss, a number expected to double by 2050, mostly due to the rising prevalence of diabetes. ${ }^{1,2}$ However, fewer than half of amputees ever receive a prescription for a prosthetic device. ${ }^{3,4}$ The management of lower limb amputees with respect to lower limb prostheses (LLPs) is complicated. LLP candidates are a heterogeneous group with distinct needs dependent upon age, etiology of limb loss, level of amputation, comorbidities and health status, postoperative stage, and rehabilitation status. Many LLP options exist, comprising numerous permutations of components, the anatomy they replace, their sophistication, and other attributes, including those pertaining to cosmesis and comfort.

The current standard approach for matching patients to prostheses relies heavily on performance-based assessments, self-assessments, and, in some instances, wearable monitoring technologies that record patient activity; ${ }^{5}$ although prosthetists and treating clinicians often rely on clinical judgment to match patients to prostheses. Insurance coverage policies often dictate which prostheses and components are selected for a given patient. Numerous instruments exist to assess the patient functional status, but no consensus "gold standard" assessment schema exists.

The major contextual challenges in providing data to inform matching of LLP components to patients pertain to the large heterogeneity in patient characteristics and attributes of LLPs; the lack of data on patient characteristics and LLP attributes that are important to best match a patient to a specific LLP; disagreements about what constitutes an optimal matching of patients with LLPs; and poor clinical outcomes and wasted resources associated with suboptimal LLP matching.

\section{Objectives}

This review's Key Questions and study eligibility criteria were designed to assist Centers for Medicare \& Medicaid Services to better understand the state of the evidence regarding how best to match patients with LLPs that would yield best outcomes for them, and related issues. It is important to note that this review does cover all aspects of LLP evaluation. Specifically, it excludes from evaluation biomechanical and other nonpatient-centered intermediate outcomes. It also does not attempt to review all evidence comparing specific components. Instead, it largely focuses on those comparisons that provide within-study data to allow assessment of heterogeneity of treatment effects (i.e., whether outcomes with specific devices vary across individuals based on different characteristics such as age or health status). The review also focuses on people who may be eligible for Medicare coverage, whether due to age or disability. Thus, we categorize studies based on their likely generalizability to amputees with Medicare. Based on discussions with our Technical Expert Panel, this includes studies with a mean age at least 65 years and those in which the percentage of participants with dysvascular disease (including diabetes) is broadly similar to the Medicare amputee population (i.e., at least 50\%). Furthermore, the review excludes studies of exclusively military amputees with battle-related trauma (who are generally covered by Department of Defense and/or Veterans Health Administration insurance); however, we do include studies of veterans with multiple etiologies 
of amputation. Furthermore, the review excludes studies from low-income or low-resource settings not applicable to the United States.

\section{Key Questions}

The following summarized Key Questions (KQs) are addressed by the review:

KQ 1. What assessment techniques used to measure functional ability of adults with major lower limb amputation have been evaluated in the published literature?

KQ 2. What prediction tools used to predict functional outcomes in adults with major lower limb amputation have been evaluated in the published literature?

KQ 3. What functional outcome measurement tools used to assess adults who use an LLP have been evaluated in the published literature?

KQ 4. In adults who use a lower limb prosthesis, how do ambulatory, functional, and patient-centered outcomes with different prosthetic components vary based on study participant characteristics?

KQ 5. How do study participants' preprescription expectations of ambulation align with their functional outcomes?

KQ 6. What is the level of patient satisfaction with the process of accessing an LLP (including experiences with both providers and payers)?

KQ 7. At 6 months, 1 year, and 5 years after receipt of an LLP, (accounting for intervening mortality, subsequent surgeries, or injuries) what percentage of individuals...?

i. Maintain bipedal ambulation

ii. Use their prostheses only for transfers

iii Use prostheses only indoors

iv. Have abandoned their prostheses

v. Have major problems with prosthesis 


\section{Methods}

The Brown Evidence-based Practice Center conducted a systematic review of the published scientific literature, using established methodologies as outlined in the Agency for Healthcare Research and Quality (AHRQ) Methods Guide for Effectiveness and Comparative Effectiveness Reviews. ${ }^{6}$ The review was registered with PROSPERO (CRD42017058488).

The searches were conducted on October 30, 2017. Study eligibility criteria are described in the full report.

\section{Results}

\section{Summary of Studies}

The literature searches yielded 10,765 citations and an additional 357 references were screened from review articles, existing systematic reviews, and from reviewers of the draft report. Of these, 425 articles were retrieved in full text. We excluded 348 articles. Of note, 89 studies compared lower limb prosthesis (LLP) components or configurations but did not report either subgroup analyses, regression analyses, or individual patient data which would allow subgroup analyses. Overall, we found 80 eligible studies (in 77 articles), of which 55 studies evaluated psychometric properties addressing Key Questions (KQ) 1 to 3, 14 studies provided data relevant to KQ 4, no studies for KQ 5, two studies for KQ 6, and eight studies for KQ 7.

\section{Key Questions 1 to 3. Assessment Techniques, Prediction Tools, Functional Outcome Measurement Tools}

Studies provided evidence regarding psychometric properties of 50 instruments for people with lower limb amputations. In total, 55 studies in 52 articles met criteria to provide evidence regarding instrument psychometrics in people with lower limb amputations. The evidence is summarized for each instrument in the main report.

We categorized instruments (or subscales, etc. of instruments) by whether studies that evaluated them were generalizable to the Medicare population (i.e., study mean age $\geq 65$ years or $\geq 50 \%$ of participants had dysvascular disease) and by whether there is supporting evidence for validity and/or reliability.

The instruments evaluated are:

- 1 Leg Standing Balance

- 180 Degree Turn Test

- $\quad$ 2MWT (2 Minute Walk Test)

- 6MWT (6 Minute Walk Test)

- AAS (Amputee Activity Survey)

- ABC (Activities-specific Balance Confidence)

- ADAPT (Assessment of Daily Activity Performance in Transfemoral Amputees)

- AMP (Amputee Mobility Predictor with, AMPPRO, or without prosthesis, AMPnoPRO)

- AMPSIMM (Amputee Single Item Mobility Measure)

- Barthel Index

- BBS (Berg Balance Scale)

- Climbing Stairs Questionnaire 
- Employment Questionnaire

- FAC (Functional Ambulation Categories)

- FAI (Frenchay Activities Index)

- FIM (Functional Independence Measure)

- FSST (Four Square Step Test)

- Functional Reach Test

- Houghton Scale

- L Test (L Test of Functional Mobility)

- LCI (Locomotor Capabilities Index)

- LEMOCOT (Lower-Extremity Motor Coordination Test)

- NQ-ACGC (Quality of Life in Neurological Conditions - Applied Cognition/General Concerns)

- OPCS (Office of Population Censuses and Surveys Scale)

- OPUS (Orthotics Prosthetics Users Survey)

- Patient Activity Monitor

- PEQ, PEQ-MS (Prosthetic Evaluation Questionnaire, Mobility Subscale)

- PFI (Physical Function Index)

- PGI (Patient Generated Index)

- PLUS-M (Prosthetic Limb Users Survey of Mobility)

- PPA (Prosthetic Profile of the Amputee)

- PROMIS-29 (Patient-Reported Outcomes Measurement Information System 29-Item Profile)

- PROS (Prosthetist's Perception of Client's Ambulatory Abilities)

- PSFS (Patient-Specific Functional Scale)

- Q-TFA (Questionnaire for Persons with a Transfemoral Amputation)

- Rising and Sitting Down Questionnaire

- RMI (Rivermead Mobility Index)

- SAT-PRO (Satisfaction with Prosthesis Questionnaire)

- SCS (Socket Comfort Score)

- SF-12/SF-36/SF-36V (Short Form Health Surveys 12, 36, and 36V)

- SIGAM (Special Interest Group of Amputation Medicine)

- Single beam test

- SIP-PD (Sickness Impact Profile-Physical Dimension)

- Tandem Test

- TAPES (Trinity Amputation and Prosthesis Experience Scales)

- TFP (Transfemoral Fitting Predictor)

- TUG (Timed Up and Go)

- TWT (Timed Walking Test)

- Walking Questionnaire

- WHOQOL-BREF (World Health Organization Quality-of-Life Scale - Brief Version) 


\section{Key Question 1. Assessment Techniques}

Based on explicit reporting within articles that instruments were evaluated at the time of initial assessment or prosthesis fitting, 10 studies evaluated 12 instruments as initial assessment tools.

Eleven of the instruments have evidence of test validity from studies generalizable to the Medicare population. These include 1 Leg Standing Balance, 2MWT, AMPnoPRO, FAC, FAI, FIM, LEMOCOT, OPCS, PROS, SF, and TFP. For SF, more specifically, test validity has been found for SF-12 Physical Component Score, SF-12 Role Physical, SF-12 Bodily Pain, SF-36 Physical Functioning (where a modified 15-item version performed better than the original 10item version). Three of the 11 instruments were also reported to have evidence of test reliability when evaluated at initial assessment: AMPnoPRO, TMP, and for SF-12 the subscales for Role Emotional, Role Physical, Bodily Pain, and Mental Health.

One instrument, LCI, was evaluated at initial assessment only in a study that is not generalizable to the Medicare population. Both the LCI-4 and LCI-5 versions of the instrument were found to have evidence of test validity, reliability, and responsiveness. Floor and ceiling percentages were reported for LCI-4, and no such effects were found.

\section{Key Question 2. Prediction Tools}

Based on reporting of metrics relevant to predictive validity, eight studies evaluated 13 instruments as prediction tools. However, all but one study reported only correlations of the instrument results with occurrence or test scores at a future time point. Thus, these are not true evaluations of the predictive accuracy of these instruments. Only one study reported on diagnostic test accuracy (sensitivity and specificity) for several instruments.

Twelve instruments have been reported to have predictive validity in whole or in part in studies that are generalizable to the Medicare population. These include the 1 Leg Standing Balance, 180 Degree Turn Test, 2MWT, AMPnoPRO, FAC, FAI, FIM, FSST, LCI-4 Advanced, LEMOCOT, OPCS, and TUG. Two instruments were evaluated for predictive validity only in studies that were not generalizable to the Medicare population. Both AMPSIMM and LCI-5 were reported to be correlated with future functional status.

One study evaluated four of these instruments in a study deemed generalizable to the Medicare population for test accuracy to predict two or more falls during a 6-month followup period. ${ }^{7}$ The Turn Time and Turn Test components of the 180 Degree Turn Test, FSST and TUG all had high sensitivity (85\% to $100 \%$ ) and specificity (74\% to 93\%) to predict falls. The Advanced components portion of LCI-4 had high specificity (91\%) but low sensitivity (43\%) to predict falls, which overall was reported to be statistically significant $(\mathrm{P}<0.01)$. The Turn Steadiness component of the 180 Degree Turn Test also had high sensitivity (85\%) but low sensitivity (31\%) to predict falls, but this test overall was not statistically significant $(\mathrm{P}=0.22)$.

\section{Key Question 3. Functional Outcome Measurement Tools}

All 50 evaluated instruments were deemed to be relevant functional outcome measurement tools. The findings are summarized in Tables A to D. In brief, 34 instruments (in whole or in part) had supporting evidence generalizable to the Medicare population, of which, in Table A, 17 instruments (or parts thereof) have evidence to support validity and reliability, and in Table B, 13 instruments have evidence of validity alone and 7 instruments have evidence of reliability alone. As noted in the tables, two of the instruments (PEQ and SF-12/36/36V), specific instrument 
items have supporting evidence for both validity and reliability, or for either validity or reliability alone. There are also 19 instruments (in whole or in part) that have supporting evidence only from studies not generalizable to the Medicare population. Of these, in Table C, 13 instruments (or parts thereof) have evidence to support validity and reliability, and in Table $\mathrm{D}$, four instruments have evidence of validity only, three more have evidence of validity but explicitly not reliability, and 4 have evidence of reliability only. As noted in the tables, five of these instruments with evidence not generalizable to the Medicare population also have evidence for specific items that was generalizable to the Medicare population. Also, as noted in the tables, five other instruments have evidence for both validity and reliability for some subscales not only validity or reliability for others.

Table A. Instruments with evidence of both validity and reliability generalizable to the Medicare population

\begin{tabular}{|c|c|c|c|c|}
\hline Rep* & Instrument & MCare & Validity & Reliability \\
\hline & 2MWT (2 Minute Walk Test) & Gen & Valid & Reliable \\
\hline & 6MWT (6 Minute Walk Test) & Gen & Valid & Reliable \\
\hline & ABC (Activities-specific Balance Confidence) & Gen & Valid & Reliable \\
\hline & $\begin{array}{l}\text { AMP (Amputee Mobility Predictor) } \\
\text { Both AMPnoPRO (without prosthesis) and AMPPRO (with prosthesis) }\end{array}$ & Gen & Valid & Reliable \\
\hline & Climbing Stairs Questionnaire & Gen & Valid & Reliable \\
\hline & Functional Reach Test & Gen & Valid & Reliable \\
\hline & $\begin{array}{l}\text { Houghton Scale } \\
\text { Both total Scale score and a subscale of items } 1 \text { to } 3 \text { (on prosthesis wear } \\
\text { and use) }\end{array}$ & Gen & Valid & Reliable \\
\hline 1 & $\begin{array}{l}\mathrm{LCl}(\text { Locomotor Capabilities Index) } \\
\text { Specifically: } \mathrm{LCl}-4 \text { (LCl with a 4-point ordinal scale) }\end{array}$ & Gen & Valid & Reliable \\
\hline \multirow[t]{5}{*}{2} & $\begin{array}{l}\text { PEQ (Prosthetic Evaluation Questionnaire) }{ }^{\ddagger} \\
\text { Specifically, the PEQ-MS } 13 / 11 \text { (the Mobility Subscale with } 13 \text { items and } \\
11 \text { categories) }\end{array}$ & Gen & Valid & Reliable \\
\hline & $\begin{array}{l}\text { PPA (Prosthetic Profile of the Amputee) } \\
\text { Specifically: Prosthesis use (outdoors), and Acceptance / Adaptation }\end{array}$ & Gen & Valid & Reliable \\
\hline & Rising and Sitting Down Questionnaire & Gen & Valid & Reliable \\
\hline & RMI (Rivermead Mobility Index) & Gen & Valid & Reliable \\
\hline & SCS (Socket Comfort Score) & Gen & Valid & Reliable \\
\hline \multirow[t]{4}{*}{3} & $\begin{array}{l}\text { SF-12 (Short Form Health Survey 12) } \\
\text { Specifically: SF-12 PCS (Physical Component Score), SF-12 RP-2 (Role } \\
\text { Physical), and SF-12 BP-2 (Bodily Pain) }\end{array}$ & Gen & Valid & Reliable \\
\hline & TFP (Transfemoral Fitting Predictor) & Gen & Valid & Reliable \\
\hline & TUG (Timed Up and Go) & Gen & Valid & Reliable \\
\hline & Walking Questionnaire & Gen & Valid & Reliable \\
\hline
\end{tabular}

Abbreviations: Gen = generalizable to the Medicare population, MCare = Medicare (generalizability), Rep = repeated (see note for explanation).

Note: Instruments are organized across Tables A to D by whether the studies that evaluated them were generalizable to the Medicare (MCare) population (indicated by "Gen" in the MCare column) and by whether there was evidence of both validity and reliability, validity only, reliability only, and evidence of lack of reliability (indicated by "No" in the Reliability column of the relevant tables). Across tables, blank cells in the Validity or Reliability columns indicate that there was not evidence to support validity or reliability (not that the studies were found to be not valid or not reliable). In the Rep column, instruments that had parts that were variably generalizable, validated, or found to be reliable, and are thus repeated in different tables (or sections of tables), are noted with unique indicators (unique numbers) for each instrument. Instruments with blank cells in the Rep column are presented only in this table.

*Instruments that are included in multiple sections (repeated [Rep]) are indicated by unique numbers.

†LCI-4 (the total instrument) has been reported to be both valid and reliable in studies generalizable to the Medicare population. LCI-4 Basic, LCI-5, and LCI1-4 were not evaluated among studies generalizable to the Medicare population.

$\ddagger$ PEQ MS 13/11 has been reported to be both valid and reliable in studies generalizable to the Medicare population. The overall PEQ scale and each of the items, except shower and bathe safely (version with seven categories, 1 to 7 ) were reported to have reliability but were not evaluated for test validity in a study generalizable to the Medicare population.

§Also see listings for LCI, which is included in the PPA, but is evaluated separately in this table. 
Table B. Instruments with evidence of either validity or reliability generalizable to the Medicare population

\begin{tabular}{|c|c|c|c|c|c|}
\hline & $\operatorname{Rep}^{*}$ & Instrument & MCare & Validity & Reliability \\
\hline \multirow{13}{*}{$\begin{array}{l}\text { Instruments } \\
\text { With Evidence } \\
\text { of Validity } \\
\text { (Only) } \\
\text { Generalizable } \\
\text { to the Medicare } \\
\text { Population }\end{array}$} & & 1 Leg Standing Balance & Gen & Valid & \\
\hline & & $\begin{array}{l}180 \text { Degree Turn Test } \\
\text { Specifically: Turn Time and Turn Steps components }\end{array}$ & Gen & Valid & \\
\hline & & AAS (Amputee Activity Survey) & Gen & Valid & \\
\hline & 4 & 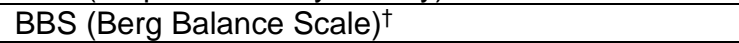 & Gen & Valid & \\
\hline & & FAC (Functional Ambulation Categories) & Gen & Valid & \\
\hline & 5 & FAI (Frenchay Activities Index) ${ }^{\dagger}$ & Gen & Valid & \\
\hline & & $\begin{array}{l}\text { FIM (Functional Independence Measure), total } \\
\text { score }\end{array}$ & Gen & Valid & \\
\hline & & FSST (Four Square Step Test) & Gen & Valid & \\
\hline & & $\begin{array}{l}\text { LEMOCOT (Lower-Extremity Motor Coordination } \\
\text { Test) }\end{array}$ & Gen & Valid & \\
\hline & & $\begin{array}{l}\text { OPCS (Office of Population Censuses and Surveys } \\
\text { Scale) }\end{array}$ & Gen & Valid & \\
\hline & & $\begin{array}{l}\text { PROS (Prosthetist's Perception of Client's } \\
\text { Ambulatory Abilities) }\end{array}$ & Gen & Valid & \\
\hline & 6 & $\begin{array}{l}\text { SIGAM (Special Interest Group of Amputation } \\
\text { Medicine) }\end{array}$ & Gen & Valid & \\
\hline & 3 & $\begin{array}{l}\text { SF-12 and SF-36 (Short Form Health Surveys } 12 \\
\text { and 36) } \\
\text { Specifically: SF-12 total score and SF-36 PF } \\
\text { (Physical Functioning subscale, PF } 15 \text { performed } \\
\text { better than PF-10) }\end{array}$ & Gen & Valid & \\
\hline \multirow{7}{*}{$\begin{array}{l}\text { Instruments } \\
\text { with Evidence } \\
\text { of Reliability } \\
\text { (Only) } \\
\text { Generalizable } \\
\text { to the Medicare } \\
\text { Population }\end{array}$} & & $\begin{array}{l}\text { OPUS (Office of Population Censuses and Surveys } \\
\text { Scale) } \\
\text { Specifically: subscales Quality of Life, Lower Limb } \\
\text { Function, and Satisfaction }\end{array}$ & Gen & & Reliable \\
\hline & 2 & $\begin{array}{l}\text { PEQ (Prosthetic Evaluation Questionnaire) } \\
\text { Specifically: the overall scale and each of the items, } \\
\text { including PEQ-MS 13/7, except the items shower } \\
\text { and bathe safely (version with } 7 \text { categories, } 1 \text { to } 7 \text { ) }\end{array}$ & Gen & & Reliable \\
\hline & & PGI (Patient Generated Index) & Gen & & Reliable \\
\hline & & PSFS (Patient-Specific Functional Scale) & Gen & & Reliable \\
\hline & & $\begin{array}{l}\text { SAT-PRO (Satisfaction with Prosthesis } \\
\text { Questionnaire) }\end{array}$ & Gen & & Reliable \\
\hline & 3 & $\begin{array}{l}\text { SF-36V (Short Form Health Survey } 36 \text { for use with } \\
\text { veterans) } \\
\text { Specifically: SF-36V subscales General Health, } \\
\text { Physical Functioning, and Role Physical }\end{array}$ & Gen & & Reliable \\
\hline & & Walking Speed, 10 meters & Gen & & Reliable \\
\hline
\end{tabular}

Abbreviations: Gen = generalizable to the Medicare population, MCare = Medicare (generalizability), Rep = repeated (see note for explanation).

Note: Instruments are organized across Tables A to D by whether the studies that evaluated them were generalizable to the Medicare (MCare) population (indicated by "Gen" in the MCare column) and by whether there was evidence of both validity and reliability, validity only, reliability only, and evidence of lack of reliability (indicated by "No" in the Reliability column of the relevant tables). Across tables, blank cells in the Validity or Reliability columns indicate that there was not evidence to support validity or reliability (not that the studies were found to be not valid or not reliable). In the Rep column, instruments that had parts that were variably generalizable, validated, or found to be reliable, and are thus repeated in different tables (or sections of tables), are noted with unique indicators (unique numbers) for each instrument. Instruments with blank cells in the Rep column are presented only in this table.

*Instruments that are included in multiple sections (repeated [Rep]) are indicated by unique numbers.

†BBS, FAI, and SIGAM have evidence of validity among studies generalizable to the Medicare population, but evidence of both validity and reliability among studies not generalizable to the Medicare population.

$\ddagger$ PEQ MS 13/11 has been reported to be both valid and reliable in studies generalizable to the Medicare population. The overall PEQ scale and each of the items, except shower and bathe safely (version with seven categories, 1 to 7 ) were reported to have reliability but were not evaluated for test validity in a study generalizable to the Medicare population. 
Table C. Instruments with evidence of both validity and reliability not generalizable to the Medicare population

\begin{tabular}{|c|c|c|c|c|}
\hline Rep* & Instrument & MCare & Validity & Reliability \\
\hline 4 & 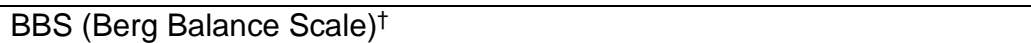 & No & Valid & Reliable \\
\hline \multirow[t]{2}{*}{5} & $\mathrm{FAI}_{(\text {Frenchay Activities Index) }}^{\dagger}$ & No & Valid & Reliable \\
\hline & L Test (L Test of Functional Mobility) & No & Valid & Reliable \\
\hline 1 & $\begin{array}{l}\text { LCI (Locomotor Capabilities Index) }{ }^{\ddagger} \\
\text { Specifically: LCl-4 Basic and Advanced (Basic and Advanced } \\
\text { components, separately, with a 4-point ordinal scale), LCI-5 (LCI with a } \\
\text { 5-point ordinal scale), and LCI10-4 (10-item scale which combined two of } \\
\text { the response levels from LCl-5) }\end{array}$ & No & Valid & Reliable \\
\hline 7 & $\begin{array}{l}\text { Patient Activity Monitor } \\
\text { Specifically: Walking Velocity }\end{array}$ & No & Valid & Reliable \\
\hline \multirow[t]{2}{*}{2} & $\begin{array}{l}\text { PEQ (Prosthetic Evaluation Questionnaire) } \\
\text { Specifically: the Function subscale Residual limb health, the Mobility } \\
\text { subscale Ambulation, the Psychosocial subscales Frustration and Social } \\
\text { Burden, and the Global subscale Well-Being; and PEQ MS } 12 / 5 \text { (the } \\
\text { Mobility Subscale with } 12 \text { items and } 5 \text { categories) }\end{array}$ & No & Valid & Reliable \\
\hline & $\begin{array}{l}\text { PFI (Physical Function Index) } \\
\text { Including the overall instrument and the four subscales Squat to Pick Up } \\
\text { Object, Walk at Steady Pace, Run at Steady Pace, and Climb Stairs }\end{array}$ & No & Valid & Reliable \\
\hline 8 & $\begin{array}{l}\text { PLUS-M (Prosthetic Limb Users Survey of Mobility) } \\
\text { Specifically: the form version SF-12 }{ }^{\#}\end{array}$ & No & Valid & Reliable \\
\hline 9 & $\begin{array}{l}\text { PROMIS-29 (Patient-Reported Outcomes Measurement Information } \\
\text { System 29-Item Profile) } \\
\text { Specifically: the Physical Function subscale }\end{array}$ & No & Valid & Reliable \\
\hline 10 & $\begin{array}{l}\text { Q-TFA (Questionnaire for Persons with a Transfemoral Amputation) } \\
\text { Specifically: the subscales Prosthetic Use, Prosthetic Mobility, and } \\
\text { Problem }\end{array}$ & No & Valid & Reliable \\
\hline \multirow[t]{2}{*}{6} & SIGAM (Special Interest Group of Amputation Medicine) ${ }^{\dagger}$ & No & Valid & Reliable \\
\hline & $\begin{array}{l}\text { SIP-PD (Sickness Impact Profile-Physical Dimension) } \\
\text { Including the overall instrument and the three subscales Ambulation, } \\
\text { Body Care and Movement, and Mobility }\end{array}$ & No & Valid & Reliable \\
\hline 11 & $\begin{array}{l}\text { TAPES (Trinity Amputation and Prosthesis Experience Scales) } \\
\text { All subscales of TAPES and TAPES-R except Weight Satisfaction (from } \\
\text { the original TAPES) and Satisfaction with Prosthesis Subscale } 1 \\
\text { (esthetics, from TAPES-R) }\end{array}$ & No & Valid & Reliable \\
\hline
\end{tabular}

Abbreviations: Gen = generalizable to the Medicare population, MCare = Medicare (generalizability), Rep = repeated (see note for explanation).

Note: Instruments are organized across Tables A to D by whether the studies that evaluated them were generalizable to the Medicare (MCare) population (indicated by "Gen" in the MCare column) and by whether there was evidence of both validity and reliability, validity only, reliability only, and evidence of lack of reliability (indicated by "No" in the Reliability column of the relevant tables). Across tables, blank cells in the Validity or Reliability columns indicate that there was not evidence to support validity or reliability (not that the studies were found to be not valid or not reliable). In the Rep column, instruments that had parts that were variably generalizable, validated, or found to be reliable, and are thus repeated in different tables (or sections of tables), are noted with unique indicators (unique numbers) for each instrument. Instruments with blank cells in the Rep column are presented only in this table.

*Instruments that are included in multiple sections (repeated [Rep]) are indicated by unique numbers.

†BBS, FAI, and SIGAM have evidence of validity among studies generalizable to the Medicare population, but evidence of both validity and reliability among studies not generalizable to the Medicare population.

$\ddagger$ LCI-4 (the total instrument) has been reported to be both valid and reliable in studies generalizable to the Medicare population. LCI-4 Basic, LCI-5, and LCI1-4 were not evaluated among studies generalizable to the Medicare population.

§PEQ MS 13/11 has been reported to be both valid and reliable in studies generalizable to the Medicare population. The overall PEQ scale and each of the items, except shower and bathe safely (version with seven categories, 1 to 7) were reported to have reliability but were not evaluated for test validity in a study generalizable to the Medicare population.

\#The form version SF-12 (not to be confused with the Short Form Health Survey SF-12) has evidence for both test validity and reliability. 
Table D. Instruments with evidence of either validity or reliability not generalizable to the Medicare population

\begin{tabular}{|c|c|c|c|c|c|}
\hline & $\operatorname{Rep}^{*}$ & Instrument & MCare & Validity & Reliability \\
\hline \multirow{4}{*}{$\begin{array}{l}\text { Instruments With } \\
\text { Evidence of Validity } \\
\text { (Only) } \\
\text { Not Generalizable to } \\
\text { the Medicare } \\
\text { Population }\end{array}$} & & $\begin{array}{l}\text { AMPSIMM (Amputee Single Item Mobility } \\
\text { Measure) }\end{array}$ & No & Valid & \\
\hline & & Employment Questionnaire & No & Valid & \\
\hline & & TWT (Timed Walking Test) & No & Valid & \\
\hline & & $\begin{array}{l}\text { WHOQOL-BREF (World Health Organization } \\
\text { Quality of Life-Brief Version) } \\
\text { Specifically: the Physical Health, } \\
\text { Psychological Health, Social Relations, and } \\
\text { Environmental subscales }\end{array}$ & No & Valid & \\
\hline \multirow{3}{*}{$\begin{array}{l}\text { Instruments With } \\
\text { Evidence of Validity } \\
\text { But Not Reliability } \\
\text { Not Generalizable to } \\
\text { the Medicare } \\
\text { Population }\end{array}$} & 7 & $\begin{array}{l}\text { Patient Activity Monitor } \\
\text { Specifically: Step Count and Step Length }\end{array}$ & No & Valid & No \\
\hline & 10 & $\begin{array}{l}\text { Q-TFA (Questionnaire for Persons with a } \\
\text { Transfemoral Amputation) } \\
\text { Specifically: Global Health subscale }\end{array}$ & No & Valid & No \\
\hline & 11 & $\begin{array}{l}\text { TAPES (Trinity Amputation and Prosthesis } \\
\text { Experience Scales) } \\
\text { Specifically: the Satisfaction with Prosthesis } \\
\text { Subscale } 1 \text { (esthetics) from TAPES R }\end{array}$ & No & Valid & No \\
\hline \multirow{4}{*}{$\begin{array}{l}\text { Instruments With } \\
\text { Evidence of Reliability } \\
\text { (Only) } \\
\text { Not Generalizable to } \\
\text { the Medicare } \\
\text { Population }\end{array}$} & & $\begin{array}{l}\text { ADAPT (Assessment of Daily Activity } \\
\text { Performance in Transfemoral Amputees) } \\
\text { Specifically: Items } 10 \text { to 18; items } 1 \text { to } 9 \text { were } \\
\text { not evaluated }\end{array}$ & No & & Reliable \\
\hline & & $\begin{array}{l}\text { NQ-ACGC (Quality of Life in Neurological } \\
\text { Conditions - Applied Cognition / General } \\
\text { Concerns) }\end{array}$ & No & & Reliable \\
\hline & 8 & $\begin{array}{l}\text { PLUS-M (Prosthetic Limb Users Survey of } \\
\text { Mobility) } \\
\text { Specifically: the form versions CAT } \\
\text { (Computer Adaptive Test) and SF-7 (a short } \\
\text { form version) }\end{array}$ & No & & Reliable \\
\hline & 9 & $\begin{array}{l}\text { PROMIS-29 (Patient-Reported Outcomes } \\
\text { Measurement Information System 29-Item } \\
\text { Profile) } \\
\text { Specifically: the Anxiety, Depression, } \\
\text { Fatigue, Pain Intensity, Pain Interference, } \\
\text { Physical Function, Sleep Disturbance, and } \\
\text { Social Role Satisfaction subscales }\end{array}$ & No & & Reliable \\
\hline
\end{tabular}

Abbreviations: Gen = generalizable to the Medicare population, MCare = Medicare (generalizability), Rep = repeated (see note for explanation).

Note: Instruments are organized across Tables A to D by whether the studies that evaluated them were generalizable to the Medicare (MCare) population (indicated by "Gen” in the MCare column) and by whether there was evidence of both validity and reliability, validity only, reliability only, and evidence of lack of reliability (indicated by "No" in the Reliability column of the relevant tables). Across tables, blank cells in the Validity or Reliability columns indicate that there was not evidence to support validity or reliability (not that the studies were found to be not valid or not reliable). In the Rep column, instruments that had parts that were variably generalizable, validated, or found to be reliable, and are thus repeated in different tables (or sections of tables), are noted with unique indicators (unique numbers) for each instrument. Instruments with blank cells in the Rep column are presented only in this table.

*Instruments that are included in multiple sections (repeated [Rep]) are indicated by unique numbers.

\section{Key Question 4. LLP Comparative Effectiveness by Subgroup}

It should be noted that this review makes no attempt to make conclusions about the overall effects of different LLP components or configurations. Key Question 4 addressed whether there is evidence regarding heterogeneity of treatment effects (whether outcomes with specific devices vary across individuals based on different characteristics such as age or health status) in the field of LLP research and whether studies used validated measures. 
A relatively small percentage of comparative studies report sufficient data to allow subgroup analysis and evaluation of heterogeneity of treatment effect (14\%, 15 of 104 otherwise eligible articles). These studies either address or provide sufficient data that allowed us to address the focused question of whether the relative effect of different components or configurations differs across different subgroups of lower limb amputees.

Twelve of the 14 studies included between 5 and 168 users of LLPs, one included 899 amputees, and one 1013. Seven studies evaluated microprocessor knees (compared to mechanical knees), two evaluated other knee components, three evaluated ankle/foot components, and one each evaluated pylons or sockets. One large study developed a regression model to evaluate the predictive ability of a wide range of participant characteristics. Another study (Hahn 2015) conducted correlation and regression analyses but did not fully report the results of these analyses. Overall, studies that investigated subgroup effects did not identify participant characteristics that predict which lower limb amputees would benefit most or least from any given component (low strength of evidence).

Of the 13 studies, only seven used validated predictor and outcome measures. Only one of the eligible studies was a randomized trial, but it evaluated atypical, nonvalidated predictor variables (subgroups of the Medicare Functional Classification Level K2). Only two studies explicitly evaluated heterogeneity of treatment effect; others reported individual participant level data without conducting their own subgroup analyses. Across studies, a scattering of statistically significant differences in relative effects of different components were found based on different subgroup comparisons. However, these findings were not consistent across, and often within, studies. Only one study, which compared a specific microprocessor knee (Genium ${ }^{\mathrm{TM}}$ ) to any prior used knee (mostly another microprocessor knee, C-Leg ${ }^{\mathrm{TM}}$ ), analyzed the most important aspect of the KQ, namely whether any study participant characteristics (or set of characteristics) could accurately and effectively predict which patients would benefit most or least from a given component. However, there were methodological and analytic concerns with this study. Despite finding numerous statistically significant associations between participant characteristics and functional outcomes, the study concluded that no model accurately predicted relative effect (between the Genium microprocessor knee and, mostly, the C-Leg microprocessor knee).

Overall, studies that investigated subgroup effects did not identify participant characteristics that predict which lower limb amputees would benefit most or least from a given LLP component or configuration. Based on the methodology used to assess strength of evidence, the studies warrant a low strength of evidence that patient characteristics evaluated in the studies do not predict which patients would benefit most or least from a given LLP component or configuration (Table E). Although one large study attempted to develop a model to predict success with microprocessor knees, the study did not use a validated outcome and had several methodological and analytic issues. It, therefore, provided insufficient additional evidence regarding who would be more likely or less likely to benefit from a microprocessor knee. An additional issue across almost all studies was that study participants were in general not likely to be representative of the Medicare population, being both mostly young and with amputations due to trauma, with relatively few people with dysvascular disease.

\section{Key Question 5. Expectations of Ambulation}

We found no study that addressed this key question. 


\section{Key Question 6. Patient Satisfaction With Process}

Two studies addressed this Key Question. Note that this Key Question did not address satisfaction with the LLP itself. Studies addressing satisfaction with LLPs (or function with the prosthesis) would have been eligible for Key Question 4 if they reported subgroup analyses. One study surveyed individuals about satisfaction with upper or lower prosthetic limbs and related services. The second study, designed to assess the reliability and construct validity of the Orthotics and Prosthetics National Office Outcomes Tool in clients with LLPs, reported data about satisfaction with the prosthetist appointments.

A moderate risk of bias study (of generally younger adults about one-third of whom had dysvascular disease) found that at least three-quarters of people receiving an LLP were satisfied with the process of accessing their LLP and a high risk of bias study (in which about half had Medicare or Medicaid insurance) found that on average clients were satisfied with their visits to their prosthetists' offices (average score about 83 of 100). Together, the studies provide low strength evidence that people are satisfied with their encounters with their prosthetists (Table F). 
Table E. Key Question 4 evidence profile

\begin{tabular}{|c|c|c|c|c|c|c|c|c|c|}
\hline Outcome & $\begin{array}{l}\text { No. Studies } \\
\text { (N) }\end{array}$ & $\begin{array}{l}\text { Study } \\
\text { Limitations }\end{array}$ & Consistency & Precision & $\begin{array}{l}\text { Reporting } \\
\text { Bias }\end{array}$ & Directness* $^{*}$ & Other Issues & Findings & SoE Grade \\
\hline $\begin{array}{l}\text { Validated } \\
\text { predictors and } \\
\text { outcomes } \\
\text { (univariable) }\end{array}$ & $\begin{array}{l}8 \text { (1096, } \\
1013 \text { in } 1 \\
\text { study) }\end{array}$ & Medium $\dagger$ & Consistent & Imprecise & Undetected & Indirectł & $\begin{array}{l}\text { High degree } \\
\text { of multiple } \\
\text { testing; mostly } \\
\text { evaluations of } \\
\text { knee } \\
\text { components; } \\
\text { mostly K2 or } \\
\text { K3 level, } \\
\text { unilateral } \\
\text { transfemoral } \\
\text { amputations } \\
\text { due to } \\
\text { traumatic } \\
\text { etiologies }\end{array}$ & $\begin{array}{l}\text { Some trends of } \\
\text { differences in } \\
\text { relative effect } \\
\text { based on } \\
\text { participant } \\
\text { characteristics, } \\
\text { however, none } \\
\text { statistically } \\
\text { significant after } \\
\text { correcting for } \\
\text { multiple testing }\end{array}$ & Low \\
\hline $\begin{array}{l}\text { All outcomes } \\
\text { (univariable) }\end{array}$ & $\begin{array}{l}13(1328, \\
1013 \text { in one } \\
\text { study) }\end{array}$ & Medium† & Consistent & Imprecise & Undetected & Indirectf & $\begin{array}{l}\text { Nonvalidated } \\
\text { outcomes, } \\
\text { high degree of } \\
\text { multiple } \\
\text { testing; mostly } \\
\text { K2 to K4 level, } \\
\text { unilateral } \\
\text { transfemoral } \\
\text { amputations } \\
\text { due to } \\
\text { traumatic } \\
\text { etiologies }\end{array}$ & $\begin{array}{l}\text { Some trends of } \\
\text { differences in } \\
\text { relative effect } \\
\text { based on } \\
\text { participant } \\
\text { characteristics, } \\
\text { however, none } \\
\text { statistically } \\
\text { significant after } \\
\text { correcting for } \\
\text { multiple testing }\end{array}$ & Low \\
\hline $\begin{array}{l}\text { Ambulatory and } \\
\text { functional } \\
\text { outcomes, } \\
\text { nonvalidated } \\
\text { (multivariable } \\
\text { model) }\end{array}$ & 1 (899) & High§ & NA & Precise & Undetected & Indirect\# & $\begin{array}{l}\text { K2 to K4 } \\
\text { (mostly K3) } \\
\text { level, mostly } \\
\text { traumatic } \\
\text { etiologies. } \\
\text { Study does } \\
\text { not directly } \\
\text { address Key } \\
\text { Question. }\end{array}$ & $\begin{array}{l}\text { A large set of } \\
\text { variables } \\
\text { individually were } \\
\text { associated with } \\
\text { better outcomes } \\
\text { with the } \\
\text { microprocessor } \\
\text { knee. No model } \\
\text { predicted who } \\
\text { would most benefit } \\
\text { from knee. }\end{array}$ & Insufficient \\
\hline
\end{tabular}

Abbreviations: $\mathrm{NA}=$ not applicable, $\mathrm{RoB}=$ risk of bias, $\mathrm{SoE}=$ strength of evidence. 
*Representative of either (or both) older adults ( $\geq 65$ years old) or those with dysvascular amputations.

$†$ Nonrandomized studies, univariable analyses (mostly individual participant data reports), generally lack of evaluation of heterogeneity of treatment effect, mostly small studies. ¥Both relatively young age amputees and primarily people with amputations due to trauma in most studies. Almost all (that reported) had unilateral transfemoral amputations. §Nonrandomized, likely biased sample of participants, nonvalidated outcomes, unclear which outcome(s) used in final models. See text.

\#Highly selected participants who had been assessed as likely to benefit from a microprocessor knee, possibly biased dropouts, relatively young and two-thirds had trauma etiology.

Table F. Key Questions 5 and 6 evidence profile

\begin{tabular}{|l|l|l|l|l|l|l|l|l|}
\hline Outcome & $\begin{array}{l}\text { No. Studies } \\
(\mathbf{N})\end{array}$ & $\begin{array}{l}\text { Study } \\
\text { Limitations }\end{array}$ & Consistency & Precision & $\begin{array}{l}\text { Reporting } \\
\text { Bias }\end{array}$ & Directness* & Other Issues & $\begin{array}{l}\text { Findings } \\
\text { Grade }\end{array}$ \\
\hline $\begin{array}{l}\text { Alignment of } \\
\text { outcomes with } \\
\text { expectations } \\
\text { (KQ 5) }\end{array}$ & 0 & NA & NA & NA & NA & NA & NA \\
\hline $\begin{array}{l}\text { Satisfaction with } \\
\text { process (KQ 6) }\end{array}$ & $2(\sim 1663)$ & Medium & Consistent & Precise & Undetected & Direct † & $\begin{array}{l}\text { Nonvalidated } \\
\text { outcomes }\end{array}$ & $\begin{array}{l}\text { Clients generally } \\
\text { satisfied with their } \\
\text { encounters with } \\
\text { their prosthetists }\end{array}$ \\
\hline
\end{tabular}

Abbreviations: KQ = Key Question, NA = not applicable, SoE = strength of evidence.

*Representative of either (or both) older adults ( $\geq 65$ years old) or those with dysvascular amputations.

†One study included a wide range of prosthetics practices; about half the participants had Medicare or Medicaid as a primary payer. The other study was less representative. 


\section{Key Question 7. Long-Term Outcomes}

We found eight studies with at least 100 participants who were followed for at least 6 months after prescription of an LLP. The studies analyzed data from 109 to 555 participants followed for 1 to 7 years (except for two studies that implied long-term followup, but did not report a timeframe). The studies only sparsely covered the subquestions pertaining to specific outcomes, particularly related to questions about different outcomes in different subgroups of amputees. Studies did not explicitly account for intervening mortality or subsequent surgeries or injuries.

Table G summarizes the strength of evidence for each outcome and subgroup analysis with data. For all outcomes of interest, there is low or insufficient strength of evidence because evidence is sparse, most studies were conducted in the 1990s or earlier, and only one of the studies was conducted in the United States, with its unique healthcare system and standards for prosthesis prescription. Also, most studies had methodological limitations, most populations analyzed were not directly applicable to the Medicare population, and some study findings were inconsistent with each other. Subgroup analyses in single studies tended to be underpowered to detect differences, mostly leading to determinations that the evidence was insufficient.

We found a low strength of evidence, based on six studies, that about 11 to 22 percent of lower limb amputees who receive an LLP prescription abandon the prosthesis (stop using it) at about 1 year. These studies are generally representative of people with LLP, in particular older adults and those with dysvascular etiologies. However, only one of the studies was conducted in the United States and it used hospital data as of 1998; most other studies were also old. Three of these studies provide low strength of evidence that people with unilateral transfemoral amputations are about twice as likely to abandon their LLP than those with unilateral transtibial amputations. Potential differences among other subgroups had insufficient evidence due to conflicting results among three studies or only a single, imprecise study with data.

Based primarily on two generally representative studies, there is low strength of evidence that 24 to 29 percent of LLP recipients use their prostheses only indoors at 1 year. There is low strength of evidence about how likely different subgroups of people use their prostheses only indoors, suggesting that people with transfemoral amputations, or who are older, or with bilateral amputations are more likely to be limited to indoor use. There is insufficient evidence about the rates of failure to maintain bipedal ambulation ( 1 study, $7 \%$ at 7 years), use of prostheses only for transfer (1 study, $4 \%$ at 1 year), and why people abandon their prostheses. No study reported on "major problems" with prostheses. 
Table G. Key Question 7 evidence profile

\begin{tabular}{|c|c|c|c|c|c|c|c|c|c|c|}
\hline Outcome & Subgroup & $\begin{array}{l}\text { No. Studies } \\
\text { (N) }\end{array}$ & $\begin{array}{l}\text { Study } \\
\text { Limitations }\end{array}$ & Consistency & Precision & $\begin{array}{l}\text { Reporting } \\
\text { Bias }\end{array}$ & Directness* & $\begin{array}{l}\text { Other } \\
\text { Issues }\end{array}$ & Findings & $\begin{array}{l}\text { SoE } \\
\text { Grade }\end{array}$ \\
\hline $\begin{array}{l}\text { Failure to } \\
\text { maintain } \\
\text { bipedal } \\
\text { ambulation }\end{array}$ & $\begin{array}{l}\text { All } \\
\text { participants }\end{array}$ & $1(148)$ & High & NA & Precise & Undetected & Indirect & $\begin{array}{l}\text { Unclear } \\
\text { outcome, } \\
\text { old study }\end{array}$ & $7 \%$ at 7 years & Insufficient \\
\hline \multirow{3}{*}{$\begin{array}{l}\text { Use of } \\
\text { prosthesis } \\
\text { only for } \\
\text { transfers }\end{array}$} & $\begin{array}{l}\text { All } \\
\text { participants }\end{array}$ & 1 (196) & High & NA & Precise & Undetected & Indirect & $\begin{array}{l}\text { Single } \\
25 \text { year } \\
\text { old study }\end{array}$ & $4 \%$ at 1 year & Insufficient \\
\hline & TF vs. TT & 1 (196) & High & NA & Precise & Undetected & Indirect & $\begin{array}{l}\text { see } \\
\text { above }\end{array}$ & $\begin{array}{l}\text { No significant } \\
\text { difference }\end{array}$ & Insufficient \\
\hline & Age & 1 (196) & High & NA & Precise & Undetected & Indirect & $\begin{array}{l}\text { see } \\
\text { above }\end{array}$ & $\begin{array}{l}\text { Nonsignificantly } \\
\text { higher limited } \\
\text { used with older } \\
\text { age }\end{array}$ & Insufficient \\
\hline \multirow[t]{4}{*}{$\begin{array}{l}\text { Use of } \\
\text { prosthesis } \\
\text { only indoors }\end{array}$} & $\begin{array}{l}\text { All } \\
\text { participants }\end{array}$ & $4(1040)$ & Medium & Inconsistent & Imprecise & Undetected & Direct & $\begin{array}{l}\text { Mostly } \\
\text { old, non- } \\
\text { U.S. }\end{array}$ & $\begin{array}{l}24-29 \% \text { at } 1 \\
\text { year }\end{array}$ & Low \\
\hline & TF vs. TT & $2(337)$ & High & Inconsistent & Precise & Undetected & Direct & $\begin{array}{l}\text { see } \\
\text { above }\end{array}$ & $\begin{array}{l}\text { Twice as many } \\
\text { TF use only } \\
\text { indoors ( } 1 \\
\text { study, } \\
\mathrm{P}=0.008) \text { ), no } \\
\text { difference ( } 1 \\
\text { study) }\end{array}$ & Insufficient \\
\hline & Age & 1 (196) & High & NA & Precise & Undetected & Direct & $\begin{array}{l}\text { see } \\
\text { above }\end{array}$ & $\begin{array}{l}\text { Older more } \\
\text { likely to use } \\
\text { only indoors } \\
(\mathrm{P}=0.042)\end{array}$ & Insufficient \\
\hline & $\begin{array}{l}\text { Bilateral } \\
\text { vs. } \\
\text { unilateral }\end{array}$ & $1(141)$ & High & NA & Precise & Undetected & Direct & $\begin{array}{l}\text { see } \\
\text { above }\end{array}$ & $\begin{array}{l}\text { Bilateral more } \\
\text { than twice as } \\
\text { likely to use } \\
\text { only indoors } \\
(P=0.0006)\end{array}$ & Insufficient \\
\hline
\end{tabular}




\begin{tabular}{|c|c|c|c|c|c|c|c|c|c|c|}
\hline Outcome & Subgroup & $\begin{array}{l}\text { No. Studies } \\
\text { (N) }\end{array}$ & $\begin{array}{l}\text { Study } \\
\text { Limitations }\end{array}$ & Consistency & Precision & $\begin{array}{l}\text { Reporting } \\
\text { Bias }\end{array}$ & Directness* & $\begin{array}{l}\text { Other } \\
\text { Issues }\end{array}$ & Findings & $\begin{array}{l}\text { SoE } \\
\text { Grade }\end{array}$ \\
\hline \multirow[t]{5}{*}{$\begin{array}{l}\text { Abandonment } \\
\text { of prosthesis }\end{array}$} & $\begin{array}{l}\text { All } \\
\text { participants }\end{array}$ & $6(1153)$ & Medium & Consistent † & Precise & Undetected & Direct & $\begin{array}{l}\text { Mostly } \\
\text { old, non- } \\
\text { U.S. }\end{array}$ & $\begin{array}{l}11-22 \% \text { at } 1 \\
\text { year (or } \\
\text { undefined) } \dagger\end{array}$ & Low \\
\hline & TF vs. TT & $3(538)$ & High & Consistent & Precise & Undetected & Direct & $\begin{array}{l}\text { see } \\
\text { above }\end{array}$ & $\begin{array}{l}\text { TF more likely } \\
\text { to abandon } \\
\text { prosthesis than } \\
\text { TT }\end{array}$ & Low \\
\hline & $\begin{array}{l}\text { Bilateral } \\
\text { vs. } \\
\text { unilateral }\end{array}$ & $3(452)$ & High & Inconsistent & Precise & Undetected & Direct & $\begin{array}{l}\text { see } \\
\text { above }\end{array}$ & $\begin{array}{l}\text { Nonsignificant, } \\
\text { but conflicting } \\
\text { directionality }\end{array}$ & Insufficient \\
\hline & Age & $2(397)$ & High & Inconsistent & Precise & Undetected & Direct & $\begin{array}{l}\text { see } \\
\text { above }\end{array}$ & $\begin{array}{l}\text { Older } \\
\text { nonsignificantly } \\
\text { more likely to } \\
\text { abandon (1 } \\
\text { study), no } \\
\text { difference in } \\
\text { age (1 study) }\end{array}$ & Insufficient \\
\hline & Multiple & $1(201)$ & High & NA & Precise & Undetected & Indirect & $\begin{array}{l}\text { Multiple } \\
\text { testing }\end{array}$ & $\begin{array}{l}\text { No significant } \\
\text { associations }\end{array}$ & Insufficient \\
\hline $\begin{array}{l}\text { Major } \\
\text { problems with } \\
\text { prosthesis }\end{array}$ & $\begin{array}{l}\text { All } \\
\text { participants }\end{array}$ & 0 & NA & NA & NA & NA & NA & NA & None & Insufficient \\
\hline $\begin{array}{l}\text { Reasons for } \\
\text { poor } \\
\text { outcomes }\end{array}$ & $\begin{array}{l}\text { All } \\
\text { participants }\end{array}$ & 1 (201) & High & NA & Imprecise & Undetected & Indirect & $\begin{array}{l}\text { Single } \\
\text { non-U.S. } \\
\text { study }\end{array}$ & $\begin{array}{l}\text { Various general } \\
\text { categories of } \\
\text { reasons } \\
\text { reported }\end{array}$ & Insufficient \\
\hline
\end{tabular}

Abbreviations: NA = not applicable, RoB = risk of bias, SoE = strength of evidence, TF = transfemoral amputation, TT = transtibial amputation.

*Applicability to the Medicare population (based on mean age and percent with dysvascular amputations).

$\dagger$ Except that one outlier study from Taiwan found that only $0.9 \%$ of study participants abandoned their prostheses at a mean of 28 months. 


\section{Discussion}

A large number of studies have evaluated LLP for people with major lower limb amputations. We found over 100 studies that compared at least two LLP components or configurations that reported ambulatory, functional, or other patient-centered outcomes. We found many additional studies that evaluated only biomechanical properties of the components (which this review does not evaluate) and likely several hundred studies that evaluate just a single component. However, we found few studies that evaluated (or at least provided data to allow us to evaluate) heterogeneity of treatment effect. Overall, the evidence is currently sparse and fails to adequately address whether different subgroups of amputees are more likely or less likely to benefit from specific LLP components or configurations. We also found generally sparse evidence regarding patient expectations, patient satisfaction with care, and long-term outcomes.

From the amputee's and the clinician's perspective, among the most important questions is which LLP configuration (comprised of which prosthetic components) would best enable maximal health, function, and quality of life for a given individual. Given the large number of component types (knee, foot/ankle, socket, liner, etc.) and the range of features for each of these, the process of determining which LLP component or configuration is best for individuals is quite complex. However, the majority of the evidence addresses the question of which LLP component or configuration maximizes ambulation and function in the average patient, as opposed to which LLP component or configuration would best suit the needs of a given individual. In other words, few studies address the issue of heterogeneity of treatment effect. Suboptimal matching of patients to LLPs may unnecessarily increase health care utilization, prevent attainment of maximal patient function, and defer realization of improved quality of life attainable with an appropriate prosthesis, and unnecessarily increase health care expenditures.

We found evidence to enable the evaluation of the psychometric properties of 50 instruments (many containing evaluated subscales and items) in people with lower limb amputations. Many of the studies that evaluated instrument psychometric properties, however, were conducted in samples of participants who were arguably different than typical lower limb amputees with Medicare insurance, many of whom have dysvascular conditions including diabetes and peripheral vascular disease, or who are older and are, thus, more typical of lower limb amputees with Medicare insurance. We found that 39 of the 50 instruments have been evaluated in studies deemed generalizable to the Medicare population. Seventeen of these instruments were found, as a whole or in part, to have evidence supporting both reliability and validity. However, we recommend that researchers who are using this report to determine which instruments to use for their own studies also review the primary studies to determine whether the instruments have been sufficiently validated for their needs, are responsive to clinically important change, and have been evaluated in a sample of people representative of their study population.

Notably, no study has evaluated psychometric properties of the Medicare Functional Classification Level (MFCL or K level) system. Furthermore, the reader is reminded that lack of evidence regarding the psychometric properties of instruments does not imply that these measures are not valid or reliable, only that they have not been (adequately) evaluated. Standards for psychometric testing have changed over the years, so older instruments, evaluated by earlier studies, may not have psychometric property evaluations more commonly reported now.

Nevertheless, we strongly encourage future researchers to maximize the use of instruments with evidence of validity and reliability in the population of interest. Where such measures are 
lacking, the validity of the instruments being used as pivotal outcomes should be examined before use in future studies. We also encourage journal editors to require use of validated and reliable instruments when appropriate and feasible. However, we recognize that it will remain common that unvalidated measures may be appropriate in select instances (e.g., when measures to assess a particular trait or construct do not exist).

\section{Evidence Limitations}

Despite the large literature base for research on LLP, relatively few studies address the questions of interest for this review, particularly related to heterogeneity of treatment effect, patient expectations and satisfaction, and long-term use of LLP after prescription.

The applicability of these studies to the general population of people with LLPs may be somewhat limited, as the studies mostly evaluated prosthetic knees and were mostly conducted in younger men with unilateral transfemoral amputations due to trauma. Furthermore, implicitly or explicitly, most of these studies included only people who were deemed (by their prosthetists) to be likely to benefit from their new (generally more complex) device. Most of the studies that analyzed heterogeneity of treatment effect or provided data to allow subgroup analyses were observational and did not control for underlying differences during use of one component or the other. Studies evaluating heterogeneity of treatment effect also evaluated a limited set of patient characteristics such as age, amputation level, or amputation etiology. None analyzed differences in treatment effect by subgroups based on any assessment techniques, prediction tools, or outcome measures. Eligible studies reporting long-term LLP use after prescription were almost all conducted outside the United States and were mostly more than an decade old. Additional evidence limitations are discussed in the full report.

\section{Analysis Limitations}

Assessment of reliability, validity, and other psychometric properties is open to interpretation. By the strictest definition, an instrument would be considered to be valid and appropriate for use in a given study only if there is good evidence regarding the multiple aspects of validity for the specific population, conditions, and outcomes under evaluation. That an instrument demonstrates convergent validity with a given related measure does not imply that it also can distinguish differences related to subgroups of patients or an intervention effect. That an instrument has predictive validity regarding one outcome, such as future successful use of an LLP, does not imply predictive validity for other ambulatory outcomes, such as speed of walking or community ambulation. Despite these challenges, and the lack of a universal gold standard for determining absolute validity, we took a liberal approach in our literature synthesis. We considered an instrument to have evidence of validity if there was evidence of any type of validity (other than face/content). We, thus, categorized the evidence and dichotomized data so that instruments were classified as valid or not. It is incumbent on each study's researchers to determine whether given instruments and measures have sufficient evidence of validity and are appropriate for their study purposes. Additional evidence limitations are discussed in the full report.

\section{Future Research Recommendations}

Future research is needed to adequately address most of the questions in this review. While numerous instruments have evidence of validity, at least in part, additional studies are needed to 
confirm their psychometric properties and to better understand specific aspects of validity. Wellconducted studies, using validated predictors and outcomes, are needed to evaluate which devices would be most effective to achieve successful outcomes for which patients. To as great an extent as possible, studies should assess validated, patient-centered outcomes related to ambulation, function, quality of life, and related outcomes. Continued use of ad hoc and nonvalidated measures greatly limits the interpretability, usability, representativeness, and overall value of the studies. Ideally, studies should use a core set of validated, patient-centered outcomes that incorporate the perspectives of patient and other key stakeholders (a core outcome set); in addition, studies may measure other specific outcomes, as needed. This would allow comparability across studies and pooling of study findings (e.g., meta-analysis). Creation of such a core outcome set would likely require a consensus development process among a range of stakeholders. More specific recommendations for studies of heterogeneity of treatment effect and studies on expectations, satisfaction with services, and long-term followup are provided in the full report.

\section{Conclusions and Clinical Implications}

Numerous instruments that assess ambulation, function, quality of life, and other patientcentered outcomes exist for people with lower limb amputations and LLPs. Researchers should minimize the use of nonvalidated or ad hoc measures. Those who wish to use new or previously unvalidated instruments should validate these measures before using them. Researchers with an interest in assessing LLPs for the Medicare population would be best served to focus on those instruments with evidence of reliability and validity for this population or validate the measures in this population. The majority of the evidence on LLPs addresses the question of which LLP component or configuration maximizes ambulation and function in the average patient, as opposed to which LLP would best suit the needs of a given individual. In other words, few studies address the issue of heterogeneity of treatment effect. A small evidence base does not provide data to guide LLP selection for a specific patient to maximize their ambulation, function, and quality of life or to minimize abandonment or limited use. However, this does not imply that the evidence suggests patient characteristics cannot effectively predict which patients would benefit most or least from one or another specific component; only that the current evidence does not support use of any given predictor. There is low strength of evidence that patients are generally satisfied with the prosthetic services they receive. Further high-quality research is needed to better assess the psychometric properties of instruments (whether assessment techniques, prediction tools, or outcome measures) and to answer the Key Questions addressed in this systematic review. 


\section{References}

1. Boyle JP, Thompson TJ, Gregg EW, et al. Projection of the year 2050 burden of diabetes in the US adult population: dynamic modeling of incidence, mortality, and prediabetes prevalence. Popul Health Metr. 2010 Oct 22;8:29. doi: 10.1186/1478-7954-8-29. PMID: 20969750.

2. Ziegler-Graham K, MacKenzie EJ, Ephraim PL, et al. Estimating the prevalence of limb loss in the United States: 2005 to 2050. Arch Phys Med Rehabil. 2008 Mar;89(3):422-9. doi: 10.1016/j.apmr.2007.11.005. PMID: 18295618.

3. Etter K, Borgia M, Resnik L. Prescription and repair rates of prosthetic limbs in the VA healthcare system: implications for national prosthetic parity. Disabil Rehabil Assist Technol. 2014 May 22:1-8. doi: 10.3109/17483107.2014.921246. PMID: 24852068.

4. Resnik L, Borgia M. Predicting prosthetic prescription after major lower-limb amputation. J Rehabil Res Dev. 2015;52(6):641-52. doi: 10.1682/jrrd.2014.09.0216. PMID: 26562228.
5. Borrenpohl D, Kaluf B, Major MJ. Survey of U.S. Practitioners on the Validity of the Medicare Functional Classification Level System and Utility of Clinical Outcome Measures for Aiding K-Level Assignment. Arch Phys Med Rehabil. 2016 Jul;97(7):1053-63. doi: 10.1016/j.apmr.2016.02.024. PMID: 27016261.

6. AHRQ Methods for Effective Health Care. Methods Guide for Effectiveness and Comparative Effectiveness Reviews. Rockville (MD): Agency for Healthcare Research and Quality (US); 2011.

7. Dite W, Connor HJ, Curtis HC. Clinical identification of multiple fall risk early after unilateral transtibial amputation. Arch Phys Med Rehabil. 2007 Jan;88(1):109-14. doi: 10.1016/j.apmr.2006.10.015. PMID: 17207685. 


\section{Introduction}

\section{Background}

An estimated 1.9 million people in the United States are living with limb loss, a number expected to double by 2050 mostly due to the rising prevalence of diabetes. ${ }^{1,2}$ However, fewer than half of amputees ever receive a prescription for a prosthetic device. ${ }^{3,4}$ Prescription rates are even lower among older amputees, African Americans, and Americans living in the southern United States ${ }^{4}$ The management of lower limb amputees with respect to lower limb prostheses (LLPs) is a complicated problem. LLP candidates are a heterogeneous group with distinct needs dependent upon age, etiology of limb loss, level of amputation, comorbidities and health status, postoperative stage, and rehabilitation status. Many LLP options exist, comprising numerous permutations of components, the anatomy they replace, their sophistication, and other attributes, including those pertaining to cosmesis and comfort. In addition, patients may require multiple LLPs (initial, preparatory, definitive, or replacement prostheses, or those for specific types of activities). Compared to the general population, LLP patients exhibit lower overall physical and emotional health (e.g., increased risk for cardiovascular disease, ${ }^{8}$ anxiety, and depression ${ }^{9}$ ) and higher mortality (estimated 5-year mortality rates for amputees range between $50^{10}$ and 74 percent $^{11}$; estimated 1-year mortality is $36 \%$ for amputees $>65$ years old ${ }^{12}$ ). However, in a study of Medicare beneficiaries, amputees who received an LLP were significantly more likely to remain in the home and less likely to have an emergency room admission. ${ }^{13}$

The most common cause of major lower limb loss among adults is dysvascular disease, primarily due to diabetes and peripheral artery disease, accounting for about 81 percent of lower limb amputees. ${ }^{2}$ Trauma accounts for about 17 percent of major lower limb amputation. Cancer is a relatively uncommon cause of lower limb amputation in adults (2\%). However, individuals who lost their limb from etiologies other than dysvascular disease are disproportionately represented in the total limb loss community. ${ }^{2}$ This is likely due to the relatively high mortality rate among those with dysvascular conditions. About two-thirds or all amputees are men; although among older adults ( $\geq 65$ years), 46 percent are women. Dysvascular disease is a more common amputation etiology among older than younger adults. Amputation etiology has an important impact on patient survival and functional ability. Among Medicare recipients, about the same percentage of lower limb amputees have transfemoral as transtibial amputations. ${ }^{14}$

The current standard approach for matching patients to prostheses relies heavily on performance-based assessments, self-assessments, and, in some instances, wearable monitoring technologies that record patient activity; ${ }^{5}$ although prosthetists and treating clinicians often rely on clinical judgment to match patients to prostheses. Insurance coverage policies often dictate which prostheses and components are selected for a given patient. Numerous instruments exist to assess the patient functional status, but no consensus "gold standard" assessment schema exists. Similarly, numerous instruments (or techniques) are used to assess current amputee function or status and tools have been developed to predict future outcomes, including successful use of LLPs. Constructs of reliability (e.g., test-retest, interrater, internal consistency) or validity (e.g., face, content, construct, criterion) of existing outcome measurement tools (OMTs), assessment techniques, and prediction tools have been evaluated in the amputee population for the most frequently used instruments. ${ }^{15}$ However, it is unclear to what degree studies with functional and patient-centered outcomes use validated instruments and outcomes. It is also unclear whether the population of amputees included in validation (etc.) studies is generalizable to the population of 
participants in studies of LLP components and, in turn, whether these study populations are applicable to the more general population of users of LLPs.

LLPs replace the functionality of a missing limb, ideally, to as great a degree as possible. Medicare covers custom fabricated LLPs in accordance with Local Coverage Determination (LCD): Lower Limb Prostheses (L33787). ${ }^{16}$ As for all items to be covered by Medicare, it must: (1) be eligible for a defined Medicare benefit category, (2) be reasonable and necessary for the diagnosis or treatment of illness or injury or to improve the functioning of a malformed body member, and (3) meet all other applicable Medicare statutory and regulatory requirements. An LLP is covered when the beneficiary: (1) will reach or maintain a defined functional state within a reasonable period of time; and (2) is motivated to ambulate. Potential functional ability is based on the reasonable expectations of the prosthetist and treating physician, considering factors including, but not limited to, the beneficiary's past medical history, the beneficiary's current overall health condition including the status of the residual limb, and the nature of other medical problems. Some prosthesis components are limited to beneficiaries with a functional ability at or above a certain level.

As indicated by Medicare coverage guidance, ${ }^{16}$ clinical assessments of beneficiary rehabilitation potential must be based on the classification levels listed in Table 1 . The Medicare Functional Classification Level (MFCL or K level) system broadly defines five classification levels that can be attained with an LLP and range from 0 (no ability or potential to ambulate or transfer; LLP will not enhance quality of life or mobility) to 4 (ability or potential to exceed basic ambulation skills). The classification level assigned is used to determine the potential value of certain componentry, and thus to match the most appropriate LLP to fit the beneficiary's clinical needs.

Table 1. Lower limb extremity prosthesis Medicare Functional Classification Levels (K levels) Level 0: $\quad$ Does not have the ability or potential to ambulate or transfer safely with or without assistance and a prosthesis does not enhance their quality of life or mobility

Level 1: $\quad$ Has the ability or potential to use a prosthesis for transfers or ambulation on level surfaces at fixed cadence. Typical of the limited and unlimited household ambulator.

Level 2: $\quad$ Has the ability or potential for ambulation with the ability to traverse low level environmental barriers such as curbs, stairs, or uneven surfaces. Typical of the limited community ambulator.

Level 3: $\quad$ Has the ability or potential for ambulation with variable cadence. Typical of the community ambulator who has the ability to traverse most environmental barriers and may have vocational, therapeutic, or exercise activity that demands prosthetic utilization beyond simple locomotion.

Level 4: Has the ability or potential for prosthetic ambulation that exceeds basic ambulation skills, exhibiting high impact, stress, or energy levels. Typical of the prosthetic demands of the child, active adult, or athlete.

Note: Definitions per Centers for Medicare \& Medicaid Services. ${ }^{16}$

In practice it is difficult for clinicians to determine the most appropriate component for a given patient (whether of higher or lower level or sophistication). Determination of a patient's potential functional abilities requires an assessment of current condition and ability and potential to ambulate. In practice, therefore, OMTs must both assess and predict function to help guide 
prosthetists, treating physicians, and beneficiaries. However, it is unclear to what extent measures of current function and status are able to predict future function.

A major methodological challenge in addressing selection of OMTs for routine use pertains to the assessment of predictive validity. Predictive tests should be valued with respect to their ability to predict future important outcomes. However, outcomes are determined by the whole patient management strategy which involves the baseline assessment, the LLP that a patient is given based on this assessment, patient health and changes in patient health, and any additional care (e.g., physical therapy, rehabilitation) that the patient receives. Thus, it is inherently challenging to assess the value of a baseline OMT assessment by itself, particularly if the choice of LLP is influenced by the initial OMT assessment.

Variability and subjectivity in assigning or predicting the K level of prospective LLP recipients may inadvertently lead to inefficient or inappropriate LLP matching. ${ }^{17}$ This can occur if a person receives an LLP allowed for lower K levels when an LLP allowed only for higher K levels would enable better function, or if a person receives an LLP approved for higher K levels, which might be unnecessarily complex for an individual who would have equivalent or better function with a simpler component.

Options for configuring LLPs are abundant, as LLP are highly customized devices, comprising combinations of components that replace missing anatomy and function. Components of a given type can differ in terms of functional sophistication (e.g., articulated componentry may be passive, with undamped movement, have mechanical or hydraulic dampening, or have electronic control), materials used, weight, aesthetics, comfort, and other factors. A major question is how to match patients with LLPs (both by K levels as well as by other characteristics) to optimize functional and other patient-centered outcomes. Because there are many different patients and many possible LLPs, there are numerous possible matchings. However, it is unclear which patient-level characteristics or LLP-level attributes predict a good matching, or how to weigh patient functional potential against their current functional level in the matching process.

The major contextual challenges in providing data to inform matching of LLP components to patients pertain to the large heterogeneity in patient characteristics and attributes of the LLPs; the lack of data on patient characteristics and LLP attributes that are important to best match a patient to a specific LLP; disagreements about what constitutes an optimal matching of patients with LLPs; and poor clinical outcomes and wasted resources associated with suboptimal LLP matching. Specifically, patients who are in need of LLPs are heterogeneous in terms of etiology of limb loss, amputation type (level of amputation, uni- or bilateral), age, comorbidities, frailty, general health status factors, expected life span, mental health status (e.g., depression, posttraumatic stress syndrome), family and social support, and many other factors, including whether they have fragile skin or allergies towards socket liners or other materials. These factors may affect their actual and perceived current and maximum attainable functional ability, and the likelihood that they will receive and use an LLP. ${ }^{8,16}$

\section{Objectives}

The purposes of this systematic review are to (1) identify validated patient assessment techniques, prediction tools and OMTs that have been validated for use in persons with lower limb amputation; (2) identify and summarize studies that compare the differential relative effect of LLP components based on LLP users' characteristics; (3) determine whether these studies use instruments and OMTs that have been validated in the lower limb amputee population; 4) 
determine whether patient expectations align with their outcomes with LLPs; 5) evaluate whether patients are satisfied with the process of obtaining their LLPs; and 6) describe the long-term continued use of LLPs by those prescribed a prosthesis. This systematic review may also identify areas where evidence gaps exist related to the prescription of LLP so that recommendations may be made concerning the study designs and outcome measures that best inform patient oriented function, quality of life and service satisfaction in this realm.

This review's Key Questions and study eligibility criteria were designed to assist the Centers for Medicare \& Medicaid Services to better understand the state of the evidence regarding how best to match patients with LLPs that would yield best outcomes for them, and related issues. It is important to note that this review does not fully cover all aspects of LLP evaluation. Specifically, it excludes from evaluation biomechanical and other nonpatient-centered intermediate outcomes. It also does not attempt to review all evidence comparing specific components. Instead, it largely focuses on those comparisons that provide assessment of heterogeneity of treatment effects (i.e., whether outcomes with specific devices vary across individuals based on different characteristics such as age or health status). The review also focuses on people who may be eligible for Medicare coverage, whether due to age or disability. Thus, we categorize studies based on their likely generalizability to amputees with Medicare. Based on discussions with our Technical Expert Panel, this includes studies with a mean age at least 65 years and those in which the percentage of participants with dysvascular disease (including diabetes) is broadly similar to the Medicare amputee population (i.e., at least 50\%). Furthermore, the review excludes studies of exclusively military amputees with battle-related trauma (who are generally covered by Department of Defense and/or Veterans Health Administration insurance); however, we do include studies of veterans with multiple etiologies of amputation. Furthermore, the review excludes studies from low-income or low-resource settings not applicable to the United States.

\section{Key Questions}

Preliminary Key Questions (KQs) and protocol were discussed in depth with a panel of key informants (stakeholders representing patients [amputees], clinicians, prosthetists, rehabilitation, and physical therapy), with the sponsor, and were publicly posted in December, 2016. Based on feedback from commenters and further discussion with the sponsor the KQs (and study eligibility criteria) were revised to improve clarity, focus the topics more closely with the sponsor's needs, and to evaluate measures and outcomes of interest to stakeholders.

The following are the KQs addressed by the review:

KQ 1. What assessment techniques used to measure functional ability of adults with major lower limb amputation have been evaluated in the published literature?
1a. What are the measurement properties of these techniques, including: reliability, validity, responsiveness, minimal detectable change, and minimal important difference?
1b. What are the characteristics of the participants in these studies? 
KQ 2. What prediction tools used to predict functional outcomes in adults with major lower limb amputation have been evaluated in the published literature?

2a. What are their characteristics, including technical quality (reliability, validity, responsiveness), minimal detectable change, and minimal important difference?

2b. What are the characteristics of the participants in these studies?

KQ 3. What functional outcome measurement tools used to assess adults who use an LLP have been evaluated in the published literature?

3a. What are their characteristics, including technical quality (reliability, validity, responsiveness), minimal detectable change, and minimal important difference?

3b. What are the characteristics of the participants in these studies?

KQ 4. In adults who use a lower limb prosthesis, how do ambulatory, functional, and patient-centered outcomes with different prosthesis components vary based on study participant characteristics?

Prosthesis components include:

- Foot/ankle

- Knee

- Socket

- Liner

- Suspension

- Pylon

- Other

Study participant characteristics of interest include:

- Medicare Functional Classification Level (K level)

- Level of amputation

- Etiology of amputation

- Prior function (prior to new or replacement LLP)

- Current function

- Expected potential function/level of activity and activities (e.g., athletics, uneven surface walking)

- Time since amputation

- Initial vs. subsequent limb LLP 
- Unilateral vs bilateral LLP

- Time since last assessment

- Age

- Comorbidities that may affect use of LLP (e.g., congestive heart failure, vascular dysfunction, skin ulceration/damage, visual dysfunction, peripheral neuropathy, local cancer treatment, other lower limb disease)

- Type, setting, and description of rehabilitation, physical therapy, training

- Periamputation surgery information, including surgical details, inpatient rehabilitation details, wound status

- Residence setting

- Use of assistive devices

- Comfort of existing prosthesis (for patients receiving replacement LLP)

- Psychosocial characteristics

- Cognitive function

- Family (etc.) support system

- Training and acclimation with LLP

4a. What assessment techniques that have been evaluated for measurement properties were used in these studies?

4a.i. How do the characteristics of the participants in eligible studies that used these specific assessment techniques compare to the characteristics of the participants in the studies that evaluated the assessment techniques (as per KQ 1b)?

4a.ii. What is the association between these preprescription assessment techniques and validated outcomes with the LLP in these studies?

4b. What prediction tools that have been evaluated for measurement properties were used in these studies?

4b.i. How do the characteristics of the participants in eligible studies that used these specific prediction tools compare to the characteristics of the participants in the studies that evaluated the prediction tools (as per KQ 2b)? 
4b.ii. What is the association between preprescription assessment techniques and validated outcomes with the LLP in these studies?

4c. What functional outcome measurement tools that have been evaluated for measurement properties were used in these studies?

4a.i. How do the characteristics of the participants in eligible studies that used these specific functional outcomes compare to the characteristics of the participants in the studies that evaluated the outcomes (as per KQ $3 b$ )?

KQ 5. How do study participants' preprescription expectations of ambulation align with their functional outcomes?

$5 a$. How does the level of agreement vary based on the characteristics listed in KQ 4, including level of componentry incorporated into their LLP?

KQ 6. What is the level of patient satisfaction with the process of accessing an LLP (including experiences with both providers and payers)?

6a. How does the level of patient satisfaction vary based on the characteristics listed in KQ 4, including level of componentry incorporated into their LLP?

KQ 7. At $\mathbf{6}$ months, 1 year, and 5 years after receipt of an LLP, (accounting for intervening mortality, subsequent surgeries, or injuries) what percentage of individuals...?

i. Maintain bipedal ambulation

ii. Use their prostheses only for transfers

iii Use prostheses only indoors

iv. Have abandoned their prostheses

v. Have major problems with prosthesis

7a. How do these percentages vary based on the following characteristics?

- Patient residence and setting

o Living situation (e.g., homebound, institutionalized, community ambulation)

o Setting for rehabilitation, physical therapy, or training (e.g., in-home or at facility) 
- Patient characteristics

o Age

o Level of amputation

o Number of lower limbs amputated (unilateral vs. bilateral)

o Prior level of function (prior to onset of extremity disability)

o Current level of function

o Etiology of amputation

o Time since amputation

o Comorbidities (e.g., diabetes, cardiovascular or peripheral vascular disease)

o Operative treatment

o Use of assistive device

o Cosmesis of the prosthesis

o Comfort of the prosthesis

o Cognitive function

o Other

- Prosthesis componentry

7b. What were the reasons for suboptimal use of the prosthesis device?

\section{Analytic Framework}

The following analytic framework (Figure 1) graphically illustrates the synthesis of the KQs and their elements. 
Figure 1. Analytic framework for assessment and assignment of lower limb prostheses

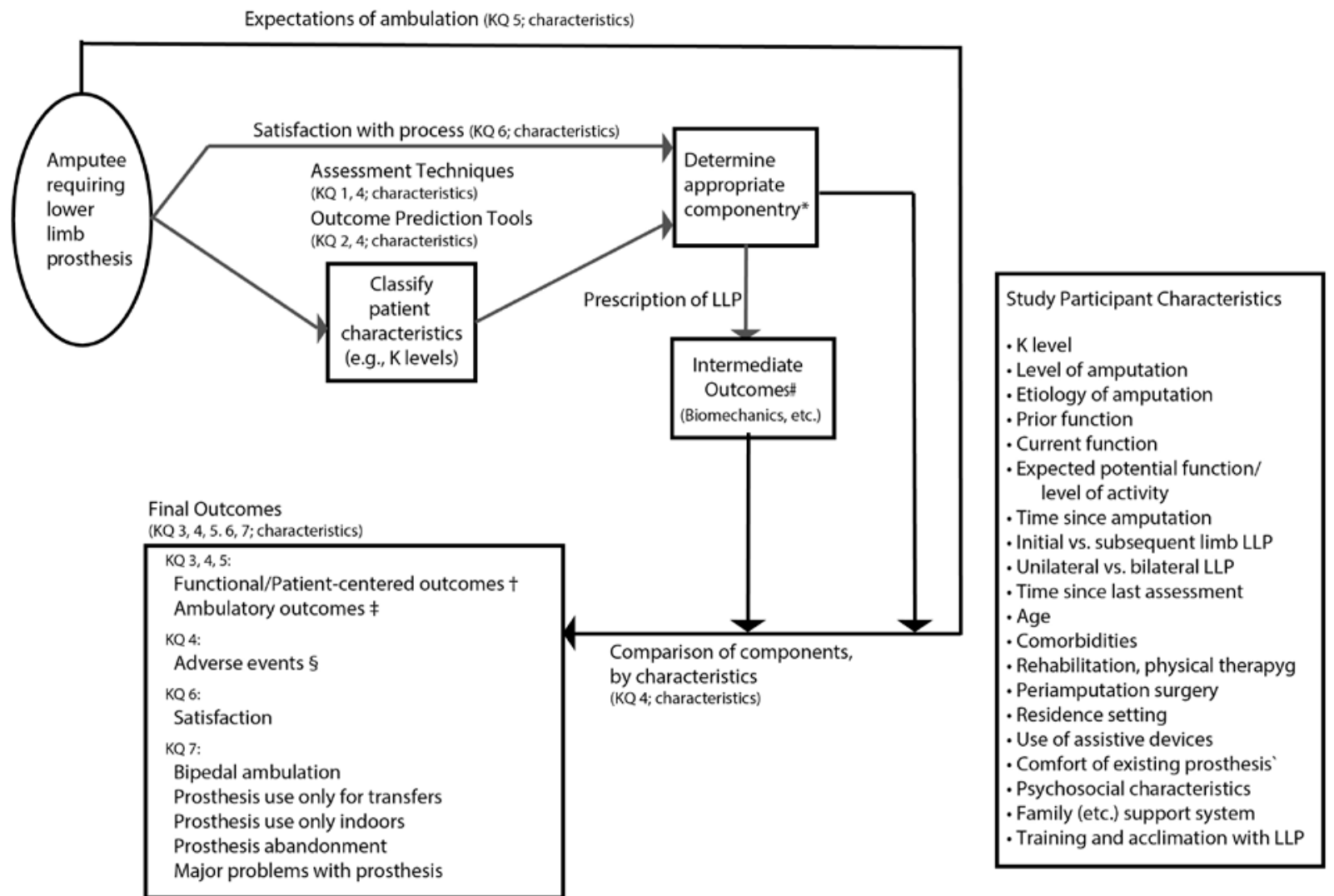

Abbreviations: KQ = Key Question(s), LLP = lower limb prosthesis.

*Components include: feet/ankles, knees, sockets, liners, suspension, pylons, and others.

$\dagger$ Functional and patient-centered outcomes include: quality of life, disability measures, activities of daily living, mobility measures, including use of prostheses only for transfers, self-care, pain, fatigue after use (e.g., end of day), daily activity, time LLP worn per day, falls, satisfaction with LLP, and others (but not simple preference of one component over another).

$\ddagger$ Ambulatory outcomes include: gait speed, step count, walk distance; uneven or wet surface, low lighting walking; ramps and incline traversing; step/stair climbing function; ambulatory function measured in the community setting (e.g., self-report or activity monitors); achievement of bipedal ambulation; and other patient-centered ambulatory function measures.

§Adverse events include: skin ulcers and infections, injuries from falls due to mechanical failure, and other problems with prostheses.

\#Biomechanical outcomes are not included among the outcomes of interest in this review. 


\section{Methods}

The Brown Evidence-based Practice Center conducted a systematic review of the published scientific literature, using established methodologies as outlined in the Agency for Healthcare Research and Quality (AHRQ) Methods Guide for Effectiveness and Comparative Effectiveness Reviews. ${ }^{6}$ The review was registered with PROSPERO (CRD42017058488).

\section{Search Strategy}

We conducted literature searches of studies in PubMed ${ }^{\circledR}$, both the Cochrane Central Trials Registry and Cochrane Database of Systematic Reviews, Embase ${ }^{\circledR}$, and CINAHL ${ }^{\circledR} /$ PsycINFO $^{\circledR}$ databases to identify primary research studies and systematic reviews meeting our criteria. The searches were conducted on October 30, 2017. No publication date or language restrictions were applied. Appendix A presents the literature search strategies (for each searched database). We perused the reference lists of published relevant systematic reviews. Any comparative studies (Key Question [KQ] 4) or long-term followup studies (KQ 7) found from existing systematic reviews were assessed and incorporated de novo from the original article. For KQ 1-3, we searched for existing systematic reviews (about validation of instruments) and for additional primary studies. Peer and public review provided an additional opportunity for experts in the field and others to ensure that no relevant publications have been missed.

\section{Study Eligibility Criteria}

Specific eligibility criteria varied for each KQ, but criteria for populations, interventions, and study designs of interest were the same for most KQ. For each criterion category, we state which KQ each set of criteria apply to.

\section{Population of Interest}

\section{All KQ:}

- Adults with lower limb amputation who are being evaluated for or already have a lower limb prosthesis (LLP)

o Exclude if study clearly and explicitly includes only participants with battle-related trauma (this does not apply to studies of veterans with multiple amputation etiologies)

o Exclude if study includes only congenital amputations

o Exclude if study includes only children $\leq 18$ years old

- If a study has a mixed population (related to battle trauma, congenital amputations, or pediatrics) and they report subgroup data based on these factors, include analyses of relevant populations (exclude substudy data on excluded populations). If study reports only combined data (e.g., adults and children), include overall study, but note issue related to the indirectness of the population.

o Exclude if study conducted in low- or middle-income country, per the World Bank ${ }^{18}$ (the interventions, management, and characteristics of people in low-income countries (such as Haiti) or middle-income countries (such as Cambodia or Iraq) are too different to be applicable to the U.S. population) 


\section{KQ 1-2:}

- Also allow studies of amputees, whether or not they use LLPs (i.e., allow studies evaluating assessment techniques and prediction tools in amputees who do not [yet] have an LLP)

\section{Interventions or Predictors of Interest (and Instruments for KQ 1-3)}

\section{All KQ:}

- Custom fabricated lower limb prosthesis

- Specific prosthesis components, including foot/ankle, knee, socket, liner, pylon and suspension, or components with specific characteristics (e.g., shock absorbing, torque, multiaxial, computer assisted, powered, flexion, microprocessor)

- New or existing definitive or replacement prostheses

o Exclude immediate postoperative prostheses (used temporarily prior to definitive or replacement prostheses immediately after amputation surgery)

o Exclude evaluation of orthotics and of implanted devices

\section{KQ 1-3 Instruments:}

- Assessment techniques (measures or tools used prior to prescription to assess patient's overall functional status) (KQ 1)

o Tests, scales, questionnaires that assess current functional or health status

0 Include patient history and physical examination

o Measures of physical function and functional capacity (e.g., parallel bar ambulation without LLP)

- Exclude single factors (e.g., time since surgery, fasting blood glucose)

- Prediction tools (used prior to prescription to predict functional outcomes with prosthesis) (KQ 2)

o Tests, scales, questionnaires

- Exclude single factors (e.g., time since surgery, fasting blood glucose)

- Outcome measures (assessed in people using LLP) (KQ 3)

o Functional, patient centered, or ambulatory outcomes per KQ 4

\section{KQ 4:}

- As listed for all KQ

KQ 5, 7:

- Receipt of a definitive or replacement LLP (regardless of componentry)

KQ 6:

- Undergo process of accessing a definitive or replacement LLP (regardless of componentry)

\section{Comparators of Interest}

\section{KQ 1-3:}

- Reference standards, as applicable 


\section{KQ 4:}

- LLPs with different components (e.g., feet/ankles, knees, sockets, pylons, liners, suspension), or that differ in other ways (studies must be comparative)

\section{KQ 5-7:}

- No comparators required

\section{Outcomes of Interest}

KQ 1-3:

- Report data to support assessments of reliability, validity, responsiveness, minimal detectable change, minimal important difference, or floor/ceiling effect

KQ 4, 5:

- Functional or patient-centered outcomes (measured or related to status in the community)

o Quality of life

o Disability measures

o Activities of daily living

o Mobility measures, including use of prostheses only for transfers

o Self-care

o Pain

o Fatigue after use (e.g., end of day)

o Daily activity

o Time LLP worn per day

o Falls

o Satisfaction with LLP

- Exclude (simple) preference, which is not a functional or related outcome specific to a given LLP component or configuration

- Ambulatory functional outcomes

o Gait speed, step count, walk distance

o Uneven or wet surface, low lighting walking

o Ramps and incline traversing

o Step/stair climbing function

o Ambulatory function measured in the community setting (e.g., self-report or activity monitors)

o Achievement of bipedal ambulation

0 Other patient-centered ambulatory function measures

- Exclude biomechanical measures

- Adverse effects of LLP

o Skin ulcers/infections, (injuries from) falls due to mechanical failure, etc.

o Other problems with prosthesis

KQ 6:

- Patient satisfaction measures with process of accessing LLP 


\section{KQ 7:}

- Maintenance of bipedal ambulation

- Use of prostheses only for transfers

- Use of prostheses only indoors

- Abandonment of prostheses (not using prosthesis)

- Major problems with prosthesis

- Reasons for suboptimal use of LLP (as defined by above outcomes)

\section{Eligible Study Designs}
All KQ:
- Published, peer reviewed study or publicly available theses, dissertations, etc.
- Any language (that can be read by research team or machine translated)
- No publication or study date restriction
o Exclude case reports

\section{KQ 1-3:}

- Any assessment of validity, reliability, and related characteristics

o Exclude studies of validation of translations of instruments (e.g., evaluation of the French translation of a scale designed in English).

- Any study design

- $\mathrm{N} \geq 20$ lower limb amputees (an arbitrary threshold chosen to ensure a sufficient number of study participants for statistically meaningful correlation and comparison analyses within each study)

- No minimum followup time

\section{KQ 4:}

- Direct comparison between any two components, any relevant study design

- Must include an analysis or reporting of differences in relative effect between components by a patient characteristic of interest (see text of KQ 4) or report sufficient participant-level data to allow such an analysis

- No minimum sample size (other than excluding case reports)

- No minimum followup time

KQ 5, 6:

- Any study design, including qualitative studies

- No minimum sample size (other than excluding case reports)

- No minimum followup time

\section{KQ 7:}

- Either longitudinal with followup since original lower limb prosthesis prescription or cross-sectional at timepoint after amputation or prescription

- Minimum followup time

$0 \geq 6$ month followup from time of LLP prescription, or

$0 \geq 1$ year followup from time of amputation, if no data reported about time since LLP prescription 
- Minimum sample size: $\mathrm{N} \geq 100$ (smaller studies are numerous but lack precision)

\section{Setting}

- Any residence including community ambulation, homebound, and institutionalized

- Clinical or laboratory setting (for evaluation of specific ambulatory function outcomes)

- Rehabilitation setting (e.g., physical therapy clinic, in-home)

o Exclude exclusively postacute (postsurgical) setting or inpatient rehabilitation (immediately postamputation)

\section{Study Selection}

All citations (abstracts) found by literature searches and other sources were independently screened by two researchers. At the start of abstract screening, we implemented a training session, in which all researchers screened the same articles and conflicts were discussed. During double-screening, the team met regularly to reconcile conflicts and continue training. All screening was done in the open-source, online software Abstrackr (http://abstrackr.cebm.brown.edu/). During abstract screening, liberal eligibility criteria were applied to minimize the risk of rejecting pertinent studies. All potentially relevant studies were entered into an evidence map, in which basic study data were extracted from the abstract (KQ addressed, study design, country, sample size, instrument(s) being validated or assessed [for KQ 1-3), and rejection reason [as applicable]). Remaining studies relevant to KQ 1-3 were reviewed in full text and instruments being validated by the studies were entered into the evidence map; we also noted whether these studies were already included in known existing systematic reviews. Studies pertaining to KQ 4 (subgroup comparisons) were reviewed in full-text and information regarding whether the articles reported subgroup or regression analyses or individual patient level characteristics and results were entered into the evidence map; full-text articles were also reviewed to determine whether outcomes of interest were reported. Studies pertaining to KQ 7 (long-term follow-up) were also reviewed in full text to confirm that outcomes of interest were reported and to enter duration of follow-up into the evidence map. Studies pertaining to KQ 5 and 6 were also reviewed in full text to confirm eligibility, but no additional data were entered into the evidence map.

\section{Data Extraction}

For all KQ, we extracted publication information, study design, eligibility and population descriptions including details about lower limb status (e.g., amputation level), outcome descriptions, and results.

For KQ 1 to 3, data were extracted into a specially designed spreadsheet form. We captured sample descriptors (amputation level, amputation etiology, mean age, sample size), instrument type (assessment techniques, prediction tools, and outcome measures), instrument name, instrument subscale/item as appropriate, instrument description or definition, evaluated property (validity, reliability, responsiveness, minimal detectable change, minimal important difference, and floor/ceiling effect), aspect of the instrument (e.g., internal consistency, testretest reliability, interrater reliability, content/face validity, criterion validity, convergent/concurrent validity, divergent/discriminant validity, predictive validity, construct validity, structural validity), the comparator (what the instrument is being compared to), the metric used to assess the instrument (e.g., Spearman r or effect size), the value of the metric, and 
the strength of the property (if relevant). There is no universal standard for how to evaluate and summarize psychometric properties; however, the measurement properties were scored based on overall results using methods adapted from others. ${ }^{19-24}$ Based on criteria summarized in Table 2, we determined whether each aspect is supported within each study.

Reliability addresses whether the instrument gives a consistent answer. For the reliability property, we determined that instruments were "reliable" with each study if any reliability metric (internal consistency, test-retest, interrater, or intrarater) was deemed to be adequate.

Validity addresses whether an instrument measures what it claims to measure. There are several aspects of validity. Content (or face) validity considers the common sense and intrinsic meaning of the instrument (e.g., that steps per day measures walking activity). Criterion validity addresses the extent to which an instrument is related (e.g., correlated) to the "gold standard"; however, since "gold standards" do not exist for the functional outcomes of interest, this specific metric is largely theoretical for our purposes. Convergent (or concurrent) validity assesses the degree to which two instruments hypothesized to be related are actually statistically related. Predictive validity refers to the comparison with a future outcome (e.g., current health status, physical function or ambulation, independent living, and future mortality). Divergent (or discriminant) validity tests whether instruments that are theoretically not related are, in fact, statistically unrelated (e.g., lack of correlation between age and comfort measures). Construct validity addresses, overall, whether an instrument measures what it claims to be measuring. Structural validity, assessed through factor analysis, Rasch or item response theory methods, assesses the fit of a model (a set of questions or traits). Rasch analysis may be conducted to maximize the homogeneity of the trait and to allow greater reduction of redundancy (i.e., increase simplicity) without sacrificing information.

For the validity property, we noted content validity, but did not use it to determine overall validity. If a study had an a priori hypothesis about the criteria necessary to determine validity, we used these criteria. Otherwise, we required evidence of either convergent, construct, structural, or predictive validity. For KQ 2 (prediction tools), if an instrument was evaluated for predictive validity, this instrument was included.

Responsiveness addresses whether an instrument is sufficiently sensitive to capture important changes in the measure. Instruments were "responsive" if they met any of the predetermined cutoffs for metrics such as effect size and standardized response mean.

Minimal detectible change and minimum (clinical) important difference were both extracted as reported.

Floor/ceiling effects were deemed to be present if more than 15 percent of the sample had the minimum or maximum possible value for the given scale (i.e., they hit the floor or ceiling of the scale). When this occurred, we captured a description of the sample characteristics.

Each study was assessed to determine whether the instruments being evaluated were assessment techniques, prediction tools, or outcome measures. Although conceptually these categories of instruments are distinct, in practice distinguishing which category a study and instrument belongs in is open to interpretation. To categorize outcomes, we used the following approach: For KQ 1 (assessment techniques), we included instruments described by studies as assessment techniques and studies that included lower limb amputees either prior to prosthesis use or at the time of evaluation for a new or replacement LLP. For KQ 2 (prediction tools), we included instruments for which predictive validity was assessed. For KQ 3 (outcome measures), we included other instruments, which were evaluated in people with existing LLPs or were described (explicitly or implicitly) as outcome measures. 
Table 2. Metrics for evaluation of reliability, validity, and related psychometric properties

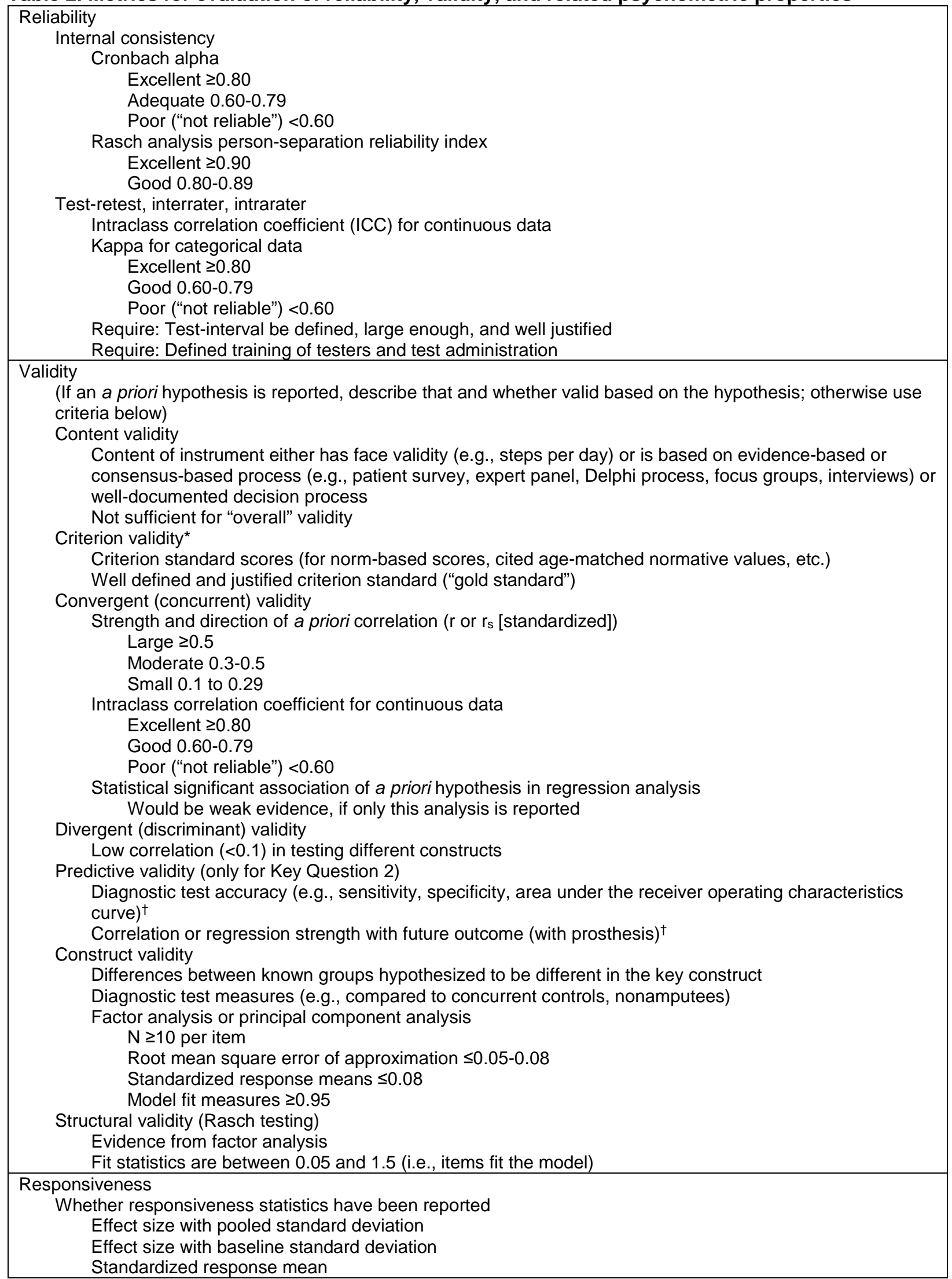




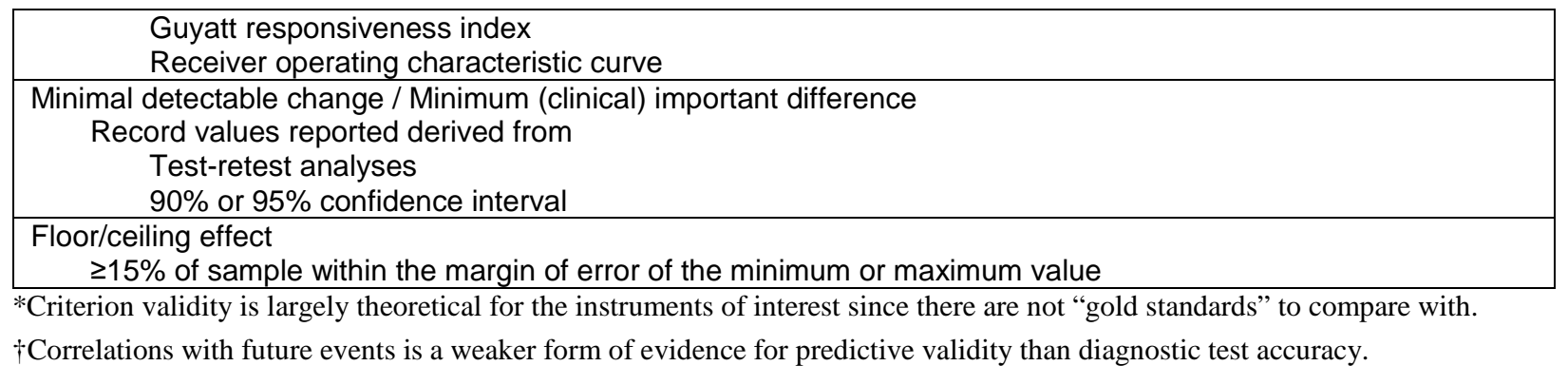

For KQs 4 and 7, data were extracted into the Systematic Review Data Repository (SRDR, https://srdr.ahrq.gov/projects/1091) into specially-designed data extraction forms. Studies that reported comparisons of interest were fully extracted into SRDR; however, for studies that reported only individual patient data, we extracted those data into spreadsheet forms. From these data, we calculated means and ran t-tests to compare subgroups of interest.

Studies pertaining to KQs 5 and 6 were extracted qualitatively directly into text describing the studies.

\section{Study Generalizability Categorization}

For KQs 1-3, we categorized studies regarding their generalizability to the Medicare population. Studies were not excluded based on this categorization, but instead descriptions of each instrument's psychometric properties and summaries across instruments were categorized based on likely generalizability to the Medicare population. The two primary reasons people are eligible for Medicare are being at least 65 years of age or being certified to have a disability based on Medicare criteria. Lower limb amputation alone is an insufficient criterion to meet Medicare eligibility criteria. Based on the age criterion for Medicare coverage, we determined that studies with an average age of 65 years or higher (where at least half the study sample are likely to be over age 65 years) are generalizable to the Medicare population. Considering the age and disability requirements for eligibility, the most prevalent amputation etiology among Medicare recipients are dysvascular conditions. In discussion with Centers for Medicard \& Medicaid Services representatives and our Technical Expert Panel we determined that an additional reasonable determinant for studies being generalizable to the Medicare population (when average age is less than 65 years) is whether at least half the sample are reported to have dysvascular conditions as their amputation etiology. We recognize that these criteria are arbitrary and imperfect, but they were necessary to allow us to categorize studies for the purposes of this review.

\section{Risk of Bias Assessment}

For KQs 4-7, we assessed risk of bias with the Cochrane Risk of Bias tool (assessing randomization, allocation concealment, blinding, intention-to-treat analysis, reporting bias, attrition bias, and other biases), and selected questions from the Newcastle-Ottawa Scale for observational studies (assessing representativeness of the study sample, outcome assessment, comparability of the people in compared study groups, and analytic method ${ }^{25,26}$ —in particular whether multivariable analyses were conducted). For each risk of bias/study quality question, we assessed whether there was high risk of bias (e.g., lack of blinding), low risk of bias (e.g., adequate randomization), or unclear risk of bias (if there was inadequate reporting to assess). For KQ 4, we also assessed whether adequate heterogeneity of treatment effect analyses were conducted. 
For each study, we determined an "overall quality” based on the risk of bias for each assessed factor. The overall quality assessment was based on the best judgment of the reviewers. Special emphasis was placed on whether outcome assessors were blinded and, for KQ 4, whether outcomes were validated and multivariable analyses were conducted. Overall quality was assessed as high, moderate, or low risk of bias. Specific and overall risk of bias assessments were made by at least two experience systematic reviewers and where there were discrepancies these were discussed and finalized by the team as a whole.

\section{Data Synthesis}

\section{Narrative and Tabular Synthesis}

Included studies are presented in summary tables with the important features of the study populations, design, intervention, and risk of bias.

For KQ 1 to 3, each instrument assessed by the eligible studies is described in terms of its validity, reliability, and other psychometric properties.

For KQ 4, studies are organized by whether they used and reported validated measures, as per KQ 1 to 3). Findings of the studies are summarized within this construct. Studies for KQ 5 and 6 are briefly summarized. Studies for KQ 7 are summarized, with an emphasis on betweengroup comparisons, where available.

\section{Post Hoc Analyses}

For KQ 4, most studies did not report statistical analyses comparing subgroups. Either they reported subgroup findings without statistically comparing the subgroups or they reported individual patient data for both participant characteristics and outcomes. In these cases, we compared subgroups of interest with t-tests or chi-squared tests. For all analyses (reported or conducted by us), we report the $\mathrm{P}$ value of the comparison between subgroups. Where $\mathrm{P}<0.05$, we provide the quantitative difference between subgroup effects in the Appendix D results data tables and, in the main text tables summarizing each study, a narrative description of which subgroup has a greater effect with which LLP component or configuration. Where $\mathrm{P} \geq 0.05$, we omit the comparative data.

We further calculated a Bonferroni-corrected $\mathrm{P}$ value for each study. To calculate the corrected $\mathrm{P}$ value, we divided 0.05 by the total number of statistical analyses reported in the articles and those conducted for this review. We did not attempt to further correct for analyses conducted but not reported by the study authors. Most studies had a large number of individual analyses (up to 135 comparisons). Without correcting $\mathrm{P}$ values, a large number of analyses would be statistically significant at the $\mathrm{P}=0.05$ level due to chance alone. We chose the Bonferroni correction since it is relatively conservative (although, arguably overconservative) and we could not attempt to correct for correlations between analyses within studies. In the overall summary table of the findings of the comparative studies and in the text, we describe only the comparisons which are statistically significant after correction of the P value threshold.

\section{Summarizing Findings Across Studies}

For KQ 1 to 3, each instrument was categorized by whether relevant studies were generalizable to the Medicare population and then whether these studies provided evidence of test validity and reliability (within the generalizable or not categories). For each KQ, we created 
and present lists of instruments with evidence for both validity and reliability, for validity only, for reliability only, and for "not reliability." We did not create lists of instruments that were evaluated for but did not display evidence of validity. Given that research in this area is continually advancing, it is likely that additional evidence on measurement properties of instruments will be generated. We did not weigh the strength of evidence or create a composite score comparing measures to identify the best measure.

For KQ 4 to 7, for each comparison of interventions, we determined a conclusion (or summary of findings across studies) for each outcome with sufficient evidence (i.e., not insufficient evidence, see Grading the Strength of Evidence).

For KQ 4, we concluded the evidence "favors" one intervention (over the other) when:

- studies found a statistically significant difference in the same direction, and/or

- studies found statistically nonsignificant effect sizes that were either greater than 1.25 or less than 0.80 .

o However, if the 95 percent confidence intervals were highly imprecise (beyond both 0.50 and 2.00), the conclusion was "unclear" regardless of the magnitude of the point estimate.

o If a conclusion favoring one intervention was based on a statistically nonsignificant effect size, the strength of evidence (see below) was low (it could not be moderate or high).

We concluded that interventions had similar effects (noted in tables as favoring "either") when the studies' effect sizes were between 0.80 and 1.25 , were not statistically significant, and were not highly imprecise, as defined in the bullets above, or inconsistent (across studies).

When studies were sparse, effect size estimates were highly imprecise, or studies were highly inconsistent (e.g., with point estimates ranging from 0.14 to 3.03), we deemed the findings to be "unclear" (with an insufficient strength of evidence).

\section{Grading the Strength of Evidence}

For KQ 4 to 7, we graded the strength of the body of evidence (SoE) as per the AHRQ Methods Guide on assessing the SoE. ${ }^{27}$ We assessed the SoE for each outcome of interest. Following the standard AHRQ approach, for each intervention and comparison of intervention, and for each outcome, we assessed the number of studies, their study designs, the study limitations (i.e., risk of bias and overall methodological quality), the directness of the evidence to the KQs, the consistency of study results, the precision of any estimates of effect, the likelihood of reporting bias, and the overall findings across studies. Throughout the report, all estimates with 95 percent confidence or credible interval beyond 0.5 and 2.0 were considered to be highly imprecise. Based on these assessments, we assigned a SoE rating as being either high, moderate, low, or having insufficient evidence to estimate an effect. Outcomes with highly imprecise estimates, highly inconsistent findings across studies, or with data from only one study were deemed to have insufficient evidence to allow for a conclusion (with the exception that particularly large, generalizable single studies could provide at least low SoE). The data sources, basic study characteristics, and each $\mathrm{SoE}$ dimensional rating are summarized in "Strength of Evidence” tables detailing our reasoning for arriving at the overall SoE ratings. SoE determinations were made by at least two experience systematic reviewers and where there were discrepancies these were discussed and finalized by the team as a whole. 
We did not grade the SoE for KQ 1 to 3 regarding instrument/measure psychometrics. The SoE rubric does not fit evaluation of whether studies have assessed validity, reliability, and related concepts. Instead, we categorized instruments by whether studies that assessed them were generalizable to the Medicare population and whether they provided evidence of test validity and reliability.

\section{Peer Review}

A draft version of this report was reviewed from October 24 to November 21, 2017 by invited and public reviewers. The reviewers were either directly invited by the Evidence-based Practice Center or they offered comments through a public review process. Extensive revisions of the draft were made based on their comments. The draft and final reports were reviewed by the Task Order Officers and an Associate Editor from another Evidence-based Practice Center. However, the findings and conclusions are those of the authors, who are responsible for the contents of the report. 


\section{Results}

\section{Summary of Studies}

The literature searches yielded 10,765 citations and an additional 357 references were screened from review articles, existing systematic reviews, and from reviewers of the draft report (Figure 2). Of these, 425 articles were retrieved in full text. We excluded 348 articles for the reasons listed in Figure 2 (see Appendix B). Of note, 89 studies compared lower limb prosthesis (LLP) components or configurations but did not report either subgroup analyses, regression analyses, or individual patient data which would allow subgroup analyses. Overall, we found 80 eligible studies (in 77 articles), of which 55 studies evaluated psychometric properties addressing Key Questions (KQ) 1 to 3, 14 studies provided data relevant to KQ 4, no studies for KQ 5, two studies for KQ 6, and eight studies relevant to KQ 7.

\section{Figure 2. Literature flow}

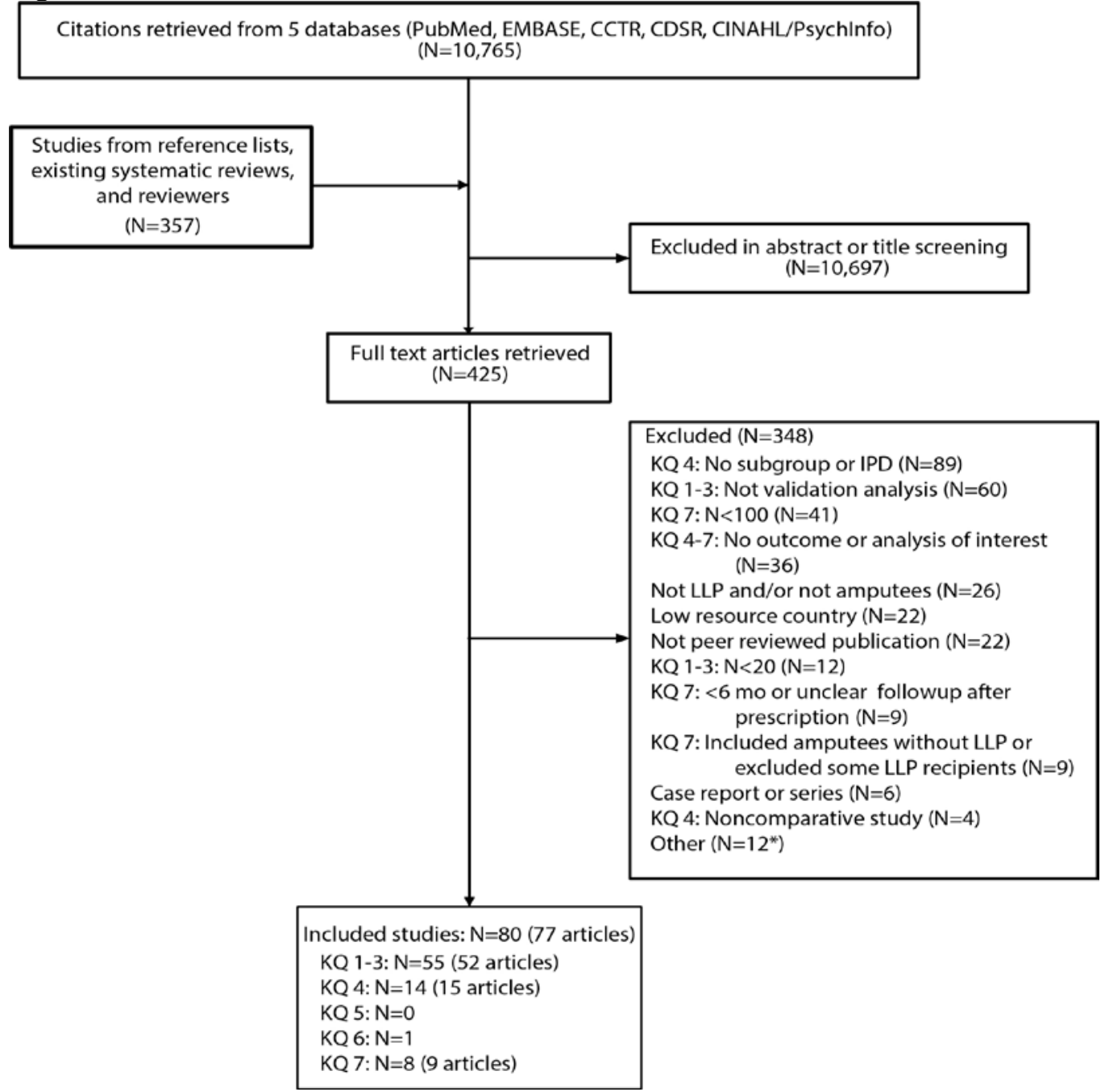

Abbreviations: CCTR = Cochrane Central Trials Registry, CDSR = Cochrane Database of Systematic Reviews, IPD = individual patient data, KQ = Key Question, LLP = lower limb prosthesis. 
*Duplicate publication: $\mathrm{N}=4$; Not available: $\mathrm{N}=2$; Pediatric population: $\mathrm{N}=2$; Battle injuries only: $\mathrm{N}=1$; Not primary study: $\mathrm{N}=1$; Retracted publication: $\mathrm{N}=1$; Unclear technology: $\mathrm{N}=1$. 


\section{Key Questions 1 to 3. Assessment Techniques, Prediction Tools, Functional Outcome Measurement Tools}

Studies provided evidence regarding psychometric properties of 50 instruments for people with lower limb amputations. In total, 55 studies in 52 articles met criteria to provide evidence regarding instrument psychometrics in people with lower limb amputations. The evidence is summarized for each instrument as listed below, followed by an overall summary across instruments. Following this, are summaries of the evidence pertaining to each specific Key Question (1 to 3). Upon review of the instruments, it became evident that determination of whether instruments should be classified as "assessment techniques" or "prediction tools" depended largely on our judgment. We also found that presentation of instruments first by Key Question (assessment techniques, prediction tools, functional outcome measurement tools) resulted in confusion and misleading duplication of findings in regards to the overall state of the evidence. Therefore, the entirety of evidence regarding all instruments is presented first, followed by descriptions of evidence pertaining to each Key Question.

The instruments evaluated are:

- 1 Leg Standing Balance

- 180 Degree Turn Test

- $\quad$ 2MWT (2 Minute Walk Test)

- 6MWT (6 Minute Walk Test)

- AAS (Amputee Activity Survey)

- ABC (Activities-specific Balance Confidence)

- ADAPT (Assessment of Daily Activity Performance in Transfemoral Amputees)

- AMP (Amputee Mobility Predictor with, AMPPRO, or without prosthesis, AMPnoPRO)

- AMPSIMM (Amputee Single Item Mobility Measure)

- Barthel Index

- $\quad$ BBS (Berg Balance Scale)

- Climbing Stairs Questionnaire

- Employment Questionnaire

- FAC (Functional Ambulation Categories)

- FAI (Frenchay Activities Index)

- FIM (Functional Independence Measure)

- $\quad$ FSST (Four Square Step Test)

- Functional Reach Test

- Houghton Scale

- L Test (L Test of Functional Mobility)

- LCI (Locomotor Capabilities Index)

- LEMOCOT (Lower-Extremity Motor Coordination Test)

- NQ-ACGC (Quality of Life in Neurological Conditions - Applied Cognition/General Concerns)

- OPCS (Office of Population Censuses and Surveys Scale)

- OPUS (Orthotics Prosthetics Users Survey)

- Patient Activity Monitor 
- PEQ, PEQ-MS (Prosthetic Evaluation Questionnaire, Mobility Subscale)

- PFI (Physical Function Index)

- PGI (Patient Generated Index)

- PLUS-M (Prosthetic Limb Users Survey of Mobility)

- PPA (Prosthetic Profile of the Amputee)

- PROMIS-29 (Patient-Reported Outcomes Measurement Information System 29-Item Profile)

- PROS (Prosthetist's Perception of Client's Ambulatory Abilities)

- PSFS (Patient-Specific Functional Scale)

- Q-TFA (Questionnaire for Persons with a Transfemoral Amputation)

- Rising and Sitting Down Questionnaire

- RMI (Rivermead Mobility Index)

- SAT-PRO (Satisfaction with Prosthesis Questionnaire)

- SCS (Socket Comfort Score)

- SF-12/SF-36/SF-36V (Short Form Health Surveys 12, 36, and 36V)

- SIGAM (Special Interest Group of Amputation Medicine)

- Single beam test

- SIP-PD (Sickness Impact Profile-Physical Dimension)

- Tandem Test

- TAPES (Trinity Amputation and Prosthesis Experience Scales)

- TFP (Transfemoral Fitting Predictor)

- TUG (Timed Up and Go)

- TWT (Timed Walking Test)

- Walking Questionnaire

- WHOQOL-BREF (World Health Organization Quality-of-Life Scale - Brief Version)

\section{Leg Standing Balance}

The 1 Leg Standing Balance test measures the time the amputee can stay balanced on their unaffected leg. Studies used various names for the same test, including One-Leg Balance and just Balance Test. Three studies ${ }^{28-30}$ reported on the psychometric properties of the 1 Leg Standing Balance test in 194 people, total, with lower limb amputations (see Tables 3 to 5). The studies were deemed to be generalizable to the Medicare population based either on the average age of study participants (75 years old in one study) or the high percentage of study participants with dysvascular disease (63\% and 66\% in the other studies) (Table 3).

Two studies provided information on predictive validity (Table 4). The 1 Leg Standing Balance test, as an initial assessment at the start of rehabilitation or prefitting, was correlated with the Barthel Index, 2MWT, TUG, and K level (the Medicare Functional Classification Level) at discharge from rehabilitation, but it did not predict admission to a skilled nursing facility. One study found that the test did not discriminate between people in different Houghton Scale categories. This latter study also found high floor (0 seconds: 34\%) and ceiling (20 seconds: $42 \%$ ) effects (Table 5).

Overall, for the 1 Leg Standing Balance test, there is evidence of predictive validity, but with a floor and ceiling effect (when conducted for 20 seconds). These findings are generalizable to the Medicare population. 


\section{Degree Turn Test}

The 180 Degree Turn Test is a video evaluation of the 180 degree turn of the Timed Up and Go test, evaluating number of steps, time to complete, and turn steadiness. One study ${ }^{7}$ evaluated the psychometric properties of the 180 Degree Turn Test in 40 people with lower limb amputations (see Tables 3 to 5). The study was deemed to be generalizable to the Medicare population based on the high percentage of study participants with dysvascular disease (65\%); although the average age was under 65 years old.

Items of the 180 Degree Turn Test, specifically “Turn Time” and "Turn Steps” were predictive of the likelihood of falling at least twice over the following 6 months with 85 percent sensitivity and 78 percent specificity (Turn Time) and 100 percent sensitivity and 74 percent specificity (Turn Steps). "Turn Steadiness” had low sensitivity for two or more falls at 6 months (31\%), but relatively high specificity (85\%); overall the accuracy was not statistically significant $(\mathrm{P}=0.22)$.

Overall, for the 180 Degree Turn Test, there is evidence of predictive validity for the three items (or parts) turn time and turn steps (but no evidence to support validity of turn steadiness). These findings are generalizable to the Medicare population.

\section{MWT}

The 2 Minute Walk Test measures the distance walked along a straight, uncarpeted hallway for a 2-minute time period. Nine studies ${ }^{29,} 31-38$ evaluated the psychometric properties of the 2MWT in 814 people, total, with lower limb amputations (see Tables 3 to 5). Five of the studies were deemed to be generalizable to the Medicare population based on either average age greater than 65 years ${ }^{32,}, 37$ or at least have the study participants having dysvascular disease. ${ }^{29,31,34}$

Among studies generalizable to the Medicare population (with 481 participants), studies provided evidence that the 2MWT had convergent validity when compared with ABC, divergent validity when compared with the Houghton Scale, and predictive validity as an initial assessment to predict Houghton Scale at discharge from rehabilitation, 2MWT at 2 months, and SF-36 PF at 3 months. The test was also found to have reliability with no floor or ceiling effects. The minimal detectable change at $90 \%$ confidence-MDC(90)—was 34.3 meters.

Among the remaining studies (with 333 participants), there was evidence that the 2MWT had convergent validity when compared with several other tests and divergent validity based on contrasts by amputation level, age, time with prosthesis, and Houghton Scale.

Overall, for the 2MWT, there is evidence of test validity and reliability, without floor or ceiling effects. These findings are generalizable to the Medicare population.

\section{MWT}

The 6 Minute Walk Test measures the distance walked along a straight, uncarpeted hallway for a 6-minute time period. Three studies ${ }^{17,36,37}$ evaluated the psychometric properties of the 6MWT in 297 people, total, with lower limb amputations (see Tables 3 to 5). Two of the studies were deemed to be generalizable to the Medicare population based on average age greater than 65 years. $^{17,37}$

Among the two studies generalizable to the Medicare population (with 211 participants), studies provided evidence that the 6MWT has convergent validity when compared with the Amputee Mobility Predictor (AMP) with or without a prosthesis, divergent validity based on contrasts by K level, and reliability. The MDC(90) was 45 meters. 
In the study not deemed generalizable to the Medicare population (with 86 participants), the 6MWT had convergent validity when compared with several other tests and divergent validity based on contrasts by amputation etiology, age, K level, and Houghton Scale.

Overall, for the 6MWT, there is evidence of test validity and reliability. These findings are generalizable to the Medicare population. 
Table 3. Study descriptive data: 1 Leg Stand through 6MWT

\begin{tabular}{|c|c|c|c|c|c|c|c|c|c|c|}
\hline Instrument & Item/Subscale & Study, PMID & $\mathbf{N}$ & Age* $^{*}$ & Dysvasc $\dagger, \%$ & Trauma†, \% & $\begin{array}{l}\text { TF†, } \\
\%\end{array}$ & $\begin{array}{l}\text { TT†, } \\
\%\end{array}$ & $\begin{array}{l}\text { Unit, } \\
\%\end{array}$ & $\begin{array}{l}\mathrm{Bi \dagger}, \\
\%\end{array}$ \\
\hline \multirow[t]{3}{*}{$\begin{array}{l}1 \text { Leg Standing } \\
\text { Balance }\end{array}$} & & $\begin{array}{l}\text { Eijk } 2012 \\
21958418 \\
\end{array}$ & 48 & $75.2(8.6)$ & 46 & nd & 35 & 48 & nd & nd \\
\hline & & $\begin{array}{l}\text { Gremeaux } 2012 \\
22389424\end{array}$ & 64 & $58(16)$ & 66 & 25 & 27 & 73 & 100 & 0 \\
\hline & & $\begin{array}{l}\text { Spaan } 2017 \\
27770064\end{array}$ & 82 & $59.2(13.3)$ & 63 & nd & nd & 55 & 100 & 0 \\
\hline $\begin{array}{l}180 \text { Degree } \\
\text { Turn Test }\end{array}$ & $\begin{array}{l}\text { Turn time } \\
\text { Turn steps } \\
\text { Turn steadiness }\end{array}$ & $\begin{array}{l}\text { Dite } 2007 \\
17207685\end{array}$ & 40 & 61.7 (nd) & 65 & nd & 0 & 100 & 100 & 0 \\
\hline \multirow[t]{9}{*}{ 2MWT } & & $\begin{array}{l}\text { Brooks } 2001 \\
11588757 \\
\end{array}$ & 290 & $66.3(13.1)$ & 67 & nd & 21 & 62 & 82 & 18 \\
\hline & & $\begin{array}{l}\text { Brooks } 2002 \\
12422326 \\
\end{array}$ & 33 & $63.6[42-80]$ & 79 & nd & 0 & 100 & 100 & 0 \\
\hline & & $\begin{array}{l}\text { Gremeaux } 2012 \\
22389424\end{array}$ & 64 & $58(16)$ & 66 & 25 & 27 & 73 & 100 & 0 \\
\hline & & $\begin{array}{l}\text { Major } 2013 \\
23856150 \\
\end{array}$ & 30 & $54(12)$ & 23 & 47 & 50 & 53 & 90 & 10 \\
\hline & & $\begin{array}{l}\text { Miller } 2003 \\
12736877 \\
\end{array}$ & 50 & $58.0(15.8)$ & 58 & nd & 24 & 76 & 100 & 0 \\
\hline & & $\begin{array}{l}\text { Newton } 2016 \\
\text { (Eur J } \\
\text { Physiother) }\end{array}$ & 37 & $57.6(7.6)$ & nd & nd & 24 & 76 & 100 & 0 \\
\hline & & $\begin{array}{l}\text { Reid } 2015 \\
25588644 \\
\end{array}$ & 86 & $60(15.3)$ & 35 & 48 & 15 & 73 & 97 & 3 \\
\hline & & $\begin{array}{l}\text { Resnik } 2011 \\
21310896 \\
\end{array}$ & 44 & 66 (13) & nd & nd & 52 & 43 & 100 & 0 \\
\hline & & $\begin{array}{l}\text { Wong } 2016 \\
26874230 \\
\end{array}$ & 180 & 55.5 (16.0) & 49 & 51 & 44 & 56 & 81 & 13 \\
\hline \multirow[t]{3}{*}{ 6MWT } & & $\begin{array}{l}\text { Gailey } 2002 \\
11994800\end{array}$ & 167 & $68.3(18.0)$ & 46 & 37 & 40 & 49 & 100 & 0 \\
\hline & & $\begin{array}{l}\text { Reid } 2015 \\
25588644\end{array}$ & 86 & $60(15.3)$ & 35 & 48 & 15 & 73 & 97 & 3 \\
\hline & & $\begin{array}{l}\text { Resnik } 2011 \\
21310896\end{array}$ & 44 & 66 (13) & nd & nd & 52 & 43 & 100 & 0 \\
\hline
\end{tabular}

Abbreviations: 2MWT = 2 Minute Walk Test, 6MWT = 6 Minute Walk Test, Bi = bilateral amputation, Dysvasc = dysvascular disease (including diabetes), nd = no data/not reported, PMID = PubMed identifier (or journal), TF = transfemoral (above the knee) amputation, TT = transtibial (below the knee) amputation, Uni = unilateral amputation.

Note: Shading included only to more clearly distinguish separate instruments. Empty cells under Item/Subscale indicate that there are no instrument items or subscales or they were not evaluated.

*Mean or median with standard deviation in parentheses and range in square brackets. 
†Percentages of study participants with other amputation etiologies, amputation levels, and unreported etiologies, levels, or unilateral versus bilateral amputation are omitted from this summary table. See Appendix C for further details. Transfemoral and transtibial data may sum to more than $100 \%$ because of double counting of participants with bilateral amputations.

Table 4. Summary of instrument psychometric validity properties: 1 Leg Stand through 6MWT

\begin{tabular}{|c|c|c|c|c|c|c|c|c|}
\hline Instrument & Item/Subscale & Study, PMID & MC* & $\begin{array}{l}\text { Convergent Validity } \\
\text { (Concurrent) }\end{array}$ & $\begin{array}{l}\text { Divergent Validity } \\
\text { (Discriminant) }\end{array}$ & $\begin{array}{l}\text { Construct } \\
\text { Validity }\end{array}$ & $\begin{array}{l}\text { Structural } \\
\text { Validity }\end{array}$ & Predictive Validity † \\
\hline \multirow[t]{3}{*}{$\begin{array}{l}1 \text { Leg } \\
\text { Standing } \\
\text { Balance }\end{array}$} & & $\begin{array}{l}\text { Eijk } 2012 \\
21958418\end{array}$ & Yes & & & & & $\begin{array}{l}\text { Yes (BI at rehab } \\
\text { discharge) } \\
\text { No (SNF status at } \\
\text { rehab discharge) }\end{array}$ \\
\hline & & $\begin{array}{l}\text { Gremeaux } \\
2012 \\
22389424 \\
\end{array}$ & Yes & & No (Houghton) & & & \\
\hline & & $\begin{array}{l}\text { Spaan } 2017 \\
27770064\end{array}$ & Yes & & & & & $\begin{array}{l}\text { Prefitting test Yes } \\
\text { (2MWT, TUG, K level } \\
\text { at end of rehab) }\end{array}$ \\
\hline \multirow{3}{*}{$\begin{array}{l}180 \text { Degree } \\
\text { Turn Test }\end{array}$} & Turn time & Dite 2007 & Yes & & & & & Yes (falls at $6 \mathrm{mo}$ ) \\
\hline & Turn steps & & & & & & & Yes (falls at $6 \mathrm{mo}$ ) \\
\hline & $\begin{array}{l}\text { Turn } \\
\text { steadiness }\end{array}$ & & & & & & & No (falls at $6 \mathrm{mo}$ ) \\
\hline \multirow[t]{8}{*}{$2 \mathrm{MWT}$} & & $\begin{array}{l}\text { Brooks } 2001 \\
11588757\end{array}$ & Yes & & & & & $\begin{array}{l}\text { Initial fitting test Yes } \\
\text { (2MWT at } 2 \text { mo, } \\
\text { SF-36 PF at } 3 \text { mo, } \\
\text { Houghton at hospital } \\
\text { discharge) }\end{array}$ \\
\hline & & $\begin{array}{l}\text { Brooks } 2002 \\
12422326\end{array}$ & Yes & & & & & \\
\hline & & $\begin{array}{l}\text { Gremeaux } \\
2012 \\
22389424\end{array}$ & Yes & & Yes (Houghton) & & & \\
\hline & & $\begin{array}{l}\text { Major } 2013 \\
23856150\end{array}$ & No & Yes (BBS) & & & & \\
\hline & & $\begin{array}{l}\text { Miller } 2003 \\
12736877 \\
\end{array}$ & Yes & Yes (ABC) & & & & \\
\hline & & $\begin{array}{l}\text { Newton } 2016 \\
\text { (Eur J } \\
\text { Physiother) } \\
\end{array}$ & No & No (TAPES) & $\begin{array}{l}\text { Yes (TT vs. TF, } \\
\text { age, time with } \\
\text { prosthesis) }\end{array}$ & & & \\
\hline & & $\begin{array}{l}\text { Reid } 2015 \\
25588644\end{array}$ & No & Yes (6MWT) & & & & \\
\hline & & $\begin{array}{l}\text { Resnik } 2011 \\
21310896\end{array}$ & Yes & & & & & \\
\hline
\end{tabular}




\begin{tabular}{|c|c|c|c|c|c|c|c|c|}
\hline Instrument & Item/Subscale & Study, PMID & $M C^{*}$ & $\begin{array}{l}\text { Convergent Validity } \\
\text { (Concurrent) }\end{array}$ & $\begin{array}{l}\text { Divergent Validity } \\
\text { (Discriminant) }\end{array}$ & $\begin{array}{l}\text { Construct } \\
\text { Validity }\end{array}$ & $\begin{array}{l}\text { Structural } \\
\text { Validity }\end{array}$ & Predictive Validity $\dagger$ \\
\hline & & $\begin{array}{l}\text { Wong } 2016 \\
26874230\end{array}$ & No & $\begin{array}{l}\text { Yes (PEQ-MS, ABC, 3- } \\
\text { BBS, TUG) }\end{array}$ & Yes (Houghton) & & & \\
\hline \multirow[t]{3}{*}{ 6MWT } & & $\begin{array}{l}\text { Gailey } 2002 \\
11994800\end{array}$ & Yes & $\begin{array}{l}\text { Yes (AMPnoPRO, } \\
\text { AMPPRO) }\end{array}$ & Yes (K levels) & & & \\
\hline & & $\begin{array}{l}\text { Reid } 2015 \\
25588644\end{array}$ & No & $\begin{array}{l}\text { Yes (2MWT, TUG, } \\
\text { LCI-5, ABC) }\end{array}$ & $\begin{array}{l}\text { Yes (Houghton, K } \\
\text { levels, amputation } \\
\text { etiology, age) }\end{array}$ & & & \\
\hline & & $\begin{array}{l}\text { Resnik } 2011 \\
21310896\end{array}$ & Yes & & & & & \\
\hline
\end{tabular}

Abbreviations: 2MWT = 2 Minute Walk Test, 6MWT = 6 Minute Walk Test, ABC = Activities-specific Balance Confidence scale, AMP(no)PRO = Amputee Mobility Predictor with (without) Prosthesis, BBS = Berg Balance Scale, BI = Barthel Index, K level = Medicare Functional Classification Level, LCI = Locomotor Capabilities Index, MC =

Medicare, mo = months, PEQ-MS = Prosthesis Evaluation Questionnaire motor score, PMID = PubMed identifier (or journal), SF-36 PF = Short Form Health Survey 36 physical function subscale, SNF = skilled nursing facility, TAPES = Trinity Amputation and Prosthesis Experience Scales, TF = transfemoral amputation, TT = transtibial amputation, TUG = Timed Up and Go test.

Note: Shading included only to more clearly distinguish separate instruments. Empty cells under Item/Subscale indicate that there are no instrument items or subscales or they were not evaluated. Empty cells in the validity columns indicate no evidence regarding this construct.

*Whether study was deemed generalizable to the Medicare population based on average age greater than 65 years and/or at least $50 \%$ of participants with dysvascular etiologies for their amputations.

†Studies evaluated for predictive validity were assessed for Key Question 2. 
Table 5. Summary of other instrument psychometric properties: 1 Leg Stand through 6MWT

\begin{tabular}{|c|c|c|c|c|c|c|c|c|c|}
\hline Instrument & Item/Subscale & Study, PMID & $M C^{*}$ & Reliability & MDC & MID & Responsiveness & Floor & Ceiling \\
\hline \multirow{3}{*}{$\begin{array}{l}1 \text { Leg Standing } \\
\text { Balance }\end{array}$} & & Eijk 201221958418 & Yes & & & & & & \\
\hline & & Gremeaux 201222389424 & Yes & & & & & $34 \%$ & $42 \%$ \\
\hline & & Spaan 201727770064 & Yes & & & & & & \\
\hline \multirow[t]{10}{*}{180 Degree Turn Test } & & Dite 200717207685 & Yes & & & & & & \\
\hline & & Brooks 200111588757 & Yes & & & & & & \\
\hline & & Brooks 200212422326 & Yes & Yes & & & & & \\
\hline & & Gremeaux 201222389424 & Yes & & & & & $0 \%$ & $0 \%$ \\
\hline & & Major 201323856150 & No & & & & & & \\
\hline & & Miller 200312736877 & Yes & & & & & & \\
\hline & & $\begin{array}{l}\text { Newton } 2016 \text { (Eur J } \\
\text { Physiother) }\end{array}$ & No & & & & & & \\
\hline & & Reid 201525588644 & No & & & & & & \\
\hline & & Resnik 201121310896 & Yes & Yes & $\begin{array}{l}\mathrm{MDC}(90) 34.3 \\
\mathrm{~m}\end{array}$ & . & & & \\
\hline & & Wong 201626874230 & No & & & & & & \\
\hline \multirow{3}{*}{\multicolumn{2}{|c|}{ 6MWT }} & Gailey 200211994800 & Yes & & & & & & \\
\hline & & Reid 201525588644 & No & & & & & & \\
\hline & & Resnik 201121310896 & Yes & Yes & MDC(90) $45 \mathrm{~m}$ & & & & \\
\hline
\end{tabular}

Abbreviations: 2MWT = 2 Minute Walk Test, 6MWT = 6 Minute Walk Test, MC = Medicare, MDC(90) = minimal detectable change at 90\% confidence, MID = minimum (clinical) important difference, PMID = PubMed identifier (or journal).

Note: Shading included only to more clearly distinguish separate instruments. Empty cells under Item/Subscale indicate that there are no instrument items or subscales or they were not evaluated. Empty cells in the psychometric properties columns indicate no evidence regarding this construct.

*Whether study was deemed generalizable to the Medicare population based on average age greater than 65 years and/or at least $50 \%$ of participants with dysvascular etiologies for their amputations. 


\title{
AAS
}

The Amputee Activity Survey is a 20-item questionnaire that allows amputee subjects to describe their average daily activity level. Two studies ${ }^{17,39}$ evaluated the psychometric properties of the AAS in 201 people, total, with lower limb amputations (see Tables 6 to 8). Both studies were deemed to be generalizable to the Medicare population based on average age greater than 65 years, and in one study all participants had dysvascular disease.

The studies provided evidence that AAS has convergent validity with AMPPRO and AMPnoPRO, correlates with duration of rehabilitation stay, and discriminates between people with different K levels.

Overall, for the AAS, there is evidence of test validity. This finding is generalizable to the Medicare population.

\section{ABC}

The Activities-specific Balance Confidence scale assesses self-reported balance confidence. Seven studies ${ }^{33,34,36,38,40-42}$ evaluated the psychometric properties of ABC in 1194 people, total, with lower limb amputations (see Tables 6 to 8). However, only two studies, ${ }^{34,42}$ with 120 people, were deemed to be generalizable to the Medicare population based on average age greater than 65 years in one study and high percentage of people with dysvascular disease (58\%, $62 \%$ ) in both studies.

The studies found convergent validity with several other instruments, including the 2MWT, 6MWT, the BBS, PEQ-MS, and TUG. The instrument discriminated between several patient characteristics, including K level, amputation etiology, use of mobility device, walking distance, and automatic stepping, but not amputation level. One of the studies that is generalizable to the Medicare population ${ }^{42}$ conducted a Rasch analysis resulting in a simplified 5-option response format. The analysis concluded that two items in the full ABC (Item 5: Reaching while standing on your tiptoes; Item 13: Walking in a crowd or getting bumped) should be removed or reworded. Studies also found evidence of reliability. Two studies, ${ }^{38,41}$ not generalizable to the Medicare population found no floor or ceiling effect.

Overall, for the ABC scale, there is evidence of test validity and reliability, from studies generalizable to the Medicare population. Other studies also found no floor or ceiling effect.

\section{ADAPT}

The Assessment of Daily Activity Performance in Transfemoral Amputees test measures the functional ability of transfemoral amputees in regard to daily activities. One study ${ }^{43}$ evaluated ADAPT in 20 people, not generalizable to the Medicare population (see Tables 6 to 8).

Regarding psychometric properties, the study reported only reliability for half the study items (items 10 to 18); reliability was not assessed in the other items. In addition, no ceiling effect was found.

Overall, for the ADAPT test, there is evidence that it has, in part, reliability and no ceiling effect, from a study not generalizable to the Medicare population.

\begin{abstract}
AMP
The Amputee Mobility Predictor measures functional capabilities of an amputee either with a prosthesis (AMPPRO) or without a prosthesis (AMPnoPRO).
\end{abstract}


Four studies $^{17,30,37,40}$ evaluated the psychometric properties of AMP (see Tables 6 to 8).

\section{AMPnoPRo}

Two studies ${ }^{17,30}$ evaluated AMPnoPRO (without a prosthesis) in 249 people with lower limb amputations, both generalizable to the Medicare population based on their average age (68 years in one study) or with a high percentage of people with dysvascular disease (63\%).

One study reported evidence of convergent validity between AMPnoPRO and both the 6MWT and AAS, and that AMPnoPRO discriminated between people based on their K levels. The other study reported that AMPnoPRO had predictive validity, when conducted prefitting as an initial assessment for the 2MWT, TUG, and K level at the end of rehabilitation. One study provided evidence of reliability.

\section{AMPPRO}

Three of the studies ${ }^{17,37,40}$ evaluated AMPPRO (with a prosthesis) in 410 people, total, with lower limb amputations. Two of these studies ${ }^{17,37}$ were deemed generalizable to the Medicare population based on the average age of the included study participants (66 and 68 years).

As for AMPnoPRO, one study reported evidence of convergent validity between AMPnoPRO and both the 6MWT and AAS. AMPnoPRO also discriminated between people based on their $\mathrm{K}$ levels and was reported to have reliability.

\section{Overall}

Overall, for AMP—-when used both with (AMPPRO) and without (AMPnoPRO) the patient's prosthesis - there is evidence of test validity and reliability, from studies generalizable to the Medicare population. In addition, AMPnoPRO, as an initial assessment tool, has been reported to have predictive validity, also in a population generalizable to the Medicare population.

\section{AMPSIMM}

The Amputee Single Item Mobility Measure is a single-item self-reported mobility measure wherein amputees select one statement about their level of mobility. One study ${ }^{44}$ evaluated the psychometric properties of AMPSIMM in 113 people with lower limb amputations (see Tables 6 to 8). The study was deemed to not be generalizable to the Medicare population.

The study found convergent validity for AMPSIMM with LCI-5 and TAPES. It also found predictive validity for these same measures and both prosthesis use per day and satisfaction with mobility at 4 and 12 months followup. The study found evidence of responsiveness, with no floor or ceiling effect.

Overall, for AMPSIMM, there is evidence of test validity and responsiveness, without floor or ceiling effect. However, these findings are not generalizable to the Medicare population. 
Table 6. Study descriptive data: AAS through AMPSIMM

\begin{tabular}{|c|c|c|c|c|c|c|c|c|c|c|}
\hline Instrument & Item/Subscale & Study, PMID & $\mathbf{N}$ & Age* $^{*}$ & Dysvasc $\dagger, \%$ & Trauma†, \% & TF†, \% & TT†, \% & Uni†, \% & Bi†, \% \\
\hline \multirow[t]{2}{*}{ AAS } & & Gailey 200211994800 & 167 & $68.3(18.0)$ & 46 & 37 & 40 & 49 & 100 & 0 \\
\hline & & Panesar 200111330761 & 34 & $67[44-85]$ & 100 & 0 & 53 & 44 & 94 & 6 \\
\hline \multirow[t]{6}{*}{ ABC } & & Hafner 201628273329 & 201 & $60.2(11.4)$ & 23 & 60 & 35 & 65 & nd & nd \\
\hline & & Hafner 201727590443 & 199 & $55.4(14.3)$ & 44 & 41 & 18 & 76 & 100 & 0 \\
\hline & & Major 201323856150 & 30 & $54(12)$ & 23 & 47 & 50 & 53 & 90 & 10 \\
\hline & & Miller 200312736877 & 50 & $58.0(15.8)$ & 58 & nd & 24 & 76 & 100 & 0 \\
\hline & & Reid 201525588644 & 86 & $60.0(15.3)$ & 35 & 48 & 15 & 73 & 97 & 3 \\
\hline & 5-item & Sakakibara 201121704978 & 448 & $68.1(10.3)$ & 62 & 27 & 25 & 67 & 95 & 5 \\
\hline ADAPT & & Theeven 201020809056 & 20 & $50.3(10.7)$ & 30 & 60 & 100 & 0 & nd & nd \\
\hline \multirow[t]{5}{*}{ AMP } & AMPnoPRO & Gailey 200211994800 & 167 & $68.3(18.0)$ & 46 & 37 & 40 & 49 & 100 & 0 \\
\hline & & Spaan 201727770064 & 82 & $59.2(13.3)$ & 63 & nd & nd & 55 & 100 & 0 \\
\hline & AMPPRO & Gailey 200211994800 & 167 & $68.3(18.0)$ & 46 & 37 & 40 & 49 & 100 & 0 \\
\hline & & Hafner 201727590443 & 199 & $55.4(14.3)$ & 44 & 41 & 18 & 76 & 100 & 0 \\
\hline & & Resnik 201121310896 & 44 & $66(13)$ & nd & nd & 52 & 43 & 100 & 0 \\
\hline AMPSIMM & & Norvell 201627496697 & 113 & $63.5(8.1)$ & nd & nd & 25 & 52 & 100 & 0 \\
\hline
\end{tabular}

Abbreviations: AAS = Amputees Activity Survey, ABC = Activities-specific Balance Confidence, ADAPT = Assessment of Daily Activity Performance in Transfemoral amputees, AMP = Amputee Mobility Predictor, AMPnoPRO = Amputee Mobility Predictor without use of a prosthesis, AMPPRO = Amputee Mobility Predictor with use of a prosthesis, AMPSIMM = Amputee Single Item Mobility Measure, Dysvasc = dysvascular disease (including diabetes), nd = no data/not reported, PMID = PubMed identifier (or journal), $\mathrm{TF}=$ transfemoral (above the knee) amputation, $\mathrm{TT}=$ transtibial (below the knee) amputation, Uni = unilateral amputation.

Note: Shading included only to more clearly distinguish separate instruments. Empty cells under Item/Subscale indicate that there are no instrument items or subscales or they were not evaluated.

*Mean or median with standard deviation in parentheses and range in square brackets.

†Percentages of study participants with other amputation etiologies, amputation levels, and unreported etiologies, levels, or unilateral versus bilateral amputation are omitted from this summary table. See Appendix C for further details. Transfemoral and transtibial data may sum to more than $100 \%$ because of double counting of participants with bilateral amputations. 
Table 7. Summary of instrument psychometric validity properties: AAS through AMPSIMM

\begin{tabular}{|c|c|c|c|c|c|c|c|c|}
\hline Instrument & Item/Subscale & Study, PMID & $M C^{*}$ & $\begin{array}{l}\text { Convergent Validity } \\
\text { (Concurrent) }\end{array}$ & $\begin{array}{l}\text { Divergent Validity } \\
\text { (Discriminant) }\end{array}$ & $\begin{array}{l}\text { Construct } \\
\text { Validity }\end{array}$ & $\begin{array}{l}\text { Structural } \\
\text { Validity }\end{array}$ & $\begin{array}{l}\text { Predictive Validity } \\
\dagger\end{array}$ \\
\hline \multirow[t]{2}{*}{ AAS } & & $\begin{array}{r}\text { Gailey } 2002 \\
11994800 \\
\end{array}$ & Yes & $\begin{array}{l}\text { Yes (AMPnoPRO, } \\
\text { AMPPRO) }\end{array}$ & Yes (K levels) & & & \\
\hline & & $\begin{array}{l}\text { Panesar } \\
2001 \\
11330761\end{array}$ & Yes & & & $\begin{array}{l}\text { Yes } \\
\text { (duration } \\
\text { of rehab } \\
\text { stay) } \\
\end{array}$ & & \\
\hline \multirow[t]{7}{*}{$A B C$} & & $\begin{array}{r}\text { Hafner } 2016 \\
28273329 \\
\end{array}$ & No & & & & & \\
\hline & & $\begin{array}{r}\text { Hafner } 2017 \\
27590443 \\
\end{array}$ & No & & Yes (K levels) & & & \\
\hline & & $\begin{array}{c}\text { Major } 2013 \\
23856150 \\
\end{array}$ & No & Yes (BBS) & & & & \\
\hline & & $\begin{array}{c}\text { Miller } 2003 \\
12736877\end{array}$ & Yes & Yes (2MWT, TUG) & $\begin{array}{l}\text { Yes (amputation } \\
\text { etiology, use of } \\
\text { mobility device, } \\
\text { walking distance, } \\
\text { automatic } \\
\text { stepping), } \\
\text { No (TT vs. TF) }\end{array}$ & & & \\
\hline & & $\begin{array}{l}\text { Reid } 2015 \\
25588644 \\
\end{array}$ & No & Yes (6MWT) & & & & \\
\hline & 5-item & $\begin{array}{l}\text { Sakakibara } \\
2011 \\
21704978\end{array}$ & Yes & & & & $\begin{array}{l}\text { Rasch } \\
\text { Exploratory } \\
\text { factor analysis: } \\
\text { items } 5 \text { and } 13 \\
\text { problematic } \neq \\
\end{array}$ & \\
\hline & & $\begin{array}{l}\text { Wong } 2016 \\
26874230\end{array}$ & No & $\begin{array}{l}\text { Yes (PEQ-MS, } \\
\text { 2MWT, 3-BBS, } \\
\text { TUG) }\end{array}$ & Yes (Houghton) & & . & \\
\hline$\overline{A D A P T}$ & & $\begin{array}{l}\text { Theeven } \\
2010 \\
20809056 \\
\end{array}$ & No & & & & & \\
\hline \multirow[t]{2}{*}{ AMP } & AMPnoPRO & $\begin{array}{r}\text { Gailey } 2002 \\
11994800 \\
\end{array}$ & Yes & Yes (6MWT, AAS) & Yes (K levels) & & & \\
\hline & & $\begin{array}{r}\text { Spaan } 2017 \\
27770064\end{array}$ & Yes & & & & & $\begin{array}{l}\text { Prefitting test Yes } \\
\text { (2MWT, TUG, K } \\
\text { level at end of } \\
\text { rehab) }\end{array}$ \\
\hline
\end{tabular}




\begin{tabular}{|c|c|c|c|c|c|c|c|c|}
\hline Instrument & Item/Subscale & Study, PMID & $M C^{*}$ & $\begin{array}{l}\text { Convergent Validity } \\
\text { (Concurrent) }\end{array}$ & $\begin{array}{l}\text { Divergent Validity } \\
\text { (Discriminant) }\end{array}$ & $\begin{array}{l}\text { Construct } \\
\text { Validity }\end{array}$ & $\begin{array}{l}\text { Structural } \\
\text { Validity }\end{array}$ & $\begin{array}{l}\text { Predictive Validity } \\
\dagger\end{array}$ \\
\hline & \multirow[t]{3}{*}{ AMPPRO } & $\begin{array}{r}\text { Gailey } 2002 \\
11994800\end{array}$ & Yes & Yes (6MWT, AAS) & Yes (K levels) & & & \\
\hline & & $\begin{array}{r}\text { Hafner } 2017 \\
27590443\end{array}$ & No & & Yes (K levels) & & & \\
\hline & & $\begin{array}{r}\text { Resnik } 2011 \\
21310896\end{array}$ & Yes & & & & & \\
\hline AMPSIMM & & $\begin{array}{r}\text { Norvell } 2016 \\
27496697\end{array}$ & No & Yes (LCl-5, TAPES) & & & & $\begin{array}{l}\text { Yes (prosthesis use } \\
\text { per day, } 4 \text { \& } 12 \\
\text { mo; TAPES } 4 \text { \& } \\
12 \text { mo; } \\
\text { satisfaction with } \\
\text { mobility } 4 \text { \& } 12 \\
\text { mo; LCl-5 } 4 \text { mo) }\end{array}$ \\
\hline
\end{tabular}

Abbreviations: 2MWT $=2$ Minute Walk Test, $6 \mathrm{MWT}=6$ Minute Walk Test, AAS = Amputees Activity Survey, ABC $=$ Activities-specific Balance Confidence, ADAPT = Assessment of Daily Activity Performance in Transfemoral amputees, AMP = Amputee Mobility Predictor, AMPnoPRO = Amputee Mobility Predictor without use of a prosthesis, $\mathrm{AMPPRO}=$ Amputee Mobility Predictor with use of a prosthesis, AMPSIMM = Amputee Single Item Mobility Measure, BBS $=$ Berg Balance Scale, Dysvasc = dysvascular disease (including diabetes) $\mathrm{K}$ level $=$ Medicare Functional Classification Level, LCI $=$ Locomotor Capabilities Index, $\mathrm{MC}=\mathrm{Medicare}$, mo $=$ months, $\mathrm{nd}=$ no data/not reported, PEQ-MS = Prosthesis Evaluation Questionnaire - Mobility Subscale, PMID = PubMed identifier (or journal), TAPES = Trinity Amputation and Prosthesis Experience Scales, TF = transfemoral (above the knee) amputation, TT = transtibial (below the knee) amputation, TUG = Timed Up and Go.

Note: Shading included only to more clearly distinguish separate instruments. Empty cells under Item/Subscale indicate that there are no instrument items or subscales or they were not evaluated. Empty cells in the validity columns indicate no evidence regarding this construct.

*Whether study was deemed generalizable to the Medicare population based on average age greater than 65 years and/or at least $50 \%$ of participants with dysvascular etiologies for their amputations.

†Studies evaluated for predictive validity were assessed for Key Question 2.

$\ddagger$ Item 5: Reaching while standing on your tiptoes; Item 13: Walking in a crowd or getting bumped. 
Table 8. Summary of other instrument psychometric properties: AAS through AMPSIMM

\begin{tabular}{|c|c|c|c|c|c|c|c|c|c|}
\hline Instrument & Item/Subscale & Study, PMID & $\mathrm{MC}^{*}$ & Reliability & MDC & MID & Responsiveness & Floor & Ceiling \\
\hline \multirow[t]{2}{*}{ AAS } & & $\begin{array}{l}\text { Gailey } 2002 \\
11994800\end{array}$ & Yes & & & & & & \\
\hline & & $\begin{array}{l}\text { Panesar } 2001 \\
11330761 \\
\end{array}$ & Yes & & & & & & \\
\hline \multirow[t]{7}{*}{$A B C$} & & $\begin{array}{l}\text { Hafner } 2016 \\
28273329\end{array}$ & No & Yes & $\begin{array}{l}\operatorname{MDC}(90) \\
0.49 \\
\operatorname{MDC}(95) \\
0.58 \\
\end{array}$ & & & $0 \%$ & $0 \%$ \\
\hline & & $\begin{array}{l}\text { Hafner } 2017 \\
27590443 \\
\end{array}$ & No & & & & & & \\
\hline & & Major 201323856150 & No & & & & & & \\
\hline & & Miller 200312736877 & Yes & Yes & & & & & \\
\hline & & Reid 201525588644 & No & & & & & & \\
\hline & 5-item & $\begin{array}{l}\text { Sakakibara } 2011 \\
21704978\end{array}$ & Yes & Yes & & & & & \\
\hline & & $\begin{array}{l}\text { Wong } 2016 \\
26874230 \\
\end{array}$ & No & & & & & $\begin{array}{r}\text { "no floor } \\
\text { effect" }\end{array}$ & $\begin{array}{c}\text { "no ceiling } \\
\text { effect" }\end{array}$ \\
\hline ADAPT & & $\begin{array}{l}\text { Theeven } 2010 \\
20809056\end{array}$ & No & $\begin{array}{l}\text { Yes (items 10- } \\
18, \\
\text { items 1-9 } \\
\text { nd) }\end{array}$ & & & & & $\begin{array}{l}\text { "no ceiling } \\
\text { effect" }\end{array}$ \\
\hline \multirow[t]{5}{*}{ AMP } & AMPnoPRO & $\begin{array}{l}\text { Gailey } 2002 \\
11994800 \\
\end{array}$ & Yes & Yes & & & & & \\
\hline & & $\begin{array}{l}\text { Spaan } 2017 \\
27770064 \\
\end{array}$ & Yes & & & & & & \\
\hline & AMPPRO & $\begin{array}{l}\text { Gailey } 2002 \\
11994800 \\
\end{array}$ & Yes & Yes & & & & & \\
\hline & & $\begin{array}{l}\text { Hafner } 2017 \\
27590443 \\
\end{array}$ & No & & & & & & \\
\hline & & $\begin{array}{l}\text { Resnik } 2011 \\
21310896 \\
\end{array}$ & Yes & Yes & $\begin{array}{l}\mathrm{MDC}(90) \\
3.4 \\
\end{array}$ & . & & & \\
\hline AMPSIMM & . & $\begin{array}{l}\text { Norvell } 2016 \\
27496697\end{array}$ & No & & & & $\begin{array}{l}\text { Yes (SMR "large } \\
\text { effect") }\end{array}$ & $2.2-6.5 \%$ & $0-6.1 \%$ \\
\hline
\end{tabular}

Abbreviations: AAS = Amputees Activity Survey, ABC = Activities-specific Balance Confidence, ADAPT = Assessment of Daily Activity Performance in Transfemoral amputees, AMP = Amputee Mobility Predictor, AMPnoPRO = Amputee Mobility Predictor without use of a prosthesis, AMPPRO = Amputee Mobility Predictor with use of a prosthesis, AMPSIMM = Amputee Single Item Mobility Measure, MDC(90/95) = minimal detectable change at 90/95\% confidence, MID = minimum (clinical) important difference, PMID = PubMed identifier (or journal), SMR = standardized mean response. 
Note: Shading included only to more clearly distinguish separate instruments. Empty cells under Item/Subscale indicate that there are no instrument items or subscales or they were not evaluated. Empty cells in the psychometric properties columns indicate no evidence regarding this construct.

*Whether study was deemed generalizable to the Medicare population based on average age greater than 65 years and/or at least $50 \%$ of participants with dysvascular etiologies for their amputations.

\section{Barthel Index}

The Barthel Index measures independence in activities of daily living. One study ${ }^{28}$ evaluated the psychometric properties of the Barthel Index in a relatively older sample of people with lower limb amputations (see Tables 9 to 11). Based on the study's average age (75 years), the study was deemed to be generalizable to the Medicare population.

The study found that the Barthel index as an assessment tool did not have predictive validity for discharge to a skilled nursing facility after rehabilitation. Other assessments of validity or other psychometric properties were not reported.

Overall, the evidence does not support validity of the Barthel Index for people with lower limb amputations in a study generalizable to the Medicare population. However, given that an instrument assessing independence in activities of daily living might not be expected to predict need for skilled nursing facility placement, it may be reasonable to conclude that the Barthel Index has not adequately had psychometric properties evaluated.

\section{BBS}

The Berg Balance Scale is a 14-item performance measure designed to assess balance. Three studies $^{29,33,38}$ evaluated the psychometric properties of BBS in 274 people, total, with lower limb amputations (see Tables 9 to 11). One of the studies ${ }^{29}$ was deemed to be generalizable to the Medicare population based on a relatively high percentage of participants with dysvascular conditions (66\%); the studies' average ages were all under 60 years.

The study generalizable to the Medicare population provided evidence of divergent validity based on the Houghton Scale. The other two studies, not generalizable to the Medicare population, reported convergent validity with the 2MWT, ABC, FAI, L Test, PEQ-MS, and TUG, and divergent validity to distinguish those with fear of falling, those who required daily use of a mobility aid, and the Houghton Scale; it did not distinguish by amputation level or etiology, or number of falls.

Overall, for BBS, there is evidence of test validity, including in a study generalizable to the Medicare population.

\section{Climbing Stairs Questionnaire}

The Climbing Stairs Questionnaire assesses perceived limitations in walking and climbing stairs among those with lower limb amputations who live at home. One study ${ }^{45}$ evaluated the psychometric properties of this instrument in 172 people with lower limb amputations (see Tables 9 to 11). The study was deemed generalizable to the Medicare population based on the average age of the participants (65 years) and the relatively high percentage with dysvascular conditions (83\%).

The study reported reliability of the measure as well as convergent validity with the LCI, the Rising and Sitting Down Questionnaire, and the Walking Questionnaire.

Overall, for the Climbing Stairs Questionnaire, there is evidence of test validity and reliability in a study generalizable to the Medicare population. 


\section{Employment Questionnaire}

The Employment Questionnaire includes questions about employment status. One study ${ }^{46}$ evaluated the psychometric properties of this instrument in 100 people with lower limb amputations (see Tables 9 to 11). The study was deemed not to be generalizable to the Medicare population based on a relatively low average age (47 years) and percentage with dysvascular conditions (47\%).

The study reported convergent validity with the London Handicap Scale .

Overall, for the Employment Questionnaire, there is evidence of test validity, but in a population not generalizable to the Medicare population. 
Table 9. Study descriptive data: Barthel Index through Employment Questionnaire

\begin{tabular}{|c|c|c|c|c|c|c|c|c|c|c|}
\hline Instrument & Item/Subscale & Study, PMID & $\mathbf{N}$ & Age* $^{*}$ & $\begin{array}{l}\text { Dysvasc } \dagger \text {, } \\
\%\end{array}$ & $\begin{array}{l}\text { Trauma†, } \\
\%\end{array}$ & $\begin{array}{l}\text { TF†, } \\
\%\end{array}$ & $\begin{array}{l}\mathrm{TT} \dagger, \\
\%\end{array}$ & $\begin{array}{l}\text { Uni†, } \\
\%\end{array}$ & $\begin{array}{l}\mathrm{Bi \dagger}, \\
\%\end{array}$ \\
\hline Barthel Index & & Eijk 201221958418 & 48 & $75.2(8.6)$ & 46 & nd & 35 & 48 & $\mathrm{nd}$ & $\mathrm{nd}$ \\
\hline \multirow{3}{*}{\multicolumn{2}{|c|}{ BBS }} & $\begin{array}{c}\text { Gremeaux } 2012 \\
22389424 \\
\end{array}$ & 64 & $58(16)$ & 66 & 25 & 27 & 73 & 100 & 0 \\
\hline & & Major 201323856150 & 30 & $54(12)$ & 23 & 47 & 50 & 53 & 90 & 10 \\
\hline & & Wong 201626874230 & 180 & $55.5(16.0)$ & 49 & 51 & 44 & 56 & 81 & 13 \\
\hline $\begin{array}{l}\text { Climbing Stairs } \\
\text { Questionnaire }\end{array}$ & & $\begin{array}{c}\text { de Laat } 2010 \\
20801258 \\
\end{array}$ & 172 & $\begin{array}{l}65(11)[37- \\
92]\end{array}$ & 83 & 8 & 32 & 54 & 93 & 7 \\
\hline $\begin{array}{l}\text { Employment } \\
\text { Questionnaire }\end{array}$ & & Fisher 200312601268 & 100 & $47.4(11.05)$ & 24 & 64 & 43 & 50 & 100 & 0 \\
\hline
\end{tabular}

Abbreviations: BBS = Berg Balance Scale, Bi = bilateral amputation, Dysvasc = dysvascular disease (including diabetes), nd = no data/not reported, PMID = PubMed identifier (or journal), $\mathrm{TF}=$ transfemoral (above the knee) amputation, $\mathrm{TT}=$ transtibial (below the knee) amputation, Uni = unilateral amputation.

Note: Shading included only to more clearly distinguish separate instruments. Empty cells under Item/Subscale indicate that there are no instrument items or subscales or they were not evaluated.

*Mean or median with standard deviation in parentheses and range in square brackets.

†Percentages of study participants with other amputation etiologies, amputation levels, and unreported etiologies, levels, or unilateral versus bilateral amputation are omitted from this summary table. See Appendix C for further details. Transfemoral and transtibial data may sum to more than 100\% because of double counting of participants with bilateral amputations. 
Table 10. Summary of instrument psychometric validity properties: Barthel Index through Employment Questionnaire

\begin{tabular}{|c|c|c|c|c|c|c|c|c|}
\hline Instrument & Item/Subscale & $\begin{array}{l}\text { Study, } \\
\text { PMID }\end{array}$ & $M C^{*}$ & $\begin{array}{l}\text { Convergent Validity } \\
\text { (Concurrent) }\end{array}$ & $\begin{array}{l}\text { Divergent Validity } \\
\text { (Discriminant) }\end{array}$ & $\begin{array}{l}\text { Construct } \\
\text { Validity }\end{array}$ & $\begin{array}{l}\text { Structural } \\
\text { Validity }\end{array}$ & $\begin{array}{l}\text { Predictive } \\
\text { Validity } \dagger\end{array}$ \\
\hline Barthel Index & & $\begin{array}{l}\text { Eijk } 2012 \\
21958418\end{array}$ & Yes & & & & & $\begin{array}{l}\text { No (SNF } \\
\text { status at } \\
\text { rehab } \\
\text { discharge) }\end{array}$ \\
\hline \multirow{3}{*}{\multicolumn{2}{|c|}{ BBS }} & $\begin{array}{l}\text { Gremeaux } \\
2012 \\
22389424\end{array}$ & Yes & & Yes (Houghton) & & & \\
\hline & & $\begin{array}{l}\text { Major } 2013 \\
23856150\end{array}$ & No & $\begin{array}{l}\text { Yes (ABC, PEQ-MS, } \\
\text { FAI, 2MWT, L Test) }\end{array}$ & $\begin{array}{l}\text { Yes (fear of falling, daily } \\
\text { use of mobility aid), No } \\
\text { (amputation level, } \\
\text { amputation etiology, } \\
\text { number of falls) }\end{array}$ & & & \\
\hline & & $\begin{array}{l}\text { Wong } 2016 \\
26874230\end{array}$ & No & $\begin{array}{l}\text { Yes (PEQ-MS, ABC, } \\
2 M W T, T U G)\end{array}$ & Yes (Houghton) & & & \\
\hline $\begin{array}{l}\text { Climbing Stairs } \\
\text { Questionnaire }\end{array}$ & & $\begin{array}{l}\text { de Laat } \\
2010 \\
20801258\end{array}$ & Yes & Yes (LCI, RSQ, WQ) & & & & \\
\hline $\begin{array}{l}\text { Employment } \\
\text { Questionnaire }\end{array}$ & & $\begin{array}{l}\text { Fisher } 2003 \\
12601268\end{array}$ & No & Yes (LHS) & & & & \\
\hline
\end{tabular}

Abbreviations: 2MWT = 2 Minute Walk Test, ABC = Activities-specific Balance Confidence scale, BBS = Berg Balance Scale, FAI = Frenchay Activities Index, LCI =

Locomotor Capabilities Index, LHS = London Handicap Scale, L Test = L Test of Functional Mobility, MC = Medicare, PEQ-MS = Prosthesis Evaluation Questionnaire -

Mobility Subscale, PMID = PubMed identifier (or journal), RSQ = Rising and Sitting Down Questionnaire, SNF = skilled nursing facility, TUG = Timed Up and Go, WQ =

Walking Questionnaire.

Note: Shading included only to more clearly distinguish separate instruments. Empty cells under Item/Subscale indicate that there are no instrument items or subscales or they were not evaluated. Empty cells in the validity columns indicate no evidence regarding this construct.

*Whether study was deemed generalizable to the Medicare population based on average age greater than 65 years and/or at least $50 \%$ of participants with dysvascular etiologies

for their amputations.

†Studies evaluated for predictive validity were assessed for Key Question 2. 
Table 11. Summary of other instrument psychometric properties: Barthel Index through Employment Questionnaire

\begin{tabular}{|c|c|c|c|c|c|c|c|c|c|}
\hline Instrument & Item/Subscale & Study, PMID & $M C^{*}$ & Reliability & MDC & MID & Responsiveness & Floor & Ceiling \\
\hline Barthel Index & & Eijk 201221958418 & Yes & & & & & & \\
\hline \multirow[t]{3}{*}{ BBS } & & $\begin{array}{l}\text { Gremeaux } 2012 \\
22389424\end{array}$ & Yes & & & & & $0 \%$ & $0 \%$ \\
\hline & & Major 201323856150 & No & Yes & & & & $0 \%$ & $10 \%$ \\
\hline & & Wong 201626874230 & No & & & & & $\begin{array}{l}\text { "no floor } \\
\text { effect" }\end{array}$ & $\begin{array}{l}\text { "no ceiling } \\
\text { effect" }\end{array}$ \\
\hline $\begin{array}{l}\text { Climbing Stairs } \\
\text { Questionnaire }\end{array}$ & & $\begin{array}{l}\text { de Laat } 2010 \\
20801258\end{array}$ & Yes & Yes & & & & & \\
\hline $\begin{array}{l}\text { Employment } \\
\text { Questionnaire }\end{array}$ & & Fisher 200312601268 & No & & & & & & \\
\hline
\end{tabular}

Questionnaire

Abbreviations: BBS = Berg Balance Scale, MC = Medicare, MDC = minimal detectable change, MID = minimum (clinical) important difference, PMID = PubMed identifier (or journal).

Note: Shading included only to more clearly distinguish separate instruments. Empty cells under Item/Subscale indicate that there are no instrument items or subscales or they were not evaluated. Empty cells in the psychometric properties columns indicate no evidence regarding this construct.

*Whether study was deemed generalizable to the Medicare population based on average age greater than 65 years and/or at least $50 \%$ of participants with dysvascular etiologies for their amputations. 


\section{FAC}

The Functional Ambulation Categories instrument measures independence of gait from total dependency to independent walking on all surfaces. One study ${ }^{28}$ evaluated the psychometric properties of FAC in 48 people with lower limb amputations (see Tables12 to 14). The study was deemed to be generalizable to the Medicare population based on the average age of study participants (75 years); although fewer than half had dysvascular etiologies for their amputations.

The study provided information on predictive validity. The FAC, as an initial assessment at the start of rehabilitation was correlated with the Barthel index at discharge from rehabilitation, but it did not predict admission to a skilled nursing facility.

Overall, for FAC, a study generalizable to the Medicare population provided evidence of predictive validity for future Barthel index, but not for admission to a skilled nursing facility.

\section{FAI}

The Frenchay Activities Index measures instrumental activities of daily living in patients recovering from stroke. Three studies ${ }^{28,33,47}$ evaluated the psychometric properties of FAI in 162 people, total, with lower limb amputations (see Tables 12 to 14). One of the studies was deemed to be generalizable to the Medicare population based on the average age of the study participants (75 years); the other two studies included people of lower average age (54 and 57 years), but in all studies, fewer than half the participants had dysvascular conditions.

The study generalizable to the Medicare population provided information on predictive validity. The FAI as an initial assessment at the start of rehabilitation was correlated with the Barthel index at discharge from rehabilitation.

Among the other studies, there was evidence that FAI had convergent validity when compared with a number of other instruments including BBS, 2MWT, TUG, PEQ-MS, and ABC. One of the studies deemed to be not generalizable to the Medicare population provided information that FAI was reliable.

Overall, for FAI, there is evidence of test validity, including predictive validity for future Barthel index but not admission to a skilled nursing facility in a study generalizable to the Medicare population. There is also evidence of test reliability.

\section{FIM}

The Functional Independence Measure determines the level of disability of patients, as reflected by their need for assistance and/or aids during activities of daily living. Four studies ${ }^{39}$, 48, 49 evaluated the psychometric properties of FIM in 224 people, total, with lower limb amputations (see Tables 12 to 14). While the instrument has subscales for motor and cognitive domains, it was evaluated as a total score and for the items Chair Transfer, Walk on Level Surface, and Climb Stairs. One of the studies was deemed to be generalizable to the Medicare population based on both the average age of the study participants (67 years) and the proportion of participants with dysvascular conditions (100); two studies included people of lower average age (35 and 51 years) and fewer than half had dysvascular conditions; and one study did not report age and proportion of participants with dysvascular conditions.

The study deemed to be generalizable to the Medicare population provided information on construct validity of FIM. The FIM total score as an initial assessment at the start of rehabilitation was correlated with the duration of stay. Among the other studies, one study 
showed provided information on construct validity. Neither the individual items nor FIM overall were correlated with walking speed or return to usual activity. Two studies provided information on divergent validity. FIM score did not differ notably by amputation level, injury severity score, age, and comorbidities. FIM score did not differ by Houghton Scale categories. FIM as an initial assessment at the start of rehabilitation was found to not have predictive validity for a future Houghton Scale, but FIM at discharge from rehabilitation did have predictive validity for the Houghton Scale 3 to 12 months later.

One of the studies deemed to be not generalizable to the Medicare population provided information that the overall score and the three examined items were reliable. The same study also provided information that FIM, overall, was responsive to walking speed but not return to usual activity. Two of the items, Chair Transfer and Climb Stairs were also responsive to walking speed but not return to usual activity. The item Walk on Level Surface, however, was responsive to neither. The same study also provided information about floor and ceiling effects of FIM and the items. There was no evidence for a floor effect, but there was a ceiling effect (53\%) for the Chair Transfer item.

Overall, for FIM, there is evidence of test validity in studies both generalizable and not generalizable to the Medicare population; although, one study evaluated the individual items but did not find evidence of their validity. In studies not generalizable to the Medicare population, there is evidence of predictive validity for FIM assessed at discharge from, but not for FIM assessed at initiation of, rehabilitation; there is also evidence of test reliability (both overall and for the evaluated items) and responsiveness of FIM. The Chair Transfer item was also found to have a ceiling effect.

\section{FSST}

The Four Square Step Test measures dynamic balance through assessment of the patient's ability to step over objects forward, sideways, and backwards. One study ${ }^{7}$ evaluated the psychometric properties of FSST in 40 people with lower limb amputations (see Tables 12 to 141). The study was deemed to be generalizable to the Medicare population based on the proportion of study participants with dysvascular etiologies for their amputations (65\%); participants' average age was 62 years.

The study provided information on predictive validity. The FSST at discharge from rehabilitation was predictive of two or more falls at 6 months after discharge (sensitivity 92\% and specificity 93\%).

Overall, for FSST, there is evidence of predictive validity in a study generalizable to the Medicare population.

\section{Functional Reach Test}

The Functional Reach Test assesses a patient's stability by measuring the maximum distance the patient reaches forward while standing in a fixed position. One study ${ }^{29}$ evaluated the psychometric properties of the Functional Reach Test in 64 people with lower limb amputations (see Tables 12 to 14). The study was deemed to be generalizable to the Medicare population based on the proportion of study participants with dysvascular etiologies for their amputations (66\%); participants' average age was 64 years. The study provided evidence of divergent validity for The Functional Reach Test to discriminate people based on the Houghton Scale.

Overall, for the Functional reach test, there is evidence of test validity from a study generalizable to the Medicare population. 
Table 12. Study descriptive data: FAC through Functional Reach Test

\begin{tabular}{|c|c|c|c|c|c|c|c|c|c|c|}
\hline Instrument & Item/Subscale & Study, PMID & $\mathbf{N}$ & $\mathrm{Age}^{*}$ & $\begin{array}{l}\text { Dysvasc } \dagger \text {, } \\
\%\end{array}$ & $\begin{array}{l}\text { Trauma } \dagger, \\
\%\end{array}$ & $\begin{array}{l}\text { TF†, } \\
\%\end{array}$ & $\begin{array}{l}\text { TTt, } \\
\%\end{array}$ & $\begin{array}{l}\text { Unit, } \\
\%\end{array}$ & $\begin{array}{l}\mathrm{Bi \dagger}, \\
\%\end{array}$ \\
\hline FAC & & Eijk 201221958418 & 48 & $\begin{array}{l}75.2 \\
(8.6)\end{array}$ & 46 & $\overline{n d}$ & 35 & 48 & $\overline{\mathrm{nd}}$ & nd \\
\hline \multirow[t]{3}{*}{ FAI } & & Eijk 201221958418 & 48 & $\begin{array}{l}75.2 \\
(8.6)\end{array}$ & 46 & nd & 35 & 48 & nd & nd \\
\hline & & Major 201323856150 & 30 & $54(12)$ & 23 & 47 & 50 & 53 & 90 & 10 \\
\hline & & Miller 200415180125 & 84 & $\begin{array}{l}56.5 \\
(13.0)\end{array}$ & 40 & 60 & 29 & 71 & 100 & 0 \\
\hline \multirow[t]{4}{*}{ FIM } & & $\begin{array}{l}\text { Franchignoni } 2004 \\
15129398\end{array}$ & 50 & $\begin{array}{l}51 \text { (nd } \\
{[21-86]}\end{array}$ & 32 & 58 & 60 & 40 & 100 & 0 \\
\hline & & Leung 19968831480 & 33 & nd & nd & nd & 24 & 73 & 97 & 3 \\
\hline & & Panesar 200111330761 & 34 & $\begin{array}{l}67[44- \\
85]\end{array}$ & 100 & 0 & 53 & 44 & 94 & 6 \\
\hline & $\begin{array}{l}\text { Chair transfer } \\
\text { Walk on level surface } \\
\text { Climb stairs } \\
\text { Total (Overall) }\end{array}$ & $\begin{array}{l}\text { Cyril } 2001 \text { (Johns } \\
\text { Hopkins) }\end{array}$ & 107 & $35(12.5)$ & 0 & 100 & 21 & 67 & 100 & 0 \\
\hline FSST & & Dite 200717207685 & 40 & $61.7(\mathrm{nd})$ & 65 & nd & 0 & 100 & 100 & 0 \\
\hline $\begin{array}{l}\text { Functional } \\
\text { Reach Test }\end{array}$ & & $\begin{array}{l}\text { Gremeaux } 2012 \\
22389424\end{array}$ & 64 & $58(16)$ & 66 & 25 & 27 & 73 & 100 & 0 \\
\hline
\end{tabular}

Abbreviations: $\mathrm{Bi}$ = bilateral amputation, Dysvasc = dysvascular disease (including diabetes), FAC = Functional Ambulation Categories, FAI = Frenchay Activities Index, FIM = Functional Independence Measure, FSST = Four Square Step Test, nd = no data/not reported, PMID = PubMed identifier (or journal), TF = transfemoral (above the knee) amputation, TT = transtibial (below the knee) amputation, Uni = unilateral amputation.

Note: Shading included only to more clearly distinguish separate instruments. Empty cells under Item/Subscale indicate that there are no instrument items or subscales or they were not evaluated.

*Mean or median with standard deviation in parentheses and range in square brackets.

†Percentages of study participants with other amputation etiologies, amputation levels, and unreported etiologies, levels, or unilateral versus bilateral amputation are omitted from this summary table. See Appendix C for further details. Transfemoral and transtibial data may sum to more than $100 \%$ because of double counting of participants with bilateral amputations. 
Table 13. Summary of instrument psychometric validity properties: FAC through Functional Reach Test

\begin{tabular}{|c|c|c|c|c|c|c|c|c|}
\hline Instrument & Item/Subscale & Study, PMID & $M C^{*}$ & $\begin{array}{l}\text { Convergent } \\
\text { Validity } \\
\text { (Concurrent) } \\
\end{array}$ & $\begin{array}{l}\text { Divergent Validity } \\
\text { (Discriminant) }\end{array}$ & $\begin{array}{l}\text { Construct } \\
\text { Validity }\end{array}$ & $\begin{array}{l}\text { Structural } \\
\text { Validity }\end{array}$ & $\begin{array}{l}\text { Predictive } \\
\text { Validity } \dagger\end{array}$ \\
\hline FAC & & $\begin{array}{l}\text { Eijk } 2012 \\
21958418\end{array}$ & Yes & . & . & . & . & $\begin{array}{l}\text { Yes (BI at rehab } \\
\text { discharge) } \\
\text { No (SNF status at } \\
\text { rehab discharge) }\end{array}$ \\
\hline \multirow{3}{*}{\multicolumn{2}{|c|}{ FAI }} & $\begin{array}{l}\text { Eijk } 2012 \\
21958418\end{array}$ & Yes & . & . & . & . & $\begin{array}{l}\text { Yes (BI at rehab } \\
\text { discharge) } \\
\text { No (SNF status at } \\
\text { rehab discharge) }\end{array}$ \\
\hline & & $\begin{array}{l}\text { Major } 2013 \\
23856150\end{array}$ & No & Yes (BBS) & . & . & . & . \\
\hline & & $\begin{array}{l}\text { Miller } 2004 \\
15180125\end{array}$ & No & $\begin{array}{l}\text { Yes (2MWT, TUG, } \\
\text { PEQ-MS, ABC) }\end{array}$ & $\begin{array}{l}\text { Yes (amputation } \\
\text { etiology, use of } \\
\text { mobility device, } \\
\text { age, years as } \\
\text { amputee), No (TT } \\
\text { vs. TF) }\end{array}$ & . & . & . \\
\hline \multirow[t]{4}{*}{ FIM } & & $\begin{array}{l}\text { Franchignoni } \\
2004 \\
15129398\end{array}$ & No & $\begin{array}{l}\text { Yes (LCl, LCl-5, } \\
\text { RMI) }\end{array}$ & & . & . & . \\
\hline & & $\begin{array}{l}\text { Leung } 1996 \\
8831480\end{array}$ & No & . & Mixed (Houghton) & . & . & $\begin{array}{l}\text { Mixed: } \\
\text { Discharge FIM Yes } \\
\text { (Houghton } \geq 9 \text { at } 3 \text { - } \\
12 \text { mo), } \\
\text { Admission FIM No } \\
\text { (Houghton } \geq 9 \text { at } 3- \\
12 \mathrm{mo} \text { ) }\end{array}$ \\
\hline & & $\begin{array}{l}\text { Panesar } 2001 \\
11330761\end{array}$ & Yes & . & . & $\begin{array}{l}\text { Yes } \\
\text { (duration of } \\
\text { stay) }\end{array}$ & . & . \\
\hline & & $\begin{array}{l}\text { Cyril } 2001 \\
\text { (Johns } \\
\text { Hopkins) }\end{array}$ & No & . & $\begin{array}{l}\text { No (amputation } \\
\text { level, injury } \\
\text { severity score, } \\
\text { age, comorbidities) }\end{array}$ & $\begin{array}{l}\text { No } \\
\text { (walking } \\
\text { speed, } \\
\text { return to } \\
\text { usual } \\
\text { activity) }\end{array}$ & . & . \\
\hline
\end{tabular}




\begin{tabular}{|c|c|c|c|c|c|c|c|c|}
\hline Instrument & Item/Subscale & Study, PMID & $M C^{*}$ & $\begin{array}{l}\text { Convergent } \\
\text { Validity } \\
\text { (Concurrent) }\end{array}$ & $\begin{array}{l}\text { Divergent Validity } \\
\text { (Discriminant) }\end{array}$ & $\begin{array}{l}\text { Construct } \\
\text { Validity }\end{array}$ & $\begin{array}{l}\text { Structural } \\
\text { Validity }\end{array}$ & $\begin{array}{l}\text { Predictive } \\
\text { Validity } \dagger\end{array}$ \\
\hline & Chair transfer & $\begin{array}{l}\text { Cyril 2001 } \\
\text { (Johns } \\
\text { Hopkins) }\end{array}$ & No & . & No (same) & No (same) & . & . \\
\hline & Walk on level surface & & No & . & No (same) & No (same) & . & . \\
\hline & Climb stairs & & No & . & No (same) & No (same) & . & . \\
\hline FSST & & $\begin{array}{l}\text { Dite } 2007 \\
17207685\end{array}$ & Yes & - & . & . & . & Yes (falls at $6 \mathrm{mo}$ ) \\
\hline $\begin{array}{l}\text { Functional } \\
\text { Reach Test }\end{array}$ & & $\begin{array}{l}\text { Gremeaux } \\
2012 \\
22389424 \\
\end{array}$ & Yes & & Yes (Houghton) & . & . & . \\
\hline
\end{tabular}

Abbreviations: $2 \mathrm{MWT}=2$ Minute Walk Test, ABC = Activities-specific Balance scale, BBS = Berg Balance Scale, BI = Barthel Index, Dysvasc = dysvascular disease (including diabetes), FAC = Functional Ambulation Categories, FAI = Frenchay Activities Index, FIM = Functional Independence Measure, FSST = Four Square Step Test, LCI =

Locomotor Capabilities Index, MC = Medicare, mo = months, nd = no data/not reported, PEQ-MS = Prosthesis Evaluation Questionnaire motor score, PMID = PubMed identifier (or journal), RMI = Rivermead Mobility Index, SNF = skilled nursing facility, TF = transfemoral (above the knee) amputation, TT = transtibial (below the knee) amputation, TUG = Timed Up and Go.

Note: Shading included only to more clearly distinguish separate instruments. Empty cells under Item/Subscale indicate that there are no instrument items or subscales or they were not evaluated. Empty cells (in the validity columns indicate no evidence regarding this construct.

*Whether study was deemed generalizable to the Medicare population based on average age greater than 65 years and/or at least $50 \%$ of participants with dysvascular etiologies for their amputations.

†Studies evaluated for predictive validity were assessed for Key Question 2. 
Table 14. Summary of instrument psychometric validity properties: FAC through Functional Reach Test

\begin{tabular}{|c|c|c|c|c|c|c|c|c|c|}
\hline Instrument & Item/Subscale & Study, PMID & $M C^{*}$ & Reliability & MDC & MID & Responsiveness & Floor & Ceiling \\
\hline$\overline{F A C}$ & & $\begin{array}{l}\text { Eijk } 2012 \\
21958418\end{array}$ & Yes & & & & & & \\
\hline \multirow[t]{3}{*}{ FAI } & & $\begin{array}{l}\text { Eijk } 2012 \\
21958418\end{array}$ & Yes & & & & & & \\
\hline & & $\begin{array}{l}\text { Major } 2013 \\
23856150\end{array}$ & No & & & & & & \\
\hline & & $\begin{array}{l}\text { Miller } 2004 \\
15180125\end{array}$ & No & Yes & & & & & \\
\hline \multirow[t]{7}{*}{ FIM } & & $\begin{array}{l}\text { Franchignoni } 2004 \\
15129398\end{array}$ & No & & & & & & \\
\hline & & $\begin{array}{l}\text { Leung } 1996 \\
8831480\end{array}$ & No & & & & & & \\
\hline & & $\begin{array}{l}\text { Panesar } 2001 \\
11330761\end{array}$ & Yes & & & & & & \\
\hline & & $\begin{array}{l}\text { Cyril } 2001 \text { (Johns } \\
\text { Hopkins) }\end{array}$ & No & Yes & & & $\begin{array}{l}\text { Yes (walking } \\
\text { speed), } \\
\text { No (return to } \\
\text { usual activity) }\end{array}$ & $0 \%$ & $0 \%$ \\
\hline & Chair transfer & $\begin{array}{l}\text { Cyril } 2001 \text { (Johns } \\
\text { Hopkins) }\end{array}$ & No & Yes & & & $\begin{array}{l}\text { Yes (walking } \\
\text { speed), } \\
\text { No (return to } \\
\text { usual activity) }\end{array}$ & $1.0 \%$ & $53.3 \%$ \\
\hline & Walk on level surface & & No & Yes & & & $\begin{array}{l}\text { No (walking } \\
\text { speed, return to } \\
\text { usual activity) }\end{array}$ & $2.0 \%$ & $0 \%$ \\
\hline & Climb stairs & & No & Yes & & & $\begin{array}{l}\text { Yes (walking } \\
\text { speed), } \\
\text { No (return to } \\
\text { usual activity) }\end{array}$ & $4.7 \%$ & $0 \%$ \\
\hline FSST & & $\begin{array}{l}\text { Dite } 2007 \\
17207685\end{array}$ & Yes & & & & & & \\
\hline $\begin{array}{l}\text { Functional } \\
\text { Reach Test }\end{array}$ & & $\begin{array}{l}\text { Gremeaux } 2012 \\
22389424\end{array}$ & Yes & & & & & $1.5 \%$ & $3 \%$ \\
\hline
\end{tabular}

22389424

Abbreviations: FAC = Functional Ambulation Categories, FAI = Frenchay Activities Index, FIM = Functional Independence Measure, FSST = Four Square Step Test, MDC = minimal detectable change, MID = minimum (clinical) important difference, nd = no data/not reported, PMID = PubMed identifier (or journal).

Note: Shading included only to more clearly distinguish separate instruments. Empty cells under Item/Subscale indicate that there are no instrument items or subscales or they were not evaluated. Empty cells $n$ the validity columns indicate no evidence regarding this construct.

*Whether study was deemed generalizable to the Medicare (MC) population based on average age greater than 65 years and/or at least $50 \%$ of participants with dysvascular etiologies for their amputations. 


\section{Houghton Scale}

The Houghton Scale reflects a patient's perception of prosthesis use, including items for wearing and using prostheses, and stability walking in different settings. Eight studies (in seven articles) $)^{29}, 32,36,38,50,51$ evaluated the psychometric properties of the Houghton Scale in 836 people, total, with lower limb amputations (see Tables 15 to 17). Six of the studies were deemed to be generalizable to the Medicare population, of which two studies were generalizable based on both the average age of the study participants (66 years) and the percentage of participants with dysvascular conditions (53\% to 66\%). The other two studies included people of lower average age and fewer than half with dysvascular conditions.

Among the studies deemed to be generalizable to the Medicare population, there was evidence that the Houghton Scale had convergent validity when compared with a number of other instruments including SF-36 PCS, 2MWT, TUG, PEQ-MS, ABC, and PPA-LCI. One of these studies also provided evidence of mixed divergent validity of a combined subset of items 1 to 3 in the Scale regarding wearing and using the prosthesis. When assessed at discharge from rehabilitation, The Houghton Scale successfully discriminated participants by their amputation level; however, when assessed at 3 month followup, it did not do so, nor did it discriminate between unilateral vs. bilateral amputation or by age at either time point.

Two of the studies deemed to be generalizable to the Medicare population provided information on reliability of the Houghton Scale. The Houghton Scale was found to be reliable overall and for items 1-3. The Houghton Scale was also reported to be responsive to change. One study reported floor and ceiling effects of the Houghton Scale and its items when measured both at discharge from rehabilitation and at 3 month followup. No floor or ceiling effect was found for the overall Scale, but each of the items had either a floor or ceiling effect at one or both time points. Three other studies also did not find floor or ceiling effects for the overall score, but one other study did find a ceiling effect of the overall Scale (in a French language version).

Overall, for the Houghton Scale, among studies generalizable to the Medicare population (and other studies), there is evidence of test validity, reliability, and responsiveness. Studies mostly found no floor or ceiling effect for the overall Scale. One study reported test validity and reliability for a subset of items related to prosthesis use, but floor or ceiling effects for individual items.

\section{Test}

The L Test of Functional Mobility is a modified version of the TUG Test that incorporates two transfers and four turns, of which at least one would be to the opposite side. Three studies ${ }^{33}$, 52, 53 evaluated the psychometric properties of the L Test in 156 people, total, with lower limb amputations (see Tables 15 to 17). One of the studies was deemed to be generalizable to the Medicare population based on the proportion of participants with dysvascular conditions (58\%); the other two studies included a lower proportion of participants with dysvascular conditions (23\% and 40\%) and people of lower average age.

The studies not generalizable to the Medicare population reported evidence of convergent validity with BBS, TUG, 2MWT, 10 meter Walk Test, ABC, FAI, and PEQ-MS. Also, one of these studies reported that the L Test was able to discriminate between patients by amputation level, amputation cause, walking aid use, autowalk ("not having to consciously think about each step”), and age. 
One of the studies deemed to be not generalizable to the Medicare population reported evidence that the L Test was reliable, had an MDC of $6.2 \mathrm{sec}$ and an MIC of $4.5 \mathrm{sec}$. Thestudy that was generalizable to the Medicare population reported only that the $\mathrm{L}$ test was not responsive to Global Rating of Change scores.

Overall, for the L Test, there is evidence of test validity and reliability in studies not generalizable to the Medicare population, but the one study that was generalizable to the Medicare population suggests that it may lack responsiveness to change. 
Table 15. Study descriptive data: Houghton Scale through L Test

\begin{tabular}{|c|c|c|c|c|c|c|c|c|c|c|}
\hline Instrument & Item/Subscale & Study, PMID & $\mathbf{N}$ & Age* $^{*}$ & $\begin{array}{l}\text { Dysvasc } \dagger \text {, } \\
\%\end{array}$ & $\begin{array}{l}\text { Traumat, } \\
\%\end{array}$ & $\begin{array}{l}\text { TF†, } \\
\%\end{array}$ & $\begin{array}{l}\text { TT†, } \\
\%\end{array}$ & $\begin{array}{l}\text { Uni†, } \\
\%\end{array}$ & $\begin{array}{l}\mathrm{Bi \dagger}, \\
\%\end{array}$ \\
\hline \multirow[t]{8}{*}{ Houghton } & & $\begin{array}{l}\text { Brooks } 2001 \\
11588757\end{array}$ & 56 & $\begin{array}{l}66.3 \\
(13.1)\end{array}$ & 66 & nd & 21 & 63 & 82 & 18 \\
\hline & & $\begin{array}{l}\text { Devlin } 2004 \\
15295762 \text { - Sample } \\
1\end{array}$ & 49 & $\begin{array}{l}60.9 \\
(16.8)\end{array}$ & 53 & nd & 20 & 84 & 88 & 8 \\
\hline & & $\begin{array}{l}\text { Gremeaux } 2012 \\
22389424\end{array}$ & 64 & $58(16)$ & 66 & 25 & 27 & 73 & 100 & 0 \\
\hline & & $\begin{array}{l}\text { Miller } 2001 \\
\text { 11588750 (sample } \\
\text { 1) }\end{array}$ & 60 & $\begin{array}{l}58.4 \\
(15.5)\end{array}$ & 53 & nd & 28 & 72 & 100 & 0 \\
\hline & & $\begin{array}{l}\text { Miller } 2001 \\
\text { 11588750 (sample } \\
\text { 2) }\end{array}$ & 329 & $\begin{array}{l}59.9 \\
(16.7)\end{array}$ & 53 & nd & 26 & 74 & 100 & 0 \\
\hline & & $\begin{array}{l}\text { Reid } 2015 \\
25588644\end{array}$ & 86 & 60 (15.3) & 35 & 48 & 15 & 73 & 97 & 3 \\
\hline & & $\begin{array}{l}\text { Wong } 2016 \\
26874230\end{array}$ & 180 & $\begin{array}{l}55.5 \\
(16.0)\end{array}$ & 49 & 51 & 44 & 56 & 81 & 13 \\
\hline & $\begin{array}{l}\text { Total (overall) } \\
\text { Wear prosthesis (item 1) } \\
\text { Use prosthesis to walk (item 2) } \\
\text { Flat surface walking stability (item } \\
4 \text { a) } \\
\text { Slope walking stability (item 4b) } \\
\text { Rough ground stability (item 4c) } \\
\text { Walking stability (item } 4 \text { total) } \\
\text { Items 1-3 }\end{array}$ & $\begin{array}{l}\text { Devlin } 2004 \\
15295762 \text { - Sample } \\
2\end{array}$ & 76 & $\begin{array}{l}65.5 \\
(13.6)\end{array}$ & 82 & nd & 11 & 59 & 36 & 61 \\
\hline \multirow[t]{3}{*}{ L Test } & & $\begin{array}{l}\text { Major } 2013 \\
23856150\end{array}$ & 30 & $54(12)$ & 23 & 47 & 50 & 53 & 90 & 10 \\
\hline & & $\begin{array}{l}\text { Rushton } 2015 \\
25134533\end{array}$ & 33 & $\begin{array}{l}60.0 \\
(13.0)\end{array}$ & 58 & nd & 18 & 82 & 100 & 0 \\
\hline & & $\begin{array}{l}\text { Deathe } 2005 \\
15982169\end{array}$ & 93 & $\begin{array}{l}55.9 \\
(14.2)\end{array}$ & 40 & 60 & 26 & 74 & 100 & 0 \\
\hline
\end{tabular}

Abbreviations: Bi = bilateral amputation, Dysvasc = dysvascular disease (including diabetes), L Test = L Test of Functional Mobility, nd = no data/not reported, PMID = PubMed identifier (or journal), TF = transfemoral (above the knee) amputation, TT = transtibial (below the knee) amputation, Uni = unilateral amputation.

Note: Shading included only to more clearly distinguish separate instruments. Empty cells under Item/Subscale indicate that there are no instrument items or subscales or they were not evaluated.

*Mean or median with standard deviation in parentheses and range in square brackets. 
+Percentages of study participants with other amputation etiologies, amputation levels, and unreported etiologies, levels, or unilateral versus bilateral amputation are omitted from this summary table. See Appendix C for further details. Transfemoral and transtibial data may sum to more than $100 \%$ because of double counting of participants with bilateral amputations.

Table 16. Summary of instrument psychometric validity properties: Houghton Scale through L Test

\begin{tabular}{|c|c|c|c|c|c|c|c|c|}
\hline Instrument & Item/Subscale & Study, PMID & $\mathrm{MC}^{*}$ & $\begin{array}{l}\text { Convergent Validity } \\
\text { (Concurrent) }\end{array}$ & $\begin{array}{l}\text { Divergent } \\
\text { Validity } \\
\text { (Discriminant) }\end{array}$ & $\begin{array}{l}\text { Construct } \\
\text { Validity }\end{array}$ & $\begin{array}{l}\text { Structural } \\
\text { Validity }\end{array}$ & $\begin{array}{l}\text { Predictive Validity } \\
\dagger\end{array}$ \\
\hline \multirow[t]{8}{*}{ Houghton } & & $\begin{array}{l}\text { Brooks } 2001 \\
11588757\end{array}$ & Yes & & & & & \\
\hline & & $\begin{array}{l}\text { Devlin } 2004 \\
15295762 \text { - } \\
\text { Sample } 1\end{array}$ & Yes & & & & & \\
\hline & & $\begin{array}{l}\text { Devlin } 2004 \\
\text { 15295762 - } \\
\text { Sample } 2\end{array}$ & Yes & $\begin{array}{l}\text { Yes (SF-36 PCS, } \\
\text { 2MWT) }\end{array}$ & $\begin{array}{l}\text { Mixed (TT vs. TF) } \\
\ddagger, \text { No (uni vs. bi, } \\
\text { age) }\end{array}$ & & & \\
\hline & & $\begin{array}{l}\text { Gremeaux } \\
2012 \\
22389424\end{array}$ & Yes & & & & & \\
\hline & & $\begin{array}{l}\text { Miller } 2001 \\
11588750 \\
\text { (sample 1) }\end{array}$ & Yes & $\begin{array}{l}\text { Yes (2MWT, TUG, } \\
\text { ABC, PPA-LCI, } \\
\text { PEQ-MS) }\end{array}$ & & & & \\
\hline & & $\begin{array}{l}\text { Miller } 2001 \\
11588750 \\
\text { (sample 2) }\end{array}$ & Yes & $\begin{array}{l}\text { Yes (ABC, PPA-LCI, } \\
\text { PEQ-MS) }\end{array}$ & & & & \\
\hline & & $\begin{array}{l}\text { Reid } 2015 \\
25588644\end{array}$ & No & Yes (6MWT) & & & & \\
\hline & & $\begin{array}{l}\text { Wong } 2016 \\
26874230\end{array}$ & No & $\begin{array}{l}\text { Yes (2MWT, PEQ- } \\
\text { MS, ABC, 3-BBS, } \\
2 M W T)\end{array}$ & & & & \\
\hline
\end{tabular}




\begin{tabular}{|c|c|c|c|c|c|c|c|c|}
\hline Instrument & Item/Subscale & Study, PMID & $M C^{*}$ & $\begin{array}{l}\text { Convergent Validity } \\
\text { (Concurrent) }\end{array}$ & $\begin{array}{l}\text { Divergent } \\
\text { Validity } \\
\text { (Discriminant) }\end{array}$ & $\begin{array}{l}\text { Construct } \\
\text { Validity }\end{array}$ & $\begin{array}{l}\text { Structural } \\
\text { Validity }\end{array}$ & $\begin{array}{l}\text { Predictive Validity } \\
\dagger\end{array}$ \\
\hline & $\begin{array}{l}\text { Wear } \\
\text { prosthesis (item 1) } \\
\text { Use prosthesis to walk } \\
\text { (item 2) } \\
\text { Use prosthesis } \\
\text { outdoors (item 3) } \\
\text { Flat surface walking } \\
\text { stability (item 4a) } \\
\text { Slope walking stability } \\
\text { (item 4b) } \\
\text { Rough ground stability } \\
\text { (item 4c) } \\
\text { Walking stability (item } 4 \\
\text { total) }\end{array}$ & $\begin{array}{l}\text { Devlin } 2004 \\
15295762 \text { - } \\
\text { Sample } 2\end{array}$ & Yes & . & & & & \\
\hline & Items 1-3 & & Yes & $\begin{array}{l}\text { Yes (SF-36 PCS, } \\
\text { MCS, } 2 M W T)\end{array}$ & $\begin{array}{l}\text { Mixed (TT vs. TF) } \\
\ddagger, \text { No (uni vs. bi, } \\
\text { age) }\end{array}$ & & & \\
\hline \multirow[t]{3}{*}{ L Test } & & $\begin{array}{l}\text { Major } 2013 \\
23856150\end{array}$ & No & Yes (BBS) & & & & \\
\hline & & $\begin{array}{l}\text { Rushton } 2015 \\
25134533\end{array}$ & Yes & & & & & \\
\hline & & $\begin{array}{l}\text { Deathe } 2005 \\
15982169\end{array}$ & No & $\begin{array}{l}\text { Yes (TUG, 2MWT, } \\
\text { 10MWT, ABC, FAI, } \\
\text { PEQ-MS) }\end{array}$ & $\begin{array}{l}\text { Yes (amputation } \\
\text { level, amputation } \\
\text { cause, walking aid } \\
\text { use, autowalk, } \\
\text { age) }\end{array}$ & & & \\
\hline
\end{tabular}

Abbreviations: $10 \mathrm{MWT}=10$ meter walk test, $2 \mathrm{MWT}=2$ minute walk test, $6 \mathrm{MWT}=6$ minute walk test, $\mathrm{ABC}=$ Activities-specific Balance scale, $\mathrm{BBS}=\mathrm{Berg}$ Balance Scale, $\mathrm{Bi}$

$=$ bilateral amputation, Dysvasc $=$ dysvascular disease (including diabetes), FAI $=$ Frenchay Activities Index, L Test $=\mathrm{L}$ Test of Functional Mobility, MC $=$ Medicare, MCS $=$

Mental Component Score, nd = no data/not reported, PCS = Physical Component Score, PEQ-MS = Prosthesis Evaluation Questionnaire motor score, PMID = PubMed identifier (or journal), PPA-LCI = Prosthetic Profile of the Amputee - Locomotor Capabilities Index, SF-36 = Short Form Health Survey-36, TF = transfemoral (above the knee) amputation, TT $=$ transtibial (below the knee) amputation, TUG = Timed Up and Go, Uni = unilateral amputation.

Note: Shading included only to more clearly distinguish separate instruments. Empty cells under Item/Subscale indicate that there are no instrument items or subscales or they were not evaluated. Empty cells in the validity columns indicate no evidence regarding this construct.

*Whether study was deemed generalizable to the Medicare population based on average age greater than 65 years and/or at least $50 \%$ of participants with dysvascular etiologies for their amputations.

†Studies evaluated for predictive validity were assessed for Key Question 2.

$\ddagger$ Discriminated when assessed at rehabilitation discharge, but not when assessed at 3 month followup. 
Table 17. Summary of instrument psychometric validity properties: Houghton Scale through L Test

\begin{tabular}{|c|c|c|c|c|c|c|c|c|c|}
\hline Instrument & Item/Subscale & Study, PMID & $\mathrm{MC}^{*}$ & Reliability & MDC & MID & Responsiveness & Floor & Ceiling \\
\hline \multirow[t]{16}{*}{ Houghton } & & $\begin{array}{l}\text { Brooks } 2001 \\
11588757\end{array}$ & Yes & & & & & & \\
\hline & & $\begin{array}{l}\text { Devlin } 2004 \\
15295762 \text { - Sample } \\
1\end{array}$ & Yes & Yes & & & & & \\
\hline & Total (Overall) & \multirow{8}{*}{$\begin{array}{l}\text { Devlin } 2004 \\
15295762 \text { Sample } 2\end{array}$} & Yes & Yes & & & Yes $(E S=0.60)$ & $0 / 1.3 \% \dagger$ & 1.3/1.3† \\
\hline & $\begin{array}{l}\text { Wear prosthesis (item } \\
\text { 1) }\end{array}$ & & Yes & & & & & $3.9 / 12 \% \dagger$ & $28 / 57 \% \dagger$ \\
\hline & $\begin{array}{l}\text { Use prosthesis to walk } \\
\text { (item 2) }\end{array}$ & & Yes & & & & & $2.6 / 2.6 \% \dagger$ & $22 / 78 \% \dagger$ \\
\hline & $\begin{array}{l}\text { Use prosthesis outdoors } \\
\text { (item 3) }\end{array}$ & & Yes & & & & & 29/18\%† & $1.3 / 6.6 \% \dagger$ \\
\hline & $\begin{array}{l}\text { Flat surface walking } \\
\text { stability (item 4a) }\end{array}$ & & Yes & & & & & 0/14.6\%† & 91/85\%† \\
\hline & $\begin{array}{l}\text { Slope walking stability } \\
\text { (item 4b) }\end{array}$ & & Yes & & & & & $47 / 62 \% \dagger$ & $53 / 38 \% \dagger$ \\
\hline & $\begin{array}{l}\text { Rough ground stability } \\
\text { (item 4c) }\end{array}$ & & Yes & & & & & $67 / 64 \% \dagger$ & 33/36\%† \\
\hline & $\begin{array}{l}\text { Walking stability (item } 4 \\
\text { total) }\end{array}$ & & Yes & & & & & 9.2/10.5\%† & $29 / 24 \% \dagger$ \\
\hline & \multirow[t]{6}{*}{ Items 1-3 } & $\begin{array}{l}\text { Devlin } 2004 \\
15295762 \text { Sample } 2\end{array}$ & Yes & Yes & & & & $0 / 2.6 \% \dagger$ & $1.3 / 3.9 \% \dagger$ \\
\hline & & $\begin{array}{l}\text { Gremeaux } 2012 \\
22389424\end{array}$ & Yes & & & & & $0 \%$ & $23 \%$ \\
\hline & & $\begin{array}{l}\text { Miller } 2001 \\
11588750 \text { (sample 1) }\end{array}$ & Yes & & & & & $0 \%$ & $12.9 \%$ \\
\hline & & $\begin{array}{l}\text { Miller } 2001 \\
11588750 \text { (sample 2) }\end{array}$ & Yes & & & & & $0.3 \%$ & $6.0 \%$ \\
\hline & & Reid 201525588644 & No & & & & & & \\
\hline & & $\begin{array}{l}\text { Wong } 2016 \\
26874230\end{array}$ & No & & & & & & \\
\hline \multirow[t]{3}{*}{ L Test } & & $\begin{array}{l}\text { Major } 2013 \\
23856150\end{array}$ & No & & & & & & \\
\hline & & $\begin{array}{l}\text { Rushton } 2015 \\
25134533\end{array}$ & Yes & & & & No (GRC) & & \\
\hline & & $\begin{array}{l}\text { Deathe } 2005 \\
15982169\end{array}$ & No & Yes & $6.2 \mathrm{sec}$ & $\begin{array}{l}4.5 \\
\text { sec }\end{array}$ & & & \\
\hline
\end{tabular}


Abbreviations: $\mathrm{ES}=$ effect size, GRC = Global Rating of Change score, L Test $=$ L Test of Functional Mobility, MC $=$ Medicare, MDC = minimal detectable change, MID = minimum (clinical) important difference, nd = no data/not reported, PMID = PubMed identifier (or journal), PMID = PubMed identifier (or journal), sec $=$ seconds.

Note: Shading included only to more clearly distinguish separate instruments. Empty cells under Item/Subscale indicate that there are no instrument items or subscales or they were not evaluated. Empty cells in the validity columns indicate no evidence regarding this construct.

*Whether study was deemed generalizable to the Medicare population based on average age greater than 65 years and/or at least $50 \%$ of participants with dysvascular etiologies for their amputations.

†Floor or ceiling effects at rehabilitation discharge/at 3 month followup.

\section{LCI}

The Locomotor Capabilities Index assesses an individual's perceived independence in performing 14 activities while wearing a prosthesis. The entire LCI may be summed to provide a single score or two 7-item subscales: basic and advanced capabilities. The original version used a 4-point ordinal scale; hence it is often called the LCI-4. The LCI-5 was designed to reduce potential ceiling effects of the LCI, by adding a fifth level to the response scale. The LCI10-4 is a 10-item scale which combined two of the response levels from LCI-5, as described below. Eleven studies, in 10 articles, 7, 36, 43, 48, 51, 54-58 evaluated the variations of LCI in 1182 people, total, with lower limb amputations (see Tables 18 to 20). Eight of the studies, in seven articles, ${ }^{43}$, 48, 51, 54-56, 58 evaluated the original LCI-4 as an overall (total) score in 933 people. Two of these studies $^{48,55}$ evaluated the basic subscale in 157 people. Three studies ${ }^{7,48,55}$ evaluated the advanced subscale in 197 people. Three studies ${ }^{36,48,57}$ evaluated LCI-5 in 259 people. One study $^{57}$ created and evaluated LCI10-4 in 123 people. Across these 11 studies, six were deemed generalizable to the Medicare population based on average age (65 and 68 years) and/or relatively high percentage of people with dysvascular conditions (53\% to 83\%). These studies all evaluated LCI-4. Evaluations of the basic subscale, LCI-5, and LCI10-4 have not been conducted in studies generalizable to the Medicare population.

\section{LCl-4 and Subscales}

The original LCI-4 has been reported to have convergent validity with various other instruments, including SIP-PD, PFI, the Rising and Sitting Down Questionnaire, RMI, FIM, the Reintegration to Normal Living Index daily activity subscale, 2MWT, TUG, ABC (and LCI-5). Two of three studies reported that LCI-4 discriminated people based on their amputation level, amputation etiology, use of mobility device, walking distance, and automatic walking, but the third study found that it did not discriminate based on amputation level, injury severity, age, or comorbidities. One study also found that LCI-4 correlated with walking speed but not return to usual activity. One study that was not generalizable to the Medicare Population reported that LCI-4 as in initial assessment at start of rehabilitation had predictive validity by correlation with TWT, RMI, and FIM at discharge from rehabilitation. LCI-4 was also reported to have reliability, responsiveness, but floor (54\%) and ceiling effects (up to 70\%) when measured at some time points (e.g., after rehabilitation).

The basic capabilities subscale of LCI-4, in studies not generalizable to the Medicare population, was reported to discriminate by amputation level in one study, but another found that it did not discriminate based on amputation level, injury severity, age, or comorbidities. One study also found that the basic subscale correlated with walking speed but not return to usual activity. The subscale was reported to have reliability, but a high floor effect (90\%) in one study.

The advanced capabilities subscale of LCI-4 was reported to discriminate by amputation level in one study, but another found that it did not discriminate based on amputation level, 
injury severity, age, or comorbidities. One study also found that the basic subscale correlated with walking speed but not return to usual activity. These two studies were not generalizable to the Medicare population. A third study, generalizable to the Medicare population reported predictive validity with low sensitivity (43\%) but high specificity (91\%) for two or more falls at 6 months after testing; overall the accuracy was reported to be statistically significant $(\mathrm{P}<0.01)$. One study reported reliability but a high floor effect (54\%).

\section{LCl-5}

In studies not generalizable to the Medicare population, LCI-5 was reported to have convergent validity with several other instruments, including RMI, FIM, PEQ-MS, PPA, the 6MWT (and LCI-4). One study reported that LCI-5 administered in the initial assessment at start of rehabilitation had predictive validity by correlation with TWT, RMI, and FIM at discharge from rehabilitation. This study also reported reliability, responsiveness, but a high ceiling effect at the end of rehabilitation (22\%). One study conducted a Rasch analysis of LCI-5 and concluded that it lacked structural validity with four of the 14 items having poor fit.

\section{LCI10-4}

Based on the above-mentioned Rasch analysis, four items were dropped from the instrument and two of the intermediate response options ("yes, if someone helps me" and "yes, if someone is near me"). The study, which was not generalizable to the Medicare population, reported there were similar statistically significant correlations with PEQ-MS and PPA as LCI-5 and reliability, but was better fitting by Rasch analysis.

\section{Overall}

Overall, for the various versions and subscales of LCI, there is evidence of test validity and reliability for each version, but with floor and ceiling effects, depending when the instrument was used (in relation to rehabilitation). These conclusions are generalizable to the Medicare population only for LCI-4. LCI-4 and LCI-5 were reported to also have predictive validity at 6 months, in a study not generalizable to the Medicare population. The advanced capabilities subscale was reported to have low sensitivity, but high specificity, for falls at 6 months in a study generalizable to the Medicare population. 
Table 18. Study descriptive data: LCI

\begin{tabular}{|c|c|c|c|c|c|c|c|c|c|c|}
\hline Instrument & Item/Subscale & Study, PMID & $\mathbf{N}$ & Age* $^{*}$ & $\begin{array}{l}\text { Dysvasc } \dagger \text {, } \\
\%\end{array}$ & $\begin{array}{l}\text { Trauma†, } \\
\%\end{array}$ & $\begin{array}{l}\text { TF†, } \\
\%\end{array}$ & $\begin{array}{l}\begin{array}{l}\text { TT†, } \\
\%\end{array} \\
\end{array}$ & $\begin{array}{l}\text { Uni†, } \\
\%\end{array}$ & $\begin{array}{l}\text { Bi†, } \\
\%\end{array}$ \\
\hline \multirow[t]{11}{*}{$\mathrm{LCl}$} & $\mathrm{LCl}-4$ & Callaghan 200212227445 & 133 & $\begin{array}{l}67.8(16.1)[16- \\
101]\end{array}$ & 83 & 11 & 0 & 100 & 100 & 0 \\
\hline & $\begin{array}{l}\text { LCl-4 (total) } \\
\text { Basic } \\
\text { Advanced }\end{array}$ & Cyril 2001 (Johns Hopkins) & 107 & $35(12.5)$ & 0 & 100 & 21 & 67 & 100 & 0 \\
\hline & $\mathrm{LCl}-4$ & de Laat 201121807151 & 164 & 65 (11) [37-92] & 83 & 8 & 33 & 57 & 97 & 7 \\
\hline & Advanced & Dite 200717207685 & 40 & $61.7(\mathrm{nd})$ & 65 & nd & 0 & 100 & 100 & 0 \\
\hline & $\begin{array}{l}\text { LCl-4 (total) } \\
\text { Basic } \\
\text { Advanced } \\
\text { LCl-5 }\end{array}$ & Franchignoni 200415129398 & 50 & $51[21-86]$ & 32 & 58 & 60 & 40 & 100 & 0 \\
\hline & $\begin{array}{l}\text { LCl-5 } \\
\text { LCl10-4 }\end{array}$ & Franchignoni 200718050010 & 123 & 54 [IQR 36-65] & 35 & 56 & 64 & 41 & 89 & 11 \\
\hline & $\mathrm{LCl}-4$ & $\begin{array}{l}\text { Gauthier-Gagnon } 1994 \\
7993169\end{array}$ & 70 & $60.6(16.8)$ & 70 & 23 & 50 & 50 & 100 & 0 \\
\hline & $\mathrm{LCl}-4$ & $\begin{array}{l}\text { Miller } 200111588750 \\
\text { (sample 1) }\end{array}$ & 60 & $58.4(15.5)$ & 53 & nd & 28 & 72 & 100 & 0 \\
\hline & $\mathrm{LCl}-4$ & $\begin{array}{l}\text { Miller } 200111588750 \\
\text { (sample 2) }\end{array}$ & 329 & $59.9(16.7)$ & 53 & nd & 26 & 74 & 100 & 0 \\
\hline & $\mathrm{LCl}-5$ & Reid 201525588644 & 86 & $60(15.3)$ & 35 & 48 & 15 & 73 & 97 & 3 \\
\hline & $\mathrm{LCl}-4$ & Theeven 201020809056 & 20 & $50.3(10.7)$ & 30 & 60 & 100 & 0 & nd & nd \\
\hline
\end{tabular}

Abbreviations: $\mathrm{Bi}$ = bilateral amputation, Dysvasc = dysvascular disease (including diabetes), IQR = interquartile range, LCI = Locomotor Capabilities Index, nd = no data/not reported, PMID = PubMed identifier (or journal), TF = transfemoral (above the knee) amputation, TT = transtibial (below the knee) amputation, Uni = unilateral amputation.

Note: Shading included only to more clearly distinguish separate instruments. Empty cells under Item/Subscale indicate that there are no instrument items or subscales or they were not evaluated.

*Mean or median with standard deviation in parentheses and range in square brackets.

$\dagger$ Percentages of study participants with other amputation etiologies, amputation levels, and unreported etiologies, levels, or unilateral versus bilateral amputation are omitted from this summary table. See Appendix C for further details. Transfemoral and transtibial data may sum to more than $100 \%$ because of double counting of participants with bilateral amputations. 
Table 19. Summary of instrument psychometric validity properties: LCI

\begin{tabular}{|c|c|c|c|c|c|c|c|c|}
\hline Instrument & Item/Subscale & Study, PMID & MC* & $\begin{array}{l}\text { Convergent Validity } \\
\text { (Concurrent) }\end{array}$ & $\begin{array}{l}\text { Divergent Validity } \\
\text { (Discriminant) }\end{array}$ & $\begin{array}{l}\text { Construct } \\
\text { Validity }\end{array}$ & $\begin{array}{l}\text { Structural } \\
\text { Validity }\end{array}$ & $\begin{array}{l}\text { Predictive } \\
\text { Validity } \dagger \\
\end{array}$ \\
\hline \multirow[t]{10}{*}{$\mathrm{LCl}$} & \multirow[t]{8}{*}{$\mathrm{LCl}-4$} & $\begin{array}{l}\text { Callaghan } \\
2002 \\
12227445\end{array}$ & Yes & & & & & \\
\hline & & $\begin{array}{l}\text { Cyril } 2001 \\
\text { (Johns } \\
\text { Hopkins) }\end{array}$ & No & $\begin{array}{l}\text { Moderate (SIP-PD, } \\
\text { PFI) }\end{array}$ & $\begin{array}{l}\text { No (amputation level, injury } \\
\text { severity score, age, } \\
\text { comorbidities) }\end{array}$ & $\begin{array}{l}\text { Yes } \\
\text { (walking } \\
\text { speed), } \\
\text { No (return } \\
\text { to usual } \\
\text { activity) }\end{array}$ & & \\
\hline & & $\begin{array}{l}\text { de Laat } 2011 \\
21807151\end{array}$ & Yes & $\begin{array}{l}\text { Yes (Rising and } \\
\text { Sitting Down } \\
\text { Questionnaire) }\end{array}$ & & & & \\
\hline & & $\begin{array}{l}\text { Franchignoni } \\
2004 \\
15129398\end{array}$ & No & $\begin{array}{l}\text { Yes (LCl-5, RMI, } \\
\text { FIM) }\end{array}$ & Yes (TT vs. TF) & & & $\begin{array}{l}\text { Yes (TWT, } \\
\text { RMI, FIM at } \\
\text { rehab } \\
\text { discharge) }\end{array}$ \\
\hline & & $\begin{array}{l}\text { Gauthier- } \\
\text { Gagnon } 1994 \\
7993169\end{array}$ & Yes & $\begin{array}{l}\text { Yes (RNL daily } \\
\text { activity), No (RNL } \\
\text { perception of self) }\end{array}$ & & & & \\
\hline & & $\begin{array}{l}\text { Miller } 2001 \\
11588750 \\
\text { (sample 1) }\end{array}$ & Yes & $\begin{array}{l}\text { Yes (2MWT, TUG, } \\
\text { ABC) }\end{array}$ & & & & \\
\hline & & $\begin{array}{l}\text { Miller } 2001 \\
11588750 \\
\text { (sample 2) }\end{array}$ & Yes & Yes (ABC) & $\begin{array}{l}\text { Yes (TT vs. TF, amputation } \\
\text { etiology, use of mobility } \\
\text { device, walking distance, } \\
\text { automatic walking) }\end{array}$ & & & \\
\hline & & $\begin{array}{l}\text { Theeven } \\
2010 \\
20809056\end{array}$ & No & & & & & \\
\hline & \multirow[t]{2}{*}{ Basic } & $\begin{array}{l}\text { Cyril } 2001 \\
\text { (Johns } \\
\text { Hopkins) }\end{array}$ & No & & $\begin{array}{l}\text { No (amputation level, injury } \\
\text { severity score, age, } \\
\text { comorbidities) }\end{array}$ & $\begin{array}{l}\text { Yes } \\
\text { (walking } \\
\text { speed), } \\
\text { No (return } \\
\text { to usual } \\
\text { activity) }\end{array}$ & & \\
\hline & & $\begin{array}{l}\text { Franchignoni } \\
2004 \\
15129398\end{array}$ & No & & Yes (TT vs. TF) & & & \\
\hline
\end{tabular}




\begin{tabular}{|c|c|c|c|c|c|c|c|c|}
\hline Instrument & Item/Subscale & Study, PMID & MC* & $\begin{array}{l}\text { Convergent Validity } \\
\text { (Concurrent) }\end{array}$ & $\begin{array}{l}\text { Divergent Validity } \\
\text { (Discriminant) }\end{array}$ & $\begin{array}{l}\text { Construct } \\
\text { Validity }\end{array}$ & $\begin{array}{l}\text { Structural } \\
\text { Validity }\end{array}$ & $\begin{array}{l}\text { Predictive } \\
\text { Validity } \dagger\end{array}$ \\
\hline & \multirow[t]{3}{*}{ Advanced } & $\begin{array}{l}\text { Cyril 2001 } \\
\text { (Johns } \\
\text { Hopkins) }\end{array}$ & No & & $\begin{array}{l}\text { No (amputation level, injury } \\
\text { severity score, age, } \\
\text { comorbidities) }\end{array}$ & $\begin{array}{l}\text { Yes } \\
\text { (walking } \\
\text { speed), } \\
\text { No (return } \\
\text { to usual } \\
\text { activity) }\end{array}$ & & \\
\hline & & $\begin{array}{l}\text { Dite } 2007 \\
17207685\end{array}$ & Yes & & & & & $\begin{array}{l}\text { Mixed (Sn } \\
43 \%, \mathrm{Sp} 91 \% \\
\text { for falls at } 6 \\
\text { mo) }\end{array}$ \\
\hline & & $\begin{array}{l}\text { Franchignoni } \\
2004 \\
15129398\end{array}$ & No & & Yes (TT vs. TF) & & & \\
\hline & \multirow[t]{3}{*}{$\mathrm{LCl}-5$} & $\begin{array}{l}\text { Franchignoni } \\
2004 \\
15129398\end{array}$ & No & $\begin{array}{l}\text { Yes (LCl-4, RMI, } \\
\text { FIM) }\end{array}$ & & & & $\begin{array}{l}\text { Yes (TWT, } \\
\text { RMI, FIM at } \\
\text { rehab } \\
\text { discharge) }\end{array}$ \\
\hline & & $\begin{array}{l}\text { Franchignoni } \\
2007 \\
18050010\end{array}$ & No & Yes (PEQ-MS, PPA) & & & $\begin{array}{l}\text { Rasch: Lacks } \\
\text { structural } \\
\text { validity, } 4 / 14 \\
\text { items with poor } \\
\text { fit }\end{array}$ & \\
\hline & & $\begin{array}{l}\text { Reid } 2015 \\
25588644\end{array}$ & No & Yes (6MWT) & & & . & \\
\hline & $\mathrm{LCl} 10-4$ & $\begin{array}{l}\text { Franchignoni } \\
2007 \\
18050010\end{array}$ & No & $\begin{array}{l}\text { Similar significant } \\
\text { correlations as LCl-5 }\end{array}$ & & & Rasch: good fit & \\
\hline
\end{tabular}

Evaluation Questionnaire - Mobility Subscale, PFI = Physical Function Index, PMID = PubMed identifier (or journal), PPA = Prosthetic Profile of the Amputee, RMI =

Rivermead Mobility Index, RNL = Reintegration to Normal Living Index, SIP-PD = Sickness Impact Profile-Physical Dimension, Sn = sensitivity, Sp = specificity, TF = transfemoral (above the knee) amputation, TT = transtibial (below the knee) amputation, TWT $=$ Timed Walk Test.

Note: Shading included only to more clearly distinguish separate instruments. Empty cells under Item/Subscale indicate that there are no instrument items or subscales or they were not evaluated. Empty cells in the validity columns indicate no evidence regarding this construct.

*Whether study was deemed generalizable to the Medicare population based on average age greater than 65 years and/or at least $50 \%$ of participants with dysvascular etiologies for their amputations.

†Studies evaluated for predictive validity were assessed for Key Question 2. 
Table 20. Summary of other instrument psychometric properties: $\mathrm{LCl}$

\begin{tabular}{|c|c|c|c|c|c|c|c|c|c|}
\hline Instrument & Item/Subscale & Study, PMID & MC* & Reliability & MDC & MID & Responsiveness & Floor & Ceiling \\
\hline \multirow[t]{17}{*}{$\mathrm{LCl}$} & \multirow[t]{8}{*}{$\mathrm{LCl}-4$} & Callaghan 200212227445 & Yes & Yes & & & & & \\
\hline & & Cyril 2001 (Johns Hopkins) & No & & & & & $54.2 \%$ & $0 \%$ \\
\hline & & de Laat 201121807151 & Yes & & & & & & \\
\hline & & $\begin{array}{l}\text { Franchignoni } 2004 \\
15129398\end{array}$ & No & Yes & & & Yes $(E S=1.09)$ & & $\begin{array}{l}2 \% \text { at beginning; } 46 \% \text { at end of } \\
\text { program }\end{array}$ \\
\hline & & $\begin{array}{l}\text { Gauthier-Gagnon } 1994 \\
7993169\end{array}$ & Yes & Yes & & & . & & \\
\hline & & $\begin{array}{l}\text { Miller } 200111588750 \\
\text { (sample 1) }\end{array}$ & Yes & Yes & & & . & $1.7 \%$ & $36.7 \%$ \\
\hline & & $\begin{array}{l}\text { Miller } 200111588750 \\
\text { (sample 2) }\end{array}$ & Yes & & & & . & $0.3 \%$ & $40.4 \%$ \\
\hline & & Theeven 201020809056 & No & & & & . & & $70 \%$ \\
\hline & \multirow[t]{2}{*}{ Basic } & Cyril 2001 (Johns Hopkins) & No & Yes & & & . & $89.7 \%$ & $1.0 \%$ \\
\hline & & $\begin{array}{l}\text { Franchignoni } 2004 \\
15129398\end{array}$ & No & & & & . & & \\
\hline & \multirow[t]{3}{*}{ Advanced } & Cyril 2001 (Johns Hopkins) & No & Yes & & & . & $54.2 \%$ & $1.0 \%$ \\
\hline & & Dite 200717207685 & Yes & & & & . & & \\
\hline & & $\begin{array}{l}\text { Franchignoni } 2004 \\
15129398\end{array}$ & No & & & & . & & \\
\hline & \multirow[t]{3}{*}{$\mathrm{LCl}-5$} & $\begin{array}{l}\text { Franchignoni } 2004 \\
15129398\end{array}$ & No & Yes & & & Yes $(E S=1.40)$ & & $22 \%$ at end of program \\
\hline & & $\begin{array}{l}\text { Franchignoni } 2007 \\
18050010\end{array}$ & No & & & & . & $0 \%$ & $5 \%$ \\
\hline & & Reid 201525588644 & No & & & & . & & \\
\hline & LCl 10-4 & $\begin{array}{l}\text { Franchignoni } 2007 \\
18050010\end{array}$ & No & Yes & & & . & & \\
\hline
\end{tabular}

Abbreviations: ES = effect size, LCI = Locomotor Capabilities Index, MC = Medicare, MDC = minimal detectable change, MID = minimum (clinical) important difference, PMID $=$ PubMed identifier (or journal).

Note: Shading included only to more clearly distinguish separate instruments. Empty cells under Item/Subscale indicate that there are no instrument items or subscales or they were not evaluated. Empty cells in the psychometric properties columns indicate no evidence regarding this construct.

*Whether study was deemed generalizable to the Medicare population based on average age greater than 65 years and/or at least $50 \%$ of participants with dysvascular etiologies for their amputations. 


\section{LEMOCOT}

The Lower-Extremity Motor Coordination Test measures unaffected lower limb motor coordination from a seated position. One study ${ }^{30}$ evaluated the psychometric properties of LEMOCOT in 82 people with lower limb amputations (see Tables 21 to 23). The study was deemed to be generalizable to the Medicare population based on the high percentage of study participants with dysvascular disease (63\%); although the average age was under 65 years old.

The study reported predictive validity with correlations with of the initial assessment scores with 2MWT, TUG, and K levels at the end of rehabilitation.

Overall, for LEMOCOT there is evidence of predictive validity from a study generalizable to the Medicare population.

\section{NQ-ACGC}

The Quality of Life in Neurological Conditions - Applied Cognition/General Concerns is a short form of a larger item bank that measures general cognitive abilities, including memory, attention, and decision making. One study ${ }^{41}$ evaluated the psychometric properties of NQ-ACGC in 201 people with lower limb amputations (see Tables 21 to 23). The study was not deemed to be generalizable to the Medicare population due to their relatively low average ages (60 years) and low percentage of study participants with dysvascular conditions (23\%).

The study found evidence of good reliability. The study reported MDC(90) to be 6.67 and MDC(95) to be 7.94. Ceiling effects were observed at 17\%; no floor effects were observed. The study did not report on test validity.

Overall, for NQ-ACGC, there is evidence of test reliability, but with a ceiling effect in a study not generalizable to the Medicare population.

\section{OPCS}

The Office of Population Censuses and Surveys Scale assesses disability and impairment in the community. One study ${ }^{39}$ evaluated the psychometric properties of SIP-PD in 34 people with lower limb amputations (see Tables 21 to 23). The study was deemed to be generalizable to the Medicare population based on average age (66 years) and that all study participants had dysvascular disease.

The study provided evidence that OPCS administered at initial assessment had predictive validity in that it correlated with duration of stay in a postoperative rehabilitation unit.

Overall, for OPCS, there is evidence of test validity from a study generalizable to the Medicare population.

\section{OPUS}

The Orthotics Prosthetics Users Survey is a self-report survey that contains separate subscales measuring lower limb function, health-related quality of life, and satisfaction with an orthotic or prosthetic device specifically for individuals who use orthotic or prosthetic devices. The OPUS also contains a subscale relevant only to users of upper extremity prostheses/orthoses, which is not summarized here. One study ${ }^{37}$ evaluated the psychometric properties of the three lower limb relevant OPUS subscales in 44 people with lower limb amputations (see Tables 21 to 23). The study was deemed to be generalizable to the Medicare population based on the average 
age of participants (66 years); although the number of people with dysvascular conditions was not reported.

The study provided evidence of reliability for all three subscales, and the study reported the MDC(90) to range from 9.2 to 15.7. No floor effects or ceiling effects were observed for any of the subscales. The study did not assess test validity, per se.

Overall, for OPUS, there is evidence of test reliability without a floor or ceiling effect in a study generalizable to the Medicare population.

\section{Patient Activity Monitor}

The Patient Activity Monitor is a small walking activity monitor that was designed for the evaluation of lower limb amputee gait patterns. One study ${ }^{59}$ evaluated the psychometric properties of the Patient Activity Monitor in 22 people with lower limb amputations (see Tables 21 to 23). The study was not deemed to be generalizable to the Medicare population; the average age of participants was 50 years old, and the study did not report the number of participants with dysvascular etiologies for their amputations.

The study provided evidence of convergent validity for the measures of walking velocity and step length when compared to the Qualisys motion analysis system for fast, medium, and slow walk; the study also provided evidence of convergent validity for walking velocity and manual count of steps. Regarding reliability, the Patient Activity Monitor on average underestimated the step count by 11 (standard deviation [SD] 16) steps, with a wide Bland-Altman limits of agreement. Measures of walking velocity were reliable. For step length, average estimates were accurate, but the Patient Activity Monitor recorded lower values that Qualisys with shorter step lengths and higher values with longer step lengths.

Overall, for the Patient Activity Monitor, from a study not generalizable to the Medicare population, there is evidence of test validity and good reliability for walking velocity, but not step count or step length. 
Table 21. Study descriptive data: LEMOCOT through Patient Activity Monitor

\begin{tabular}{|c|c|c|c|c|c|c|c|c|c|c|}
\hline Instrument & Item/Subscale & Study, PMID & $\mathbf{N}$ & Age* & $\begin{array}{l}\text { Dysvasc } \dagger \text {, } \\
\%\end{array}$ & $\begin{array}{l}\text { Trauma } \dagger, \\
\%\end{array}$ & $\begin{array}{l}\text { TF†, } \\
\%\end{array}$ & $\begin{array}{l}\begin{array}{l}\text { TT†, } \\
\%\end{array} \\
\end{array}$ & $\begin{array}{l}\text { Uni†, } \\
\%\end{array}$ & $\begin{array}{l}\mathrm{Bi \dagger}, \\
\%\end{array}$ \\
\hline LEMOCOT & & Spaan 201727770064 & 82 & $\begin{array}{l}59.2 \\
(13.3)\end{array}$ & 63 & nd & nd & 55 & 100 & nd \\
\hline NQ-ACGC & & Hafner 201628273329 & 201 & $\begin{array}{l}60.2 \\
(11.4)\end{array}$ & 23 & 60 & 35 & 65 & nd & nd \\
\hline OPCS & & Panesar 200111330761 & 34 & $67[44-85]$ & 100 & 0 & 53 & 44 & 94 & 6 \\
\hline OPUS & $\begin{array}{l}\text { Quality of life } \\
\text { Lower limb } \\
\text { function } \\
\text { Satisfaction }\end{array}$ & Resnik 201121310896 & 44 & $66(13)$ & nd & nd & 52 & 43 & 100 & 0 \\
\hline $\begin{array}{l}\text { Patient Activity } \\
\text { Monitor }\end{array}$ & $\begin{array}{l}\text { Step count } \\
\text { Walking velocity } \\
\text { Step length }\end{array}$ & $\begin{array}{l}\text { Ramstrand } 2007 \\
17520493\end{array}$ & 22 & $50(\mathrm{nd})$ & nd & nd & 55 & 45 & nd & nd \\
\hline
\end{tabular}

Abbreviations: Bi = bilateral amputation, Dysvasc = dysvascular disease (including diabetes), LEMOCOT = Lower-Extremity Motor Coordination Test, nd = no data/not reported, NQ-ACGC = Quality of Life in Neurological Conditions - Applied Cognition/General Concerns, OPCS = Office of Population Censuses and Surveys Scale, OPUS = Orthotics Prosthetics Users Survey, PMID = PubMed identifier (or journal), TF = transfemoral (above the knee) amputation, TT = transtibial (below the knee) amputation, Uni = unilateral amputation.

Note: Shading included only to more clearly distinguish separate instruments. Empty cells under Item/Subscale indicate that there are no instrument items or subscales or they were not evaluated.

*Mean or median with standard deviation in parentheses and range in square brackets.

†Percentages of study participants with other amputation etiologies, amputation levels, and unreported etiologies, levels, or unilateral versus bilateral amputation are omitted from this summary table. See Appendix C for further details. Transfemoral and transtibial data may sum to more than $100 \%$ because of double counting of participants with bilateral amputations. 
Table 22. Summary of instrument psychometric validity properties: LEMOCOT through Patient Activity Monitor

\begin{tabular}{|c|c|c|c|c|c|c|c|c|}
\hline Instrument & Item/Subscale & Study, PMID & $M C^{*}$ & $\begin{array}{l}\text { Convergent Validity } \\
\text { (Concurrent) }\end{array}$ & $\begin{array}{l}\text { Divergent } \\
\text { Validity } \\
\text { (Discriminant) } \\
\end{array}$ & $\begin{array}{l}\text { Construct } \\
\text { Validity }\end{array}$ & $\begin{array}{l}\text { Structural } \\
\text { Validity }\end{array}$ & $\begin{array}{l}\text { Predictive } \\
\text { Validity } \dagger\end{array}$ \\
\hline LEMOCOT & & $\begin{array}{l}\text { Spaan } 2017 \\
27770064\end{array}$ & Yes & & & & & $\begin{array}{l}\text { Prefitting test Yes } \\
(2 \mathrm{MWT}, \mathrm{TUG}, \mathrm{K} \\
\text { level at end of } \\
\text { rehab) }\end{array}$ \\
\hline NQ-ACGC & & $\begin{array}{l}\text { Hafner } 2016 \\
28273329\end{array}$ & No & & & & & \\
\hline OPCS & & $\begin{array}{l}\text { Panesar } \\
2001 \\
11330761 \\
\end{array}$ & Yes & & & & & $\begin{array}{l}\text { Yes (duration of } \\
\text { stay) }\end{array}$ \\
\hline OPUS & $\begin{array}{l}\text { Quality of life } \\
\text { Lower limb } \\
\text { function } \\
\text { Satisfaction }\end{array}$ & $\begin{array}{l}\text { Resnik } 2011 \\
21310896\end{array}$ & Yes & & & & & \\
\hline \multirow[t]{3}{*}{$\begin{array}{l}\text { Patient } \\
\text { Activity } \\
\text { Monitor }\end{array}$} & Step count & \multirow[t]{3}{*}{$\begin{array}{l}\text { Ramstrand } \\
2007 \\
17520493\end{array}$} & No & $\begin{array}{l}\text { Yes (Hand count, Qualisys } \\
\text { motion analysis system) for } \\
\text { fast, medium, slow walk }\end{array}$ & & & & \\
\hline & $\begin{array}{l}\text { Walking } \\
\text { velocity }\end{array}$ & & No & $\begin{array}{l}\text { Yes (Qualisys motion analysis } \\
\text { system) for fast, medium, slow } \\
\text { walk }\end{array}$ & & & & \\
\hline & Step length & & No & $\begin{array}{l}\text { Yes (Qualisys motion analysis } \\
\text { system) for fast, medium walk; } \\
\text { Moderate for, slow walk }\end{array}$ & & & & \\
\hline
\end{tabular}

Abbreviations: 2MWT = 2 minute walk test, K level = Medicare Functional Classification Level, LEMOCOT = Lower-Extremity Motor Coordination Test, MC = Medicare, NQACGC = Quality of Life in Neurological Conditions - Applied Cognition/General Concerns, OPCS = Office of Population Censuses and Surveys Scale, OPUS = Orthotics Prosthetics Users Survey, PMID = PubMed identifier (or journal), TUG = Timed Up and Go.

Note: Shading included only to more clearly distinguish separate instruments. Empty cells under Item/Subscale indicate that there are no instrument items or subscales or they were not evaluated. Empty cells in the validity columns indicate no evidence regarding this construct.

*Whether study was deemed generalizable to the Medicare population based on average age greater than 65 years and/or at least $50 \%$ of participants with dysvascular etiologies for their amputations.

†Studies evaluated for predictive validity were assessed for Key Question 2. 
Table 23. Summary of other instrument psychometric properties: LEMOCOT through Patient Activity Monitor

\begin{tabular}{|c|c|c|c|c|c|c|c|c|c|}
\hline Instrument & Item/Subscale & Study, PMID & MC* & Reliability & MDC & MID & Responsiveness & Floor & Ceiling \\
\hline LEMOCOT & & $\begin{array}{l}\text { Spaan } 2017 \\
27770064\end{array}$ & Yes & & & & & & \\
\hline NQ-ACGC & & $\begin{array}{l}\text { Hafner } 2016 \\
28273329\end{array}$ & No & Yes & $\begin{array}{l}\operatorname{MDC}(90) 6.67 \\
\operatorname{MDC}(95) 7.94\end{array}$ & & & nd & $17 \%$ \\
\hline OPCS & & $\begin{array}{l}\text { Panesar } 2001 \\
11330761\end{array}$ & Yes & & & & & & \\
\hline \multirow[t]{3}{*}{ OPUS } & Quality of life & \multirow[t]{3}{*}{$\begin{array}{l}\text { Resnik } 2011 \\
21310896\end{array}$} & Yes & Yes & MDC(90) 9.2 & & & $\begin{array}{l}\text { No } \\
\text { effect }\end{array}$ & $\begin{array}{l}\text { No } \\
\text { effect }\end{array}$ \\
\hline & $\begin{array}{l}\text { Lower limb } \\
\text { function }\end{array}$ & & Yes & Yes & $\operatorname{MDC}(90) 10.3$ & & & $\begin{array}{l}\text { No } \\
\text { effect }\end{array}$ & $\begin{array}{l}\text { No } \\
\text { effect }\end{array}$ \\
\hline & Satisfaction & & Yes & Yes & MDC(90) 15.7 & & & $\begin{array}{l}\text { No } \\
\text { effect }\end{array}$ & $\begin{array}{l}\text { No } \\
\text { effect }\end{array}$ \\
\hline \multirow[t]{3}{*}{$\begin{array}{l}\text { Patient Activity } \\
\text { Monitor }\end{array}$} & Step count & \multirow[t]{3}{*}{$\begin{array}{l}\text { Ramstrand } 2007 \\
17520493\end{array}$} & No & $\begin{array}{l}\text { No (BA LOA - } 43.1 \text { to } 21.3 \\
\text { steps in } 5 \text { min (vs. } \\
\text { Qualisys) }\end{array}$ & & & & & \\
\hline & Walking velocity & & No & $\begin{array}{l}\text { Yes (BA LOA }-0.11 \text { to } 0.09 \\
\mathrm{~m} / \mathrm{sec} \text { ) }\end{array}$ & & & & & \\
\hline & Step length & & No & $\begin{array}{l}\text { No (BA LOA }-0.07 \text { to } 0.14 \\
\text { m, bias) }\end{array}$ & & & & & \\
\hline
\end{tabular}

Abbreviations: BA LOA = Bland-Altman limits of agreement, LEMOCOT = Lower-Extremity Motor Coordination Test, MC = Medicare, MDC(90) $=$ minimal detectable change (at $90 \%$ confidence), MID = minimum (clinical) important difference, $\mathrm{m}=$ meters, $\min =$ minutes, nd = no data/not reported, NQ-ACGC = Quality of Life in Neurological Conditions - Applied Cognition/General Concerns, OPCS = Office of Population Censuses and Surveys Scale, OPUS = Orthotics Prosthetics Users Survey, PMID = PubMed identifier (or journal), sec $=$ seconds

Note: Shading included only to more clearly distinguish separate instruments. Empty cells under Item/Subscale indicate that there are no instrument items or subscales or they were not evaluated. Empty cells in the psychometric properties columns indicate no evidence regarding this construct.

*Whether study was deemed generalizable to the Medicare population based on average age greater than 65 years and/or at least $50 \%$ of participants with dysvascular etiologies for their amputations. 


\section{PEQ}

The Prosthetic Evaluation Questionnaire measures perceived ability to perform a range of ambulation and transfer tasks with a lower limb prosthesis. Its original version had 82 items organized into 9 validated scales related to prosthesis function (4 scales), mobility (1 scale), psychosocial issues (3 scales), and well-being (1 scale), and individual items. The items each had a $100 \mathrm{~mm}$ visual analog scale (VAS). The scoring was subsequently modified to an 11-category (0 to 10) numeric scale and then, in a further modification, a 7-category (1 to 7) numeric scale. The ambulation scale and individual items related to transfer were combined into a Mobility Subscale (PEQ-MS) with 13 items and 11 categories ("13/11”). A subsequent modification, described below, simplified the PEQ-MS to a 12-item scale each with 5 categories (0 to 4) dubbed PEQ-MS 12/5. A further modification used 8 categories (0 to 7). Overall, nine studies (in eight articles evaluated the variations of PEQ in a total of 1258 people with lower limb amputations. $^{33,37,38,40,41,51,60,61}$ Tables 24 to 26 summarize studies of all versions of PEQ.

\section{PEQ, Original (9 Scales)}

Two studies evaluated the psychometric properties of all scales of the PEQ in 136 people, total, with lower limb amputations. The original study reporting PEQ, which used a $100 \mathrm{~mm}$ VAS was not generalizable to the Medicare population (age and etiology data not reported. ${ }^{60}$ ) An evaluation that used a 7-category (1 to 7) numeric scale was generalizable to the Medicare population (average age 66 years). ${ }^{37}$

For the version with VAS scoring, the study reported convergent validity of the Ambulation subscale with the SF-36 physical function scale, of the Social Burden subscale with both SF-36 social function and SIP social interaction, and of the Well-Being subscale with the Profile of Mood States (POMS-SF) scale. Most of the subscales did not discriminate between people based on amputation level, comorbidities, years since amputation, or age. However, the Residual Limb Health and Frustration subscales discriminated by age and the Ambulation subscale discriminated by comorbidities. Both studies found that all subscales (and the overall scale) had reliability. One study provided MDC(90) estimates for each subscale. Both studies found ceiling effects for Transfers (25\% and 27\%) and one study each (but not the other) found a floor effect for Frustration (22\%, "no effect”) and ceiling effects for Perceived Responses (17\%, "no effect”) and Well-Being (34\% and 8\%).

\section{PEQ-MS 13/11}

Four studies, in three articles, evaluated the psychometric properties of the original version of PEQ-MS with all original 13 items, scored 0 to 10 (11 categories) in 498 people, total. ${ }^{33,51,61}$ Two of the studies were generalizable to the Medicare population based on more than half the sample having dysvascular conditions (53\%); average ages of the studies ranged from 54 to 60 years. Four of the studies reported convergent validity with a variety of other instruments, including LCI, PPA, BBS, 2MWT, TUG, and ABC. One study reported that the PEQ-MS 13/11 had similar but slightly lower correlations with LCI and PPI than the PEQ-MS 12/5 (see below) ${ }^{61}$ This study found a misfit of the bathing item by Rasch analysis. One study found that the PEQ-MS 13/11 discriminated people based on amputation etiology, use of mobility device, walking distance, and automatic walking, but not by amputation level.

Two studies, one generalizable to the Medicare population, reported good reliability of the instrument and no floor or ceiling effects were found in three studies. 


\section{PEQ-MS 12/5}

Four studies evaluated the psychometric properties of a modification of the PEQ 13/11 in which the bathing item was dropped based on Rasch analysis and the scoring had five categories (0 to 4). ${ }^{38,40,41,61}$ The studies evaluated 703 people, total. None of the studies was generalizable to the Medicare population (average ages 54 to 60 years, $23 \%$ to $49 \%$ with dysvascular conditions).

Rasch analysis found better structural validity than the PEQ-MS 13/11 instrument. Two studies reported convergent validity with LCI, PPA, 2MWT, ABC, BBS, and TUG. Two studies also found that PEQ0MS 12/5 discriminated among people by K level and Houghton Scale. Two studies reported good reliability and one study reported MDC(90) and MDC(95) estimates. No floor or ceiling effects were found.

\section{PEQ-MS 13/7}

One study that is generalizable to the Medicare population (average age 66 years) evaluated a modified version of PEQ-MS in which there were 7 categories (1 to 7). ${ }^{37}$. The study did not evaluate test validity, but found the subscale to be reliable without floor or ceiling effect. An MDC(90) estimate was reported.

\section{Overall}

Overall, for PEQ scales and variations, there is evidence of reliability for each of the scales and the overall instrument in a study generalizable to the Medicare population, but with ceiling effects for Transfers and Well-Being. There is also evidence of test validity for PEQ-MS 13/11 and PEQ-MS 12/5, and test reliability without floor or ceiling effects for all three variations of PEQ-MS (13/11, 12/5, and 13/7) in studies generalizable to the Medicare population.

There is corroborating evidence in studies not generalizable to the Medicare population of test validity (of the original versions) of the PEQ items individually, but with floor or ceiling effects for Transfers, Perceived Responses, and Frustration. Also in studies not generalizable to the Medicare population, there is evidence of better structural validity of PEQ-MS 12/5 than PEQ-MS 13/11 with test validity, reliability, and no floor or ceiling effect. 
Table 24. Study descriptive data: PEQ

\begin{tabular}{|c|c|c|c|c|c|c|c|c|c|c|}
\hline Instrument & Item/Subscale & Study, PMID & $\mathbf{N}$ & Age* $^{*}$ & $\begin{array}{l}\text { Dysvasc } †, \\
\%\end{array}$ & $\begin{array}{l}\text { Trauma†, } \\
\%\end{array}$ & $\begin{array}{l}\text { TF†, } \\
\%\end{array}$ & $\begin{array}{l}\text { TT†, } \\
\%\end{array}$ & $\begin{array}{l}\text { Unit, } \\
\%\end{array}$ & $\begin{array}{l}\mathrm{Bi \dagger}, \\
\%\end{array}$ \\
\hline \multirow[t]{9}{*}{ PEQ } & $\begin{array}{l}\text { MS } 13 / 11 \text { (original) } \\
\text { MS } 12 / 5\end{array}$ & $\begin{array}{l}\text { Franchignoni } 2007 \\
17351696\end{array}$ & 123 & $\begin{array}{l}54 \text { [IQR } \\
36-65]\end{array}$ & 35 & 56 & 64 & 41 & 89 & 11 \\
\hline & MS 12/5 & Hafner 201628273329 & 201 & $60.2(11.4)$ & 23 & 60 & 35 & 65 & nd & nd \\
\hline & MS 12/5 & Hafner 201727590443 & 199 & $55.4(14.3)$ & 44 & 41 & 18 & 76 & 100 & 0 \\
\hline & $\begin{array}{l}\text { Function: Usefulness (VAS) } \\
\text { Function: Residual limb health } \\
\text { (VAS) } \\
\text { Function: Appearance (VAS) } \\
\text { Function: Sounds (VAS) } \\
\text { Mobility: Ambulation (VAS) } \\
\text { Mobility: Transfers (VAS) } \\
\text { Psychosocial: Perceived } \\
\text { responses (VAS) } \\
\text { Psychosocial: Frustration } \\
\text { (VAS) } \\
\text { Psychosocial: Social burden } \\
\text { (VAS) } \\
\text { Global: Well-being (VAS) }\end{array}$ & Legro 19989710165 & 92 & nd & nd & 66 & 25 & 63 & nd & nd \\
\hline & MS 13/11 & Major 201323856150 & 30 & $54(12)$ & 23 & 47 & 50 & 53 & 90 & 10 \\
\hline & MS 13/11 & $\begin{array}{l}\text { Miller } 200111588750 \\
\text { (sample 1) }\end{array}$ & 60 & $58.4(15.5)$ & 53 & nd & 28 & 72 & 100 & 0 \\
\hline & MS 13/11 & $\begin{array}{l}\text { Miller } 200111588750 \\
\text { (sample 2) }\end{array}$ & 329 & $59.9(16.7)$ & 53 & nd & 26 & 74 & 100 & 0 \\
\hline & $\begin{array}{l}\text { Overall scale (all modified to } 7 \\
\text { categories) } \\
\text { Function: Usefulness } \\
\text { Function: Residual limb health } \\
\text { Function: Appearance } \\
\text { Function: Sounds } \\
\text { Mobility: Ambulation } \\
\text { Mobility: Transfers } \\
\text { Psychosocial: Perceived } \\
\text { responses } \\
\text { Psychosocial: Frustration } \\
\text { Psychosocial: Social burden } \\
\text { Global: Well-being } \\
\text { MS 13/7 }\end{array}$ & Resnik 201121310896 & 44 & $66(13)$ & nd & nd & 52 & 43 & 100 & 0 \\
\hline & MS 12/5 & Wong 201626874230 & 180 & $55.5(16.0)$ & 49 & 51 & 44 & 56 & 81 & 13 \\
\hline
\end{tabular}


Abbreviations: $\mathrm{Bi}=$ bilateral amputation, $\mathrm{IQR}=$ interquartile range, $\mathrm{MS}=$ Mobility Scales, nd $=$ no data/not reported, $\mathrm{PEQ}=$ Prosthesis Evaluation Questionnaire, $\mathrm{PMID}=$ PubMed identifier (or journal), TF = transfemoral (above the knee) amputation, TT = transtibial (below the knee) amputation, Uni = unilateral amputation, VAS $=$ Visual Analog Scale.

Note: Shading included only to more clearly distinguish separate instruments. Empty cells under Item/Subscale indicate that there are no instrument items or subscales or they were not evaluated.

*Mean or median with standard deviation in parentheses and range in square brackets.

†Percentages of study participants with other amputation etiologies, amputation levels, and unreported etiologies, levels, or unilateral versus bilateral amputation are omitted from this summary table. See Appendix C for further details. Transfemoral and transtibial data may sum to more than $100 \%$ because of double counting of participants with bilateral amputations.

\section{Table 25. Summary of instrument psychometric validity properties: PEQ}

\begin{tabular}{|c|c|c|c|c|c|c|c|c|}
\hline Instrument & Item/Subscale & Study, PMID & MC* & $\begin{array}{l}\text { Convergent Validity } \\
\text { (Concurrent) }\end{array}$ & $\begin{array}{l}\text { Divergent Validity } \\
\text { (Discriminant) }\end{array}$ & $\begin{array}{l}\text { Construct } \\
\text { Validity }\end{array}$ & $\begin{array}{l}\text { Structural } \\
\text { Validity }\end{array}$ & $\begin{array}{l}\text { Predictive } \\
\text { Validity } \dagger\end{array}$ \\
\hline \multirow[t]{9}{*}{ PEQ } & $\begin{array}{l}\text { Function: } \\
\text { Usefulness (VAS) }\end{array}$ & \multirow[t]{9}{*}{$\begin{array}{l}\text { Legro } 1998 \\
9710165\end{array}$} & No & & $\begin{array}{l}\text { No (amputation level, } \\
\text { comorbidities, years } \\
\text { since amputation, age) }\end{array}$ & & & \\
\hline & $\begin{array}{l}\text { Function: } \\
\text { Residual limb } \\
\text { health (VAS) }\end{array}$ & & No & & $\begin{array}{l}\text { Yes (age) } \\
\text { No (amputation level, } \\
\text { comorbidities, years } \\
\text { since amputation) }\end{array}$ & & & \\
\hline & $\begin{array}{l}\text { Function: } \\
\text { Appearance } \\
\text { (VAS) }\end{array}$ & & No & & $\begin{array}{l}\text { No (amputation level, } \\
\text { comorbidities, years } \\
\text { since amputation, age) }\end{array}$ & & & \\
\hline & $\begin{array}{l}\text { Function: Sounds } \\
\text { (VAS) }\end{array}$ & & No & & $\begin{array}{l}\text { No (amputation level, } \\
\text { comorbidities, years } \\
\text { since amputation, age) }\end{array}$ & & & \\
\hline & $\begin{array}{l}\text { Mobility: } \\
\text { Ambulation (VAS) }\end{array}$ & & No & $\begin{array}{l}\text { Yes (SF-36 physical } \\
\text { function) }\end{array}$ & $\begin{array}{l}\text { Yes (comorbidities) } \\
\text { No (amputation level, } \\
\text { years since amputation, } \\
\text { age) }\end{array}$ & & & \\
\hline & $\begin{array}{l}\text { Mobility: Transfers } \\
\text { (VAS) }\end{array}$ & & No & & $\begin{array}{l}\text { No (amputation level, } \\
\text { comorbidities, years } \\
\text { since amputation, age) }\end{array}$ & & & \\
\hline & $\begin{array}{l}\text { Psychosocial: } \\
\text { Perceived } \\
\text { responses (VAS) }\end{array}$ & & No & & $\begin{array}{l}\text { No (amputation level, } \\
\text { comorbidities, years } \\
\text { since amputation, age) }\end{array}$ & & & \\
\hline & $\begin{array}{l}\text { Psychosocial: } \\
\text { Frustration (VAS) }\end{array}$ & & No & & $\begin{array}{l}\text { Yes (age) } \\
\text { No (amputation level, } \\
\text { comorbidities, years } \\
\text { since amputation) }\end{array}$ & & & \\
\hline & $\begin{array}{l}\text { Psychosocial: } \\
\text { Social burden } \\
\text { (VAS) }\end{array}$ & & No & $\begin{array}{l}\text { Yes (SF-36 social } \\
\text { function, SIP social } \\
\text { interaction) }\end{array}$ & $\begin{array}{l}\text { No (amputation level, } \\
\text { years since amputation, } \\
\text { comorbidities, age) }\end{array}$ & & & \\
\hline
\end{tabular}




\begin{tabular}{|c|c|c|c|c|c|c|c|c|}
\hline Instrument & Item/Subscale & Study, PMID & $\mathrm{MC}^{*}$ & $\begin{array}{l}\text { Convergent Validity } \\
\text { (Concurrent) }\end{array}$ & $\begin{array}{l}\text { Divergent Validity } \\
\text { (Discriminant) }\end{array}$ & $\begin{array}{l}\text { Construct } \\
\text { Validity }\end{array}$ & $\begin{array}{l}\text { Structural } \\
\text { Validity }\end{array}$ & $\begin{array}{l}\text { Predictive } \\
\text { Validity } \dagger\end{array}$ \\
\hline & $\begin{array}{l}\text { Global: Well-being } \\
\text { (VAS) }\end{array}$ & & No & Yes (POMS-SF) & $\begin{array}{l}\text { No (amputation level, } \\
\text { years since amputation, } \\
\text { comorbidities, age) }\end{array}$ & & & \\
\hline & $\begin{array}{l}\text { Overall and } \\
\text { subscales }\end{array}$ & $\begin{array}{l}\text { Resnik } 2011 \\
21310896\end{array}$ & Yes & & & & & \\
\hline & MS 13/11 & $\begin{array}{l}\text { Franchignoni } \\
2007 \\
17351696\end{array}$ & No & $\begin{array}{l}\text { Similar but slightly lower } \\
\text { correlations than PEQ- } \\
\text { MS } 12 / 5\end{array}$ & & & $\begin{array}{l}\text { Rasch: Misfit } \\
\text { of one item } \\
\text { (bathing) }\end{array}$ & \\
\hline & & $\begin{array}{l}\text { Major } 2013 \\
23856150\end{array}$ & No & Yes (BBS) & & & & \\
\hline & & $\begin{array}{l}\text { Miller } 2001 \\
11588750 \\
\text { (sample 1) }\end{array}$ & Yes & $\begin{array}{l}\text { Yes (2MWT, TUG, ABC, } \\
\text { PPA-LCI) }\end{array}$ & & & & \\
\hline & & $\begin{array}{l}\text { Miller } 2001 \\
11588750 \\
\text { (sample 2) }\end{array}$ & Yes & Yes (ABC, PPA-LCI) & $\begin{array}{l}\text { Yes (amputation } \\
\text { etiology, use of mobility } \\
\text { device, walking } \\
\text { distance, automatic } \\
\text { walking) } \\
\text { No (TT vs. TF) }\end{array}$ & & & \\
\hline & MS $12 / 5$ & $\begin{array}{l}\text { Franchignoni } \\
2007 \\
17351696\end{array}$ & No & Yes (LCl, PPA) & & & $\begin{array}{l}\text { Rasch: Better } \\
\text { structural } \\
\text { validity than } \\
13 / 11\end{array}$ & \\
\hline & & $\begin{array}{l}\text { Hafner } 2016 \\
28273329\end{array}$ & No & & & & & \\
\hline & & $\begin{array}{l}\text { Hafner } 2017 \\
27590443\end{array}$ & No & & Yes (K levels) & & & \\
\hline & & $\begin{array}{l}\text { Wong } 2016 \\
26874230\end{array}$ & No & $\begin{array}{l}\text { Yes (2MWT, ABC, 3- } \\
\text { BBS, TUG) }\end{array}$ & Yes (Houghton) & & & \\
\hline
\end{tabular}

Abbreviations: 2MWT = 2 minute walk test, 3-BBS = total sum score of 3 Berg Balance Scale items, ABC = Activities-Specific Balance Confidence scale, BBS = Berg Balance Scale, $\mathrm{Bi}=$ bilateral amputation, IQR = interquartile range, $\mathrm{K}$ level $=$ Medicare Functional Classification Level, LCI = Locomotor Capabilities Index, MC = Medicare, MS = Mobility Scales, nd = no data/not reported, PEQ = Prosthesis Evaluation Questionnaire, PEQ-MS = Prosthesis Evaluation Questionnaire motor score, PMID = PubMed identifier (or journal), PPA = Prosthetic Profile of the Amputee, PPA-LCI = Prosthetic Profile of the Amputee - Locomotor Capabilities, SF-36 = Short Form Health Survey-36, TF = transfemoral (above the knee) amputation, TT = transtibial (below the knee) amputation, TUG = Timed Up and Go, Uni = unilateral amputation, VAS = Visual Analog Scale.

Note: Shading included only to more clearly distinguish separate instruments. Empty cells under Item/Subscale indicate that there are no instrument items or subscales or they were not evaluated. Empty cells in the validity columns indicate no evidence regarding this construct.

*Whether study was deemed generalizable to the Medicare population based on average age greater than 65 years and/or at least $50 \%$ of participants with dysvascular etiologies for their amputations.

†Studies evaluated for predictive validity were assessed for Key Question 2. 
Table 26. Summary of other instrument psychometric properties: PEQ

\begin{tabular}{|c|c|c|c|c|c|c|c|c|}
\hline Instrument & Item/Subscale & Study, PMID & $M C^{*}$ & Reliability & MDC & MID $\quad$ Responsiveness & Floor & Ceiling \\
\hline \multirow[t]{22}{*}{ PEQ } & $\begin{array}{l}\text { Function: Usefulness } \\
\text { (VAS) }\end{array}$ & $\begin{array}{l}\text { Legro } 1998 \\
9710165\end{array}$ & No & Yes & & & $0 \%$ & $2 \%$ \\
\hline & $\begin{array}{l}\text { Function: Residual limb } \\
\text { health (VAS) }\end{array}$ & & No & Yes & & & $0 \%$ & $2 \%$ \\
\hline & $\begin{array}{l}\text { Function: Appearance } \\
\text { (VAS) }\end{array}$ & & No & Yes & & & $0 \%$ & $7 \%$ \\
\hline & Function: Sounds (VAS) & & No & Yes & & & $1 \%$ & $10 \%$ \\
\hline & $\begin{array}{l}\text { Mobility: Ambulation } \\
\text { (VAS) }\end{array}$ & & No & Yes & & & $0 \%$ & $2 \%$ \\
\hline & Mobility: Transfers (VAS) & & No & Yes & & & $0 \%$ & $25 \%$ \\
\hline & $\begin{array}{l}\text { Psychosocial: Perceived } \\
\text { responses (VAS) }\end{array}$ & & No & Yes & & & $0 \%$ & $17 \%$ \\
\hline & $\begin{array}{l}\text { Psychosocial: Frustration } \\
\text { (VAS) }\end{array}$ & & No & Yes & & & $22 \%$ & $1 \%$ \\
\hline & $\begin{array}{l}\text { Psychosocial: Social } \\
\text { burden (VAS) }\end{array}$ & & No & Yes & & & $10 \%$ & $0 \%$ \\
\hline & Global: Well-being (VAS) & & No & Yes & & & $0 \%$ & $8 \%$ \\
\hline & $\begin{array}{l}\text { Overall scale (modified } 7 \\
\text { categories) }\end{array}$ & $\begin{array}{l}\text { Resnik } 2011 \\
21310896\end{array}$ & Yes & $\begin{array}{l}\text { Yes (except } \\
\text { shower and bathe } \\
\text { safely) }\end{array}$ & & & No effect & No effect \\
\hline & $\begin{array}{l}\text { Function: Usefulness ( } 7 \\
\text { categories) }\end{array}$ & & Yes & Yes & $\operatorname{MDC}(90) 1.2$ & & No effect & No effect \\
\hline & $\begin{array}{l}\text { Function: Residual limb } \\
\text { health ( } 7 \text { categories) }\end{array}$ & & Yes & Yes & MDC(90) 0.8 & & No effect & No effect \\
\hline & $\begin{array}{l}\text { Function: Appearance ( } 7 \\
\text { categories) }\end{array}$ & & Yes & Yes & $\operatorname{MDC}(90) 1.4$ & & No effect & No effect \\
\hline & $\begin{array}{l}\text { Function: Sounds ( } 7 \\
\text { categories) }\end{array}$ & & Yes & Yes & $\operatorname{MDC}(90) 1.7$ & & No effect & No effect \\
\hline & $\begin{array}{l}\text { Mobility: Ambulation ( } 7 \\
\text { categories) }\end{array}$ & & Yes & Yes & $\operatorname{MDC}(90) 1.1$ & & No effect & No effect \\
\hline & $\begin{array}{l}\text { Mobility: Transfers ( } 7 \\
\text { categories) }\end{array}$ & & Yes & Yes & $\operatorname{MDC}(90) 1.3$ & & $0 \%$ & $27 \%$ \\
\hline & $\begin{array}{l}\text { Psychosocial: Perceived } \\
\text { responses ( } 7 \text { categories) }\end{array}$ & & Yes & Yes & $\operatorname{MDC}(90) 0.9$ & & No effect & No effect \\
\hline & $\begin{array}{l}\text { Psychosocial: Frustration } \\
\text { (7 categories) }\end{array}$ & & Yes & Yes & $\operatorname{MDC}(90) 1.6$ & & No effect & No effect \\
\hline & $\begin{array}{l}\text { Psychosocial: Social } \\
\text { burden ( } 7 \text { categories) }\end{array}$ & & Yes & Yes & $\operatorname{MDC}(90) 1.4$ & & No effect & No effect \\
\hline & $\begin{array}{l}\text { Global: Well-being ( } 7 \\
\text { categories) }\end{array}$ & & Yes & Yes & $\operatorname{MDC}(90) 1.4$ & & $0 \%$ & $34 \%$ \\
\hline & MS 13/7 & & Yes & Yes & MDC(90) 0.8 & & No effect & No effect \\
\hline
\end{tabular}




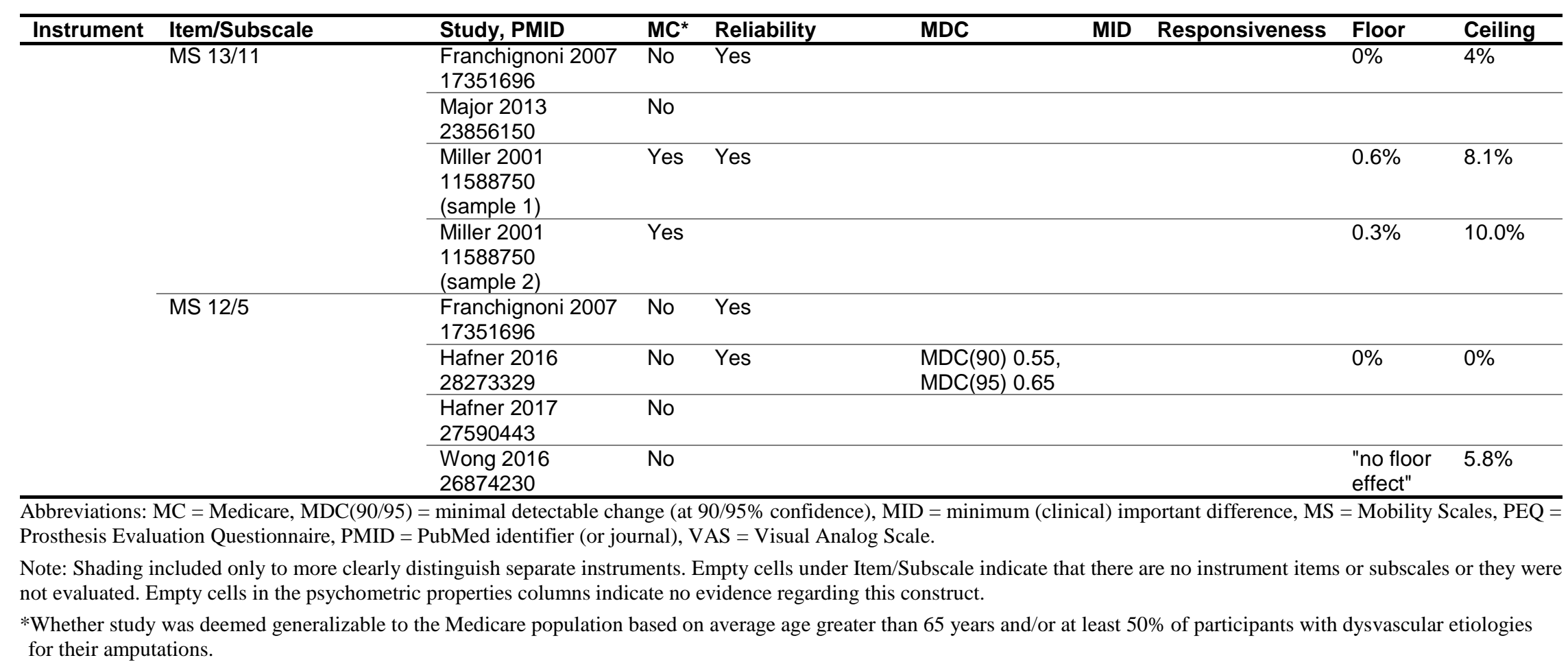




\section{PFI}

The Physical Function Index is a generic measure of ability to perform various physical tasks. One study ${ }^{55}$ evaluated the psychometric properties of the PFI in 107 people with lower limb amputations (see Tables 27 to 29). The study evaluated the instrument scored in total and also the individual items Squat to pick up object, Walk at steady pace, Run at steady pace, and Climb stairs. The study was not deemed generalizable to the Medicare population based on the young age of the participants (average 35 years) and that none had dysvascular conditions.

The study provided moderate evidence of convergent validity for the PFI instrument as a whole when compared with LCI and SIP-PD. The study found that the PFI did not discriminate participants by amputation level, injury severity score, age, or comorbidities for any of the subscales, including the overall instrument. All subscales were found to have construct validity when compared to walking speed, and the subscales of Walk at a steady pace and Run at a steady pace were additionally found to have construct validity with return to usual activity. The remaining subscales were not found to have construct validity with return to usual activity.

The study reported good reliability for all subscales and the total instrument. Responsiveness of the subscales was mixed, as the items of Squat to pick up object, Climb stairs, and the overall instrument were not found to have significance changes from 3 to 12 months in correlation with Return to walking speed or Usual activity, but the remaining subscales were found to have responsiveness correlated with Walking speed alone. Large ceiling effects were observed for each of the subscales and large floor effects were observed for Walk at steady pace and Climb stairs. Neither floor nor ceiling effects were observed for the overall instrument.

Overall, for PFI, in a study not generalizable to the Medicare population, there is evidence of test validity and reliability for the instrument as a whole and its subscales. Two of the subscales demonstrate responsiveness. The subscales, but not the instrument as a whole have floor and ceiling effects.

\section{PGI}

Patient-centered quality of life is assessed through the Patient Generated Index, in which patients are asked to list important areas of their life that have been impacted by their condition, and then rate those areas, and the importance of those areas to them. One study ${ }^{62}$ evaluated the psychometric properties of the PGI in 42 people with lower limb amputations (see Tables 27 to 29). The study was deemed to be generalizable to the Medicare population based on the relatively high percentage of study participants with dysvascular disease (86\%) although the average age in all three studies was not reported.

The study did not assess test validity, but it provided evidence of reliability for the PGI.

Overall, there is evidence of reliability of the PGI in a study generalizable to the Medicare population.

\section{PLUS-M}

The Prosthetic Limb Users Survey of Mobility is a self-reported instrument that assesses perceived mobility in people with lower limb amputation. Three studies ${ }^{40,41,63}$ evaluated the psychometric properties of the PLUS-M in 599 people, total, with lower limb amputations (see Tables 27 to 29). The instrument was evaluated in two different short-form lengths (SF-7 and SF-12, which should not be confused with the Short Form Health Survey instrument SF-12) as 
well as by Computer Adaptive Test (CAT). The studies were not deemed generalizable to the Medicare population based on average age less than 65 years (55 to 60 years) and the low percentage of study participants with dysvascular disease (23\% to $44 \%)$.

One of the studies reported convergent validity of the PLUS-M SF-12 (compared with the PEQ-MS, ABC, PROMIS-PF, AMP, TUG, and MFCL) and found that it discriminated people based on K levels. The other two studies reported evidence of reliability for the PLUS-M CAT, SF-7, and SF-12; although for SF-7, the reliability was rated as poor in one study. One study reported MDC(90) and MDC(95) estimates for the three instrument forms. No floor or ceiling effects were observed across all versions of the PLUS-M.

Overall, for PLUS-M, from studies not generalizable to the Medicare population there is evidence of test validity and reliability (with mixed evidence), without floor or ceiling effects for all three instrument forms.

\section{PPA}

The Prosthetic Profile of the Amputee assesses frequency of wear and the use of lower limb prosthesis, along with factors potentially associated with prosthesis use. The instrument includes the LCI instrument, which has been described above. This section includes only other items from PPA that were assessed separately from LCI. One study ${ }^{58}$ evaluated the psychometric properties of PPA items other than LCI in 70 people with lower limb amputations (see Tables 27 to 29). The study evaluated psychometric properties of the Prosthetic Use outdoor and indoor, and Acceptance/Adaptation. The study was deemed to be generalizable to the Medicare population based on the relatively high percentage of study participants with dysvascular disease (0\%); although the average age was less than 65 years (61 years).

The study reported convergent validity of the Prosthesis Use (Outdoor Use) subscale with Reintegration to Normal Living Index daily activity subscale and the Acceptance/Adaptation subscale with the Reintegration to Normal Living Index, overall. Prosthetic Use (Indoor Use) did not correlate with the Reintegration to Normal Living Index. The study also reported that each of the items had test reliability.

Overall, for the PPA items (other than LCI), from a study generalizable to the Medicare population, there is evidence of test validity for Prosthetic Use (outdoor use), and Acceptance/Adaptation, but not the Prosthetic Use (indoor use). All items have evidence of reliability. 
Table 27. Study descriptive data: PFI through PPA

\begin{tabular}{|c|c|c|c|c|c|c|c|c|c|c|}
\hline Instrument & Item/Subscale & Study, PMID & $\mathbf{N}$ & Age $^{*}$ & $\begin{array}{l}\text { Dysvasc } \dagger \text {, } \\
\%\end{array}$ & $\begin{array}{l}\text { Trauma }{ }, \\
\%\end{array}$ & $\begin{array}{l}\text { TF†, } \\
\%\end{array}$ & $\begin{array}{l}\text { TTt, } \\
\%\end{array}$ & $\begin{array}{l}\text { Unit, } \\
\%\end{array}$ & $\begin{array}{l}\text { Bi†, } \\
\%\end{array}$ \\
\hline $\mathrm{PFI}$ & $\begin{array}{l}\text { Squat to pick up object } \\
\text { Walk at a steady pace } \\
\text { Run at a steady pace } \\
\text { Climb stairs } \\
\text { Total (Overall) }\end{array}$ & Cyril 2001 (Johns Hopkins) & 107 & $35(12.5)$ & 0 & 100 & 21 & 67 & 100 & 0 \\
\hline PGI & & Callaghan 200314682557 & 42 & nd & 86 & nd & 100 & 0 & 100 & 0 \\
\hline \multirow[t]{3}{*}{ PLUS-M } & $\begin{array}{l}\text { CAT } \\
\text { SF-7 } \\
\text { SF-12 }\end{array}$ & Amtmann 201728866959 & 199 & $\begin{array}{l}55.2 \\
(14.4)\end{array}$ & 42 & 41 & 17 & 73 & 100 & 0 \\
\hline & $\begin{array}{l}\text { CAT } \\
\text { SF-7 } \\
\text { SF-12 }\end{array}$ & Hafner 201628273329 & 201 & $\begin{array}{l}60.2 \\
(11.4)\end{array}$ & 23 & 60 & 35 & 65 & nd & nd \\
\hline & SF-12 & Hafner 201727590443 & 199 & $\begin{array}{l}55.4 \\
(14.3)\end{array}$ & 44 & 41 & 18 & 76 & 100 & 0 \\
\hline PPA $^{\ddagger}$ & $\begin{array}{l}\text { Prosthesis use, outdoor } \\
\text { use } \\
\text { Prosthesis use, indoor use } \\
\text { Acceptance/adaptation }\end{array}$ & $\begin{array}{l}\text { Gauthier-Gagnon } 1994 \\
7993169\end{array}$ & 70 & $\begin{array}{l}60.6 \\
(16.8)\end{array}$ & 70 & 23 & 50 & 50 & 100 & 0 \\
\hline
\end{tabular}

Abbreviations: $\mathrm{Bi}=$ bilateral amputation, $\mathrm{CAT}=$ Computer Adaptive Test, Dysvasc $=$ dysvascular disease (including diabetes), $\mathrm{nd}=$ no data/not reported, $\mathrm{PFI}=\mathrm{Physical}$ Function Index, PGI = Patient Generated Index, PLUS-M = Prosthetic Limb Users Survey of Mobility, PMID = PubMed identifier (or journal), PPA = Prosthetic Profile of the Amputee, SF-12 = short form-12 item (PLUS-M), SF-7 = short form-7 item (PLUS-M), TF = transfemoral (above the knee) amputation, TT = transtibial (below the knee) amputation, Uni = unilateral amputation.

Note: Shading included only to more clearly distinguish separate instruments. Empty cells under Item/Subscale indicate that there are no instrument items or subscales or they were not evaluated.

*Mean or median with standard deviation in parentheses and range in square brackets.

†Percentages of study participants with other amputation etiologies, amputation levels, and unreported etiologies, levels, or unilateral versus bilateral amputation are omitted from this summary table. See Appendix C for further details. Transfemoral and transtibial data may sum to more than $100 \%$ because of double counting of participants with bilateral amputations.

¥The Locomotor capabilities portion of the PPA has been incorporated in together with the Locomotor Capabilities Index (LCI) instrument and is not repeated here. 
Table 28. Summary of instrument psychometric validity properties: PFI through PPA

\begin{tabular}{|c|c|c|c|c|c|c|c|c|}
\hline Instrument & Item/Subscale & $\begin{array}{l}\text { Study, } \\
\text { PMID } \\
\end{array}$ & MC* & $\begin{array}{l}\text { Convergent Validity } \\
\text { (Concurrent) }\end{array}$ & $\begin{array}{l}\text { Divergent Validity } \\
\text { (Discriminant) }\end{array}$ & $\begin{array}{l}\text { Construct } \\
\text { Validity }\end{array}$ & $\begin{array}{l}\text { Structural } \\
\text { Validity }\end{array}$ & $\begin{array}{l}\text { Predictive } \\
\text { Validity } \dagger\end{array}$ \\
\hline \multirow[t]{5}{*}{ PFI } & & \multirow[t]{5}{*}{$\begin{array}{l}\text { Cyril 2001 } \\
\text { (Johns } \\
\text { Hopkins) }\end{array}$} & No & Moderate (LCI, SIP-PD) & $\begin{array}{l}\text { No (amputation } \\
\text { level, injury severity } \\
\text { score, age, } \\
\text { comorbidities) }\end{array}$ & $\begin{array}{l}\text { Yes (walking } \\
\text { speed), No } \\
\text { (return to usual } \\
\text { activity) }\end{array}$ & & \\
\hline & Squat to pick up object & & No & & $\begin{array}{l}\text { No (amputation } \\
\text { level, injury severity } \\
\text { score, age, } \\
\text { comorbidities) }\end{array}$ & $\begin{array}{l}\text { Yes (walking } \\
\text { speed), No } \\
\text { (return to usual } \\
\text { activity) }\end{array}$ & & \\
\hline & Walk at steady pace & & No & & $\begin{array}{l}\text { No (amputation } \\
\text { level, injury severity } \\
\text { score, age, } \\
\text { comorbidities) }\end{array}$ & $\begin{array}{l}\text { Yes (walking } \\
\text { speed, return } \\
\text { to usual } \\
\text { activity) }\end{array}$ & & \\
\hline & Run at steady pace & & No & & $\begin{array}{l}\text { No (amputation } \\
\text { level, injury severity } \\
\text { score, age, } \\
\text { comorbidities) }\end{array}$ & $\begin{array}{l}\text { Yes (walking } \\
\text { speed, return } \\
\text { to usual } \\
\text { activity) }\end{array}$ & & \\
\hline & Climb stairs & & No & & $\begin{array}{l}\text { No (amputation } \\
\text { level, injury severity } \\
\text { score, age, } \\
\text { comorbidities) }\end{array}$ & $\begin{array}{l}\text { Yes (walking } \\
\text { speed), No } \\
\text { (return to usual } \\
\text { activity) }\end{array}$ & & \\
\hline PGI & & $\begin{array}{l}\text { Callaghan } \\
2003 \\
14682557\end{array}$ & Yes & & & & & \\
\hline \multirow[t]{3}{*}{ PLUS-M } & $\begin{array}{l}\text { CAT } \\
\text { SF-7 } \\
\text { SF-12 }\end{array}$ & $\begin{array}{l}\text { Amtmann } \\
2017 \\
28866959\end{array}$ & No & & & & & \\
\hline & $\begin{array}{l}\text { CAT } \\
\text { SF-7 } \\
\text { SF-12 }\end{array}$ & $\begin{array}{l}\text { Hafner } 2016 \\
28273329\end{array}$ & No & & & & & \\
\hline & SF-12 & $\begin{array}{l}\text { Hafner } 2017 \\
27590443\end{array}$ & No & $\begin{array}{l}\text { Yes (PEQ-MS, ABC, } \\
\text { PROMIS-PF, AMP, } \\
\text { TUG, MFCL) }\end{array}$ & Yes (K levels) & & & \\
\hline \multirow[t]{3}{*}{ PPA } & $\begin{array}{l}\text { Prosthesis use, } \\
\text { outdoor use }\end{array}$ & \multirow[t]{3}{*}{$\begin{array}{l}\text { Gauthier- } \\
\text { Gagnon } \\
1994 \\
7993169\end{array}$} & Yes & $\begin{array}{l}\text { Yes (RNL daily activity), } \\
\text { No (RNL perception of } \\
\text { self) }\end{array}$ & & & & \\
\hline & $\begin{array}{l}\text { Prosthesis use, indoor } \\
\text { use }\end{array}$ & & Yes & No (RNL) & & & & \\
\hline & Acceptance/adaptation & & Yes & Yes (RNL) & & & & \\
\hline
\end{tabular}

Abbreviations: 2MWT = 2 minute walk test, ABC = Activities-specific Balance scale, AMP = Amputee Mobility Predictor, CAT = computer adaptive test, $\mathrm{K}$ level = Medicare

Functional Classification Level, LCI = Locomotor Capabilities Index, MC = Medicare, MFCL = Medicare Functional Classification Level, PCS = Physical Component Score, 
PEQ-MS = Prosthesis Evaluation Questionnaire-Mobility Scale, PFI = Physical Function Index, PGI = Patient Generated Index, PLUS-M = Prosthetic Limb Users Survey of Mobility, PMID = PubMed identifier (or journal), RNL = Reintegration to Normal Living Index, SF-12 = short form 12 item (PLUS-M), SF-7 = short form 7 item (PLUS-M), SIP$\mathrm{PD}=$ Sickness Impact Profile-Physical Dimension, TF = transfemoral (above the knee) amputation, TT = transtibial (below the knee) amputation, TUG = Timed Up and Go.

Note: Shading included only to more clearly distinguish separate instruments. Empty cells under Item/Subscale indicate that there are no instrument items or subscales or they were not evaluated. Empty cells in the validity columns indicate no evidence regarding this construct.

*Whether study was deemed generalizable to the Medicare population based on average age greater than 65 years and/or at least $50 \%$ of participants with dysvascular etiologies for their amputations.

†Studies evaluated for predictive validity were assessed for Key Question 2. 
Table 29. Summary of other instrument psychometric properties: PFI through PPA

\begin{tabular}{|c|c|c|c|c|c|c|c|c|c|}
\hline Instrument & Item/Subscale & Study, PMID & $\mathrm{MC}^{*}$ & Reliability & $\overline{M D C}$ & MID & Responsiveness & Floor & Ceiling \\
\hline \multirow[t]{5}{*}{$\mathrm{PFI}$} & Squat to pick up object & $\begin{array}{l}\text { Cyril } 2001 \text { (Johns } \\
\text { Hopkins) }\end{array}$ & No & Yes & & & $\begin{array}{l}\text { No (walking speed, return to } \\
\text { usual activity) }\end{array}$ & $8.4 \%$ & $36.4 \%$ \\
\hline & Walk at steady pace & & No & Yes & & & $\begin{array}{l}\text { Yes (walking speed), No } \\
\text { (return to usual activity) }\end{array}$ & $17.8 \%$ & $31.8 \%$ \\
\hline & Run at steady pace & & No & Yes & & & $\begin{array}{l}\text { Yes (walking speed), No } \\
\text { (return to usual activity) }\end{array}$ & $2.8 \%$ & $85.0 \%$ \\
\hline & Climb stairs & & No & Yes & & & $\begin{array}{l}\text { No (walking speed, return to } \\
\text { usual activity) }\end{array}$ & $41.1 \%$ & $16.8 \%$ \\
\hline & Total (Overall) & & No & Yes & & & $\begin{array}{l}\text { No (walking speed, return to } \\
\text { usual activity) }\end{array}$ & $0 \%$ & $12.1 \%$ \\
\hline PGI & & $\begin{array}{l}\text { Callaghan } 2003 \\
14682557\end{array}$ & Yes & Yes & & & & & \\
\hline \multirow[t]{7}{*}{ PLUS-M } & CAT & $\begin{array}{l}\text { Amtmann } 2017 \\
28866959\end{array}$ & No & Yes & & & & & \\
\hline & SF-12 & & No & Yes & & & & & \\
\hline & SF-7 & & No & Poor & & & & & \\
\hline & CAT & $\begin{array}{l}\text { Hafner } 2016 \\
28273329\end{array}$ & No & Yes & $\begin{array}{l}\operatorname{MDC}(90) 6.67 \\
\operatorname{MDC}(95) 7.94\end{array}$ & & & $0 \%$ & $0 \%$ \\
\hline & SF-12 & & No & Yes & $\begin{array}{l}\operatorname{MDC}(90) 6.67 \\
\operatorname{MDC}(95) 7.94\end{array}$ & & & $0 \%$ & $0 \%$ \\
\hline & SF-7 & & No & Yes & $\begin{array}{l}\operatorname{MDC}(90) 4.69 \\
\operatorname{MDC}(95) 5.59\end{array}$ & & & $0 \%$ & $0 \%$ \\
\hline & SF-12 & $\begin{array}{l}\text { Hafner } 2017 \\
27590443\end{array}$ & No & & & & & $0 \%$ & $1 \%$ \\
\hline \multirow[t]{3}{*}{ PPA } & $\begin{array}{l}\text { Prosthesis use, outdoor } \\
\text { use }\end{array}$ & $\begin{array}{l}\text { Gauthier-Gagnon } \\
19947993169\end{array}$ & Yes & Yes & & & & & \\
\hline & $\begin{array}{l}\text { Prosthesis use, indoor } \\
\text { use }\end{array}$ & & Yes & Yes & & & & & \\
\hline & Acceptance/adaptation & & Yes & Yes & & & & & \\
\hline
\end{tabular}

Abbreviations: CAT = computer adaptive test, MC = Medicare, MDC(90/95) = minimal detectable change (at 90/95\% confidence), MID = minimum (clinical) important difference, PFI = Physical Function Index, PGI = Patient Generated Index, PLUS-M = Prosthetic Limb Users Survey of Mobility, PMID = PubMed identifier (or journal), PPA = Prosthetic Profile of the Amputee, SF-12 = short form 12 item (PLUS-M), SF-7 = short form 7 item (PLUS-M).

Note: Shading included only to more clearly distinguish separate instruments. Empty cells under Item/Subscale indicate that there are no instrument items or subscales or they were not evaluated. Empty cells in the psychometric properties columns indicate no evidence regarding this construct.

*Whether study was deemed generalizable to the Medicare population based on average age greater than 65 years and/or at least $50 \%$ of participants with dysvascular etiologies for their amputations. 


\section{PROMIS-29}

The Patient-Reported Outcomes Measurement Information System 29-Item Profile is a compilation of self-report instruments that measure symptom and quality of life constructs: physical function, anxiety, depression, fatigue, sleep disturbance, social role satisfaction, pain interference, and pain intensity. Three studies ${ }^{40,41,64}$ evaluated the psychometric properties of the PROMIS-29 subscales in 1491 people, total, with lower limb amputations (see Tables 30 to32). The studies were not deemed generalizable to the Medicare population based on average age less than 65 years (55 to 60 years) and the low percentage of study participants with dysvascular disease (23\% to $45 \%)$.

One study reported that the Physical Function subscale discriminated participants by $\mathrm{K}$ levels. Another study reported MDC(90) and MDC(95) estimates for each subscale and that each had reliability. For the Physical Function subscale, one study found the minimum (clinical) important difference, MID, to be 8 (of 100 points). Large floor effects were found for the subscales of Anxiety, Depression, and Pain Interference, but not for Pain Intensity, in one study, and a large ceiling effect was also reported for Social Role Satisfaction, but not Physical Function. Data for the floor or ceiling effects of remaining subscales were not reported.

Overall, for the PROMIS-29 subscales, among studies not generalizable to the Medicare population, there is evidence of test validity for the Physical Function subscale, reliability for all subscales, but large floor or ceiling effects for the Anxiety, Depression, Pain Interference, and Social Role Satisfaction subscales.

\section{PROS}

The Prosthetist's Perception of Client's Ambulatory Abilities is one of the subscales developed for the Orthotics and Prosthetics National Office Outcomes Tool (OPOT). The PROS consists of a series of questions asked of the prosthetist to assess the client's ability to climb stairs, walk, and use assistive devices. One study ${ }^{65}$ evaluated the psychometric properties of the PROS in 840 people with lower limb amputations who were being evaluated for their first or replacement prosthesis (see Tables 30 to 32). The study was deemed to be generalizable to the Medicare population based on the relatively high percentage of study participants with dysvascular disease (58\%) although the average age of participants was less than 65 years.

The study reported that the PROS did not have convergent validity when compared with the SF-36 PF-10 or PCS. The PROS was, however, found to discriminate by K levels.

Overall, for PROS, there is evidence of test validity from a study generalizable to the Medicare population. 
Table 30. Study descriptive data: PROMIS through PROS

\begin{tabular}{|c|c|c|c|c|c|c|c|c|c|c|}
\hline Instrument & Item/Subscale & $\begin{array}{l}\text { Study, } \\
\text { PMID } \\
\end{array}$ & $\mathbf{N}$ & Age* $^{*}$ & $\begin{array}{l}\text { Dysvasc } \dagger \text {, } \\
\%\end{array}$ & $\begin{array}{l}\text { Traumat, } \\
\%\end{array}$ & $\begin{array}{l}\text { TF†, } \\
\%\end{array}$ & $\begin{array}{l}\text { TT†, } \\
\%\end{array}$ & $\begin{array}{l}\text { Uni†, } \\
\%\end{array}$ & $\begin{array}{l}\mathrm{Bi \dagger}, \\
\%\end{array}$ \\
\hline \multirow[t]{3}{*}{ PROMIS-29 } & Physical function & $\begin{array}{l}\text { Amtmann } \\
2015 \\
25917819\end{array}$ & 1091 & $\begin{array}{l}55.0 \\
(13.4)\end{array}$ & 45 & 55 & 35 & 65 & 100 & 0 \\
\hline & $\begin{array}{l}\text { Anxiety } \\
\text { Depression } \\
\text { Fatigue } \\
\text { Pain intensity } \\
\text { Pain interference } \\
\text { Physical function } \\
\text { Sleep disturbance } \\
\text { Social role satisfaction }\end{array}$ & $\begin{array}{l}\text { Hafner } 2016 \\
28273329\end{array}$ & 201 & $\begin{array}{l}60.2 \\
(11.4)\end{array}$ & 23 & 60 & 35 & 65 & nd & nd \\
\hline & Physical function & $\begin{array}{l}\text { Hafner } 2017 \\
27590443\end{array}$ & 199 & $\begin{array}{l}55.4 \\
(14.3)\end{array}$ & 44 & 41 & 18 & 76 & 100 & 0 \\
\hline PROS & & $\begin{array}{l}\text { Hart } 1999 \\
\text { (J Prosthet } \\
\text { Orthot) }\end{array}$ & 840 & $\begin{array}{l}56.3 \\
(\sim 17)\end{array}$ & 58 & 29 & 19 & 73 & nd & nd \\
\hline
\end{tabular}

Abbreviations: $\mathrm{Bi}$ = bilateral amputation, Dysvasc = dysvascular disease (including diabetes), nd = no data/not reported, PMID = PubMed identifier (or journal), PROMIS = Patient-Reported Outcomes Measurement Information System, PROS = Prosthetist's Perception of Client's Ambulatory Abilities, TF = transfemoral (above the knee) amputation, $\mathrm{TT}=$ transtibial (below the knee) amputation, Uni = unilateral amputation.

Note: Shading included only to more clearly distinguish separate instruments. Empty cells under Item/Subscale indicate that there are no instrument items or subscales or they were not evaluated.

*Mean or median with standard deviation in parentheses and range in square brackets.

†Percentages of study participants with other amputation etiologies, amputation levels, and unreported etiologies, levels, or unilateral versus bilateral amputation are omitted from this summary table. See Appendix C for further details. Transfemoral and transtibial data may sum to more than $100 \%$ because of double counting of participants with bilateral amputations. 
Table 31. Summary of instrument psychometric validity properties: PROMIS through PROS

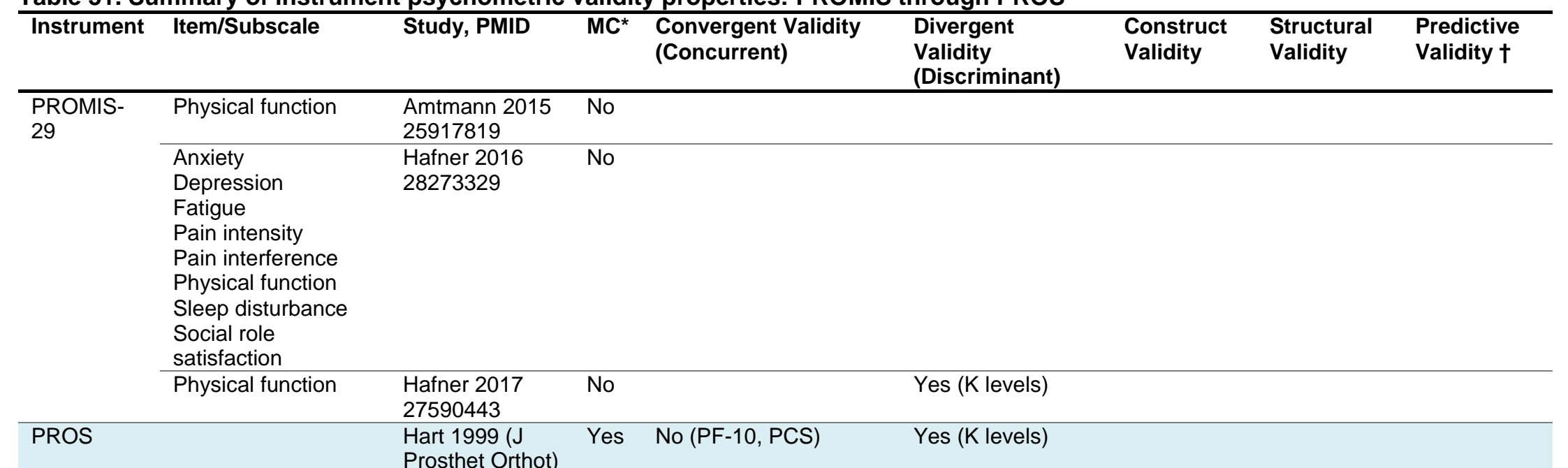

Abbreviations: K level = Medicare Functional Classification Level, MC = Medicare, PCS = Physical Component Score, PF-10 = Physical Functioning (10-item), PMID = PubMed identifier (or journal), PMID = PubMed identifier (or journal), PROMIS = Patient-Reported Outcomes Measurement Information System, PROS = Prosthetist's Perception of Client's Ambulatory Abilities.

Note: Shading included only to more clearly distinguish separate instruments. Empty cells under Item/Subscale indicate that there are no instrument items or subscales or they were not evaluated. Empty cells in the validity columns indicate no evidence regarding this construct.

*Whether study was deemed generalizable to the Medicare population based on average age greater than 65 years and/or at least $50 \%$ of participants with dysvascular etiologies for their amputations.

†Studies evaluated for predictive validity were assessed for Key Question 2. 
Table 32. Summary of other instrument psychometric properties: PROMIS through PROS

Instrument Item/Subscale Study, PMID $\quad$ MC* Reliability MDC $^{*}$

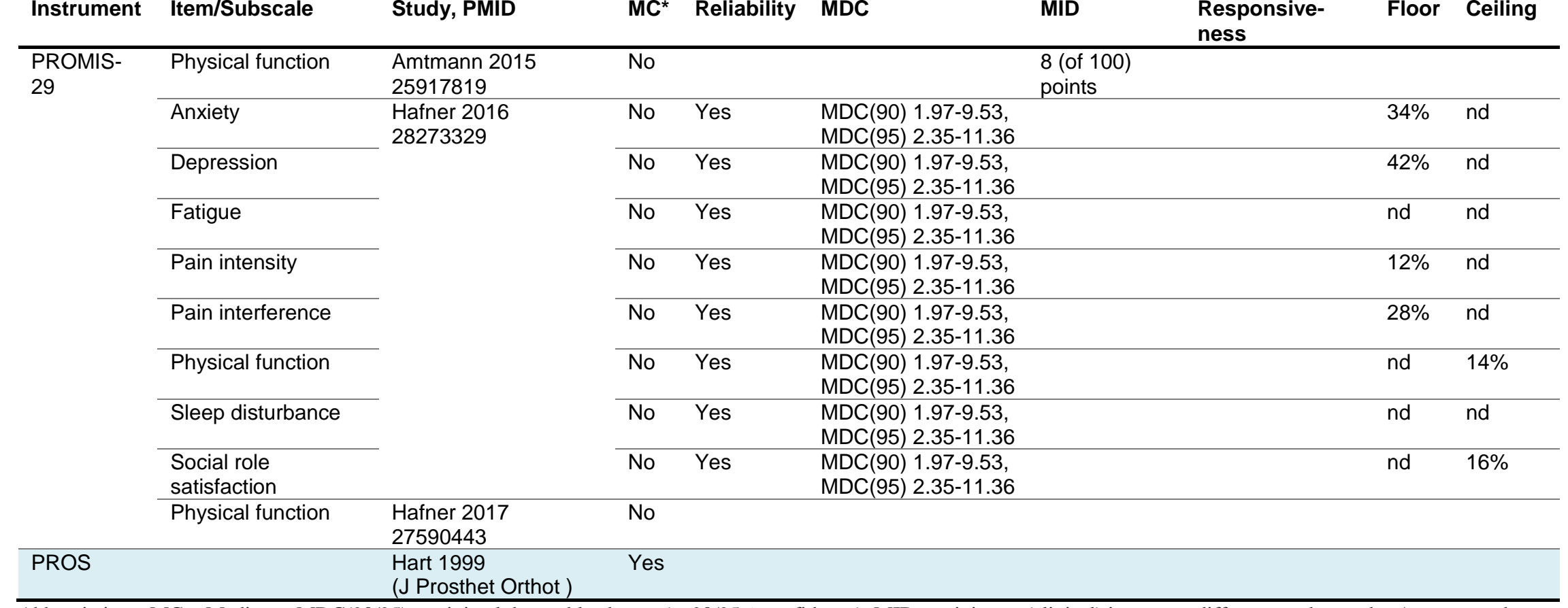

Abbreviations: MC = Medicare, MDC(90/95) = minimal detectable change (at 90/95\% confidence), MID = minimum (clinical) important difference, nd = no data/not reported, PMID = PubMed identifier (or journal), PROMIS = Patient-Reported Outcomes Measurement Information System, PROS = Prosthetist's Perception of Client's Ambulatory Abilities.

Note: Shading included only to more clearly distinguish separate instruments. Empty cells under Item/Subscale indicate that there are no instrument items or subscales or they were not evaluated. Empty cells in the psychometric properties columns indicate no evidence regarding this construct.

*Whether study was deemed generalizable to the Medicare population based on average age greater than 65 years and/or at least $50 \%$ of participants with dysvascular etiologies for their amputations. 


\section{PSFS}

The Patient-Specific Functional Scale is an individualized assessment of patient-specific activities that they find difficult to perform due to their amputation and how they would rate their current abilities to complete those activities. One study ${ }^{37}$ evaluated the psychometric properties of the PSFS in 44 people with lower limb amputations (see Tables 33 to 35). The study was deemed to be generalizable to the Medicare population for the average age of participants (66 years) although the percentage of study participants with dysvascular disease not reported.

The study provided evidence of reliability, an MDC(90) of 11.2, and no floor nor ceiling effects.

Overall, for PSFS, in a study generalizable to the Medicare population there is evidence of reliability without a floor or ceiling effect.

\section{Q-TFA}

The Questionnaire for Persons with a Transfemoral Amputation measures Prosthetic Use, Prosthetic Mobility, Problem, and Global Health as separate scores for nonelderly transfemoral amputees. One study ${ }^{66}$ evaluated the psychometric properties of the Q-TFA in 156 people with lower limb amputations (see Tables 33 to 35). The study was not deemed to be generalizable to the Medicare population based on average age less than 65 years and the percentage of study participants with dysvascular disease not being reported.

The study reported convergent validity compared with the SF-36 and the PCS. As predicted, the SF-36 MCS did not have convergent validity with Q-TFA. The subscales Prosthetic Use, Prosthetic Mobility, and Problem were found to be reliable, but not Global Health. A ceiling effect was found for the Prosthetic Use subscale (31\%), but not the other subscales.

Overall, for Q-TFA, from a study not generalizable to the Medicare population, there is evidence of test validity, reliability for the subscales Prosthetic Use, Prosthetic Mobility, and Problems, but not Global Health, and a ceiling effect for just the Prosthetic Use subscale.

\section{Rising and Sitting Down Questionnaire}

The Rising and Sitting Down Questionnaire is a 39 item self-report measure assessing limitations in the activities of rising and sitting down, using a dichotomous response format. One study ${ }^{56}$ evaluated the psychometric properties of the Rising and Sitting Down Questionnaire in 171 people with lower limb amputations (see Tables 33 to 35). The study was deemed to be generalizable to the Medicare population for the average age of participants (65 years) and the relatively high percentage of study participants with dysvascular disease (83\%).

The study reported convergent validity compared with the LCI, the Climbing Stairs Questionnaire, and the Walking Questionnaire. The study also provided evidence of reliability.

Overall, for the Rising and Sitting Down Questionnaire, from a study generalizable to the Medicare population, there is evidence of test validity and reliability.

\section{RMI}

The Rivermead Mobility Index assesses mobility as a cumulative index. Three studies ${ }^{48,67,68}$ evaluated the psychometric properties of the RMI in 390, total, people with lower limb amputations (see Tables 33 to 35). One of the studies was deemed to be generalizable to the 
Medicare population based on the relatively high percentage of study participants with dysvascular disease (53\%) although the average age in all three studies was less than 65 years.

The studies reported convergent validity compared with the FIM Motor subscale, TWT, LCI and LCI-5, and the RMI. Structural validity of the RMI was supported in one of the studies through Rasch analysis; most items fit the model, but some redundancy was observed. Two of the studies provided evidence of reliability for RMI, and evidence of responsiveness was found in one (effect size of 1.35). No floor or ceiling effects were observed.

Overall, for RMI, there is evidence, including from a study generalizable to the Medicare population, of test validity, reliability, responsiveness, and no floor or ceiling effect.

\section{SAT-PRO}

The Satisfaction with Prosthesis Questionnaire is a self-report tool measuring satisfaction with a prosthesis. One study ${ }^{69}$ evaluated the psychometric properties of the SAT-PRO in 61 people with lower limb amputations (see Tables 33 to 35). The study was deemed to be generalizable to the Medicare population based on the average age of participants (71 years) and that all participants had dysvascular disease (100\%).

The study reported evidence of reliability for the SAT-PRO.

Overall, for SAT-PRO, from a study generalizable to the Medicare population, there is evidence of reliability.

\section{SCS}

The Socket Comfort Score is a one-item measure of prosthetic socket comfort. Two studies ${ }^{41 \text {, }}$ 70 evaluated the psychometric properties of the SCS in 93 people with lower limb amputations (see Tables 33 to 35). One study was deemed to be generalizable to the Medicare population for the average age of participants (67 years) and the relatively high percentage of study participants with dysvascular disease (66\%); the other study was not deemed generalizable to the Medicare population based on average age less than 65 years and the relatively low percentage of study participants with dysvascular disease (23\%).

The study generalizable to the Medicare population reported construct validity between the SCS and a prosthesis fit assessment conducted by a prosthetist or physician. Both studies provided evidence of reliability. One of the studies reported the minimal detectable change at $90 \%$ confidence, MDC(90), for ranging from 2.31 to 3.03; the MDC(95) ranged from 2.75 to 3.61. Neither floor nor ceiling effects were observed.

Overall, for the SCS, there is evidence of test validity and reliability from a study generalizable to the Medicare population. Another study provided evidence of a lack of floor or ceiling effect. 
Table 33. Study descriptive data: PSFS through SCS

\begin{tabular}{|c|c|c|c|c|c|c|c|c|c|c|}
\hline Instrument & Item/Subscale & Study, PMID & $\mathbf{N}$ & Age* $^{*}$ & $\begin{array}{l}\text { Dysvasc } \dagger \text {, } \\
\%\end{array}$ & $\begin{array}{l}\text { Traumat, } \\
\%\end{array}$ & $\begin{array}{l}\text { TF†, } \\
\%\end{array}$ & $\begin{array}{l}\text { TT†, } \\
\%\end{array}$ & $\begin{array}{l}\text { Uni†, } \\
\%\end{array}$ & $\begin{array}{l}\mathrm{Bi \dagger}, \\
\%\end{array}$ \\
\hline PSFS & & $\begin{array}{l}\text { Resnik } 2011 \\
21310896\end{array}$ & 44 & $66(13)$ & nd & nd & 52 & 43 & 100 & 0 \\
\hline Q-TFA & $\begin{array}{l}\text { Global health } \\
\text { Prosthetic use } \\
\text { Prosthetic } \\
\text { mobility } \\
\text { Problem }\end{array}$ & $\begin{array}{l}\text { Hagberg } 2004 \\
15558399\end{array}$ & 156 & $51(13.1)$ & 8 & 55 & 100 & 0 & 100 & 0 \\
\hline $\begin{array}{l}\text { Rising and Sitting Down } \\
\text { Questionnaire }\end{array}$ & & $\begin{array}{l}\text { de Laat } 2011 \\
21807151\end{array}$ & 171 & $\begin{array}{l}65(11)[37- \\
92]\end{array}$ & 83 & 8 & 32 & 54 & 93 & 7 \\
\hline \multirow[t]{3}{*}{ RMI } & & $\begin{array}{l}\text { Franchignoni } 2003 \\
12809197\end{array}$ & 140 & $57(18)$ & 53 & 32 & 56 & 44 & 100 & 0 \\
\hline & & $\begin{array}{l}\text { Franchignoni } 2004 \\
15129398\end{array}$ & 50 & $51[21-86]$ & 32 & 58 & 60 & 40 & 100 & 0 \\
\hline & & Ryall 200312648004 & 200 & $\begin{array}{l}57.2(17.7) \\
{[13-90]}\end{array}$ & 32 & 40 & 41 & 57 & 88 & 13 \\
\hline SAT-PRO & & $\begin{array}{l}\text { Bilodeau } 1999 \\
10462879\end{array}$ & 61 & $71.3(6.3)$ & 100 & 0 & 44 & 56 & 100 & 0 \\
\hline \multirow[t]{2}{*}{ SCS } & & $\begin{array}{l}\text { Hafner } 2016 \\
28273329\end{array}$ & 201 & $60.2(11.4)$ & 23 & 60 & 35 & 65 & nd & nd \\
\hline & & $\begin{array}{l}\text { Hanspal } 2003 \\
14617445 \\
\end{array}$ & 44 & $66.8(13.0)$ & 66 & 23 & 41 & 73 & 84 & 16 \\
\hline
\end{tabular}

Abbreviations: $\mathrm{Bi}=$ bilateral amputation, Dysvasc = dysvascular disease (including diabetes), nd = no data/not reported, PMID = PubMed identifier (or journal), PSFS = Patient-

Specific Functional Scale, Q-TFA = Questionnaire for Person with a Transfemoral Amputation, RMI = Rivermead Mobility Index, SAT-PRO = Satisfaction with Prosthesis

Questionnaire, SCS = Socket Comfort Score, TF = transfemoral (above the knee) amputation, TT = transtibial (below the knee) amputation, Uni = unilateral amputation.

Note: Shading included only to more clearly distinguish separate instruments. Empty cells under Item/Subscale indicate that there are no instrument items or subscales or they were not evaluated.

*Mean or median with standard deviation in parentheses and range in square brackets.

†Percentages of study participants with other amputation etiologies, amputation levels, and unreported etiologies, levels, or unilateral versus bilateral amputation are omitted from this summary table. See Appendix C for further details. Transfemoraland transtibial data may sum to more than 100\% because of double counting of participants with bilateral amputations. 
Table 34. Summary of instrument psychometric validity properties: PSFS through SCS

\begin{tabular}{|c|c|c|c|c|c|c|c|c|}
\hline Instrument & Item/Subscale & Study, PMID & $M C^{*}$ & $\begin{array}{l}\text { Convergent Validity } \\
\text { (Concurrent) }\end{array}$ & $\begin{array}{l}\text { Divergent } \\
\text { Validity } \\
\text { (Discriminant) }\end{array}$ & Construct Validity & $\begin{array}{l}\text { Structural } \\
\text { Validity }\end{array}$ & $\begin{array}{l}\text { Predictive } \\
\text { Validity } \dagger\end{array}$ \\
\hline PSFS & & $\begin{array}{l}\text { Resnik } 2011 \\
21310896\end{array}$ & Yes & & & & & \\
\hline \multirow[t]{4}{*}{ Q-TFA } & Global health & $\begin{array}{l}\text { Hagberg } 2004 \\
15558399\end{array}$ & No & Yes (SF-36) & & & & \\
\hline & Prosthetic use & & No & $\begin{array}{l}\text { Yes (PCS), Mixed } \\
\text { (MCS), as predicted }\end{array}$ & & & & \\
\hline & Prosthetic mobility & & No & $\begin{array}{l}\text { Yes (PCS), Mixed } \\
\text { (MCS), as predicted }\end{array}$ & & & & \\
\hline & Problem & & No & Yes (SF-36) & & & & \\
\hline $\begin{array}{l}\text { Rising and } \\
\text { Sitting Down } \\
\text { Questionnaire }\end{array}$ & & $\begin{array}{l}\text { de Laat } 2011 \\
21807151\end{array}$ & Yes & $\begin{array}{l}\text { Yes (LCl, Climbing } \\
\text { Stairs Questionnaire, } \\
\text { Walking } \\
\text { Questionnaire) }\end{array}$ & & & & \\
\hline \multirow[t]{3}{*}{ RMI } & & $\begin{array}{l}\text { Franchignoni } \\
200312809197\end{array}$ & Yes & $\begin{array}{l}\text { Yes (FIM motor, } \\
\text { TWT) }\end{array}$ & & & & \\
\hline & & $\begin{array}{l}\text { Franchignoni } \\
200415129398\end{array}$ & No & $\begin{array}{l}\text { Yes (LCl, LCl-5, } \\
\text { RMI) }\end{array}$ & & & & \\
\hline & & $\begin{array}{l}\text { Ryall } 2003 \\
12648004\end{array}$ & No & Yes (TWT) & & & $\begin{array}{l}\text { Rasch: Most } \\
\text { items fit } \\
\text { model but } \\
\text { some } \\
\text { redundancy }\end{array}$ & \\
\hline SAT-PRO & & $\begin{array}{l}\text { Bilodeau } 1999 \\
10462879\end{array}$ & Yes & . & & & . & \\
\hline \multirow[t]{2}{*}{ SCS } & & $\begin{array}{l}\text { Hafner } 2016 \\
28273329\end{array}$ & No & & & & & \\
\hline & & $\begin{array}{l}\text { Hanspal } 2003 \\
14617445\end{array}$ & Yes & & & $\begin{array}{l}\text { Yes } \\
\text { (Prosthetist/Physician } \\
\text { fit assessment) }\end{array}$ & & \\
\hline
\end{tabular}

Abbreviations: FIM = Functional Independence Measure, LCI = Locomotor Capabilities Index, MC = Medicare, MCS = Mental Component Score, PCS = Physical Component Score, PMID = PubMed identifier (or journal), PSFS = Patient-Specific Functional Scale, Q-TFA = Questionnaire for Person with a Transfemoral Amputation, RMI = Rivermead Mobility Index, SAT-PRO = Satisfaction with Prosthesis Questionnaire, SCS = Socket Comfort Score, SF-36 = Short Form Health Survey-36, TWT = Timed Walk Test.

Note: Shading included only to more clearly distinguish separate instruments. Empty cells under Item/Subscale indicate that there are no instrument items or subscales or they were not evaluated. Empty cells in the validity columns indicate no evidence regarding this construct.

*Whether study was deemed generalizable to the Medicare population based on average age greater than 65 years and/or at least 50\% of participants with dysvascular etiologies for their amputations.

†Studies evaluated for predictive validity were assessed for Key Question 2. 
Table 35. Summary of other instrument psychometric properties: PSFS through SCS

\begin{tabular}{|c|c|c|c|c|c|c|c|c|c|}
\hline Instrument & Item/Subscale & Study, PMID & $M C^{*}$ & Reliability & MDC & MID & Responsiveness & Floor & Ceiling \\
\hline PSFS & . & $\begin{array}{l}\text { Resnik } 2011 \\
21310896\end{array}$ & Yes & Yes & MDC(90) 11.2 & & & No effect & $\begin{array}{l}\text { No } \\
\text { effect }\end{array}$ \\
\hline \multirow[t]{4}{*}{ Q-TFA } & Global health & $\begin{array}{l}\text { Hagberg } 2004 \\
15558399\end{array}$ & No & No & & & & $1 \%$ & $5 \%$ \\
\hline & Prosthetic use & & No & Yes & & & & $0 \%$ & $31 \%$ \\
\hline & $\begin{array}{l}\text { Prosthetic } \\
\text { mobility }\end{array}$ & & No & Yes & & & & $0 \%$ & $0 \%$ \\
\hline & Problem & & No & Yes & & & & $0 \%$ & $0 \%$ \\
\hline $\begin{array}{l}\text { Rising and Sitting } \\
\text { Down Questionnaire }\end{array}$ & & $\begin{array}{l}\text { de Laat } 2011 \\
21807151\end{array}$ & Yes & Yes & & & & & \\
\hline \multirow[t]{3}{*}{ RMI } & & $\begin{array}{l}\text { Franchignoni } 2003 \\
12809197\end{array}$ & Yes & Yes & & & Yes $(E S=1.35)$ & $0 \%$ & $0 \%$ \\
\hline & & $\begin{array}{l}\text { Franchignoni } 2004 \\
15129398\end{array}$ & No & & & & & & \\
\hline & & $\begin{array}{l}\text { Ryall } 2003 \\
12648004\end{array}$ & No & Yes & & & & $\begin{array}{l}0 \% \\
\text { (implied) }\end{array}$ & $11 \%$ \\
\hline SAT-PRO & & $\begin{array}{l}\text { Bilodeau } 1999 \\
10462879\end{array}$ & Yes & Yes & & & & . & . \\
\hline \multirow[t]{2}{*}{ SCS } & & $\begin{array}{l}\text { Hafner } 2016 \\
28273329\end{array}$ & No & Yes & $\begin{array}{l}\text { MDC(90) 2.31-3.03, } \\
\text { MDC(95) 2.75-3.61 }\end{array}$ & & & nd & $14 \%$ \\
\hline & & $\begin{array}{l}\text { Hanspal } 2003 \\
14617445\end{array}$ & Yes & Yes & & & & & \\
\hline
\end{tabular}

Abbreviations: ES = effect size, MC = Medicare, MDC(90/95) = minimal detectable change (at 90/95\% confidence), MID = minimum (clinical) important difference, nd = no data/not reported, PMID = PubMed identifier (or journal), PSFS = Patient-Specific Functional Scale, Q-TFA = Questionnaire for Person with a Transfemoral Amputation, RMI = Rivermead Mobility Index, SAT-PRO = Satisfaction with Prosthesis Questionnaire, SCS = Socket Comfort Score.

Note: Shading included only to more clearly distinguish separate instruments. Empty cells under Item/Subscale indicate that there are no instrument items or subscales or they were not evaluated. Empty cells in the psychometric properties columns indicate no evidence regarding this construct.

*Whether study was deemed generalizable to the Medicare population based on average age greater than 65 years and/or at least $50 \%$ of participants with dysvascular etiologies for their amputations. 


\section{SF-12/SF-36/SF-36V}

The Short Form Health Surveys (SF-12 and SF-36) are generic measures of health-related quality of life (QoL) designed originally for the general population; the Short Form Health Survey-36 for use with veterans (SF-36V, also known as VR-36) is an adaptation designed for assessing the health status among the veteran population. The SF instruments can be scored as two summary measures, called the physical component score (PCS) and the mental component score (MCS) and include subscales (including physical functioning, bodily pain, role limitations due to physical health problems [role physical], role limitations due to personal or emotional problems [role emotional], emotional well-being, social functioning, energy/fatigue, and general health perceptions). Among people with LLPs, the SF instruments have been analyzed as a whole, as subscales, and parsed into numerous components subsets (from pairs of specific questions to the whole score). Two studies ${ }^{37,65}$ evaluated the psychometric properties of the SF12, SF-36, and SF-36V in 884 people with lower limb amputations (see Tables 36 to 38). Both studies were deemed to be generalizable to the Medicare population either for the average age of participants (66 years) or a relatively high percentage of study participants with dysvascular conditions (58\%).

\section{SF-12}

One study provided evidence that the SF-12 subscale PCS did not have convergent validity with PROS in people who were being evaluated for their first or replacement prosthesis. ${ }^{65}$ Rasch analysis of the SF-12 PCS supported clinically logical hierarchical ordering of the items within the subscale. The other subscales were not evaluated for convergent validity or by Rasch analysis. The SF-12 PCS, Role Physical (RP-2), and Bodily Pain (BP-2) discriminated among people by K level. The other evaluated scales did not (MCS, Role Emotional, and Mental Health). Test reliability was reported for RE-2, RP-2, BP-2, and MH-2.

\section{SF-36}

One study provided evidence that the SF-36 subscale PF-10 (10-item Physical Functioning score) did not have convergent validity with the PROS in people who were being evaluated for their first or replacement prosthesis. ${ }^{65}$ ) There was mixed evidence of divergent validity in discrimination by K levels for SF-36, such that the instrument differentiated three of the six possible pairs of K levels. One study provided evidence of structural validity for both. Rasch analysis supporting clinically logical hierarchical ordering of the items for PF-10 and PF-15 (a newly created15-item Physical Functioning score), but better fit was observed for PF-15 than PF10 .

\section{SF-36V}

One study provided evidence of reliability for all three subscales of the SF-36V. The study reported MDC(90) estimates for the subscales. Neither floor nor ceiling effects were observed for General Health or for Physical Function, but there was a ceiling effect for Role Physical $(18 \%)$.

\section{Overall}

The evidence supporting test validity of the SF instruments in the lower limb amputee population is mixed in studies generalizable to the Medicare population. There is evidence of test 
validity for: SF-12 PCS, Role Physical, Bodily Pain, and PF-15. There was also test validity for PF-10, but it performed poorer than a newly created PF-15. Studies have not provided evidence of test validity for Role Emotional or Mental Health. SF-36V has not been assessed for test validity. Evidence of reliability has been reported for PCS, Role Emotional, Role Physical, Bodily Pain, Mental Health, and three aspects of SF-36V. A ceiling effect has been reported for SF-36V Role Physical; the General Health, and Physical Functioning subscales did not have floor or ceiling effects.

\section{SIGAM}

The Special Interest Group of Amputation Medicine scale measures ambulation mobility (with walking aids if necessary) among lower limb amputees. Three studies (in two articles) ${ }^{71,72}$ evaluated the psychometric properties of the SIGAM in 267 people, total, with lower limb amputations (see Tables 36 to 38). One of the studies was deemed to be generalizable to the Medicare population due to the average age of participants (66 years); although the study did not report the number of participants with dysvascular etiologies for their amputations. The remaining two studies were not deemed to be generalizable to the Medicare population due to their relatively low average ages (57 and 61 years) and low percentages of study participants with dysvascular conditions (32\% and 17\%).

The one study deemed generalizable to the Medicare population provided evidence that the SIGAM had convergent validity with the Walking Questionnaire. One study provided evidence of structural validity through Rasch analysis supporting calibration between the SIGAM and RMI and an acceptable infit and outfit for the SIGAM. Two studies provided evidence of reliability and one study provided evidence of responsiveness with an effect size of 10.66 . No floor or ceiling effect were reported.

Overall, for SIGAM, there is evidence of test validity, including from a study generalizable to the Medicare population. From a study not generalizable to the Medicare population, there is also evidence of test reliability, responsiveness, and no floor or ceiling effect.

\section{Single Beam Test}

The Single Beam Test is measure of balance performance on three beams each 5.5 meters long. The three beams are narrow, intermediate width, or wide. One study ${ }^{69}$ evaluated the psychometric properties of the Single Beam Test in 93 people with lower limb amputations (see Tables 36 to 38). The study was not deemed to be generalizable to the Medicare population based on average age less than 65 years (47 years); the percentage of study participants with dysvascular disease was not reported.

The study provided evidence of a large floor effect ("too easy") for the wide (87\%) and intermediate (40\%) beams. The narrow beam had a large ceiling effect (32\% "too hard”), but no ceiling effect was observed for the wide or intermediate beams. Of note, the study reported that "each participant had at least one beam that was appropriately challenging to assess his or her balance ability."

Overall, for the Single Beam Test, from a study not generalizable to the Medicare population, across the three beams there is no floor or ceiling effect. 
Table 36. Study descriptive data: Short Form Health Surveys through Single Beam Test

\begin{tabular}{|c|c|c|c|c|c|c|c|c|c|c|}
\hline Instrument & Item/Subscale & Study, PMID & $\mathbf{N}$ & Age* $^{*}$ & $\begin{array}{l}\text { Dysvasc } \dagger, \\
\%\end{array}$ & $\begin{array}{l}\text { Trauma†, } \\
\%\end{array}$ & $\begin{array}{l}\text { TF†, } \\
\%\end{array}$ & $\begin{array}{l}\text { TT†, } \\
\%\end{array}$ & $\begin{array}{l}\text { Uni†, } \\
\%\end{array}$ & $\begin{array}{l}\text { Bi†, } \\
\%\end{array}$ \\
\hline \multirow[t]{3}{*}{$\begin{array}{l}\text { Short Form } \\
\text { Health } \\
\text { Surveys }\end{array}$} & $\begin{array}{l}\text { SF-12: MCS } \\
\text { PCS } \\
\text { Role emotional (RE-2) } \\
\text { Role Physical (RP-2) } \\
\text { Bodily Pain (BP-2) } \\
\text { Mental Health (MH-2) }\end{array}$ & $\begin{array}{l}\text { Hart } 1999 \text { (J Prosthet } \\
\text { Orthot) }\end{array}$ & 840 & $\begin{array}{l}56.3 \\
(\sim 17)\end{array}$ & 58 & 19 & 73 & nd & nd & 19 \\
\hline & $\begin{array}{l}\text { SF-36: Physical functioning (PF-15) } \\
\text { Physical functioning (PF-10) }\end{array}$ & $\begin{array}{l}\text { Hart } 1999 \text { (J Prosthet } \\
\text { Orthot) }\end{array}$ & 840 & $\begin{array}{l}56.3 \\
(\sim 17)\end{array}$ & 58 & 19 & 73 & nd & nd & 19 \\
\hline & $\begin{array}{l}\text { SF-36V: General health } \\
\text { Physical functioning } \\
\text { Role physical }\end{array}$ & Resnik 201121310896 & 44 & $\begin{array}{l}66 \\
(13)\end{array}$ & nd & nd & 52 & 43 & 100 & 0 \\
\hline \multirow[t]{3}{*}{ SIGAM } & & $\begin{array}{l}\text { de Laat } 2012 \\
22424695\end{array}$ & 34 & $\begin{array}{l}65 \\
(11) \\
{[37-} \\
92]\end{array}$ & nd & nd & nd & nd & nd & nd \\
\hline & & $\begin{array}{l}\text { Ryall } 200212851094 \text { - } \\
\text { Study } 1\end{array}$ & 200 & $\begin{array}{l}57.2 \\
(17.7) \\
{[13-} \\
90]\end{array}$ & 32 & 40 & 41 & 57 & 88 & 13 \\
\hline & & $\begin{array}{l}\text { Ryall } 200212851094 \text { - } \\
\text { Study } 2\end{array}$ & 33 & $\begin{array}{l}60.7 \\
(14.5)\end{array}$ & 17 & 12 & 48 & 48 & 100 & 0 \\
\hline $\begin{array}{l}\text { Single } \\
\text { Beam Test }\end{array}$ & $\begin{array}{l}\text { Wide Beam } \\
\text { Intermediate Beam } \\
\text { Narrow Beam }\end{array}$ & $\begin{array}{l}\text { Sawers } 2017 \\
28948848\end{array}$ & 30 & $\begin{array}{l}47.0 \\
(14.4)\end{array}$ & nd & nd & 37 & 63 & 100 & 0 \\
\hline
\end{tabular}

Abbreviations: $\mathrm{Bi}=$ bilateral amputation, Dysvasc = dysvascular disease (including diabetes), MCS = Mental Component Score, nd = no data/not reported, PCS = Physical

Component Score, PMID = PubMed identifier (or journal), SF-12 = Short Form Health Survey-12, SF-36 = Short Form Health Survey-36, SF-36V = Short Form Health Survey-36 adapted for veterans, SIGAM = Special Interest Group of Amputation Medicine scale, TF = transfemoral (above the knee) amputation, TT = transtibial (below the knee) amputation, Uni = unilateral amputation.

Note: Shading included only to more clearly distinguish separate instruments. Empty cells under Item/Subscale indicate that there are no instrument items or subscales or they were not evaluated.

*Mean or median with standard deviation in parentheses and range in square brackets.

†Percentages of study participants with other amputation etiologies, amputation levels, and unreported etiologies, levels, or unilateral versus bilateral amputation are omitted from this summary table. See Appendix C for further details. Transfemoral and transtibial data may sum to more than $100 \%$ because of double counting of participants with bilateral amputations. 
Table 37. Summary of instrument psychometric validity properties: Short Form Health Surveys through Single Beam Test

\begin{tabular}{|c|c|c|c|c|c|c|c|c|}
\hline Instrument & Item/Subscale & $\begin{array}{l}\text { Study, } \\
\text { PMID }\end{array}$ & $M C^{*}$ & $\begin{array}{l}\text { Convergent Validity } \\
\text { (Concurrent) }\end{array}$ & $\begin{array}{l}\text { Divergent } \\
\text { Validity } \\
\text { (Discriminant) }\end{array}$ & $\begin{array}{l}\text { Construct } \\
\text { Validity }\end{array}$ & $\begin{array}{l}\text { Structural } \\
\text { Validity }\end{array}$ & $\begin{array}{l}\text { Predictive } \\
\text { Validity } \dagger\end{array}$ \\
\hline \multirow{9}{*}{$\begin{array}{l}\text { Short Form } \\
\text { Health } \\
\text { Surveys }\end{array}$} & SF-12: MCS & \multirow{8}{*}{$\begin{array}{l}\text { Hart } 1999 \\
\text { (J Prosthet } \\
\text { Orthot) }\end{array}$} & Yes & & No (K levels) & & & \\
\hline & SF-12: PCS & & Yes & & Yes (K levels) & & $\begin{array}{l}\text { Rasch: } \\
\text { Clinically } \\
\text { logical } \\
\text { hierarchical } \\
\text { ordering }\end{array}$ & \\
\hline & SF-12: Role emotional (RE-2) & & Yes & & No (K levels) & & . & \\
\hline & SF-12: Role physical (RP-2) & & Yes & & Yes (K levels) & & . & \\
\hline & SF-12: Bodily pain (BP-2) & & Yes & & Yes (K levels) & & . & \\
\hline & SF-12: Mental Health (MH-2) & & Yes & & No (K levels) & & -1 & \\
\hline & $\begin{array}{l}\text { SF-36: Physical functioning } \\
\text { (PF-15) }\end{array}$ & & Yes & & . & & $\begin{array}{l}\text { Rasch: } \\
\text { Clinically } \\
\text { logical } \\
\text { hierarchical } \\
\text { ordering, } \\
\text { better fit than } \\
\text { PF-10 }\end{array}$ & \\
\hline & $\begin{array}{l}\text { SF-36: Physical functioning } \\
\text { (PF-10) }\end{array}$ & & Yes & No (PROS) & Mixed (K levels) & & $\begin{array}{l}\text { Rasch: } \\
\text { Clinically } \\
\text { logical } \\
\text { hierarchical } \\
\text { ordering }\end{array}$ & \\
\hline & $\begin{array}{l}\text { SF-36V: General health } \\
\text { Physical functioning } \\
\text { Role physical }\end{array}$ & $\begin{array}{l}\text { Resnik } \\
2011 \\
21310896 \\
\end{array}$ & Yes & . & & & & \\
\hline \multirow[t]{3}{*}{ SIGAM } & & $\begin{array}{l}\text { de Laat } \\
2012 \\
22424695\end{array}$ & Yes & $\begin{array}{l}\text { Yes (Walking } \\
\text { Questionnaire) }\end{array}$ & & & & \\
\hline & & $\begin{array}{l}\text { Ryall } 2002 \\
12851094- \\
\text { Study } 1\end{array}$ & No & & & & $\begin{array}{l}\text { Rasch: } \\
\text { Calibrates to } \\
\text { RMI, } \\
\text { acceptable } \\
\text { infit and outfit }\end{array}$ & \\
\hline & & $\begin{array}{l}\text { Ryall } 2002 \\
12851094- \\
\text { Study } 2\end{array}$ & No & & & & . & \\
\hline
\end{tabular}




\begin{tabular}{llllll}
\hline Instrument & Item/Subscale & MC* & $\begin{array}{l}\text { Convergent Validity } \\
\text { (Concurrent) }\end{array}$ & $\begin{array}{l}\text { Divergent } \\
\text { Validity } \\
\text { (Discriminant) }\end{array}$ & $\begin{array}{l}\text { Construct } \\
\text { Validity }\end{array}$ \\
\hline Single & Wide Beam & $\begin{array}{l}\text { Structural } \\
\text { Validity }\end{array}$ & $\begin{array}{l}\text { Predictive } \\
\text { Validity } \dagger\end{array}$ \\
Beam Test & Intermediate Beam & Sawers & No & & \\
& Narrow Beam & 2017 & & \\
\hline
\end{tabular}

Abbreviations: K level = Medicare Functional Classification Level, MC = Medicare, MCS = Mental Component Score, PCS = Physical Component Score, PMID = PubMed

identifier (or journal), PROS = prosthetist's perception of client's functional abilities, RMI = Rivermead Mobility Index, SF-12 = Short Form Health Survey-12, SF-36 = Short Form Health Survey-36, SF-36V = Short Form Health Survey-36 adapted for veterans, SIGAM = Special Interest Group of Amputation Medicine scale.

Note: Shading included only to more clearly distinguish separate instruments. Empty cells (with “.”) in the validity columns indicate no evidence regarding this construct.

*Whether study was deemed generalizable to the Medicare population based on average age greater than 65 years and/or at least $50 \%$ of participants with dysvascular etiologies for their amputations.

†Studies evaluated for predictive validity were assessed for Key Question 2. 
Table 38. Summary of other instrument psychometric properties: Short Form Health Surveys through Single Beam Test

\begin{tabular}{|c|c|c|c|c|c|c|c|c|c|}
\hline Instrument & Item/Subscale & Study, PMID & $\mathrm{MC}^{*}$ & Reliability & MDC & MID & Responsiveness & Floor & Ceiling \\
\hline \multirow{10}{*}{$\begin{array}{l}\text { Short Form Health } \\
\text { Surveys }\end{array}$} & SF-12: MCS & \multirow{7}{*}{$\begin{array}{l}\text { Hart } 1999(\mathrm{~J} \\
\text { Prosthet Orthot) }\end{array}$} & Yes & & & & & & \\
\hline & SF-12: PCS & & Yes & Yes & & & & & \\
\hline & $\begin{array}{l}\text { SF-12: Role emotional } \\
\text { (RE-2) }\end{array}$ & & Yes & Yes & & & & & \\
\hline & $\begin{array}{l}\text { SF-12: Role physical } \\
\text { (RP-2) }\end{array}$ & & Yes & Yes & & & & & \\
\hline & $\begin{array}{l}\text { SF-12: Bodily pain } \\
\text { (BP-2) }\end{array}$ & & Yes & Yes & & & & & \\
\hline & $\begin{array}{l}\text { SF-12: Mental Health } \\
(\mathrm{MH}-2)\end{array}$ & & Yes & Yes & & & & & \\
\hline & $\begin{array}{l}\text { SF-36: Physical } \\
\text { functioning (PF-15) } \\
\text { Physical functioning } \\
\text { (PF-10) }\end{array}$ & & Yes & . & & & & & \\
\hline & SF-36V: General health & \multirow[t]{3}{*}{$\begin{array}{l}\text { Resnik } 2011 \\
21310896\end{array}$} & Yes & Yes & $\begin{array}{l}\operatorname{MDC}(90) \\
17.1\end{array}$ & & & No effect & No effect \\
\hline & $\begin{array}{l}\text { SF-36V: Physical } \\
\text { functioning }\end{array}$ & & Yes & Yes & $\begin{array}{l}\operatorname{MDC}(90) \\
34.2\end{array}$ & & & No effect & No effect \\
\hline & SF-36V: Role physical & & Yes & Yes & $\begin{array}{l}\operatorname{MDC}(90) \\
26.3\end{array}$ & & & $3 \%$ & $18 \%$ \\
\hline \multirow[t]{3}{*}{ SIGAM } & . & $\begin{array}{l}\text { de Laat } 2012 \\
22424695\end{array}$ & Yes & & & & & & \\
\hline & . & $\begin{array}{l}\text { Ryall } 2002 \\
12851094 \text { - Study } 1\end{array}$ & No & Yes & & & & $\begin{array}{l}6.5 \% \text { floor or } \\
\text { ceiling }\end{array}$ & \\
\hline & . & $\begin{array}{l}\text { Ryall } 2002 \\
12851094 \text { - Study } 2\end{array}$ & No & Yes & & & Yes $(E S=10.66)$ & & \\
\hline \multirow[t]{3}{*}{ Single Beam Test } & Wide Beam & \multirow[t]{3}{*}{$\begin{array}{l}\text { Sawers } 2017 \\
28948848\end{array}$} & No & & & & & $87 \%$ & $0 \%$ \\
\hline & Intermediate Beam & & No & & & & & $40 \%$ & $10 \%$ \\
\hline & Narrow Beam & & No & & & & & $3 \%$ & $32 \%$ \\
\hline
\end{tabular}

Abbreviations: ES = effect size, MC = Medicare, MDC(90) = minimal detectable change (at 90\% confidence), MID = minimum (clinical) important difference, PMID = PubMed identifier (or journal), SF-12 = Short Form Health Survey-12, SF-36 = Short Form Health Survey-36, SF-36V = Short Form Health Survey-36 adapted for veterans, SIGAM = Special Interest Group of Amputation Medicine scale.

Note: Shading included only to more clearly distinguish separate instruments. Empty cells under Item/Subscale indicate that there are no instrument items or subscales or they were not evaluated. Empty cells in the psychometric properties columns indicate no evidence regarding this construct.

*Whether study was deemed generalizable to the Medicare population based on average age greater than 65 years and/or at least $50 \%$ of participants with dysvascular etiologies for their amputations. 


\section{SIP-PD}

The Sickness Impact Profile-Physical Dimension is a generic, self-report measure used to assess the impact of illness on health-related functional status. The instrument can be scored in total and has three subscales: Ambulation, Body Care and Movement, and Mobility. One study ${ }^{55}$ evaluated the psychometric properties of the SIP-PD in 107 people with lower limb amputations (see Tables 39 to 41). The study was not deemed to be generalizable to the Medicare population; the average age of participants was 35 years old and no participants had dysvascular etiologies for their amputations.

The study provided evidence of moderate convergent validity between the overall SIP-PD instrument and both LCI and PFI. The overall instrument and the subscales of Ambulation, Body care and movement, and Mobility did not discriminate based on amputation level, injury severity score, age, or comorbidities. There was evidence of construct validity for the three subscales and the overall instrument when compared to walking speed and return to usual activity (except that the Ambulation subscale did not correlate with return to usual activity). The total instrument and the three subscales were found to have reliability, but not responsiveness for walking speed or return to usual activity. Floor effects were observed for the subscales of Ambulation (16\%), Body care and movement (36\%), and Mobility (64\%), but not for the overall instrument; no ceiling effects were observed.

Overall, for SIP-PD, there is evidence of test validity and reliability, but not responsiveness, for the overall instrument and its three subscales. The three subscales, but not the overall instrument, were reported to have floor effects. However, these findings are not generalizable to the Medicare population.

\section{Tandem Test}

The Tandem Test measures duration of maintaining a full-tandem stance without support, with the amputated limb placed behind the unaffected limb. One study ${ }^{29}$ evaluated the psychometric properties of the Tandem Test in 64 people with lower limb amputations (see Tables 39 to 41). The study was deemed to be generalizable to the Medicare population based on the high percentage of study participants with dysvascular disease (66\%); although the average age was under 65 years old.

The study reported that the Tandem Test did not have divergent validity to discriminate people based on the Houghton Scale. Large floor and ceiling effects were observed (each 44\%).

Overall, for the Tandem Test, there is not evidence of test validity and the instrument has large floor and ceiling effects in a study generalizable to the Medicare population. 
Table 39. Study descriptive data: SIP-PD through Tandem Test

\begin{tabular}{|c|c|c|c|c|c|c|c|c|c|c|}
\hline Instrument & Item/Subscale & Study, PMID & $\mathbf{N}$ & Age* $^{*}$ & Dysvasc $\dagger, \%$ & Trauma†, \% & $\begin{array}{l}\text { TF†, } \\
\%\end{array}$ & $\begin{array}{l}\text { TT†, } \\
\%\end{array}$ & $\begin{array}{l}\text { Uni†, } \\
\%\end{array}$ & $\begin{array}{l}\mathrm{Bi \dagger}, \\
\%\end{array}$ \\
\hline SIP-PD & $\begin{array}{l}\text { Ambulation } \\
\text { Body care and movement } \\
\text { Mobility } \\
\text { Total (Overall) }\end{array}$ & $\begin{array}{l}\text { Cyril } 2001 \text { (Johns } \\
\text { Hopkins) }\end{array}$ & 107 & $\begin{array}{l}35 \\
(12.5)\end{array}$ & 0 & 100 & 21 & 67 & 100 & 0 \\
\hline Tandem Test & & $\begin{array}{l}\text { Gremeaux } 2012 \\
22389424\end{array}$ & 64 & $58(16)$ & 66 & 25 & 27 & 73 & 100 & 0 \\
\hline
\end{tabular}

Abbreviation: Bi = bilateral amputation, Dysvasc = dysvascular disease (including diabetes), nd = no data/not reported, PMID = PubMed identifier (or journal), SIP-PD = Sickness Impact Profile-Physical Dimension, TF = transfemoral (above the knee) amputation, TT = transtibial (below the knee) amputation, Uni $=$ unilateral amputation.

Note: Shading included only to more clearly distinguish separate instruments. Empty cells under Item/Subscale indicate that there are no instrument items or subscales or they were not evaluated.

*Mean or median with standard deviation in parentheses and range in square brackets.

†Percentages of study participants with other amputation etiologies, amputation levels, and unreported etiologies, levels, or unilateral versus bilateral amputation are omitted from this summary table. See Appendix C for further details. Transfemoral and transtibial data may sum to more than $100 \%$ because of double counting of participants with bilateral amputations.

\section{Table 40. Summary of instrument psychometric validity properties: SIP-PD through Tandem Test}

\begin{tabular}{|c|c|c|c|c|c|c|c|c|}
\hline Instrument & Item/Subscale & Study, PMID & $\mathrm{MC}^{*}$ & $\begin{array}{l}\text { Convergent Validity } \\
\text { (Concurrent) }\end{array}$ & $\begin{array}{l}\text { Divergent Validity } \\
\text { (Discriminant) }\end{array}$ & $\begin{array}{l}\text { Construct } \\
\text { Validity }\end{array}$ & $\begin{array}{l}\text { Structural } \\
\text { Validity }\end{array}$ & $\begin{array}{l}\text { Predictive } \\
\text { Validity } \dagger \\
\end{array}$ \\
\hline \multirow[t]{4}{*}{ SIP-PD } & & \multirow[t]{4}{*}{$\begin{array}{l}\text { Cyril } 2001 \\
\text { (Johns } \\
\text { Hopkins) }\end{array}$} & No & Moderate (LCl, PFI) & $\begin{array}{l}\text { No (amputation level, } \\
\text { injury severity score, } \\
\text { age, comorbidities) }\end{array}$ & $\begin{array}{l}\text { Yes (walking } \\
\text { speed, return to } \\
\text { usual activity) }\end{array}$ & & \\
\hline & Ambulation & & No & & $\begin{array}{l}\text { No (amputation level, } \\
\text { injury severity score, } \\
\text { age, comorbidities) }\end{array}$ & $\begin{array}{l}\text { Yes (walking } \\
\text { speed), } \\
\text { No (return to } \\
\text { usual activity) }\end{array}$ & & \\
\hline & $\begin{array}{l}\text { Body care and } \\
\text { movement }\end{array}$ & & No & & $\begin{array}{l}\text { No (amputation level, } \\
\text { injury severity score, } \\
\text { age, comorbidities) }\end{array}$ & $\begin{array}{l}\text { Yes (walking } \\
\text { speed, return to } \\
\text { usual activity) }\end{array}$ & & \\
\hline & Mobility & & No & & $\begin{array}{l}\text { No (amputation level, } \\
\text { injury severity score, } \\
\text { age, comorbidities) }\end{array}$ & $\begin{array}{l}\text { Yes (walking } \\
\text { speed, return to } \\
\text { usual activity) }\end{array}$ & & \\
\hline $\begin{array}{l}\text { Tandem } \\
\text { Test }\end{array}$ & & $\begin{array}{l}\text { Gremeaux } \\
2012 \\
22389424\end{array}$ & Yes & & No (Houghton) & & & \\
\hline
\end{tabular}

Abbreviations: LCI = Locomotor Capabilities Index, MC = Medicare, PFI = Physical Function Index, PMID = PubMed identifier (or journal), SIP-PD = Sickness Impact ProfilePhysical Dimension.

Note: Shading included only to more clearly distinguish separate instruments. Empty cells under Item/Subscale indicate that there are no instrument items or subscales or they were not evaluated. Empty cells (with “.”) in the validity columns indicate no evidence regarding this construct. 
*Whether study was deemed generalizable to the Medicare population based on average age greater than 65 years and/or at least $50 \%$ of participants with dysvascular etiologies for their amputations.

†Studies evaluated for predictive validity were assessed for Key Question 2.

Table 41. Summary of other instrument psychometric properties: SIP-PD through Tandem Test

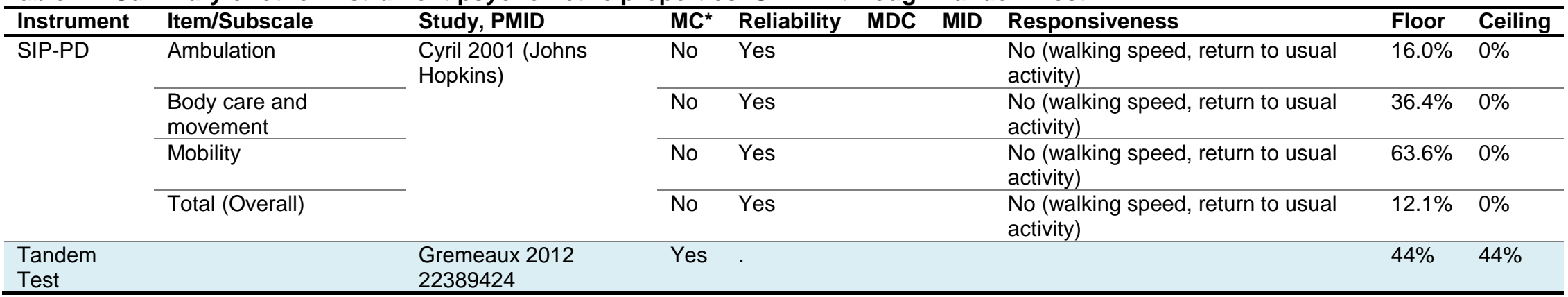

Abbreviations: MC = Medicare, MDC = minimal detectable change, MID = minimum (clinical) important difference, PMID = PubMed identifier (or journal), SIP-PD = Sickness Impact Profile-Physical Dimension.

Note: Shading included only to more clearly distinguish separate instruments. Empty cells under Item/Subscale indicate that there are no instrument items or subscales or they were not evaluated. Empty cells in the psychometric properties columns indicate no evidence regarding this construct.

*Whether study was deemed generalizable to the Medicare\population based on average age greater than 65 years and/or at least $50 \%$ of participants with dysvascular etiologies for their amputations. 


\section{TAPES}

The Trinity Amputation and Prosthesis Experience Scales is a multidimensional self-report instrument that evaluates the experience of amputation and adjustment to a lower limb prosthesis. Two studies ${ }^{73,74}$ the psychometric properties of the TAPES in 123 people, total, with lower limb amputations and a third study ${ }^{75}$ evaluated the revised version of the TAPES (TAPESR) in 359 people with lower limb amputations (see Tables 42 to 44). The original TAPES has three main sections: Psychomotor, Activity Restriction, and Prosthesis Satisfaction. Each of these has three different aspects, as listed in the tables. The revised version had items divided somewhat differently, as listed in the tables. The three studies were not deemed to be generalizable to the Medicare population due to their relatively low average ages (47-55 years) and low percentage of study participants with dysvascular conditions $(<50 \%)$.

\section{TAPES (Original)}

The studies provided evidence that the TAPES subscales mostly had convergent validity with several other tests (WHOQOL-BREF, Impact of Events Scale, TMMS), in at least one study. Satisfaction with weight was evaluated only in one study and was not reported to have convergent validity with WHOQOL-BREF. Several subscales had construct validity in regards to the number of hours per day of prosthesis worn , including General adjustment, Functional restriction, Social restriction, Athletic restriction, and Functional satisfaction. One study reported evidence of reliability for each of the TAPES subscales.

\section{TAPES-R}

The revised version of the Trinity Amputation and Prosthesis Experience Scales (TAPES-R), like the original TAPES, evaluates the experience of amputation and adjustment to a lower limb prosthesis; the TAPES-R uses a simplified structure including reworded or removed items and changes to rating scales. The study of TAPES- $\mathrm{R}^{75}$ provided evidence of structural validity for each of the subscales by Rasch analysis and of reliability for all the subscales except Satisfaction with Prostheses Subscale 1, which included four items about esthetics (color, shape, and appearance).

\section{Overall}

Overall, for both the original TAPES and the revised TAPES-R, there is evidence of test validity and reliability for the various subscales except Weight Satisfaction (which was reported to have reliability but not test validity) and the esthetic portion of the TAPES-R Satisfaction with Prosthesis Subscale (which lacked reliability). These findings are not generalizable to the Medicare population. 


\section{Table 42. Study descriptive data: TAPES}

\begin{tabular}{|c|c|c|c|c|c|c|c|c|c|c|}
\hline Instrument & Item/Subscale & Study, PMID & $\mathbf{N}$ & Age* $^{*}$ & Dysvasc $†, \%$ & Trauma†, \% & $\begin{array}{l}\text { TF†, } \\
\%\end{array}$ & $\begin{array}{l}\begin{array}{l}\text { TT†, } \\
\%\end{array} \\
\end{array}$ & $\begin{array}{l}\text { Uni†, } \\
\%\end{array}$ & $\begin{array}{l}\mathrm{Bi \dagger}, \\
\%\end{array}$ \\
\hline \multirow[t]{3}{*}{ TAPES } & $\begin{array}{l}\text { Psychosocial: General } \\
\text { Adjustment } \\
\text { Psychosocial: Social } \\
\text { Adjustment } \\
\text { Psychosocial: Adjustment to } \\
\text { Limitation } \\
\text { Activity: Functional } \\
\text { Restriction } \\
\text { Activity: Social Restriction } \\
\text { Activity: Athletic Restriction } \\
\text { Satisfaction: Functional } \\
\text { Satisfaction } \\
\text { Satisfaction: Aesthetic } \\
\text { Satisfaction }\end{array}$ & $\begin{array}{l}\text { Gallagher } 2000 \\
\text { (Rehab Psychol) }\end{array}$ & 60 & $\begin{array}{l}47.1[19- \\
84]\end{array}$ & 12 & 45 & 33 & 48 & 98 & 2 \\
\hline & Same as Gallagher 2000 & $\begin{array}{l}\text { Gallagher } 2004 \\
15129396\end{array}$ & 63 & $\begin{array}{l}47.5 \\
(18.4)\end{array}$ & nd & 43 & 40 & 57 & 100 & 0 \\
\hline & Revised (TAPES-R) & $\begin{array}{l}\text { Gallagher } 2010 \\
20489393\end{array}$ & 359 & $\begin{array}{l}54.8 \\
(18.6)\end{array}$ & 49 & 47 & 47 & 80 & 94 & 6 \\
\hline
\end{tabular}

Shading included only to more clearly distinguish separate instruments. Empty cells under Item/Subscale indicate that there are no instrument items or subscales or they were not evaluated.

Abbreviations: $\mathrm{Bi}=$ bilateral amputation, Dysvasc $=$ dysvascular disease (including diabetes), $\mathrm{nd}=$ no data/not reported, PMID $=$ PubMed identifier $($ or journal), TAPES $=$ Trinity Amputation and Prosthesis Experience Scales, TF $=$ transfemoral (above the knee) amputation, $\mathrm{TT}=$ transtibial (below the knee) amputation, Uni $=$ unilateral amputation.

*Mean or median with standard deviation in parentheses and range in square brackets.

$\dagger$ Percentages of study participants with other amputation etiologies, amputation levels, and unreported etiologies, levels, or unilateral versus bilateral amputation are omitted from this summary table. See Appendix C for further details. Transfemoral and transtibial data may sum to more than $100 \%$ because of double counting of participants with bilateral amputations. 
Table 43. Summary of instrument psychometric validity properties: TAPES

\begin{tabular}{|c|c|c|c|c|c|c|c|c|}
\hline Instrument & Item/Subscale & $\begin{array}{l}\text { Study, } \\
\text { PMID }\end{array}$ & MC* & $\begin{array}{l}\text { Convergent Validity } \\
\text { (Concurrent) }\end{array}$ & $\begin{array}{l}\text { Divergent } \\
\text { Validity } \\
\text { (Discriminant) } \\
\end{array}$ & $\begin{array}{l}\text { Construct } \\
\text { Validity }\end{array}$ & $\begin{array}{l}\text { Structural } \\
\text { Validity }\end{array}$ & $\begin{array}{l}\text { Predictive } \\
\text { Validity } \dagger\end{array}$ \\
\hline \multirow[t]{13}{*}{ TAPES } & $\begin{array}{l}\text { Psychosocial: General } \\
\text { Adjustment }\end{array}$ & \multirow[t]{9}{*}{$\begin{array}{l}\text { Gallagher } \\
2000 \\
\text { (Rehab } \\
\text { Psychol) }\end{array}$} & No & $\begin{array}{l}\text { Yes (WHOQOL-BREF } \\
\text { psychological; IES } \\
\text { intrusion, avoidance; } \\
\text { TMMS clarity of feelings, } \\
\text { repair) }\end{array}$ & & $\begin{array}{l}\text { Yes (hours } \\
\text { worn per } \\
\text { day) }\end{array}$ & & \\
\hline & $\begin{array}{l}\text { Psychosocial: Social } \\
\text { Adjustment }\end{array}$ & & No & $\begin{array}{l}\text { Yes (WHOQOL-BREF } \\
\text { social relationships; IES } \\
\text { intrusion, avoidance; } \\
\text { TMMS clarity of feelings, } \\
\text { repair) }\end{array}$ & & & & \\
\hline & $\begin{array}{l}\text { Psychosocial: Adjustment } \\
\text { to Limitation }\end{array}$ & & No & $\begin{array}{l}\text { Yes (WHOQOL-BREF } \\
\text { physical health; IES } \\
\text { intrusion, avoidance; } \\
\text { TMMS clarity of feelings, } \\
\text { repair) }\end{array}$ & & & & \\
\hline & $\begin{array}{l}\text { Activity: Functional } \\
\text { Restriction }\end{array}$ & & No & $\begin{array}{l}\text { Yes (WHOQOL-BREF } \\
\text { physical health) }\end{array}$ & & $\begin{array}{l}\text { Yes (hours } \\
\text { worn/day) }\end{array}$ & & \\
\hline & Activity: Social Restriction & & No & $\begin{array}{l}\text { Yes (WHOQOL-BREF } \\
\text { social relationships) }\end{array}$ & & $\begin{array}{l}\text { Yes (hours } \\
\text { worn/day) }\end{array}$ & & \\
\hline & $\begin{array}{l}\text { Activity: Athletic } \\
\text { Restriction }\end{array}$ & & No & $\begin{array}{l}\text { Yes (WHOQOL-BREF } \\
\text { physical health) }\end{array}$ & & $\begin{array}{l}\text { Yes (hours } \\
\text { worn/day) }\end{array}$ & & \\
\hline & $\begin{array}{l}\text { Satisfaction: Functional } \\
\text { Satisfaction }\end{array}$ & & No & $\begin{array}{l}\text { Yes (WHOQOL-BREF } \\
\text { social relationships) }\end{array}$ & & $\begin{array}{l}\text { Yes (hours } \\
\text { worn/day) }\end{array}$ & & \\
\hline & $\begin{array}{l}\text { Satisfaction: Aesthetic } \\
\text { Satisfaction }\end{array}$ & & No & $\begin{array}{l}\text { Yes (WHOQOL-BREF } \\
\text { social relationships) }\end{array}$ & & & & \\
\hline & $\begin{array}{l}\text { Satisfaction: Weight } \\
\text { Satisfaction }\end{array}$ & & & & & & & \\
\hline & $\begin{array}{l}\text { Psychosocial: General } \\
\text { Adjustment }\end{array}$ & \multirow[t]{4}{*}{$\begin{array}{l}\text { Gallagher } \\
2004 \\
15129396\end{array}$} & No & $\begin{array}{l}\text { Yes (WHOQOL-BREF } \\
\text { Physical health, } \\
\text { Psychological health, } \\
\text { Social relations, } \\
\text { Environment) }\end{array}$ & & & & \\
\hline & $\begin{array}{l}\text { Psychosocial: Social } \\
\text { Adjustment }\end{array}$ & & No & $\begin{array}{l}\text { Yes (WHOQOL-BREF } \\
\text { Psychological health, } \\
\text { Social relations) }\end{array}$ & & & & \\
\hline & $\begin{array}{l}\text { Psychosocial: Adjustment } \\
\text { to Limitation }\end{array}$ & & No & $\begin{array}{l}\text { Yes (WHOQOL-BREF } \\
\text { Physical health) }\end{array}$ & & & & \\
\hline & $\begin{array}{l}\text { Activity: Functional } \\
\text { Restriction }\end{array}$ & & No & $\begin{array}{l}\text { Yes (WHOQOL-BREF } \\
\text { Physical health) }\end{array}$ & & & & \\
\hline
\end{tabular}




\begin{tabular}{|c|c|c|c|c|c|c|c|c|}
\hline Instrument & Item/Subscale & $\begin{array}{l}\text { Study, } \\
\text { PMID }\end{array}$ & $M C^{*}$ & $\begin{array}{l}\text { Convergent Validity } \\
\text { (Concurrent) }\end{array}$ & $\begin{array}{l}\text { Divergent } \\
\text { Validity } \\
\text { (Discriminant) }\end{array}$ & $\begin{array}{l}\text { Construct } \\
\text { Validity }\end{array}$ & $\begin{array}{l}\text { Structural } \\
\text { Validity }\end{array}$ & $\begin{array}{l}\text { Predictive } \\
\text { Validity } \dagger\end{array}$ \\
\hline & Activity: Social Restriction & & No & $\begin{array}{l}\text { No (WHOQOL-BREF } \\
\text { subscales) }\end{array}$ & & & & \\
\hline & $\begin{array}{l}\text { Activity: Athletic } \\
\text { Restriction }\end{array}$ & & No & $\begin{array}{l}\text { No (WHOQOL-BREF } \\
\text { subscales) }\end{array}$ & & & & \\
\hline & $\begin{array}{l}\text { Satisfaction: Functional } \\
\text { Satisfaction }\end{array}$ & & No & $\begin{array}{l}\text { No (WHOQOL-BREF } \\
\text { subscales) }\end{array}$ & & & & \\
\hline & $\begin{array}{l}\text { Satisfaction: Aesthetic } \\
\text { Satisfaction }\end{array}$ & & No & $\begin{array}{l}\text { Yes (WHOQOL-BREF } \\
\text { Psychological health) }\end{array}$ & & & & \\
\hline & $\begin{array}{l}\text { Satisfaction: Weight } \\
\text { Satisfaction }\end{array}$ & & No & $\begin{array}{l}\text { No (WHOQOL-BREF } \\
\text { subscales) }\end{array}$ & & & & \\
\hline \multirow[t]{6}{*}{ TAPES-R } & $\begin{array}{l}\text { Psychomotor Adjustment } \\
\text { Subscale } 1 \text { (General } \\
\text { Adjustment) }\end{array}$ & \multirow[t]{6}{*}{$\begin{array}{l}\text { Gallagher } \\
2010 \\
20489393\end{array}$} & No & & & & $\begin{array}{l}\text { Variance } \\
\text { explained } \\
\text { (Rasch) 65\% }\end{array}$ & \\
\hline & $\begin{array}{l}\text { Psychomotor Adjustment } \\
\text { Subscale } 2 \text { (Social } \\
\text { Adjustment) }\end{array}$ & & No & & & & $\begin{array}{l}\text { Variance } \\
\text { explained } \\
\text { (Rasch) 60\% }\end{array}$ & \\
\hline & $\begin{array}{l}\text { Psychomotor Adjustment } \\
\text { Subscale } 3 \text { (Adjustment } \\
\text { to Limitation) }\end{array}$ & & No & & & & $\begin{array}{l}\text { Variance } \\
\text { explained } \\
\text { (Rasch) } 64 \%\end{array}$ & \\
\hline & Activity Restriction & & No & & & & $\begin{array}{l}\text { Variance } \\
\text { explained } \\
\text { (Rasch) 95\% }\end{array}$ & \\
\hline & $\begin{array}{l}\text { Satisfaction with } \\
\text { Prosthesis Subscale } 1\end{array}$ & & No & & & & $\begin{array}{l}\text { Variance } \\
\text { explained } \\
\text { (Rasch) 55\% }\end{array}$ & \\
\hline & $\begin{array}{l}\text { Satisfaction with } \\
\text { Prosthesis Subscale } 2\end{array}$ & & No & & & & $\begin{array}{l}\text { Variance } \\
\text { explained } \\
\text { (Rasch) } 62 \% \\
\end{array}$ & \\
\hline \multicolumn{9}{|c|}{$\begin{array}{l}\text { Abbreviations: IES = Impact of Events Scale, MC = Medicare, PMID = PubMed identifier (or journal), TAPES = Trinity Amputation and Prosthesis Experience Scales, TAPES-R } \\
=\text { Trinity Amputation and Prosthesis Experience Scales-Revised, TMMS =Trait Meta Mood Scale, WHOQOL-BREF = World Health Organization Quality of Life-Brief Version. }\end{array}$} \\
\hline \multicolumn{9}{|c|}{$\begin{array}{l}\text { Note: Shading included only to more clearly distinguish separate instruments. Empty cells under Item/Subscale indicate that there are no instrument items or subscales or they were } \\
\text { not evaluated. Empty cells (with “.”) in the validity columns indicate no evidence regarding this construct. }\end{array}$} \\
\hline
\end{tabular}


Table 44. Summary of other instrument psychometric properties: TAPES

\begin{tabular}{|c|c|c|c|c|c|c|c|c|c|}
\hline Instrument & Item/Subscale & Study, PMID & $M C^{*}$ & Reliability & MDC & MID & Responsiveness & Floor & Ceiling \\
\hline \multirow[t]{10}{*}{ TAPES } & Psychosocial: General Adjustment & \multirow{9}{*}{$\begin{array}{l}\text { Gallagher } 2000 \text { (Rehab } \\
\text { Psychol) }\end{array}$} & No & Yes & & & & & \\
\hline & Psychosocial: Social Adjustment & & No & Yes & & & & & \\
\hline & Psychosocial: Adjustment to Limitation & & No & Yes & & & & & \\
\hline & Activity: Functional Restriction & & No & Yes & & & & & \\
\hline & Activity: Social Restriction & & No & Yes & & & & & \\
\hline & Activity: Athletic Restriction & & No & Yes & & & & & \\
\hline & Satisfaction: Functional Satisfaction & & No & Yes & & & & & \\
\hline & Satisfaction: Aesthetic Satisfaction & & No & Yes & & & & & \\
\hline & Satisfaction: Weight Satisfaction & & No & Yes & & & & & \\
\hline & & $\begin{array}{l}\text { Gallagher } 2004 \\
15129396\end{array}$ & No & & & & & & \\
\hline \multirow[t]{6}{*}{ TAPES-R } & $\begin{array}{l}\text { Psychomotor Adjustment Subscale } 1 \\
\text { (General Adjustment) }\end{array}$ & \multirow[t]{6}{*}{$\begin{array}{l}\text { Gallagher } 2010 \\
20489393\end{array}$} & No & Yes & & & & & \\
\hline & $\begin{array}{l}\text { Psychomotor Adjustment Subscale } 2 \text { (Social } \\
\text { Adjustment) }\end{array}$ & & No & Yes & & & & & \\
\hline & $\begin{array}{l}\text { Psychomotor Adjustment Subscale } 3 \\
\text { (Adjustment to Limitation) }\end{array}$ & & No & Yes & & & & & \\
\hline & Activity Restriction & & No & Yes & & & & & \\
\hline & $\begin{array}{l}\text { Satisfaction with Prosthesis Subscale } 1 \\
\text { (items 1-4) }\end{array}$ & & No & No & & & & & \\
\hline & $\begin{array}{l}\text { Satisfaction with Prosthesis Subscale } 2 \\
\text { (items 5-9) }\end{array}$ & & No & Yes & & & & & \\
\hline
\end{tabular}

Shading included only to more clearly distinguish separate instruments. Empty cells under Item/Subscale indicate that there are no instrument items or subscales or they were not evaluated. Empty cells (with “.”) in the psychometric properties columns indicate no evidence regarding this construct.

Abbreviations: $\mathrm{MC}=$ Medicare, MDC = minimal detectable change, MID = minimum (clinical) important difference, PMID = PubMed identifier (or journal), TAPES = Trinity Amputation and Prosthesis Experience Scales, TAPES-R = Trinity Amputation and Prosthesis Experience Scales-Revised.

*Whether study was deemed generalizable to the Medicare population based on average age greater than 65 years and/or at least $50 \%$ of participants with dysvascular etiologies for their amputations. 


\section{TFP}

The Transfemoral Fitting Predictor is a 9-item instrument with two subscales that describes graded tasks and aims to assess the prosthetic potential of transfemoral amputees. One study ${ }^{69}$ evaluated the psychometric properties of the TFP in 93 people with lower limb amputations (see Tables 45 to 47). The study was deemed to be generalizable to the Medicare population based on average age greater than 65 years and a high percentage of study participants with dysvascular disease (94\%).

The study provided evidence of construct validity as the TFP at initial assessment correctly classified $90 \%$ of those who went on to LLP or not. The study also found evidence of structural validity for the TFP with 74\% of the variance explained by principal component analysis (PCA), and excellent reliability.

Overall, for TFP, from a study generalizable to the Medicare population, there is evidence of test validity and reliability.

\section{TUG}

The Timed Up and Go test measures the amount of time it takes an amputee to get up from an armless chair. Ten studies ${ }^{7,29,34-38,40,76,77}$ evaluated the psychometric properties of the TUG in 850 people, total, with lower limb amputations (see Tables 45 to 47). Five of the studies were deemed to be generalizable to the Medicare population based on average age greater than 65 years or high percentage of study participants with dysvascular disease. . $^{29,}$, 34, 37, 77

The studies reported evidence of convergent validity when compared with several other instruments, including ABC, PLUS-M, the 2MWT and 6MWT, the Groningen Activity Restriction Scale, PEQ-MS, BBS, and the mobility control subscale of SIP. There was not convergent validity with TAPES or other subscales of SIP. TUG discriminated among people based on Houghton Scale (in one of two studies), K level, age, and time with prosthesis. Two studies had different findings related to whether TUG discriminated people based on amputation level. One study, generalizable to the Medicare population, reported predictive validity when predicting the number of falls ( $\geq 2$ falls) at 6 months after testing (sensitivity $85 \%$ and specificity $74 \%$ ). Studies found evidence of reliability and two studies reported MDC(90) to be 1.3 or 3.6 seconds No floor or ceiling effects were reported in a single study generalizable to the Medicare population.

Overall, for TUG, there is evidence in studies generalizable to the Medicare population of test validity, including predictive validity for falls 6 months after testing, and reliability without a floor or ceiling effect. 
Table 45. Study descriptive data: TFP through TUG

\begin{tabular}{|c|c|c|c|c|c|c|c|c|c|c|}
\hline Instrument & Item/Subscale & Study, PMID & $\mathbf{N}$ & Age* & Dysvasc $\dagger, \%$ & Trauma ${ }^{\prime}, \%$ & TF†, \% & TT†, \% & Unit, \% & $\mathrm{Bi \dagger}, \%$ \\
\hline TFP & & Condie 201121807149 & 93 & $68.8(10.6)$ & 94 & nd & 100 & 0 & 100 & 0 \\
\hline \multirow[t]{10}{*}{ TUG } & & Clemens 201728862042 & 118 & $48(13.7)$ & nd & nd & 53 & 47 & 100 & 0 \\
\hline & & Dite 200717207685 & 40 & 61.7 (nd) & 65 & nd & 0 & 100 & 100 & 0 \\
\hline & & Gremeaux 201222389424 & 64 & $58(16)$ & 66 & 25 & 27 & 73 & 100 & 0 \\
\hline & & Hafner 201727590443 & 199 & $55.4(14.3)$ & 44 & 41 & 18 & 76 & 100 & 0 \\
\hline & & Miller 200312736877 & 50 & $58.0(15.8)$ & 58 & nd & 24 & 76 & 100 & 0 \\
\hline & & Newton 2016 (Eur J Physiother) & 37 & $57.6(7.6)$ & nd & nd & 24 & 76 & 100 & 0 \\
\hline & & Reid 201525588644 & 86 & $60(15.3)$ & 35 & 48 & 15 & 73 & 97 & 3 \\
\hline & & Resnik 201121310896 & 44 & $66(13)$ & nd & nd & 52 & 43 & 100 & 0 \\
\hline & & Schoppen 199910414769 & 32 & 73.3 (nd) & nd & nd & 16 & 84 & 100 & 0 \\
\hline & & Wong 201626874230 & 180 & $55.5(16.0)$ & 49 & 51 & 44 & 56 & 81 & 13 \\
\hline
\end{tabular}

Abbreviations: $\mathrm{Bi}=$ bilateral amputation, Dysvasc = dysvascular disease (including diabetes), nd = no data/not reported, PMID = PubMed identifier (or journal), TF = transfemoral (above the knee) amputation, TFP = Transfemoral Fitting Predictor, TT = transtibial (below the knee) amputation, TUG = Timed Up and Go, Uni $=$ unilateral amputation.

*Mean or median with standard deviation in parentheses and range in square brackets.

Note: Shading included only to more clearly distinguish separate instruments. Empty cells under Item/Subscale indicate that there are no instrument items or subscales or they were not evaluated.

$†$ Percentages of study participants with other amputation etiologies, amputation levels, and unreported etiologies, levels, or unilateral versus bilateral amputation are omitted from this summary table. See Appendix C for further details. Transfemoral and transtibial data may sum to more than $100 \%$ because of double counting of participants with bilateral amputations. 
Table 46. Summary of instrument psychometric validity properties: TFP through TUG

\begin{tabular}{|c|c|c|c|c|c|c|c|}
\hline Instrument Item/Subscale & Study, PMID & MC* & $\begin{array}{l}\text { Convergent Validity } \\
\text { (Concurrent) }\end{array}$ & $\begin{array}{l}\text { Divergent } \\
\text { Validity } \\
\text { (Discriminant) }\end{array}$ & Construct Validity & $\begin{array}{l}\text { Structural } \\
\text { Validity }\end{array}$ & $\begin{array}{l}\text { Predictive } \\
\text { Validity } \dagger\end{array}$ \\
\hline TFP & $\begin{array}{l}\text { Condie } 2011 \\
21807149\end{array}$ & Yes & & & $\begin{array}{l}\text { Correctly classifies } \\
\text { those who went on } \\
\text { to LLP or not LLP } \\
90.3 \%\end{array}$ & Yes (PCA) & \\
\hline \multirow[t]{10}{*}{ TUG } & $\begin{array}{l}\text { Clemens } 2017 \\
28862042\end{array}$ & No & Yes (PLUS-M, ABC) & Yes (TT vs. TF) & & & \\
\hline & $\begin{array}{l}\text { Dite } \\
200717207685\end{array}$ & Yes & & . & & & $\begin{array}{l}\text { Yes (falls at } \\
6 \mathrm{mo} \text { ) }\end{array}$ \\
\hline & $\begin{array}{l}\text { Gremeaux } 2012 \\
22389424\end{array}$ & Yes & & No (Houghton) & & & \\
\hline & $\begin{array}{l}\text { Hafner } 2017 \\
27590443\end{array}$ & No & & Yes (K levels) & & & \\
\hline & $\begin{array}{l}\text { Miller } 2003 \\
12736877\end{array}$ & Yes & Yes (ABC) & & & & \\
\hline & $\begin{array}{l}\text { Newton } 2016 \text { (Eur } \\
\text { J Physiother) }\end{array}$ & No & No (TAPES) & $\begin{array}{l}\text { Yes (age, time } \\
\text { with prosthesis), } \\
\text { No TT vs. TF) }\end{array}$ & & & \\
\hline & $\begin{array}{l}\text { Reid } 2015 \\
25588644\end{array}$ & No & Yes (6MWT) & & & & \\
\hline & $\begin{array}{l}\text { Resnik } 2011 \\
21310896\end{array}$ & Yes & & & & & \\
\hline & $\begin{array}{l}\text { Schoppen } 1999 \\
10414769\end{array}$ & Yes & $\begin{array}{l}\text { Yes (GARS, SIP } \\
\text { mobility control), } \\
\text { No SIP other subscales }\end{array}$ & & & & \\
\hline & $\begin{array}{l}\text { Wong } 2016 \\
26874230\end{array}$ & No & $\begin{array}{l}\text { Yes (PEQ-MS, ABC, 3- } \\
\text { BBS, 2MWT) }\end{array}$ & Yes (Houghton) & & & \\
\hline
\end{tabular}

Abbreviations: 2MWT = 2 minute walk test, 3-BBS = total sum score of 3 Berg Balance Scale items, $6 \mathrm{MWT}=6$ minute walk test, ABC = Activities-Specific Balance Confidence scale, GARS $=$ Groningen Activity Restriction Scale, $\mathrm{K}$ level $=$ Medicare Functional Classification Level, $\mathrm{LLP}=$ lower limb prosthesis, MC $=$ Medicare, mo $=$ months, $\mathrm{PCA}=$

Principal Component Analysis, PEQ-MS = Prosthesis Evaluation Questionnaire motor score, PLUS-M = Prosthetic Limb Users Survey of Mobility, PMID = PubMed identifier (or journal), SIP $=$ Sickness Impact Profile, TAPES $=$ Trinity Amputation and Prosthesis Experience Scales, $\mathrm{TF}=$ transfemoral (above the knee) amputation, TFP $=$ Transfemoral Fitting Predictor, TT = transtibial (below the knee) amputation, TUG = Timed Up and Go test, TWT = Timed Walk Test.

Note: Shading included only to more clearly distinguish separate instruments. Empty cells under Item/Subscale indicate that there are no instrument items or subscales or they were not evaluated. Empty cells in the validity columns indicate no evidence regarding this construct.

*Whether study was deemed generalizable to the Medicare population based on average age greater than 65 years and/or at least $50 \%$ of participants with dysvascular etiologies for their amputations.

†Studies evaluated for predictive validity were assessed for Key Question 2. 
Table 47. Summary of other instrument psychometric properties: TFP through TUG

\begin{tabular}{|c|c|c|c|c|c|c|c|c|c|}
\hline Instrument & Item/Subscale & Study, PMID & $M C^{*}$ & Reliability & MDC & MID & Responsiveness & Floor & Ceiling \\
\hline TFP & & Condie 201121807149 & Yes & Yes & & & & & \\
\hline \multirow[t]{9}{*}{ TUG } & & Clemens 201728862042 & No & Yes & MDC(90) $1.28 \mathrm{sec}$ & & & & \\
\hline & & Dite 200717207685 & Yes & & & & & & \\
\hline & & Gremeaux 201222389424 & Yes & & & & & $0 \%$ & $0 \%$ \\
\hline & & Hafner 201727590443 & No & & & & & & \\
\hline & & Miller 200312736877 & Yes & & & & & & \\
\hline & & Newton 2016 (Eur J Physiother) & No & & & & & & \\
\hline & & Reid 201525588644 & No & & & & & & \\
\hline & & Schoppen 199910414769 & Yes & Yes & & & & & \\
\hline & & Wong 201626874230 & No & & & & & & \\
\hline
\end{tabular}

Abbreviations: MC = Medicare, MDC(90) = minimal detectable change (at 90\% confidence), MID = minimum (clinical) important difference, PMID = PubMed identifier (or journal), sec $=$ seconds, TFP $=$ Transfemoral Fitting Predictor, TUG $=$ Timed Up and Go test.

Note: Shading included only to more clearly distinguish separate instruments. Empty cells (with “.”) in the psychometric properties columns indicate no evidence regarding this construct.

*Whether study was deemed generalizable to the Medicare population based on average age greater than 65 years and/or at least $50 \%$ of participants with dysvascular etiologies for their amputations. 


\section{TWT}

The Timed Walking Test measures the time to walk 5 meters forward, turn 180 degrees, and walk 5 meters back to the starting point, with the use of any usual walking aids necessary. Two studies $^{68,72}$ evaluated the psychometric properties of the TWT in 233 people, total, with lower limb amputations (see Tables 48 to 50). The studies were not deemed to be generalizable to the Medicare population due to relatively low average age (57 and 61 years) and relatively few people with dysvascular conditions (27\% and 32\%).

One study provided evidence that the TWT had good convergent validity when compared with RMI. Evidence of responsiveness was found in one study with an effect size of 8.56.

Overall, for TWT, there is evidence of test validity and responsiveness from studies not generalizable to the Medicare population.

\section{Walking Questionnaire}

The Walking Questionnaire is a self-report measure of activity limitations when walking inside and outside the house. One study ${ }^{71}$ evaluated the psychometric properties of the Walking Questionnaire in 172 people with lower limb amputations (see Tables 48 to 50). The study was deemed to be generalizable to the Medicare population based on average age of 65 years and a high percentage of study participants with dysvascular disease (83\%).

The study found evidence of moderate convergent validity when compared with several other tests including LCI, PPA, RSQ, and CSQ. The study found the Walking Questionnaire to have good reliability.

Overall, for the Walking Questionnaire there is evidence from a study generalizable to the Medicare population of test validity and reliability.

\section{WHOQOL-BREF}

The World Health Organization Quality-of-Life Scale - Brief Version is an instrument measuring the quality of life of amputees. The instrument has several subscales, including: environment, physical health, psychological, social relationships, and general health and overall quality of life. One study ${ }^{73}$ evaluated the psychometric properties of the WHOQOL-BREF in 63 people with lower limb amputations (see Tables 48 to 50). The study not deemed to be generalizable to the Medicare population, with a relatively low average age (47 years) and an unreported percentage of people with dysvascular conditions.

The study found all WHOQOL-BREF subscales had convergent validity when compared to TAPES.

Overall, for WHOQOL-BREF, from a study not generalizable to the Medicare population, there is evidence of test validity for the individual subscales. 
Table 48. Study descriptive data: TWT through WHOQOL-BREF

\begin{tabular}{|c|c|c|c|c|c|c|c|c|c|c|}
\hline Instrument & Item/Subscale & Study, PMID & $\mathbf{N}$ & Age* $^{*}$ & $\begin{array}{l}\text { Dysvasc } \dagger \text {, } \\
\%\end{array}$ & $\begin{array}{l}\text { Trauma†, } \\
\%\end{array}$ & $\begin{array}{l}\text { TF†, } \\
\%\end{array}$ & $\begin{array}{l}\text { TT†, } \\
\%\end{array}$ & $\begin{array}{l}\text { Uni†, } \\
\%\end{array}$ & $\begin{array}{l}\mathrm{Bi \dagger}, \\
\%\end{array}$ \\
\hline \multirow[t]{2}{*}{ TWT } & & $\begin{array}{l}\text { Ryall } 200212851094 \text { - } \\
\text { Study } 2\end{array}$ & 33 & $60.7(14.5)$ & 27 & 12 & 48 & 48 & 100 & 0 \\
\hline & & Ryall 200312648004 & 200 & $\begin{array}{l}57.2(17.7) \\
{[13-90]}\end{array}$ & 32 & 40 & 41 & 57 & 88 & 13 \\
\hline $\begin{array}{l}\text { Walking } \\
\text { Questionnaire }\end{array}$ & & de Laat 201222424695 & 172 & $\begin{array}{l}65(11)[37- \\
92]\end{array}$ & 83 & 8 & 32 & 54 & 93 & 7 \\
\hline WHOQOL-BREF & $\begin{array}{l}\text { Physical Health } \\
\text { Psychological } \\
\text { Health } \\
\text { Social Relations } \\
\text { Environmental }\end{array}$ & $\begin{array}{l}\text { Gallagher } 2004 \\
15129396\end{array}$ & 63 & $47.5(18.4)$ & nd & 43 & 40 & 57 & 100 & 0 \\
\hline
\end{tabular}

Abbreviations: $\mathrm{Bi}$ = bilateral amputation, Dysvasc = dysvascular disease (including diabetes), nd = no data/not reported, PMID = PubMed identifier (or journal), TF = transfemoral (above the knee) amputation, TT = transtibial (below the knee) amputation, TWT = Timed Walking Test, Uni = unilateral amputation, WHOQOL-BREF = World Health Organization Quality of Life-Brief Version.

Note: Shading included only to more clearly distinguish separate instruments. Empty cells under Item/Subscale indicate that there are no instrument items or subscales or they were not evaluated.

*Mean or median with standard deviation in parentheses and range in square brackets.

†Percentages of study participants with other amputation etiologies, amputation levels, and unreported etiologies, levels, or unilateral versus bilateral amputation are omitted from this summary table. See Appendix C for further details. Transfemoral and transtibial data may sum to more than $100 \%$ because of double counting of participants with bilateral amputations. 
Table 49. Summary of instrument psychometric validity properties: TWT through WHOQOL-BREF

\begin{tabular}{|c|c|c|c|c|c|c|c|c|}
\hline Instrument & Item/Subscale & Study, PMID & $\mathrm{MC}^{*}$ & $\begin{array}{l}\text { Convergent Validity } \\
\text { (Concurrent) }\end{array}$ & $\begin{array}{l}\text { Divergent Validity } \\
\text { (Discriminant) }\end{array}$ & $\begin{array}{l}\text { Construct } \\
\text { Validity }\end{array}$ & $\begin{array}{l}\text { Structural } \\
\text { Validity }\end{array}$ & $\begin{array}{l}\text { Predictive } \\
\text { Validity } \dagger\end{array}$ \\
\hline \multirow[t]{2}{*}{$\overline{T W T}$} & & $\begin{array}{l}\text { Ryall } 2002 \\
12851094- \\
\text { Study } 2\end{array}$ & No & & & & & \\
\hline & & $\begin{array}{l}\text { Ryall } 2003 \\
12648004\end{array}$ & No & Yes (RMI) & . & 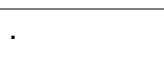 & . & . \\
\hline $\begin{array}{l}\text { Walking } \\
\text { Questionnaire }\end{array}$ & & $\begin{array}{l}\text { de Laat } 2012 \\
22424695\end{array}$ & Yes & $\begin{array}{l}\text { Yes (LCI, PPA, RSQ, } \\
\text { CSQ) }\end{array}$ & & & & \\
\hline \multirow[t]{4}{*}{$\begin{array}{l}\text { WHOQOL- } \\
\text { BREF }\end{array}$} & Physical Health & $\begin{array}{l}\text { Gallagher } 2004 \\
15129396\end{array}$ & No & Yes (TAPES) & & & & \\
\hline & $\begin{array}{l}\text { Psychological } \\
\text { Health }\end{array}$ & & No & Yes (TAPES) & & & & \\
\hline & Social Relations & & No & Yes (TAPES) & & & & \\
\hline & Environmental & & No & Yes (TAPES) & & & & \\
\hline
\end{tabular}

Abbreviations: CSQ = Climbing Stairs Questionnaire, LCI = Locomotor Capabilities Index, MC = Medicare, PMID = PubMed identifier (or journal), PPA = Prosthetic Profile of the Amputee, RMI = Rivermead Mobility Index, RSQ = Questionnaire Rising and Sitting Down, TAPES = Trinity Amputation and Prosthesis Experience Scales, TWT = Timed Walk Test, WHOQOL-BREF = World Health Organization Quality of Life-Brief Version.

Note: Shading included only to more clearly distinguish separate instruments. Empty cells under Item/Subscale indicate that there are no instrument items or subscales or they were not evaluated. Empty cells in the validity columns indicate no evidence regarding this construct.

*Whether study was deemed generalizable to the Medicare population based on average age greater than 65 years and/or at least $50 \%$ of participants with dysvascular etiologies

for their amputations.

†Studies evaluated for predictive validity were assessed for Key Question 2.

Table 50. Summary of other instrument psychometric properties: TWT through WHOQOL-BREF

\begin{tabular}{|c|c|c|c|c|c|c|c|c|c|}
\hline Instrument & Item/Subscale & Study, PMID & $M C^{*}$ & Reliability & MDC & MID & Responsiveness & Floor & Ceiling \\
\hline \multirow[t]{2}{*}{ TWT } & & Ryall 200212851094 - Study 2 & No & & & & Yes (ES 8.56) & & \\
\hline & & Ryall 200312648004 & No & & & & & & \\
\hline Walking Questionnaire & & de Laat 201222424695 & Yes & Yes & & & & & \\
\hline WHOQOL-BREF & & Gallagher 200415129396 & No & & & & & & \\
\hline
\end{tabular}

Abbreviations: ES = effect size, MC = Medicare, MDC = minimal detectable change, MID = minimum (clinical) important difference, PMID = PubMed identifier (or journal), TWT $=$ Timed Walk Test, WHOQOL-BREF $=$ World Health Organization Quality of Life-Brief Version.

Note: Shading included only to more clearly distinguish separate instruments. Empty cells under Item/Subscale indicate that there are no instrument items or subscales or they were not evaluated. Empty cells in the psychometric properties columns indicate no evidence regarding this construct.

*Whether study was deemed generalizable to the Medicare population based on average age greater than 65 years and/or at least $50 \%$ of participants with dysvascular etiologies

for their amputations. 


\section{Key Question 1. Assessment Techniques}

\section{Key Points}

- Twelve instruments have been evaluated as initial assessment tools

o Eleven of the instruments have evidence of test validity from studies generalizable to the Medicare population

o One instrument had evidence of test validity in a study not generalizable to the Medicare population

Based on explicit reporting within articles that instruments were evaluated at the time of initial assessment or prosthesis fitting, 10 studies evaluated 12 instruments as initial assessment tools (Table 51). ${ }^{17,28,30,32,39,48,49,65,69}$ The evaluated instruments are:

- 1 Leg Standing Balance

- $\quad$ 2MWT (2 Minute Walk Test)

- AMPnoPRO (Amputee Mobility Predictor without use of prosthesis)

- FAC (Functional Ambulation Categories)

- FAI (Frenchay Activities Index)

- FIM (Functional Independence Measure)

- LCI (Locomotor Capabilities Index)

- LEMOCOT (Lower-Extremity Motor Coordination Test)

- OPCS (Office of Population Censuses and Surveys Scale)

- PROS (Prosthetist's Perception of Client's Ambulatory Abilities)

- SF-12 (Short Form Health Survey 12)

- TFP (Transfemoral Fitting Predictor)

\section{Findings}

\section{Studies Generalizable to Medicare Population}

Eleven of the instruments have evidence of test validity from studies generalizable to the Medicare population (i.e., study mean age $\geq 65$ years or $\geq 50 \%$ of participants had dysvascular disease). These include 1 Leg Standing Balance, 2MWT, AMPnoPRO, FAC, FAI, FIM, LEMOCOT, OPCS, PROS, SF, and TFP. For SF, more specifically, test validity has been found for SF-12 Physical Component Score, SF-12 Role Physical, SF-12 Bodily Pain, SF-36 Physical Functioning (where a modified 15-item version performed better than the original 10-item version). Three of the 11 instruments were also reported to have evidence of test reliability when evaluated at initial assessment: AMPnoPRO, TMP, and for SF-12 the subscales for Role Emotional, Role Physical, Bodily Pain, and Mental Health.

\section{Studies Not Generalizable to Medicare Population}

One instrument, LCI, was evaluated at initial assessment only in a study that is not generalizable to the Medicare population. Both the LCI-4 and LCI-5 versions of the instrument were reported to have test validity, reliability, and responsiveness. Floor and ceiling percentages were reported for LCI-4, and no such effects were found. 
Table 51. Summary of psychometric properties of instruments evaluated as initial assessment tools

\begin{tabular}{|c|c|c|c|c|c|c|}
\hline Instrument & Study, PMID & MC* & Test Validity & Reliability & Responsiveness & $\begin{array}{l}\text { Floor/Ceiling } \\
\text { Effect }\end{array}$ \\
\hline $\begin{array}{l}1 \text { Leg Standing } \\
\text { Balance }\end{array}$ & $\begin{array}{l}\text { Eijk } 2012 \\
21958418 \\
\text { Spaan } 2017 \\
27770064 \\
\end{array}$ & Yes & Yes & & & \\
\hline 2MWT & $\begin{array}{l}\text { Brooks } 2001 \\
11588757\end{array}$ & Yes & Yes & & & \\
\hline AMPnoPRO & $\begin{array}{l}\text { Gailey } 2002 \\
11994800\end{array}$ & Yes & Yes & Yes & & \\
\hline FAC & $\begin{array}{l}\text { Eijk } 2012 \\
21958418\end{array}$ & Yes & Yes & & & \\
\hline FAI & $\begin{array}{l}\text { Eijk } 2012 \\
21958418\end{array}$ & Yes & Yes & & & \\
\hline FIM & $\begin{array}{l}\text { Leung } 1996 \\
8831480 \\
\text { Panesar } 2001 \\
11330761\end{array}$ & Yes & Yes & & & \\
\hline $\mathrm{LCl}$ & $\begin{array}{l}\text { Franchignoni } \\
200415129398\end{array}$ & No & $\begin{array}{l}\text { Yes } \\
\text { (LCl-4, LCl-5) }\end{array}$ & $\begin{array}{l}\text { Yes } \\
(\mathrm{LCl}-4, \mathrm{LCl}-5)\end{array}$ & $\begin{array}{l}\text { Yes } \\
\text { (LCl-4, LCl-5) }\end{array}$ & $\begin{array}{l}\text { No } \\
\text { (LCl-4) }\end{array}$ \\
\hline LEMOCOT & $\begin{array}{l}\text { Spaan } 2017 \\
27770064\end{array}$ & Yes & Yes & & & \\
\hline OPCS & $\begin{array}{l}\text { Panesar } 2001 \\
11330761\end{array}$ & Yes & Yes & & & \\
\hline PROS & $\begin{array}{l}\text { Hart } 1999 \\
\text { (J Prosthet } \\
\text { Orthot) }\end{array}$ & Yes & Yes & & & \\
\hline $\begin{array}{l}\text { SF-12 and } \\
\text { SF-36 }\end{array}$ & $\begin{array}{l}\text { Hart } 1999 \\
\text { (J Prosthet } \\
\text { Orthot) }\end{array}$ & Yes & Mixed $\dagger$ & Yes $\ddagger$ & & \\
\hline TFP & $\begin{array}{l}\text { Condie } 2011 \\
21807149\end{array}$ & Yes & Yes & Yes & & \\
\hline
\end{tabular}

Abbreviations: 2MWT = 2 minute walk test, AMPnoPRO = Amputee Mobility Predictor without use of a prosthesis, FAC $=$ Functional Ambulation Categories, FAI = Frenchay Activities Index, FIM = Functional Independence Measure, LCI = Locomotor Capabilities Index, LEMOCOT = Lower-Extremity Motor Coordination Test, MC = Medicare, OPCS = Office of Population Censuses and Surveys Scale, PMID = PubMed identifier (or journal), PROS = prosthetist's perception of client's functional abilities, SF = Short Form Health Survey, TFP = Transfemoral Fitting Predictor.

Note: These assessments are specific to the studies that evaluated the instruments as initial assessment tools. The findings may differ from the overall findings among all studies that evaluated the instruments. Empty cells indicate no data.

*Whether study was deemed generalizable to the Medicare population based on average age greater than 65 years and/or at least $50 \%$ of participants with dysvascular etiologies for their amputations.

†Evidence of test validity for SF-12 Physical Component Score, SF-12 Role Physical, SF-12 Bodily Pain, SF-36 Physical Functioning (15-item version performed better than 10-item version). Evidence of lack of test validity for SF-12 Mental Component Score, SF-12 Role Emotional, and SF-12 Mental Health.

¥SF-12 Role Emotional, Role Physical, Bodily Pain, and Mental Health. No data for other versions and subscales.

\section{Key Question 2. Prediction Tools}

\section{Key Points}

- Thirteen instruments have been evaluated as prediction tools

o Twelve of the instruments have evidence of predictive validity from studies generalizable to the Medicare population

0 One instrument (and a variation of one of the other 12 instruments) had evidence of predictive validity studies not generalizable to the Medicare population 


\section{Findings}

Based on reporting of metrics relevant to predictive validity, eight studies evaluated 13 instruments as prediction tools (Table 52). ${ }^{7,28,30,32,39,44,48,49}$ However, all but one study reported only correlations of the instrument results with occurrence or test scores at a future time point. Thus, these are not truly evaluations of the predictive accuracy of these instruments. One study, as described below, reported on diagnostic test accuracy (sensitivity and specificity) for several instruments. The evaluated instruments are:

- 1 Leg Standing Balance

- 180 Degree Turn Test

- 2MWT (2 Minute Walk Test)

- AMPnoPRO (Amputee Mobility Predictor without Prosthesis)

- AMPSIMM (Amputee Single Item Mobility Measure)

- FAC (Functional Ambulation Categories)

- FAI (Frenchay Activities Index)

- FIM (Functional Independence Measure)

- FSST (Four Square Step Test)

- LCI (Locomotor Capabilities Index)

- LEMOCOT (Lower-Extremity Motor Coordination Test)

- OPCS (Office of Population Censuses and Surveys Scale)

- TUG (Timed Up and Go)

\section{Studies Generalizable to Medicare Population}

Twelve instruments have been reported to have predictive validity in whole or in part in studies that are generalizable to the Medicare population (i.e., study mean age $\geq 65$ years or $\geq 50 \%$ of participants had dysvascular disease). These include the 1 Leg Standing Balance, 180 Degree Turn Test, 2MWT, AMPnoPRO, FAC, FAI, FIM, FSST, LCI-4 Advanced, LEMOCOT, OPCS, and TUG.

One study evaluated four of these instruments for test accuracy to predict two or more falls during a 6 month followup period. ${ }^{7}$ The Turn Time and Turn Test components of the 180 Degree Turn Test, FSST and TUG all had high sensitivity (85\% to $100 \%$ ) and specificity (74\% to $93 \%$ ) to predict falls. The Advanced components portion of LCI-4 had high specificity (91\%) but low sensitivity (43\%) to predict falls, which overall was reported to be statistically significant $(\mathrm{P}<0.01)$. The Turn Steadiness component of the 180 Degree Turn Test also had high sensitivity (85\%) but low sensitivity (31\%) to predict falls, but this test overall was not statistically significant $(\mathrm{P}=0.22)$.

Six instruments-1 Leg Standing Balance, 2MWT, AMPnoPRO, FAC, FAI, and LEMOCOT - were reported to have predictive validity based on correlations with functional status (measured by different instruments) at either discharge from rehabilitation or 3 month followup.

FIM was reported to be correlated with a high Houghton Scale score $(\geq 9)$ at 3 to 12 months follow up when assessed at discharge from, but not admission to, rehabilitation.

OPCS was reported to be correlated with duration of stay in a rehabilitation unit. 


\section{Studies Not Generalizable to Medicare Population}

Two instruments were evaluated for predictive validity only in studies that were not generalizable to the Medicare population. Both AMPSIMM and LCI-5 were reported to be correlated with future functional status.

Table 52. Summary of predictive validity of instruments.

\begin{tabular}{|c|c|c|c|c|}
\hline Instrument & Study, PMID & MC* & Predictive Validity & Predicted Variable \\
\hline \multirow[t]{2}{*}{$\begin{array}{l}1 \text { Leg Standing } \\
\text { Balance }\end{array}$} & \multirow{2}{*}{$\begin{array}{l}\text { Eijk } 201221958418 \\
\text { Spaan } 2017 \\
27770064\end{array}$} & \multirow[t]{2}{*}{ Yes } & Yes & $\begin{array}{l}\mathrm{BI}, 2 \mathrm{MWT} \text {, TUG, } \\
\mathrm{K} \text { level at discharge }\end{array}$ \\
\hline & & & No & SNF at discharge \\
\hline $\begin{array}{l}180 \text { Degree Turn } \\
\text { Test }\end{array}$ & Dite 200717207685 & Yes & $\begin{array}{l}\text { Turn time }(\geq 3.7 \mathrm{sec}): \text { Sn } 85 \% \text {, Sp } 78 \% \\
\text { Turn steps }(\geq 6) \text { : Sn } 100 \% \text {, Sp } 74 \% \\
\text { Turn steadiness (No): Sn 31\%, Sp } 85 \% \dagger\end{array}$ & $\geq 2$ Falls at $6 \mathrm{mo}$ \\
\hline 2MWT & $\begin{array}{l}\text { Brooks } 2001 \\
11588757\end{array}$ & Yes & Yes & $\begin{array}{l}\text { Houghton at } \\
\text { discharge } \\
\text { SF-36 PF at } 3 \text { mo }\end{array}$ \\
\hline AMPnoPRO & $\begin{array}{l}\text { Spaan } 2017 \\
27770064\end{array}$ & Yes & Yes & $\begin{array}{l}\text { 2MWT, TUG, } \\
\mathrm{K} \text { level at discharge }\end{array}$ \\
\hline AMPSIMM & $\begin{array}{l}\text { Norvell } 2016 \\
27496697\end{array}$ & No & Yes & $\begin{array}{l}\text { Prosthesis use, } \\
\text { TAPES, } \\
\text { Mobility satisfaction } \\
\text { at } 4 \text { and } 12 \text { mo } \\
\text { LCl-5 at } 4 \text { mo }\end{array}$ \\
\hline \multirow[t]{2}{*}{ FAC } & \multirow[t]{2}{*}{ Eijk 201221958418} & \multirow[t]{2}{*}{ Yes } & Yes & $\mathrm{BI}$ at discharge \\
\hline & & & No & SNF at discharge \\
\hline \multirow[t]{2}{*}{ FAI } & \multirow[t]{2}{*}{ Eijk 201221958418} & \multirow[t]{2}{*}{ Yes } & Yes & $\mathrm{BI}$ at discharge \\
\hline & & & No & SNF at discharge \\
\hline \multirow[t]{2}{*}{ FIM } & \multirow[t]{2}{*}{$\begin{array}{l}\text { Leung } 1996 \\
8831480\end{array}$} & \multirow[t]{2}{*}{ Yes } & At admission: No & $\begin{array}{l}\text { Houghton } \geq 9 \text { at } \\
3-12 \text { mo }\end{array}$ \\
\hline & & & At discharge: Yes & $\begin{array}{l}\text { Houghton } \geq 9 \text { at } \\
3-12 \text { mo }\end{array}$ \\
\hline FSST & Dite 200717207685 & Yes & $\geq 24$ sec: Sn 92\%, Sp 93\% & $\geq 2$ Falls at $6 \mathrm{mo}$ \\
\hline LCl-4 Advanced & Dite 200717207685 & Yes & $\leq 15:$ Sn 43\%, Sp 91\% & $\geq 2$ Falls at $6 \mathrm{mo}$ \\
\hline $\mathrm{LCl}-5$ & $\begin{array}{l}\text { Franchignoni } 2004 \\
15129398\end{array}$ & No & Yes & $\begin{array}{l}\text { TWT, RMI, FMI at } \\
\text { discharge }\end{array}$ \\
\hline LEMOCOT & $\begin{array}{l}\text { Spaan } 2017 \\
27770064\end{array}$ & Yes & Yes & $\begin{array}{l}\text { 2MWT, TUG, } \\
\mathrm{K} \text { level at discharge }\end{array}$ \\
\hline OPCS & $\begin{array}{l}\text { Panesar } 2001 \\
11330761\end{array}$ & Yes & Yes & $\begin{array}{l}\text { Duration of } \\
\text { rehabilitation }\end{array}$ \\
\hline TUG & Dite 200717207685 & Yes & $\geq 19$ sec: Sn $85 \%$, Sp $74 \%$ & $\geq 2$ Falls at $6 \mathrm{mo}$ \\
\hline
\end{tabular}

Abbreviations: 2MWT = 2 minute walk test, AMPnoPRO = Amputee Mobility Predictor without use of a prosthesis, AMPSIMM

= Amputee Single Item Mobility Measure, BI = Barthel Index, FAC = Functional Ambulation Categories, FAI = Frenchay

Activities Index, FIM = Functional Independence Measure, FSST = Four Square Step Test, $\mathrm{K}$ level = Medicare Functional Classification Level, LCI = Locomotor Capabilities Index, LCI = Locomotor Capabilities Index, LEMOCOT = Lower-Extremity Motor Coordination Test, MC = Medicare, mo = months, OPCS = Office of Population Censuses and Surveys Scale, PMID = PubMed identifier (or journal), RMI = Rivermead Mobility Index, sec = seconds, $\mathrm{Sn}$ = sensitivity, SNF = skilled nursing facility, $\mathrm{Sp}=$ specificity, TAPES = Trinity Amputation and Prosthesis Experience Scale, TUG $=$ Timed Up and Go, TWT = Timed Walk Test.

Note: These assessments are specific to the studies that evaluated the instruments as prediction tools. The findings may differ from the overall findings among all studies that evaluated the instruments.

*Whether study was deemed generalizable to the Medicare population based on average age greater than 65 years and/or at least $50 \%$ of participants with dysvascular etiologies for their amputations.

$\dagger \mathrm{P}=0.22$.

$\ddagger \mathrm{P}<0.01$. 


\section{Key Question 3. Functional Outcome Measurement Tools}

\section{Key Points}

- Fifty instruments have been evaluated as functional outcome measurement tools

o There are 34 instruments (in whole or in part) that have supporting evidence generalizable to the Medicare population

- Seventeen instruments (or parts thereof) have evidence to support validity and reliability

- Thirteen instruments have evidence of validity alone

- Seven instruments have evidence of reliability alone

o There are 19 instruments (in whole or in part) that have supporting evidence only from studies not generalizable to the Medicare population

- Thirteen instruments (or parts thereof) have evidence to support validity and reliability

- Four instruments have evidence to support validity (without evidence regarding reliability)

- Three instruments have evidence of validity but explicitly not reliability

- Four instruments have evidence of reliability alone

\section{Findings}

All 50 evaluated instruments were deemed to be relevant functional outcome measurement tools. Here we first focus on summarizing instruments with generalizability to the Medicare population (i.e., study mean age $\geq 65$ years or $\geq 50 \%$ of participants had dysvascular disease), test validity, and reliability; this is followed by summaries of instruments with evidence only from studies not generalizable to the Medicare population. Descriptions about other psychometric properties can be found in the descriptions of each instrument, above.

\section{Studies Generalizable to Medicare Population Instruments With Evidence of Validity and Reliability}

Seventeen instruments have, in whole or in part, been reported to have both test validity and reliability in studies generalizable to the Medicare population. These include:

- 2MWT (2 Minute Walk Test)

- 6MWT (6 Minute Walk Test)

- ABC (Activities-specific Balance Confidence)

- AMP (Amputee Mobility Predictor)

o Both AMPnoPRO (without prosthesis) and AMPPRO (with prosthesis)

- Climbing Stairs Questionnaire

- Functional Reach Test

- Houghton Scale

o Both total Scale score and a subscale of items 1 to 3 (on prosthesis wear and use)

- LCI (Locomotor Capabilities Index)

o Specifically: LCI-4 (LCI with a 4-point ordinal scale)

- PEQ (Prosthetic Evaluation Questionnaire) 
o Specifically the PEQ-MS 13/11 (the Mobility Subscale with 13 items and 11 categories)

- PPA (Prosthetic Profile of the Amputee)

o Specifically: Prosthesis use (outdoors), and Acceptance/Adaptation; also see listings for LCI, which is included in the PPA, but evaluated separately here.

- Rising and Sitting Down Questionnaire

- RMI (Rivermead Mobility Index)

- SCS (Socket Comfort Score)

- SF-12 (Short Form Health Survey 12)

o Specifically: SF-12 PCS (Physical Component Score), SF-12 RP-2 (Role Physical), and SF-12 BP-2 (Bodily Pain)

- TFP (Transfemoral Fitting Predictor)

- TUG (Timed Up and Go)

- Walking Questionnaire

\section{Instruments With Evidence of Validity (Only)}

Thirteen instruments have, in whole or in part, been reported to have test validity but have not been reported to have reliability in studies generalizable to the Medicare population. None of the studies explicitly reported a lack of reliability, instead evaluations of reliability were not reported. In some instances reliability was reported among other studies not generalizable to the Medicare population; these are listed below in the appropriate section. The instruments with evidence of test validity, but not reported reliability in studies generalizable to the Medicare population include:

- 1 Leg Standing Balance

- 180 Degree Turn Test

o Specifically: Turn Time and Turn Steps components

- AAS (Amputee Activity Survey)

- BBS (Berg Balance Scale)

- FAC (Functional Ambulation Categories)

- FAI (Frenchay Activities Index)

- FIM (Functional Independence Measure), total score

- FSST (Four Square Step Test)

- LEMOCOT (Lower-Extremity Motor Coordination Test)

- OPCS (Office of Population Censuses and Surveys Scale)

- PROS (Prosthetist's Perception of Client's Ambulatory Abilities)

- SIGAM (Special Interest Group of Amputation Medicine)

- SF-12 and SF-36 (Short Form Health Surveys 12 and 36)

o Specifically: SF-12 total score and SF-36 PF (Physical Functioning subscale, PF-15 performed better than PF-10)

\section{Instruments With Evidence of Reliability (Only)}

Seven instruments have, in whole or in part, been reported to have reliability but have not been reported to have test validity in studies generalizable to the Medicare population. This list includes only those instruments for which test validity was not assessed. The instruments with 
evidence of test reliability, but no report about test validity in studies generalizable to the Medicare population include:

- OPUS (Office of Population Censuses and Surveys Scale)

o Specifically: subscales Quality of Life, Lower Limb Function, and Satisfaction

- PEQ (Prosthetic Evaluation Questionnaire)

o Specifically: the overall scale and each of the items, including PEQ-MS 13/7, except the items shower and bathe safely (version with 7 categories, 1 to 7 )

- PGI (Patient Generated Index)

- PSFS (Patient-Specific Functional Scale)

- SAT-PRO (Satisfaction with Prosthesis Questionnaire)

- SF-36V (Short Form Health Survey 36 for use with veterans)

o Specifically: SF-36V subscales General Health, Physical Functioning, and Role Physical

- Walking Speed, 10 meters

\section{Studies Not Generalizable to Medicare Population Instruments With Evidence of Validity and Reliability}

Thirteen instruments have, in whole or in part, been reported to have both test validity and reliability only in studies not generalizable to the Medicare population. A number of these instruments have evidence for either test validity or reliability, but not both, in studies generalizable to the Medicare population; these are further discussed in the notes under the bullet list. The instruments with evidence of test validity and reliability only from studies not generalizable to the Medicare population include:

- BBS (Berg Balance Scale), see note below

- FAI (Frenchay Activities Index), see note below

- L Test (L Test of Functional Mobility)

- LCI (Locomotor Capabilities Index), see note below

o Specifically: LCI-4 Basic and Advanced (Basic and Advanced components, separately, with a 4-point ordinal scale), LCI-5 (LCI with a 5-point ordinal scale), and LCI10-4 (10-item scale which combined two of the response levels from LCI-5)

- Patient Activity Monitor

o Specifically: Walking Velocity

- PEQ (Prosthetic Evaluation Questionnaire), see note below

o Specifically: the Function subscale Residual limb health, the Mobility subscale Ambulation, the Psychosocial subscales Frustration and Social Burden, and the Global subscale Well-Being; and PEQ MS 12/5 (the Mobility Subscale with 12 items and 5 categories)

- PFI (Physical Function Index)

o Including the overall instrument and the four subscales Squat to Pick Up Object, Walk at Steady Pace, Run at Steady Pace, and Climb Stairs

- PLUS-M (Prosthetic Limb Users Survey of Mobility)

o Specifically: the form version SF-12

- PROMIS-29 (Patient-Reported Outcomes Measurement Information System 29-Item Profile)

o Specifically: the Physical Function subscale 
- Q-TFA (Questionnaire for Persons with a Transfemoral Amputation) o Specifically: the subscales Prosthetic Use, Prosthetic Mobility, and Problem

- SIGAM (Special Interest Group of Amputation Medicine), see note below

- SIP-PD (Sickness Impact Profile-Physical Dimension)

o Including the overall instrument and the three subscales Ambulation, Body Care and Movement, and Mobility

- TAPES (Trinity Amputation and Prosthesis Experience Scales)

- All subscales of TAPES and TAPES-R except Weight Satisfaction (from the original TAPES) and Satisfaction with Prosthesis Subscale 1 (esthetics, from TAPES-R)

\section{Supporting Evidence From Medicare-Generalizable Studies}

Note that BBS, FAI, and SIGAM have been reported to be validated among studies generalizable to the Medicare population, but were not assessed for reliability.

Note that LCI-4 (the total instrument) has been reported to be both valid and reliable in studies generalizable to the Medicare population. LCI-4 Basic, LCI-5, and LCI1-4 were not evaluated among studies generalizable to the Medicare population.

Note that PEQ MS 13/11 has been reported to be both valid and reliable in studies generalizable to the Medicare population. The overall PEQ scale and each of the items, except shower and bathe safely (version with seven categories, 1 to 7 ) were reported to have reliability but were not evaluated for test validity in a study generalizable to the Medicare population.

\section{Instruments With Evidence of Validity (Only)}

Four instruments have, in whole or in part, been reported to have test validity but have not been reported to have reliability in studies not generalizable to the Medicare population. These include:

- AMPSIMM (Amputee Single Item Mobility Measure)

- Employment Questionnaire

- TWT (Timed Walking Test)

- WHOQOL-BREF (World Health Organization Quality of Life-Brief Version)

o Specifically: the Physical Health, Psychological Health, Social Relations, and Environmental subscales.

\section{Instruments With Evidence of Validity But Not Reliability}

Subscales from three instruments have been reported to have test validity but not reliability in studies not generalizable to the Medicare population. This instrument is:

- Patient Activity Monitor

o Specifically: Step Count and Step Length

- Q-TFA (Questionnaire for Persons with a Transfemoral Amputation)

o Specifically: the Global Health score

- TAPES (Trinity Amputation and Prosthesis Experience Scales)

o Specifically: the Satisfaction with Prosthesis Subscale 1 (esthetics) from TAPES-R

\section{Instruments With Evidence of Reliability (Only)}

Four instruments have, in whole or in part, been reported to have reliability but have not been reported to have test validity in studies not generalizable to the Medicare population. This list includes only those instruments for which test validity was not assessed. The instruments with 
evidence of test reliability, but no report about test validity in studies not generalizable to the Medicare population include:

- ADAPT (Assessment of Daily Activity Performance in Transfemoral Amputees)

o Specifically: Items 10 to 18; items 1 to 9 were not evaluated

- NQ-ACGC (Quality of Life in Neurological Conditions - Applied Cognition/General Concerns)

- $\quad$ PLUS-M (Prosthetic Limb Users Survey of Mobility)

o Specifically: the form versions CAT (Computer Adaptive Test) and SF-7 (a short form version); the form version SF-12 (not to be confused with the Short Form Health Survey SF-12) has evidence for both test validity and reliability

- PROMIS-29 (Patient-Reported Outcomes Measurement Information System 29-Item Profile)

o Specifically: the Anxiety, Depression, Fatigue, Pain Intensity, Pain Interference, Physical Function, Sleep Disturbance, and Social Role Satisfaction subscales

Note that the Single Beam Test was evaluated for only floor and ceiling effects, in a study not generalizable to the Medicare population, and thus is not in any of the above lists of instruments with evidence of validity or reliability. The Barthel Index was also omitted from these lists because it has only been reported that it failed to predict skilled nursing home placement, which does not adequately address whether the instrument has test validity.

\section{Key Question 4. LLP Comparative Effectiveness by Subgroup}

\section{Key Points}

- $\quad$ Fourteen studies provided sufficient data to evaluate Key Question 4

o Eight studies evaluated validated predictors and outcomes

o Six studies evaluated nonvalidated predictors and/or outcomes

o Only one study specifically analyzed whether any study participant characteristics could accurately and effectively predict which patients will benefit most or least from a given component, but with nonvalidated outcomes

- Overall, studies that investigated subgroup effects did not identify participant characteristics that predict which lower limb amputees would benefit most or least from a given component or configuration (low strength of evidence)

\section{Comments on Key Question and Evidence Base}

It should be noted that this review makes no attempt to make conclusions about the overall effects of different LLP components or configurations. Key Question 4 addressed whether there is evidence regarding heterogeneity of treatment effects (whether outcomes with specific devices vary across individuals based on different characteristics such as age or health status) in the field of LLP research and whether studies used validated measures.

A relatively small percentage of comparative studies report sufficient data to allow subgroup analysis and evaluation of heterogeneity of treatment effect (14\%, 15 of 104 otherwise eligible articles). It is also important to note that this Key Question (and the entire review) evaluates clinical and patient-centered outcomes only. This focus does not diminish the vital importance of biomechanical testing that is used develop and evaluate LLP components or configurations. 
Although not all will agree, the decision was made to focus on only the outcomes important to LLP recipients, prosthetists, and providers.

\section{Overall Summary of Studies}

In total, we found 14 studies (in 15 articles) that directly compared different LLP components or configurations and provided sufficient data to allow subgroup analyses based on participant characteristics. ${ }^{78-91}$ These studies either address or provide sufficient data to allow us to address the focused question of whether the relative effect of different components differs across different subgroups of lower limb amputees. The following summary does not focus on the relative effect of different components nor does it include the majority of studies that compare components (but do not provide subgroup analyses). Nor does it evaluate components based on biomechanical or other nonpatient-centered intermediate outcomes. Of the 104 articles we screened that potentially reported clinical outcomes in comparisons of different LLP components, 89 articles did not report subgroup analyses, evaluations of heterogeneity of treatment effect, predictor models, or sufficient patient-level data to allow post hoc subgroup analyses. These studies were excluded.

Twelve of the 14 studies included between 5 and 168 users of LLP, one included 899 amputees, and one 1013. Seven studies evaluated microprocessor knees (compared to mechanical knees), two evaluated other knee components, three evaluated ankle/foot components, and one each evaluated pylons or sockets. One large study (Hahn 2016) developed a regression model to evaluate the predictive ability of a wide range of participant characteristics. ${ }^{83}$ Another study (Hahn 2015) conducted correlation and regression analyses but did not fully report the results of these analyses. ${ }^{78}$ An older study (Alaranta 1994) reported a correlation analysis between participant characteristics and outcomes and also performed subgroup analyses without statistical comparisons between subgroups. ${ }^{79}$ One study (De Asha 2014) provided subgroup comparisons with statistical analyses ${ }^{80}$; four studies reported subgroup results but did not statistically compare subgroups (Gard 2003, Hafner 2009, Moore 2017, Theeven 2011) 81, 82, 86, 91; and seven studies reported individual patient data which allowed post hoc subgroup analyses (Gard 2003, Hasenoehrl 2017, Isakov 1985, Kahle 2008, Silver-Thorn 2009, Traballesi 2011, Wong 2015). ${ }^{81,84,85,88-90}$ Overall, studies that investigated subgroup effects did not identify participant characteristics that predict which lower limb amputees would benefit most or least from any given component (low strength of evidence).

The following summary tables present summaries of all eligible studies for reference in the next sections. Detailed results summaries are tabulated separately for each study to improve formatting and readability. Table 53 summarizes the study design and participant characteristics of the 14 studies. In each of the studies, all patients were assessed with all components compared, either per study design protocol or through the natural history of people being prescribed a new prosthesis. Among studies that reported prior prosthesis use history, people were all experienced LLP users, with at least 3 months, but generally longer, of experience. The large majority of study participants were male (85\% across studies with reported data) with unilateral amputations (100\% in 9 studies). The level of amputation varied depending on the components being tested. The studies of knees, and the study of sockets, included almost all patients with transfemoral amputations. The study of pylons included only patients with transtibial amputations. The three ankle/foot studies included both patients with transtibial and transfemoral amputations. Twelve of the 14 studies reported the K level (the Medicare Functional Classification Level) of included patients. Except for four studies that included only 
K2 level patients, most study participants were at K3 (or K4) level, except for the Hahn 2015 study of C-Leg in which 93 percent were MOBIS level 2 or 3 (equivalent to K2 or K3). ${ }^{78}$ Only Wong 2015 explicitly included people at K1 level. The amputation etiologies across studies varied more widely, although with three exceptions, at least about half of patients had traumarelated amputations. Only Isakov 1985 and Moore 2017 included a majority of people with dysvascular disease-related amputations (14/17, 82\%). The study participants were relatively young in 11 studies, with mean ages ranging from 34 to 61 years, suggesting that well over half the amputees were less than 65 years old. One small study (Hasenoehrl 2017) included mostly people over age 65 years (mean 68, range 56 to 75 ).

Table 54 describes the components that were compared in the studies. Table 55 describes the risk of bias (study quality) of the studies. Eight of the studies were deemed to be at moderate risk of bias overall and six studies at high risk of bias. Briefly, only one study was randomized. No study attempted to blind patients or providers (which may have been impossible for many components), but studies also did not blind outcome assessors (which may have been difficult for most studies). Since all studies were one- or two-way crossover studies, by definition the groups of patients evaluating each component were equivalent. Dropout rates were low across studies. Two studies conducted multivariable analyses comparing subgroups, but only one reported details of the analysis. Only three studies statistically evaluated heterogeneity of treatment effect (differences among subgroups).

Table 56 provides an overall summary of subgroup comparisons across all studies and Tables 57 to 70 provide the summary results for each study individually. Narrative summaries follow the tables. 
Table 53. Study design and participant characteristics of studies comparing components

\begin{tabular}{|c|c|c|c|c|c|c|c|c|c|c|c|}
\hline $\begin{array}{l}\text { Study Year } \\
\text { (PMID) } \\
\text { Country }\end{array}$ & $\begin{array}{l}\text { Study } \\
\text { Design }\end{array}$ & $\begin{array}{l}\text { Funding } \\
\text { Source }\end{array}$ & Components & $\begin{array}{l}\text { Amputation } \\
\text { and } \\
\text { Prosthesis } \\
\text { Use } \\
\text { History }\end{array}$ & $\begin{array}{l}\mathrm{N} \\
\text { Analyzed }\end{array}$ & $\begin{array}{l}\text { Mean } \\
\text { Age } \\
\text { (SD) }\end{array}$ & Male & K Level & $\begin{array}{l}\text { Amputation } \\
\text { Level }\end{array}$ & $\begin{array}{l}\text { Uni- } \\
\text { lateral }\end{array}$ & Etiology \\
\hline $\begin{array}{l}\text { Alaranta } \\
1994 \\
\text { (7991366) } \\
\text { Finland } \\
\end{array}$ & $\begin{array}{l}\text { NRCS, } \\
\text { retrospective }\end{array}$ & $\begin{array}{l}\text { Not } \\
\text { reported / } \\
\text { unclear }\end{array}$ & $\begin{array}{l}\text { Foot/Ankle, } \\
\text { energy-storing } \\
\text { vs. } \\
\text { conventional }\end{array}$ & $\begin{array}{l}\text { Prosthesis } \\
\geq 6 \mathrm{mo}\end{array}$ & 168 & 58.4 & $93 \%$ & $\begin{array}{l}\text { K3-4 } \\
100 \%\end{array}$ & $\begin{array}{l}\text { TT 84\%, TF } \\
16 \%\end{array}$ & $93 \%$ & $\begin{array}{l}\text { Tr } 86 \%, \\
\text { Dysv 5\%, } \\
\text { other } 9 \%\end{array}$ \\
\hline $\begin{array}{l}\text { De Asha } \\
2014 \\
(24997811) \\
\text { UK }\end{array}$ & $\begin{array}{l}\text { NRCS, } \\
\text { prospective }\end{array}$ & $\begin{array}{l}\text { Industry } \\
\text { provided } \\
\text { materials }\end{array}$ & $\begin{array}{l}\text { Foot/Ankle, } \\
\text { hydraulic vs. } \\
\text { rigid }\end{array}$ & $\begin{array}{l}\text { Amputation } \\
\geq 2 \text { y prior, } \\
\text { prosthesis } \\
\geq 6 \text { mo }\end{array}$ & 19 & $\begin{array}{l}44.5 \\
(12.5)\end{array}$ & nd & $\begin{array}{l}\text { K3-4 } \\
100 \%\end{array}$ & $\begin{array}{l}\text { TT 58\%, TF } \\
42 \%\end{array}$ & $100 \%$ & $\begin{array}{l}\text { Tr 84\%, } \\
\text { Dysv 0\%, } \\
\text { CA } 16 \%\end{array}$ \\
\hline $\begin{array}{l}\text { Gard } 2003 \\
(15077637) \\
\text { USA }\end{array}$ & $\begin{array}{l}\text { Pre-post, } \\
\text { prospective }\end{array}$ & Nonindustry & $\begin{array}{l}\text { Pylon, shock- } \\
\text { absorbing vs. } \\
\text { conventional }\end{array}$ & $\begin{array}{l}\text { Prosthesis } \\
\geq 6 \mathrm{mo}\end{array}$ & 10 & $\begin{array}{l}54 \\
(17) \\
{[32-79]}\end{array}$ & $90 \%$ & nd & TT 100\% & $100 \%$ & $\begin{array}{l}\operatorname{Tr} 70 \%, \\
\text { Dysv 30\% }\end{array}$ \\
\hline $\begin{array}{l}\text { Hafner } \\
2009 \\
(19675993) \\
\text { USA }\end{array}$ & $\begin{array}{l}\mathrm{RCT} \\
\text { (crossover) }\end{array}$ & $\begin{array}{l}\text { Industry } \\
\text { funded }\end{array}$ & $\begin{array}{l}\text { Knee, } \\
\text { microprocessor } \\
\text { vs. } \\
\text { conventional }\end{array}$ & $\begin{array}{l}\text { Amputation } \\
\geq 2 \text { y prior }\end{array}$ & 17 & $\begin{array}{l}49.1 \\
(16.4)\end{array}$ & $76 \%$ & $\begin{array}{l}\text { K2 47\%, } \\
\text { K3 53\% }\end{array}$ & TF 100\% & $100 \%$ & $\begin{array}{l}\text { Tr 59\%, } \\
\text { Dysv 6\%, } \\
\text { CA } 18 \% \text {, } \\
\text { Inf } 12 \% \text {, } \\
\text { other } 6 \%\end{array}$ \\
\hline $\begin{array}{l}\text { Hahn } 2015 \\
\text { (J Prosthet } \\
\text { Orthot) } \\
\text { Germany }\end{array}$ & $\begin{array}{l}\text { NRCS, } \\
\text { retrospective }\end{array}$ & $\begin{array}{l}\text { None } \\
\text { (employees } \\
\text { of Otto } \\
\text { Bock } \\
\text { Healthcare) }\end{array}$ & $\begin{array}{l}\text { Knee, } \\
\text { microprocessor } \\
\text { vs. } \\
\text { conventional }\end{array}$ & $\begin{array}{l}\text { Prosthesis } \\
\geq 12 \text { mo } \\
\text { (implied) } \\
\text { Amputation } \\
17.5 \mathrm{yr} \\
\text { (mean) }\end{array}$ & 1013 & $\begin{array}{l}55.6 \\
(15.1)\end{array}$ & $83 \%$ & $\begin{array}{l}\text { MG2 46\%, } \\
\text { MG3 47\%, } \\
\text { MG4 8\% }\end{array}$ & TF $100 \%$ & nd & $\begin{array}{l}\operatorname{Tr} 43 \%, \\
\text { Dysv } 26 \% \text {, } \\
\text { CA } 13 \% \text {, } \\
\text { Inf } 6 \% \text {, } \\
\text { other } 12 \%\end{array}$ \\
\hline $\begin{array}{l}\text { Hahn } 2016 \\
(27828871) \\
\text { Germany }\end{array}$ & $\begin{array}{l}\text { Single } \\
\text { group, } \\
\text { retrospective }\end{array}$ & $\begin{array}{l}\text { Industry } \\
\text { provided } \\
\text { materials } \\
\text { (employees } \\
\text { of Otto } \\
\text { Bock } \\
\text { Healthcare) }\end{array}$ & $\begin{array}{l}\text { Knee, } \\
\text { microprocessor, } \\
\text { hydraulic vs. } \\
\text { conventional }\end{array}$ & nd & 899 & $\begin{array}{l}49.0 \\
(12.9)\end{array}$ & $83 \%$ & $\begin{array}{l}\text { K2 13\%, } \\
\text { K3 64\%, } \\
\text { K4 23\% }\end{array}$ & $\begin{array}{l}\text { Knee 19\%, } \\
\text { TF 80\% }\end{array}$ & nd & $\begin{array}{l}\text { Tr 69\%, } \\
\text { Dysv 6\%, } \\
\text { CA 16\%, } \\
\text { other } 10 \%\end{array}$ \\
\hline $\begin{array}{l}\text { Hasenoehrl } \\
2017 \\
\text { (28399722) } \\
\text { Austria } \\
\end{array}$ & $\begin{array}{l}\text { Pre-post, } \\
\text { prospective }\end{array}$ & $\begin{array}{l}\text { Industry } \\
\text { provided } \\
\text { materials }\end{array}$ & $\begin{array}{l}\text { Knee, } \\
\text { microprocessor } \\
\text { vs. } \\
\text { conventional }\end{array}$ & $\begin{array}{l}\text { Prosthesis } \\
\geq 12 \text { mo }\end{array}$ & 5 & $\begin{array}{l}68.2 \\
(7.6)\end{array}$ & $80 \%$ & K2: $100 \%$ & TF: $100 \%$ & $100 \%$ & $\begin{array}{l}\operatorname{Tr} 20 \%, \\
\text { Dysv } 20 \% \text {, } \\
\text { other } 60 \%\end{array}$ \\
\hline $\begin{array}{l}\text { Isakov } 1985 \\
(3868034) \\
\text { Israel }\end{array}$ & $\begin{array}{l}\text { Pre-post, } \\
\text { prospective }\end{array}$ & $\begin{array}{l}\text { Not } \\
\text { reported / } \\
\text { unclear } \\
\end{array}$ & $\begin{array}{l}\text { Knee, locking } \\
\text { vs. open }\end{array}$ & nd & 17 & $\begin{array}{l}55.6 \\
(12.1)\end{array}$ & $94 \%$ & nd & TF $100 \%$ & $100 \%$ & $\begin{array}{l}\operatorname{Tr} 18 \%, \\
\text { Dysv } 82 \%\end{array}$ \\
\hline
\end{tabular}




\begin{tabular}{|c|c|c|c|c|c|c|c|c|c|c|c|}
\hline $\begin{array}{l}\text { Study Year } \\
\text { (PMID) } \\
\text { Country }\end{array}$ & $\begin{array}{l}\text { Study } \\
\text { Design }\end{array}$ & $\begin{array}{l}\text { Funding } \\
\text { Source }\end{array}$ & Components & $\begin{array}{l}\text { Amputation } \\
\text { and } \\
\text { Prosthesis } \\
\text { Use } \\
\text { History }\end{array}$ & $\begin{array}{l}\mathbf{N} \\
\text { Analyzed }\end{array}$ & $\begin{array}{l}\text { Mean } \\
\text { Age } \\
\text { (SD) }\end{array}$ & Male & K Level & $\begin{array}{l}\text { Amputation } \\
\text { Level }\end{array}$ & $\begin{array}{l}\text { Uni- } \\
\text { lateral }\end{array}$ & Etiology \\
\hline $\begin{array}{l}\text { Kahle } 2008 \\
(18566922) \\
\text { USA }\end{array}$ & $\begin{array}{l}\text { Pre-post, } \\
\text { prospective }\end{array}$ & Nonindustry & $\begin{array}{l}\text { Knee, } \\
\text { microprocessor } \\
\text { vs. } \\
\text { conventional }\end{array}$ & $\begin{array}{l}\text { Prosthesis } \\
\geq 90 \mathrm{~d}\end{array}$ & 15 & $\begin{array}{l}51 \\
(19)\end{array}$ & nd & $\begin{array}{l}\text { K2 60\%,* } \\
\text { K3 33\%,* } \\
\text { K4 } 7 \%\end{array}$ & nd & $100 \%$ & $\begin{array}{l}\operatorname{Tr} 47 \%, \\
\text { Dysv } 47 \%, \\
\text { other } 6 \%\end{array}$ \\
\hline $\begin{array}{l}\text { Moore } 2017 \\
\text { (J Prosth } \\
\text { Orthot) } \\
\text { UK }\end{array}$ & $\begin{array}{l}\text { Pre-post, } \\
\text { prospective }\end{array}$ & $\begin{array}{l}\text { Not } \\
\text { reported / } \\
\text { unclear }\end{array}$ & $\begin{array}{l}\text { Foot/ankle, } \\
\text { hydraulic vs. } \\
\text { conventional }\end{array}$ & nd & 14 & $38-84$ & $86 \%$ & K2 100\% & $\begin{array}{l}\text { TT } 86 \% \\
\text { TF } 14 \%\end{array}$ & $93 \%$ & $\begin{array}{l}\text { Tr14\%, } \\
\text { Dysv } 71 \% \text {, } \\
\text { Inf } 14 \%\end{array}$ \\
\hline $\begin{array}{l}\text { Silver- } \\
\text { Thorn } 2009 \\
\text { (J Prosth } \\
\text { Orthot) } \\
\text { USA }\end{array}$ & $\begin{array}{l}\text { NRCS, } \\
\text { prospective }\end{array}$ & Nonindustry & $\begin{array}{l}\text { Knee, locking } \\
\text { vs. hydraulic }\end{array}$ & nd & 5 & $\begin{array}{l}44.8 \\
(9.3)\end{array}$ & nd & K2 100\% & TF 100\% & $100 \%$ & $\begin{array}{l}\text { Tr } 80 \% \\
\text { Dysv 0\%, } \\
\text { CA 20\% }\end{array}$ \\
\hline $\begin{array}{l}\text { Theeven } \\
2011 \\
(21947182, \\
22549656) \\
\text { Netherlands } \\
\text { and } \\
\text { Belgium } \\
\end{array}$ & $\begin{array}{l}\text { RCT } \\
\text { (crossover) }\end{array}$ & Nonindustry & $\begin{array}{l}\text { Knee, } \\
\text { microprocessor } \\
\text { ( } 2 \text { types) vs. } \\
\text { conventional }\end{array}$ & $\begin{array}{l}\text { Amputation } \\
\geq 1 \text { y prior }\end{array}$ & 41 & $\begin{array}{l}59.1 \\
(12.6)\end{array}$ & $73 \%$ & K2 100\% & TF 100\% & $100 \%$ & $\begin{array}{l}\operatorname{Tr} 77 \%, \\
\text { Dysv 20\%, } \\
\text { other } 3 \%\end{array}$ \\
\hline $\begin{array}{l}\text { Traballesi } \\
2011 \\
(21684165) \\
\text { Italy }\end{array}$ & $\begin{array}{l}\text { Pre-post, } \\
\text { prospective }\end{array}$ & $\begin{array}{l}\text { Not } \\
\text { reported / } \\
\text { unclear }\end{array}$ & $\begin{array}{l}\text { Socket, Marlo } \\
\text { vs. ischial } \\
\text { containment }\end{array}$ & $\begin{array}{l}\text { Prosthesis } \\
\geq 1 \mathrm{y}\end{array}$ & 12 & $\begin{array}{l}33.9 \\
(9.4)\end{array}$ & $86 \%$ & $\begin{array}{l}\text { K3-4 } \\
100 \%\end{array}$ & TF 100\% & $100 \%$ & $\begin{array}{l}\operatorname{Tr} 86 \%, \\
\text { Dysv 0\%, } \\
\text { CA } 14 \%\end{array}$ \\
\hline $\begin{array}{l}\text { Wong } 2015 \\
(25768067) \\
\text { USA }\end{array}$ & $\begin{array}{l}\text { NRCS, } \\
\text { prospective }\end{array}$ & $\begin{array}{l}\text { Industry } \\
\text { funded }\end{array}$ & $\begin{array}{l}\text { Knee, } \\
\text { microprocessor } \\
\text { vs. } \\
\text { conventional }\end{array}$ & nd & 8 & $\begin{array}{l}60.8 \\
(11.3)\end{array}$ & nd & $\begin{array}{l}\text { K1 25\%, } \\
\text { K2 25\%, } \\
\text { K3 50\% }\end{array}$ & TF $100 \%$ & $75 \%$ & nd \\
\hline
\end{tabular}

Abbreviations: Dysv = dysvascular disease, Inf = infection, Knee = at level of knee amputation, MG = MOBIS grade (per article, equivalent to K level [Medicare Functional

Classification Level]), nd = no data (not reported), NRCS = nonrandomized comparative study, PMID = PubMed identifier (or journal), RCT = randomized comparative study,

$\mathrm{SD}=$ standard deviation, $\mathrm{TF}=$ transfemoral amputation, $\mathrm{Tr}=$ trauma, $\mathrm{TT}=$ transtibial amputation.

*4 of 9 patients who were K2 when evaluated with their conventional knee were K3 when evaluated with the microprocessor knee; 3 of 5 patients who were K3 when evaluated with their conventional knee were $\mathrm{K} 4$ when evaluated with the microprocessor knee. 
Table 54. Components evaluated in eligible comparative studies

\begin{tabular}{|c|c|c|c|}
\hline Study Year (PMID) & Component Type & Arm & Component Name/Description (Manufacturer) \\
\hline \multirow[t]{2}{*}{ Alaranta 1994 (7991366) } & \multirow[t]{2}{*}{ Foot/Ankle } & Energy storing prostheses & Flexible plastic/carbon fiber leaf spring \\
\hline & & Conventional prostheses & Solid-ankle-cushion-heel \\
\hline \multirow[t]{2}{*}{ De Asha 2014 (24997811) } & \multirow[t]{2}{*}{ Foot/Ankle } & Hydraulic & Echelon (Endolite) \\
\hline & & Rigid & Varied, habitual \\
\hline \multirow[t]{2}{*}{ Gard 2003 (15077637) } & \multirow[t]{2}{*}{ Pylon } & Shock-absorbing pylon & Telescopic-Torsion Pylon (Endolite) \\
\hline & & Conventional pylon & Varied, habitual \\
\hline \multirow[t]{2}{*}{ Hafner 2009 (19675993) } & \multirow[t]{2}{*}{ Knee } & Microprocessor & C-Leg Model 3C98 (Otto Bock) \\
\hline & & Nonmicroprocessor & Varied, habitual \\
\hline \multirow[t]{2}{*}{ Hahn 2015 (J Prosthet Orthot) } & \multirow[t]{2}{*}{ Knee } & Microprocessor & C-Leg or C-Leg Compact (Otto Bock) \\
\hline & & Conventional prostheses & Varied, habitual \\
\hline \multirow[t]{2}{*}{ Hahn 2016 (27828871) } & \multirow[t]{2}{*}{ Knee } & Microprocessor, hydraulic & Genium (Otto Bock) \\
\hline & & Conventional prostheses & Varied, habitual \\
\hline \multirow[t]{2}{*}{ Hasenoehrl 2017 (28399722) } & \multirow[t]{2}{*}{ Knee } & Microprocessor (swing phase) & Genium with Cenior-Leg ruleset (Otto Bock) \\
\hline & & Nonmicroprocessor & Varied, habitual \\
\hline \multirow[t]{2}{*}{ Isakov 1985 (3868034) } & \multirow[t]{2}{*}{ Knee } & Locking system & 3R17 (Otto Bock) \\
\hline & & Load-dependent brake ("open") & 3R15 (Otto Bock) \\
\hline \multirow[t]{2}{*}{ Kahle 2008 (18566922) } & \multirow[t]{2}{*}{ Knee } & Microprocessor & C-Leg (Otto Bock) \\
\hline & & Nonmicroprocessor & Varied, habitual $^{\star}$ \\
\hline \multirow[t]{2}{*}{ Moore 2017 (J Prosth Orthot) } & \multirow[t]{2}{*}{ Foot/Ankle } & Hydraulic & Avalon (Endolite) \\
\hline & & Multiaxial, nonhydraulic & Multiflex (Endolite) \\
\hline \multirow{2}{*}{ Silver-Thorn 2009 (J Prosth Orthot) } & \multirow[t]{2}{*}{ Knee } & Locking system & Total Knee 2000 (Össur) \\
\hline & & Hydraulic & 3R80 (Otto Bock) \\
\hline \multirow[t]{3}{*}{ Theeven 2011 (21947182, 22549656) } & \multirow[t]{3}{*}{ Knee } & Microprocessor (stance and swing phases) & C-Leg (Otto Bock) \\
\hline & & Microprocessor (stance phase) & C-Leg Compact (Otto Bock) \\
\hline & & Nonmicroprocessor & Varied, habitual† \\
\hline \multirow[t]{2}{*}{ Traballesi 2011 (21684165) } & \multirow[t]{2}{*}{ Socket } & Marlo Anatomical Socket & Lower anterior and posterior trim lines \\
\hline & & Ischial Containment Socket & Typical socket shape \\
\hline \multirow[t]{2}{*}{ Wong 2015 (25768067) } & \multirow[t]{2}{*}{ Knee } & Microprocessor & C-Leg $(n=5)$ or C-Leg Compact $(n=3)$ (Otto Bock) \\
\hline & & Nonmicroprocessor & Varied, habitual $\ddagger$ \\
\hline
\end{tabular}

Abbreviation: PMID = PubMed identifier (or journal).

*4-bar multiaxial knee joint with hydraulic swing-phase control (n=5), Total Knee 2000® Polycentric knee with geometric locking system (Össur) (n=5), Mauch Single axis hydraulic knee system with swing and stance control SNS ${ }^{\circledR}$ (Össur) $(\mathrm{n}=4)$, Weight-activated stance-phase brake mechanism with pneumatic swing-phase control (n=3), Single axis friction ( $\mathrm{n}=1)$, Weight-activated stance-phase brake mechanism with friction swing-phase control (n=1).

†3R80, 3R106, 3R60, 3R92 (Otto Bock); Acphapend (Proteval); Ultimate (Ortho Europe); Total Knee, Mauch Knee (Össur); Graph-Lite (Teh Lin); or manual locking knee. ¥3R60 or 3R80 (n=3), Mauch Knee (Össur) (n=2), Total Knee 1900 or 2000 (Össur) (n=2), or Locking 3R41 (Otto Bock) (n=1) 
Table 55. Comparative study risk of bias/study quality

\begin{tabular}{|c|c|c|c|c|c|c|c|c|c|c|c|}
\hline $\begin{array}{l}\text { Study } \\
\text { Year } \\
\text { (PMID) }\end{array}$ & $\begin{array}{l}\text { Random- } \\
\text { ization }\end{array}$ & $\begin{array}{l}\text { Allocation } \\
\text { Conceal- } \\
\text { ment }\end{array}$ & $\begin{array}{l}\text { Blinding, } \\
\text { Patients }\end{array}$ & $\begin{array}{l}\text { Blinding, } \\
\text { Providers }\end{array}$ & $\begin{array}{l}\text { Blinding, } \\
\text { Outcome } \\
\text { Assessors }\end{array}$ & $\begin{array}{l}\text { Outcome } \\
\text { Assess- } \\
\text { ment, } \\
\text { Validation }\end{array}$ & $\begin{array}{l}\text { Equivalent } \\
\text { Groups }\end{array}$ & Dropouts & $\begin{array}{l}\text { Multi- } \\
\text { variable }\end{array}$ & $\begin{array}{l}\text { HTE } \\
\text { Analyzed? }\end{array}$ & $\begin{array}{l}\text { Overall } \\
\text { Quality }\end{array}$ \\
\hline $\begin{array}{l}\text { Alaranta } \\
1994 \\
(7991366)\end{array}$ & $\begin{array}{l}\text { High RoB } \\
\text { (non- } \\
\text { randomized) }\end{array}$ & $\begin{array}{l}\text { NA (cross- } \\
\text { over) }\end{array}$ & $\begin{array}{l}\text { High } \\
\text { RoB }\end{array}$ & High RoB & High RoB & $\begin{array}{l}\text { Low RoB, } \\
\text { not } \\
\text { validated }\end{array}$ & $\begin{array}{l}\text { Low RoB } \\
\text { (pre-post) }\end{array}$ & Low RoB & $\begin{array}{l}\text { High } \\
\text { RoB } \\
\text { (no) }\end{array}$ & Partially* & $\begin{array}{l}\text { High } \\
\text { RoB }\end{array}$ \\
\hline $\begin{array}{l}\text { De Asha } \\
2014 \\
(24997811)\end{array}$ & $\begin{array}{l}\text { High RoB } \\
\text { (non- } \\
\text { randomized) }\end{array}$ & $\begin{array}{l}\text { NA (cross- } \\
\text { over) }\end{array}$ & $\begin{array}{l}\text { High } \\
\text { RoB }\end{array}$ & High RoB & High RoB & $\begin{array}{l}\text { Low RoB, } \\
\text { not } \\
\text { validated }\end{array}$ & $\begin{array}{l}\text { Low RoB } \\
\text { (pre-post) }\end{array}$ & Low RoB & $\begin{array}{l}\text { High } \\
\text { RoB } \\
\text { (no) }\end{array}$ & $\begin{array}{l}\text { Yes } \\
\text { (interaction) }\end{array}$ & $\begin{array}{l}\text { High } \\
\text { RoB }\end{array}$ \\
\hline $\begin{array}{l}\text { Gard } 2003 \\
(15077637)\end{array}$ & $\begin{array}{l}\text { High RoB } \\
\text { (non- } \\
\text { randomized) }\end{array}$ & $\begin{array}{l}\text { NA (cross- } \\
\text { over) }\end{array}$ & $\begin{array}{l}\text { High } \\
\text { RoB }\end{array}$ & High RoB & High RoB & $\begin{array}{l}\text { Low RoB, } \\
\text { not } \\
\text { validated }\end{array}$ & $\begin{array}{l}\text { Low RoB } \\
\text { (pre-post) }\end{array}$ & Low RoB & $\begin{array}{l}\text { High } \\
\text { RoB } \\
\text { (no) }\end{array}$ & $\begin{array}{l}\text { No (IPD } \\
\text { reported) }\end{array}$ & $\begin{array}{l}\text { High } \\
\text { RoB }\end{array}$ \\
\hline $\begin{array}{l}\text { Hafner } \\
2009 \\
(19675993)\end{array}$ & $\begin{array}{l}\text { High RoB } \\
\text { (non- } \\
\text { randomized) }\end{array}$ & $\begin{array}{l}\text { NA (cross- } \\
\text { over) }\end{array}$ & $\begin{array}{l}\text { High } \\
\text { RoB }\end{array}$ & High RoB & $\begin{array}{l}\text { Unclear } \\
\text { RoB }\end{array}$ & $\begin{array}{l}\text { Low RoB, } \\
\text { validated }\end{array}$ & $\begin{array}{l}\text { Low RoB } \\
\text { (crossover) }\end{array}$ & Low RoB & $\begin{array}{l}\text { High } \\
\text { RoB } \\
\text { (no) }\end{array}$ & Indirectly† & $\begin{array}{l}\text { Moderate } \\
\text { RoB }\end{array}$ \\
\hline $\begin{array}{l}\text { Hahn } 2015 \\
\text { (J Prosthet } \\
\text { Orthot) }\end{array}$ & $\begin{array}{l}\text { High RoB } \\
\text { (non- } \\
\text { randomized) }\end{array}$ & $\begin{array}{l}\text { NA (cross- } \\
\text { over) }\end{array}$ & $\begin{array}{l}\text { High } \\
\text { RoB }\end{array}$ & High RoB & High RoB & $\begin{array}{l}\text { Low RoB, } \\
\text { validated }\end{array}$ & $\begin{array}{l}\text { Low RoB } \\
\text { (crossover) }\end{array}$ & Low RoB & $\begin{array}{l}\text { Low } \\
\text { RoB } \\
\text { (yes) }\end{array}$ & $\begin{array}{l}\text { Yes } \\
\text { (model) }\end{array}$ & $\begin{array}{l}\text { Moderate } \\
\text { RoB }\end{array}$ \\
\hline $\begin{array}{l}\text { Hahn } 2016 \\
(27828871)\end{array}$ & $\begin{array}{l}\text { High RoB } \\
\text { (non- } \\
\text { randomized) }\end{array}$ & $\begin{array}{l}\text { NA (cross- } \\
\text { over) }\end{array}$ & $\begin{array}{l}\text { High } \\
\text { RoB }\end{array}$ & High RoB & High RoB & $\begin{array}{l}\text { Low RoB, } \\
\text { not } \\
\text { validated }\end{array}$ & $\begin{array}{l}\text { Low RoB } \\
\text { (pre-post) }\end{array}$ & Low RoB & $\begin{array}{l}\text { Low } \\
\text { RoB } \\
\text { (yes) }\end{array}$ & $\begin{array}{l}\text { Yes } \\
\text { (model) }\end{array}$ & $\begin{array}{l}\text { Moderate } \\
\text { RoB }\end{array}$ \\
\hline $\begin{array}{l}\text { Hasenoehrl } \\
2017 \\
(28399722)\end{array}$ & $\begin{array}{l}\text { High RoB } \\
\text { (non- } \\
\text { randomized) }\end{array}$ & $\begin{array}{l}\text { NA (cross- } \\
\text { over) }\end{array}$ & $\begin{array}{l}\text { High } \\
\text { RoB }\end{array}$ & High RoB & High RoB & $\begin{array}{l}\text { Low RoB, } \\
\text { validated }\end{array}$ & $\begin{array}{l}\text { Low RoB } \\
\text { (crossover) }\end{array}$ & Low RoB & $\begin{array}{l}\text { High } \\
\text { RoB } \\
\text { (no) }\end{array}$ & Indirectly† & $\begin{array}{l}\text { Moderate } \\
\text { RoB }\end{array}$ \\
\hline $\begin{array}{l}\text { Isakov } \\
1985 \\
(3868034)\end{array}$ & $\begin{array}{l}\text { High RoB } \\
\text { (non- } \\
\text { randomized) }\end{array}$ & $\begin{array}{l}\text { NA (cross- } \\
\text { over) }\end{array}$ & $\begin{array}{l}\text { High } \\
\text { RoB }\end{array}$ & High RoB & $\begin{array}{l}\text { Unclear } \\
\text { RoB }\end{array}$ & $\begin{array}{l}\text { Low RoB, } \\
\text { validated }\end{array}$ & $\begin{array}{l}\text { Low RoB } \\
\text { (crossover) }\end{array}$ & Low RoB & $\begin{array}{l}\text { High } \\
\text { RoB } \\
\text { (no) }\end{array}$ & $\begin{array}{l}\text { No (IPD } \\
\text { reported) }\end{array}$ & $\begin{array}{l}\text { Moderate } \\
\text { RoB }\end{array}$ \\
\hline $\begin{array}{l}\text { Kahle } 2008 \\
(18566922)\end{array}$ & $\begin{array}{l}\text { High RoB } \\
\text { (non- } \\
\text { randomized) }\end{array}$ & $\begin{array}{l}\text { NA (cross- } \\
\text { over) }\end{array}$ & $\begin{array}{l}\text { High } \\
\text { RoB }\end{array}$ & High RoB & High RoB & $\begin{array}{l}\text { Low RoB, } \\
\text { validated }\end{array}$ & $\begin{array}{l}\text { Low RoB } \\
\text { (pre-post) }\end{array}$ & Low RoB & $\begin{array}{l}\text { High } \\
\text { RoB } \\
\text { (no) }\end{array}$ & $\begin{array}{l}\text { No (IPD } \\
\text { reported) }\end{array}$ & $\begin{array}{l}\text { Moderate } \\
\text { RoB }\end{array}$ \\
\hline $\begin{array}{l}\text { Moore } \\
2017(\mathrm{~J} \\
\text { Prosth } \\
\text { Orthot) }\end{array}$ & $\begin{array}{l}\text { High RoB } \\
\text { (non- } \\
\text { randomized) }\end{array}$ & $\begin{array}{l}\text { NA (cross- } \\
\text { over) }\end{array}$ & $\begin{array}{l}\text { High } \\
\text { RoB }\end{array}$ & High RoB & High RoB & $\begin{array}{l}\text { Low RoB, } \\
\text { validated }\end{array}$ & $\begin{array}{l}\text { Low RoB } \\
\text { (pre-post) }\end{array}$ & Low RoB & $\begin{array}{l}\text { High } \\
\text { RoB } \\
\text { (no) }\end{array}$ & Partially* & $\begin{array}{l}\text { Moderate } \\
\text { RoB }\end{array}$ \\
\hline $\begin{array}{l}\text { Silver- } \\
\text { Thorn } 2009 \\
\text { (J Prosth } \\
\text { Orthot) }\end{array}$ & $\begin{array}{l}\text { High RoB } \\
\text { (non- } \\
\text { randomized) }\end{array}$ & $\begin{array}{l}\text { NA (cross- } \\
\text { over) }\end{array}$ & $\begin{array}{l}\text { High } \\
\text { RoB }\end{array}$ & High RoB & High RoB & $\begin{array}{l}\text { Low RoB, } \\
\text { not } \\
\text { validated }\end{array}$ & $\begin{array}{l}\text { Low RoB } \\
\text { (crossover) }\end{array}$ & Low RoB & $\begin{array}{l}\text { High } \\
\text { RoB } \\
\text { (no) }\end{array}$ & $\begin{array}{l}\text { No (IPD } \\
\text { reported) }\end{array}$ & $\begin{array}{l}\text { High } \\
\text { RoB }\end{array}$ \\
\hline
\end{tabular}




\begin{tabular}{|c|c|c|c|c|c|c|c|c|c|c|c|}
\hline $\begin{array}{l}\text { Study } \\
\text { Year } \\
\text { (PMID) }\end{array}$ & $\begin{array}{l}\text { Random- } \\
\text { ization }\end{array}$ & $\begin{array}{l}\text { Allocation } \\
\text { Conceal- } \\
\text { ment }\end{array}$ & $\begin{array}{l}\text { Blinding, } \\
\text { Patients }\end{array}$ & $\begin{array}{l}\text { Blinding, } \\
\text { Providers }\end{array}$ & $\begin{array}{l}\text { Blinding, } \\
\text { Outcome } \\
\text { Assessors }\end{array}$ & $\begin{array}{l}\text { Outcome } \\
\text { Assess- } \\
\text { ment, } \\
\text { Validation }\end{array}$ & $\begin{array}{l}\text { Equivalent } \\
\text { Groups }\end{array}$ & Dropouts & $\begin{array}{l}\text { Multi- } \\
\text { variable }\end{array}$ & $\begin{array}{l}\text { HTE } \\
\text { Analyzed? }\end{array}$ & $\begin{array}{l}\text { Overall } \\
\text { Quality }\end{array}$ \\
\hline $\begin{array}{l}\text { Theeven } \\
2011 \\
(21947182, \\
22549656)\end{array}$ & Low RoB & $\begin{array}{l}\text { NA (cross- } \\
\text { over) }\end{array}$ & $\begin{array}{l}\text { High } \\
\text { RoB }\end{array}$ & High RoB & High RoB & $\begin{array}{l}\text { High RoB } \\
\text { (some } \\
\text { outcome } \\
\text { unclear), } \\
\text { validated }\end{array}$ & $\begin{array}{l}\text { Low RoB } \\
\text { (crossover) }\end{array}$ & Low RoB & $\begin{array}{l}\text { High } \\
\text { RoB } \\
\text { (no) }\end{array}$ & Indirectly† & $\begin{array}{l}\text { High } \\
\text { RoB }\end{array}$ \\
\hline $\begin{array}{l}\text { Traballesi } \\
2011 \\
(21684165)\end{array}$ & $\begin{array}{l}\text { High RoB } \\
\text { (non- } \\
\text { randomized) }\end{array}$ & $\begin{array}{l}\text { NA (cross- } \\
\text { over) }\end{array}$ & $\begin{array}{l}\text { High } \\
\text { RoB }\end{array}$ & High RoB & High RoB & $\begin{array}{l}\text { Low RoB, } \\
\text { validated }\end{array}$ & $\begin{array}{l}\text { Low RoB } \\
\text { (pre-post) }\end{array}$ & Low RoB & $\begin{array}{l}\text { High } \\
\text { RoB } \\
\text { (no) }\end{array}$ & $\begin{array}{l}\text { No (IPD } \\
\text { reported) }\end{array}$ & $\begin{array}{l}\text { Moderate } \\
\text { RoB }\end{array}$ \\
\hline $\begin{array}{l}\text { Wong } 2015 \\
\text { (25768067) }\end{array}$ & $\begin{array}{l}\text { High RoB } \\
\text { (non- } \\
\text { randomized) }\end{array}$ & $\begin{array}{l}\text { NA (cross- } \\
\text { over) }\end{array}$ & $\begin{array}{l}\text { High } \\
\text { RoB }\end{array}$ & High RoB & High RoB & $\begin{array}{l}\text { Low RoB, } \\
\text { validated }\end{array}$ & $\begin{array}{l}\text { Low RoB } \\
\text { (pre-post) }\end{array}$ & Low RoB & $\begin{array}{l}\text { High } \\
\text { RoB } \\
\text { (no) }\end{array}$ & $\begin{array}{l}\text { No (IPD } \\
\text { reported) }\end{array}$ & $\begin{array}{l}\text { Moderate } \\
\text { RoB }\end{array}$ \\
\hline
\end{tabular}

Abbreviations: HTE = heterogeneity of treatment effect (difference in effect/association between different subgroups of participants), IPD = individual participant data, NA = not applicable, PMID = PubMed identifier (or journal), RoB = risk of bias.

*Reported transtibial and transfemoral analyses separately; did not report statistical analyses comparing subgroups; correlations of differences in effect of two components with other outcomes reported.

†Reported subgroup analyses separately; did not report statistical analyses comparing subgroups.

\section{Table 56. Summary of subgroup comparisons}

\begin{tabular}{|c|c|c|c|c|c|c|c|}
\hline $\begin{array}{l}\text { Study Year } \\
\text { (PMID) }\end{array}$ & Components & $\begin{array}{l}\text { Total } \\
\mathrm{N}\end{array}$ & $\begin{array}{l}\text { Subgroup Comparison } \\
\text { Findings ( } P \text { value*) }\end{array}$ & Subgroups & $\begin{array}{l}\text { Subgroups } \\
\text { Validated? }\end{array}$ & Outcomes & $\begin{array}{l}\text { Outcomes } \\
\text { Validated? }\end{array}$ \\
\hline $\begin{array}{l}\text { Alaranta } \\
1994 \\
(7991366)\end{array}$ & $\begin{array}{l}\text { Energy-storing vs. } \\
\text { conventional } \\
\text { ankle/foot }\end{array}$ & 168 & $\begin{array}{l}\text { Younger age weakly } \\
\text { correlated with favoring } \\
\text { energy-storing for total } \\
\text { movement disability } \\
(<0.01 \dagger) \text {. } \\
\text { Lighter body weight } \\
\text { weakly correlated with } \\
\text { favoring energy-storing } \\
\text { for total movement } \\
\text { disability }(<0.01 \dagger) \text {. } \\
\text { Other analyses NS. }\end{array}$ & $\begin{array}{l}\text { TF vs. TT } \\
\text { Age } \\
\text { Age at amputation } \\
\text { Body weight/BMI }\end{array}$ & Yes, all & $\begin{array}{l}\text { Movement disability } \\
\text { index subquestions and } \\
\text { total }\end{array}$ & No \\
\hline $\begin{array}{l}\text { De Asha } \\
2014 \\
(24997811)\end{array}$ & $\begin{array}{l}\text { Hydraulic vs. rigid } \\
\text { ankle/foot }\end{array}$ & 19 & NS for both outcomes & TF vs. TT & Yes & $\begin{array}{l}\text { Gait speed (8 meters) } \\
\text { Cadence ( } 8 \text { meters) }\end{array}$ & Noł \\
\hline
\end{tabular}




\begin{tabular}{|c|c|c|c|c|c|c|c|}
\hline $\begin{array}{l}\text { Study Year } \\
\text { (PMID) }\end{array}$ & Components & $\begin{array}{l}\text { Total } \\
\mathrm{N}\end{array}$ & $\begin{array}{l}\text { Subgroup Comparison } \\
\text { Findings (P value*) }\end{array}$ & Subgroups & $\begin{array}{l}\text { Subgroups } \\
\text { Validated? }\end{array}$ & Outcomes & $\begin{array}{l}\text { Outcomes } \\
\text { Validated? }\end{array}$ \\
\hline $\begin{array}{l}\text { Gard } 2003 \\
(15077637)\end{array}$ & $\begin{array}{l}\text { Shock-absorbing } \\
\text { vs. non-shock- } \\
\text { absorbing pylon }\end{array}$ & 10 & $\begin{array}{l}\text { One woman favored the } \\
\text { shock-absorbing pylon } \\
\text { more than men did for } \\
\text { self-selected walking } \\
\text { speed }(0.0002) \text { and fast } \\
\text { walking speed }(<0.0001) \text {. } \\
\text { Other analyses NS. }\end{array}$ & $\begin{array}{l}\text { Vascular vs. traumatic } \\
\text { Sex } \\
\text { Age } \\
\text { Height } \\
\text { Time since amputation }\end{array}$ & Yes, all & $\begin{array}{l}\text { Walking speed } \\
\text { (distance undefined) } \\
\text { Fast walking speed } \\
\text { (distance undefined) }\end{array}$ & Noł \\
\hline \multirow[t]{13}{*}{$\begin{array}{l}\text { Hafner } 2009 \\
(19675993)\end{array}$} & \multirow[t]{13}{*}{$\begin{array}{l}\text { Microprocessor vs. } \\
\text { mechanical knee }\end{array}$} & \multirow[t]{13}{*}{17} & \multirow[t]{13}{*}{ NS, for all outcomes } & \multirow[t]{13}{*}{ K2 vs. K3 } & \multirow[t]{13}{*}{ Yes } & $\begin{array}{l}\text { PEQ subscales: } \\
\text { Ambulation }\end{array}$ & Yes \\
\hline & & & & & & Appearance & No \\
\hline & & & & & & Frustration & Yes \\
\hline & & & & & & Perceived Response & No \\
\hline & & & & & & Residual Limb & Yes \\
\hline & & & & & & Social Burden & Yes \\
\hline & & & & & & Sounds & No \\
\hline & & & & & & Utility & No \\
\hline & & & & & & Well-being & Yes \\
\hline & & & & & & $\begin{array}{l}\text { Falls \& stumbles, } \\
\text { reported }\end{array}$ & Yes \\
\hline & & & & & & $\begin{array}{l}\text { Walking speeds, } \\
\text { various }\end{array}$ & No \\
\hline & & & & & & Stair Assessment Index & No \\
\hline & & & & & & $\begin{array}{l}\text { Self-reported } \\
\text { abilities/difficulties }\end{array}$ & No \\
\hline \multirow{3}{*}{$\begin{array}{l}\text { Hahn } 2015 \\
\text { (J Prosthet } \\
\text { Orthot) }\end{array}$} & \multirow[t]{3}{*}{$\begin{array}{l}\text { Microprocessor vs. } \\
\text { mechanical knee }\end{array}$} & \multirow[t]{3}{*}{1013} & \multirow[t]{3}{*}{ NS, for all analyses $\ddagger$} & \multirow{3}{*}{$\begin{array}{l}\text { Age } \\
\text { Vascular vs. other } \\
\text { K2 vs. K3 vs. K4 }\end{array}$} & \multirow[t]{3}{*}{ Yes } & $\begin{array}{l}\text { Fear of falling } \\
\text { (undefined) }\end{array}$ & No \\
\hline & & & & & & Safety (10 point scale) & No \\
\hline & & & & & & Use of walking aids & Yes \\
\hline $\begin{array}{l}\text { Hahn } 2016 \\
(27828871)\end{array}$ & $\begin{array}{l}\text { Microprocessor, } \\
\text { hydraulic vs. } \\
\text { mechanical knee }\end{array}$ & 899 & $\begin{array}{l}\text { "None of the variables } \\
\text { and none of the } \\
\text { regression models yield } \\
\text { explanatory predictive } \\
\text { power." }\end{array}$ & $\begin{array}{l}\text { Multiple (not all explicitly } \\
\text { listed) }\end{array}$ & Yes, mostly & $\begin{array}{l}\text { Ambulatory, functional, } \\
\text { other activities, and } \\
\text { speed measures }\end{array}$ & No \\
\hline \multirow{5}{*}{$\begin{array}{l}\text { Hasenoehrl } \\
2017 \\
(28399722)\end{array}$} & \multirow{5}{*}{$\begin{array}{l}\text { Microprocessor vs. } \\
\text { mechanical knee }\end{array}$} & \multirow[t]{5}{*}{5} & \multirow[t]{5}{*}{ NS, for all analyses } & \multirow{5}{*}{$\begin{array}{l}\text { Vascular vs. nonvascular } \\
\text { Sex } \\
\text { Age } \\
\text { BMI } \\
\text { Time since amputation }\end{array}$} & \multirow[t]{5}{*}{ Yes, all } & TUG & Yes \\
\hline & & & & & & $2 \mathrm{MWT}$ & Yes \\
\hline & & & & & & 10 meter walk & No \\
\hline & & & & & & AMPPRO & Yes \\
\hline & & & & & & BBS & Yes \\
\hline
\end{tabular}




\begin{tabular}{|l|l|l|l|l|l|l|}
\hline $\begin{array}{l}\text { Study Year } \\
\text { (PMID) }\end{array}$ & Components & $\begin{array}{l}\text { Total } \\
\mathbf{N}\end{array}$ & $\begin{array}{l}\text { Subgroup Comparison } \\
\text { Findings (P value*) }\end{array}$ & Subgroups & $\begin{array}{l}\text { Subgroups } \\
\text { Validated? }\end{array}$ & $\begin{array}{l}\text { Outcomes } \\
\text { Validated? }\end{array}$ \\
\hline $\begin{array}{l}\text { Isakov 1985 } \\
(3868034)\end{array}$ & $\begin{array}{l}\text { Locking vs. open } \\
\text { knee }\end{array}$ & 17 & NS, for all subgroups & $\begin{array}{l}\text { Vascular vs. nonvascular } \\
\text { Sex } \\
\text { Age }\end{array}$ & Yes, all & $6 \mathrm{MWT}$ \\
\end{tabular}




\begin{tabular}{|c|c|c|c|c|c|c|c|}
\hline $\begin{array}{l}\text { Study Year } \\
\text { (PMID) }\end{array}$ & Components & $\begin{array}{l}\text { Total } \\
\mathrm{N}\end{array}$ & $\begin{array}{l}\text { Subgroup Comparison } \\
\text { Findings }\left(P \text { value }{ }^{*}\right)\end{array}$ & Subgroups & $\begin{array}{l}\text { Subgroups } \\
\text { Validated? }\end{array}$ & Outcomes & $\begin{array}{l}\text { Outcomes } \\
\text { Validated? }\end{array}$ \\
\hline \multirow[t]{3}{*}{$\begin{array}{l}\text { Kahle } 2008 \\
(18566922)\end{array}$} & \multirow{3}{*}{$\begin{array}{l}\text { Microprocessor (C- } \\
\text { Leg) vs. } \\
\text { mechanical knee }\end{array}$} & \multirow[t]{3}{*}{15} & \multirow[t]{3}{*}{ NS, for all analyses } & \multirow{3}{*}{$\begin{array}{l}\text { K level }(2,3,4) \\
\text { Age } \\
\text { Vascular vs. nonvascular } \\
\text { Height } \\
\text { Employment status } \\
\text { Prosthesis use duration } \\
\text { Residual limb firmness } \\
\text { Residual limb length } \\
\end{array}$} & \multirow{3}{*}{$\begin{array}{l}\text { Yes, all } \\
\text { except } \\
\text { residual } \\
\text { limb } \\
\text { firmness }\end{array}$} & $\begin{array}{l}\text { Falls \& stumbles, } \\
\text { reported }\end{array}$ & Yes \\
\hline & & & & & & Walking speeds, varied & No \\
\hline & & & & & & $\begin{array}{l}\text { Montreal Rehabilitation } \\
\text { Performance Profile }\end{array}$ & No \\
\hline \multirow{6}{*}{$\begin{array}{l}\text { Moore } 2017 \\
\text { (J Prosth } \\
\text { Orthot) }\end{array}$} & \multirow{6}{*}{$\begin{array}{l}\text { Hydraulic (Avalon) } \\
\text { vs. nonhydraulic } \\
\text { (Multiflex) } \\
\text { ankle/foot }\end{array}$} & \multirow[t]{6}{*}{14} & \multirow[t]{6}{*}{ NS, for all outcomes } & \multirow[t]{6}{*}{ TF vs. TT } & \multirow[t]{6}{*}{ Yes } & $\begin{array}{l}\text { PEQ subscales: } \\
\text { Ambulation }\end{array}$ & Yes \\
\hline & & & & & & Transferring & No \\
\hline & & & & & & Utility & No \\
\hline & & & & & & Well-being & Yes \\
\hline & & & & & & Prosthesis satisfaction & No \\
\hline & & & & & & Gait satisfaction & No \\
\hline $\begin{array}{l}\text { Silver-Thorn } \\
2009(\mathrm{~J} \\
\text { Prosth } \\
\text { Orthot) }\end{array}$ & $\begin{array}{l}\text { Locking (Total } \\
\text { Knee } 2000 \text { ) vs. } \\
\text { hydraulic knee }\end{array}$ & 5 & NS, for all analyses & $\begin{array}{l}\text { Age } \\
\text { Time since amputation } \\
\text { Height } \\
\text { Residual limb length }\end{array}$ & Yes, all & $\begin{array}{l}\text { Gait speed (distance } \\
\text { undefined) } \\
\text { Cadence (distance } \\
\text { undefined) } \\
\text { Comfort measures } \\
\text { Confidence } \\
\text { Stability, perceived } \\
\text { Borg Rating of } \\
\text { Perceived Exertion } \\
\end{array}$ & No, all\# \\
\hline \multirow{10}{*}{$\begin{array}{l}\text { Theeven } \\
2011 \\
(21947182, \\
22549656)\end{array}$} & \multirow{10}{*}{$\begin{array}{l}\text { Microprocessor ( } 2 \\
\text { settings) vs. } \\
\text { mechanical knee }\end{array}$} & \multirow[t]{10}{*}{30} & \multirow[t]{10}{*}{ NS, for all outcomes } & \multirow{10}{*}{$\begin{array}{l}\text { K2 subgroups (high, } \\
\text { intermediate, low) }\end{array}$} & \multirow[t]{10}{*}{ No } & Activity measures & No \\
\hline & & & & & & $\begin{array}{l}\text { PEQ subscales: } \\
\text { Ambulation }\end{array}$ & Yes \\
\hline & & & & & & Appearance & No \\
\hline & & & & & & Residual limb health & Yes \\
\hline & & & & & & Sounds & No \\
\hline & & & & & & Utility & No \\
\hline & & & & & & Well-being & Yes \\
\hline & & & & & & Prosthesis satisfaction & No \\
\hline & & & & & & Gait satisfaction & No \\
\hline & & & & & & Perceived difficulties & No \\
\hline $\begin{array}{l}\text { Traballesi } \\
2011 \\
(21684165)\end{array}$ & $\begin{array}{l}\text { Marlo anatomic vs. } \\
\text { ischial component } \\
\text { socket }\end{array}$ & 7 & NS, for all subgrous & $\begin{array}{l}\text { Sex } \\
\text { Age } \\
\text { Height } \\
\text { Time since amputation }\end{array}$ & Yes, all & PEQ MS 13/11 & Yes \\
\hline
\end{tabular}




\begin{tabular}{|c|c|c|c|c|c|c|c|}
\hline $\begin{array}{l}\text { Study Year } \\
\text { (PMID) }\end{array}$ & Components & $\begin{array}{l}\text { Total } \\
\mathrm{N}\end{array}$ & $\begin{array}{l}\text { Subgroup Comparison } \\
\text { Findings ( } \mathrm{P} \text { value*) }\end{array}$ & Subgroups & $\begin{array}{l}\text { Subgroups } \\
\text { Validated? }\end{array}$ & Outcomes & $\begin{array}{l}\text { Outcomes } \\
\text { Validated? }\end{array}$ \\
\hline \multirow{6}{*}{$\begin{array}{l}\text { Wong } 2015 \\
(25768067)\end{array}$} & \multirow{6}{*}{$\begin{array}{l}\text { Microprocessor vs. } \\
\text { mechanical knee }\end{array}$} & \multirow[t]{6}{*}{8} & \multirow{6}{*}{$\begin{array}{l}\text { K2-3 favored } \\
\text { microprocessor knee } \\
\text { more than K1 did on TUG } \\
\text { walking scale (0.0001). } \\
\text { Other analyses NS. }\end{array}$} & \multirow{6}{*}{$\begin{array}{l}\text { K level }(1,2,3) \\
\text { Age } \\
\text { Time since ambulation } \\
\text { Bilateral vs. unilateral }\end{array}$} & \multirow[t]{6}{*}{ Yes, all } & ABC balance, & Yes \\
\hline & & & & & & BBS & Yes \\
\hline & & & & & & Houghton scale & Yes \\
\hline & & & & & & TUG & Yes \\
\hline & & & & & & Falls, reported & Yes \\
\hline & & & & & & Fear of falling & No \\
\hline
\end{tabular}

Abbreviations: 2MWT = 2 Minute Walk Test, 6MWT = 6 Minute Walk Test, ABC = Activities-Specific Balance Confidence, AMPPRO = Amputee Mobility Predictor with use of a prosthesis, BBS = Berg Balance Scale, K level = Medicare Functional Classification Level (also indicated by K1, K2, K3, and K4), NS = not statistically significant, PEQ = Prosthesis evaluation questionnaire, PEQ MS 13/11 = PEQ Mobility Subscale with 13 items and 11 categories, PMID = PubMed identifier (or journal), TF = transfemoral amputation, $\mathrm{TT}=$ transtibial amputation, TUG = timed up and go test.

*Whether statistically significant difference in effect/association by subgroup, based on Bonferroni P-value.

$\dagger \mathrm{P}$ value reported as $<0.01$; Bonferroni $\mathrm{P}$ value threshold $=0.0036$

$\ddagger$ By unadjusted comparisons, implicit, or based on correlation analysis

\#For gait speed and cadence, we included the distance or time walked as an integral part of the measure. To be considered validated, the specific time or distance walk had to have evidence of validity. Walking tests without reported time or distance are considered to be nonvalidated. 
Table 57. Subgroup analyses: Alaranta, 1994, comparing energy-storing versus conventional ankle/foot components

\begin{tabular}{|c|c|c|c|c|c|c|c|c|c|}
\hline Outcome & $\begin{array}{l}\text { Overall } \\
\text { Favors* } \\
\text { (P value) }\end{array}$ & $\begin{array}{l}\mathrm{N} \\
\text { Total }\end{array}$ & Subgroup & $\begin{array}{l}\text { N } \\
\text { Subgroup }\end{array}$ & Comparator & $\begin{array}{l}\mathbf{N} \\
\text { Comparator }\end{array}$ & $\begin{array}{l}\mathbf{P} \\
\text { Difference } \dagger \\
\text { (Categorical) }\end{array}$ & $\begin{array}{l}\mathbf{P} \\
\text { Difference } \dagger \\
\text { (Continuous) }\end{array}$ & Findings \\
\hline $\begin{array}{l}\text { Movement disability index: } \\
\text { Indoors }\end{array}$ & $\begin{array}{l}\text { ES } \\
(<0.001)\end{array}$ & 168 & Transfemoral & 27 & Transtibial & 141 & 1.00 & & \\
\hline $\begin{array}{l}\text { Movement disability index: } \\
\text { Upstairs }\end{array}$ & $\begin{array}{l}\text { ES } \\
(<0.001)\end{array}$ & 168 & Transfemoral & 27 & Transtibial & 141 & 0.59 & & \\
\hline $\begin{array}{l}\text { Movement disability index: } \\
\text { Downstairs }\end{array}$ & $\begin{array}{l}\text { ES } \\
(<0.001)\end{array}$ & 168 & Transfemoral & 27 & Transtibial & 141 & 0.86 & & \\
\hline $\begin{array}{l}\text { Movement disability index: } \\
\text { Uneven ground }\end{array}$ & $\begin{array}{l}\text { ES } \\
(<0.001)\end{array}$ & 168 & Transfemoral & 27 & Transtibial & 141 & 0.51 & & \\
\hline $\begin{array}{l}\text { Movement disability index: Uphill } \\
\text { street }\end{array}$ & $\begin{array}{l}\text { ES } \\
(<0.001)\end{array}$ & 168 & Transfemoral & 27 & Transtibial & 141 & 0.89 & & \\
\hline $\begin{array}{l}\text { Movement disability index: Swift } \\
\text { walking }\end{array}$ & $\begin{array}{l}\text { ES } \\
(<0.001)\end{array}$ & 168 & Transfemoral & 27 & Transtibial & 141 & 0.79 & & \\
\hline \multirow[t]{4}{*}{ Movement disability index: Total } & \multirow[t]{4}{*}{ no data } & 168 & Age & & & & & $<0.01$ & $\begin{array}{l}\text { Younger } \\
\text { age } \\
\text { weakly } \\
\text { correlated } \\
\text { with } \\
\text { favoring } \\
\text { ES }\end{array}$ \\
\hline & & 168 & $\begin{array}{l}\text { Age at } \\
\text { amputation }\end{array}$ & & & & & NS & \\
\hline & & 168 & Body weight & & & & & $<0.01$ & $\begin{array}{l}\text { Lighter } \\
\text { body } \\
\text { weight } \\
\text { weakly } \\
\text { correlated } \\
\text { with } \\
\text { favoring } \\
\text { ES }\end{array}$ \\
\hline & & 168 & $\begin{array}{l}\text { Body mass } \\
\text { index }\end{array}$ & & & & & NS & \\
\hline
\end{tabular}

Abbreviation: ES = energy storing prosthesis

Note: Data for Alaranta 1994 (PMID 7991366). ${ }^{79}$ Additional details in Appendix D. Across Tables 57 to 70, P values $<0.05$ are bolded and associated “findings" are noted; however see footnote about Bonferroni P value threshold; italic bold P values are statistically significant below the Bonferroni P value. Empty cells indicate either not applicable (e.g., categorical data for continuous outcomes or "no findings" if the association was not statistically significant).

*Statistically significant difference favoring listed component over comparator.

†Bonferroni $\mathrm{P}=0.0036$ (due to multiple testing, to be considered to be statistically significant, the P values for differences between subgroups had to be less than this value). A separate Bonferroni P value was calculated for each study based on the number of analyses (including subgroup analyses) analyzed by the study researchers and by this review. 
Table 58. Subgroup analyses: De Asha, 2014, comparing hydraulic versus rigid ankle/foot components

\begin{tabular}{|l|l|l|l|l|l|l|l|l|}
\hline Outcome & $\begin{array}{l}\text { Overall } \\
\text { Favors* } \\
\text { (P value) }\end{array}$ & $\begin{array}{l}\text { N } \\
\text { Total }\end{array}$ & Subgroup & $\begin{array}{l}\mathbf{N} \\
\text { Subgroup }\end{array}$ & Comparator & $\begin{array}{l}\text { N } \\
\text { Comparator }\end{array}$ & $\begin{array}{l}\text { P Difference } \\
\text { (Categorical) }\end{array}$ & $\begin{array}{l}\text { P Difference† } \\
\text { (Continuous) }\end{array}$ \\
\hline $\begin{array}{l}\text { Gait speed } \\
\text { (m/s), } 8 \mathrm{~m}\end{array}$ & $\begin{array}{l}\text { Hydraulic } \\
(0.005)\end{array}$ & 19 & Transfemoral & 8 & Transtibial & 11 & 0.12 \\
\hline $\begin{array}{l}\text { Cadence } \\
\text { (steps/min), } 8 \mathrm{~m}\end{array}$ & Neither (0.84) & 19 & Transfemoral & 8 & Transtibial & 11 & 0.53 & \\
\hline
\end{tabular}

Data for De Asha 2014 (PMID 24997811). ${ }^{80}$ Additional details in Appendix D. Across Tables 57 to 70 , P values $<0.05$ are bolded and associated "findings” are noted; however see footnote about Bonferroni P value threshold; italic bold P values are statistically significant below the Bonferroni P value. Empty cells indicate either not applicable (e.g.,

categorical data for continuous outcomes or "no findings" if the association was not statistically significant).

*Statistically significant difference favoring listed component over comparator. "Neither" does not distinguish between evidence of no difference and lack of statistical power to find a difference (due to imprecision).

†Bonferroni $\mathrm{P}=0.005$ (due to multiple testing, to be considered to be statistically significant, the $\mathrm{P}$ values for differences between subgroups had to be less than this value). A separate Bonferroni P value was calculated for each study based on the number of analyses (including subgroup analyses) analyzed by the study researchers and by this review. 
Table 59. Subgroup analyses: Gard, 2003, comparing shock-absorbing versus non-shock-absorbing pylons

\begin{tabular}{|c|c|c|c|c|c|c|c|c|c|}
\hline Outcome & $\begin{array}{l}\text { Overall } \\
\text { Favors* } \\
\text { (P value) }\end{array}$ & $\begin{array}{l}\mathbf{N} \\
\text { Total }\end{array}$ & Subgroup & $\begin{array}{l}\mathrm{N} \\
\text { Subgroup }\end{array}$ & Comparator & $\begin{array}{l}\mathrm{N} \\
\text { Comparator }\end{array}$ & $\begin{array}{l}\text { P Difference }{ }^{\circ} \\
\text { (Categorical) }\end{array}$ & $\begin{array}{l}\text { P Difference } \\
\text { (Continuous) }\end{array}$ & Findings \\
\hline \multirow{5}{*}{$\begin{array}{l}\text { Self-selected } \\
\text { walking speed } \\
\text { (m/s), distance } \\
\text { undefined }\end{array}$} & \multirow{5}{*}{$\begin{array}{l}\text { Neither } \\
\text { (NS) }\end{array}$} & 10 & Vascular & 3 & Traumatic & 7 & 0.87 & & \\
\hline & & 10 & Male & 9 & Female & 1 & 0.0002 & & $\begin{array}{l}\text { One woman } \\
\text { favored SAP more } \\
\text { than men did }\end{array}$ \\
\hline & & 10 & Age 31-46 y & 5 & $57-79 y$ & 5 & 0.78 & 0.81 & \\
\hline & & 10 & $\begin{array}{l}\text { Height } \\
1.73-1.81 \mathrm{~m}\end{array}$ & 5 & $1.82-1.88 \mathrm{~m}$ & 5 & 0.022 & 0.010 & $\begin{array}{l}\text { Shorter favored } \\
\text { SAP more than } \\
\text { taller did }\end{array}$ \\
\hline & & 10 & $\begin{array}{l}\text { Time since } \\
\text { amputation } \\
1-2 y\end{array}$ & 4 & $4-50 y$ & 6 & 0.34 & 0.76 & \\
\hline \multirow{5}{*}{$\begin{array}{l}\text { Fast walking } \\
\text { speed }(\mathrm{m} / \mathrm{s}) \text {, } \\
\text { distance } \\
\text { undefined }\end{array}$} & \multirow{5}{*}{$\begin{array}{l}\text { Neither } \\
\text { (NS) }\end{array}$} & 10 & Vascular & 3 & Traumatic & 7 & 0.67 & & \\
\hline & & 10 & Male & 9 & Female & 1 & $<0.0001$ & & $\begin{array}{l}\text { One woman } \\
\text { favored SAP more } \\
\text { than men did }\end{array}$ \\
\hline & & 10 & Age 31-46 y & 5 & Age 57-79 y & 5 & 0.64 & 0.84 & \\
\hline & & 10 & $\begin{array}{l}\text { Height } \\
1.73-1.81 \mathrm{~m}\end{array}$ & 5 & $1.82-1.88 \mathrm{~m}$ & 5 & 0.077 & 0.17 & \\
\hline & & 10 & $\begin{array}{l}\text { Time since } \\
\text { amputation } \\
1-2 y\end{array}$ & 4 & $4-50$ y & 6 & 0.045 & 0.096 & $\begin{array}{l}\text { More recent } \\
\text { amputation } \\
\text { favored SAP more } \\
\text { than more distant } \\
\text { did }\end{array}$ \\
\hline
\end{tabular}

Abbreviations: NS = not statistically significant, SAP = shock-absorbing pylon

Note: Data for Gard 2003 (PMID 15077637). ${ }^{81}$ Additional details in Appendix D. Across Tables 57 to 70, P values $<0.05$ are bolded and associated “findings” are noted; however see footnote about Bonferroni P value threshold; italic bold P values are statistically significant below the Bonferroni P value. Empty cells indicate either not applicable (e.g., categorical data for continuous outcomes or "no findings" if the association was not statistically significant).

*Statistically significant difference favoring listed component over comparator. "Neither" does not distinguish between evidence of no difference and lack of statistical power to find a difference (due to imprecision).

†Bonferroni $\mathrm{P}=0.0028$ (due to multiple testing, to be considered to be statistically significant, the P values for differences between subgroups had to be less than this value). A separate Bonferroni P value was calculated for each study based on the number of analyses (including subgroup analyses) analyzed by the study researchers and by this review. 
Table 60. Subgroup analyses: Hafner, 2009, comparing microprocessor versus mechanical knee components

\begin{tabular}{|c|c|c|c|c|c|c|c|c|c|}
\hline Outcome & $\begin{array}{l}\text { Overall Favors* } \\
\text { (P value) }\end{array}$ & $\begin{array}{l}\mathbf{N} \\
\text { Total }\end{array}$ & Subgroup & $\begin{array}{l}\mathbf{N} \\
\text { Subgroup }\end{array}$ & Comparator & $\begin{array}{l}\mathrm{N} \\
\text { Comparator }\end{array}$ & $\begin{array}{l}\text { P Difference } \\
\text { (Categorical) }\end{array}$ & $\begin{array}{l}\text { P Difference } \dagger \\
\text { (Continuous) }\end{array}$ & Findings \\
\hline $\begin{array}{l}\text { Stair Assessment } \\
\text { Index }\end{array}$ & $\begin{array}{l}\text { Microprocessor } \\
(<0.001)\end{array}$ & 17 & K level 2 & 8 & K level 3 & 9 & 0.96 & & \\
\hline $\begin{array}{l}\text { Hill Assessment } \\
\text { Index }\end{array}$ & $\begin{array}{l}\text { Microprocessor } \\
(<0.001)\end{array}$ & 17 & K level 2 & 8 & K level 3 & 9 & 0.41 & & \\
\hline Hill speed (m/s) & $\begin{array}{l}\text { Microprocessor } \\
(<0.001)\end{array}$ & 17 & K level 2 & 8 & K level 3 & 9 & 0.24 & & \\
\hline $\begin{array}{l}\text { Obstacle course } \\
\text { speed }(\mathrm{m} / \mathrm{s})\end{array}$ & $\begin{array}{l}\text { Microprocessor } \\
(<0.001)\end{array}$ & 17 & K level 2 & 8 & K level 3 & 9 & 0.65 & & \\
\hline $\begin{array}{l}\text { Attention speed } \\
(\mathrm{m} / \mathrm{s})\end{array}$ & $\begin{array}{l}\text { Microprocessor } \\
(<0.001)\end{array}$ & 17 & K level 2 & 8 & K level 3 & 9 & 0.14 & & \\
\hline $\begin{array}{l}\text { Attention accuracy } \\
\text { (\% correct) }\end{array}$ & Neither $(>0.05)$ & 17 & K level 2 & 8 & K level 3 & 9 & 0.97 & & \\
\hline PEQ Ambulation & $\begin{array}{l}\text { Microprocessor } \\
(0.008)\end{array}$ & 17 & K level 2 & 8 & K level 3 & 9 & 0.14 & & \\
\hline PEQ Appearance & Neither (0.50) & 17 & K level 2 & 8 & K level 3 & 9 & 0.90 & & \\
\hline PEQ Frustration & Neither (0.11) & 17 & K level 2 & 8 & K level 3 & 9 & 0.16 & & \\
\hline $\begin{array}{l}\text { PEQ Perceived } \\
\text { response }\end{array}$ & Neither (0.07) & 17 & K level 2 & 8 & K level 3 & 9 & 0.75 & & \\
\hline $\begin{array}{l}\text { PEQ Residual limb } \\
\text { health }\end{array}$ & Neither (0.50) & 17 & K level 2 & 8 & K level 3 & 9 & 0.93 & & \\
\hline PEQ Social burden & Neither (0.54) & 17 & K level 2 & 8 & K level 3 & 9 & 1.00 & & \\
\hline PEQ Sounds & Neither (0.07) & 17 & K level 2 & 8 & K level 3 & 9 & 0.25 & & \\
\hline PEQ Utility & Neither (0.07) & 17 & K level 2 & 8 & K level 3 & 9 & 0.14 & & \\
\hline PEQ Well-being & $\begin{array}{l}\text { Microprocessor } \\
(0.016)\end{array}$ & 17 & K level 2 & 8 & K level 3 & 9 & 0.83 & & \\
\hline $\begin{array}{l}\text { Mental Energy } \\
\text { expenditure (VAS) }\end{array}$ & $\begin{array}{l}\text { Microprocessor } \\
(0.02)\end{array}$ & 17 & K level 2 & 8 & K level 3 & 9 & 0.43 & & \\
\hline $\begin{array}{l}\text { Confidence while } \\
\text { walking (VAS) }\end{array}$ & $\begin{array}{l}\text { Microprocessor } \\
(0.001)\end{array}$ & 17 & K level 2 & 8 & K level 3 & 9 & 0.47 & & \\
\hline $\begin{array}{l}\text { Multitasking while } \\
\text { walking (VAS) }\end{array}$ & $\begin{array}{l}\text { Microprocessor } \\
(0.002)\end{array}$ & 17 & K level 2 & 8 & K level 3 & 9 & 0.82 & & \\
\hline $\begin{array}{l}\text { Difficulty with } \\
\text { concentration (VAS) }\end{array}$ & Neither (0.07) & 17 & K level 2 & 8 & K level 3 & 9 & 0.98 & & \\
\hline $\begin{array}{l}\text { Activity avoidance } \\
\text { (VAS) }\end{array}$ & Neither (0.10) & 17 & K level 2 & 8 & K level 3 & 9 & 0.11 & & \\
\hline $\begin{array}{l}\text { Frustration with falls } \\
\text { (VAS) }\end{array}$ & $\begin{array}{l}\text { Microprocessor } \\
(0.005)\end{array}$ & 17 & K level 2 & 8 & K level 3 & 9 & 0.81 & & \\
\hline $\begin{array}{l}\text { Embarrassment with } \\
\text { falls (VAS) }\end{array}$ & Neither (0.23) & 17 & K level 2 & 8 & K level 3 & 9 & 0.87 & & \\
\hline
\end{tabular}




\begin{tabular}{|c|c|c|c|c|c|c|c|c|c|}
\hline Outcome & $\begin{array}{l}\text { Overall Favors* } \\
\text { (P value) }\end{array}$ & $\begin{array}{l}\mathbf{N} \\
\text { Total }\end{array}$ & Subgroup & $\begin{array}{l}\mathbf{N} \\
\text { Subgroup }\end{array}$ & Comparator & $\begin{array}{l}\mathbf{N} \\
\text { Comparator }\end{array}$ & $\begin{array}{l}\text { P Difference } \\
\text { (Categorical) }\end{array}$ & $\begin{array}{l}\text { P Difference } \dagger \\
\text { (Continuous) }\end{array}$ & Findings \\
\hline Stumbles (VAS) & $\begin{array}{l}\text { Microprocessor } \\
(0.05)\end{array}$ & 17 & K level 2 & 8 & K level 3 & 9 & 0.49 & & \\
\hline $\begin{array}{l}\text { Stumbles (number, } \\
\text { reported) }\end{array}$ & $\begin{array}{l}\text { Microprocessor } \\
(0.003)\end{array}$ & 17 & K level 2 & 8 & K level 3 & 9 & 0.40 & & \\
\hline $\begin{array}{l}\text { Semicontrolled falls } \\
\text { (VAS) }\end{array}$ & Neither (0.64) & 17 & K level 2 & 8 & K level 3 & 9 & 0.91 & & \\
\hline $\begin{array}{l}\text { Semicontrolled falls } \\
\text { (number, reported) }\end{array}$ & $\begin{array}{l}\text { Microprocessor } \\
(0.03)\end{array}$ & 17 & K level 2 & 8 & K level 3 & 9 & 0.53 & & \\
\hline
\end{tabular}

Abbreviations: $\mathrm{K}$ level = Medicare Functional Classification Level, $\mathrm{PEQ}=$ Prosthesis evaluation questionnaire, VAS = visual analogue scale.

Data for Hafner 2009 (PMID 19675993). ${ }^{82}$ Additional details in Appendix D. Across Tables 57 to 70, P values of differences (comparisons) <0.05 are bolded and associated

"findings" are noted; however see footnote about Bonferroni P value threshold; italic bold P values are statistically significant below the Bonferroni P value. Empty cells indicate either not applicable (e.g., categorical data for continuous outcomes or "no findings" if the association was not statistically significant).

*Statistically significant difference favoring listed component over comparator. "Neither" does not distinguish between evidence of no difference and lack of statistical power to find a difference (due to imprecision).

†Bonferroni $\mathrm{P}=0.0018$ (due to multiple testing, to be considered to be statistically significant, the $\mathrm{P}$ values for differences between subgroups had to be less than this value). A separate Bonferroni $\mathrm{P}$ value was calculated for each study based on the number of analyses (including subgroup analyses) analyzed by the study researchers and by this review.

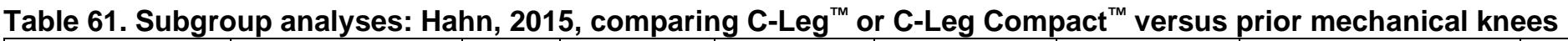

\begin{tabular}{|c|c|c|c|c|c|c|c|c|c|}
\hline Outcome & $\begin{array}{l}\text { Overall Favors* } \\
\text { (P value) }\end{array}$ & $\begin{array}{l}\mathbf{N} \\
\text { Total }\end{array}$ & Subgroup & $\begin{array}{l}\text { N } \\
\text { Subgroup }\end{array}$ & Comparator & $\begin{array}{l}\mathrm{N} \\
\text { Comparator }\end{array}$ & $\begin{array}{l}\text { P Difference } \dagger \\
\text { (Categorical) }\end{array}$ & $\begin{array}{l}\text { P Difference } \\
\text { (Continuous) }\end{array}$ & Findings \\
\hline \multirow[t]{2}{*}{$\begin{array}{l}\text { Fear of falling } \\
\text { (not described) }\end{array}$} & \multirow{2}{*}{$\begin{array}{l}\text { Microprocessor } \\
\text { (86\% said } \\
\text { reduced) }\end{array}$} & 1013 & $\begin{array}{r}\text { Age } 21-40 \\
41-60\end{array}$ & $\begin{array}{l}\sim 143 \\
\sim 465\end{array}$ & Age $>60$ & $\sim 406$ & NS (implied) & & \\
\hline & & 1013 & K level 2 & $\sim 463$ & $\begin{array}{l}\mathrm{K} \text { level } 3 \\
\mathrm{~K} \text { level } 4 \\
\end{array}$ & $\begin{array}{l}472 \\
\sim 78\end{array}$ & NS (implied) & & \\
\hline \multirow[t]{3}{*}{$\begin{array}{l}\text { Safety (10 point } \\
\text { scale) }\end{array}$} & \multirow[t]{3}{*}{$\begin{array}{l}\text { Microprocessor } \\
\text { (83\% said safer) }\end{array}$} & 1013 & $\begin{array}{r}\text { Age } 21-40 \\
41-60 \\
\end{array}$ & $\begin{array}{l}143 \\
\sim 465 \\
\end{array}$ & Age $>60$ & $\sim 406$ & $\begin{array}{l}\text { NS (by correlation } \\
\text { analysis) }\end{array}$ & & \\
\hline & & 1013 & K level 2 & $\sim 463$ & $\begin{array}{l}\mathrm{K} \text { level } 3 \\
\mathrm{~K} \text { level } 4 \\
\end{array}$ & $\begin{array}{l}\sim 472 \\
\sim 78\end{array}$ & $\begin{array}{l}\text { NS (by correlation } \\
\text { analysis) }\end{array}$ & & \\
\hline & & 1013 & Vascular & $\sim 263$ & $\begin{array}{l}\text { Other } \\
\text { etiology }\end{array}$ & $\sim 750$ & $\begin{array}{l}\text { NS (by correlation } \\
\text { analysis) }\end{array}$ & & \\
\hline \multirow[t]{3}{*}{$\begin{array}{l}\text { Use of walking } \\
\text { aids } \\
\text { (use/nonuse) † }\end{array}$} & \multirow[t]{3}{*}{$\begin{array}{l}\text { Microprocessor } \\
\text { (46\% stopped } \\
\text { using) }\end{array}$} & nd & $\begin{array}{r}\text { Age } 21-40 \\
41-60\end{array}$ & nd & Age $>60$ & nd & $\begin{array}{l}\text { NS (implied): Decline } \\
\text { with age group: } 67 \% \\
\text { vs. } 51 \% \text { vs. } 38 \%\end{array}$ & & \\
\hline & & nd & K level 2 & nd & $\begin{array}{l}\mathrm{K} \text { level } 3 \\
\mathrm{~K} \text { level } 4 \\
\end{array}$ & nd & $\begin{array}{l}\text { NS (implied): } 41 \% \\
\text { vs. } 57 \% \text { vs. } 0 \%\end{array}$ & & \\
\hline & & nd & Vascular & nd & $\begin{array}{l}\text { Other } \\
\text { etiology }\end{array}$ & nd & NS (implied) & & \\
\hline
\end{tabular}

Abbreviations: K level = Medicare Functional Classification Level, nd = no data, NS = not statistically .signficant.

Note: Data for Hahn 2015. ${ }^{78}$ Additional details in Appendix D. Additional details in Appendix D. Across Tables 57 to 70 , P values of differences (comparisons) $<0.05$ are bolded and associated "findings" are noted; however see footnote about Bonferroni P value threshold; italic bold P values are statistically significant below the Bonferroni P value. Empty cells indicate either not applicable (e.g., categorical data for continuous outcomes or "no findings" if the association was not statistically significant). 
*Statistically significant difference favoring listed component over comparator.

$\dagger$ Analysis included here is of people using walking aids with mechanical aids. Article also reports use of walking aids across all participants.

Table 62. Subgroup analyses: Hahn, 2016, comparing Genium ${ }^{\mathrm{TM}}$ microprocessor versus prior knee components (mostly C-Leg ${ }^{\mathrm{TM}}$ microprocessor knee)

\begin{tabular}{|c|c|c|c|}
\hline Outcomes* & $\begin{array}{l}\text { Overall } \\
\text { Favors } \dagger \\
\text { (P value) }\end{array}$ & $\begin{array}{l}\mathbf{N} \\
\text { Total }\end{array}$ & Study Conclusions $\ddagger$ \\
\hline $\begin{array}{l}\text { Functional benefits (safety, harmonization of gait } \\
\text { pattern, relief of the contralateral limb, possibility to } \\
\text { divide attention, capability to vary gait speed, } \\
\text { reduction of overall effort, reduction in number of } \\
\text { aids, and change of mobility grade) } \\
\text { Perception (of safety) } \\
\text { Advanced maneuvers (assessed by prosthetist) } \\
\text { Variable gait speed (capability to vary speed) } \\
\text { Toileting } \\
\text { Walking stairs alternatingly (up/down) }\end{array}$ & $\begin{array}{l}\text { Genium } \\
\text { (implied } \\
<0.05 \text { ) }\end{array}$ & 899 & $\begin{array}{l}\text { Many variables were statistically significant in multivariable regression analyses } \\
\text { for different outcomes (see text). However, "None of the variables and none of } \\
\text { the regression models yield explanatory predictive power" regarding who would } \\
\text { most benefit from a microprocessor knee. These variables included: } \\
\text { age, years wearing prosthesis, distance walked per day, gender, vascular } \\
\text { disease etiology, amputation level, bilateral amputation, no comorbidity, diabetes } \\
\text { mellitus, cardiovascular disease, "distortion circulation leg", hip problem, "further } \\
\text { disability", profession, residual limb condition, residual limb length, residual limb } \\
\text { loading, adhesion, number of falls per year, mobility grade. } \\
\text { In addition, these variables were determined to have no overall predictive value: } \\
\text { body mass index, neuropathy, visual impairment, artificial hip, back pain, paresis } \\
\text { lower extremity, paresis upper extremity, further amputation, malformation, } \\
\text { contralateral joint instability/joint replacement/pain, osteoarthritis of the lower } \\
\text { limb joints, hip contracture, scarred residual limb, and annual falls (yes/no). }\end{array}$ \\
\hline
\end{tabular}

Note: Data for Hahn 2016 (PMID 27828871). ${ }^{83}$ Additional details in Appendix D.

*Listed outcomes. Unclear which outcomes were used in the final models.

†Statistically significant difference favoring listed component over comparator.

¥There were many important biases and other concerns with the study and analyses. 
Table 63. Subgroup analyses: Hasenoehrl, 2017, comparing microprocessor versus mechanical knees

\begin{tabular}{|c|c|c|c|c|c|c|c|c|c|}
\hline Outcome & $\begin{array}{l}\text { Overall } \\
\text { Favors* } \\
\text { (P value) }\end{array}$ & $\begin{array}{l}\mathbf{N} \\
\text { Total }\end{array}$ & Subgroup & $\begin{array}{l}\mathbf{N} \\
\text { Subgroup }\end{array}$ & Comparator & $\begin{array}{l}\mathrm{N} \\
\text { Comparator }\end{array}$ & $\begin{array}{l}\text { P Difference } \dagger \\
\text { (Categorical) }\end{array}$ & $\begin{array}{l}\text { P Difference } \\
\text { (Continuous) }\end{array}$ & Findings \\
\hline \multirow[t]{5}{*}{ TUG } & \multirow{5}{*}{$\begin{array}{l}\text { Neither } \\
(P=0.09)\end{array}$} & 5 & Female & 1 & Male & 4 & 0.46 & & \\
\hline & & 5 & Age 56-66 y & 2 & $71-75$ y & 3 & 0.54 & 0.77 & \\
\hline & & 5 & $\begin{array}{l}\text { BMI } 26.6- \\
29.9 \text { kg/m² }\end{array}$ & 2 & $\begin{array}{l}30.0-38.7 \\
\mathrm{~kg} / \mathrm{m}^{2}\end{array}$ & 3 & 0.54 & 0.081 & \\
\hline & & 5 & $\begin{array}{l}\text { Time since } \\
\text { amputation } \\
3-4 \mathrm{y}\end{array}$ & 3 & $5 y$ & 2 & 0.49 & 0.55 & \\
\hline & & 5 & Dysvascular & 1 & $\begin{array}{l}\text { Other } \\
\text { etiology }\end{array}$ & 4 & 0.38 & & \\
\hline \multirow{5}{*}{ 2MWT } & \multirow{5}{*}{$\begin{array}{l}\text { Neither } \\
(P=0.32)\end{array}$} & 5 & Female & 1 & Male & 4 & 0.64 & & \\
\hline & & 5 & Age 56-66 y & 2 & $71-75 y$ & 3 & 0.49 & 0.81 & \\
\hline & & 5 & $\begin{array}{l}\text { BMI } 26.6- \\
29.9 \text { kg/m² }\end{array}$ & 2 & $\begin{array}{l}30.0-38.7 \\
\mathrm{~kg} / \mathrm{m}^{2}\end{array}$ & 3 & 0.49 & 0.93 & \\
\hline & & 5 & $\begin{array}{l}\text { Time since } \\
\text { amputation } \\
3-4 \mathrm{y}\end{array}$ & 3 & $5 y$ & 2 & 0.50 & 0.85 & \\
\hline & & 5 & Dysvascular & 1 & $\begin{array}{l}\text { Other } \\
\text { etiology }\end{array}$ & 4 & 0.045 & & $\begin{array}{l}\text { Dysvascular favored } \\
\text { microprocessor knee } \\
\text { more than other } \\
\text { etiology did }\end{array}$ \\
\hline \multirow{5}{*}{$\begin{array}{l}10 \text { meter } \\
\text { walk, self- } \\
\text { selected } \\
\text { speed }\end{array}$} & \multirow[t]{5}{*}{$\begin{array}{l}\text { Neither } \\
(P=0.10)\end{array}$} & 5 & Female & 1 & Male & 4 & 0.006 & & $\begin{array}{l}\text { Men favored } \\
\text { microprocessor knee } \\
\text { more than woman did }\end{array}$ \\
\hline & & 5 & Age 56-66 y & 2 & $71-75$ y & 3 & 0.69 & 0.71 & \\
\hline & & 5 & $\begin{array}{l}\text { BMI } 26.6- \\
29.9 \text { kg/m² }\end{array}$ & 2 & $\begin{array}{l}30.0-38.7 \\
\mathrm{~kg} / \mathrm{m}^{2}\end{array}$ & 3 & 0.69 & 0.88 & \\
\hline & & 5 & $\begin{array}{l}\text { Time since } \\
\text { amputation } \\
3-4 \mathrm{y}\end{array}$ & 3 & $5 y$ & 2 & 0.31 & 0.082 & \\
\hline & & 5 & Dysvascular & 1 & $\begin{array}{l}\text { Other } \\
\text { etiology }\end{array}$ & 4 & 0.068 & & \\
\hline \multirow{5}{*}{$\begin{array}{l}10 \text { meter } \\
\text { walk, fast }\end{array}$} & \multirow{5}{*}{$\begin{array}{l}\text { Non- } \\
\text { mechanical } \\
(P=0.008)\end{array}$} & 5 & Female & 1 & Male & 4 & 0.97 & & \\
\hline & & 5 & Age 56-66 y & 2 & $71-75 y$ & 3 & 0.25 & 0.23 & \\
\hline & & 5 & $\begin{array}{l}\text { BMI } 26.6- \\
29.9 \text { kg/m² }\end{array}$ & 2 & $\begin{array}{l}30.0-38.7 \\
\mathrm{~kg} / \mathrm{m}^{2}\end{array}$ & 3 & 0.25 & 0.053 & \\
\hline & & 5 & $\begin{array}{l}\text { Time since } \\
\text { amputation } \\
3-4 \mathrm{y}\end{array}$ & 3 & $5 y$ & 2 & 0.45 & 0.78 & \\
\hline & & 5 & Dysvascular & 1 & $\begin{array}{l}\text { Other } \\
\text { etiology }\end{array}$ & 4 & 0.48 & & \\
\hline
\end{tabular}




\begin{tabular}{|c|c|c|c|c|c|c|c|c|c|}
\hline Outcome & $\begin{array}{l}\text { Overall } \\
\text { Favors* } \\
\text { (P value) }\end{array}$ & $\begin{array}{l}\mathbf{N} \\
\text { Total }\end{array}$ & Subgroup & $\begin{array}{l}\mathbf{N} \\
\text { Subgroup }\end{array}$ & Comparator & $\begin{array}{l}\mathbf{N} \\
\text { Comparator }\end{array}$ & $\begin{array}{l}\text { P Difference } \dagger \\
\text { (Categorical) }\end{array}$ & $\begin{array}{l}\text { P Difference } \\
\text { (Continuous) }\end{array}$ & Findings \\
\hline \multirow{5}{*}{ AMPPRO } & \multirow{5}{*}{$\begin{array}{l}\text { Neither } \\
(P=0.06)\end{array}$} & 5 & Female & 1 & Male & 4 & 0.57 & & \\
\hline & & 5 & Age 56-66 y & 2 & $71-75$ y & 3 & 0.32 & 0.68 & \\
\hline & & 5 & $\begin{array}{l}\text { BMI 26.6- } \\
29.9 \mathrm{~kg} / \mathrm{m}^{2}\end{array}$ & 2 & $\begin{array}{l}30.0-38.7 \\
\mathrm{~kg} / \mathrm{m}^{2}\end{array}$ & 3 & 0.32 & 0.027 & $\begin{array}{l}\text { Higher BMI favored } \\
\text { microprocessor more } \\
\text { than lower BMI did } \\
\text { (continuous BMI) }\end{array}$ \\
\hline & & 5 & $\begin{array}{l}\text { Time since } \\
\text { amputation } \\
3-4 y\end{array}$ & 3 & $5 y$ & 2 & 0.53 & 0.57 & \\
\hline & & 5 & Dysvascular & 1 & $\begin{array}{l}\text { Other } \\
\text { etiology }\end{array}$ & 4 & 0.42 & & \\
\hline \multirow[t]{5}{*}{ BBS } & \multirow{5}{*}{$\begin{array}{l}\text { Neither } \\
(P=0.63)\end{array}$} & 5 & Female & 1 & Male & 4 & 0.29 & & \\
\hline & & 5 & Age 56-66 y & 2 & $71-75 y$ & 3 & 0.58 & 0.68 & \\
\hline & & 5 & $\begin{array}{l}\text { BMI 26.6- } \\
29.9 \mathrm{~kg} / \mathrm{m}^{2}\end{array}$ & 2 & $\begin{array}{l}30.0-38.7 \\
\mathrm{~kg} / \mathrm{m}^{2}\end{array}$ & 3 & 0.58 & 0.12 & \\
\hline & & 5 & $\begin{array}{l}\text { Time since } \\
\text { amputation } \\
3-4 \mathrm{y}\end{array}$ & 3 & $5 y$ & 2 & 0.15 & 0.37 & \\
\hline & & 5 & Dysvascular & 1 & $\begin{array}{l}\text { Other } \\
\text { etiology }\end{array}$ & 4 & 0.46 & 0.84 & \\
\hline
\end{tabular}

Abbreviations: $2 \mathrm{MWT}=2$ Minute Walk Test, AMPPRO = Amputee Mobility Predictor with use of a prosthesis, BBS = Berg Balance Score, BMI = body mass index, TUG = Timed Up and Go.

Note: Data for Hasenoehrl 2017 (PMID 28399722)..$^{90}$ Additional details in Appendix D. Across Tables 57 to 70 , P values of differences (comparisons) $<0.05$ are bolded and associated "findings" are noted; however see footnote about Bonferroni P value threshold; italic bold P values are statistically significant below the Bonferroni P value. Empty cells indicate either not applicable (e.g., categorical data for continuous outcomes or "no findings" if the association was not statistically significant).

*Statistically significant difference favoring listed component over comparator. "Neither" does not distinguish between evidence of no difference and lack of statistical power to find a difference (due to imprecision).

†Bonferroni $\mathrm{P}=0.001$ (due to multiple testing, to be considered to be statistically significant, the P values for differences between subgroups had to be less than this value). A separate Bonferroni $\mathrm{P}$ value was calculated for each study based on the number of analyses (including subgroup analyses) analyzed by the study researchers and by this review. 
Table 64. Subgroup analyses: Isakov, 1985, comparing locking versus open knee components

\begin{tabular}{|c|c|c|c|c|c|c|c|c|c|}
\hline Outcome & $\begin{array}{l}\text { Overall } \\
\text { Favors* } \\
\text { (P value) }\end{array}$ & $\begin{array}{l}\mathbf{N} \\
\text { Total }\end{array}$ & Subgroup & $\begin{array}{l}\mathrm{N} \\
\text { Subgroup }\end{array}$ & Comparator & $\begin{array}{l}\mathrm{N} \\
\text { Comparator }\end{array}$ & $\begin{array}{l}\text { P Difference } \dagger \\
\text { (Categorical) }\end{array}$ & $\begin{array}{l}\text { P Difference } \dagger \\
\text { (Continuous) }\end{array}$ & Findings \\
\hline \multirow[t]{3}{*}{$\begin{array}{l}\text { Gait speed } \\
\text { ( } \mathrm{m} / \mathrm{min}), \\
6 \text { minutes }\end{array}$} & \multirow[t]{3}{*}{$\begin{array}{l}\text { Neither } \\
(0.060)\end{array}$} & 17 & Vascular & 14 & Nonvascular & 3 & 0.016 & & $\begin{array}{l}\text { Nonvascular } \\
\text { favored open knee } \\
\text { more than vascular } \\
\text { did }\end{array}$ \\
\hline & & 17 & Male & 16 & Female & 1 & 0.59 & & \\
\hline & & 17 & Age $26-50$ y & 8 & $55-75 y$ & 9 & 0.004 & 0.014 & $\begin{array}{l}\text { Younger favored } \\
\text { open knee more } \\
\text { than older did }\end{array}$ \\
\hline
\end{tabular}

Note: Data for Isakov 1985 (PMID 3868034). ${ }^{84}$ Additional details in Appendix D. Across Tables 57 to 70 , P values $<0.05$ of differences (comparisons) are bolded and associated

"findings" are noted; however see footnote about Bonferroni P value threshold; italic bold P values are statistically significant below the Bonferroni P value. Empty cells indicate either not applicable (e.g., categorical data for continuous outcomes or "no findings" if the association was not statistically significant).

*Statistically significant difference favoring listed component over comparator. "Neither" does not distinguish between evidence of no difference and lack of statistical power to find a difference (due to imprecision).

†Bonferroni $\mathrm{P}=0.010$ (due to multiple testing, to be considered to be statistically significant, the $\mathrm{P}$ values for differences between subgroups had to be less than this value). A separate Bonferroni P value was calculated for each study based on the number of analyses (including subgroup analyses) analyzed by the study researchers and by this review. 
Table 65. Subgroup analyses: Kahle, 2008, comparing microprocessor (C-Leg ${ }^{\mathrm{TM}}$ ) versus mechanical knee components

\begin{tabular}{|c|c|c|c|c|c|c|c|c|c|}
\hline Outcome & $\begin{array}{l}\text { Overall } \\
\text { Favors* } \\
\text { (P value) }\end{array}$ & $\begin{array}{l}\mathbf{N} \\
\text { Total }\end{array}$ & Subgroup & $\begin{array}{l}\mathbf{N} \\
\text { Subgroup }\end{array}$ & Comparator & $\begin{array}{l}\mathrm{N} \\
\text { Comparator }\end{array}$ & $\begin{array}{l}\text { P Difference } \\
\text { (Categorical) }\end{array}$ & $\begin{array}{l}\text { P Difference } \\
\text { (Continuous) }\end{array}$ & Findings \\
\hline \multirow{11}{*}{$\begin{array}{l}\text { Stumbles, } \\
\text { reported }\end{array}$} & \multirow{11}{*}{$\begin{array}{l}\text { Microprocessor } \\
(0.006)\end{array}$} & 15 & K level 2 & 10 & K level 3-4 & 5 & 0.14 & & \\
\hline & & 15 & K level 2-3 & 4 & K level 4 & 11 & 0.030 & & $\begin{array}{l}\text { K2-3 favored } \\
\text { C-Leg more } \\
\text { than K4 did }\end{array}$ \\
\hline & & 15 & Age 28-57 y & 8 & $58-83$ y & 7 & 0.53 & 0.38 & \\
\hline & & 15 & Vascular & 7 & Nonvascular & 8 & 0.056 & & \\
\hline & & 15 & $\begin{array}{l}\text { Height } \\
160-170 \mathrm{~cm}\end{array}$ & 5 & $173-188 \mathrm{~cm}$ & 10 & 0.44 & 0.93 & \\
\hline & & 14 & Employed & 7 & $\begin{array}{l}\text { Not } \\
\text { employed }\end{array}$ & 7 & 0.75 & & \\
\hline & & 15 & $\begin{array}{l}\text { Prosthesis use } \\
6-12 \text { mo }\end{array}$ & 9 & $>12 \mathrm{mo}$ & 6 & 0.13 & & \\
\hline & & 15 & $\begin{array}{l}\text { Residual limb } \\
\text { "firm" }\end{array}$ & 7 & $\begin{array}{l}\text { "soft" or } \\
\text { "medium" }\end{array}$ & 8 & 0.38 & & \\
\hline & & 15 & $\begin{array}{l}\text { Residual limb } \\
\text { "medium" or } \\
\text { "firm" }\end{array}$ & 13 & "soft" & 2 & 0.51 & & \\
\hline & & 15 & $\begin{array}{l}\text { Residual limb } \\
\text { length 32-43 } \\
\mathrm{cm}\end{array}$ & 8 & $11-31 \mathrm{~cm}$ & 7 & 0.19 & 0.71 & \\
\hline & & 15 & $\begin{array}{l}\text { Residual limb } \\
\text { as percent of } \\
\text { femur } 74- \\
100 \%\end{array}$ & 8 & $27-73 \%$ & 7 & 0.40 & 0.74 & \\
\hline \multirow[t]{8}{*}{ Falls, reported } & \multirow{8}{*}{$\begin{array}{l}\text { Microprocessor } \\
(0.03)\end{array}$} & 15 & K level 2 & 10 & K level 3-4 & 5 & 0.48 & & \\
\hline & & 15 & K level 2-3 & 4 & K level 4 & 11 & 0.089 & & \\
\hline & & 15 & Age 28-57 y & 8 & $58-83$ y & 7 & 0.48 & 0.10 & \\
\hline & & 15 & Vascular & 7 & Nonvascular & 8 & 0.24 & & \\
\hline & & 15 & $\begin{array}{l}\text { Height } \\
160-170 \mathrm{~cm}\end{array}$ & 5 & $173-188 \mathrm{~cm}$ & 10 & 0.48 & 0.48 & \\
\hline & & 14 & Employed & 7 & $\begin{array}{l}\text { Not } \\
\text { employed }\end{array}$ & 7 & 0.15 & & \\
\hline & & 15 & $\begin{array}{l}\text { Prosthesis use } \\
6-12 \mathrm{mo}\end{array}$ & 9 & $>12 \mathrm{mo}$ & 6 & 0.29 & & \\
\hline & & 15 & $\begin{array}{l}\text { Residual limb } \\
\text { "firm" }\end{array}$ & 7 & $\begin{array}{l}\text { "soft" or } \\
\text { "medium" }\end{array}$ & 8 & 0.20 & & \\
\hline
\end{tabular}




\begin{tabular}{|c|c|c|c|c|c|c|c|c|c|}
\hline Outcome & $\begin{array}{l}\text { Overall } \\
\text { Favors* } \\
\text { (P value) }\end{array}$ & $\begin{array}{l}\mathbf{N} \\
\text { Total }\end{array}$ & Subgroup & $\begin{array}{l}\mathrm{N} \\
\text { Subgroup }\end{array}$ & Comparator & $\begin{array}{l}\mathrm{N} \\
\text { Comparator }\end{array}$ & $\begin{array}{l}\text { P Difference } \dagger \\
\text { (Categorical) }\end{array}$ & $\begin{array}{l}\text { P Difference } \dagger \\
\text { (Continuous) }\end{array}$ & Findings \\
\hline & & 15 & $\begin{array}{l}\text { Residual limb } \\
\text { "medium" or } \\
\text { "firm" }\end{array}$ & 13 & "soft" & 2 & 0.84 & & \\
\hline & & 15 & $\begin{array}{l}\text { Residual limb } \\
\text { length } 32-43 \\
\mathrm{~cm}\end{array}$ & 8 & $11-31 \mathrm{~cm}$ & 7 & 0.37 & 0.68 & \\
\hline & & 15 & $\begin{array}{l}\text { Residual limb } \\
\text { as percent of } \\
\text { femur } 74- \\
100 \%\end{array}$ & 8 & $27-73 \%$ & 7 & 0.48 & 0.80 & \\
\hline \multirow{11}{*}{$\begin{array}{l}\text { Self-selected } \\
\text { walking speed, } \\
75 \mathrm{~m}\end{array}$} & \multirow{11}{*}{$\begin{array}{l}\text { Microprocessor } \\
(0.03)\end{array}$} & 15 & K level 2 & 10 & K level 3-4 & 5 & 0.84 & & \\
\hline & & 15 & K level 2-3 & 4 & K level 4 & 11 & 0.75 & & \\
\hline & & 15 & Age 28-57 y & 8 & $58-83$ y & 7 & 0.82 & 0.80 & \\
\hline & & 15 & Vascular & 7 & Nonvascular & 8 & 0.27 & & \\
\hline & & 15 & $\begin{array}{l}\text { Height } \\
160-170 \mathrm{~cm}\end{array}$ & 5 & $173-188 \mathrm{~cm}$ & 10 & 0.20 & 0.33 & \\
\hline & & 14 & Employed & 7 & $\begin{array}{l}\text { Not } \\
\text { employed }\end{array}$ & 7 & 0.67 & & \\
\hline & & 15 & $\begin{array}{l}\text { Prosthesis use } \\
6-12 \mathrm{mo}\end{array}$ & 9 & $>12 \mathrm{mo}$ & 6 & 0.46 & & \\
\hline & & 15 & $\begin{array}{l}\text { Residual limb } \\
\text { "firm" }\end{array}$ & 7 & $\begin{array}{l}\text { "soft" or } \\
\text { "medium" }\end{array}$ & 8 & 0.51 & & \\
\hline & & 15 & $\begin{array}{l}\text { Residual limb } \\
\text { "medium" or } \\
\text { "firm" }\end{array}$ & 13 & "soft" & 2 & 0.70 & & \\
\hline & & 15 & $\begin{array}{l}\text { Residual limb } \\
\text { length } 32-43 \\
\mathrm{~cm}\end{array}$ & 8 & $11-31 \mathrm{~cm}$ & 7 & 0.63 & 0.50 & \\
\hline & & 15 & $\begin{array}{l}\text { Residual limb } \\
\text { as percent of } \\
\text { femur } 74- \\
100 \%\end{array}$ & 8 & $27-73 \%$ & 7 & 0.16 & 0.49 & \\
\hline
\end{tabular}




\begin{tabular}{|c|c|c|c|c|c|c|c|c|c|}
\hline Outcome & $\begin{array}{l}\text { Overall } \\
\text { Favors* } \\
\text { (P value) }\end{array}$ & $\begin{array}{l}\mathbf{N} \\
\text { Total }\end{array}$ & Subgroup & $\begin{array}{l}\mathbf{N} \\
\text { Subgroup }\end{array}$ & Comparator & $\begin{array}{l}\mathbf{N} \\
\text { Comparator }\end{array}$ & $\begin{array}{l}\text { P Difference } \dagger \\
\text { (Categorical) }\end{array}$ & $\begin{array}{l}\text { P Difference } † \\
\text { (Continuous) }\end{array}$ & Findings \\
\hline \multirow{11}{*}{$\begin{array}{l}\text { Fastest walking } \\
\text { on even terrain, } \\
75 \mathrm{~m}\end{array}$} & \multirow{11}{*}{$\begin{array}{l}\text { Microprocessor } \\
(0.005)\end{array}$} & 15 & K level 2 & 10 & K level 3-4 & 5 & 0.64 & & \\
\hline & & 15 & K level 2-3 & 4 & K level 4 & 11 & 0.93 & & \\
\hline & & 15 & Age $28-57$ y & 8 & $58-83$ y & 7 & 0.75 & 0.41 & \\
\hline & & 15 & Vascular & 7 & Nonvascular & 8 & 0.41 & & \\
\hline & & 15 & $\begin{array}{l}\text { Height } \\
160-170 \mathrm{~cm}\end{array}$ & 5 & $173-188 \mathrm{~cm}$ & 10 & 0.18 & 0.26 & \\
\hline & & 14 & Employed & 7 & $\begin{array}{l}\text { Not } \\
\text { employed }\end{array}$ & 7 & 0.76 & & \\
\hline & & 15 & $\begin{array}{l}\text { Prosthesis use } \\
6-12 \text { mo }\end{array}$ & 9 & $>12 \mathrm{mo}$ & 6 & 0.43 & & \\
\hline & & 15 & $\begin{array}{l}\text { Residual limb } \\
\text { "firm" }\end{array}$ & 7 & $\begin{array}{l}\text { "soft" or } \\
\text { "medium" }\end{array}$ & 8 & 0.34 & & \\
\hline & & 15 & $\begin{array}{l}\text { Residual limb } \\
\text { "medium" or } \\
\text { "firm" } \\
\end{array}$ & 13 & "soft" & 2 & 0.60 & & \\
\hline & & 15 & $\begin{array}{l}\text { Residual limb } \\
\text { length } 32-43 \\
\mathrm{~cm}\end{array}$ & 8 & $11-31 \mathrm{~cm}$ & 7 & 0.34 & & \\
\hline & & 15 & $\begin{array}{l}\text { Residual limb } \\
\text { as percent of } \\
\text { femur 74- } \\
100 \%\end{array}$ & 8 & $27-73 \%$ & 7 & 0.18 & 0.46 & \\
\hline \multirow{10}{*}{$\begin{array}{l}\text { Fastest walking } \\
\text { on uneven } \\
\text { terrain, } 38 \mathrm{~m}\end{array}$} & \multirow{10}{*}{$\begin{array}{l}\text { Microprocessor } \\
(<0.001)\end{array}$} & 15 & K level 2 & 10 & K level 3-4 & 5 & 0.76 & & \\
\hline & & 15 & K level 2-3 & 4 & K level 4 & 11 & 0.068 & & \\
\hline & & 15 & Age $28-57$ y & 8 & $58-83$ y & 7 & 0.77 & 0.071 & \\
\hline & & 15 & Vascular & 7 & Nonvascular & 8 & 0.13 & & \\
\hline & & 15 & $\begin{array}{l}\text { Height } \\
160-170 \mathrm{~cm} \\
\end{array}$ & 5 & $173-188 \mathrm{~cm}$ & 10 & 0.44 & 0.41 & \\
\hline & & 14 & Employed & 7 & $\begin{array}{l}\text { Not } \\
\text { employed }\end{array}$ & 7 & 0.41 & & \\
\hline & & 15 & $\begin{array}{l}\text { Prosthesis use } \\
6-12 \text { mo }\end{array}$ & 9 & $>12 \mathrm{mo}$ & 6 & 0.94 & & \\
\hline & & 15 & $\begin{array}{l}\text { Residual limb } \\
\text { "firm" }\end{array}$ & 7 & $\begin{array}{l}\text { "soft" or } \\
\text { "medium" }\end{array}$ & 8 & 0.12 & & \\
\hline & & 15 & $\begin{array}{l}\text { Residual limb } \\
\text { "medium" or } \\
\text { "firm" }\end{array}$ & 13 & "soft" & 2 & 0.052 & & \\
\hline & & 15 & $\begin{array}{l}\text { Residual limb } \\
\text { length } 32-43 \\
\mathrm{~cm} \\
\end{array}$ & 8 & $11-31 \mathrm{~cm}$ & 7 & 0.30 & 0.17 & \\
\hline
\end{tabular}




\begin{tabular}{|c|c|c|c|c|c|c|c|c|c|}
\hline Outcome & $\begin{array}{l}\text { Overall } \\
\text { Favors* } \\
\text { (P value) }\end{array}$ & $\begin{array}{l}\mathbf{N} \\
\text { Total }\end{array}$ & Subgroup & $\begin{array}{l}\mathbf{N} \\
\text { Subgroup }\end{array}$ & Comparator & $\begin{array}{l}\mathrm{N} \\
\text { Comparator }\end{array}$ & $\begin{array}{l}\text { P Difference } \dagger \\
\text { (Categorical) }\end{array}$ & $\begin{array}{l}\text { P Difference } † \\
\text { (Continuous) }\end{array}$ & Findings \\
\hline & & 15 & $\begin{array}{l}\text { Residual limb } \\
\text { as percent of } \\
\text { femur 74- } \\
100 \%\end{array}$ & 8 & $27-73 \%$ & 7 & 0.77 & 0.13 & \\
\hline \multirow{11}{*}{$\begin{array}{l}\text { Fastest walking } \\
\text { on even terrain, } \\
6 \mathrm{~m}\end{array}$} & \multirow{11}{*}{$\begin{array}{l}\text { Microprocessor } \\
(0.001)\end{array}$} & 15 & K level 2 & 10 & K level 3-4 & 5 & 0.38 & & \\
\hline & & 15 & K level 2-3 & 4 & K level 4 & 11 & 0.98 & & \\
\hline & & 15 & Age $28-57$ y & 8 & $58-83$ y & 7 & 0.71 & 0.48 & \\
\hline & & 15 & Vascular & 7 & Nonvascular & 8 & 0.65 & & \\
\hline & & 15 & $\begin{array}{l}\text { Height } \\
160-170 \mathrm{~cm}\end{array}$ & 5 & $173-188 \mathrm{~cm}$ & 10 & 0.64 & 0.79 & \\
\hline & & 14 & Employed & 7 & $\begin{array}{l}\text { Not } \\
\text { employed }\end{array}$ & 7 & 0.030 & & $\begin{array}{l}\text { Employed } \\
\text { favored C- } \\
\text { Leg more } \\
\text { than not } \\
\text { employed did }\end{array}$ \\
\hline & & 15 & $\begin{array}{l}\text { Prosthesis use } \\
6-12 \text { mo }\end{array}$ & 9 & $>12 \mathrm{mo}$ & 6 & 0.44 & & \\
\hline & & 15 & $\begin{array}{l}\text { Residual limb } \\
\text { "firm" }\end{array}$ & 7 & $\begin{array}{l}\text { "soft" or } \\
\text { "medium" }\end{array}$ & 8 & 0.50 & & \\
\hline & & 15 & $\begin{array}{l}\text { Residual limb } \\
\text { "medium" or } \\
\text { "firm" }\end{array}$ & 13 & "soft" & 2 & 0.71 & & \\
\hline & & 15 & $\begin{array}{l}\text { Residual limb } \\
\text { length } 32-43 \\
\mathrm{~cm}\end{array}$ & 8 & $11-31 \mathrm{~cm}$ & 7 & 0.14 & 0.72 & \\
\hline & & 15 & $\begin{array}{l}\text { Residual limb } \\
\text { as percent of } \\
\text { femur } 74- \\
100 \%\end{array}$ & 8 & $27-73 \%$ & 7 & 0.36 & 0.78 & \\
\hline
\end{tabular}




\begin{tabular}{|c|c|c|c|c|c|c|c|c|c|}
\hline Outcome & $\begin{array}{l}\text { Overall } \\
\text { Favors* } \\
\text { (P value) }\end{array}$ & $\begin{array}{l}\mathbf{N} \\
\text { Total }\end{array}$ & Subgroup & $\begin{array}{l}\mathrm{N} \\
\text { Subgroup }\end{array}$ & Comparator & $\begin{array}{l}\mathrm{N} \\
\text { Comparator }\end{array}$ & $\begin{array}{l}\text { P Difference } † \\
\text { (Categorical) }\end{array}$ & $\begin{array}{l}\text { P Difference } † \\
\text { (Continuous) }\end{array}$ & Findings \\
\hline \multirow{11}{*}{$\begin{array}{l}\text { Montreal } \\
\text { Rehabilitation } \\
\text { Performance } \\
\text { Profile }\end{array}$} & \multirow{11}{*}{$\begin{array}{l}\text { Microprocessor } \\
(<0.001)\end{array}$} & 15 & K level 2 & 10 & K level 3-4 & 5 & 0.15 & & \\
\hline & & 15 & K level 2-3 & 4 & K level 4 & 11 & 0.38 & & \\
\hline & & 15 & Age 28-57 y & 8 & $58-83 y$ & 7 & 0.20 & & \\
\hline & & 15 & Vascular & 7 & Nonvascular & 8 & 0.21 & & \\
\hline & & 15 & $\begin{array}{l}\text { Height } \\
160-170 \mathrm{~cm}\end{array}$ & 5 & $173-188 \mathrm{~cm}$ & 10 & 0.44 & 0.88 & \\
\hline & & 14 & Employed & 7 & $\begin{array}{l}\text { Not } \\
\text { employed }\end{array}$ & 7 & 0.32 & & \\
\hline & & 15 & $\begin{array}{l}\text { Prosthesis use } \\
6-12 \text { mo }\end{array}$ & 9 & $>12 \mathrm{mo}$ & 6 & 0.37 & & \\
\hline & & 15 & $\begin{array}{l}\text { Residual limb } \\
\text { "firm" }\end{array}$ & 7 & $\begin{array}{l}\text { "soft" or } \\
\text { "medium" }\end{array}$ & 8 & 0.16 & & \\
\hline & & 15 & $\begin{array}{l}\text { Residual limb } \\
\text { "medium" or } \\
\text { "firm" }\end{array}$ & 13 & "soft" & 2 & 0.30 & & \\
\hline & & 15 & $\begin{array}{l}\text { Residual limb } \\
\text { length 32-43 } \\
\mathrm{cm}\end{array}$ & 8 & $11-31 \mathrm{~cm}$ & 7 & 0.12 & 0.97 & \\
\hline & & 15 & $\begin{array}{l}\text { Residual limb } \\
\text { as percent of } \\
\text { femur } 74- \\
100 \%\end{array}$ & 8 & $27-73 \%$ & 7 & 0.19 & 0.998 & \\
\hline
\end{tabular}

Abbreviation: K level = Medicare Functional Classification Level.

Note: Data for Kahle 2008 (PMID 18566922). ${ }^{85}$ Additional details in Appendix D. Across Tables 57 to 70, P values of differences (comparisons) <0.05 are bolded and associated "findings" are noted; however see footnote about Bonferroni P value threshold. Italic bold P values are statistically significant below the Bonferroni P value. Empty cells indicate either not applicable (e.g., categorical data for continuous outcomes or "no findings" if the association was not statistically significant).

*Statistically significant difference favoring listed component over comparator.

†Bonferroni $\mathrm{P}=0.00040$ (due to multiple testing, to be considered to be statistically significant, the P values for differences between subgroups had to be less than this value). A separate Bonferroni P value was calculated for each study based on the number of analyses (including subgroup analyses) analyzed by the study researchers and by this review. 
Table 66. Subgroup analyses: Moore, 2017, comparing hydraulic versus nonhydraulic foot/ankle components

\begin{tabular}{|c|c|c|c|c|c|c|c|c|}
\hline Outcome & $\begin{array}{l}\text { Overall } \\
\text { Favors*, } \\
\text { (P value) }\end{array}$ & $\begin{array}{l}\mathbf{N} \\
\text { Total }\end{array}$ & Subgroup & $\begin{array}{l}\mathrm{N} \\
\text { Subgroup }\end{array}$ & Comparator & $\begin{array}{l}\mathrm{N} \\
\text { Comparator }\end{array}$ & $\begin{array}{l}\text { P Difference } \\
\text { (Categorical) }\end{array}$ & Findings \\
\hline PEQ Ambulation & $\begin{array}{l}\text { Hydraulic } \\
(0.005)\end{array}$ & 14 & Transtibial & 12 & Transfemoral & 2 & 0.26 & \\
\hline PEQ Transfer & $\begin{array}{l}\text { Hydraulic } \\
(0.02)\end{array}$ & 14 & Transtibial & 12 & Transfemoral & 2 & 0.37 & \\
\hline PEQ Utility & $\begin{array}{l}\text { Hydraulic } \\
(0.005)\end{array}$ & 14 & Transtibial & 12 & Transfemoral & 2 & 0.35 & \\
\hline PEQ Wellbeing & Neither $(0.08)$ & 14 & Transtibial & 12 & Transfemoral & 2 & 0.10 & \\
\hline $\begin{array}{l}\text { PEQ Satisfaction, } \\
\text { prosthesis }\end{array}$ & $\begin{array}{l}\text { Hydraulic } \\
(0.0003)\end{array}$ & 14 & Transtibial & 12 & Transfemoral & 2 & 0.011 & $\begin{array}{l}\text { Transtibial amputees favored } \\
\text { hydraulic more than } \\
\text { transfemoral did }\end{array}$ \\
\hline $\begin{array}{l}\text { PEQ Satisfaction, } \\
\text { gait }\end{array}$ & $\begin{array}{l}\text { Hydraulic } \\
(0.0007)\end{array}$ & 14 & Transtibial & 12 & Transfemoral & 2 & 0.022 & $\begin{array}{l}\text { Transtibial amputees favored } \\
\text { hydraulic more than } \\
\text { transfemoral did }\end{array}$ \\
\hline
\end{tabular}

Abbreviation: PEQ = Prosthesis Evaluation Questionnaire.

Note: Data for Moore $2017^{91}$ (J Prosthet Orthot) Additional details in Appendix D. Across Tables 57 to 70 , P values of differences (comparisons) $<0.05$ are bolded and associated "findings" are noted; however see footnote about Bonferroni P value threshold. Italic bold P values are statistically significant below the Bonferroni P value. Empty cells indicate either not applicable (e.g., categorical data for continuous outcomes or "no findings" if the association was not statistically significant)

*Statistically significant difference favoring listed component over comparator. "Neither" does not distinguish between evidence of no difference and lack of statistical power to find a difference (due to imprecision).

†Bonferroni $\mathrm{P}=0.0083$ (due to multiple testing, to be considered to be statistically significant, the P values for differences between subgroups had to be less than this value). A separate Bonferroni P value was calculated for each study based on the number of analyses (including subgroup analyses) analyzed by the study researchers and by this review. 
Table 67. Subgroup analyses: Silver-Thorn, 2009, comparing locking (Total Knee $2000^{\mathrm{TM}}$ ) versus hydraulic knee components

\begin{tabular}{|c|c|c|c|c|c|c|c|c|c|}
\hline Outcome & $\begin{array}{l}\text { Overall } \\
\text { Favors* } \\
\text { (P value) }\end{array}$ & $\begin{array}{l}\mathbf{N} \\
\text { Total }\end{array}$ & Subgroup & $\begin{array}{l}\mathrm{N} \\
\text { Subgroup }\end{array}$ & Comparator & $\begin{array}{l}\mathrm{N} \\
\text { Comparator }\end{array}$ & $\begin{array}{l}\text { P Difference } \dagger \\
\text { (Categorical) }\end{array}$ & $\begin{array}{l}\text { P Difference } \dagger \\
\text { (Continuous) }\end{array}$ & Findings \\
\hline \multirow{4}{*}{$\begin{array}{l}\text { Borg Rating of } \\
\text { Perceived } \\
\text { Exertion test }\end{array}$} & \multirow{4}{*}{$\begin{array}{l}\text { Neither } \\
(1.00)\end{array}$} & 4 & Age 33-41 y & 2 & $43-58 y$ & 2 & 0.47 & 0.91 & \\
\hline & & 4 & $\begin{array}{l}\text { Time since } \\
\text { amputation } \\
8-20 \text { y }\end{array}$ & 2 & $31-34$ y & 2 & 0.20 & 0.30 & \\
\hline & & 4 & $\begin{array}{l}\text { Height } \\
171-173 \mathrm{~cm}\end{array}$ & 2 & $178-184 \mathrm{~cm}$ & 2 & 0.47 & 0.15 & \\
\hline & & 4 & $\begin{array}{l}\text { Residual limb } \\
\text { length 23-28 } \\
\mathrm{cm}\end{array}$ & 2 & $43-58$ y & 2 & 0.20 & 0.029 & $\begin{array}{l}\text { Shorter residual limb } \\
\text { favored Total Knee } \\
2000 \text { more than } \\
\text { longer residual did }\end{array}$ \\
\hline \multirow{4}{*}{$\begin{array}{l}\text { Confidence } \\
\text { (Likert) }\end{array}$} & \multirow{4}{*}{$\begin{array}{l}\text { Neither } \\
(0.32)\end{array}$} & 4 & Age 33-41 y & 2 & $31-34$ y & 2 & 0.77 & 0.34 & \\
\hline & & 4 & $\begin{array}{l}\text { Time since } \\
\text { amputation } \\
8-20 \text { y }\end{array}$ & 2 & $178-184$ cm & 2 & 0.31 & 0.075 & \\
\hline & & 4 & $\begin{array}{l}\text { Height } \\
171-173 \mathrm{~cm}\end{array}$ & 2 & $32-36 \mathrm{~cm}$ & 2 & 0.77 & 0.80 & \\
\hline & & 4 & $\begin{array}{l}\text { Residual limb } \\
\text { length 23-28 } \\
\mathrm{cm} \\
\end{array}$ & 2 & $43-58$ y & 2 & 0.31 & 0.46 & \\
\hline \multirow{4}{*}{$\begin{array}{l}\text { Perceived } \\
\text { stability }\end{array}$} & \multirow{4}{*}{$\begin{array}{l}\text { Neither } \\
(0.32)\end{array}$} & 4 & Age $33-41$ y & 2 & $31-34$ y & 2 & 0.77 & 0.34 & \\
\hline & & 4 & $\begin{array}{l}\text { Time since } \\
\text { amputation } \\
8-20 \mathrm{y}\end{array}$ & 2 & $178-184 \mathrm{~cm}$ & 2 & 0.31 & 0.075 & \\
\hline & & 4 & $\begin{array}{l}\text { Height } \\
171-173 \mathrm{~cm}\end{array}$ & 2 & $32-36 \mathrm{~cm}$ & 2 & 0.77 & 0.80 & \\
\hline & & 4 & $\begin{array}{l}\text { Residual limb } \\
\text { length 23-28 } \\
\mathrm{cm}\end{array}$ & 2 & $43-58$ y & 2 & 0.31 & 0.45 & \\
\hline
\end{tabular}




\begin{tabular}{|c|c|c|c|c|c|c|c|c|c|}
\hline Outcome & $\begin{array}{l}\text { Overall } \\
\text { Favors* } \\
\text { (P value) }\end{array}$ & $\begin{array}{l}\mathbf{N} \\
\text { Total }\end{array}$ & Subgroup & $\begin{array}{l}\mathbf{N} \\
\text { Subgroup }\end{array}$ & Comparator & $\begin{array}{l}\mathrm{N} \\
\text { Comparator }\end{array}$ & $\begin{array}{l}\text { P Difference } \dagger \\
\text { (Categorical) }\end{array}$ & $\begin{array}{l}\text { P Difference } \dagger \\
\text { (Continuous) }\end{array}$ & Findings \\
\hline \multirow{4}{*}{$\begin{array}{l}\text { Comfort on } \\
\text { uneven terrain }\end{array}$} & \multirow{4}{*}{$\begin{array}{l}\text { Neither } \\
(0.19)\end{array}$} & 4 & Age 33-41 y & 2 & $31-34 y$ & 2 & 0.81 & 0.56 & \\
\hline & & 4 & $\begin{array}{l}\text { Time since } \\
\text { amputation } \\
8-20 y\end{array}$ & 2 & $178-184 \mathrm{~cm}$ & 2 & 0.037 & 0.10 & $\begin{array}{l}\text { More recent } \\
\text { amputation favored } \\
\text { Total Knee } 2000 \\
\text { more than more } \\
\text { distant amputation } \\
\text { did }\end{array}$ \\
\hline & & 4 & $\begin{array}{l}\text { Height } \\
171-173 \mathrm{~cm}\end{array}$ & 2 & $32-36 \mathrm{~cm}$ & 2 & 0.81 & 0.41 & \\
\hline & & 4 & $\begin{array}{l}\text { Residual limb } \\
\text { length 23-28 } \\
\mathrm{cm}\end{array}$ & 2 & $43-58 y$ & 2 & 0.037 & 0.051 & $\begin{array}{l}\text { Longer residual limb } \\
\text { favored Total Knee } \\
2000 \text { more than } \\
\text { more shorter did }\end{array}$ \\
\hline \multirow{4}{*}{$\begin{array}{l}\text { Comfort up } \\
\text { stairs }\end{array}$} & \multirow{4}{*}{$\begin{array}{l}\text { Neither } \\
(0.092)\end{array}$} & 4 & Age 33-41 y & 2 & $31-34 y$ & 2 & 0.29 & 0.88 & \\
\hline & & 4 & $\begin{array}{l}\text { Time since } \\
\text { amputation } \\
8-20 y\end{array}$ & 2 & $178-184 \mathrm{~cm}$ & 2 & 0.29 & 0.52 & \\
\hline & & 4 & $\begin{array}{l}\text { Height } \\
171-173 \mathrm{~cm}\end{array}$ & 2 & $32-36 \mathrm{~cm}$ & 2 & 0.29 & 0.085 & \\
\hline & & 4 & $\begin{array}{l}\text { Residual limb } \\
\text { length 23-28 } \\
\mathrm{cm}\end{array}$ & 2 & $43-58 y$ & 2 & 0.29 & 0.046 & $\begin{array}{l}\text { Shorter residual limb } \\
\text { favored Total Knee } \\
2000 \text { more than } \\
\text { more longer did }\end{array}$ \\
\hline \multirow{4}{*}{$\begin{array}{l}\text { Comfort in a } \\
\text { crowd }\end{array}$} & \multirow{4}{*}{$\begin{array}{l}\text { Neither } \\
(0.39)\end{array}$} & 4 & Age 33-41 y & 2 & $31-34$ y & 2 & 0.42 & 0.95 & \\
\hline & & 4 & $\begin{array}{l}\text { Time since } \\
\text { amputation } \\
8-20 y\end{array}$ & 2 & $178-184 \mathrm{~cm}$ & 2 & 0.42 & 0.39 & \\
\hline & & 4 & $\begin{array}{l}\text { Height } \\
171-173 \mathrm{~cm}\end{array}$ & 2 & $32-36 \mathrm{~cm}$ & 2 & 0.42 & 0.14 & \\
\hline & & 4 & $\begin{array}{l}\text { Residual limb } \\
\text { length 23-28 } \\
\mathrm{cm} \\
\end{array}$ & 2 & $43-58 y$ & 2 & 0.42 & 0.19 & \\
\hline \multirow{4}{*}{$\begin{array}{l}\text { Gait speed } \\
\text { (m/s), distance } \\
\text { undefined }\end{array}$} & \multirow{4}{*}{$\begin{array}{l}\text { Neither } \\
(0.072)\end{array}$} & 5 & Age 33-41 y & 2 & $31-34 \mathrm{y}$ & 3 & 0.67 & 0.53 & \\
\hline & & 5 & $\begin{array}{l}\text { Time since } \\
\text { amputation } \\
8-20 y\end{array}$ & 3 & $178-184 \mathrm{~cm}$ & 2 & 0.14 & 0.10 & \\
\hline & & 5 & $\begin{array}{l}\text { Height } \\
171-173 \mathrm{~cm}\end{array}$ & 2 & $32-36 \mathrm{~cm}$ & 3 & 0.50 & 0.87 & \\
\hline & & 5 & $\begin{array}{l}\text { Residual limb } \\
\text { length 23-28 } \\
\mathrm{cm}\end{array}$ & 3 & $43-58$ y & 2 & 0.071 & 0.20 & \\
\hline
\end{tabular}




\begin{tabular}{|c|c|c|c|c|c|c|c|c|c|}
\hline Outcome & $\begin{array}{l}\text { Overall } \\
\text { Favors* } \\
\text { (P value) }\end{array}$ & $\begin{array}{l}\mathbf{N} \\
\text { Total }\end{array}$ & Subgroup & $\begin{array}{l}\mathbf{N} \\
\text { Subgroup }\end{array}$ & Comparator & $\begin{array}{l}\mathrm{N} \\
\text { Comparator }\end{array}$ & $\begin{array}{l}\text { P Difference } \\
\text { (Categorical) }\end{array}$ & $\begin{array}{l}\text { P Difference } \\
\text { (Continuous) }\end{array}$ & Findings \\
\hline \multirow{4}{*}{$\begin{array}{l}\text { Cadence } \\
\text { (steps/min), } \\
\text { distance } \\
\text { undefined }\end{array}$} & \multirow{4}{*}{$\begin{array}{l}\text { Neither } \\
(0.20)\end{array}$} & 5 & Age 33-41 y & 2 & $31-34 y$ & 3 & 0.74 & 0.39 & \\
\hline & & 5 & $\begin{array}{l}\text { Time since } \\
\text { amputation } \\
8-20 y\end{array}$ & 3 & $178-184 \mathrm{~cm}$ & 2 & 0.37 & 0.36 & \\
\hline & & 5 & $\begin{array}{l}\text { Height } \\
171-173 \mathrm{~cm}\end{array}$ & 2 & $32-36 \mathrm{~cm}$ & 3 & 0.16 & 0.48 & \\
\hline & & 5 & $\begin{array}{l}\text { Residual limb } \\
\text { length } 23-28 \\
\mathrm{~cm}\end{array}$ & 3 & $43-58 y$ & 2 & 0.30 & 0.28 & \\
\hline
\end{tabular}

Note: Data for Silver-Thorn 2009 (no PMID) ${ }^{89}$ Additional details in Appendix D. Across Tables 57 to 70 , P values of differences (comparisons) $<0.05$ are bolded and associated

"findings" are noted; however see footnote about Bonferroni P value threshold. Italic bold P values are statistically significant below the Bonferroni P value. Empty cells indicate either not applicable (e.g., categorical data for continuous outcomes or "no findings" if the association was not statistically significant).

*Statistically significant difference favoring listed component over comparator. "Neither" does not distinguish between evidence of no difference and lack of statistical power to find a difference (due to imprecision).

†Bonferroni $\mathrm{P}=0.00078$ (due to multiple testing, to be considered to be statistically significant, the $\mathrm{P}$ values for differences between subgroups had to be less than this value). A separate Bonferroni P value was calculated for each study based on the number of analyses (including subgroup analyses) analyzed by the study researchers and by this review. 
Table 68. Subgroup analyses: Theeven, 2011, comparing microprocessor (2 settings) versus mechanical knee components

\begin{tabular}{|c|c|c|c|c|c|c|c|c|c|}
\hline Outcome & $\begin{array}{l}\text { Overall } \\
\text { Favors*, } \uparrow \\
\text { (P value) }\end{array}$ & $\begin{array}{l}\mathrm{N} \\
\text { Total }\end{array}$ & Subgroups & $\begin{array}{l}\mathrm{N} \\
\text { Subgroups } \ddagger\end{array}$ & Comparator & $\begin{array}{l}\mathrm{N} \\
\text { Comparator }\end{array}$ & $\begin{array}{l}\mathbf{P} \\
\text { Difference§ } \\
\text { (Categorical) }\end{array}$ & $\begin{array}{l}\text { P } \\
\text { Difference\# } \\
\text { (Continuous) }\end{array}$ & Findings $\dagger$ \\
\hline $\begin{array}{l}\text { Activity time (\% } \\
\text { of up time) }\end{array}$ & $\begin{array}{l}\text { Neither } \\
(0.86,0.90)\end{array}$ & 30 & $\begin{array}{l}\text { K2 High, } \\
\text { Intermediate§ }\end{array}$ & 12,12 & K2 Low§ & 6 & & $>0.42$ (all§) & \\
\hline $\begin{array}{l}\text { Bouts of activity } \\
\text { (number) }\end{array}$ & $\begin{array}{l}\text { Neither } \\
(0.99,0.95)\end{array}$ & 30 & $\begin{array}{l}\text { K2 High, } \\
\text { Intermediate§ }\end{array}$ & 12,12 & K2 Low§ & 6 & & $>0.42$ (all§) & \\
\hline $\begin{array}{l}\text { Daily activity } \\
\text { "counts" }\end{array}$ & $\begin{array}{l}\text { Neither } \\
(0.94,0.89)\end{array}$ & 30 & $\begin{array}{l}\text { K2 High, } \\
\text { Intermediate§ }\end{array}$ & 12,12 & K2 Low§ & 6 & & $>0.31$ (all§) & \\
\hline PEQ Ambulation & $\begin{array}{l}\text { Microprocessor } \\
\text { A }(0.01,0.14)\end{array}$ & 30 & $\begin{array}{l}\text { K2 High, } \\
\text { Intermediate§ }\end{array}$ & 12,12 & K2 Low§ & 6 & & $>0.018$ (all§) & $\begin{array}{l}\text { High K2 } \\
\text { favored micro- } \\
\text { processor knee } \\
\text { B more than } \\
\text { low K2 } \\
\text { subgroup; } \\
\text { other } \\
\text { comparisons } \\
P>0.13\end{array}$ \\
\hline PEQ Appearance & $\begin{array}{l}\text { Neither } \\
(0.55,0.33)\end{array}$ & 30 & $\begin{array}{l}\text { K2 High, } \\
\text { Intermediate§ }\end{array}$ & 12,12 & K2 Low§ & 6 & & $>0.69$ (all§) & \\
\hline $\begin{array}{l}\text { PEQ Residual } \\
\text { limb health }\end{array}$ & $\begin{array}{l}\text { Microprocessors } \\
(0.003,<0.001)\end{array}$ & 30 & $\begin{array}{l}\text { K2 High, } \\
\text { Intermediate§ }\end{array}$ & 12,12 & K2 Low§ & 6 & & $>0.29$ (all§) & \\
\hline $\begin{array}{l}\text { PEQ Satisfaction } \\
\text { with prosthesis }\end{array}$ & $\begin{array}{l}\text { Neither } \\
(0.050 .14)\end{array}$ & 30 & $\begin{array}{l}\text { K2 High, } \\
\text { Intermediate§ }\end{array}$ & 12,12 & K2 Low§ & 6 & & $>0.28$ (all§) & \\
\hline $\begin{array}{l}\text { PEQ Satisfaction } \\
\text { with walking }\end{array}$ & $\begin{array}{l}\text { Microprocessor } \\
\text { A }(0.003,0.19)\end{array}$ & 30 & $\begin{array}{l}\text { K2 High, } \\
\text { Intermediate§ }\end{array}$ & 12,12 & K2 Low§ & 6 & & $>0.006$ (all§) & $\begin{array}{l}\text { Intermediate } \\
\text { K2 favored } \\
\text { both } \\
\text { microprocessor } \\
\text { knees more } \\
\text { than low K2 } \\
\text { subgroup } \\
\text { ( } \mathrm{P}=0.28 \text {, } \\
\text { 0.006), high K2 } \\
\text { favored } \\
\text { microprocessor } \\
\text { knee B more } \\
\text { than } \\
\text { intermediate } \\
\mathrm{K} 2 \text { subgroup } \\
(\mathrm{P}=0.041) ; \\
\text { other } \\
\text { comparisons } \\
\mathrm{P}=0.066-0.44\end{array}$ \\
\hline
\end{tabular}




\begin{tabular}{|c|c|c|c|c|c|c|c|c|c|}
\hline Outcome & $\begin{array}{l}\text { Overall } \\
\text { Favors*, } \\
\text { (P value) }\end{array}$ & $\begin{array}{l}\mathbf{N} \\
\text { Total }\end{array}$ & Subgroups & $\begin{array}{l}\mathbf{N} \\
\text { Subgroups } \ddagger\end{array}$ & Comparator & $\begin{array}{l}\mathbf{N} \\
\text { Comparator }\end{array}$ & $\begin{array}{l}\mathbf{P} \\
\text { Difference§ } \\
\text { (Categorical) }\end{array}$ & $\begin{array}{l}\mathbf{P} \\
\text { Difference\# } \\
\text { (Continuous) }\end{array}$ & Findings $\dagger$ \\
\hline PEQ Sounds & $\begin{array}{l}\text { Neither }(0.52 \text {, } \\
0.33)\end{array}$ & 30 & $\begin{array}{l}\text { K2 High, } \\
\text { Intermediate§ }\end{array}$ & 12,12 & K2 Low§ & 6 & & $>0.33$ (all§) & \\
\hline PEQ Utility & $\begin{array}{l}\text { Microprocessors } \\
(0.006,0.02)\end{array}$ & 30 & $\begin{array}{l}\text { K2 High, } \\
\text { Intermediate§ }\end{array}$ & 12,12 & K2 Low§ & 6 & & $>0.25$ (all§) & \\
\hline PEQ Well-being & $\begin{array}{l}\text { Neither }(0.30, \\
0.93)\end{array}$ & 30 & $\begin{array}{l}\text { K2 High, } \\
\text { Intermediate§ }\end{array}$ & 12,12 & K2 Low§ & 6 & & $>0.54$ (all§) & \\
\hline $\begin{array}{l}\text { Perceived } \\
\text { difficulty } \\
\text { ambulation } \\
\text { requiring } \\
\text { prosthesis skill } \\
\end{array}$ & $\begin{array}{l}\text { Neither }(0.63, \\
0.72)\end{array}$ & 30 & $\begin{array}{l}\text { K2 High, } \\
\text { Intermediate§ }\end{array}$ & 12,12 & K2 Low§ & 6 & & $>0.48$ (all§) & \\
\hline $\begin{array}{l}\text { Perceived } \\
\text { difficulty balance }\end{array}$ & $\begin{array}{l}\text { Neither }(0.56 \text {, } \\
0.60)\end{array}$ & 30 & $\begin{array}{l}\text { K2 High, } \\
\text { Intermediate§ }\end{array}$ & 12,12 & K2 Low§ & 6 & & $>0.69$ (all§) & \\
\hline $\begin{array}{l}\text { Perceived } \\
\text { difficulty sitting } \\
\text { and standing }\end{array}$ & $\begin{array}{l}\text { Neither }(0.62, \\
0.57)\end{array}$ & 30 & $\begin{array}{l}\text { K2 High, } \\
\text { Intermediate§ }\end{array}$ & 12,12 & K2 Low§ & 6 & & $>0.54$ (all§) & \\
\hline $\begin{array}{l}\text { Performance } \\
\text { time ambulation } \\
\text { requiring } \\
\text { prosthesis skill } \\
\text { (min) }\end{array}$ & $\begin{array}{l}\text { Microprocessor } \\
\text { B (NS, 0.023) }\end{array}$ & 30 & $\begin{array}{l}\text { K2 High, } \\
\text { Intermediate§ }\end{array}$ & 12,12 & K2 Low§ & 6 & & $>0.68$ (all§) & \\
\hline $\begin{array}{l}\text { Performance } \\
\text { time requiring } \\
\text { balance (min) }\end{array}$ & $\begin{array}{l}\text { Microprocessors } \\
(<0.001,0.002)\end{array}$ & 30 & $\begin{array}{l}\text { K2 High, } \\
\text { Intermediate§ }\end{array}$ & 12,12 & K2 Low§ & 6 & & $>0.31$ (all§) & \\
\hline $\begin{array}{l}\text { Performance } \\
\text { time requiring } \\
\text { sitting and } \\
\text { standing (min) }\end{array}$ & $\begin{array}{l}\text { Neither }(0.87 \text {, } \\
1.00)\end{array}$ & 30 & $\begin{array}{l}\text { K2 High, } \\
\text { Intermediate§ }\end{array}$ & 12,12 & K2 Low§ & 6 & & $>0.51$ (all§) & \\
\hline
\end{tabular}

Abbreviation: K level = Medicare Functional Classification Level, PEQ = Prosthesis Evaluation Questionnaire.

Note: Data for Theeven 2011 (PMID 21947182, 22549656). ${ }^{86,87}$ Additional details in Appendix D. Across Tables 57 to 70 , P values of differences (comparisons) $<0.05$ are bolded and associated "findings" are noted; however see footnote about Bonferroni P value threshold. Italic bold P values are statistically significant below the Bonferroni P value. Empty cells indicate either not applicable (e.g., categorical data for continuous outcomes or "no findings" if the association was not statistically significant).

*Statistically significant difference favoring listed component over comparator. "Neither" does not distinguish between evidence of no difference and lack of statistical power to find a difference (due to imprecision).

$†$ The two values for statistical significance indicate the separate analyses for the two microprocessor settings (“A” and "B”).

$\ddagger$ The numbers of participants in each of the two subgroups (high K2 and intermediate K2).

\#Bonferroni $\mathrm{P}=0.00037$ (due to multiple testing, to be considered to be statistically significant, the P values for differences between subgroups had to be less than this value). A separate Bonferroni P value was calculated for each study based on the number of analyses (including subgroup analyses) analyzed by the study researchers and by this review. 
§Six comparisons summarized: "High” vs. "intermediate” K2, "high” vs. "low” K2, and "intermediate” vs. "low” K2 for both microprocessor knees A and B vs. mechanical knee. "High," "intermediate," and "low” functional mobility levels were assigned by "three independent experts (a physical therapist, a rehabilitation physician and a prosthetist) based on participants’ daily activity level, mean comfortable walking speed, past medical history, psychosocial status and current physical condition.” 
Table 69. Subgroup analyses: Traballesi, 2011, comparing Marlo anatomic versus ischial component socket components

\begin{tabular}{|c|c|c|c|c|c|c|c|c|c|}
\hline Outcome & $\begin{array}{l}\text { Overall } \\
\text { Favors* } \\
\text { (P value) }\end{array}$ & $\begin{array}{l}\mathbf{N} \\
\text { Total }\end{array}$ & Subgroup & $\begin{array}{l}\mathbf{N} \\
\text { Subgroup }\end{array}$ & Comparator & $\begin{array}{l}\mathrm{N} \\
\text { Comparator }\end{array}$ & $\begin{array}{l}\text { P Difference } \dagger \\
\text { (Categorical) }\end{array}$ & $\begin{array}{l}\text { P Difference } \\
\text { (Continuous) }\end{array}$ & Findings \\
\hline \multirow[t]{4}{*}{$\begin{array}{l}\text { PEQ } \\
\text { Mobility }\end{array}$} & \multirow[t]{4}{*}{$\begin{array}{l}\text { Marlo } \\
\text { Anatomic } \\
\text { Socket } \\
(0.018)\end{array}$} & 7 & Male & 6 & Female & 1 & 0.022 & & $\begin{array}{l}\text { One woman favored } \\
\text { Marlo Anatomic } \\
\text { Socket more than } \\
\text { men did }\end{array}$ \\
\hline & & 7 & Age 25-28 y & 3 & $41-46 y$ & 4 & 0.42 & 0.28 & \\
\hline & & 6 & $\begin{array}{l}\text { Height 174- } \\
180 \mathrm{~cm}\end{array}$ & 2 & $184-185 \mathrm{~cm}$ & 4 & 0.074 & 0.017 & $\begin{array}{l}\text { Shorter favored Marlo } \\
\text { Anatomic Socket } \\
\text { more than taller did, } \\
\text { among men }\end{array}$ \\
\hline & & 7 & $\begin{array}{l}\text { Time since } \\
\text { amputation } \\
2-9 \mathrm{y}\end{array}$ & 3 & $10-26 y$ & 4 & 0.56 & 0.69 & \\
\hline
\end{tabular}

Abbreviation: PEQ = Prosthesis evaluation questionnaire.

Note: Data for Traballesi 2011 (PMID 21684165). ${ }^{88}$ Additional details in Appendix D. Across Tables 57 to 70 , P values of differences (comparisons) $<0.05$ are bolded and associated "findings" are noted; however see footnote about Bonferroni P value threshold. Italic bold P values are statistically significant below the Bonferroni P value. Empty cells indicate either not applicable (e.g., categorical data for continuous outcomes or "no findings" if the association was not statistically significant).

*Statistically significant difference favoring listed component over comparator.

†Bonferroni $\mathrm{P}=0.0071$ (due to multiple testing, to be considered to be statistically significant, the $\mathrm{P}$ values for differences between subgroups had to be less than this value). A separate Bonferroni P value was calculated for each study based on the number of analyses (including subgroup analyses) analyzed by the study researchers and by this review. 
Table 70. Subgroup analyses: Wong, 2015, comparing microprocessor versus mechanical knee components

\begin{tabular}{|c|c|c|c|c|c|c|c|c|c|}
\hline Outcome & $\begin{array}{l}\text { Overall Favors* } \\
\text { (P value) }\end{array}$ & $\begin{array}{l}\mathbf{N} \\
\text { Total } \\
\end{array}$ & Subgroup & $\begin{array}{l}\mathbf{N} \\
\text { Subgroup }\end{array}$ & Comparator & $\begin{array}{l}\mathbf{N} \\
\text { Comparator }\end{array}$ & $\begin{array}{l}\text { P Difference } \dagger \\
\text { (Categorical) }\end{array}$ & $\begin{array}{l}\text { P Difference } \dagger \\
\text { (Continuous) }\end{array}$ & Findings \\
\hline \multirow{5}{*}{$\begin{array}{l}\text { Falls, } \\
\text { number }\end{array}$} & \multirow{5}{*}{$\begin{array}{l}\text { Microprocessor } \\
(0.020)\end{array}$} & 8 & K level 1 & 6 & K level 2-3 & 2 & 0.12 & & \\
\hline & & 8 & K level 1-2 & 4 & K level 3 & 4 & 0.040 & & $\begin{array}{l}\text { K1-2 favored } \\
\text { microprocessor knee } \\
\text { more than K3 did }\end{array}$ \\
\hline & & 8 & Age 43-61 y & 4 & $63-74$ y & 4 & 0.040 & 0.027 & $\begin{array}{l}\text { Older favored } \\
\text { microprocessor knee } \\
\text { more than younger } \\
\text { did }\end{array}$ \\
\hline & & 8 & $\begin{array}{l}\text { Time since } \\
\text { amputation } \\
0.5-2 \mathrm{y}\end{array}$ & 4 & $4-47 y$ & 4 & 0.73 & 0.67 & \\
\hline & & 8 & Bilateral & 2 & Unilateral & 6 & 0.12 & & \\
\hline \multirow[t]{5}{*}{$\begin{array}{l}\text { ABC } \\
\text { Balance }\end{array}$} & \multirow[t]{5}{*}{$\begin{array}{l}\text { Microprocessor } \\
(0.012)\end{array}$} & 8 & K level 1 & 6 & K level 2-3 & 2 & 0.016 & & $\begin{array}{l}\text { K2-3 favored } \\
\text { microprocessor knee } \\
\text { more than K1 did }\end{array}$ \\
\hline & & 8 & K level 1-2 & 4 & K level 3 & 4 & 0.16 & & \\
\hline & & 8 & Age 43-61 y & 4 & $63-74$ y & 4 & 0.10 & 0.021 & $\begin{array}{l}\text { Younger favored } \\
\text { microprocessor knee } \\
\text { more than older did }\end{array}$ \\
\hline & & 8 & $\begin{array}{l}\text { Time since } \\
\text { amputation } \\
0.5-2 \text { y }\end{array}$ & 4 & $4-47 y$ & 4 & 0.22 & 0.96 & \\
\hline & & 8 & Bilateral & 2 & Unilateral & 6 & 0.016 & & $\begin{array}{l}\text { Bilateral favored } \\
\text { microprocessor knee } \\
\text { more than unilateral } \\
\text { did }\end{array}$ \\
\hline \multirow{5}{*}{$\begin{array}{l}\text { Houghton } \\
\text { Scale }\end{array}$} & \multirow[t]{5}{*}{ Neither (0.058) } & 8 & K level 1 & 6 & K level 2-3 & 2 & 0.61 & & \\
\hline & & 8 & K level 1-2 & 4 & K level 3 & 4 & 0.37 & & \\
\hline & & 8 & Age 43-61 y & 4 & $63-74 \mathrm{y}$ & 4 & 0.37 & 0.10 & \\
\hline & & 8 & $\begin{array}{l}\text { Time since } \\
\text { amputation } \\
0.5-2 \text { y }\end{array}$ & 4 & $4-47 y$ & 4 & 0.13 & 0.47 & \\
\hline & & 8 & Bilateral & 2 & Unilateral & 6 & 0.61 & & \\
\hline
\end{tabular}




\begin{tabular}{|c|c|c|c|c|c|c|c|c|c|}
\hline Outcome & $\begin{array}{l}\text { Overall Favors* } \\
\text { (P value) }\end{array}$ & $\begin{array}{l}\mathbf{N} \\
\text { Total }\end{array}$ & Subgroup & $\begin{array}{l}\mathbf{N} \\
\text { Subgroup }\end{array}$ & Comparator & $\begin{array}{l}\mathrm{N} \\
\text { Comparator }\end{array}$ & $\begin{array}{l}\text { P Difference }{ }^{-} \\
\text {(Categorical) }\end{array}$ & $\begin{array}{l}\text { P Difference } \\
\text { (Continuous) }\end{array}$ & Findings \\
\hline \multirow{5}{*}{$\begin{array}{l}\text { BBS } \\
\text { Balance }\end{array}$} & \multirow{5}{*}{ Neither (0.11) } & 8 & K level 1 & 6 & K level 2-3 & 2 & 0.81 & & \\
\hline & & 8 & K level 1-2 & 4 & K level 3 & 4 & 0.51 & & \\
\hline & & 8 & Age 43-61 y & 4 & $63-74 y$ & 4 & 0.95 & 0.93 & \\
\hline & & 8 & $\begin{array}{l}\text { Time since } \\
\text { amputation } \\
0.5-2 \mathrm{y}\end{array}$ & 4 & $4-47 y$ & 4 & 0.77 & 0.33 & \\
\hline & & 8 & Bilateral & 2 & Unilateral & 6 & 0.81 & & \\
\hline \multirow[t]{5}{*}{$\begin{array}{l}\text { TUG } \\
\text { Walking }\end{array}$} & \multirow[t]{5}{*}{$\begin{array}{l}\text { Microprocessor } \\
(0.043)\end{array}$} & 8 & K level 1 & 6 & K level 2-3 & 2 & 0.0001 & & $\begin{array}{l}\text { K2-3 favored } \\
\text { microprocessor knee } \\
\text { more than K1 did }\end{array}$ \\
\hline & & 8 & K level 1-2 & 4 & K level 3 & 4 & 0.24 & & \\
\hline & & 8 & Age 43-61 y & 4 & $63-74 y$ & 4 & 0.28 & 0.17 & \\
\hline & & 8 & $\begin{array}{l}\text { Time since } \\
\text { amputation } \\
0.5-2 \mathrm{y}\end{array}$ & 4 & $4-47 y$ & 4 & 0.37 & 0.78 & \\
\hline & & 8 & Bilateral & 2 & Unilateral & 6 & 0.0001 & & $\begin{array}{l}\text { Bilateral favored } \\
\text { microprocessor knee } \\
\text { more than unilateral } \\
\text { did }\end{array}$ \\
\hline \multirow{5}{*}{$\begin{array}{l}\text { Fear of } \\
\text { falling }\end{array}$} & \multirow{5}{*}{$\begin{array}{l}\text { Microprocessor } \\
(0.042)\end{array}$} & 8 & K level 1 & 6 & K level 2-3 & 2 & 0.11 & & \\
\hline & & 8 & K level 1-2 & 4 & K level 3 & 4 & 0.62 & & \\
\hline & & 8 & Age 43-61 y & 4 & $63-74 y$ & 4 & 0.35 & 0.24 & \\
\hline & & 8 & $\begin{array}{l}\text { Time since } \\
\text { amputation } \\
0.5-2 \mathrm{y}\end{array}$ & 4 & $4-47 y$ & 4 & 0.48 & 0.51 & \\
\hline & & 8 & Bilateral & 2 & Unilateral & 6 & 0.11 & & \\
\hline
\end{tabular}

Abbreviations: ABC = Activities-Specific Balance Confidence, BBS = Berg Balance Scale, $\mathrm{K}$ level $=$ Medicare Functional Classification Level, TUG = timed up and go test.

Note: Data for Wong 2015 (PMID 25768067). ${ }^{92}$ Additional details in Appendix D. Across Tables 57 to 70, P values of differences (comparisons) <0.05 are bolded and associated "findings” are noted; however see footnote about Bonferroni P value threshold. Italic bold P values are statistically significant below the Bonferroni P value. Empty cells indicate either not applicable (e.g., categorical data for continuous outcomes or "no findings" if the association was not statistically significant).

*Statistically significant difference favoring listed component over comparator. "Neither" does not distinguish between evidence of no difference and lack of statistical power to find a difference (due to imprecision).

†Bonferroni $\mathrm{P}=0.0010$ (due to multiple testing, to be considered to be statistically significant, the $\mathrm{P}$ values for differences between subgroups had to be less than this value). A separate Bonferroni P value was calculated for each study based on the number of analyses (including subgroup analyses) analyzed by the study researchers and by this review. 


\section{Evaluated Predictors}

Of the 14 studies that directly compared different LLP components or configurations and provided sufficient data to allow subgroup analyses, 12 reported on basic patient characteristics such as age, sex, limb length, amputation level, and amputation etiology. We considered these to be potentially important predictors and therefore handle them as if they were validated predictors. Four studies (Hafner 2009, Hahn 2015 Kahle 2008, Wong 2015) evaluated K levels, ${ }^{78,82,85,92}$ which we also assumed to be equivalent to validated, although we found no studies assessing K level validity, per se. One study (Theeven 2011) evaluated only K2 level subgroups ("high," "intermediate," and "low"), which were unique to the study and we considered to be not validated. ${ }^{86,87}$ We omit evaluation of residual limb firmness (an ad hoc descriptor) as a nonvalidated outcome predictor as was reported by one study (Kahle 2008). ${ }^{85}$ None of the validated assessment techniques or prediction tools were used to characterize subgroups.

\section{Studies That Evaluated Validated Predictors and Outcomes}

Studies evaluated numerous outcomes, most of which have not been validated in lower limb amputees. Only eight of the studies, at least in part, analyzed validated outcomes with validated predictors (Hafner 2009, Hahn 2015, Hasenoehrl 2017, Isakov 1985, Kahle 2008, Moore 2017, Traballesi 2011, and Wong 2015). These eight studies were all deemed to be at moderate risk of bias. Five of these studies reported data on subgroups based on patient characteristics that we considered valid; three studies reported subgroup results separately but did not statistically analyze between-group differences (we calculated these differences based on reported data). Studies also reported events (e.g., falls) that we considered to be valid, by definition. The validated outcomes among these studies included the 2 and 6 minute walk tests (2MWT, 6MWT), reported falls, ABC, BBS, Houghton scale, TUG, and PEQ. Of note, the PEQ MS 13/11, evaluated by Trabellesi 2011, has been validated in studies generalizable to the Medicare population. The PEQ subscales, evaluated by Hafner 2009, Moore 2017, and Theeven 2011 have been validated only in studies not generalizable to the Medicare population; in addition, only some of the subscales have demonstrated test validity.

The applicability of these studies to the overall population of people receiving LLPs varies. Most patients in the studies were on the younger side (less than about 50 years old), particularly in the Traballesi 2011 study comparing sockets, in which the average age was 34 years. Only one study included mostly people over age 65 years (Hasenoehrl 2017). Most study participants were men; however, the percentage of men varied from 76 to 94 percent (among the five studies that reported patient sex). Among six studies that characterized patients K levels at baseline, only one study (Wong 2015) included people at K1 level (25\%), five studies included people at K2 level (25 to 100\%), one study (Traballesi 2011) included people at either K3 or K4 level, four additional studies included people at K3 level (33 to 53\%), and one additional study included one additional patient (7\%) at K4 level. The five studies that reported amputation etiologies displayed wide heterogeneity across studies. In three studies, trauma accounted for about half or more of amputations (47 to 86\%). In one study (Isakov 1985), 82 percent had dysvascular causes and only 18 percent trauma. In contrast, in Traballesi 2011, 86 percent had trauma as an etiology and the remainder cancer (none had dysvascular disease). Similarly, Hafner 2009 had a majority of people with trauma (59\%), but only 6 percent with dysvascular etiologies. On the other hand, in Kahle 2008, about half each had trauma or dysvascular etiologies (excluding patients with congenital amputations). 


\section{Microprocessor Knees}

Hafner 2009 (Table 60) compared the C-Leg microprocessor knee and mechanical knees in 17 people with unilateral transfemoral amputations, 59 percent due to trauma (and only 6 percent due to dysvascular disease). The participants were split approximately equally between K2 and K3. The study reported subgroup analyses by K level, but did not report statistical analyses comparing the subgroups. Among the outcomes reported, they reported PEQ subscales, some of which have been validated, and the numbers of reported stumbles and falls. Overall, people using the microprocessor knee had fewer stumbles and falls and also scored better on PEQ Ambulation and Well-being subscales, compared to mechanical knees, but no differences were found between knees on the other PEQ subscales. Post hoc analyses comparing the K2 and K3 subgroups found no differences in effect (microprocessor vs. mechanical knee) between the subgroups. Overall, the study does not support differences in benefit of the microprocessor between people classified as K2 or K3.

Hahn 2015 (Table 61) compared the C-Leg or C-Leg compact microprocessor knee and prior mechanical knees in 1013 people, 43 due to trauma and 26 percent due to dysvascular disease. The participants were split approximately equally between MOBIS grade 2 and 3 (equivalent to K2 and K3), with 8 percent at grade 4 . The study outcomes were generally poorly defined (in terms of what the actual questions being asked were). Most study outcomes did not appear to be comparisons between when people were using the C-Leg or their prior leg. We considered only the objective question of whether people were using a walking aid to be validated. Among the unreported number of those people who had been using walking aids with their mechanical knees, younger people were more likely to stop using the walking aids than older, and possibly those at K3 were more likely to stop using the walking aids than those at K2; however, no significant differences by age, K level, or amputation etiology were reported. Among the unvalidated outcomes, no significant differences in reduction in fear of falling were observed based on age or $\mathrm{K}$ level, and by correlation analysis no significant differences in changes in rating of safety were found based on age, K level, or etiology.

Hasenoehrl 2017 (Table 63) compared a microprocessor knee (Genium with Cenior Leg ruleset, which was designed for people at K level 1 or 2 function) and their own no microprocessor knee in five people with unilateral transfemoral amputation who were at K level 2 at the start of the study. The participants were mostly over age 65 years; only one had dysvascular conditions. Overall, functional performance was similar with the two sets of knees; although participants walked 10 meters faster at fast speed with the nonmechanical knee. The article reported individual participant data which allowed multiple subgroup analyses based on amputation etiology, sex, age, BMI, and time since amputation. After accounting for multiple testing, no statistically significant differences were found between subgroups regarding relative benefit of the microprocessor knee to improve several validated walking and function instruments, including TUG, 2MWT, 10 meter walk (at self-selected or fast speed), AMPPRO, and BBS. However, the one participant with a dysvascular condition walked significantly farther with the microprocessor knee than the mechanical knee compared with the other participants. Similarly, the one woman walked 10 meters (at self-selected speed) slower with the microprocessor knee than the mechanical knee, compared with the men. In addition, by regression analysis, those with higher BMI favored microprocessor knees by the AMPPRO instrument more than those with lower BMI. However, these findings did not persist after correcting for multiple testing. Overall, the study does not support any differences in benefit of microprocessor knees based on patient characteristics. 
Kahle 2008 (Table 65) compared a microprocessor knee (C-Leg) with a mechanical knee in 15 people with unilateral amputations (amputation level not described), excluding four people with congenital amputations. The participants had K level 2 or greater function, but half of them moved up a K level when using the microprocessor knee. About one-third each had dysvascular and traumatic causes of their amputations. Overall, people reported fewer stumbles and falls (as separate outcomes) with the microprocessor knee. Other nonvalidated outcomes were also assessed. The article reported individual participant data which allowed multiple subgroup analyses based on $\mathrm{K}$ level, amputation etiology, age, height, employment status, and residual limb length. The study also reported on a nonvalidated measure of residual limb firmness. After accounting for multiple testing, no statistically significant differences were found between subgroups regarding relative benefit of the microprocessor knee to prevent stumbles and falls. While not statistically significant after accounting for multiple testing, K2 or K3 participants tended to have relatively fewer stumbles with the microprocessor knee than K4 amputees did. Overall, however, the study does not support any differences in benefit of microprocessor knees based on patient or residual limb characteristics.

Wong 2015 (Table 70) compared the C-Leg microprocessor and mechanical knees in 8 people classified as K1 to K3 with transfemoral amputations, three-quarters of which were unilateral. Overall, the study found mostly better outcomes with the microprocessor knee. The study reported individual participant data which allowed multiple subgroup analyses based on $\mathrm{K}$ levels, age, time since amputation, and bilateral versus unilateral amputation. The study analyzed several validated outcomes along with reported falls. For the TUG outcome, the study found that those classified as K2 or K3 did relatively better with the microprocessor knee compared to mechanical knees than those classified as K1. People with bilateral amputations also did relatively better with the microprocessor knees compared to those with unilateral amputations. No differences were found in effect between older and younger patients or based on time since amputation. Across the other validated outcomes (reported falls, ABC Balance, BBS, fear of falling, and Houghton scale) no statistically significant differences were found between subgroups after accounting for multiple testing. For several subgroup comparisons, there was a tendency for one subgroup to perform relatively better with the microprocessor knee than another subgroup (i.e., $\mathrm{P}<0.05$, but not significant after accounting for multiple testing); however, there was not consistency across subgroups or outcomes (see Table 70). Overall, there was evidence of subgroup differences in the effect of microprocessor knees on TUG walking based on K level and bilateral versus unilateral amputation, but no consistent patterns were found across subgroups and outcomes.

\section{Other Components Locking Knee}

Isakov 1985 (Table 64) compared two Otto Bock prostheses with a locking system knee (model 3R17) and with an “open” load-dependent brake knee (model 3R15) in 17 people with unilateral transfemoral amputations, 82 percent of which were due to dysvascular disease. Overall, people had similar gait speeds with both knees. They reported gait speed averaged over 6 minutes (6MWT) and provided individual participant data that allowed subgroup analyses based on amputation etiology, sex, and age. Those 50 years or younger were more likely to have faster walking speed with the open knee, in contrast to those who were 55 years and older $(\mathrm{P}=0.004)$; however linear regression failed to find a significant association (after accounting for multiple testing). Participants with nonvascular amputation etiologies also tended to walk faster 
with the open knee, in contrast to those with vascular amputations; however, this finding was not statistically significant after accounting for multiple testing. Differences in gait speed between the two prostheses were similar in the one woman and the 16 men in the study. Overall, younger lower limb amputees favored the open knee over the locking knee significantly more than older amputees.

\section{Hydraulic Ankle/Foot Prosthesis}

Moore 2017 (Table 66) compared a hydraulic to a nonhydraulic ankle/foot prosthesis in 14 people with K2 function; most had amputations due to dysvascular conditions. Overall, people had better function, as measured by most of the PEQ subscales, with the hydraulic foot. The study reported subgroup data for the 12 people with transtibial amputations and the two people with transfemoral amputations, but did not formally compare the subgroups. Based on satisfaction with prosthesis and gait, transtibial amputees tended to favor the hydraulic foot more than transfemoral amputees did. But these findings were not statistically significant after accounting for multiple testing. Overall, the study does not support any differences in benefit of hydraulic ankle/foot prostheses over nonhydraulic components based on amputation level.

\section{Ischial Containment Socket}

Traballesi 2011 (Table 69) compared the Marlo Anatomic Socket with an ischial containment socket in 7 people with unilateral transfemoral amputations with K3 to K4 function; the large majority (86\%) had amputations due to trauma. Overall, people had better mobility, per the PEQMS 13/11, with the Marlo Anatomic Socket. The article reported individual participant data, which allowed multiple subgroup analyses based on patient characteristics and time since amputation. After accounting for multiple testing, no statistically significant differences were found between subgroups regarding relative benefit of the Marlo Anatomic Socket. The single woman in the study did tend to have even better mobility with the Marlo Anatomic Socket than the ischial component socket than the six men did; but the woman differed from the men in more ways than just her sex and the clinical significance of this finding is questionable. Shorter men also tended to have relatively better mobility with the Marlo Anatomic Socket than taller men, but this finding was also not statistically significant after accounting for multiple testing. Overall, the study does not support any differences in benefit of the Marlo Anatomic Socket over the ischial component socket based on patient characteristics.

\section{Studies Using Only Nonvalidated Measures}

\section{All Studies}

Six studies reported analyses based only on nonvalidated outcome measures (Alaranta 1994, De Asha 2014, Gard 2003, Hahn 2016, Silver-Thorn 2009) or based on nonvalidated predictors (Theeven 2011). Theeven 2011 reported subgroup data only for ad hoc subclassifications of the K2 level (high, intermediate, and low; and it can also be noted that K levels overall have not been validated), but used validated and nonvalidated outcome measures (Table 68). Other studies are summarized in Tables 58, 59, 62, and 67.

As summarized in Table 56, studies found no significant differences in the relative effectiveness of different components based on subgroup classifications, after adjustment for multiple comparisons. 


\section{Study With Regression Analysis: Genium Knee Versus C-Leg}

Hahn 2016 was the largest eligible study, which conducted the most comprehensive analysis (Table 62). ${ }^{83}$ It was the only eligible study to attempt to assess heterogeneity of treatment effect (how effects may differ in different people). The study created multivariable regression models with the goal of predicting which patients would benefit most from a Genium ${ }^{\circledR}$ microprocessor knee compared to people's prior knee (mostly an alternative microprocessor knee, the C-Leg; both from Otto Bock Healthcare Products Austria).

Given the large size of the study (899 people with knee or higher amputations, mostly due to trauma [69\%] who were classified as K2 to K4) and the use of regression analyses to investigate heterogeneity of treatment effect, the study was included for review. However, because of the imprecise comparison among LLP components used, strictly speaking, an argument could have been made to reject the study from this review, which is asking what patient characteristics (or functional status measures) differentiate who are most likely to have better functional outcomes with which specific component. Hahn 2016, however, did not compare distinct components (or types of components). Instead, they compared newly-prescribed Genium knees to participants' prior knee prostheses. Among the 899 participants, 689 (76.6\%) had used the C-Leg (a similar microprocessor knee), 38 (4.2\%) used mechanical hydraulic knees, 22 (2.4\%) pneumatic knees, 15 (1.7\%) 4-axis polycentric knees, 19 (2.1\%) other polycentric knees, 9 (1.0\%) brake knees, and $3(0.3 \%)$ locked knees. The article did not report on the other 104 (11.7\%) prior knees. Thus, the analysis is partially a comparison of two different microprocessor knees, but in reality is an evaluation of just the Genium knee without a specific comparator. Of note, a somewhat similar study was conducted by the same group analyzing the C-Leg (or C-Leg compact) in 1223 participants, but this study was rejected since there was no description of, or clear comparison with, the prior knees. ${ }^{78}$

The participants in the Genium study were all considered to be candidates most likely to benefit from the Genium prosthesis by their prosthetist's assessment. It is unclear exactly how the prosthetists made the assessments. The study participants were probably selected because they were deemed more likely to respond to the Genium prosthesis than other amputees. As noted, 77 percent were already users of microprocessor knees (the C-Leg or C-Leg compact). Ideally, a comparison of a component to evaluate heterogeneity of treatment effect would have included all potential users of the component, not only those deemed most likely to benefit. Furthermore, the analytic method used further limited the number of people included in the model. The researchers required complete datasets for all selected variables and did not report having imputed missing data. Thus, at most the 425 people with data about their residual limb condition could have been included in a multivariate model with all predictors listed in the study. The final numbers analyzed in the models were not reported.

The study outcomes were based primarily on prosthetists' and participants' ratings assessments as indicated in an existing database. (NB. The outcomes reported in this paper were assessed by a 2008 thesis conducted at the Universitätsklinikum Münster in Germany, which is not available). However, the authors state that "the data do not rely on validated outcomes as recommended in controlled trials. This limits the accuracy of the findings specifically with respect to magnitude of the effects."

Across the various specific outcomes evaluated, the total responsiveness related to subject perception ranged from 67 to 96 percent. Total responsiveness rated by the prosthetists ranged from 95 to 97 percent, suggesting that most people had some improvement with the Genium prosthesis according to the prosthetist's assessment. For inclusion in their models, the 
researchers chose the most responsive items within each of the performance areas: safety, harmonization of gait pattern, relief of contralateral limb, possibility to divide attention, capability to vary gait speed, reduction of overall effort, reduction in number of aids, change of mobility grade, perceived safety on stairs and slopes, variation of gait speed, walking with small steps, more difficult walking requirements, and more difficult walking environments. However, the study does not report the percentage of patients who were responsive for each modeled outcome; furthermore, the actual outcome(s) used in the final model are unclear. If the percentage was indeed high (as is the total responsiveness rated by the prosthetist), there may be "class imbalance" where the proportion of failures is so small, there is little room for a model to improve over an intercept-only model that simply classifies everyone as a responder. In other words, the "best" possible model may not differentiate people as likely responders and nonresponders much better than an assumption that all will respond, since in reality almost all did respond. Thus, based on the chosen outcome, it may have been inevitable that no factors successfully predicted which people did better with one prosthesis or the other. However, it is not clear which "responsiveness" outcome(s) were used in their final model(s). These issues may have been a direct consequence of the prosthetists' abilities to successfully select patients to receive the Genium knee.

A very large set of variables related to patient characteristics, amputation and residual limb characteristics, and current type of prosthesis used, among others were tested for inclusion as predictors in the models. The analyses found numerous highly statistically significant predictors of the outcomes. However, overall, the authors reported that "none of the variables and none of the regression models yield[ed] explanatory predictive power.” They were also not able to determine a coherent, stable, reproducible variable set.

The paper, though, does not, in fact, perform an analysis of the predictive performance of logistic regression models to identify people with better outcomes with a Genium knee. The only metric of predictive performance reported was a Nagelkerke's $\mathrm{R}^{2}$ value, which is not sufficient to make conclusions for several reasons. While the $\mathrm{R}^{2}$ value can be considered as a metric of global predictive performance, it is not generally a very informative one. ${ }^{93,94}$ For this and related reasons, the study does not provide compelling evidence about the predictive performance of the analyzed variables.

The article does not report the actual final model(s), and as noted, it is not abundantly clear which outcomes were used in the final models. However, they report linear regressions between a long list of participant and component variables and outcomes. It is implied that the outcomes are the differential response to the Genium knee (whether there was a relative difference with the Genium and the prior prostheses-mostly C-Leg). In addition, many of the associations were highly statistically significant. Among these, for the outcome "variable gait speed", younger age, longer distance walked per day (presumably on their old knee), nonvascular etiology, amputation level (unclear how defined), unilateral amputation, no comorbidities, no diabetes, no cardiovascular disease, no leg peripheral vascular disease, no further disability, profession (not defined), better residual limb condition, longer residual limb length, greater residual limb loading, greater number of falls per year, and higher mobility grade were all statistically significantly associated with better variable gait speed with the Genium knee (than people with the opposite states). $\mathrm{P}$ values for these variables ranged from $10^{-26}$ (mobility grade) to 0.025 (further disability). Similar findings were reported for toileting and walking up stairs alternatingly. 
In brief, while relative effectiveness of the Genium microprocessor knee was highly statistically significantly different for many subgroups versus prior knee prostheses (mostly the C-Leg microprocessor knee), the study reported that no set of variables were found to accurately predict which patients would benefit most from the microprocessor knee. However, there are numerous concerns about a number of critical issues. There was likely selection bias: the included subpopulation was chosen based on their assessed likelihood of succeeding with the microprocessor knee, and analyzed participants had to have available data for all included variables. The primary comparison was between newly prescribed microprocessor Genium knees and a mix of prior prosthesis knees, mostly another microprocessor knee, the C-Leg, but also various mechanical knees and a large number of unknown prosthesis types. The average participant may have been too likely to respond well to the microprocessor knee to allow for the possibility of determining who, on average, would be likely to fail with the knee. The study's analytic methodology and findings were too incompletely reported to assess how the model fared and if correct methodologies were used.

\section{Summary}

Table 71 provides an overall summary the study findings and the evidence. Be reminded that this review does not make conclusions about the overall effectiveness of different LLP components and configurations. Key Question 4 addressed whether there is evidence regarding heterogeneity of treatment effects, particularly with validated measures, in the field of LLP research. A relatively small percentage of comparative studies report sufficient data to allow subgroup analysis and evaluation of heterogeneity of treatment effect (14\%, 15 of 104 otherwise eligible articles).

Of these 14 studies, only eight used validated predictor and outcome measures. Only one of the eligible studies was a randomized trial (Theeven 2011), but it did not evaluate validated subgroups. Only three studies (De Asha 2014, Hahn 2015, Hahn 2016) evaluated heterogeneity of treatment effect (analysis of differences in effect across subgroups); others reported individual participant level data without conducting their own subgroup analyses. Across studies, a scattering of statistically significant differences in relative effects of different components were found based on different subgroup comparisons. However, these findings were not consistent across, and often within, studies. Only one study (Hahn 2016) analyzed the most important aspect of the KQ, namely whether any study participant characteristics (or set of characteristics) could accurately and effectively predict which patients will benefit most or least from a given component. However, there were methodological and analytical issues with this study, which compared a specific microprocessor knee (Genium) to any prior used knee (mostly another microprocessor knee, C-Leg). Despite finding numerous statistically significant associations between participant characteristics and functional outcomes, the study concluded that no model accurately predicted relative effect (between the Genium microprocessor knee and, mostly, the C-Leg microprocessor knee).

Overall, studies that investigated subgroup effects did not identify participant characteristics that predict which lower limb amputees would benefit most or least from a given component or configuration. Based on the methodology used to assess strength of evidence, the studies warrant a low strength of evidence that patient characteristics evaluated in the studies do not predict which patients would benefit most or least from a given LLP component or configuration. However, it may be more accurate to conclude that the evidence is currently too sparse and, thus, fails to adequately address whether different subgroups of amputees are more likely or less likely 
to benefit from given specific LLP components or configurations. Most studies were very underpowered to find statistically significant evidence of differences among subgroups, with on average only about 30 participants per study (excepting two larger studies). Only eight of the 14 studies used validated predictors and outcomes. Similar conclusions are reached for this subset of studies. One large study attempted to develop a model to predict success with microprocessor knees; however, the study did not use a validated outcome and had several methodological and analytic concerns. It, therefore, provided insufficient additional evidence regarding who would benefit most from a microprocessor knee. An additional issue across almost all studies was that study participants were in general not likely to be representative of the Medicare population, being both mostly young and with amputations due to trauma, with relatively few people with dysvascular disease. 
Table 71. Key Question 4 evidence profile

\begin{tabular}{|c|c|c|c|c|c|c|c|c|c|}
\hline Outcome & $\begin{array}{l}\text { No. Studies } \\
\text { (N) }\end{array}$ & $\begin{array}{l}\text { Study } \\
\text { Limitations }\end{array}$ & Consistency & Precision & $\begin{array}{l}\text { Reporting } \\
\text { Bias }\end{array}$ & Directness* & Other Issues & Findings & SoE Grade \\
\hline $\begin{array}{l}\text { Validated } \\
\text { predictors and } \\
\text { outcomes } \\
\text { (univariable) }\end{array}$ & $\begin{array}{l}8(1096, \\
1013 \text { in } 1 \\
\text { study) }\end{array}$ & Medium $\dagger$ & Consistent & Imprecise & Undetected & Indirect $\neq$ & $\begin{array}{l}\text { High degree } \\
\text { of multiple } \\
\text { testing; mostly } \\
\text { evaluations of } \\
\text { knee } \\
\text { components; } \\
\text { mostly K2 or } \\
\text { K3 level, } \\
\text { unilateral } \\
\text { transfemoral } \\
\text { amputations } \\
\text { due to } \\
\text { traumatic } \\
\text { etiologies }\end{array}$ & $\begin{array}{l}\text { Some trends of } \\
\text { differences in } \\
\text { relative effect } \\
\text { based on } \\
\text { participant } \\
\text { characteristics, } \\
\text { however, none } \\
\text { statistically } \\
\text { significant after } \\
\text { correcting for } \\
\text { multiple testing }\end{array}$ & Low \\
\hline $\begin{array}{l}\text { All outcomes } \\
\text { (univariable) }\end{array}$ & $\begin{array}{l}13(1328, \\
1013 \text { in one } \\
\text { study) }\end{array}$ & Medium† & Consistent & Imprecise & Undetected & Indirect‡ & $\begin{array}{l}\text { Nonvalidated } \\
\text { outcomes, } \\
\text { high degree of } \\
\text { multiple } \\
\text { testing; mostly } \\
\text { K2 to K4 level, } \\
\text { unilateral } \\
\text { transfemoral } \\
\text { amputations } \\
\text { due to } \\
\text { traumatic } \\
\text { etiologies }\end{array}$ & $\begin{array}{l}\text { Some trends of } \\
\text { differences in } \\
\text { relative effect } \\
\text { based on } \\
\text { participant } \\
\text { characteristics, } \\
\text { however, none } \\
\text { statistically } \\
\text { significant after } \\
\text { correcting for } \\
\text { multiple testing }\end{array}$ & Low \\
\hline $\begin{array}{l}\text { Ambulatory and } \\
\text { functional } \\
\text { outcomes, } \\
\text { nonvalidated } \\
\text { (multivariable } \\
\text { model) }\end{array}$ & 1 (899) & High§ & NA & Precise & Undetected & Indirect\# & $\begin{array}{l}\text { K2 to K4 } \\
\text { (mostly K3) } \\
\text { level, mostly } \\
\text { traumatic } \\
\text { etiologies. } \\
\text { Study does } \\
\text { not directly } \\
\text { address Key } \\
\text { Question. }\end{array}$ & $\begin{array}{l}\text { A large set of } \\
\text { variables } \\
\text { individually were } \\
\text { associated with } \\
\text { better outcomes } \\
\text { with the } \\
\text { microprocessor } \\
\text { knee. No model } \\
\text { predicted who } \\
\text { would most benefit } \\
\text { from knee. }\end{array}$ & Insufficient \\
\hline
\end{tabular}

Abbreviations: NA = not applicable, RoB = risk of bias, SoE = strength of evidence.

*Representative of either (or both) older adults ( $\geq 65$ years old) or those with dysvascular amputations. 
†Nonrandomized studies, univariable analyses (mostly individual participant data reports), generally lack of evaluation of heterogeneity of treatment effect, mostly small studies.

$\ddagger$ Both relatively young age amputees and primarily people with amputations due to trauma in most studies. Almost all (that reported) had unilateral transfemoral amputations.

$\S$ Nonrandomized, likely biased sample of participants, nonvalidated outcomes, unclear which outcome(s) used in final models. See text.

\#Highly selected participants who had been assessed as likely to benefit from a microprocessor knee, possibly biased dropouts, relatively young and two-thirds had trauma etiology.

\section{Key Question 5. Expectations of Ambulation}

KQ 5 asked how study participants’ preprescription expectations of ambulation align with their functional outcomes. We found no study that addressed this issue.

\section{Key Question 6. Patient Satisfaction With Process}

\section{Key Points}

- Two studies evaluated patient satisfaction with the process of accessing an LLP

- The studies suggest that people are satisfied with their encounters with their prosthetists (low strength of evidence)

\section{Findings}

We found two studies that addressed this question. Note that this Key Question did not address satisfaction with the LLP. Studies addressing satisfaction with the LLP (or function with the prosthesis) would have been eligible for Key Question 4 if they reported subgroup analyses. Pezzin 2004 surveyed individuals about satisfaction with upper or lower prosthetic limbs and related services. ${ }^{95}$ Hart 1999 reported data about satisfaction with the prosthetist appointments in a study designed to assess the reliability and construct validity of the OPOT in clients with LLPs. ${ }^{65}$

In the more recent study (Pezzin 2004), study participants were asked 12 questions about the prosthetist from whom they received care in the past 12 months. ${ }^{95}$ Based on their responses, 3 dimensions of prosthetist quality assessment were examined: technical skills, information giving, and interpersonal manner. These questions were answered by approximately 823 study participants who had seen a prosthetist in the past 12 months. Participant descriptive data were given for 935 adults in the United States, including the 12 percent who had not recently seen a prosthetist. Overall, the study was deemed to be at moderate risk of bias. Approximately 30 percent of potentially eligible patients could not be reached or refused to participate; no assessment of whether they were systematically different than respondents. However, multivariable analyses were conducted where appropriate.

Study participants were 18 to 84 years old (mean 50.5 years) who had either a lower limb amputation $(\geq 78.9 \%)$ or upper limb amputation $(\geq 10.0 \%)$; the 10.8 percent of participants with bilateral amputations were not further categorized as having upper or lower limb amputations (but people with both upper and lower limb amputations were excluded). Amputation was due to dysvascular diseases (37.8\%), trauma (38.7\%), or cancer (23.4\%). Lower limb amputees were almost evenly split between above-knee (38.5\%) and below-knee (40.4\%) amputations. Amputation occurred during childhood in 12.5 percent and after age 64 years in 8.8 percent of participants. Among participants, 20.7 percent had Medicare insurance and 15.4 percent 
Medicaid (participants were categorized as having only a single type of insurance). Most participants (94.6\%) were currently using a prosthesis. They used their prostheses for an average of 71 (SD 41) hours per week and had a mean 9 (SD 11) visits to a prosthetist in the past 12 months, but a median of 5 visits; 12 percent did not visit a prosthetist in the past year.

The study found that more than 75 percent consistently agreed or strongly agreed with positive statements across all items related to prosthetist technical skills, information giving, and interpersonal manner. Participants were most satisfied with prosthetist's technical skills: they agreed or strongly agreed that prosthetists check everything (93\%), are competent (95\%), understand patients' medical history (89\%), understand what is wrong (86\%), and are current on technology (90\%). Participants were also mostly satisfied with prosthetists’ information giving: they agreed or strongly agreed that prosthetists tell them all they want to know (88\%), answer all questions (93\%), have the patients' confidence (88\%), and, to a lesser extent, can be depended on (75\%). Regarding interpersonal skills, participants agreed or strongly agreed that prosthetists were not in a hurry (83\%), explained things (87\%), and discussed things (85\%). As reported, "less favorable ratings related to being able to depend on the prosthetist for the individual's physical wellbeing (26\% disagreed or strongly disagreed).”

Multivariable regression models were used to examine the correlates of positive perceptions of a prosthetist's quality for the three summary dimensions of provider care (technical skills, information giving, and interpersonal manner); however, numerical data regarding the models were not reported. Females, whites, those with higher levels of education, those with above-knee amputation or bilateral amputation, and those who had undergone an amputation more recently were more likely to have favorable perceptions about their prosthetist $(\mathrm{P}<0.05)$. Patients with Medicaid insurance had lower satisfaction $(\mathrm{P}<0.05$, implied) than those with private or commercial insurance, but no differences were found among those with Medicare, other public insurance, or the uninsured. No differences in satisfaction were found based on amputation etiology or geographic region of residence (in the United States). The study did not evaluate satisfaction with payers.

In the older study validating OPOT, Hart 1999 surveyed 840 adults requiring LLP who were seen in 56 practices in the United States. ${ }^{65}$ Almost half had Medicare (43.6\%) or Medicaid (7.2\%) as a primary payer. The clients were on average about 56 years old (men 55.6 [SD 16.2] years, women 58.1 [SD 17.9] years), with K levels (Medicare Functional Classification Levels) ranging from K0 (0.4\%) to K4 (14.0\%); about half were classified as K3 (47.6\%) and about onequarter K2 (29.8\%). Seventy percent were men. About three-quarters (73.4\%) had transtibial or below-knee amputations and most of the rest (19.2\%) had transfemoral amputations. Nearly twothirds had dysvascular causes of amputation (58.2\%) and nearly one-third trauma (29.2\%).

About two-thirds were being evaluated for a replacement prosthesis (67.6\%), as opposed to first prosthesis (32.4\%).

Clients were surveyed at initial fitting (of their first or new prosthesis) and at followup on average 82 days later (SD 44). Clients were asked five questions covering receiving an appointment within a reasonable time period, location of office, courtesy from staff, waiting room staff, and ability to express client concerns about the limb; other questions pertained to satisfaction with their LLP and function. These questions were transformed into a single client satisfaction with prosthetist performance score ranging from 0 to 100 (best). The average scores were similar at both visits at 81.9 (SD 12.3) and 84.6 (SD 10.8). Of note, client satisfaction was not correlated with SF-12, SF-12 subscales, or a measure of overall health status. Also of note, 
the clients mostly found the question of satisfaction to be important (mean 86 [SD 16], also on a scale of 0-100).

A limitation of this study was that a high percentage of clients did not answer the survey questions at both initial and follow-up visits. Of 840 included clients, only 417 (50\%) gave answers at the initial visit and only 348 (41\%) at follow-up; only 203 (24\%) answered both surveys. Overall, the study was deemed to be at high risk of bias due to nonresponse without an assessment or full description of who did not answer the survey. No analyses were conducted to assess which clients were satisfied or dissatisfied, or why.

In summary, a moderate risk of bias study (of generally younger adults about one-third of whom had dysvascular disease) found that at least three-quarters of people receiving an LLP were satisfied with the process of accessing their LLP and a high risk of bias study (in which about half had Medicare or Medicaid insurance) found that on average clients were satisfied with their visits to their prosthetists' offices (average score about 83 of 100). Together, the studies provides low strength evidence that people are satisfied with their encounters with their prosthetists (Table 72). 
Table 72. Key Questions 5 and 6 evidence profile

\begin{tabular}{|l|l|l|l|l|l|l|l|l|l|}
\hline Outcome & $\begin{array}{l}\text { No. Studies } \\
\text { (N) }\end{array}$ & $\begin{array}{l}\text { Study } \\
\text { Limitations }\end{array}$ & Consistency & Precision & $\begin{array}{l}\text { Reporting } \\
\text { Bias }\end{array}$ & Directness* & Other Issues & Findings \\
\hline $\begin{array}{l}\text { Alignment of } \\
\text { outcomes with } \\
\text { expectations } \\
\text { (KQ 5) }\end{array}$ & 0 & NA & NA & NA & NA & NA & NA & None \\
\hline $\begin{array}{l}\text { Satisfaction with } \\
\text { process (KQ 6) }\end{array}$ & $2(-1663)$ & Medium & Consistent & Precise & Undetected & Direct † & $\begin{array}{l}\text { Nonvalidated } \\
\text { outcomes }\end{array}$ & $\begin{array}{l}\text { Clients generally } \\
\text { satisfied with their } \\
\text { encounters with } \\
\text { their prosthetists }\end{array}$ & $\begin{array}{l}\text { Low } \\
\text { pufficient }\end{array}$ \\
\hline
\end{tabular}

Abbreviations: KQ = Key Question, NA = not applicable, SoE = strength of evidence.

*Representative of either (or both) older adults ( $\geq 65$ years old) or those with dysvascular amputations.

†One study included a wide range of prosthetics practices; about half the participants had Medicare or Medicaid as a primary payer. The other study was less representative. 


\section{Key Question 7. Long-Term Outcomes}

\section{Key Points}

- Eight studies with at least 100 participants followed patients at least 6 months after prescription of an LLP; however, studies suffered from high risk of bias, incomplete reporting, and limited applicability to current lower limb amputees in the United States.

- Among lower limb amputees who receive an LLP prescription, 11 to 22 percent abandon the prosthesis at about 1 year (low strength of evidence)

o People with unilateral transfemoral amputations are about twice as likely to abandon their LLP than those with unilateral transtibial amputations (low strength of evidence)

- Among LLP recipients, 24 to 29 percent use their prostheses only indoors at 1 year (low strength of evidence)

o People with transfemoral amputations, or who are older, or with bilateral amputations are more likely to be limited to indoor use (low strength of evidence)

- There is insufficient evidence regarding other long-term outcomes of interest

\section{Findings}

We found eight studies (in nine articles) with at least 100 participants who were followed for at least 6 months after prescription of an LLP ${ }^{96-104}$ Most studies of amputees with outcomes of interest were rejected because the analyses were not restricted to people with prescribed prostheses and were thus mostly analyses of predictors for not receiving a prescription for LLP. The studies analyzed data from 109 to 555 participants followed for 1 to 7 years (except for two studies that implied long-term followup, but did not report a timeframe. ${ }^{98,100}$ The studies only sparsely covered the subquestions pertaining to specific outcomes, particularly related to different subgroups of amputees. Studies did not explicitly account for intervening mortality or subsequent surgeries or injuries.

Table 73 summarizes the study design and participant characteristics of the eight studies. The studies mostly included older adults, 65 to 80 percent of whom were men. However, they were each representative of different cohorts of lower limb amputees as indicated by their amputation level and etiologies. Four studies were restricted to all (or almost all) unilateral amputees, ${ }^{96-99}$ while four included about 10 to 20 percent bilateral amputees. ${ }^{100-102,104}$ Three of the studies included approximately similar percentages of people classified as having transfemoral and transtibial amputations (and no amputations at other levels). ${ }^{97,}$, 99,100 One study was restricted to people with transtibial amputations. ${ }^{98}$ Four studies included at least twice as many people with transtibial than transfemoral amputations. ${ }^{100-102,104}$ One of these latter studies included a small percentage of people with amputations at the hip and 11 percent with foot or ankle amputations. ${ }^{101}$ This study (Matsen 2000) also included 12 percent of people who had congenital amputations. Five of the studies evaluated people who mostly (about 80-95\%) had diabetes or other vascular diseases as the etiology of their amputation. ${ }^{96-99,} 102$ In addition to congenital amputations, Matsen 2000 also included an atypically large percentage of people with traumatic (50\%) and infectious (21\%) etiologies. ${ }^{101}$ Roffman 2016 similarly had large percentages with traumatic (57\%) and infectious (43\%) etiologies. ${ }^{103,} 104$ Marmann 1994 did not report amputation etiologies. ${ }^{100}$ Dudkiewicz 2011 stated that 537 of 557 (96\%) of participants had solid ankle cushion heel static prosthetic feet and suggested (or unclearly stated) that these people were at 
Medicare Functional Classification Level 1 (K level 1, indoor ambulation) at the time of LLP prosthesis. ${ }^{98}$

Table 74 describes the risk of bias (study quality) of the studies. In addition to the studies each being representative of different types of amputees, most studies failed to include between about 25 and 85 percent of potentially eligible participants, mostly due to failure of people to respond to surveys. These studies did not attempt to demonstrate that the included participants were representative of their populations and were deemed to have high risk of sample bias. This was the primary concern for three studies, which were deemed to be at moderate risk of bias (Davies 2003, Gauthier-Gagnon 1999, and Roffman 2016). ${ }^{97,99,104}$ Notably, Matsen 2000 had a very low survey response rate and self-described their population as nonrepresentative; the study also poorly defined its outcomes and did not clearly report the results for the outcomes of interest; this study was deemed to have high overall risk of bias. ${ }^{101}$ Dudkiewicz 2011 and Marmann 1994 did not report when their surveys were done in relation to LLP prescription, and were deemed to have high overall risk of bias. ${ }^{98,} 100$ Only two studies were deemed to be at overall low risk of bias (Chen 2008 and Pohjolainen 1990). ${ }^{96,102}$ However, only four studies reported subgroup (predictor) analyses (Davies 2003, Marmann 1994, Pohjolainen 1990, and Roffman 2016); none of them reported multivariable analyses for the predictors and outcomes of interest. Thus, the four subgroup analyses were all deemed to be subject to high risk of bias.

Table 75 provides the outcome results of interest across studies. The summarized data represent the proportion of study participants who had the outcome of interest at the time of follow-up in the studies (e.g., the percentage of people failed to ambulate bipedally at time of followup). Except as noted, studies generally were not explicit about how many people had the outcomes at the time of LLP prescription (e.g., how many people were able to walk bipedally when they received their prostheses). 
Table 73. Study design and participant characteristics of studies reporting long-term followup after prosthesis prescription

\begin{tabular}{|c|c|c|c|c|c|c|c|c|c|}
\hline $\begin{array}{l}\text { Study Year } \\
\text { (PMID) } \\
\text { Country }\end{array}$ & Study Design* & $\begin{array}{l}\text { N Surveyed } \\
\text { (Eligible) }\end{array}$ & Population & $\begin{array}{l}\text { Mean } \\
\text { Age (SD) } \\
\text { [Range] }\end{array}$ & Male & $\begin{array}{l}\text { K } \\
\text { level }\end{array}$ & $\begin{array}{l}\text { Amputation } \\
\text { Level }\end{array}$ & Unilateral & Etiology \\
\hline $\begin{array}{l}\text { Chen } 2008 \\
\text { (18724135) } \\
\text { Taiwan }\end{array}$ & Retrospective & $109(120)$ & $\begin{array}{l}\text { Major lower limb } \\
\text { amputation, } \\
\text { received } \\
\text { prosthesis }\end{array}$ & $\begin{array}{l}64.3 \\
(12.9)[28- \\
85]\end{array}$ & $65 \%$ & nd & TF 14\%, TT 86\% & $97 \%$ & $\begin{array}{l}\text { Vascular 94\%, } \\
\text { trauma } 6 \%\end{array}$ \\
\hline $\begin{array}{l}\text { Davies } 2003 \\
(14727699) \\
\text { UK }\end{array}$ & Retrospective & $196(357)$ & $\begin{array}{l}\text { Unilateral lower } \\
\text { limb amputation } \\
\text { with prosthesis }\end{array}$ & 68 & $70 \%$ & nd & TF 49\%, TT 51\% & $100 \%$ & $\begin{array}{l}\text { Vascular } 88 \%, \text { other } \\
12 \%\end{array}$ \\
\hline $\begin{array}{l}\text { Dudkiewicz } \\
2011 \\
(21303214) \\
\text { Israel }\end{array}$ & Retrospective & $557(717)$ & $\begin{array}{l}\text { Below knee } \\
\text { amputation with } \\
\text { prosthesis. 96\% K } \\
\text { level } 1 \text { (unclear } ¥ \text { ) }\end{array}$ & 64.2 & $75 \%$ & nd & TT 100\% & $94 \%$ & $\begin{array}{l}\text { Vascular/DM 83\%, } \\
\text { trauma } 3 \% \text {, infection } \\
11 \% \text {, other } 3 \%\end{array}$ \\
\hline $\begin{array}{l}\text { Gauthier- } \\
\text { Gagnon } 1999 \\
\text { (10378500) } \\
\text { Canada }\end{array}$ & Retrospective & 396 (nd) & $\begin{array}{l}\text { Unilateral lower } \\
\text { limb amputation, } \\
\text { completed } 1 \mathrm{y} \\
\text { prosthetic training }\end{array}$ & $\begin{array}{l}62.6 \\
(15.9)\end{array}$ & $74 \%$ & nd & TF 42\%, TT 58\% & $100 \%$ & $\begin{array}{l}\text { Vascular/DM 78\%, } \\
\text { trauma } 17 \% \text {, other } \\
5 \%\end{array}$ \\
\hline $\begin{array}{l}\text { Marmann } \\
1994 \text { (none) } \\
\text { Germany }\end{array}$ & Retrospective & 110 (399) & $\begin{array}{l}\text { Lower limb } \\
\text { prosthesis able to } \\
\text { walk }\end{array}$ & 73 & nd & nd & TF 60\%, TT 40\% & $90 \%$ & nd \\
\hline $\begin{array}{l}\text { Matsen 2000 } \\
\text { (10954097) } \\
\text { USA }\end{array}$ & Retrospective & $148(1035)$ & $\begin{array}{l}\text { Lower limb } \\
\text { amputation, with } \\
\text { prosthesis } \\
\text { (implied) }\end{array}$ & $\begin{array}{l}50.1 \\
(16.2)\end{array}$ & $72 \%$ & nd & $\begin{array}{l}\text { Hip 3\%, TF 23\%, } \\
\text { Knee 9\%, TT } \\
55 \%, \text { Foot/ankle } \\
11 \%\end{array}$ & $87 \%$ & $\begin{array}{l}\text { Vascular/DM 21\%, } \\
\text { trauma } 50 \%, \\
\text { infection } 21 \%, \\
\text { cancer } 2 \%, \\
\text { congenital } 12 \% \dagger\end{array}$ \\
\hline $\begin{array}{l}\text { Pohjolainen } \\
1990 \\
(2235304) \\
\text { Finland }\end{array}$ & Retrospective & 175 (175) & $\begin{array}{l}\text { Lower limb } \\
\text { amputation, with } \\
\text { prosthesis }\end{array}$ & $\begin{array}{l}62.2[14- \\
87]\end{array}$ & $73 \%$ & nd & TF 36\%, TT 64\% & $89 \%$ & $\begin{array}{l}\text { Vascular } 81 \%, \\
\text { trauma } 10 \% \text {, cancer } \\
6 \% \text {, other } 3 \%\end{array}$ \\
\hline $\begin{array}{l}\text { Roffman } 2016 \\
(26637652, \\
25450484) \\
\text { Australia }\end{array}$ & $\begin{array}{l}\text { Prospective } \\
(n=66), \\
\text { retrospective } \\
(n=135)\end{array}$ & 201 (nd) & $\begin{array}{l}\text { Lower limb } \\
\text { amputation, } \\
\text { previously } \\
\text { ambulatory, } \\
\text { prosthesis rehab }\end{array}$ & 55 & $80 \%$ & $1-4$ & $\begin{array}{l}\text { TF 27\%, Knee } \\
3 \% \text {, TT 70\% }\end{array}$ & $85 \%$ & $\begin{array}{l}\text { Vascular } 26 \% \text {, } \\
\text { trauma } 27 \% \text {, } \\
\text { infection } 43 \% \text {, } \\
\text { cancer } 4 \%\end{array}$ \\
\hline
\end{tabular}

Abbreviations: $\mathrm{DM}=$ diabetes mellitus, $\mathrm{K}$ level = Medicare Functional Classification Level, nd = no data, PMID = PubMed identifier (or journal), SD = standard deviation, TF = transfemoral amputation, TT = transtibial amputation.

*Funding source for all studies was nonindustry.

†Some patients listed more than one reason for amputation.

$\ddagger$ Almost all had solid ankle cushion heel prosthetic feet and had lower K level classification than 20 participants with single axis feet. It is likely that these people were at K level 1 , but this is unclear. 
Table 74. Long-term followup study risk of bias/study quality

\begin{tabular}{|c|c|c|c|c|c|c|}
\hline Study Year (PMID) & $\begin{array}{l}\text { Sample } \\
\text { Bias }\end{array}$ & $\begin{array}{l}\text { Outcome } \\
\text { Assessment }\end{array}$ & $\begin{array}{l}\text { Predictors/Variables } \\
\text { Definitions }\end{array}$ & $\begin{array}{l}\text { Multivariable } \\
\text { Analysis }\end{array}$ & Other & Overall Quality \\
\hline $\begin{array}{l}\text { Chen } 2008 \\
(18724135)\end{array}$ & Low RoB & Low RoB & $N^{*}{ }^{*}$ & $N A^{*}$ & & $\begin{array}{l}\text { Low RoB (no subgroup } \\
\text { analyses) }\end{array}$ \\
\hline $\begin{array}{l}\text { Davies } 2003 \\
(14727699)\end{array}$ & High RoB & Low RoB & Low RoB & High RoB (no) & & $\begin{array}{l}\text { Moderate RoB, except } \\
\text { high RoB for subgroup } \\
\text { analyses }\end{array}$ \\
\hline $\begin{array}{l}\text { Dudkiewicz } 2011 \\
(21303214)\end{array}$ & High RoB & Low RoB & $\mathrm{NA}^{*}$ & $N A^{*}$ & $\begin{array}{l}\text { Follow-up time not } \\
\text { reported }\end{array}$ & $\begin{array}{l}\text { High RoB (no subgroup } \\
\text { analyses) }\end{array}$ \\
\hline $\begin{array}{l}\text { Gauthier-Gagnon } \\
1999(10378500) \\
\end{array}$ & $\begin{array}{l}\text { Unclear } \\
\text { RoB }\end{array}$ & Low RoB & $\mathrm{NA}^{*}$ & $\mathrm{NA}^{*}$ & & $\begin{array}{l}\text { Moderate RoB (no } \\
\text { subgroup analyses) }\end{array}$ \\
\hline $\begin{array}{l}\text { Marmann } 1994 \\
\text { (none) }\end{array}$ & High RoB & Low RoB & Low RoB & High RoB (no) & $\begin{array}{l}\text { Follow-up time not } \\
\text { reported }\end{array}$ & High RoB \\
\hline $\begin{array}{l}\text { Matsen } 2000 \\
(10954097)\end{array}$ & High RoB & $\begin{array}{l}\text { High RoB (outcomes } \\
\text { poorly described) }\end{array}$ & $\mathrm{NA}^{*}$ & $\mathrm{NA}^{*}$ & $\begin{array}{l}\text { Incomplete } \\
\text { reporting of } \\
\text { results; } \\
12 \% \text { congenital } \\
\text { amputees }\end{array}$ & $\begin{array}{l}\text { High RoB (no subgroup } \\
\text { analyses) }\end{array}$ \\
\hline $\begin{array}{l}\text { Pohjolainen } 1990 \\
\text { (2235304) }\end{array}$ & Low RoB & Low RoB & Low RoB & High (no) & & $\begin{array}{l}\text { Low RoB, except high } \\
\text { RoB for subgroup } \\
\text { analyses }\end{array}$ \\
\hline $\begin{array}{l}\text { Roffman } 2016 \\
(26637652, \\
25450484) \\
\end{array}$ & $\begin{array}{l}\text { Unclear } \\
\text { RoB }\end{array}$ & Low RoB & Low RoB & High (no) & & $\begin{array}{l}\text { Moderate RoB, except } \\
\text { high RoB for subgroup } \\
\text { analyses }\end{array}$ \\
\hline
\end{tabular}

Abbreviations: NA = not applicable, PMID = PubMed identifier (or journal), RoB = risk of bias.

*No predictor/subgroup analyses reported; only overall rate reported. 
Table 75. Long-term followup results

\begin{tabular}{|c|c|c|c|c|c|c|}
\hline Author & Outcome & Outcome Description & Timepoint & $\begin{array}{l}\text { Comparison } \\
\text { (P Value) }\end{array}$ & Subgroup & $\%(\mathrm{n} / \mathrm{N})$ \\
\hline $\begin{array}{l}\text { Chen } 2008 \\
(18724135) \\
\end{array}$ & $\begin{array}{l}\text { Abandoned } \\
\text { prostheses }\end{array}$ & "No use" & $28.3 \mathrm{mo}$ & & All participants†† & $\begin{array}{l}0.9 \% \\
(1 / 109) \\
\end{array}$ \\
\hline \multirow[t]{21}{*}{$\begin{array}{l}\text { Davies } 2003 \\
(14727699)\end{array}$} & \multirow[t]{7}{*}{$\begin{array}{l}\text { Abandoned } \\
\text { prostheses }\end{array}$} & \multirow{7}{*}{$\begin{array}{l}\text { Stanmore Harold Wood Mobility Grade } 1 \\
\text { ("has abandoned limb wearing or uses } \\
\text { only a cosmetic limb) }\end{array}$} & \multirow[t]{7}{*}{$1 \mathrm{y}$} & & All participants & $\begin{array}{l}12.2 \% \\
(24 / 196) \\
\end{array}$ \\
\hline & & & & \multirow[t]{2}{*}{$\begin{array}{l}\text { Level } \\
(0.19)\end{array}$} & Transfemoral & $\begin{array}{l}15.7 \% \\
(14 / 89) \\
\end{array}$ \\
\hline & & & & & Transtibial & $\begin{array}{l}9.3 \% \\
(10 / 107)\end{array}$ \\
\hline & & & & \multirow{4}{*}{$\begin{array}{l}\text { Age } \\
(0.18)\end{array}$} & Age $<50$ y & $0 \%(0 / 16)$ \\
\hline & & & & & $50-64$ y & $\begin{array}{l}14.2 \% \\
(7 / 49) \\
\end{array}$ \\
\hline & & & & & $65-79 y$ & $\begin{array}{l}11.3 \% \\
(13 / 115)\end{array}$ \\
\hline & & & & & $>80 y$ & $25 \%(4 / 16)$ \\
\hline & \multirow{7}{*}{$\begin{array}{l}\text { Only use for } \\
\text { transfers }\end{array}$} & \multirow{7}{*}{$\begin{array}{l}\text { Stanmore Harold Wood Mobility Grade } 2 \\
\text { (wears a prosthesis only for transfers or to } \\
\text { help with nursing; walks only with a } \\
\text { therapist or carer) }\end{array}$} & \multirow[t]{7}{*}{$1 \mathrm{y}$} & & All participants $\dagger \dagger$ & $4 \%(8 / 196)$ \\
\hline & & & & \multirow{2}{*}{$\begin{array}{l}\text { Level } \\
(0.47)\end{array}$} & Transfemoral & $5.6 \%(5 / 89)$ \\
\hline & & & & & Transtibial & $\begin{array}{l}2.8 \% \\
(3 / 107)\end{array}$ \\
\hline & & & & \multirow{4}{*}{$\begin{array}{l}\text { Age } \\
(0.62)\end{array}$} & Age $<50$ y & $0 \%(0 / 16)$ \\
\hline & & & & & $50-64$ y & $2 \%(1 / 49)$ \\
\hline & & & & & $65-79$ y & $\begin{array}{l}5.2 \% \\
(6 / 115) \\
\end{array}$ \\
\hline & & & & & $>80 \mathrm{y}$ & $6.2 \%(1 / 16)$ \\
\hline & \multirow[t]{7}{*}{$\begin{array}{l}\text { Indoor use only } \\
\text { of prosthesis }\end{array}$} & \multirow{7}{*}{$\begin{array}{l}\text { Stanmore Harold Wood Mobility Grade } 3 \\
\text { (Walks indoors only, using walking aids; } \\
\text { negligible walking outdoors) }\end{array}$} & \multirow[t]{7}{*}{$1 \mathrm{y}$} & & All participants †† & $\begin{array}{l}24.4 \% \\
(48 / 196)\end{array}$ \\
\hline & & & & \multirow[t]{2}{*}{$\begin{array}{l}\text { Level } \\
(0.0076)\end{array}$} & Transfemoral & $\begin{array}{l}33.7 \% \\
(30 / 89) \\
\end{array}$ \\
\hline & & & & & Transtibial & $\begin{array}{l}16.8 \% \\
(18 / 107) \\
\end{array}$ \\
\hline & & & & \multirow{4}{*}{$\begin{array}{l}\text { Age } \\
(0.042)\end{array}$} & Age $<50$ y & $6.2 \%(1 / 16)$ \\
\hline & & & & & $50-64$ y & $\begin{array}{l}14.2 \% \\
(7 / 49) \\
\end{array}$ \\
\hline & & & & & $65-79 y$ & $\begin{array}{l}30.4 \% \\
(35 / 115)\end{array}$ \\
\hline & & & & & $>80 y$ & $\begin{array}{l}31.2 \% \\
(5 / 16) \\
\end{array}$ \\
\hline $\begin{array}{l}\text { Dudkiewicz } 2011 \\
(21303214)\end{array}$ & $\begin{array}{l}\text { Indoor use only } \\
\text { of prosthesis }\end{array}$ & Functional usage at home & nd & & All participants $\S$ & $\begin{array}{l}37.1 \% \\
(75 / 555)^{\star \star}\end{array}$ \\
\hline $\begin{array}{l}\text { Gauthier-Gagnon } \\
1999 \text { (10378500) }\end{array}$ & $\begin{array}{l}\text { Abandoned } \\
\text { prostheses }\end{array}$ & "Nonusers" & $5 y$ & & All participants & $\begin{array}{l}15 \% \\
(\sim 58 / 396)^{\star}\end{array}$ \\
\hline
\end{tabular}




\begin{tabular}{|c|c|c|c|c|c|c|}
\hline Author & Outcome & Outcome Description & Timepoint & $\begin{array}{l}\text { Comparison } \\
\text { (P Value) }\end{array}$ & Subgroup & $\%(n / N)$ \\
\hline \multirow[t]{3}{*}{$\begin{array}{l}\text { Marmann } 1994 \\
\text { (none) }\end{array}$} & \multirow[t]{3}{*}{$\begin{array}{l}\text { Abandoned } \\
\text { prostheses }\end{array}$} & \multirow[t]{3}{*}{ Using wheelchairs (exclusively) } & \multirow[t]{3}{*}{ nd } & & All participants & $\begin{array}{l}22 \% \\
(24 / 110) \\
\end{array}$ \\
\hline & & & & \multirow{2}{*}{$\begin{array}{l}\text { Sides } \\
(0.70)\end{array}$} & Bilateral & $27 \%(3 / 11)$ \\
\hline & & & & & Unilateral & $21 \%(21 / 99)$ \\
\hline \multirow[t]{2}{*}{$\begin{array}{l}\text { Matsen 2000 } \\
(10954097)\end{array}$} & Unable to walk & Not able to walk & $\begin{array}{l}7 \mathrm{y} \text { after } \\
\text { surgery }\end{array}$ & & All participants & $7 \%(10 / 148)$ \\
\hline & $\begin{array}{l}\text { Indoor use only } \\
\text { of prosthesis }\end{array}$ & Could walk only inside the house & $\begin{array}{l}7 \text { y after } \\
\text { surgery }\end{array}$ & & All Participants & $\begin{array}{l}11 \% \\
(16 / 148)\end{array}$ \\
\hline \multirow[t]{10}{*}{$\begin{array}{l}\text { Pohjolainen } 1990 \\
(2235304)\end{array}$} & \multirow[t]{5}{*}{$\begin{array}{l}\text { Abandoned } \\
\text { prostheses }\end{array}$} & \multirow[t]{5}{*}{$\begin{array}{l}\text { Walking without prosthesis or } \\
\text { nonambulatory }\end{array}$} & \multirow[t]{5}{*}{$1 \mathrm{y}$} & & All participants & $\begin{array}{l}10.6 \% \\
(15 / 141)\end{array}$ \\
\hline & & & & \multirow{2}{*}{$\begin{array}{l}\text { Sides } \\
(0.22)\end{array}$} & Bilateral & $0 \%(0 / 16)$ \\
\hline & & & & & Unilateral & $\begin{array}{l}12.0 \% \\
(15 / 125)\end{array}$ \\
\hline & & & & \multirow[t]{2}{*}{\begin{tabular}{|l|} 
Level \\
$(\mathbf{0 . 0 0 3 2 )}$
\end{tabular}} & Transfemoral unilateral & $\begin{array}{l}23.9 \% \\
(11 / 46)\end{array}$ \\
\hline & & & & & Transtibial, unilateral & $5.0 \%(4 / 79)$ \\
\hline & \multirow[t]{5}{*}{$\begin{array}{l}\text { Indoor use only } \\
\text { of prosthesis }\end{array}$} & \multirow[t]{5}{*}{$\begin{array}{l}\text { Walking indoors (including short distances } \\
\text { only), requiring wheelchair outdoors }\end{array}$} & \multirow[t]{5}{*}{$1 \mathrm{y}$} & & All participants & $\begin{array}{l}29 \% \\
(41 / 141)\end{array}$ \\
\hline & & & & \multirow[t]{2}{*}{\begin{tabular}{|l|} 
Sides \\
$(\mathbf{0 . 0 0 0 6 )}$
\end{tabular}} & Bilateral & $\begin{array}{l}68.7 \% \\
(11 / 16)\end{array}$ \\
\hline & & & & & Unilateral & $\begin{array}{l}24.0 \% \\
(30 / 125)\end{array}$ \\
\hline & & & & \multirow[t]{2}{*}{$\begin{array}{l}\text { Level } \\
(1.00)\end{array}$} & Transfemoral unilateral & $\begin{array}{l}23.9 \% \\
(11 / 46)\end{array}$ \\
\hline & & & & & Transtibial, unilateral & $\begin{array}{l}24.1 \% \\
(19 / 79)\end{array}$ \\
\hline
\end{tabular}




\begin{tabular}{|c|c|c|c|c|c|c|}
\hline Author & Outcome & Outcome Description & Timepoint & $\begin{array}{l}\text { Comparison } \\
\text { (P Value) }\end{array}$ & Subgroup & $\%(\mathrm{n} / \mathrm{N})$ \\
\hline \multirow{18}{*}{$\begin{array}{l}\text { Roffman } 2016 \\
\text { (26637652, } \\
25450484)\end{array}$} & \multirow[t]{18}{*}{$\begin{array}{l}\text { Abandoned } \\
\text { prostheses }\end{array}$} & \multirow[t]{18}{*}{ Nonusers } & \multirow[t]{18}{*}{$1 \mathrm{y}$} & & All participants & $\begin{array}{l}17.9 \% \\
(36 / 201)\end{array}$ \\
\hline & & & & $(0.19) \dagger$ & Sex & \\
\hline & & & & $(0.98) \dagger$ & $\begin{array}{l}\text { Age at amputation } \\
\text { (continuous) }\end{array}$ & \\
\hline & & & & $(0.19) \dagger$ & $\begin{array}{l}\text { Home vs. residential } \\
\text { care }\end{array}$ & \\
\hline & & & & $(0.24) \dagger$ & $\begin{array}{l}\text { Charlson Comorbidity } \\
\text { Index (continuous) }\end{array}$ & \\
\hline & & & & $(0.15 / 0.45) \dagger$ & Diabetes, types $1 / 2$ & \\
\hline & & & & $(0.46) \dagger$ & $\begin{array}{l}\text { Peripheral artery } \\
\text { disease }\end{array}$ & \\
\hline & & & & \multirow[t]{2}{*}{$\begin{array}{l}\text { Cardiac } \\
(\mathbf{0 . 0 4}) \dagger, \ddagger\end{array}$} & Cardiac condition & $\begin{array}{l}28.0 \% \\
(21 / 75) \\
\end{array}$ \\
\hline & & & & & No cardiac condition & $\begin{array}{l}11.9 \% \\
(15 / 126)\end{array}$ \\
\hline & & & & $(0.25) \dagger$ & Renal failure & \\
\hline & & & & $(0.98) \dagger$ & Stroke & \\
\hline & & & & $(0.80) \dagger$ & Arthritis & \\
\hline & & & & $(0.055) \dagger$ & $\begin{array}{l}\text { Remaining limb } \\
\text { pathology }\end{array}$ & \\
\hline & & & & $(0.26) \dagger$ & Amputation cause & \\
\hline & & & & \multirow[t]{2}{*}{$\begin{array}{l}\text { Sides } \\
(0.08) \dagger\end{array}$} & Bilateral & $\begin{array}{l}29.0 \% \\
(9 / 31)\end{array}$ \\
\hline & & & & & Unilateral & $\begin{array}{l}15.9 \% \\
(27 / 170)\end{array}$ \\
\hline & & & & \multirow[t]{2}{*}{$\begin{array}{l}\text { Level } \\
(\mathbf{0 . 0 0 1 3}) \dagger, \ddagger\end{array}$} & Transfemoral unilateral & $\begin{array}{l}33.9 \% \\
(21 / 62)\end{array}$ \\
\hline & & & & & $\begin{array}{l}\text { Transtibial or knee, } \\
\text { unilateral }\end{array}$ & $\begin{array}{l}14.1 \% \\
(24 / 170)\end{array}$ \\
\hline
\end{tabular}

Abbreviation: nd = no data.

Note: P values $<0.05$ emphasized in bold font. Blank cells in \% $(\mathrm{n} / \mathrm{N})$ column have no data reported. Where the "subgroup" is All participants, there is no comparison, thus, no $\mathrm{P}$ value and cell is left blank.

*Data not clearly reported.

†Univariable analyses.

$\ddagger$ Bonferroni $\mathrm{P}$ value $=0.0020$

$\S$ Analyzed predictors pertain to time of survey, not to status at time of amputation or prosthesis prescription and are therefore omitted here.

**Most likely 96\% of the participants were at Medicare Functional Classification Level 1 ( K level 1) prior to prescription, suggesting an assessment they would be limited to indoor use.

$\dagger+$ Excluding participants who were not prescribed prostheses, had died, or had bilateral amputations. 


\section{Failure To Maintain Bipedal Ambulation}

No study explicitly reported maintenance of bipedal ambulation, per se. Matsen 2000, a study conducted in the United States, reported, for only the full sample, that 7 percent (10/148) were "not able to walk" at a mean of 7 years after surgery. ${ }^{101}$ The estimated $95 \%$ confidence interval about this estimate is 4 to 12 percent. This study was potentially not fully representative of typical adult amputees in the United States given that half the amputations occurred due to trauma, one-fifth due to infection, and only one-fifth due to vascular disease or diabetes. The study was deemed to be at high risk of bias, primarily due to inclusion of only a small percentage (14\%) of potentially eligible patients being included and for poor description of their outcome. The authors note that their institution predominantly serves individuals in poor health and with a low economic status. In addition, only $14 \%$ of potentially eligible amputees responded to their survey, which required completing a five-page self-assessment packet.

\section{Use of Prostheses Only for Transfers}

Only Davies $2003^{97}$ reported on use of prostheses only for transfers in 196 study participants. Of note, this study is relatively old (published in 2003) and was conducted in the UK. The study reported this outcome for people with unilateral amputations, roughly half of patients had transtibial and half transfemoral amputations. The cause of amputation was vascular or diabetes in 88 percent of the amputees. The study was deemed to be at overall moderate risk of bias. The study had a high percentage of potentially eligible patients who were not included and neither demonstrated that the survey respondents were representative of their populations. It did not perform multivariable analyses to compare subgroups.

Davies 2003, found that at 1 year eight participants (4\%, estimated exact 95\% confidence interval $2 \%$ to $8 \%$ ) used their prostheses only for transfers (and walked only with a therapist or carer). The study found no significant differences in rates of use of prostheses only for transfers based on level of amputation (transtibial vs. transfemoral), or by age. However, the study was greatly underpowered for subgroup analyses.

\section{Use of Prostheses Only Indoors}

Four studies reported on rates of prosthesis use only indoors. ${ }^{97,98,101,102}$ The studies were deemed to be of low (Pohjolainen 1990), moderate (Davies 2003) and high risk of bias (Dudkiewicz 2011, Matsen 2000), primarily due to failure to include a large or demonstrably representative proportion of their eligible population), failure to describe their outcomes poorly (Matsen 2000), and failure to report timing in relation to LLP prescription (Dudkiewicz 2011). Notably only Dudkiewicz 2011 was published relatively recently and only Matsen 2000 was conducted in the United States.

Only Dudkiewicz 2011 reported on participants’ K levels at the start of the study, suggesting that almost all had limited ambulation, possibly K level 1, at the time of prescription. For other studies it is unclear how many, if any people were homebound before LLP prescription. Overall, about 90 percent of included patients had unilateral amputations. In three of the studies, about 80 to 90 percent of patients had vascular etiologies for their amputations, but Matsen 2000 had a less typical population in whom half of amputations were due to trauma, and only about 20 percent were due to diabetes or other dysvascular diseases. The distribution of levels of amputations varied widely across the four studies. 
The four studies reported a wide range of rates of amputees using prostheses only indoors at followup. This likely is indicative of different study eligibility criteria. Matsen 2000 (described above under Maintenance of Bipedal Ambulation) reported a substantially lower rate of use only indoors than other studies at 11 percent. ${ }^{101}$ The major difference between Matsen 2000 and the other three studies (Davies 2003, Dudkiewicz 2011, and Pohjolainen 1990) is that participants in Matsen 2000 were much less likely to have had a vascular or diabetes amputation etiology (21\% vs. 81-88\%). At the other extreme, Dudkiewicz 2011 reported that 37 percent of people used prostheses indoors. However, the study (unclearly) reports that 96 percent of people were at $\mathrm{K}$ level 1 at the time of LLP prescription. This would suggest that 59 percent of the study participants (96 percent at $\mathrm{K} 1$ at initiation minus 37 percent at followup) exceeded their $\mathrm{K}$ level classification and improved to a higher K level. The remaining two studies, which both included mostly people with dysvascular etiologies for their amputations, had similar rates of indoor use only at 1 year followup (24\% and 29\%).

Two of the studies provided within-study subgroup data to allow univariable analyses. Davies 2003 (described above under Use of Prostheses Only for Transfers) found that significantly more people with transfemoral amputations (34\%) were restricted to indoor use than those with transtibial amputations $(17 \%, \mathrm{P}=0.008) .{ }^{97}$ The study also found that restriction to indoor use increased with amputees' age ( $<50$ years $6 \%$, 50-64 years 14\%, $\geq 65$ years 31\%; $\mathrm{P}=0.042$ across age groups). Pohjolainen 1990, in contrast, found no difference in indoor restriction between unilateral transfemoral and transtibial amputees (both 24\%), but it found that almost three times as many people with bilateral amputations (69\%) were restricted to indoor use than those with unilateral amputations $(24 \%, \mathrm{P}=0.0006) .{ }^{102}$

\section{Abandonment of Prostheses}

Six studies reported on rates of prosthesis abandonment (no longer using). ${ }^{96,97,99,100,102-104}$ These included Chen 2008, Davies 2003, Gauthier-Gagnon 1999, Marmann 1994, Pohjolainen 1990, and Roffman 2016. Of note, none of these studies were conducted in the United States and only Roffman 2016 was published relatively recently. Among these studies, between 85 and 100 percent of study participants had unilateral amputations. The patients' amputation levels varied widely across studies, with between 14 and 60 percent with transfemoral amputations and between 40 to 86 percent with transtibial amputations. Among four of five studies that reported amputation etiologies, the large majority (78-94\%) had amputations due to dysvascular conditions; Roffman 2016 had an atypical population in which about one-quarter of amputations were due to dysvascular etiologies and one-quarter due to trauma; 43 percent had infectious etiologies. Studies did not classify participants ambulation capabilities (i.e., K levels). Half the studies were deemed to have moderate risk of bias, primarily due to high or unclear percentage of potentially eligible patients not being included (and no demonstration that included participants were representative of the eligible population). One study was at high risk of bias; Marmann 1994 also did not report when the study was conducted in relation to LLP prescription. Two studies were at low risk of bias.

All but one study were relatively consistent, reporting that between 11 and 22 percent of amputees had stopped using their prosthesis at 1 year in 3 studies and 5 years in one study (15\%). The highest rate of abandonment (22\%) was reported in an older, high risk of bias study from Germany with no information about how long people had been using LLPs. A low risk of bias outlier study from Taiwan (Chen 2008) reported only a single person (0.9\%) who 
abandoned their prosthesis. No clear differences were found across studies based on publication year.

Four of the studies reported subgroup data. Three compared unilateral transfemoral and transtibial amputees, finding that people with transfemoral amputations were more likely to abandon their prostheses (16-34\%) than people with transtibial amputations (5-14\%). Two of the analyses (Pohjolainen 1990, Roffman 2016) were statistically significant ( $\mathrm{P}=0.0013$ and 0.003 ). The statistically nonsignificant study, Davies 2003, ( $\mathrm{P}=0.22)$ was hampered by the small number of bilateral amputees in the study $(n=16)$.

Three studies found no significant difference in likelihood of abandonment between unilateral and bilateral amputees; although their findings were conflicting. Pohjolainen 1990 found many more unilateral amputees (12\%) had abandoned their prostheses than bilateral amputees (0\%), but the difference was nonsignificant $(\mathrm{P}=0.22)$. Roffman 2016 found about twice as many people with bilateral amputation abandoned their prostheses (29\%) than people with unilateral amputation (16\%), but again the difference was nonsignificant $(\mathrm{P}=0.08)$. Marmann 1994 found similar percentages of people abandoned their prostheses among unilateral (21\%) and bilateral $(27 \%)$ amputees $(\mathrm{P}=0.70)$.

Two studies also found no significant differences based on age. Davies 2003 found that the rate of abandonment did rise with age from 0 percent of those under age 50 years to 25 percent of those over age 80 years, but was nonsignificant $(\mathrm{P}=0.18)$. Roffman 2016 found no significant association with age at amputation in linear regression $(\mathrm{P}=0.98)$.

Roffman 2016 reported a large number of subgroup analyses in addition to the analyses described above, although all were univariable for this outcome. ${ }^{104}$ This study included amputees who were more likely to have transtibial amputations and were more likely to have infection or trauma as an amputation etiology, compared to most studies. Most analyses found no significant difference between subgroups (see Table 75). People with a history of a "cardiac condition" were more likely (28\%) to have abandoned their prosthesis than those with no such history (12\%, $\mathrm{P}=0.04$ ); however, the study evaluated many comparisons and after applying the Bonferroni correction (P value threshold 0.002 ), this difference was not statistically significant. The only statistically significant finding was the difference between unilateral transfemoral amputation and transtibial or at-knee amputation, described above.

\section{Major Problems With Prostheses}

None of the studies reported outcomes that could be construed as having "major problems" with their prostheses.

\section{Reasons for Abandoning Prostheses}

Only Roffman 2016, an Australian study, reported reasons for prosthesis nonuse (or other outcomes of interest). ${ }^{104}$ Study participants were able to list multiple reasons for nonuse; however, the reported reasons were summarized in general categories lacking precise definitions. Among the 36 of 201 amputees who abandoned their prostheses, reasons for abandonment included “issues with residual limb” (36\%, n=13), "prosthetic issues” (28\%, n=10), "medical comorbidities” (28\%, $n=10)$, “issues with remaining lower limb” (25\%, $n=9)$, "pain issues” $(25 \%, n=9)$, falls or fear of falling $(14 \%, n=5)$, "high energy cost" $(8 \%, n=3)$, "unmotivated" $(8 \%, n=3)$, unable to don prosthesis $(6 \%, n=2)$, and "balance issues" $(6 \%, n=2)$. 


\section{Summary}

Table 76 summarizes the strength of evidence for each outcome and subgroup analysis with data. For all outcomes of interest, there is low or insufficient strength of evidence because evidence is sparse, most studies were conducted in the 1990s or earlier, and only one of the studies was conducted in the United States, with its unique healthcare system and standards for prosthesis prescription. Also, most studies had methodological limitations, most populations analyzed were often not directly applicable to the Medicare population, some study findings were inconsistent with each other, and few studies clearly reported the outcomes of interest. Subgroup analyses in single studies tended to be underpowered to detect differences, mostly leading to determinations that the evidence was insufficient.

We found a low strength of evidence, based on six studies, that about 11 to 22 percent of lower limb amputees who receive an LLP prescription abandon the prosthesis (stop using it) at about 1 year. These studies are generally representative of people with LLP, in particular older adults and those with dysvascular etiologies. However, only one of the studies was conducted in the United States and it used hospital data as of 1998; most other studies were also old. Three of these studies provide low strength of evidence that people with unilateral transfemoral amputations are about twice as likely to abandon their LLP than those with unilateral transtibial amputations. Potential differences among other subgroups had insufficient evidence due to conflicting results among three studies or only a single, imprecise study with data.

Based primarily on two generally representative studies, there is low strength of evidence that 24 to 29 percent of LLP recipients use their prostheses only indoors at 1 year. There is low strength of evidence about how likely different subgroups of people use their prostheses only indoors, suggesting that people with transfemoral amputations, or who are older, or with bilateral amputations are more likely to be limited to indoor use. There is insufficient evidence about the rates of failure to maintain bipedal ambulation (1 study, $7 \%$ at 7 years), use of prostheses only

for transfer ( 1 study, $4 \%$ at 1 year), and why people abandon their prostheses. No study reported on "major problems" with prostheses. 
Table 76. Key Question 7 evidence profile

\begin{tabular}{|c|c|c|c|c|c|c|c|c|c|c|}
\hline Outcome & Subgroup & $\begin{array}{l}\text { No. Studies } \\
\text { (N) }\end{array}$ & $\begin{array}{l}\text { Study } \\
\text { Limitations }\end{array}$ & Consistency & Precision & $\begin{array}{l}\text { Reporting } \\
\text { Bias }\end{array}$ & Directness* & $\begin{array}{l}\text { Other } \\
\text { Issues }\end{array}$ & Findings & $\begin{array}{l}\text { SoE } \\
\text { Grade }\end{array}$ \\
\hline $\begin{array}{l}\text { Failure to } \\
\text { maintain } \\
\text { bipedal } \\
\text { ambulation }\end{array}$ & $\begin{array}{l}\text { All } \\
\text { participants }\end{array}$ & $1(148)$ & High & NA & Precise & Undetected & Indirect & $\begin{array}{l}\text { Unclear } \\
\text { outcome, } \\
\text { old study }\end{array}$ & $7 \%$ at 7 years & Insufficient \\
\hline \multirow{3}{*}{$\begin{array}{l}\text { Use of } \\
\text { prosthesis } \\
\text { only for } \\
\text { transfers }\end{array}$} & $\begin{array}{l}\text { All } \\
\text { participants }\end{array}$ & 1 (196) & High & NA & Precise & Undetected & Indirect & $\begin{array}{l}\text { Single } \\
25 \text { year } \\
\text { old study }\end{array}$ & $4 \%$ at 1 year & Insufficient \\
\hline & TF vs. TT & 1 (196) & High & NA & Precise & Undetected & Indirect & $\begin{array}{l}\text { see } \\
\text { above }\end{array}$ & $\begin{array}{l}\text { No significant } \\
\text { difference }\end{array}$ & Insufficient \\
\hline & Age & 1 (196) & High & NA & Precise & Undetected & Indirect & $\begin{array}{l}\text { see } \\
\text { above }\end{array}$ & $\begin{array}{l}\text { Nonsignificantly } \\
\text { higher limited } \\
\text { used with older } \\
\text { age }\end{array}$ & Insufficient \\
\hline \multirow[t]{4}{*}{$\begin{array}{l}\text { Use of } \\
\text { prosthesis } \\
\text { only indoors }\end{array}$} & $\begin{array}{l}\text { All } \\
\text { participants }\end{array}$ & $4(1040)$ & Medium & Inconsistent & Imprecise & Undetected & Direct & $\begin{array}{l}\text { Mostly } \\
\text { old, non- } \\
\text { U.S. }\end{array}$ & $\begin{array}{l}24-29 \% \text { at } 1 \\
\text { year }\end{array}$ & Low \\
\hline & TF vs. TT & 2 (337) & High & Inconsistent & Precise & Undetected & Direct & $\begin{array}{l}\text { see } \\
\text { above }\end{array}$ & $\begin{array}{l}\text { Twice as many } \\
\text { TF use only } \\
\text { indoors ( } 1 \\
\text { study, } \\
\mathrm{P}=0.008) \text { ), no } \\
\text { difference ( } 1 \\
\text { study) }\end{array}$ & Insufficient \\
\hline & Age & 1 (196) & High & NA & Precise & Undetected & Direct & $\begin{array}{l}\text { see } \\
\text { above }\end{array}$ & $\begin{array}{l}\text { Older more } \\
\text { likely to use } \\
\text { only indoors } \\
(\mathrm{P}=0.042)\end{array}$ & Insufficient \\
\hline & $\begin{array}{l}\text { Bilateral } \\
\text { vs. } \\
\text { unilateral }\end{array}$ & $1(141)$ & High & NA & Precise & Undetected & Direct & $\begin{array}{l}\text { see } \\
\text { above }\end{array}$ & $\begin{array}{l}\text { Bilateral more } \\
\text { than twice as } \\
\text { likely to use } \\
\text { only indoors } \\
(P=0.0006)\end{array}$ & Insufficient \\
\hline
\end{tabular}




\begin{tabular}{|c|c|c|c|c|c|c|c|c|c|c|}
\hline Outcome & Subgroup & $\begin{array}{l}\text { No. Studies } \\
\text { (N) }\end{array}$ & $\begin{array}{l}\text { Study } \\
\text { Limitations }\end{array}$ & Consistency & Precision & $\begin{array}{l}\text { Reporting } \\
\text { Bias }\end{array}$ & Directness* & $\begin{array}{l}\text { Other } \\
\text { Issues }\end{array}$ & Findings & $\begin{array}{l}\text { SoE } \\
\text { Grade }\end{array}$ \\
\hline \multirow[t]{5}{*}{$\begin{array}{l}\text { Abandonment } \\
\text { of prosthesis }\end{array}$} & $\begin{array}{l}\text { All } \\
\text { participants }\end{array}$ & $6(1153)$ & Medium & Consistent $\dagger$ & Precise & Undetected & Direct & $\begin{array}{l}\text { Mostly } \\
\text { old, non- } \\
\text { U.S. }\end{array}$ & $\begin{array}{l}11-22 \% \text { at } 1 \\
\text { year (or } \\
\text { undefined) } \dagger\end{array}$ & Low \\
\hline & TF vs. TT & $3(538)$ & High & Consistent & Precise & Undetected & Direct & $\begin{array}{l}\text { see } \\
\text { above }\end{array}$ & $\begin{array}{l}\text { TF more likely } \\
\text { to abandon } \\
\text { prosthesis than } \\
\text { TT }\end{array}$ & Low \\
\hline & $\begin{array}{l}\text { Bilateral } \\
\text { vs. } \\
\text { unilateral }\end{array}$ & $3(452)$ & High & Inconsistent & Precise & Undetected & Direct & $\begin{array}{l}\text { see } \\
\text { above }\end{array}$ & $\begin{array}{l}\text { Nonsignificant, } \\
\text { but conflicting } \\
\text { directionality }\end{array}$ & Insufficient \\
\hline & Age & $2(397)$ & High & Inconsistent & Precise & Undetected & Direct & $\begin{array}{l}\text { see } \\
\text { above }\end{array}$ & $\begin{array}{l}\text { Older } \\
\text { nonsignificantly } \\
\text { more likely to } \\
\text { abandon (1 } \\
\text { study), no } \\
\text { difference in } \\
\text { age (1 study) }\end{array}$ & Insufficient \\
\hline & Multiple & $1(201)$ & High & NA & Precise & Undetected & Indirect & $\begin{array}{l}\text { Multiple } \\
\text { testing }\end{array}$ & $\begin{array}{l}\text { No significant } \\
\text { associations }\end{array}$ & Insufficient \\
\hline $\begin{array}{l}\text { Major } \\
\text { problems with } \\
\text { prosthesis }\end{array}$ & $\begin{array}{l}\text { All } \\
\text { participants }\end{array}$ & 0 & $\mathrm{NA}$ & NA & NA & NA & $\mathrm{NA}$ & NA & None & Insufficient \\
\hline $\begin{array}{l}\text { Reasons for } \\
\text { poor } \\
\text { outcomes }\end{array}$ & $\begin{array}{l}\text { All } \\
\text { participants }\end{array}$ & 1 (201) & High & NA & Imprecise & Undetected & Indirect & $\begin{array}{l}\text { Single } \\
\text { non-U.S. } \\
\text { study }\end{array}$ & $\begin{array}{l}\text { Various general } \\
\text { categories of } \\
\text { reasons } \\
\text { reported }\end{array}$ & Insufficient \\
\hline
\end{tabular}

Abbreviations: NA = not applicable, RoB = risk of bias, SoE = strength of evidence, TF = transfemoral amputation, TT = transtibial amputation.

*Representative of either (or both) older adults ( $\geq 65$ years old) or those with dysvascular amputations.

†Except that one outlier study from Taiwan found that only $0.9 \%$ of study participants abandoned their prostheses at a mean of 28 months. 


\section{Discussion}

A large number of studies have evaluated lower limb prostheses (LLP) for people with major lower limb amputations. We found over 100 studies that compared at least two LLP components or configurations that reported ambulatory, functional, or other patient-centered outcomes. We found many additional studies that evaluated only biomechanical properties of the components (which this review does not evaluate) and likely several hundred studies that evaluate just a single component. However, we found few studies that evaluated (or at least provided data to allow us to evaluate) heterogeneity of treatment effect. Overall, the evidence is currently sparse and fails to adequately address whether different subgroups of amputees are more likely or less likely to benefit from given specific LLP components or configurations. We also found generally sparse evidence regarding patient expectations, patient satisfaction with care, and long-term outcomes.

From the amputee's and the clinician's perspective, among the most important questions is which LLP configuration (comprised of which prosthesis components) would best enable maximal health, function, and quality of life for a given individual? Given the large number of component types (knee, foot/ankle, socket, liner, etc.) and the range of features for each of these, the process of determining which LLP component or configuration is best for individuals is quite complex. However, the majority of the evidence addresses the question of which LLP component or configuration maximizes ambulation and function in the average patient, as opposed to which LLP component or configuration of components would best suit the needs of a given individual. In other words, few studies address the issue of heterogeneity of treatment effect. Suboptimal matching of patients to LLPs may unnecessarily increase health care utilization, prevent attainment of maximal patient function, and defer realization of improved quality of life attainable with an appropriate prosthesis, and unnecessarily increase health care expenditures.

Further limiting and complicating the evidence base, there are a very large number of instruments that are used in the surgical, rehabilitation, and prosthesis literature to assess overall patient function, predict future outcomes, and measure various aspects of mobility , function, quality of life issues, and other patient-centered outcomes. While some of the scales and items used in these studies were developed specifically to assess lower limb amputees, many were designed for other populations. Furthermore, many of the measures used in LLP research studies have either not been evaluated for validity in the population of interest or were created ad hoc for each study. Our review found that among the small number of comparative studies that provided heterogeneity of treatment effects data, fewer than half used both predictor and outcome measures with evidence of test validity. However, the studies were highly variable in terms of who was analyzed, how instruments were validated, etc. We, therefore, recommend development of a consensus set of core, validated and reliable instruments to be used in future research.

However, it will remain important that researchers assess whether the instruments have sufficient evidence of validity for their needs and have been evaluated in a sample of people representative to their study population.

We found evidence to enable the evaluation of the psychometric properties of 50 instruments (many containing evaluated subscales and items) in people with lower limb amputations. Many of the studies that evaluated instrument psychometric properties, however, were conducted in samples of participants who were arguably different than typical lower limb amputees with Medicare insurance, many of whom have dysvascular conditions including diabetes and peripheral vascular disease, or who are older and are, thus, more typical of lower limb amputees 
with Medicare insurance. We found that 39 of the 50 instruments have been evaluated in studies deemed generalizable to the Medicare population. Seventeen of these instruments, as a whole or in part, to have evidence supporting both reliability and validity. However, we recommend that researchers who are using this report to determine which instruments to use for their own studies also review the primary studies to determine whether the instruments have been sufficiently validated for their needs, are responsive to clinically important change, and have been evaluated in a sample of people representative of their study population.

Notably, no study has evaluated psychometric properties of the Medicare Functional Classification Level (MFCL or K level) system. Furthermore, the reader is reminded that lack of evidence regarding the psychometric properties of instruments does not imply that these measures are not valid or reliable, only that they have not been (adequately) evaluated. Standards for psychometric testing have changed over the years, so older instruments, evaluated by earlier studies, may not have psychometric property evaluations more commonly reported now.

These instruments address many aspects of patients' function, ambulation, and quality of life. To improve the accuracy, interpretability, and, importantly, the reproducibility of the literature, we strongly encourage future researchers to maximize the use of instruments with evidence of validity and reliability in the population of interest. Where such measures are lacking, the validity of the instruments being used as pivotal outcomes should be examined before use in future studies. We also encourage journal editors to require use of validated and reliable instruments when appropriate and feasible. However, we recognize that it will remain common that unvalidated measures may be appropriate in select instances (e.g., when measures to assess a particular trait or construct do not exist).

\section{Summary of Evidence}

- This review focuses on narrow research questions and does not attempt to address many of the "big picture" topics that may also be of interest to many readers.

o The review summarizes the evidence supporting instrument psychometrics for all lower limb amputees, with a subfocus on studies likely generalizable to the Medicare population.

o The review provides a gross assessment of validity, reliability, and other psychometric properties of instruments. It does not evaluate the strength of the evidence in support of those properties, rather it dichotomizes the evidence as present or absent. The review provides overall evidence summaries by instrument, but does not provide head-to-head comparisons of measurement properties of instruments.

o The review evaluates the small subset of comparative studies that provide data to allow evaluation of heterogeneity of treatment effect of specific LLP components. It does not address the overall comparative effectiveness of different LLP components or configurations.

o The review focuses on clinical and patient-centered outcomes. Despite the importance of biomechanical measures for the development and evaluation of LLP devices and components, this review focuses on outcomes that are important to people receiving LLPs and their healthcare providers.

o The review addresses satisfaction with the process of accessing an LLP. Satisfaction with an LLP and overall satisfaction are covered only within the scope of Key Question 4 about heterogeneity of treatment effect.

o The review evaluates specific long-term outcomes related to continued use of LLPs. 
- In practice, it is difficult to cleanly make the distinction between assessment techniques (to evaluate function etc. prior to LLP prescription), prediction tools (to predict likelihood of a future outcome, such as ambulation with a prosthesis), and outcome measures (to determine actual or change in ambulation, function, etc.). Many specific measures can be used for at all stages of evaluation of function.

- Among the 50 instruments for which we found assessments of psychometric properties, we found that (for the total instrument or for one or more of their subscales or items), 41 have evidence of test validity, 35 have evidence of reliability, and 28 have evidence of both test validity and reliability. However, floor or ceiling effects were common. Responsiveness, minimal detectable change, and minimal (clinical) important difference have relatively infrequently been assessed.

- Restricting to studies deemed to be generally generalizable to the Medicare population, 39 instruments have been evaluated. Of these, 29 have evidence of validity, in whole or in part, and 23 have evidence of reliability. In total, 17 instruments have been found to have evidence of both reliability and validity, in whole or in part.

- We found 14 studies that compared LLP components and provided data to compare differences in effect among different subgroups (i.e., heterogeneity of treatment effect). However, most were small, underpowered studies, reported only participant-level data, were nonrandomized, and did not evaluate heterogeneity of treatment effect. These studies mostly evaluated knee components and mostly included younger men at K2 or K3 level, with unilateral transfemoral amputations with traumatic etiologies; populations not highly applicable to the Medicare population. Only one study had a mean age greater than 65 years; only two other studies included a majority of participants with dysvascular conditions. In addition, only eight of the studies reported on both validated predictors (or basic patient characteristic subgroups) and validated outcomes. Only a single study, using nonvalidated outcomes, attempted to comprehensively evaluate whether any or a set of patient characteristics predicted which component would yield best function for individual patients. Of note, this review did not directly address the question of average relative effect of different components; thus 89 comparative studies that did not provide subgroup analyses or patient-level data were excluded. In summary,

o Studies that used validated measures mostly evaluated knee components and were conducted in mostly younger men, at K2 or K3 level, unilateral transfemoral amputations due to trauma. These studies did not identify participant characteristics that predict which lower limb amputees would benefit most or least from a given component. There is low strength of evidence that evaluated patient characteristics do not predict which patients would benefit most from a given LLP component based on validated outcomes. However, it may be more accurate to conclude that the evidence is currently sparse and fails to adequately address whether different subgroups of amputees are more likely or less likely to benefit from given specific components.

o Overall, studies did not identify participant characteristics that predict which lower limb amputees would benefit most or least from a given LLP component or configuration, regardless of whether validated measures were used. There is low strength of evidence that evaluated patient characteristics do not predict which patients would benefit most or least from a given LLP component or configuration. However, it may again be more accurate to conclude that the evidence is currently 
sparse and fails to adequately address whether different subgroups of amputees are more likely or less likely to benefit from given specific components.

o One large study of highly selected, mostly younger men with mostly trauma-related amputations, evaluated multivariable prediction models to determine who would benefit most from a microprocessor knee based on nonvalidated outcomes. The study concluded that they failed to identify participant characteristics that predict whether individual patients would have better function with a microprocessor or mechanical knee; however, they did report numerous patient characteristics that were statistically significantly associated with differential effects between knee components. The study had several methodological limitations, including that it compared a specific microprocessor knee with a variety of other prosthetic knees (mostly including another microprocessor knee) in people selected based on the judgment of a prosthetist that they were likely to benefit from the test knee. The study, overall, provides insufficient additional evidence regarding who would benefit most or least from a microprocessor knee.

- We found no evidence regarding how study participants' preprescription expectations of ambulation align with their functional outcomes.

- Two studies provided low strength of evidence that people are satisfied with their encounters with their prosthetists. This conclusion is applicable to people who have Medicare or Medicaid as their primary payers, based principally on one of the two studies.

- Regarding long-term followup, eight eligible studies of at least 100 participants with followup of at least 6 months after LLP prescription (or 1 year after amputation) reported outcomes of interest. However, only one of these studies was conducted in the United States and most (including the U.S. study) were published more than 10 years ago.

o There is insufficient evidence regarding failure to maintain bipedal ambulation.

0 There is insufficient evidence regarding use of prostheses only for transfers.

0 There is low strength of evidence that 24 to 29 percent of people use their LLP only indoors at 1 to 7 years after prescription.

- There is insufficient evidence to assess differences in indoor-only use in different subpopulations.

0 There is low strength of evidence that 11 to 22 percent of people have abandoned their prostheses (no longer used them) at 1 year.

- There is low strength of evidence that people with transfemoral amputations are more likely to abandon their prostheses than those with transtibial prostheses, but still the majority of amputees continue to use their prostheses, regardless of level of amputation

- There is insufficient evidence to assess differences in abandonment in other subgroups of patients

o There is insufficient evidence regarding reported major problems with LLP

o There is insufficient evidence regarding reasons why people with LLP have poor outcomes (in terms of use of prostheses). 


\section{Evidence Limitations}

Despite the large literature base for research on LLP, relatively few studies address the questions of interest for this review, particularly related to heterogeneity of treatment effect, patient expectations and satisfaction, and long-term use of LLP after prescription.

The applicability of these studies to the general population of people with LLPs may be somewhat limited, as the studies mostly evaluated prosthetic knees and were mostly conducted in younger men with unilateral transfemoral amputations due to trauma. Furthermore, implicitly or explicitly, most of these studies included only people who were deemed (by their prosthetists) to be likely to benefit from their new (generally more complex) device. This may bias these studies toward finding no difference between subgroups of individuals in relative effect of the compared components since everyone was more likely than average to do better with the new component. In all of these studies, all patients used all evaluated LLPs. However, most of the studies that analyzed heterogeneity of treatment effect or provided data to allow subgroup analyses were observational and did not control for underlying differences during use of one component or the other. For example, studies did not describe or control for rehabilitation, training, or acclimation with each of the components. In particular, in the pre-post studies where everyone switched from an old (simpler) to a new (more complex) LLP over a period of time, one would expect that patient characteristics such as age, strength, and mobility will also have changed. Analyses that controlled for differences in these and other potential confounders before versus after switching could account for some of the biases inherent in these studies. These are important issues for the underlying analyses comparing the components; although, the effect of this limitation of the comparative studies on assessing heterogeneity of treatment effect is unclear. If the bias is similar in different subgroups (e.g., the new component is favored in part due to bias equally among transtibial and transfemoral amputees), then the bias would cancel out when assessing differences in relative effect (of the two components) between the two subgroups (transtibial versus transfemoral). As discussed, the single large study with regression modeling is likely highly biased and has methodological concerns, so it is insufficient to provide evidence to address the Key Question. Overall, the studies suffered from the same methodological quality limitations described by Hafner and Sawers in their secondary analysis of a systematic review of microprocessor and nonmicroprocessor knees. ${ }^{105}$ Namely, issues related to the complexity and variability of specific components used by participants; failure to use a specific, well-defined comparator component; information on how well the prosthetics were fit to the users or how adequately they were trained in use of each device; variability in experience with prior devices; lack of outcome assessor blinding; small sample size; possible bias in study eligibility criteria; and use of nonvalidated predictors and instruments.

Another limitation of the studies evaluating heterogeneity of treatment effect is that all studies evaluated only a limited set of patient characteristics such as age, amputation level, or amputation etiology. None analyzed differences in treatment effect by subgroups based on any assessment techniques, prediction tools, or outcome measures. In addition, studies of LLPs and other such devices will always have the difficulty that each LLP is matched to best fit and work for each individual. In most studies there is no "standard" intervention, but instead each LLP configuration is adjusted to best suit each individual. This inherent variability and complexity of the intervention (the LLP) will always confound analyses aiming to explain heterogeneity of treatment effects.

No or very few studies were found to address questions about patient expectations and satisfaction with care. 
Few studies met eligibility criteria regarding long-term LLP use after prescription. The primary reason why potentially relevant studies were excluded was that they evaluated long-term ambulation and function after surgery including patients who never received an LLP. We also restricted the studies to those with at least 100 people to allow for some degree of precision in estimates. Smaller studies may have provided additional data, but their estimates would have been less precise (and subgroup analyses in these studies would be even less likely to be statistically significant due to lack of power). In addition, the eligible studies were almost all conducted outside the United States, in countries with very different healthcare systems and with different criteria for determining who is eligible for what type of prosthesis. The eligible studies were also mostly more than an decade old. Among the eligible studies, the most common outcome of interest was LLP abandonment (or lack of use). Studies generally failed to report on indoor-only use of LLPs and other outcomes. Studies did not report on people's K levels or functional abilities at the time of LLP prescription or provide subgroup analyses based on $\mathrm{K}$ levels. Therefore, it is unknown to what degree the estimates of limited use varies by people's underlying functional abilities. Studies also mostly did not report information on why people limited or stopped their use of LLPs.

\section{Analysis Limitations}

Assessment of reliability, validity, and other psychometric properties is open to interpretation. By the strictest definition, an instrument would be considered to be valid and appropriate for use in a given study only if there is good evidence regarding the multiple aspects of validity for the specific population, conditions, and outcomes under evaluation. That an instrument demonstrates convergent validity with a given related measure does not imply that it also can distinguish differences related to subgroups of patients or an intervention effect. That an instrument has predictive validity regarding one outcome, such as future successful use of an LLP, does not imply predictive validity for other ambulatory outcomes, such as speed of walking or community ambulation. Despite these challenges, and the lack of a universal gold standard for determining absolute validity, we took a liberal approach in our literature synthesis. We considered an instrument to have evidence of validity if there was evidence of any type of validity (other than face/content). We, thus, categorized the evidence and dichotomized data so that instruments were classified as valid or not. We made no attempt to rank or compare instruments. Some instruments may be better than others (e.g., because they have less error associated with repeat administration or they are more responsive to change), but the relative importance of these issues will be study-dependent. The overall logic for our approach was that the question of interest for this general review of all instruments used in LLP research is whether an instrument has been validated for any purpose. The actual appropriateness of an instrument for use in a specific study may vary based on the study question, eligibility criteria, and hypotheses.

As discussed above, the distinction between assessment techniques, prediction tools, and outcome measures is arguably somewhat artificial in actual application. Many of the instruments can be used for any of these contexts. Readers may disagree with how the instruments were categorized across Key Questions 1 to 3.

This review attempts to particularly highlight the evidence applicable to the Medicare population. This is a challenge to do and requires judgment, which many may disagree with. Very few of the studies were limited to participants over the age of 65 years. None was limited to people with disabilities, at least in terms of what would allow them to qualify for Medicare. 
Extremely few studies reported the type of medical insurance study participants had (although, many of the studies were conducted in Europe and other countries other than United States). We categorized studies to be likely generalizable to the Medicare population based on having a relatively large percentage of participants with dysvascular etiologies for their lower limb amputations (also including diabetes) and/or likely including about half or more of participants over age 65 years. This system, though, is imperfect.

Although not a limitation, per se, it should be noted that this review makes no attempt to make conclusions about the overall effects of different LLP components or configurations. Key Question 4 addressed whether there is evidence regarding heterogeneity of treatment effects, particularly with validated measures, in the field of LLP research. The evidence base addressing heterogeneity of treatment effect, particularly with validated measures, is quite small. Only a single study attempted to truly address the question at hand, but did not use a validated outcome measure, and has methodological concerns.

\section{Future Research Recommendations}

\section{General Recommendations}

Future research is needed to adequately address most of the questions in this review. While numerous instruments have evidence of validity, at least in part, additional studies are needed to confirm their psychometric properties and to better understand specific aspects of validity. Additional studies are needed that compare responsiveness of validated instruments to specific prosthesis interventions. Some instruments, subscales, or specific items may be better choices because they are more responsive to the types of changes provided by specific components. For microprocessor knees, for example, instruments that include items related to walking on uneven surfaces, stairs, balance confidence, stumbles and/or falls, would likely be more responsive than instruments that focus on specific physical performance such as distance walked or speed of ambulation. These latter instruments may be more responsive in assessment of foot, ankle, and powered componentry.

As is the case for research in all clinical domains, studies should fully describe the participants' demographic information and other salient characteristics. For studies of LLPs, these include amputation level and etiology, baseline K level or equivalent, living situation, and other descriptions of people's functional status. In addition, at least for studies conducted in the United States, it would be informative to report people's insurance coverage, since insurance status may have important implications for access to prostheses and rehabilitation services.

Well-conducted studies, using validated predictors and outcomes, are needed to evaluate which LLP components and configurations would be most effective to achieve successful outcomes for which patients. To as great an extent as possible, studies should assess validated, patient-centered outcomes related to ambulation, function, quality of life, and related outcomes. Continued use of ad hoc and nonvalidated measures greatly limits the interpretability, usability, representativeness, and overall value of the studies. Ideally, studies should use a core set of validated, patient-centered outcomes that incorporate the perspectives of patient and other key stakeholders (a core outcome set); in addition, studies that measure other specific outcomes, as needed (a core outcome set). This would allow comparability across studies and pooling of study findings (e.g., meta-analysis). A large body of individual, "one-off” analyses that use unique outcomes will provide a much weaker evidence base than a smaller body of comparable studies. Noncomparable studies will continue to be more likely to be of little use to prosthetists, treating 
physicians, patients, policymakers, and other decisionmakers, and therefore will more likely be ignored. Creation of such a core outcome set would likely require a consensus development process among a range of stakeholders. Similarly, researchers should emphasize trying to include a well-representative sample of patients with LLPs, so that their studies will be applicable to the population at large.

\section{Studies of Heterogeneity of Treatment Effect}

Particularly for a clinical field as varied as lower limb prostheses, there is a great need to understand how best to choose among the myriad LLP component choices for an individual patient. However, currently the evidence is quite sparse related to differences in relative effect of different prostheses in different groups of people. Lower limb amputees are clearly a highly heterogeneous group with distinct needs dependent upon age, etiology of limb loss, level of amputation, comorbidities and health status, postoperative stage, and rehabilitation status. Better understanding of which component would be best for which patient could both maximize individual's ambulation, function, and quality of life and minimize waste due to either abandonment or due to "over-prescription," where people are given LLPs with specific capabilities that they cannot benefit from or "under-prescription," where people are given LLPs without capabilities they could benefit from. However, the evidence does not provide high, or even moderate, strength of evidence to support what patient (or other) characteristics could be used to accurately match patients with LLPs. Therefore, many more studies are needed to adequately assess heterogeneity of treatment effect. The goal of these studies should not be to simply find subgroup differences, but instead should be to predict which set of characteristics best predicts which component is best for which patient. This will require generally larger studies to allow for meaningful regression analyses. As with all studies, these should take care to include a representative and unbiased sample of lower limb amputees. Eligibility criteria and analytic methods should be employed to maximize participation and inclusion in final models. Robust analytic methods and complete and transparent reporting are essential. Appropriate, and clear, measures of model performance should be used and reported. We recommend the following specific metrics, although others may be more appropriate based on specific analyses conducted. $^{93,94,106}$ The most useful metrics of global performance are the (root) mean square error or Brier score. Less useful metrics are global statistics of fit, and the various pseudo- $\mathrm{R}^{2}$ metrics. These global metrics are difficult to interpret correctly, particularly if there is class imbalance when a small percentage of participants experience a given outcome. Metrics of discrimination should also be reported, including the receiver operating characteristics (ROC) curve, area under the ROC curve (AUC), and accuracy measures (e.g., sensitivity and specificity). It is also important to report analyses of calibration. Assessments of calibration are numerous, but the most common is a simple calibration plot that orders observations in percentiles of increased predicted risk, and plots the observed percent of responders in each percentile. Conclusions about predictive performance require a thorough evaluation of the performance itself.

We recommend that consideration be given to reanalyze the dataset evaluated by either or both of the studies by Hahn et al. (2015 and 2016) to address many of the noted concerns. ${ }^{78,83}$ However, the value of these datasets may still be highly limited, as they appear to have relatively few comparisons between microprocessor and mechanical knees, but instead, at least in the case of Hahn 2016, are comparisons of different microprocessor knees, a more focused question that may be of less generalizable interest. Nevertheless, ideally the largest, least biased sample of 
participants available should be included, minimizing exclusions based on strict eligibility criteria and analytic methods. The selected outcome (or outcomes) should be clearly stated and defined; it should clearly represent a difference in effect between the two components and should occur in a low enough percentage of participants to avoid class imbalance. Ideally, it should also be validated. Full reporting of the model and its predictive performance are necessary. However, if the available sample for reanalysis remains highly biased and it is in fact the case that the large majority of participants performed better with the microprocessor knee in part because they were preselected based on their high likelihood of succeeding with the new knee, then a reanalysis may not be warranted as it would still represent a biased, nonrepresentative group of lower limb amputees. Study conclusions would still not be applicable to the average person considering which type of knee prosthesis to use.

\section{Studies on Expectations, Satisfaction With Services, and Long-Term Followup}

Studies on the relationship between patient expectations and outcomes are needed, as are additional studies of patient satisfaction with prosthetic services (and how to improve prosthetic services to improve satisfaction).

Additional large, long-term follow-up studies are needed to understand problems and limitations people are having with their prostheses, rates of abandonment or limited use, and reasons for these limitations and abandonment. These studies should clearly include unbiased samples of people who have received LLPs. Currently many studies include only a subset of these people (e.g., those with a current LLP prescription) or also include amputees who never received an LLP. Explanations of the prevalence of abandonment and limited use of LLPs and of why this occurs can yield further research in how to minimize underuse of LLP and resultant limited ambulation.

\section{Conclusions and Clinical Implications}

Numerous instruments that assess ambulation, function, quality of life, and other patientcentered outcomes exist for people with lower limb amputations and LLPs. Researchers should minimize the use of nonvalidated or ad hoc measures. Those who wish to use new or previously unvalidated instruments should validate these measures before using them. Researchers with an interest in assessing LLPs for the Medicare population would be best served to focus on those instruments with evidence of reliability and validity for this population or validate the measures in this population. The majority of the evidence on LLPs addresses the question of which LLP component or configuration maximizes ambulation and function in the average patient, as opposed to which LLP would best suit the needs of a given individual. In other words, few studies address the issue of heterogeneity of treatment effect. A small evidence base does not provide data to guide LLP selection for a specific patient to maximize their ambulation, function, and quality of life or to minimize abandonment or limited use. However, this does not imply that the evidence suggests patient characteristics cannot effectively predict which patients would benefit most or least from one or another specific component; only that the current evidence does not support use of any given predictor. There is low strength of evidence that patients are generally satisfied with the prosthetic services they receive. Further high-quality research is needed to better assess the psychometric properties of instruments (whether assessment 
techniques, prediction tools, or outcome measures) and to answer the Key Questions addressed in this systematic review. 


\section{References}

1. Boyle JP, Thompson TJ, Gregg EW, et al. Projection of the year 2050 burden of diabetes in the US adult population: dynamic modeling of incidence, mortality, and prediabetes prevalence. Popul Health Metr. 2010 Oct 22;8:29. doi: 10.1186/1478-7954-8-29. PMID: 20969750.

2. Ziegler-Graham K, MacKenzie EJ, Ephraim PL, et al. Estimating the prevalence of limb loss in the United States: 2005 to 2050. Arch Phys Med Rehabil. 2008 Mar;89(3):422-9. doi: 10.1016/j.apmr.2007.11.005. PMID: 18295618.

3. Etter K, Borgia M, Resnik L. Prescription and repair rates of prosthetic limbs in the VA healthcare system: implications for national prosthetic parity. Disabil Rehabil Assist Technol. 2014 May 22:1-8. doi: 10.3109/17483107.2014.921246. PMID: 24852068.

4. Resnik L, Borgia M. Predicting prosthetic prescription after major lower-limb amputation. J Rehabil Res Dev. 2015;52(6):641-52. doi: 10.1682/jrrd.2014.09.0216. PMID: 26562228.

5. Borrenpohl D, Kaluf B, Major MJ. Survey of U.S. Practitioners on the Validity of the Medicare Functional Classification Level System and Utility of Clinical Outcome Measures for Aiding K-Level Assignment. Arch Phys Med Rehabil. 2016 Jul;97(7):1053-63. doi: 10.1016/j.apmr.2016.02.024. PMID: 27016261.

6. AHRQ Methods for Effective Health Care. Methods Guide for Effectiveness and Comparative Effectiveness Reviews. Rockville (MD): Agency for Healthcare Research and Quality (US); 2011.

7. Dite W, Connor HJ, Curtis HC. Clinical identification of multiple fall risk early after unilateral transtibial amputation. Arch Phys Med Rehabil. 2007 Jan;88(1):109-14. doi: 10.1016/j.apmr.2006.10.015. PMID: 17207685.

8. Naschitz JE, Lenger R. Why traumatic leg amputees are at increased risk for cardiovascular diseases. Qjm. 2008 Apr;101(4):251-9. doi: 10.1093/qjmed/hcm131. PMID: 18281705.

9. Frugoli BA, Guion KW, Joyner BA, et al. Cardiovascular Disease Risk Factors in an Amputee Population. JPO: Journal of Prosthetics and Orthotics. 2000;12(3):80-7.
10. Affairs DoV. Preservation-Amputation Care And Treatment (PACT) Program. VHA Directive.96007.

11. Robbins JM, Strauss G, Aron D, et al. Mortality rates and diabetic foot ulcers: is it time to communicate mortality risk to patients with diabetic foot ulceration? J Am Podiatr Med Assoc. 2008 Nov-Dec;98(6):489-93. PMID: 19017860.

12. Dillingham TR, Pezzin LE, Shore AD. Reamputation, mortality, and health care costs among persons with dysvascular lower-limb amputations. Arch Phys Med Rehabil. 2005 Mar;86(3):480-6. doi: 10.1016/j.apmr.2004.06.072. PMID: 15759232.

13. Dobson A, El-Gamil A, Shimer M, et al. Economic Value of Prosthetic Services Among Medicare Beneficiaries: A Claims-Based Retrospective Cohort Study. Mil Med. 2016 Feb;181(2 Suppl):18-24. doi: 10.7205/milmed-d15-00545. PMID: 26835740.

14. Goodney PP, Tarulli M, Faerber AE, et al. Fifteen-year trends in lower limb amputation, revascularization, and preventive measures among medicare patients. JAMA Surg. 2015 Jan;150(1):84-6. doi: 10.1001/jamasurg.2014.1007. PMID: 25409197.

15. Condie E, Scott H, Treweek S. Lower limb prosthetic outcome measures: a review of the literature 1995 to 2005. JPO: Journal of Prosthetics and Orthotics. 2006;18(6):P13-P45.

16. Local Coverage Determination (LCD): Lower Limb Prostheses (L33787). Centers for Medicare and Medicaid Services. .

https://www.cms.gov/medicare-coveragedatabase/details/lcddetails.aspx?LCDId $=33787 \&$ ContrId $=140 \&$ ver $=9$ \&ContrVer $=2 \&$ CntrctrSelected $=140 * 2 \&$ Cntrctr $=$ $140 \&$ name $=$ CGS + Administrators $\% 2 c+$ LLC $+(180$ 03\%2c+DME+MAC)\&DocType=Active\&LCntrc $\underline{\operatorname{tr}=140 * 2 \& b c=A g A C A A Q A A A A A A A} \% 3 \mathrm{~d} \% 3 \mathrm{~d}$ \& and http://www.oandp.org/olc/course_extended_conte nt.asp?frmCourseId=ACA066EC-443A-4822822C-89BC1CBD684E\&frmTermId=k-levels.

17. Gailey RS, Roach KE, Applegate EB, et al. The amputee mobility predictor: an instrument to assess determinants of the lower-limb amputee's ability to ambulate. Arch Phys Med Rehabil. 2002 May;83(5):613-27. PMID: 11994800. 
18. World Bank Country and Lending Groups. Washington, DC: The World Bank; 2018. https://datahelpdesk.worldbank.org/knowledgebas e/articles/906519. Accessed on May 14, 2018.

19. Jerosch-Herold C. An evidence-based approach to choosing outcome measures: a checklist for the critical appraisal of validity, reliability and responsiveness studies. British Journal of Occupational Therapy. 2005;68(8):347-53.

20. Resnik L, Borgia M, Silver B. Measuring Community Integration in Persons With Limb Trauma and Amputation: A Systematic Review. Arch Phys Med Rehabil. 2017 Mar;98(3):56180.e8. doi: 10.1016/j.apmr.2016.08.463. PMID: 27612941.

21. Tennant A, Conaghan PG. The Rasch measurement model in rheumatology: what is it and why use it? When should it be applied, and what should one look for in a Rasch paper? Arthritis Rheum. 2007 Dec 15;57(8):1358-62. doi: 10.1002/art.23108. PMID: 18050173.

22. Terwee CB, Bot SD, de Boer MR, et al. Quality criteria were proposed for measurement properties of health status questionnaires. J Clin Epidemiol. 2007 Jan;60(1):34-42. doi: 10.1016/j.jclinepi.2006.03.012. PMID: 17161752.

23. Veenhof C, Bijlsma JW, van den Ende CH, et al. Psychometric evaluation of osteoarthritis questionnaires: a systematic review of the literature. Arthritis Rheum. 2006 Jun 15;55(3):480-92. doi: 10.1002/art.22001. PMID: 16739188.

24. Wright V. Prosthetic outcome measures for use with upper limb amputees: A systematic review of the peer-reviewed literature, 1970 to 2009. JPO: Journal of Prosthetics and Orthotics. 2009;21(9):P3-P63.

25. Higgins JP, Altman DG, Gotzsche PC, et al. The Cochrane Collaboration's tool for assessing risk of bias in randomised trials. Bmj. 2011;343:d5928. doi: 10.1136/bmj.d5928. PMID: 22008217.

26. Wells GAS, B.;O'Connell, D.;Peterson, J.; Welch, V.; Losos, M.; Tugwell, P. The Newcastle-Ottawa Scale (NOS) for assessing the quality of nonrandomised studies in meta-analyses. http://www.ohri.ca/programs/clinical_epidemiolo gy/oxford.asp.
27. Berkman ND, Lohr KN, Ansari MT, et al. Grading the strength of a body of evidence when assessing health care interventions: an EPC update. J Clin Epidemiol. 2015 Nov;68(11):131224. doi: 10.1016/j.jclinepi.2014.11.023. PMID: 25721570 .

28. Eijk MS, van der Linde H, Buijck BI, et al. Geriatric rehabilitation of lower limb amputees: a multicenter study. Disabil Rehabil.

2012;34(2):145-50. doi: 10.3109/09638288.2011.591888. PMID: 21958418.

29. Gremeaux V, Damak S, Troisgros O, et al. Selecting a test for the clinical assessment of balance and walking capacity at the definitive fitting state after unilateral amputation: a comparative study. Prosthet Orthot Int. 2012 Dec;36(4):415-22. doi: 10.1177/0309364612437904. PMID: 22389424.

30. Spaan MH, Vrieling AH, van de Berg $\mathrm{P}$, et al. Predicting mobility outcome in lower limb amputees with motor ability tests used in early rehabilitation. Prosthet Orthot Int. 2017 Apr;41(2):171-7. doi: 10.1177/0309364616670397. PMID: 27770064.

31. Brooks D, Hunter JP, Parsons J, et al. Reliability of the two-minute walk test in individuals with transtibial amputation. Arch Phys Med Rehabil. 2002 Nov;83(11):1562-5. PMID: 12422326.

32. Brooks D, Parsons J, Hunter JP, et al. The 2minute walk test as a measure of functional improvement in persons with lower limb amputation. Arch Phys Med Rehabil. 2001 Oct;82(10):1478-83. doi: 10.1053/apmr.2001.25153. PMID: 11588757.

33. Major MJ, Fatone S, Roth EJ. Validity and reliability of the Berg Balance Scale for community-dwelling persons with lower-limb amputation. Arch Phys Med Rehabil. 2013 Nov;94(11):2194-202. doi: 10.1016/j.apmr.2013.07.002. PMID: 23856150.

34. Miller WC, Deathe AB, Speechley M. Psychometric properties of the Activities-specific Balance Confidence Scale among individuals with a lower-limb amputation. Arch Phys Med Rehabil. 2003 May;84(5):656-61. PMID: 12736877. 
35. Newton KL, Evans C, Osmotherly PG. The Timed Up and Go and Two-Minute Walk Test: Exploration of a method for establishing normative values for established lower limb prosthetic users. European Journal of Physiotherapy. 2016;18(3):161-6.

36. Reid L, Thomson P, Besemann M, et al. Going places: Does the two-minute walk test predict the six-minute walk test in lower extremity amputees? J Rehabil Med. 2015 Mar;47(3):25661. doi: 10.2340/16501977-1916. PMID: 25588644.

37. Resnik L, Borgia M. Reliability of outcome measures for people with lower-limb amputations: distinguishing true change from statistical error. Phys Ther. 2011 Apr;91(4):55565. doi: 10.2522/ptj.20100287. PMID: 21310896.

38. Wong CK, Gibbs W, Chen ES. Use of the Houghton Scale to Classify Community and Household Walking Ability in People With Lower-Limb Amputation: Criterion-Related Validity. Arch Phys Med Rehabil. 2016 Jul;97(7):1130-6. doi: 10.1016/j.apmr.2016.01.022. PMID: 26874230.

39. Panesar BS, Morrison P, Hunter J. A comparison of three measures of progress in early lower limb amputee rehabilitation. Clin Rehabil. 2001 Apr;15(2):157-71. PMID: 11330761.

40. Hafner BJ, Gaunaurd IA, Morgan SJ, et al. Construct Validity of the Prosthetic Limb Users Survey of Mobility (PLUS-M) in Adults With Lower Limb Amputation. Arch Phys Med Rehabil. 2017 Feb;98(2):277-85. doi: 10.1016/j.apmr.2016.07.026. PMID: 27590443.

41. Hafner BJ, Morgan SJ, Askew RL, et al. Psychometric evaluation of self-report outcome measures for prosthetic applications. J Rehabil Res Dev. 2016;53(6):797-812. doi: 10.1682/jrrd.2015.12.0228. PMID: 28273329.

42. Sakakibara BM, Miller WC, Backman CL. Rasch analyses of the Activities-specific Balance Confidence Scale with individuals 50 years and older with lower-limb amputations. Arch Phys Med Rehabil. 2011 Aug;92(8):1257-63. doi: 10.1016/j.apmr.2011.03.013. PMID: 21704978.

43. Theeven P, Hemmen B, Stevens C, et al. Feasibility of a new concept for measuring actual functional performance in daily life of transfemoral amputees. J Rehabil Med. 2010 Sep;42(8):744-51. doi: 10.2340/16501977-0591. PMID: 20809056.
44. Norvell DC, Williams RM, Turner AP, et al. The development and validation of a novel outcome measure to quantify mobility in the dysvascular lower extremity amputee: the amputee single item mobility measure. Clin Rehabil. 2016 Sep;30(9):878-89. doi: 10.1177/0269215516644308. PMID: 27496697.

45. de Laat FA, Rommers GM, Geertzen JH, et al. Construct validity and test-retest reliability of the climbing stairs questionnaire in lower-limb amputees. Arch Phys Med Rehabil. 2010 Sep;91(9):1396-401. doi: 10.1016/j.apmr.2010.06.013. PMID: 20801258.

46. Fisher K, Hanspal RS, Marks L. Return to work after lower limb amputation. Int J Rehabil Res. 2003 Mar;26(1):51-6. doi: 10.1097/01.mrr.0000054806.81886.d7. PMID: 12601268.

47. Miller WC, Deathe AB, Harris J. Measurement properties of the Frenchay Activities Index among individuals with a lower limb amputation. Clin Rehabil. 2004 Jun;18(4):414-22. doi: 10.1191/0269215504cr728oa. PMID: 15180125.

48. Franchignoni F, Orlandini D, Ferriero G, et al. Reliability, validity, and responsiveness of the locomotor capabilities index in adults with lowerlimb amputation undergoing prosthetic training. Arch Phys Med Rehabil. 2004 May;85(5):743-8. PMID: 15129398.

49. Leung EC, Rush PJ, Devlin M. Predicting prosthetic rehabilitation outcome in lower limb amputee patients with the functional independence measure. Arch Phys Med Rehabil. 1996 Jun;77(6):605-8. PMID: 8831480.

50. Devlin M, Pauley T, Head K, et al. Houghton Scale of prosthetic use in people with lowerextremity amputations: Reliability, validity, and responsiveness to change. Arch Phys Med Rehabil. 2004 Aug;85(8):1339-44. doi: 10.1016/j.apmr.2003.09.025. PMID: 15295762.

51. Miller WC, Deathe AB, Speechley M. Lower extremity prosthetic mobility: a comparison of 3 self-report scales. Arch Phys Med Rehabil. 2001 Oct;82(10):1432-40. doi: 10.1053/apmr.2001.25987. PMID: 11588750.

52. Deathe AB, Miller WC. The L test of functional mobility: measurement properties of a modified version of the timed "up \& go" test designed for people with lower-limb amputations. Phys Ther. 2005 Jul;85(7):626-35. PMID: 15982169. 
53. Rushton PW, Miller WC, Deathe AB. Minimal clinically important difference of the $\mathrm{L}$ Test for individuals with lower limb amputation: A pilot study. Prosthet Orthot Int. 2015 Dec;39(6):470-6. doi: 10.1177/0309364614545418. PMID: 25134533.

54. Callaghan BG, Sockalingam S, Treweek SP, et al. A post-discharge functional outcome measure for lower limb amputees: test-retest reliability with trans-tibial amputees. Prosthet Orthot Int. 2002 Aug;26(2):113-9. doi: 10.1080/03093640208726633. PMID: 12227445.

55. Cyril JK. Characterizing prosthetic device use and satisfaction, and evaluating measures of physical function among individuals with lower extremity amputation secondary to trauma: Johns Hopkins University; 2002.

56. de Laat FA, Rommers GM, Geertzen JH, et al. Construct validity and test-retest reliability of the questionnaire rising and sitting down in lowerlimb amputees. Arch Phys Med Rehabil. 2011 Aug;92(8):1305-10. doi: 10.1016/j.apmr.2011.03.016. PMID: 21807151.

57. Franchignoni F, Giordano A, Ferriero G, et al. Rasch analysis of the Locomotor Capabilities Index-5 in people with lower limb amputation. Prosthet Orthot Int. 2007 Dec;31(4):394-404. doi: 10.1080/03093640701253952. PMID: 18050010.

58. Gauthier-Gagnon C, Grise MC. Prosthetic profile of the amputee questionnaire: validity and reliability. Arch Phys Med Rehabil. 1994 Dec;75(12):1309-14. PMID: 7993169.

59. Ramstrand N, Nilsson KA. Validation of a patient activity monitor to quantify ambulatory activity in an amputee population. Prosthet Orthot Int. 2007 Jun;31(2):157-66. doi: 10.1080/03093640600988617. PMID: 17520493.

60. Legro MW, Reiber GD, Smith DG, et al. Prosthesis evaluation questionnaire for persons with lower limb amputations: assessing prosthesis-related quality of life. Arch Phys Med Rehabil. 1998 Aug;79(8):931-8. PMID: 9710165.

61. Franchignoni F, Giordano A, Ferriero G, et al. Measuring mobility in people with lower limb amputation: Rasch analysis of the mobility section of the prosthesis evaluation questionnaire. J Rehabil Med. 2007 Mar;39(2):138-44. doi: 10.2340/16501977-0033. PMID: 17351696.
62. Callaghan BG, Condie ME. A post-discharge quality of life outcome measure for lower limb amputees: test-retest reliability and construct validity. Clin Rehabil. 2003 Dec;17(8):858-64. doi: 10.1191/0269215503cr689oa. PMID: 14682557.

63. Amtmann D, Bamer AM, Kim J, et al. A comparison of computerized adaptive testing and fixed-length short forms for the Prosthetic Limb Users Survey of Mobility (PLUS-M(TM)). Prosthet Orthot Int. 2017 Sep

1:309364617728118. doi: 10.1177/0309364617728118. PMID: 28866959.

64. Amtmann D, Morgan SJ, Kim J, et al. Healthrelated profiles of people with lower limb loss. Arch Phys Med Rehabil. 2015 Aug;96(8):147483. doi: 10.1016/j.apmr.2015.03.024. PMID: 25917819.

65. Hart DL. Orthotics and Prosthetics National Office Outcomes Tool (OPOT): Initial Reliability and Validity Assessment for Lower Extremity Prosthetics. JPO: Journal of Prosthetics and Orthotics. 1999;11(4):101-11.

66. Hagberg K, Branemark R, Hagg O. Questionnaire for Persons with a Transfemoral Amputation (QTFA): initial validity and reliability of a new outcome measure. J Rehabil Res Dev. 2004 Sep;41(5):695-706. PMID: 15558399.

67. Franchignoni F, Brunelli S, Orlandini D, et al. Is the Rivermead Mobility Index a suitable outcome measure in lower limb amputees?--A psychometric validation study. J Rehabil Med. 2003 May;35(3):141-4. PMID: 12809197.

68. Ryall NH, Eyres SB, Neumann VC, et al. Is the Rivermead Mobility Index appropriate to measure mobility in lower limb amputees? Disabil Rehabil. 2003 Feb 04;25(3):143-53. doi: 10.1080/0963828021000024951. PMID: 12648004.

69. Condie ME, McFadyen AK, Treweek S, et al. The trans-femoral fitting predictor: a functional measure to predict prosthetic fitting in transfemoral amputees--validity and reliability. Arch Phys Med Rehabil. 2011 Aug;92(8):1293-7. doi: 10.1016/j.apmr.2011.03.021. PMID: 21807149.

70. Hanspal RS, Fisher K, Nieveen R. Prosthetic socket fit comfort score. Disabil Rehabil. 2003 Nov 18;25(22):1278-80. doi: 10.1080/09638280310001603983. PMID: 14617445. 
71. de Laat FA, Rommers GM, Geertzen JH, et al. Construct validity and test-retest reliability of the walking questionnaire in people with a lower limb amputation. Archives of physical medicine and rehabilitation. 2012;93(6):983-9.

72. Ryall NH, Eyres SB, Neumann VC, et al. The SIGAM mobility grades: a new populationspecific measure for lower limb amputees. Disabil Rehabil. 2003 Aug 05;25(15):833-44. doi: 10.1080/0963828021000056460. PMID: 12851094.

73. Gallagher P, Maclachlan M. The Trinity Amputation and Prosthesis Experience Scales and quality of life in people with lower-limb amputation. Arch Phys Med Rehabil. 2004 May;85(5):730-6. PMID: 15129396.

74. Gallagher P, MacLachlan M. Development and psychometric evaluation of the Trinity Amputation and Prosthesis Experience Scales (TAPES). Rehabilitation Psychology. 2000;45(2):130.

75. Gallagher P, Franchignoni F, Giordano A, et al. Trinity amputation and prosthesis experience scales: a psychometric assessment using classical test theory and rasch analysis. Am J Phys Med Rehabil. 2010 Jun;89(6):487-96. doi: 10.1097/PHM.0b013e3181dd8cf1. PMID: 20489393.

76. Clemens SM, Gailey RS, Bennett CL, et al. The Component Timed-Up-and-Go test: the utility and psychometric properties of using a mobile application to determine prosthetic mobility in people with lower limb amputations. Clin Rehabil. 2017 Aug 1:269215517728324. doi: 10.1177/0269215517728324. PMID: 28862042.

77. Schoppen T, Boonstra A, Groothoff JW, et al. The Timed "up and go" test: reliability and validity in persons with unilateral lower limb amputation. Arch Phys Med Rehabil. 1999 Jul;80(7):825-8. PMID: 10414769.

78. Hahn A, Lang M. Effects of mobility grade, age, and etiology on functional benefit and safety of subjects evaluated in more than 1200 C-Leg trial fittings in Germany. JPO: Journal of Prosthetics and Orthotics. 2015;27(3):86-94.

79. Alaranta H, Lempinen VM, Haavisto E, et al. Subjective benefits of energy storing prostheses. Prosthet Orthot Int. 1994 Aug;18(2):92-7. doi: 10.3109/03093649409164390. PMID: 7991366.
80. De Asha AR, Munjal R, Kulkarni J, et al. Impact on the biomechanics of overground gait of using an 'Echelon' hydraulic ankle-foot device in unilateral trans-tibial and trans-femoral amputees. Clin Biomech (Bristol, Avon). 2014 Aug;29(7):728-34. doi: 10.1016/j.clinbiomech.2014.06.009. PMID: 24997811.

81. Gard SA, Konz RJ. The effect of a shockabsorbing pylon on the gait of persons with unilateral transtibial amputation. J Rehabil Res Dev. 2003 Mar-Apr;40(2):109-24. PMID: 15077637.

82. Hafner BJ, Smith DG. Differences in function and safety between Medicare Functional Classification Level-2 and -3 transfemoral amputees and influence of prosthetic knee joint control. J Rehabil Res Dev. 2009;46(3):417-33. PMID: 19675993.

83. Hahn A, Lang M, Stuckart C. Analysis of clinically important factors on the performance of advanced hydraulic, microprocessor-controlled exo-prosthetic knee joints based on 899 trial fittings. Medicine (Baltimore). 2016 Nov;95(45):e5386. doi: 10.1097/md.0000000000005386. PMID: 27828871.

84. Isakov E, Susak Z, Becker E. Energy expenditure and cardiac response in above-knee amputees while using prostheses with open and locked knee mechanisms. Scand J Rehabil Med Suppl. 1985;12:108-11. PMID: 3868034.

85. Kahle JT, Highsmith MJ, Hubbard SL. Comparison of nonmicroprocessor knee mechanism versus C-Leg on Prosthesis Evaluation Questionnaire, stumbles, falls, walking tests, stair descent, and knee preference. J Rehabil Res Dev. 2008;45(1):1-14. PMID: 18566922.

86. Theeven P, Hemmen B, Rings F, et al. Functional added value of microprocessor-controlled knee joints in daily life performance of Medicare Functional Classification Level-2 amputees. J Rehabil Med. 2011 Oct;43(10):906-15. doi: 10.2340/16501977-0861. PMID: 21947182.

87. Theeven PJ, Hemmen B, Geers RP, et al. Influence of advanced prosthetic knee joints on perceived performance and everyday life activity level of low-functional persons with a transfemoral amputation or knee disarticulation. J Rehabil Med. 2012 May;44(5):454-61. doi: 10.2340/16501977-0969. PMID: 22549656. 
88. Traballesi M, Delussu AS, Averna T, et al. Energy cost of walking in transfemoral amputees: Comparison between Marlo Anatomical Socket and Ischial Containment Socket. Gait Posture. 2011 Jun;34(2):270-4. doi: 10.1016/j.gaitpost.2011.05.012. PMID: 21684165.

89. Silver-Thorn B GC. Functional Stability of Transfemoral Amputee Gait Using the 3R80 and Total Knee 2000 Prosthetic Knee Units. JPO Journal of Prosthetics and Orthotics. 2009;21(1).

90. Hasenoehrl T, Schmalz T, Windhager R, et al. Safety and function of a prototype microprocessor-controlled knee prosthesis for low active transfemoral amputees switching from a mechanic knee prosthesis: a pilot study. Disabil Rehabil Assist Technol. 2018 Feb;13(2):157-65. doi: 10.1080/17483107.2017.1300344. PMID: 28399722.

91. Moore R. Patient Evaluation of a Novel Prosthetic Foot with Hydraulic Ankle Aimed at Persons with Amputation with Lower Activity Levels. JPO: Journal of Prosthetics and Orthotics. 2017;29(1):44-7.

92. Wong CK, Rheinstein J, Stern MA. Benefits for Adults with Transfemoral Amputations and Peripheral Artery Disease Using Microprocessor Compared with Nonmicroprocessor Prosthetic Knees. Am J Phys Med Rehabil. 2015 Oct;94(10):804-10. doi: 10.1097/phm.0000000000000265. PMID: 25768067.

93. Steyerberg EW. Clinical prediction models: a practical approach to development, validation, and updating: Springer Science \& Business Media; 2008.

94. Steyerberg EW, Vickers AJ, Cook NR, et al. Assessing the performance of prediction models: a framework for traditional and novel measures. Epidemiology. 2010 Jan;21(1):128-38. doi: 10.1097/EDE.0b013e3181c30fb2. PMID: 20010215.

95. Pezzin LE, Dillingham TR, Mackenzie EJ, et al. Use and satisfaction with prosthetic limb devices and related services. Arch Phys Med Rehabil. 2004 May;85(5):723-9. PMID: 15129395.

96. Chen MC, Lee SS, Hsieh YL, et al. Influencing factors of outcome after lower-limb amputation: a five-year review in a plastic surgical department. Ann Plast Surg. 2008 Sep;61(3):314-8. doi: 10.1097/SAP.0b013e3181571379. PMID: 18724135.
97. Davies B, Datta D. Mobility outcome following unilateral lower limb amputation. Prosthet Orthot Int. 2003 Dec;27(3):186-90. doi: 10.1080/03093640308726681. PMID: 14727699.

98. Dudkiewicz I, Pisarenko B, Herman A, et al. Satisfaction rates amongst elderly amputees provided with a static prosthetic foot. Disabil Rehabil. 2011;33(21-22):1963-7. doi: 10.3109/09638288.2011.553705. PMID: 21303214.

99. Gauthier-Gagnon C, Grise MC, Potvin D. Enabling factors related to prosthetic use by people with transtibial and transfemoral amputation. Arch Phys Med Rehabil. 1999 Jun;80(6):706-13. PMID: 10378500.

100. Marmann C. Der geriatrisch Amputierte nach Entlassung aus erfolgreicher stationärer Rehabilitation; 1991.

101. Matsen SL, Malchow D, Matsen FA, 3rd. Correlations with patients' perspectives of the result of lower-extremity amputation. J Bone Joint Surg Am. 2000 Aug;82-a(8):1089-95. PMID: 10954097.

102. Pohjolainen T, Alaranta H, Karkkainen M. Prosthetic use and functional and social outcome following major lower limb amputation. Prosthet Orthot Int. 1990 Aug;14(2):75-9. doi: 10.3109/03093649009080326. PMID: 2235304.

103. Roffman CE, Buchanan J, Allison GT. Predictors of non-use of prostheses by people with lower limb amputation after discharge from rehabilitation: development and validation of clinical prediction rules. J Physiother. 2014 Dec;60(4):224-31. doi: 10.1016/j.jphys.2014.09.003. PMID: 25450484.

104. Roffman CE, Buchanan J, Allison GT. Locomotor Performance During Rehabilitation of People With Lower Limb Amputation and Prosthetic Nonuse 12 Months After Discharge. Phys Ther. 2016 Jul;96(7):985-94. doi: 10.2522/ptj.20140164. PMID: 26637652.

105. Hafner BJ, Sawers AB. Issues affecting the level of prosthetics research evidence: Secondary analysis of a systematic review. Prosthet Orthot Int. 2016 Feb;40(1):31-43. doi: 10.1177/0309364614550264. PMID: 25249383. 
106. Vickers AJ, Cronin AM. Everything you always wanted to know about evaluating prediction models (but were too afraid to ask). Urology. 2010 Dec;76(6):1298-301. doi:

10.1016/j.urology.2010.06.019. PMID: 21030068. 


\section{Abbreviations and Acronyms}

2MWT:

6MWT:

AAS:

ABC:

ADAPT:

AHRQ:

AMP:

AMPnoPRO:

AMPPRO:

AMPSIMM:

BA LOA:

BBS:

Bi:

BMI:

CAT:

CCTR:

CDSR:

CSQ:

Dysvasc:

FAC:

FAI:

FIM:

FSST:

IES:

IPD:

IQR:

K level:

KQ:

L Test:

LCD:

LCI:

LEMOCOT:

LHS:

LLP:

MC:

MCS:

MDC:

MFCL:

MID:

nd:

NQ-ACGC:

OMT:

OPCS:

OPOT:
2 Minute Walk Test

6 Minute Walk Test

Amputee Activity Survey

Activities-specific Balance Confidence

Assessment of Daily Activity Performance in Transfemoral Amputees

Agency for Healthcare Research and Quality

Amputee Mobility Predictor

Amputee Mobility Predictor without use of a prosthesis

Amputee Mobility Predictor with use of a prosthesis

Amputee Single Item Mobility Measure

Bland-Altman limits of agreement

Berg Balance Scale

bilateral amputation

body mass index

computer adaptive test

Cochrane Central Trials Registry

Cochrane Database of Systematic Reviews

Climbing Stairs Questionnaire

dysvascular disease

Functional Ambulation Categories

Frenchay Activities Index

Functional Independence Measure

Four Square Step Test

Impact of Events Scale

individual patient data

interquartile range

Medicare Functional Classification Level

Key Question

L Test of Functional Mobility

Local Coverage Determination

Locomotor Capabilities Index

Lower-Extremity Motor Coordination Test

London Handicap Scale

Lower limb prosthesis

Medicare

Mental Component Score

minimal detectable change

Medicare Functional Classification Level

minimum (clinical) important difference

no data/not reported

Quality of Life in Neurological Conditions - Applied

Cognition/General Concerns

Outcome Measurement Tool

Office of Population Censuses and Surveys Scale

Orthotics and Prosthetics National Office Outcomes Tool 
OPUS:

PCS:

PEQ:

PEQ-MS:

PFI:

PGI:

PLUS-M:

PMID:

PPA:

PROMIS:

PROS:

PSFS:

Q-TFA:

RMI:

RNL:

RSQ:

SAT-PRO:

SCS:

SF-12/SF-36/SF-36V:

SIGAM:

SIP:

SIP-PD:

Sn:

SNF:

SoE:

Sp:

TAPES:

TF:

TFP:

TMMS:

TT:

TUG:

TWT:

Uni:

WHOQOL-BREF:

WQ:
Orthotics Prosthetics Users Survey

Physical Component Score

Prosthesis Evaluation Questionnaire

Prosthesis Evaluation Questionnaire-Mobility Scale

Physical Function Index

Patient Generated Index

Prosthetic Limb Users Survey of Mobility

PubMed identifier

Prosthetic Profile of the Amputee

Patient-Reported Outcomes Measurement Information System

Prosthetist's Perception of Client's Ambulatory Abilities

Patient-Specific Functional Scale

Questionnaire for Persons with a Transfemoral Amputation

Rivermead Mobility Index

Reintegration to Normal Living Index

Rising and Sitting Down Questionnaire

Satisfaction with Prosthesis Questionnaire

Socket Comfort Score

Short Form Health Surveys 12, 36, and 36V

Special Interest Group of Amputation Medicine

Sickness Impact Profile

Sickness Impact Profile-Physical Dimension

sensitivity

skilled nursing facility

Strength of Evidence

specificity

Trinity Amputation and Prosthesis Experience Scales

transfemoral (above the knee) amputation

Transfemoral Fitting Predictor

Trait Meta Mood Scale

transtibial (below the knee) amputation

Timed Up and Go

Timed Walk Test

unilateral amputation

World Health Organization Quality-of-Life Scale - Brief Version

Walking Questionnaire 


\title{
Appendix A. Search Strategy
}

\author{
PUBMED \\ ("Recovery of Function"[Mesh] \\ OR "functional assessment" \\ OR "functional status" \\ OR “Mobility Limitation”[Mesh] \\ OR function \\ OR mobility \\ OR ambulation \\ OR stair* \\ OR locomotion \\ OR "treatment outcome" \\ OR walking \\ OR (abandonment and prosthe*) \\ OR (rejection* and prosthe*) \\ OR Quality of Life \\ OR Health Status) \\ AND \\ ("Artificial limb" \\ OR “Artificial limbs” \\ OR "Artificial Limbs"[Mesh] \\ OR prosthe* [text term] \\ OR Artificial Limbs) \\ AND
}

("lower limb”[Mesh] OR "leg”[Mesh] or lower extremity or foot or ankle or tibia or fibula or femur or thigh or "Membrum inferius" or leg or lower limb)

NOT

("Arthroplasty"[Mesh] or "Prosthesis Implantation"[Mesh] or "Vascular Surgical Procedures"[Mesh] or "Osteotomy"[Mesh]) OR Aneurysm*[tiab] OR Aorta*[tiab] OR Aortic*[tiab] OR Arthroplast*[tiab] OR “avascular necrosis”[tiab] OR Bypass*[tiab] OR Cement*[tiab] OR endoprosth*[tiab] OR fixat*[tiab] OR fracture*[tiab] OR Graft*[tiab] OR Implant*[tiab] OR total hip replacement*[tiab] OR total knee replacement*[tiab] OR ((Orthot*[tiab] OR Orthos*[tiab]) NOT (amput*[tiab] OR prosth*[tiab])) OR "addresses"[pt] OR "autobiography"[pt] OR "bibliography"[pt] OR "biography"[pt] OR "case reports"[pt] OR "comment"[pt] OR "congresses"[pt] OR "dictionary"[pt] OR "directory"[pt] OR "editorial"[pt] OR "festschrift"[pt] OR "government publications"[pt] OR "historical article"[pt] OR "interview"[pt] OR "lectures"[pt] OR "legal cases"[pt] OR "legislation"[pt] OR "letter"[pt] OR "news"[pt] OR "newspaper article"[pt] OR "patient education handout"[pt] OR "periodical index"[pt] OR "comment on" OR ("Animals"[Mesh] NOT "Humans"[Mesh]) OR rats[tw] OR cow[tw] OR cows[tw] OR chicken*[tw] OR horse[tw] OR horses[tw] OR mice[tw] OR mouse[tw] OR bovine[tw] OR sheep OR ovine OR murine

PUBMED: 2757 on 11/30/16 


\section{EMBASE}

\#39 \#31 NOT \#38

\#38 \#32 OR \#33 OR \#34 OR \#35 OR \#36 OR \#37

561,702

\#37 orthot* OR orthos* NOT (amput* OR prosth*)

79,418

\#36 aneurysm* OR aorta* OR aortic* OR arthroplast* OR 'avascular necrosis' OR bypass* OR cement* OR endoprosth* OR fixat* OR fracture* OR graft* OR implant* OR total AND hip AND replacement* OR totalAND knee AND replacement*

\#35 'osteotomy'/exp

25,573

37,235

\#34 'vascular surgery'/exp

384,960

\#33 'prosthesis implantation'/exp

2,151

\#32 'arthroplasty'/exp

63,011

\#31 \#24 AND \#27 AND \#30

6,991

\#30 \#28 OR \#29

377,525

\#29 lower AND extremity OR foot OR ankle OR tibia OR fibula OR femur OR thigh OR 'membrum inferius' OR leg OR lower AND limb

83,740

\#28 'leg'/exp OR 'leg'

341,178

\#27 \#25 OR \#26

287,601

\#26 artificial AND limb* OR prosthe*

287,569

\#25 'limb prosthesis'/exp OR 'limb prosthesis'

7,731

\#24 \#17 OR \#18 OR \#19 OR \#20 OR \#21 OR \#22 OR \#23

$4,097,920$

\#23 quality AND of AND life OR health AND status

474,604

\#22 rejection* AND prosthe*

\#21 abandonment AND prosthe*

1,092

\#20 function OR mobility OR ambulation OR stair* OR locomotion OR 'treatment outcome' OR walking

\#19 'walking difficulty'/exp OR 'walking difficulty' OR 'mobility'/exp OR mobility AND limitation

$3,662,274$

2,685

\#18 'functional assessment'/exp OR 'functional assessment' OR

'functional status'/exp OR 'functional status'

\#17 'convalescence'/exp OR 'convalescence' OR 'recovery'/exp OR recovery AND ('function'/exp OR function)

103,884

92,026 


\section{Cochrane}

Recovery of Function OR functional assessment OR functional status OR Mobility Limitation OR function OR mobility OR ambulation OR stair OR stairs OR locomotion OR treatment outcome OR walking OR (abandonment and prosthesis) OR (rejection and prosthesis) OR Quality of Life OR Health Status

AND

Artificial limb or Artificial limbs or prosthesis or prosthetic

AND

lower limb OR leg or lower extremity or foot or ankle or tibia or fibula or femur or thigh or "Membrum inferius"

NOT (Arthroplasty or Prosthesis Implantation or Vascular Surgical Procedures or Osteotomy OR Aneurysm OR Aorta OR Aortic OR Arthroplast OR avascular necrosis OR Bypass OR Cement OR endoprosth OR fixat OR fracture OR Graft OR Implant OR total hip replacement OR total knee replacement)

\section{CINAHL/PSYCInfo}

( Recovery of Function OR functional assessment OR functional status OR Mobility Limitation OR function OR mobility OR ambulation OR stair OR stairs OR locomotion OR treatment outcome OR walking OR (abandonment and prosthesis) OR (rejection and prosthesis) OR Quality of Life OR Health Status )

AND

(Artificial limb or Artificial limbs or prosthesis or prosthetic )

AND

(lower limb OR leg or lower extremity or foot or ankle or tibia or fibula or femur or thigh or "Membrum inferius") 


\section{Appendix B. Excluded Studies}

Adamczyk PG, Roland M, Hahn ME. Sensitivity of biomechanical outcomes to independent variations of hindfoot and forefoot stiffness in foot prostheses. Hum Mov Sci. PMID: 28499159.

KQ 4-7: No outcome or analysis of interest

Agrawal V and Gailey R and O'Toole C and Gaunaurd I and Finnieston A. Influence of gait training and prosthetic foot category on external work symmetry during unilateral transtibial amputee gait. Prosthetics and orthotics international. PMID: 23364890.

KQ 4-7: No outcome or analysis of interest

Agrawal V and Gailey RS and Gaunaurd IA and O'Toole C and Finnieston A and Tolchin R. Comparison of four different categories of prosthetic feet during ramp ambulation in unilateral transtibial amputees. Prosthet Orthot Int. PMID: 24925671.

KQ 4-7: No outcome or analysis of interest

Agrawal V and Gailey RS and Gaunaurd IA and O'Toole C and Finnieston AA. Comparison between microprocessor-controlled ankle/foot and conventional prosthetic feet during stair negotiation in people with unilateral transtibial amputation. J Rehabil Res Dev. PMID: 24301431.

KQ 4-7: No outcome or analysis of interest

Agrawal Veena R and Skrabek Ryan Q and Embil John $\mathrm{M}$ and Gross Patrick and Trepman Elly. Effect of Socioeconomic and Health Factors on Prosthetic Use after Lower-Limb Amputation. Journal of Prosthetics \& Orthotics (JPO).

KQ 7: $\mathbf{N}<100$

Agrawal Vibhor Ramchandra. A comparison of gait kinetics between prosthetic feet during functional activities -- Symmetry in External Work (SEW) approach.

KQ 1-3: $\mathbf{N}<20$

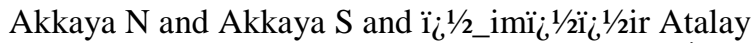

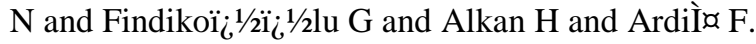
Demographic and clinical features of our lower limb amputee patients. Journal of Rheumatology and Medical Rehabilitation.

Low resource country
Aksnes, L. H., Bauer, H. C. F., Jebsen, N. L., Follerås, G., Allert, C., Haugen, G. S. and Hall, K. S. Limb-sparing surgery preserves more function than amputation: a Scandinavian Sarcoma Group study of 118 patients. Journal of Bone \& Joint Surgery, British Volume. PMID: 18539673.

\section{KQ 1-3: Not validation}

Albert MV and Deeny S and McCarthy C and Valentin $\mathrm{J}$ and Jayaraman A. Monitoring daily function in persons with transfemoral amputations using a commercial activity monitor: a feasibility study. Pm r. PMID: 24954402.

KQ 1-3: $\mathbf{N}<20$

Albert MV and McCarthy C and Valentin J and Herrmann $\mathrm{M}$ and Kording $\mathrm{K}$ and Jayaraman A. Monitoring functional capability of individuals with lower limb amputations using mobile phones. PLoS One. PMID: 23750254.

KQ 1-3: $\mathbf{N}<20$

Ali S and Abu Osman NA and Arifin N and Gholizadeh $\mathrm{H}$ and Abd Razak NA and Wan Abas WAB. Comparative study between Dermo, Pelite, and seal-in X5 liners: Effect on patient's satisfaction and perceived problems. Scientific World Journal. PMID: 25184154.

\section{Low resource country}

Ali S and Abu Osman NA and Eshraghi A and Gholizadeh H and Abd Razak NA and Wan Abas WA. Interface pressure in transtibial socket during ascent and descent on stairs and its effect on patient satisfaction. Clin Biomech (Bristol, Avon). PMID: 24161521.

Low resource country

Ali S and Osman NA and Mortaza N and Eshraghi A and Gholizadeh H and Wan Abas WA. Clinical investigation of the interface pressure in the transtibial socket with Dermo and Seal-In X5 liner during walking and their effect on patient satisfaction. Clin Biomech (Bristol, Avon). PMID: 22795863. Low resource country

Ali S and Osman NA and Razak A and Hussain S and Wan Abas WA. The effect of Dermo and Seal-In $\mathrm{X} 5$ prosthetic liners on pressure distributions and reported satisfaction during ramp ambulation in persons with transtibial limb loss. Eur J Phys Rehabil Med. PMID: 24963603.

Low resource country 
Altner PC and Rusin JJ and DeBoer A. Rehabilitation of blind patients with lower extremity amputations. Arch Phys Med Rehabil. PMID: 7369844.

\section{KQ 7: $\mathbf{N}<\mathbf{1 0 0}$}

Andrysek J and Klejman S and Torres-Moreno R and Heim W and Steinnagel B and Glasford S. Mobility function of a prosthetic knee joint with an automatic stance phase lock. Prosthet Orthot Int. PMID: 21697198.

\section{KQ 4: No subgroup}

Andrysek $\mathrm{J}$ and Rotter $\mathrm{K}$ and Garcia D and Valdebenito R and Wright V and Moreno RT and Mitchell CA and Cubillos R. Clinical field trials of a new type of prosthetic knee joint utilizing the automatic stance-phase lock mechanism. Prosthetics and Orthotics International.

KQ 4: No subgroup

Andrysek J and Wright FV and Rotter K and Garcia $\mathrm{D}$ and Valdebenito R and Mitchell CA and Rozbaczylo C and Cubillos R. Long-term clinical evaluation of the automatic stance-phase lockcontrolled prosthetic knee joint in young adults with unilateral above-knee amputation. Disabil Rehabil Assist Technol. PMID: 27376843.

KQ 4: No subgroup

Arwert HJ and van Doorn-Loogman $\mathrm{MH}$ and Koning $\mathrm{J}$ and Terburg $\mathrm{M}$ and Rol $\mathrm{M}$ and Roebroeck ME. Residual-limb quality and functional mobility 1 year after transtibial amputation caused by vascular insufficiency. Journal of rehabilitation research and development. PMID: 17943683.

KQ 7: $\mathbf{N}<\mathbf{1 0 0}$

Asano, M., Rushton, P., Miller, W. C. and Deathe, B. A. Predictors of quality of life among individuals who have a lower limb amputation. Prosthet Orthot Int. PMID: 18569891.

KQ 1-3: Not validation

Aström I, Stenström A. Effect on gait and socket comfort in unilateral trans-tibial amputees after exchange to a polyurethane concept. Prosthetics and Orthotics International. PMID: 15171575.

KQ 4: No subgroup

Azuma Y and Chin T and Takase I and Tezuka Y and Nakatsuka A and Fujie $\mathrm{H}$ and Fujiwara Y and Kurokawa M and Ochi T and Hara M and Oyabu H and Miura Y. Relation between balance function evaluated using berg balance scale and walking ability in transfemoral amputees. Physiotherapy (United Kingdom).

Not peer reviewed publication
Bai X, Ewins D, Crocombe AD, Xu W. Kinematic and biomimetic assessment of a hydraulic ankle/foot in level ground and camber walking. PLoS One.

PMID: 28704428.

\section{KQ 4: No subgroup}

Baker R and McGinley JL and Schwartz MH and Beynon S and Rozumalski A and Graham HK and Tirosh O. The Gait Profile Score and Movement Analysis Profile. Gait and Posture.

Pediatric

Barr JB and Wutzke CJ and Threlkeld AJ.

Longitudinal gait analysis of a person with a transfemoral amputation using three different prosthetic knee/foot pairs. Physiotherapy theory and practice. PMID: 22191438.

\section{Case report/series}

Bateni $\mathrm{H}$ and Olney SJ. Effect of the weight of prosthetic components on the gait of transtibial amputees. Journal of Prosthetics \& Orthotics (JPO). KQ 4: No subgroup

Baum Brian S, Hiroaki Hobara, Yoon Hyuk Kim, Jae Kun Shim. Amputee Locomotion: Ground Reaction Forces During Submaximal Running With RunningSpecific Prostheses. Journal of Applied Biomechanics. PMID: 26957365.

\section{KQ 4: No subgroup}

Beck ON, Taboga P, Grabowski AM. How do prosthetic stiffness, height and running speed affect the biomechanics of athletes with bilateral transtibial amputations?. J R Soc Interface. PMID: 28659414.

\section{KQ 4: No subgroup}

Beck ON, Taboga P, Grabowski AM. Prosthetic model, but not stiffness or height, affects the metabolic cost of running for athletes with unilateral transtibial amputations. J Appl Physiol (1985).

PMID: 28360121.

KQ 4-7: No outcome or analysis of interest

Beck ON, Taboga P, Grabowski AM. Reduced prosthetic stiffness lowers the metabolic cost of running for athletes with bilateral transtibial amputations. J Appl Physiol (1985). PMID: 28104752.

KQ 4-7: No outcome or analysis of interest

Beekman CE and Axtell LA. Prosthetic use in elderly patients with dysvascular above-knee and throughknee amputations. Phys Ther. PMID: 3659135.

KQ 7: $\mathbf{N}<100$ 
Bell EM and Pruziner AL and Wilken JM and Wolf EJ. Performance of conventional and X2(R) prosthetic knees during slope descent. Clinical biomechanics (Bristol, Avon). PMID: 26921583.

\section{KQ 4: No subgroup}

Berg KO, Maki BE, Williams JI, Holliday PJ, WoodDauphinee SL. Clinical and laboratory measures of postural balance in an elderly population. Arch Phys Med Rehabil. PMID: 1444775.

\section{Not amputees}

Berge JS and Czerniecki JM and Klute GK. Efficacy of shock-absorbing versus rigid pylons for impact reduction in transtibial amputees based on laboratory, field, and outcome metrics. J Rehabil Res Dev.

PMID: 16680617.

\section{KQ 4: No subgroup}

Berry D and Olson MD and Larntz K. Perceived stability, function, and satisfaction among transfemoral amputees using microprocessor and nonmicroprocessor controlled prosthetic knees: a multicenter survey. Journal of Prosthetics \& Orthotics (JPO).

KQ 4: No subgroup

Bilodeau S and Hebert R and Desrosiers J. [Questionnaire on the satisfaction of persons with lower-limb amputations towards their prosthesis: development and validation]. PMID: 10462879.

\section{KQ 1-3: Not validation}

Bilodeau S and Hebert R and Desrosiers J. Lower limb prosthesis utilisation by elderly amputees. Prosthet Orthot Int. PMID: 11061199.

\section{KQ 7: $\mathbf{N}<\mathbf{1 0 0}$}

Bischoff HA and Stahelin HB and Monsch AU and Iversen MD and Weyh $\mathrm{A}$ and von Dechend $\mathrm{M}$ and Akos R and Conzelmann $\mathrm{M}$ and Dick $\mathrm{W}$ and Theiler R. Identifying a cut-off point for normal mobility: a comparison of the timed 'up and go' test in community-dwelling and institutionalised elderly women. Age \& Ageing. 32(3):315-20, 2003 May. PMID: 12720619.

\section{Not amputees}

Blum C and Ehrler S and Isner ME. Assessment of therapeutic education in 135 lower limb amputees. Ann Phys Rehabil Med. PMID: 27676838.

Not peer reviewed publication

Bonnet X and Adde JN and Blanchard F and Gedouin-Toquet A and Eveno D. Evaluation of a new geriatric foot versus the Solid Ankle Cushion Heel foot for low-activity amputees. Prosthet Orthot Int. PMID: 24418934.

\section{KQ 4: No subgroup}

Boonstra AM and Fidler V and Eisma WH. Walking speed of normal subjects and amputees: aspects of validity of gait analysis. PMID: 8233772.

\section{KQ 1-3: Not validation}

Boonstra AM and Schrama JM and Eisma WH and Hof AL and Fidler V. Gait analysis of transfemoral amputee patients using prostheses with two different knee joints. Archives of Physical Medicine and Rehabilitation. PMID: 8629932.

\section{KQ 4: No subgroup}

Boutoille, D., Feraille, A., Maulaz, D. and Krempf, M. Quality of life with diabetes-associated foot complications: comparison between lower-limb amputation and chronic foot ulceration. Foot Ankle Int. PMID: 18026199.

\section{KQ 1-3: Not validation}

Boutwell E and Stine R and Gard S. Effect of longitudinal prosthesis stiffness on force transmission during transtibial amputee gait. Prosthetics and Orthotics International.

\section{KQ 4: No subgroup}

Boutwell E, Stine R, Gard S. Shock absorption during transtibial amputee gait: Does longitudinal prosthetic stiffness play a role?. Prosthet Orthot Int. PMID: 27117010.

\section{KQ 4: No subgroup}

Branemark R, Berlin O, Hagberg K, et al. A novel osseointigrated percutaneous prosthetic system for the treatment of patients with transfemoral amputation: a prospective study of 51 patients. PMID: 24395320.

\section{Not LLP}

Brodzka WK and Thornhill HL and Zarapkar SE and Malloy JA and Weiss L. Long-term function of persons with atherosclerotic bilateral below-knee amputation living in the inner city. Archives of Physical Medicine \& Rehabilitation. PMID: 2222158.

KQ 7: $\mathbf{N}<\mathbf{1 0 0}$

Brunelli S and Delussu AS and Paradisi F and Pellegrini R and Traballesi M. A comparison between the suction suspension system and the hypobaric Iceross Seal-In(R) X5 in transtibial amputees. Prosthet Orthot Int. PMID: 23436696. KQ 4: No subgroup

Brunelli S and Fusco A and Iosa M and Delussu AS and Paolucci S and Traballesi M. Mid- to long-term factors influencing functional status of people affected by lower-limb amputation associated with hemiparesis due to stroke. Disabil Rehabil. PMID: 23072255.

KQ 7: $\mathbf{N}<100$ 
Brunelli, S., Averna, T., Porcacchia, P., Paolucci, S., Di Meo, F. and Traballesi, M. Functional status and factors influencing the rehabilitation outcome of people affected by above-knee amputation and hemiparesis. Archives of Physical Medicine \& Rehabilitation. PMID: 16813789.

\section{KQ 1-3: Not validation}

Burger $\mathrm{H}$ and Marincek $\mathrm{C}$ and Isakov E. Mobility of persons after traumatic lower limb amputation.

Disabil Rehabil. PMID: 9246543.

\section{Low resource country}

Burnfield JM and Eberly VJ and Gronely JK and Perry J and Yule WJ and Mulroy SJ. Impact of stance phase microprocessor-controlled knee prosthesis on ramp negotiation and community walking function in K2 level transfemoral amputees. Prosthet Orthot Int. PMID: 22223685.

\section{KQ 4: No subgroup}

Buttenshaw P and Dolman J. The Roehampton approach to rehabilitation: A retrospective survey of prosthetic use in patients with primary unilateral lower-limb amputation. Topics in Geriatric Rehabilitation.

KQ 7: $\mathbf{N}<\mathbf{1 0 0}$

Callaghan B and Condie E and Johnston M. Using the common sense self-regulation model to determine psychological predictors of prosthetic use and activity limitations in lower limb amputees. Prosthet Orthot Int. PMID: 18825576.

KQ 7: Included amputees without LLP or excluded some LLP recipients

Callaghan BG and Johnston M and Condie ME. Using the theory of planned behaviour to develop an assessment of attitudes and beliefs towards prosthetic use in amputees. Disabil Rehabil. PMID: 15497923.

\section{KQ 4-7: No outcome or analysis of interest}

Campbell WB and Ridler BM. Predicting the use of prostheses by vascular amputees. Eur J Vasc Endovasc Surg. PMID: 8896478.

KQ 7: $\mathbf{N}<\mathbf{1 0 0}$

Cao W, Yu H, Zhao W, Li J, Wei X. Target of physiological gait: Realization of speed adaptive control for a prosthetic knee during swing flexion.

Technol Health Care. PMID: 29060946.

\section{Not available}

Casillas JM and Dulieu V and Cohen M and Marcer I and Didier JP. Bioenergetic comparison of a new energy-storing foot and SACH foot in traumatic below-knee vascular amputations. Archives of physical medicine and rehabilitation. PMID: 7811172.

KQ 4: No subgroup
Chamlian TR. Use of prostheses in lower limb amputee patients due to peripheral arterial disease. Einstein (Sao Paulo). PMID: 25628194.

KQ 7: < 6 mo or unclear f/up post-prescription

Chan KM and Tan ES. Use of lower limb prosthesis among elderly amputees. Ann Acad Med Singapore. PMID: 2130743.

KQ 7: $\mathbf{N}<\mathbf{1 0 0}$

Chan $\mathrm{T}$ and $\mathrm{Wu} \mathrm{J}$ and Bowring G. Functional outcomes of major lower limb amputation 19942006: A modern series. Internal Medicine Journal. KQ 7: <6 mo or unclear f/up post-prescription

Chou TGR and Webster JB and Shahrebani M and Roberts TL and Bloebaum RD. Characterization of step count accuracy of actigraph activity monitor in persons with lower limb amputation. Journal of Prosthetics \& Orthotics (JPO).

\section{KQ 1-3: $\mathbf{N}<20$}

Chou YL and Shi SS and Huang GF and Lin TS. Interface pressure and gait analysis in different walking speeds and on the below-knee amputees with multiple axis prosthetic foot prosthesis. Biomedical Engineering - Applications, Basis and Communications.

\section{KQ 4: Noncomparative}

Christensen J, Doherty P, Bjorner JB, Langberg H. Reliability and construct validity of a new Danish translation of the Prosthesis Evaluation Questionnaire in a population of Danish amputees. Prosthet Orthot Int. PMID: 28946825.

\section{KQ 1-3: Not validation}

Coelho A and Espanha M and Bruno PM. Six-minute walk test and timed up \& go test in persons with transfemoral amputations.

\section{KQ 1-3: Not validation}

Coffey L and Gallagher P and Desmond D and Ryall $\mathrm{N}$ and Wegener ST. Goal management tendencies predict trajectories of adjustment to lower limb amputation up to 15 months post rehabilitation discharge. Archives of physical medicine and rehabilitation. PMID: 24907639.

KQ 7: $\mathbf{N}<\mathbf{1 0 0}$

Coffey, L., Gallagher, P., Horgan, O., Desmond, D. and MacLachlan, M. Psychosocial adjustment to diabetes-related lower limb amputation. Diabet Med. PMID: 19900240.

\section{KQ 1-3: Not validation}

Cohen E and Dickstien R and Schwarz V and Pillar $\mathrm{T}$. Evaluation of the rehabilitation of geriatric amputees. Harefuah.

Not primary study 
Coleman KL and Boone DA and Laing LS and Mathews DE and Smith DG. Quantification of prosthetic outcomes: Elastomeric gel liner with locking pin suspension versus polyethylene foam liner with neoprene sleeve suspension. Journal of Rehabilitation Research and Development. PMID: 15558387.

\section{KQ 4: No subgroup}

Coleman KL and Smith DG and Boone DA and Joseph AW and del Aguila MA. Step activity monitor: long-term, continuous recording of ambulatory function. Journal of Rehabilitation Research \& Development. 36(1):8-18, 1999 Jan. PMID: 10659890.

\section{Not amputees}

Collin C and Wade DT and Cochrane GM. Functional outcome of lowe limb amputees with peripheral vascular disease. Clinical Rehabilitation. KQ 7: $\mathbf{N}<\mathbf{1 0 0}$

Columbo JA. Patient experience of early and late recovery after major leg amputation for arterial disease. Journal Vascular Surgery.

\section{Not peer reviewed publication}

Corey MR and St Julien J and Miller C and Fisher B and Cederstrand SL and Nylander WA and Guzman RJ and Dattilo JB. Patient education level affects functionality and long term mortality after major lower extremity amputation. Am J Surg. 2012 Nov;204(5):626-30. PMID: 22906244.

KQ 7: Included amputees without LLP or excluded some $L L P$ recipients

Crea S and Cipriani C and Donati M and Carrozza MC and Vitiello N. Providing time-discrete gait information by wearable feedback apparatus for lower-limb amputees: usability and functional validation. IEEE Trans Neural Syst Rehabil Eng. PMID: 25373108.

\section{Not amputees}

Creylman V, Knippels I, Janssen P, Biesbrouck E, Lechler K, Peeraer L. Assessment of transfemoral amputees using a passive microprocessor-controlled knee versus an active powered microprocessorcontrolled knee for level walking. Biomed Eng Online. PMID: 28105945.

\section{KQ 4: No subgroup}

Cull DL and Taylor SM and Hamontree SE and Langan EM and Snyder BA and Sullivan TM and Youkey JR. A reappraisal of a modified through-knee amputation in patients with peripheral vascular disease. Am J Surg. PMID: 11532414.

KQ 7: Included amputees without LLP or excluded some $L L P$ recipients
Cutti AG and Raggi M and Parel I. Assessment of Transtibial Amputees walking in real-life environments: Inter-rater reliability of a protocol based on inertial and magnetic sensors. Gait and Posture.

Not peer reviewed publication

Cutti AG, Lettieri E, Del Maestro M, Radaelli G, Luchetti M, Verni G, Masella C. Stratified costutility analysis of C-Leg versus mechanical knees: Findings from an Italian sample of transfemoral amputees. Prosthet Orthot Int. PMID: 27025244. KQ 4-7: No outcome or analysis of interest

da Silva, R., Rizzo, J. G., Gutierres Filho, P. J., Ramos, V. and Deans, S. Physical activity and quality of life of amputees in southern Brazil. Prosthet Orthot Int. PMID: 22042373.

\section{Low resource country}

Darter BJ, Bastian AJ, Wolf EJ, Husson EM, Labrecque BA, Hendershot BD. Locomotor adaptability in persons with unilateral transtibial amputation. PLoS ONE. PMID: 28704467.

KQ 4-7: No outcome or analysis of interest

Datta D and Harris I and Heller B and Howitt J and Martin R. Gait, cost and time implications for changing from PTB to ICEX sockets. Prosthet Orthot Int. PMID: 15382805.

KQ 4: No subgroup

Datta D and Howitt J. Conventional versus microchip controlled pneumatic swing phase control for transfemoral amputees: user's verdict. Prosthet Orthot Int. PMID: 9747997.

\section{KQ 4: No subgroup}

Datta D and Vaidya SK and Howitt J and Gopalan L. Outcome of fitting an ICEROSS prosthesis: views of trans-tibial amputees. Prosthet Orthot Int. PMID: 8876004.

\section{KQ 4: No subgroup}

Davidson, J. H., Khor, K. E. and Jones, L. E. A crosssectional study of post-amputation pain in upper and lower limb amputees, experience of a tertiary referral amputee clinic. Disability \& Rehabilitation.

\section{KQ 1-3: Not validation}

Davie-Smith F and Scott H. The scottish physiotherapy amputee research group (SPARG). Physiotherapy (United Kingdom).

Not peer reviewed publication 
De Asha AR and Johnson L and Munjal R and Kulkarni J and Buckley JG. Attenuation of centre-ofpressure trajectory fluctuations under the prosthetic foot when using an articulating hydraulic ankle attachment compared to fixed attachment. Clin Biomech (Bristol, Avon). PMID: 23261018.

\section{KQ 4: No subgroup}

De Asha AR and Munjal R and Kulkarni J and Buckley JG. Walking speed related joint kinetic alterations in trans-tibial amputees: impact of hydraulic 'ankle' damping. J Neuroeng Rehabil. PMID: 24134803.

\section{KQ 4: No subgroup}

de Laat, F. A., Rommers, G. M., Geertzen, J. H. and Roorda, L. D. Construct validity and test-retest reliability of the questionnaire rising and sitting down in lower-limb amputees. Archives of physical medicine and rehabilitation. PMID: 21807151. KQ 1-3: Not validation

De Luccia N and Pinto MA and Guedes JP and Albers MT. Rehabilitation after amputation for vascular disease: a follow-up study. Prosthetics \& Orthotics International. 16(2):124-8, 1992 Aug. PMID: 1408671.

\section{Low resource country}

Deans, S.A., A.K. McFadyen, and P.J. Rowe. Physical activity and quality of life: A study of a lower-limb amputee population. Prosthet Orthot Int. PMID: 18569887.

\section{KQ 1-3: Not validation}

Delussu AS and Brunelli S and Paradisi F and Iosa M and Pellegrini R and Zenardi D and Traballesi M. Assessment of the effects of carbon fiber and bionic foot during overground and treadmill walking in transtibial amputees. Gait Posture. PMID: 23702342. KQ 4: No subgroup

Delussu AS and Paradisi F and Brunelli S and Pellegrini R and Zenardi D and Traballesi M. Comparison between SACH foot and a new multiaxial prosthetic foot during walking in hypomobile transtibial amputees: physiological responses and functional assessment. Eur J Phys Rehabil Med. PMID: 26989817.

\section{KQ 4: No subgroup}

Desmond, D., Gallagher, P., Henderson-Slater, D. and Chatfield, R. Pain and psychosocial adjustment to lower limb amputation amongst prosthesis users. Prosthet Orthot Int. PMID: 18569892.

KQ 1-3: Not validation
Devan H, Hendrick P, Hale L, Carman A, Dillon MP, Ribeiro DC. Exploring Factors Influencing Low Back Pain in People With Nondysvascular Lower Limb Amputation: A National Survey. Pm r. PMID: 28214616.

KQ 4-7: No outcome or analysis of interest

Devlin M and Sinclair LB and Colman D and Parsons $\mathrm{J}$ and Nizio $\mathrm{H}$ and Campbell JE. Patient preference and gait efficiency in a geriatric population with transfemoral amputation using a free-swinging versus a locked prosthetic knee joint. Archives of Physical Medicine \& Rehabilitation. 83(2):246-9, 2002 Feb. PMID: 11833030.

\section{KQ 4: No subgroup}

Dillingham TR and Pezzin LE and MacKenzie EJ and Burgess AR. Use and satisfaction with prosthetic devices among persons with trauma-related amputations: a long-term outcome study. Am J Phys Med Rehabil. PMID: 11475475.

KQ 7: $\mathbf{N}<\mathbf{1 0 0}$

Dillon M. Can the AMP test and patient demographics predict k-level in people with lower limb amputation?. Archives of Physical Medicine and Rehabilitation.

\section{Not peer reviewed publication}

Dillon MP, Major MJ, Kaluf B, Balasanov Y, Fatone S. Predict the Medicare Functional Classification Level (K-level) using the Amputee Mobility Predictor in people with unilateral transfemoral and transtibial amputation: A pilot study. Prosthetics and orthotics international. PMID: 28534664.

\section{KQ 1-3: Not validation}

Diogo MJ. [Functional evaluation of elderly patients with lower limb amputation followed at a university hospital]. Revista latino-americana de enfermagem. PMID: 12733244.

\section{Low resource country}

Dite W and Temple VA. A clinical test of stepping and change of direction to identify multiple falling older adults. Archives of Physical Medicine \& Rehabilitation. 83(11):1566-71, 2002 Nov. PMID: 12422327.

\section{Not amputees}

Dolezal Jeanette $\mathrm{M}$ and Vernick Sanford $\mathrm{H}$ and Khan Nusrat and Lutz David and Tyndall Carl. Factors associated with use and nonuse of an AK prosthesis in a rural, southern, geriatric population. International Journal of Rehabilitation \& Health.

KQ 7: $<6$ mo or unclear f/up post-prescription 
Dötzel E, Capanni F, Engleder T, Steinacker J. Gait biomechanics of patients with forefoot amputation using a customized carbon fiber prosthesis.

Biomedizinische Technik.

Not peer reviewed publication

Duff L and Jarvis H. Walking speed and oxygen consumption of a unilateral hip disarticulation amputee during level walking using a C-leg vs a Genium. Prosthetics and Orthotics International.

\section{Case report/series}

Eberly VJ and Mulroy SJ and Gronley JK and Perry J and Yule WJ and Burnfield JM. Impact of a stance phase microprocessor-controlled knee prosthesis on level walking in lower functioning individuals with a transfemoral amputation. Prosthet Orthot Int. PMID: 24135259.

\section{KQ 4: No subgroup}

Ehrler S and Blum-Demans C and Coulon S and Isner-Horobeti ME. Assessment of therapeutic education in lower-limb amputees. Prosthetics and Orthotics International.

\section{Not peer reviewed publication}

Ehrler S and Coulon S. Under limb amputation for people with mobility 1 or 2; choice of fitting with prosthetic. Annals of Physical and Rehabilitation Medicine.

\section{Not peer reviewed publication}

Eshraghi A and Abu Osman NA and Karimi MT and Gholizadeh $\mathrm{H}$ and Ali S and Wan Abas WA. Quantitative and qualitative comparison of a new prosthetic suspension system with two existing suspension systems for lower limb amputees. American journal of physical medicine \& rehabilitation / Association of Academic Physiatrists. PMID: 23168378.

\section{Low resource country}

Fatone S, Caldwell R. Northwestern University Flexible Subischial Vacuum Socket for persons with transfemoral amputation-Part 1: Description of technique. Prosthet Orthot Int. PMID: 28094686.

\section{KQ 4: Noncomparative}

Fernandez A and Formigo J. Are Canadian prostheses used? A long-term experience. Prosthet Orthot Int. PMID: 16281726.

KQ 7: $\mathbf{N}<\mathbf{1 0 0}$

Ferris AE and Aldridge JM and Rabago CA and Wilken JM. Evaluation of a powered ankle-foot prosthetic system during walking. Archives of Physical Medicine \& Rehabilitation. 93(11):1911-8, 2012 Nov. PMID: 22732369.

KQ 4: No subgroup
Fisher K and Hanspal RS and Marks L. Return to work after lower limb amputation. International journal of rehabilitation research. Internationale Zeitschrift fur Rehabilitationsforschung. Revue internationale de recherches de readaptation. PMID: 12601268.

\section{KQ 4-7: No outcome or analysis of interest}

Fisher, K. and Hanspal, R. Body image and patients with amputations: does the prosthesis maintain the balance?. International Journal of Rehabilitation Research.

\section{KQ 1-3: Not validation}

Franchignoni $\mathrm{F}$ and Monticone $\mathrm{M}$ and Giordano A and Rocca B. Rasch validation of the Prosthetic Mobility Questionnaire: A new outcome measure for assessing mobility in people with lower limb amputation. PMID: 25783231.

\section{KQ 1-3: Not validation}

Frengopoulos C, Burley J, Viana R, Payne MW, Hunter SW. Association Between Montreal Cognitive Assessment Scores and Measures of Functional Mobility in Lower Extremity Amputees After Inpatient Rehabilitation. Arch Phys Med Rehabil. PMID: 27422347.

\section{KQ 1-3: Not validation}

Frengopoulos C, Payne MW, Viana R, Hunter SW. MoCA Item Score Analysis and Relationship to Mobility Outcomes in Dysvascular Lower Extremity Amputees. Arch Phys Med Rehabil. PMID: 28964795.

\section{KQ 1-3: Not validation}

Frlan-Vrgoc L and Vrbanic TS and Kraguljac D and Kovacevic M. Functional outcome assessment of lower limb amputees and prosthetic users with a 2minute walk test. Coll Antropol. PMID: 22397262.

\section{Low resource country}

Frossard L, Hagberg K, H€aggstrom E, et al. Functional outcome of transfemoral amputees fitted with an osseointegrated fixation: temporal gait characteristics.

\section{Not LLP}

Furse A and Cleghorn W and Andrysek J. Improving the gait performance of non-fluid-based swing-phase control mechanisms in transfemoral prostheses. IEEE Trans Biomed Eng. PMID: 21592917.

\section{KQ 4: No subgroup}

Furtado S, Briggs T, Fulton J, Russell L, Grimer R, Wren V, Cool P, Grant K, Gerrand C. Patient experience after lower extremity amputation for sarcoma in England: a national survey. Disabil Rehabil. PMID: 27384383.

KQ 4-7: No outcome or analysis of interest 
Fusetti C and Senechaud C and Merlini M. [Quality of life of vascular disease patients following amputation]. Annales de chirurgie. PMID: 11447794. KQ 7: <6 mo or unclear f/up post-prescription

Gailey RS and Gaunaurd I and Agrawal V and Finnieston A and O'Toole C and Tolchin R. Application of self-report and performance-based outcome measures to determine functional differences between four categories of prosthetic feet. J Rehabil Res Dev. PMID: 22773262.

\section{KQ 4: No subgroup}

Gallagher et al. American Journal of Physical Medicine \& Rehabilitation. PMID: 17314705. KQ 1-3: Not validation

Gardiner MD and Faux S and Jones LE. Interobserver reliability of clinical outcome measures in a lower limb amputee population. Disability and rehabilitation. PMID: 11926262.

KQ 1-3: $\mathbf{N}<20$

Gardinier ES, Kelly BM, Wensman J, Gates DH. A controlled clinical trial of a clinically-tuned powered ankle prosthesis in people with transtibial amputation. Clin Rehabil. PMID: 28750586.

KQ 4: No subgroup for outcomes of interest

Gardner David W, Redd Christian B, Cagle John C, Sanders Joan E, Hafner Brian J. Monitoring Prosthesis User Activity and Doffing Using an Activity Monitor and Proximity Sensors. Journal of Prosthetics \& Orthotics (JPO). doi: 10.1097/JPO.0000000000000093. KQ 1-3: Not validation

Gates DH and Aldridge JM and Wilken JM. Kinematic comparison of walking on uneven ground using powered and unpowered prostheses. Clinical Biomechanics. 28(4):467-72, 2013 Apr. PMID: 23602128.

\section{KQ 4: No subgroup}

Gatt A and Chockalingam N. Validity and reliability of a new ankle dorsiflexion measurement device. Prosthetics and Orthotics International. PMID: 23211471.

\section{Not amputees}

Gaunaurd I and Gailey R and Salem R and Hafner B. Construct validity of the Prosthetic Limb Users Survey of Mobility (PLUS-M). Prosthetics and Orthotics International.

\section{Duplicate publication}

Gaunaurd I, Spaulding S, Amtmann D, Salem R, Gailey R, Morgan S, Hafner B. Use of and Confidence Administering Outcome Measures among Clinical Prosthetists: Results from a National Survey and Mixed-Methods Training Program. Prosthet Orthot Intl. PMID: 24827935.

\section{Not amputees}

Gauthier-Gagnon C and Grise $\mathrm{M}$ and Lepage Y. The Locomotor Capabilities Index: content validity.

\section{KQ 1-3: Not validation}

Gholizadeh H and Abu Osman NA and Eshraghi A

and Ali S. The effects of suction and pin/lock suspension systems on transtibial amputees' gait performance. PLoS One. PMID: 24827560.

Low resource country

Gong SY and Yang P and Liu QD and Song L. Application of intelligent lower limb prostheses sensor. Journal of Clinical Rehabilitative Tissue Engineering Research.

\section{Low resource country}

González Viejo. [Clinical application of kynetic [sic] gait response and comfort analysis with seven prosthetic feet]. Rehabilitacion.

\section{KQ 4: No subgroup}

Graham LE and Datta D and Heller B and Howitt J and Pros D. A comparative study of conventional and energy-storing prosthetic feet in high-functioning transfemoral amputees. Archives of physical medicine and rehabilitation. PMID: 17532907.

\section{KQ 4: No subgroup}

Greive, A.C. and G.J. Lankhorst. Functional outcome of lower-limb amputees: a prospective descriptive study in a general hospital. Prosthet Orthot Int. PMID: 8876000.

\section{KQ 1-3: Not validation}

Guarita ML and Gaspar AP and Inghan S. Long-term prosthetic outcome of bilateral lower limb amputees: A case series. PM and R.

\section{Not peer reviewed publication}

Hafner B and Morgan S and Askew R. Reliability of self-reported outcome measures in people with lower limb loss: Implications to clinical care and research. Prosthetics and Orthotics International.

\section{Not peer reviewed publication}

Hafner BJ and Askew RL. Physical performance and self-report outcomes associated with use of passive, adaptive, and active prosthetic knees in persons with unilateral, transfemoral amputation: Randomized crossover trial. J Rehabil Res Dev. PMID: 26560243. KQ 4: No subgroup 
Hafner BJ and Morgan SJ and Abrahamson DC and Amtmann D. Characterizing mobility from the prosthetic limb user's perspective: Use of focus groups to guide development of the Prosthetic Limb Users Survey of Mobility. Prosthetics and orthotics international. PMID: 25944625.

KQ 1-3: Not validation

Hafner BJ and Willingham LL and Buell NC and Allyn KJ and Smith DG. Evaluation of function, performance, and preference as transfemoral amputees transition from mechanical to microprocessor control of the prosthetic knee. Archives of physical medicine and rehabilitation. PMID: 17270519.

KQ 4: No subgroup

Hafner BJ, Morgan SJ, Askew RA, Salem R. Psychometric evaluation of self-report outcome measures for prosthetic applications. J Rehabili Res Dev. PMID: 28273329.

KQ 1-3: Not validation

Hafner BJ, Spaulding SE, Salem R, Morgan SJ, Gaunaurd IA, Gailey RS. Prosthetists' perceptions and use of outcome measures in clinical practice: long-term effects of focused continuing education. Prosthet Orthot Int. PMID: 27638012.

\section{Not amputees}

Hagberg K and Branemark R. Consequences of nonvascular trans-femoral amputation: a survey of quality of life, prosthetic use and problems. Prosthet Orthot Int. PMID: 11860092.

KQ 7: $\mathbf{N}<\mathbf{1 0 0}$

Hagberg K, Branemark R, Gunterberg B, et al. Osseointegrated trans-femoral amputation prostheses: prospective results of general and condition-specific quality of life in 18 patients at 2-year follow-up. PMID: 18330803.

\section{Not LLP}

Hagberg K, Haggstrom E, Uden M, et al. Socket versus bone-anchored trans-femoral prostheses: hip range of motion and sitting comfort. PMID:

16281724.

Not LLP

Hagberg K, Hansson E, Branemark R. Outcome of percutaneous osseointegrated prostheses for patients with unilateral transfemoral amputation at two-year follow-up. PMID: 25064778.

Not LLP

Halsne EG and Waddingham MG and Hafner BJ. Long-term activity in and among persons with transfemoral amputation. J Rehabil Res Dev. PMID: 23934872.

KQ 7: $\mathbf{N}<100$
Ham R and de Trafford J and Van de Ven C. Patterns of recovery for lower limb amputation. Clinical Rehabilitation.

KQ 7: <6 mo or unclear f/up post-prescription

Hammarlund, C.S., et al. Prosthet Orthot Int. PMID: 21515895.

\section{KQ 1-3: Not validation}

Hansen SE. A follow-up examination of elderly amputees fitted with prostheses. Ugeskrift for Laeger. PMID: 695031.

\section{Unclear technology}

Hanspal, R. S. and Fisher, K. Assessment of cognitive and psychomotor function and rehabilitation of elderly people with prostheses. BMJ. PMID: 2032036.

\section{KQ 1-3: Not validation}

Hanspal, R. S. and Fisher, K. Prediction of achieved mobility in prosthetic rehabilitation of the elderly using cognitive and psychomotor assessment. International journal of rehabilitation research. Internationale Zeitschrift fur Rehabilitationsforschung. Revue internationale de recherches de readaptation. PMID: 9331580.

KQ 1-3: Not validation

Happich, M., John, J., Stamenitis, S., Clouth, J. and Polnau, D. The quality of life and economic burden of neuropathy in diabetic patients in Germany in 2002--results from the Diabetic Microvascular Complications (DIMICO) study. Diabetes Research \& Clinical Practice.

\section{KQ 1-3: Not validation}

Harness $\mathrm{N}$ and Pinzur MS. Health related quality of life in patients with dysvascular transtibial amputation. Clin Orthop Relat Res. PMID: 11210955.

KQ 7: $\mathbf{N}<100$

Harris KA and van Schie L and Carroll SE and Deathe A and Maryniak O and Meads GE and Sweeney JP. Rehabilitation potential of elderly patients with major amputations. J Cardiovasc Surg (Torino). PMID: 1864873.

KQ 7: $\mathbf{N}<100$

Hatfield AG. Beyond the 10-m time: a pilot study of timed walks in lower limb amputees. Clin Rehabil.

PMID: 11911519.

KQ 1-3: $\mathbf{N}<20$ 
Hefferman GM and Zhang F and Nunnery MJ and Huang H. Integration of surface electromyographic sensors with the transfemoral amputee socket: a comparison of four differing configurations. Prosthet Orthot Int. PMID: 24469430.

\section{Case report/series}

Heinemann AW, Ehrlich-Jones L, Connelly L, Semik $\mathrm{P}$, Fatone S. Enhancing quality of prosthetic services with process and outcome information. Prosthet Orthot Int. PMID: 27091865.

KQ 4-7: No outcome or analysis of interest

Heitzmann Dw, Pieschel K, Alimusaj M, Block J, Putz C, Wolf Si. Functional effects of a prosthetic torsion adapter in trans-tibial amputees during unplanned spin and step turns. Prosthetics and orthotics international. PMID: 26195621.

\section{KQ 4: No subgroup}

Hellstrand Tang U and Zï $\dot{\mathrm{c}}^{1 / 2 \_g n e r} \mathrm{R}$ and Lisovskaja $\mathrm{V}$ and Karlsson $\mathrm{J}$ and Hagberg $\mathrm{K}$ and Tranberg R. Comparison of plantar pressure in three types of insole given to patients with diabetes at risk of developing foot ulcers - A two-year, randomized trial. Journal of Clinical and Translational Endocrinology.

\section{Not LLP}

Hermodsson Y and Ekdahl C and Persson BM. Outcome after trans-tibial amputation for vascular disease. A follow-up after eight years. Scand J Caring Sci. PMID: 9801627.

KQ 7: $\mathbf{N}<\mathbf{1 0 0}$

Hermodsson Y, Ekdahl C, Persson BM, et al. Standing balance in trans-tibial amputees following vascular disease or trauma: a comparative study with healthy subjects. PMID: 7724348.

\section{Not LLP}

Herr HM and Grabowski AM. Bionic ankle-foot prosthesis normalizes walking gait for persons with leg amputation. Proceedings of the Royal Society of London - Series B: Biological Sciences.

279(1728):457-64, 2012 Feb 7. PMID: 21752817.

KQ 4: No subgroup

Hershkovitz A and Dudkiewicz I and Brill S. Rehabilitation outcome of post-acute lower limb geriatric amputees. Disabil Rehabil. PMID: 22686166.

KQ 7: $\mathbf{N}<\mathbf{1 0 0}$

Highsmith MJ and Kahle JT and Miro RM and Mengelkoch LJ. Ramp descent performance with the C-Leg and interrater reliability of the Hill Assessment Index. Prosthet Orthot Int. PMID: 23327837.

KQ 4: No subgroup
Highsmith Mj and Kahle Jt. Functional effects of the genium knee in transfemoral amputees measured with the continuous scale physical functional performance-10 (CS-PFP10) assessment. Prosthetics and orthotics international.

Not peer reviewed publication

Highsmith Mj, Kahle Jt, Miro Rm, Cress Me, Lura Dj, Quillen Ws, Carey Sl, Dubey Rv, Mengelkoch Lj. Functional performance differences between the genium and C-leg prosthetic knees and intact knees. Journal of rehabilitation research and development. PMID: 27997673.

KQ 4: No subgroup

Highsmith MJ. Comparative outcomes assessment of the C-Leg and X2 knee prosthesis.

KQ 4: No subgroup

Hoffman, R. D., Saltzman, C. L. and Buckwalter, J. A. Outcome of lower extremity malignancy survivors treated with transfemoral amputation. Archives of physical medicine and rehabilitation. PMID: 11833020.

KQ 1-3: Not validation

Holden JM and Fernie GR. Extent of artificial limb use following rehabilitation. J Orthop Res. PMID: 3681530.

KQ 4-7: No outcome or analysis of interest

Houghton AD and Taylor PR and Thurlow S and Rootes E and McColl I. Success rates for rehabilitation of vascular amputees: implications for preoperative assessment and amputation level. The British journal of surgery. PMID: 1393461.

KQ 7: < 6 mo or unclear f/up post-prescription

Howard C and Wallace C and Stokic D. Mechanical knee users improve motor function with rheo3 knee: Single-subject design. Prosthetics and Orthotics International.

\section{Not peer reviewed publication}

Hsu M. Efficacy of energy storing-releasing prosthetic feet in individuals with transtibial amputation during ambulation: physiological, functional, and temporal/distance assessments.

\section{KQ 4: No subgroup}

Hsu MJ and Nielsen DH and Lin-Chan SJ and Shurr D. The effects of prosthetic foot design on physiologic measurements, self-selected walking velocity, and physical activity in people with transtibial amputation. Arch Phys Med Rehabil. PMID: 16401450.

KQ 4: No subgroup 
Hsu MJ and Nielsen DH and Yack HJ and Shurr DG. Physiological measurements of walking and running in people with transtibial amputations with 3 different prostheses. J Orthop Sports Phys Ther. PMID:

10518294.

KQ 4: No subgroup

Huang GF and Chou YL and Su FC. Gait analysis and energy consumption of below-knee amputees wearing three different prosthetic feet. Gait Posture. PMID: 10998614.

\section{Retracted publication}

Imam B, Miller WC, Finlayson H, Eng JJ, Jarus T. A randomized controlled trial to evaluate the feasibility of the Wii Fit for improving walking in older adults with lower limb amputation. Clinical rehabilitation. PMID: 26721873.

KQ 4-7: No outcome or analysis of interest

Inderbitzi R and Buettiker $\mathrm{M}$ and Enzler $\mathrm{M}$. The long-term mobility and mortality of patients with peripheral arterial disease following bilateral amputation. European Journal of Vascular and Endovascular Surgery. PMID: 12819649.

KQ 7: $\mathbf{N}<\mathbf{1 0 0}$

Ingraham KA and Fey NP and Simon AM and Hargrove LJ. Contributions of knee swing initiation and ankle plantar flexion to the walking mechanics of amputees using a powered prosthesis. Conf Proc IEEE Eng Med Biol Soc. PMID: 25570499.

KQ 4: No subgroup

Isakov E, Mizrahi J, Ring H, et al. Standing sway and weight-bearing distribution in people with belowknee amputations. PMID: 1543414.

\section{Not LLP}

Jarl G and Heinemann AW and Lindner HY and Norling Hermansson LM. Cross-Cultural Validity and Differential Item Functioning of the Orthotics and Prosthetics Users' Survey With Swedish and United States Users of Lower-Limb Prosthesis. Arch Phys Med Rehabil. PMID: 25804528.

KQ 1-3: Not validation

Jarl GM and Heinemann AW and Norling Hermansson LM. Validity evidence for a modified version of the Orthotics and Prosthetics Users' Survey. PMID: 22439801.

KQ 1-3: Not validation

Jayakaran P and Johnson GM and Sullivan SJ. Concurrent validity of the Sensory Organization Test measures in unilateral transtibial amputees. Prosthetics and orthotics international. PMID: 22760518.

KQ 1-3: $\mathbf{N}<20$
Jayakaran P and Johnson GM and Sullivan SJ. Reliability and concurrent validity of the step quick turn test in older persons with a unilateral transtibial amputation. Am J Phys Med Rehabil. PMID: 21862909.

KQ 1-3: $\mathbf{N}<20$

Jayakaran P, Johnson GM and Sullivan SJ. Postural control in response to altered sensory conditions in persons with dysvascular and traumatic transtibial amputation.

Not LLP

Jepson F and Datta D and Harris I and Heller B and Howitt J and McLean J. A comparative evaluation of the Adaptive knee and Catech knee joints: a preliminary study. Prosthetics \& Orthotics International. 32(1):84-92, 2008 Mar. PMID: 18330807.

KQ 4: No subgroup

Jin Li, Adamczyk Peter G, Roland Michelle, Hahn Michael E. The Effect of High- and Low-Damping Prosthetic Foot Structures on Knee Loading in the Uninvolved Limb Across Different Walking Speeds. Journal of Applied Biomechanics. PMID: 26671831. Not amputees

Johannesson A and Larsson GU and Ramstrand N and Lauge-Pedersen $\mathrm{H}$ and Wagner $\mathrm{P}$ and Atroshi I. Outcomes of a standardized surgical and rehabilitation program in transtibial amputation for peripheral vascular disease: a prospective cohort study. Am J Phys Med Rehabil. PMID: 20134308. KQ 4-7: No outcome or analysis of interest

Johansson JL and Sherrill DM and Riley PO and Bonato P and Herr H. A clinical comparison of variable-damping and mechanically passive prosthetic knee devices. Am J Phys Med Rehabil. PMID: 16034225.

KQ 4-7: No outcome or analysis of interest

Johnson L and De Asha AR and Munjal R and Kulkarni J and Buckley JG. Toe clearance when walking in people with unilateral transtibial amputation: effects of passive hydraulic ankle. J Rehabil Res Dev. PMID: 25019665.

\section{KQ 4: No subgroup}

Jones L and Hall M and Schuld W. Ability or disability? A study of the functional outcome of 65 consecutive lower limb amputees treated at the Royal South Sydney Hospital in 1988-1989. Disability and rehabilitation. PMID: 8219247.

KQ 7: $N<100$ 
Jordan RW and Marks A and Higman D. The cost of major lower limb amputation: a 12-year experience. Prosthet Orthot Int. PMID: 22440579.

KQ 4-7: No outcome or analysis of interest

Kahle JT and Highsmith MJ. Transfemoral interfaces with vacuum assisted suspension comparison of gait, balance, and subjective analysis: ischial containment versus brimless. Gait Posture. PMID: 24852508. KQ 4: No subgroup

Kanade RV, Van Deursen RW, Harding KG, et al. Investigation of standing balance in patients with diabetic neuropathy at different stages of foot complications. PMID: 18644661.

Not LLP

Kannenberg Andreas and Zacharias Britta and DiplIng and Mileusnic Milana and Seyr Martin. Activities of Daily Living: Genium Bionic Prosthetic Knee Compared with C-Leg. Journal of Prosthetics \& Orthotics (JPO).

\section{KQ 4: No subgroup}

Kark L and Vickers D and McIntosh A and Simmons A. Use of gait summary measures with lower limb amputees. Gait Posture. PMID: 22000790.

KQ 1-3: $\mathbf{N}<20$

Kaufman KR and Levine JA and Brey RH and Iverson BK and McCrady SK and Padgett DJ and Joyner MJ. Gait and balance of transfemoral amputees using passive mechanical and microprocessor-controlled prosthetic knees. Gait and Posture. PMID: 17869114.

\section{KQ 4: No subgroup}

Kelly VE, Morgan SJ, Amtmann D, Salem R, Hafner BJ. Association of self-reported cognitive concerns with mobility in people with lower limb loss. Disabil Rehabil. PMID: 27756174.

\section{KQ 1-3: Not validation}

Kent JA and Stergiou N and Wurdeman SR. Step activity and stride-to-stride fluctuations are negatively correlated in individuals with transtibial amputation. Clinical biomechanics (Bristol, Avon). PMID: 26319219.

\section{KQ 1-3: Not validation}

Kent JA, Stergiou N, Wurdeman SR. Dynamic balance changes within three weeks of fitting a new prosthetic foot component. Gait Posture. PMID: 28704685.

KQ 4: No subgroup
Kiernan D, Miller RH, Baum BS, Kwon HJ, Shim JK. Amputee locomotion: Frequency content of prosthetic vs. intact limb vertical ground reaction forces during running and the effects of filter cut-off frequency. Journal of Biomechanics. PMID: 28705487.

KQ 4-7: No outcome or analysis of interest

Klute GK and Berge JS and Biggs W and Pongnumkul S and Popovic Z and Curless B. Vacuum-assisted socket suspension compared with pin suspension for lower extremity amputees: effect on fit, activity, and limb volume. Arch Phys Med Rehabil. PMID: 21963124.

\section{KQ 4: No subgroup}

Klute GK and Berge JS and Orendurff MS and Williams RM and Czerniecki JM. Prosthetic intervention effects on activity of lower-extremity amputees. Arch Phys Med Rehabil. PMID: 16635636.

\section{KQ 4: No subgroup}

Koehler-McNicholas SR, Nickel EA, Medvec J, Barrons K, Mion S, Hansen AH. The influence of a hydraulic prosthetic ankle on residual limb loading during sloped walking. PLoS One. PMID: 28278172. KQ 4-7: No outcome or analysis of interest

Kuntze Ferreira AE and Neves EB. A comparison of vacuum and KBM prosthetic fitting for unilateral transtibial amputees using the Gait Profile Score. Gait Posture. PMID: 25684145.

\section{Low resource country}

Kurichi JE and Kwong P and Vogel WB and Xie D and Cowper Ripley D and Bates BE. Effects of prosthetic limb prescription on 3-year mortality among Veterans with lower-limb amputation. Journal of Rehabilitation Research \& Development. 52(4):385-96, 2015. PMID: 26348602.

\section{KQ 4-7: No outcome or analysis of interest}

Lacraz A and Armand S and Turcot K and Carmona $\mathrm{G}$ and Stern R and Borens $\mathrm{O}$ and Assal $\mathrm{M}$. Comparison of the Otto Bock solid ankle cushion heel foot with wooden keel to the low-cost CREquipements solid ankle cushion heel foot with polypropylene keel: A randomized prospective double-blind crossover study assessing patient satisfaction and energy expenditure. Prosthet Orthot Int. PMID: 27881551.

KQ 4: No subgroup

Lacraz A and Turcot K and Sagawa Y and Lenoir J and Carmona G and Armand S and Assal M. CREQUIPEMENTSï $\dot{\mathrm{C}}^{1 / 211} \dot{\mathrm{C}}^{1 / 2}$ SACH foot versus otto BOCK $\ddot{\dot{c}}^{1 / 2 \ddot{i}} \dot{\dot{c}}^{1 / 2}$ SACH foot. Swiss Medical Weekly. Duplicate publication 
Lange R, Ljøstad U. Lower limb amputations and rehabilitation. Tidsskrift for den Norske laegeforening : tidsskrift for praktisk medicin, ny raekke. PMID: 28468477.

KQ 7: $\mathbf{N}<\mathbf{1 0 0}$

LaPre AK, Wedge RD, Umberger BR, Sup FC. Preliminary study of a robotic foot-ankle prosthesis with active alignment. IEEE Int Conf Rehabil Robot. PMID: 28814000.

\section{Case report/series}

Larsson J and Agardh CD and Apelqvist J and StenstrÌ'm A. Long term prognosis after healed amputation in patients with diabetes. Clinical Orthopaedics and Related Research. PMID: 9602814. KQ 7: $\mathbf{N}<\mathbf{1 0 0}$

Lass R and Kickinger W and Guglia P and Kubista B and Kastner J and Windhager R and Holzer G. The effect of a flexible pylon system on functional mobility of transtibial amputees. A prospective randomized study. Eur J Phys Rehabil Med. PMID: 23860421.

\section{KQ 4: No subgroup}

Ledoux ED, Goldfarb M. Control and Evaluation of a Powered Transfemoral Prosthesis for Stair Ascent. IEEE Transactions on Neural Systems and Rehabilitation Engineering. PMID: 28113346. KQ 4-7: No outcome or analysis of interest

Lee WC and Zhang M and Chan PP and Boone DA. Gait analysis of low-cost flexible-shank transtibial prostheses. IEEE transactions on neural systems and rehabilitation engineering. PMID: 17009497.

KQ 4-7: No outcome or analysis of interest

Lehmann JF and Price R and Boswell-Bessette S and Dralle A and Questad K and deLateur BJ.

Comprehensive analysis of energy storing prosthetic feet: Flex Foot and Seattle Foot Versus Standard SACH foot. Arch Phys Med Rehabil. PMID: 8239969.

\section{KQ 4: No subgroup}

Lehmann JF and Price R and Boswell-Bessette S and Dralle A and Questad K. Comprehensive analysis of dynamic elastic response feet: Seattle Ankle/Lite Foot versus SACH foot. Arch Phys Med Rehabil. PMID: 8347071.

\section{KQ 4: No subgroup}

Leijendekkers RA, van Hinte G, Frölke JP, van de Meent H, Nijhuis-van der Sanden MW, Staal JB. Comparison of bone-anchored prostheses and socket prostheses for patients with a lower extremity amputation: a systematic review. Disability and rehabilitation. PMID: 27494092.

\section{Not LLP}

Leung HB and Wong WC and Wu FC and Guerin JS. Perioperative and rehabilitation outcome after lowerlimb amputation in elderly Chinese patients in Hong Kong. J Orthop Surg (Hong Kong). PMID: 15237131.

KQ 7: <6 mo or unclear f/up post-prescription

Lim TS and Finlayson A and Thorpe JM and Sieunarine K and Mwipatayi BP and Brady A and Abbas $\mathrm{M}$ and Angel D. Outcomes of a contemporary amputation series. ANZ journal of surgery. PMID: 16768686.

KQ 7: $\mathbf{N}<\mathbf{1 0 0}$

Lindberg K and Kristensen MT. Construct validity and responsiveness of functional measures used in lower limb amputees following an outpatient prosthetic rehabilitation program. Prosthetics and Orthotics International.

\section{Not peer reviewed publication}

Lura DJ and Wernke MM and Carey SL and Kahle JT and Miro RM and Highsmith MJ. Differences in knee flexion between the Genium and C-Leg microprocessor knees while walking on level ground and ramps. Clin Biomech (Bristol, Avon). PMID: 25537443.

\section{KQ 4: No subgroup}

Lura DJ, Wernke MW, Carey SL, Kahle JT, Miro RM, Highsmith MJ. Crossover study of amputee stair ascent and descent biomechanics using Genium and C-Leg prostheses with comparison to non-amputee control. Gait Posture. PMID: 28763712.

\section{KQ 4: No subgroup}

Lythgo N and Marmaras B and Connor H. Physical function, gait, and dynamic balance of transfemoral amputees using two mechanical passive prosthetic knee devices. Archives of Physical Medicine \& Rehabilitation. 91(10):1565-70, 2010 Oct. PMID: 20875515.

\section{KQ 4: No subgroup}

Mac Neill HL and Devlin M and Pauley T and Yudin A. Long-term outcomes and survival of patients with bilateral transtibial amputations after rehabilitation. Am J Phys Med Rehabil. PMID: 18174848.

KQ 7: $\mathbf{N}<\mathbf{1 0 0}$

MacKenzie, E. J., Bosse, M. J., Pollak, A. N., Webb, L. X., Swiontkowski, M. F., Kellam, J. F., Smith, D. G., Sanders, R. W., Jones, A. L., Starr, A. J., McAndrew, M. P., Patterson, B. M., Burgess, A. R. and Castillo, R. C. Long-term persistence of disability following severe lower-limb trauma.

Results of a seven-year follow-up. J Bone Joint Surg Am. PMID: 16085622.

KQ 1-3: Not validation 
Major MJ and Johnson WB and Gard SA. Interrater reliability of mechanical tests for functional classification of transtibial prosthesis components distal to the socket. Journal of rehabilitation research and development. PMID: 26360815.

\section{KQ 1-3: Not validation}

Malchow C, Fiedler G. Effect of observation on lower limb prosthesis gait biomechanics: Preliminary results. Prosthet Orthot Int. PMID: 26420262.

KQ 4-7: No outcome or analysis of interest

Maqbool HF, Husman MA, Awad MI, Abouhossein A, Iqbal N, Dehghani-Sanij AA. A Real-Time Gait Event Detection for Lower Limb Prosthesis Control and Evaluation. IEEE Trans Neural Syst Rehabil Eng. PMID: 28114026.

KQ 1-3: Not validation

Marinakis GN. Interlimb symmetry of traumatic unilateral transtibial amputees wearing two different prosthetic feet in the early rehabilitation stage. J Rehabil Res Dev. PMID: 15558386.

KQ 4: No subgroup

Mateos Torres E and Clarï $\dot{c}^{1 / 2 \ddot{1}} \dot{c}^{1 / 2}$ A and MuniesaPortolì@s JM and Vidal-Barraquer F. The natural history of ischaemic patients who undergo belowknee amputation: A long way to autonomous walking. Angiologia.

KQ 4-7: No outcome or analysis of interest

McWhinnie DL and Gordon AC and Collin J and Gray DW and Morrison JD. Rehabilitation outcome 5 years after 100 lower-limb amputations. Br J Surg. PMID: 7827880.

KQ 7: $\mathbf{N}<100$

Meier MR and Hansen AH and Gard SA and McFadyen AK. Obstacle course: users' maneuverability and movement efficiency when using Otto Bock C-Leg, Otto Bock 3R60, and CaTech SNS prosthetic knee joints. J Rehabil Res Dev. PMID: 22773261.

KQ 4: No subgroup

Mengelkoch LJ, Kahle JT, Highsmith MJ. Energy costs and performance of transfemoral amputees and non-amputees during walking and running: A pilot study. Prosthet Orthot Int. PMID: 27885098.

KQ 4-7: No outcome or analysis of interest

Met R and Janssen LI and Wille J and Langezaal AE and van de Mortel RW and van de Pavoordt ED and de Vries JP. Functional results after through-knee and above-knee amputations: does more length mean better outcome?. Vasc Endovascular Surg. PMID: 18458050.

KQ 7: $\mathbf{N}<100$
Meulenbelt HE and Geertzen JH and Jonkman MF and Dijkstra PU. Determinants of skin problems of the stump in lower-limb amputees. Arch Phys Med Rehabil. PMID: 19154832.

KQ 4-7: No outcome or analysis of interest

Miller WC and Deathe AB and Speechley M and Koval J. The influence of falling, fear of falling, and balance confidence on prosthetic mobility and social activity among individuals with a lower extremity amputation. Arch Phys Med Rehabil. PMID: 11552197.

KQ 7: Included amputees without LLP or excluded some $L L P$ recipients

Miller, M., Wong, W. K., Wu, J., Cavenett, S., Daniels, L. and Crotty, M. Upper-arm

anthropometry: an alternative indicator of nutritional health to body mass index in unilateral lowerextremity amputees?. Arch Phys Med Rehabil. PMID: 18929034.

KQ 1-3: Not validation

Miyazaki S. Long-term unrestrained measurement of stride length and walking velocity utilizing a piezoelectric gyroscope. PMID: 9254988.

\section{KQ 1-3: Not validation}

Mizuno N and Aoyama T and Nakajima A and Kasahara T and Takami K. Functional evaluation by gait analysis of various ankle-foot assemblies used by below-knee amputees. Prosthet Orthot Int. PMID: 1491951.

KQ 4-7: No outcome or analysis of interest

Mohieldin A, Chidambaram A, Sabapathivinayagam $\mathrm{R}$, et al. Quantitative assessment of postural stability and balance between persons with lower limb amputation and normal subjects by using dynamic posturography.

\section{KQ 4: Noncomparative}

Moller S, Hagberg K, Samulesson K, Ramstrand N. Perceived self-efficacy and specific self-reported outcomes in persons with lower-limb amputation using a non-microprocessor-controlled versus a microprocessor-controlled prosthetic knee. Disabil Rehabil Assist Technol. PMID: 28366038.

\section{KQ 4: No subgroup (no interaction)}

Montalvo. Impacto del nivel socioeconómico en las amputaciones mayores de miembros inferiores.

Angiologia.

Not available 
Monteiro RP and Pfeifer LI and Soares I and Dos Santos Ade A and Sousa N. Validation of the functional and social performance - DSF-84 checklist: preliminary study. Disabil Rehabil. PMID: 23323959.

\section{Low resource country}

Moore Raymond. Effect on Stance Phase Timing Asymmetry in Individuals with Amputation Using Hydraulic Ankle Units. Journal of Prosthetics \& Orthotics (JPO). doi: 10.1097/JPO.0000000000000083.

KQ 4-7: No outcome or analysis of interest

Moore TJ and Barron $\mathrm{J}$ and Hutchinson F3rd and Golden C and Ellis C and Humphries D. Prosthetic usage following major lower extremity amputation. Clin Orthop Relat Res. PMID: 2910604.

KQ 7: Included amputees without LLP or excluded some LLP recipients

Morgan S and Askew R and Hafner B. Equivalence of electronic and paper administration for four selfreport instruments used in prosthetic clinical care. Prosthetics and Orthotics International.

\section{Not peer reviewed publication}

Morgan SJ, Amtmann D, Abrahamson DC, Kajlich AJ, Hafner BJ. Use of cognitive interviews in the development of the PLUS-M item bank. Qual Life Res. PMID: 24442531.

KQ 1-3: Not validation

Morgan SJ, Friedly JL, Amtmann D, Salem R, Hafner BJ. A cross-sectional assessment of factors related to pain intensity and pain interference in lower limb prosthesis users. Arch Phys Med Rehabil. PMID: 27742450.

KQ 1-3: Not validation

Morgan SJ, Kelly VE, Amtmann D, Salem R, Hafner BJ. Self-reported cognitive concerns in people with lower limb loss. Arch Phys Med Rehabil. PMID: 26836953.

KQ 1-3: Not validation

Moustapha A and Sagawa Junior Y and Watelain E and Thevenon A. Epidemiological cross-sectional survey of outcome in lower-limb amputees in the Nord-Pas de Calais region. Annals of Physical and Rehabilitation Medicine.

Not peer reviewed publication

Muniesa JM and Pou M and Marco E and Boza R and Guillì@nn A and Duarte E and Escalada F and Belmontey R and Tejero M. Health-related quality of life in patients with lower limb amputations.

Rehabilitacion.

KQ 4-7: No outcome or analysis of interest
Murray MP and Mollinger LA and Sepic SB and Gardner GM and Linder MT. Gait patterns in aboveknee amputee patients: hydraulic swing control vs constant-friction knee components. Arch Phys Med Rehabil. PMID: 6882172.

KQ 4: No subgroup

Nadollek H, Brauer S and Isles R. Outcomes after transtibial amputation: the relationship between quiet stance ability, strength of hip abductor muscles and gait. PMID: 12528576.

Not LLP

Naylor H and Russell P. A scoring tool to predict functional outcome in lower limb amputees (BLARt)-a pilot study. Prosthetics and Orthotics International.

Not peer reviewed publication

Nehler MR and Coll JR and Hiatt WR and Regensteiner JG and Schnickel GT and Klenke WA and Strecker PK and Anderson MW and Jones DN and Whitehill TA and Moskowitz S and Krupski WC. Functional outcome in a contemporary series of major lower extremity amputations. J Vasc Surg. PMID: 12844082.

KQ 7: $\mathbf{N}<100$

OConnell PG and Gnatz S. Hemiplegia and amputation: rehabilitation in the dual disability. Archives of physical medicine and rehabilitation. PMID: 2730308.

KQ 7: Included amputees without LLP or excluded some LLP recipients

O'Neill BF and Evans JJ. Memory and executive function predict mobility rehabilitation outcome after lower-limb amputation. Disabil Rehabil. PMID: 19280435.

KQ 7: $\mathbf{N}<100$

Orendurff MS and Segal AD and Klute GK and McDowell ML and Pecoraro JA and Czerniecki JM. Gait efficiency using the C-Leg. J Rehabil Res Dev. PMID: 16847790.

\section{KQ 4: No subgroup}

Paradisi F and Delussu AS and Brunelli S and Iosa M and Pellegrini R and Zenardi D and Traballesi M.

The Conventional Non-Articulated SACH or a Multiaxial Prosthetic Foot for Hypomobile Transtibial Amputees? A Clinical Comparison on Mobility, Balance, and Quality of Life. ScientificWorldJournal. PMID: 26078990.

KQ 4: No subgroup 
Parker, K., Kirby, R. L., Adderson, J. and Thompson, $\mathrm{K}$. Ambulation of people with lower-limb amputations: relationship between capacity and performance measures. Archives of Physical Medicine \& Rehabilitation.

\section{KQ 1-3: Not validation}

Periago RZ and Martos IF and Fernandez RR and Miralles MEM and Gaya MM and Sanchez IS. Subjective evaluation of the prosthetization of 13 amputees of the lower limb using an ICE-ROSS socket. Rehabilitacion.

KQ 4: No subgroup

Pernot HF and Winnubst GM and Cluitmans JJ and De Witte LP. Amputees in Limburg: incidence, morbidity and mortality, prosthetic supply, care utilisation and functional level after one year. Prosthet Orthot Int. PMID: 11061195.

KQ 7: $\mathbf{N}<\mathbf{1 0 0}$

Pezzin, L. E., Dillingham, T. R. and MacKenzie, E. J. Rehabilitation and the long-term outcomes of persons with trauma-related amputations. Archives of physical medicine and rehabilitation. PMID: 10724073.

KQ 1-3: Not validation

Pinzur MS and Littooy F and Daniels J and Arney C and Reddy NK and Graham G and Osterman H. Multidisciplinary preoperative assessment and late function in dysvascular amputees. Clin Orthop Relat Res. PMID: 1499219.

KQ 7: $\mathbf{N}<\mathbf{1 0 0}$

Pohjolainen T and Alaranta H. Predictive factors of functional ability after lower-limb amputation. Ann Chir Gynaecol. PMID: 1888111.

KQ 4-7: No outcome or analysis of interest

Popielarz S and Lacroix J and Munoz M and FargeasGluck MA and Salle JY and Mandigout S. Shock absorbers for vascular trans-tibial amputees in environmental situations seem more efficient on comfort than on oxygen consumption. Science and Sports.

\section{KQ 4: Noncomparative}

Postema K and Hermens HJ and de Vries J and Koopman HF and Eisma WH. Energy storage and release of prosthetic feet. Part 2: Subjective ratings of 2 energy storing and 2 conventional feet, user choice of foot and deciding factor. Prosthetics and orthotics international. PMID: 9141123.

KQ 4: No subgroup

Powell LE, Myers AM. The Activities-specific Balance Confidence (ABC) Scale. J Gerontol. Not amputees
Prinsen EC and Nederhand MJ and Olsman J and Rietman JS. Influence of a user-adaptive prosthetic knee on quality of life, balance confidence, and measures of mobility: a randomised cross-over trial. Clin Rehabil. PMID: 25288047.

\section{KQ 4: No subgroup}

Prinsen EC and Nederhand MJ and Sveinsdottir HS and Prins MR and van der Meer F and Koopman HF and Rietman JS. The influence of a user-adaptive prosthetic knee across varying walking speeds: A randomized cross-over trial. Gait Posture. PMID: 27838569.

\section{KQ 4: No subgroup}

Prinsen EC, Nederhand MJ, Koopman BF, Rietman JS. The influence of a user-adaptive prosthetic knee on planned gait termination. IEEE Int Conf Rehabil Robot. PMID: 28813993.

KQ 4-7: No outcome or analysis of interest

Probsting E, Kannenberg A, Zacharias B. Safety and walking ability of KAFO users with the C-Brace(R) Orthotronic Mobility System, a new microprocessor stance and swing control orthosis. Prosthet Orthot Int. PMID: 27151648.

\section{KQ 4: No subgroups of interest}

Quai TM, Brauer SG and Nitz JC. Somatosensation, circulation and stance balance in elderly dysvascular transtibial amputees. PMID: 16180604.

\section{Not LLP}

Rabago CA, Aldridge Whitehead J, Wilken JM. Evaluation of a Powered Ankle-Foot Prosthesis during Slope Ascent Gait. PLoS One. PMID: 27977681.

\section{KQ 4: No subgroup}

Radhakrishnan S, Kohler F, Gutenbrunner C, Jayaraman A, Li J, Pieber K, Schiappacasse C. The use of the International Classification of Functioning, Disability and Health to classify the factors influencing mobility reported by persons with an amputation: An international study. Prosthet Orthot Int. PMID: 27371642.

\section{KQ 1-3: Not validation}

Rao SS and Boyd LA and Mulroy SJ and Bontrager EL and Gronley JK and Perry J. Segment velocities in normal and transtibial amputees: prosthetic design implications. IEEE Trans Rehabil Eng. PMID:

9631330.

KQ 4: No subgroup 
Raschke SU and Orendurff MS and Mattie JL and Kenyon DE and Jones OY and Moe D and Winder L and Wong AS and Moreno-Hernandez A and Highsmith MJ and D JSanderson and Kobayashi T. Biomechanical characteristics, patient preference and activity level with different prosthetic feet: a randomized double blind trial with laboratory and community testing. J Biomech. PMID: 25480541. KQ 4: No subgroup

Raya MA and Gailey RS and Gaunaurd IA and Ganyard $\mathrm{H}$ and Knapp-Wood J and McDonough K and Palmisano T. Amputee mobility predictorbilateral: a performance-based measure of mobility for people with bilateral lower-limb loss. J Rehabil Res Dev. PMID: 24301433.

\section{Battle injury}

Redfield MT and Cagle JC and Hafner BJ and Sanders JE. Classifying prosthetic use via accelerometry in persons with transtibial amputations. J Rehabil Res Dev. PMID: 24458961. KQ 1-3: $\mathbf{N}<20$

Remes L and Isoaho R and Vahlberg $\mathrm{T}$ and Viitanen $\mathrm{M}$ and Rautava P. Predictors for institutionalization and prosthetic ambulation after major lower extremity amputation during an eight-year follow-up. Aging Clin Exp Res. PMID: 19448384.

KQ 7: $\mathbf{N}<\mathbf{1 0 0}$

Remes, Leena, Isoaho, Raimo, Vahlberg, Tero, Viitanen, Matti, Koskenvuo, Markku and Rautava, $\mathrm{P} \sqrt{\mathrm{E}} \neg \S$ ivi. Quality of life three years after major lower extremity amputation due to peripheral arterial disease. Aging Clinical \& Experimental Research. KQ 1-3: Not validation

Rink Cameron, Wernke Matthew M, Powell Heather M, Gynawali Surya, Schroeder Ryan M, Kim Jayne Y, Denune Jeffrey A, Gordillo Gayle M, Colvin James M, Sen Chandan K. Elevated vacuum suspension preserves residual-limb skin health in people with lower-limb amputation: Randomized clinical trial. Journal of Rehabilitation Research \& Development. PMID: 28355039.

KQ 4-7: No outcome or analysis of interest

Rispin K and Wright V and Andrysek J. Assessing the test-retest reliability of the lower limb function questionnaire (LLFQ). Prosthetics and Orthotics International.

\section{Pediatric}

Roffman CE and Buchanan J and Allison GT. Long term locomotor function in individuals with lower limb amputation following discharge from rehabilitation. Prosthetics and Orthotics International. Not peer reviewed publication
Rosenberg DE and Turner AP and Littman AJ and Williams RM and Norvell DC and Hakimi KM and Czerniecki JM. Body mass index patterns following dysvascular lower extremity amputation. Disability \& Rehabilitation. 35(15):1269-75, 2013 Jul. PMID: 23094934.

\section{KQ 7: $\mathbf{N}<100$}

Rushton PW and Miller WC. Goal attainment scaling in the rehabilitation of patients with lower-extremity amputations: a pilot study. Arch Phys Med Rehabil. PMID: 12048654.

KQ 1-3: $\mathbf{N}<20$

Salsich, G. B. and Mueller, M. J. Relationships between measures of function, strength and walking speed in patients with diabetes and transmetatarsal amputation. Clin Rehabil. PMID: 9065361.

\section{KQ 1-3: Not validation}

Samitier CB and Guirao L and Costea M and Camos JM and Pleguezuelos E. The benefits of using a vacuum-assisted socket system to improve balance and gait in elderly transtibial amputees. Prosthet Orthot Int. PMID: 25261489.

\section{KQ 4: No subgroup}

Sansosti LE, Crowell A, Choi ET, Meyr AJ. Rate of and Factors Associated with Ambulation After Unilateral Major Lower-Limb Amputation at an Urban US Tertiary-Care Hospital with a Multidisciplinary Limb Salvage Team. J Am Podiatr Med Assoc. PMID: 29077505.

KQ 7: Included amputees without LLP or excluded some LLP recipients

Saraf A. Mobilization status of diabetics versus nondiabetics after below knee amputation: A comparison. Prosthetics and Orthotics International. Not peer reviewed publication

Schaffalitzky E and Gallagher P and Maclachlan M and Ryall N. Understanding the benefits of prosthetic prescription: exploring the experiences of practitioners and lower limb prosthetic users. Disabil Rehabil. PMID: 21050130.

\section{KQ 1-3: Not validation}

Schoppen T and Boonstra A and Groothoff JW and van Sonderen E and Goeken LN and Eisma WH. Factors related to successful job reintegration of people with a lower limb amputation. Arch Phys Med Rehabil. PMID: 11588749.

KQ 4-7: No outcome or analysis of interest 
Schoppen T, Boonstra A, Groothoff JW, de Vries J, Göeken LN, Eisma WH. Physical, mental, and social predictors of functional outcome in unilateral lowerlimb amputees. Arch Phys Med Rehabil. PMID: 12808530.

KQ 7: $\mathbf{N}<\mathbf{1 0 0}$

Schoppen, T., Boonstra, A., Groothoff, J. W. , de Vries, J., Goeken, L. N. and Eisma, W. H.

Employment status, job characteristics, and workrelated health experience of people with a lower limb amputation in The Netherlands. Arch Phys Med Rehabil. PMID: 10414769.

\section{KQ 1-3: Not validation}

Scopes J and Van Der Linden M and Gleeson N. Minimal detectable change values of common outcome measures used in lower limb prosthetic rehabilitation in the UK. Physiotherapy (United Kingdom).

Not peer reviewed publication

Seelen HAM and Hemmen B and Schmeets AJ and Ament AJH and Evers SMA. Costs and consequences of a prosthesis with an electronically stance and swing phase controlled knee joint.

Technology \& Disability.

KQ 4: No subgroup

Segal AD and Kracht R and Klute GK. Does a torsion adapter improve functional mobility, pain, and fatigue in patients with transtibial amputation?. Clinical orthopaedics and related research. PMID: 24733445.

KQ 4: No subgroup

Segal AD and Orendurff MS and Klute GK and McDowell ML and Pecoraro JA and Shofer J and Czerniecki JM. Kinematic and kinetic comparisons of transfemoral amputee gait using C-Leg and Mauch SNS prosthetic knees. J Rehabil Res Dev. PMID: 17436172.

\section{KQ 4: No subgroup}

Seker A and Kara A and Camur S and Malkoc M and Sonmez MM and Mahirogullari M. Comparison of mortality rates and functional results after transtibial and transfemoral amputations due to diabetes in elderly patients-a retrospective study. Int J Surg. PMID: 27475745.

Low resource country
Selles Rw and Janssens Pj and Jongenengel Cd and Bussmann Jb. A randomized controlled trial comparing functional outcome and cost efficiency of a total surface-bearing socket versus a conventional patellar tendon-bearing socket in transtibial amputees. Archives of physical medicine and rehabilitation. PMID: 15641007.

\section{KQ 4: No subgroup}

Seth M, Lamberg E. Standing balance in people with trans-tibial amputation due to vascular causes: A literature review. Prosthet Orthot Int. 2017 Aug;41(4):345-355. PMID: 28067120.

Not LLP

Seymour R and Engbretson B and Kott K and Ordway N and Brooks G and Crannell J and Hickernell E and Wheeler K. Comparison between the C-leg microprocessor-controlled prosthetic knee and non-microprocessor control prosthetic knees: a preliminary study of energy expenditure, obstacle course performance, and quality of life survey. Prosthetics and orthotics international. PMID: 17365885.

\section{KQ 4: No subgroup}

Shell CE, Segal AD, Klute GK, Neptune RR. The effects of prosthetic foot stiffness on transtibial amputee walking mechanics and balance control during turning. Clin Biomech (Bristol, Avon). PMID: 28869812.

\section{KQ 4-7: No outcome or analysis of interest}

Simon Ann M, Fey Nicholas P, Ingraham Kimberly A, Finucane Suzanne B, Halsne Elizabeth G, Hargrove Levi J. Improved Weight-Bearing Symmetry for Transfemoral Amputees During Standing Up and Sitting Down With a Powered Knee-Ankle Prosthesis. Archives of Physical Medicine \& Rehabilitation. PMID: 26686876. KQ 4: No subgroup

Singh R and Venkateshwara G. Effect of fluid collections on long-term outcome after lower limb amputation. Arch Phys Med Rehabil. PMID: 22244246.

KQ 7: $\mathbf{N}<\mathbf{1 0 0}$

Sinha R and van den Heuvel WJ and Arokiasamy P and van Dijk JP. Influence of adjustments to amputation and artificial limb on quality of life in patients following lower limb amputation. Int $\mathrm{J}$ Rehabil Res. PMID: 24157864.

\section{Duplicate publication}


Sinha R and van den Heuvel WJ and Arokiasamy P. Adjustments to amputation and an artificial limb in lower limb amputees. Prosthetics and orthotics international. PMID: 23722600.

\section{Low resource country}

Sinha, R., W.J. van den Heuvel, and P. Arokiasamy,. Factors affecting quality of life in lower limb amputees. PMID: 21515894.

KQ 1-3: Not validation

Siriwardena GJ and Bertrand PV. Factors influencing rehabilitation of arteriosclerotic lower limb amputees. J Rehabil Res Dev. PMID: 1880748.

KQ 4-7: No outcome or analysis of interest

Smith DG, Horn P, Malchow D, Boone DA, Reiber GE, Hansen ST Jr. Prosthetic history, prosthetic charges, and functional outcome of the isolated, traumatic below-knee amputee. J Trauma. PMID: 7745656.

\section{KQ 1-3: Not validation}

Steinberg FU and Garcia WJ and Roettger RF and Shelton DJ. Rehabilitation of the geriatric amputee. Journal of the American Geriatrics Society. PMID: 4810416.

KQ 7: $\mathbf{N}<\mathbf{1 0 0}$

Steinberg FU and Sunwoo I and Roettger RF. Prosthetic rehabilitation of geriatric amputee patients: a follow-up study. Arch Phys Med Rehabil. PMID: 4062526.

KQ 7: $\mathbf{N}<100$

Su PF and Gard SA and Lipschutz RD and Kuiken TA. The effects of increased prosthetic ankle motions on the gait of persons with bilateral transtibial amputations. Am J Phys Med Rehabil. PMID: 20026945.

KQ 4: No subgroup

Taheri A and Karimi MT. Evaluation of the gait performance of above-knee amputees while walking with 3R20 and 3R15 knee joints. Journal of Research in Medical Sciences.

\section{KQ 4: No subgroup}

Tang KT, Spence WD, Maxwell D, Stansfield BW. Validity of method to quantify transtibial amputees' free-living prosthetic wearing times and physical activity levels when using suction suspension sockets. Journal of Rehabilitation Research \& Development. PMID: 22773201.

KQ 1-3: $\mathbf{N}<20$
Taylor SM and Kalbaugh CA and Blackhurst DW and Hamontree SE and Cull DL and Messich HS and Robertson RT and Langan EM3rd and York JW and Carsten CG3rd and Snyder BA and Jackson MR and Youkey JR. Preoperative clinical factors predict postoperative functional outcomes after major lower limb amputation: an analysis of 553 consecutive patients. J Vasc Surg. PMID: 16102618.

KQ 7: Included amputees without LLP or excluded some LLP recipients

Taylor SM and Kalbaugh CA and Cass AL and Buzzell NM and Daly CA and Cull DL and Youkey JR. 'Successful outcome' after below-knee amputation: an objective definition and influence of clinical variables. The American surgeon. PMID: 18646478.

KQ 7: Included amputees without LLP or excluded some LLP recipients

Tezuka Y and Chin T and Takase I and Azuma Y and Nakatsuka A and Fujie $\mathrm{H}$ and Kurokawa $\mathrm{M}$ and Fujiwara $\mathrm{Y}$ and Ochi T and Oyabu $\mathrm{H}$ and Honda $\mathrm{Y}$ and Kohno $\mathrm{H}$ and Miura Y. Investigation of physical functions affecting prosthetic use in unilateral transfemoral amputees. Physiotherapy (United Kingdom). KQ 7: $\mathbf{N}<\mathbf{1 0 0}$

Thomas SS and Buckon CE and Helper D and Turner $\mathrm{N}$ and Moor M and Krajbich JI. Comparison of the Seattle lite foot and Genesis II prosthetic foot during walking and running. Journal of Prosthetics \& Orthotics (JPO).

KQ 4: No subgroup

Topuz Semra and Ulcer Ozlem and Sener Gul. Effects of different prosthetic feet on the ambulation activities and gait in transtibial amputees. Turkish Journal of Physiotherapy Rehabilitation.

\section{Low resource country}

Traballesi, M., Porcacchia, P., Averna, T., Angioni, C., Lubich, S., Di Meo, F. and Brunelli, S. Prognostic factors in prosthetic rehabilitation of bilateral dysvascular above-knee amputee: is the stump condition an influencing factor?. Europa medicophysica. PMID: 16955063.

\section{KQ 1-3: Not validation}

Tranberg R, Zugner R, Karrholm J. Improvements in hip and pelvic motion for patients with osseointegrated transfemoral prostheses. PMID: 21130654.

Not LLP 
Treweek, S. P. and Condie, M. E. Three measures of functional outcome for lower limb amputees: a retrospective review. Prosthet Orthot Int. PMID: 9881605.

\section{KQ 1-3: Not validation}

Trieb K and Lang T and Stulnig T and Kickinger W. Silicone soft socket system: Its effect on the rehabilitation of geriatric patients with transfemoral amputations. Archives of Physical Medicine and Rehabilitation. PMID: 10326914.

\section{KQ 4: No subgroup}

Ulger $\mathrm{O}$ and Topuz $\mathrm{S}$ and Bayramlar K. Effects of a hydraulic knee joint on energy consumption, gait and patient satisfaction in trans-femoral amputees.

Turkish Journal of Physiotherapy Rehabilitation.

\section{Low resource country}

Van de Meent H, Hopman MT, Frolke JP. Walking ability and quality of life in subjects with transfemoral amputation: a comparison of osseointegration with socket prostheses. PMID: 23774380.

\section{Not LLP}

Van de Weg FB and Van der Windt DA. A questionnaire survey of the effect of different interface types on patient satisfaction and perceived problems among trans-tibial amputees. Prosthet Orthot Int. PMID: 16466153.

\section{KQ 1-3: Not validation}

van der Schans, C. P., Geertzen, J. H., Schoppen, T. and Dijkstra, P. U. Phantom pain and health-related quality of life in lower limb amputees. Journal of Pain \& Symptom Management.

\section{KQ 1-3: Not validation}

van der Sluis, C. K., Hartman, P. P., Schoppen, T. and Dijkstra, P. U. Job adjustments, job satisfaction and health experience in upper and lower limb amputees. Prosthet Orthot Int. PMID: 19235065. KQ 1-3: Not validation

van der Water GJ and De Vries J and Mulder MA. Comparison of the lightweight Camp Normal Activity Foot with other prosthetic feet in trans-tibial amputees: a pilot study. Prosthet Orthot Int. PMID: 9747994.

\section{Case report/series}

van Eijk MS and van der Linde $H$ and Buijck B and Geurts A and Zuidema S and Koopmans R. Predicting prosthetic use in elderly patients after major lower limb amputation. Prosthet Orthot Int. PMID: 22252778.

KQ 7: <6 mo or unclear f/up post-prescription
Visser-Meily JMA and Cluitmans JHM and Deckers JJM and Rings F. Experiences of above-knee amputees with an NML-socker in comparison with a quadrilateral-socket. Journal of Rehabilitation Sciences.

KQ 4: No subgroup

Wan Hazmy CH and Chia WYE and Fong TS and Ganendra P. Functional outcome after major lower extremity amputation: A survey on lower extremity amputees. Medical Journal of Malaysia. PMID: 17042220.

\section{Low resource country}

Webster JB and Hakimi KN and Williams RM and Turner AP and Norvell DC and Czerniecki JM. Prosthetic fitting, use, and satisfaction following lower-limb amputation: a prospective study. J Rehabil Res Dev. PMID: 23516053.

KQ 7: $\mathbf{N}<\mathbf{1 0 0}$

Williams RM and Turner AP and Green M and Norvell DC and Henderson AW and Hakimi KN and Blake DJ and Czerniecki JM. Relationship between cognition and functional outcomes after dysvascular lower extremity amputation: a prospective study. Am J Phys Med Rehabil. PMID: 25357146.

KQ 7: $\mathbf{N}<\mathbf{1 0 0}$

Willrich, A., Pinzur, M., McNeil, M., Juknelis, D. and Lavery, L. Health related quality of life, cognitive function, and depression in diabetic patients with foot ulcer or amputation. A preliminary study.

Foot Ankle Int. PMID: 15737254.

\section{KQ 1-3: Not validation}

Wong A and Heinemann A and Ehrlich-Jones L and Connelly L and Semik P and Fatone S. Comparison of the opus and FOTO's functional status measures for persons with lower limb amputation. Archives of Physical Medicine and Rehabilitation.

\section{Not peer reviewed publication}

Wong CK and Chen CC and Blackwell WM and Rahal RT and Benoy SA. Balance ability measured with the Berg balance scale: a determinant of fall history in community-dwelling adults with leg amputation. J Rehabil Med. PMID: 25223891.

\section{KQ 1-3: Not validation}

Wong CK and Chen CC. A prognostic clinical prediction rule to identify adults with lower limb loss not likely to achieve successful prosthetic function within one year. PM and R.

\section{Duplicate publication}


Wong CK and Young RS and Ow-Wing $\mathrm{C}$ and Karimi P. Determining 1-Yr Prosthetic Use for Mobility Prognoses for Community-Dwelling Adults with Lower-Limb Amputation: Development of a Clinical Prediction Rule. Am J Phys Med Rehabil. PMID: 26390393.

\section{KQ 1-3: Not validation}

Wu M, Haque MR, Shen X. Obtaining Natural Sit-toStand Motion with a Biomimetic Controller for Powered Knee Prostheses. J Healthc Eng. PMID: 29075428.

\section{Case report/series}

Wurdeman Sr, Schmid Kk, Myers Sa, Jacobsen Al, Stergiou N. Step Activity and 6-Minute Walk Test Outcomes When Wearing Low-Activity or HighActivity Prosthetic Feet. American journal of physical medicine \& rehabilitation. PMID: 27584137.

KQ 4: No subgroup

Wurdeman SR, Stevens PM, Campbell JH. Mobility Analysis of AmpuTees (MAAT I): Quality of life and satisfaction are strongly related to mobility for patients with a lower limb prosthesis. Prosthet Orthot Int. PMID: 28990467.

KQ 1-3: Not validation
Xu H, Greenland Kasey, Bloswick Donald, Jie Zhao, Merryweather Andrew. Vacuum level effects on gait characteristics for unilateral transtibial amputees with elevated vacuum suspension. Clinical Biomechanics. PMID: 28232236.

KQ 4: No subgroup

Yari, P., Dijkstra, P. U. and Geertzen, J. H. B. Functional outcome of hip disarticulation and hemipelvectomy: a cross-sectional national descriptive study in the Netherlands. Clinical Rehabilitation. PMID: 19052251.

KQ 1-3: Not validation

Yigiter $\mathrm{K}$ and Bayar K and Ulger OG and Akdogan S and Erbahceci $F$ and Yakut Y and Sener G. The effect of flexible and hard sockets on the ambulation of above knee amputees. Fizyoterapi Rehabilitasyon.

\section{Low resource country}

Yiğiter K, Sener G, Bayar K. Comparison of the effects of patellar tendon bearing and total surface bearing sockets on prosthetic fitting and rehabilitation. Prosthetics and Orthotics International. PMID: 12562067.

\section{Low resource country}

Zidarov D and Swaine B and Gauthier-Gagnon C. Life habits and prosthetic profile of persons with lower-limb amputation during rehabilitation and at 3month follow-up. Arch Phys Med Rehabil. PMID: 19887223.

KQ 7: <6 mo or unclear f/up post-prescription 